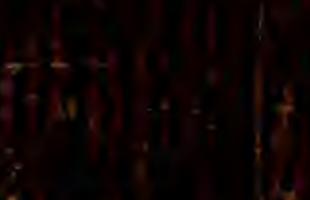

2

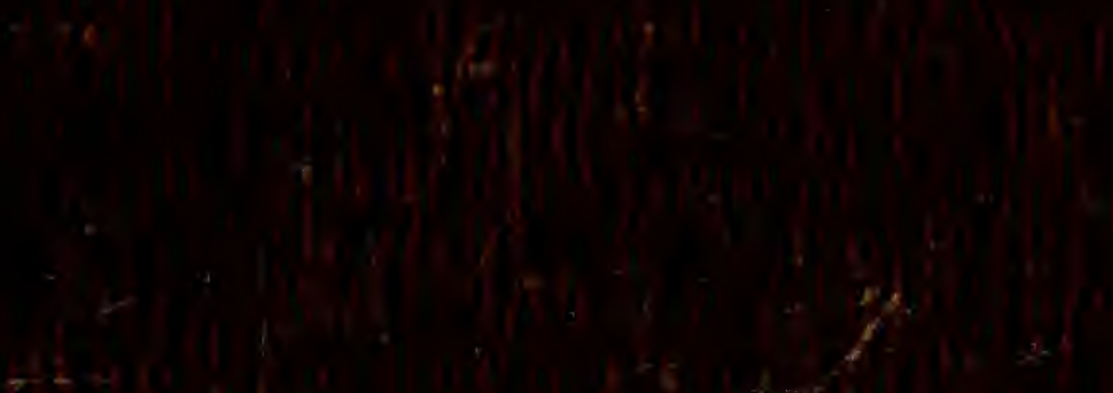

8

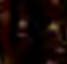

$8:$

3

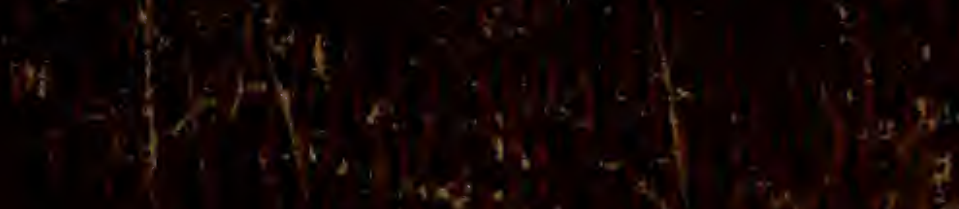

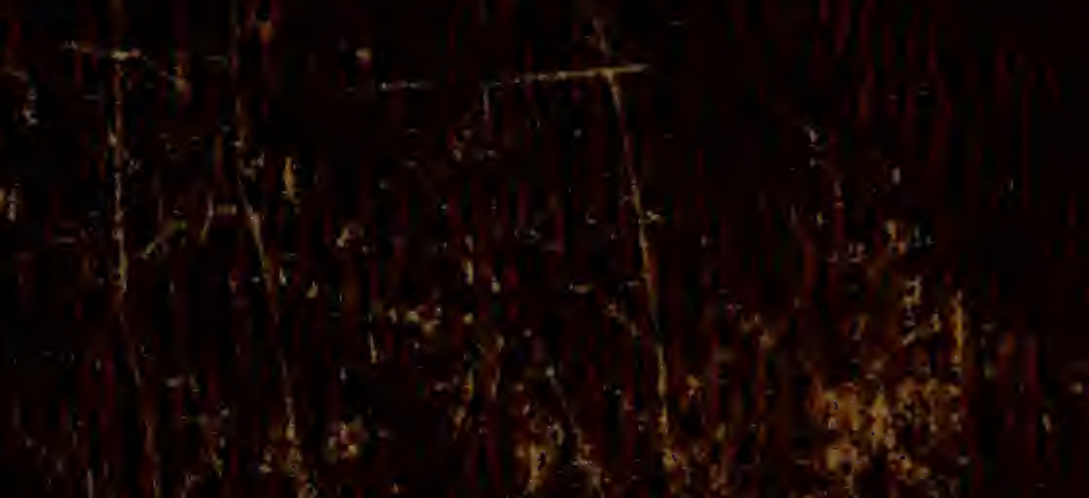

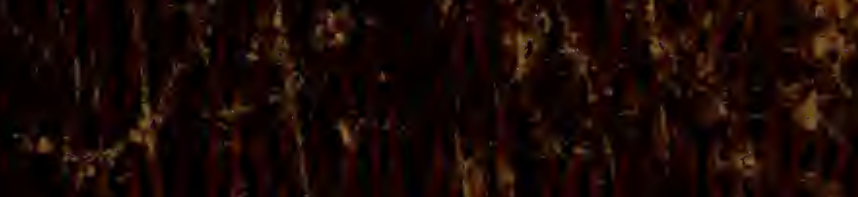
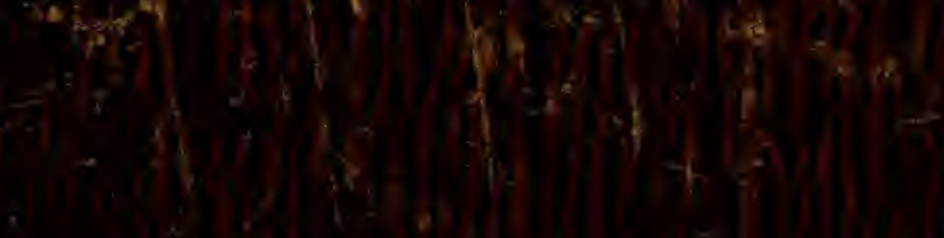


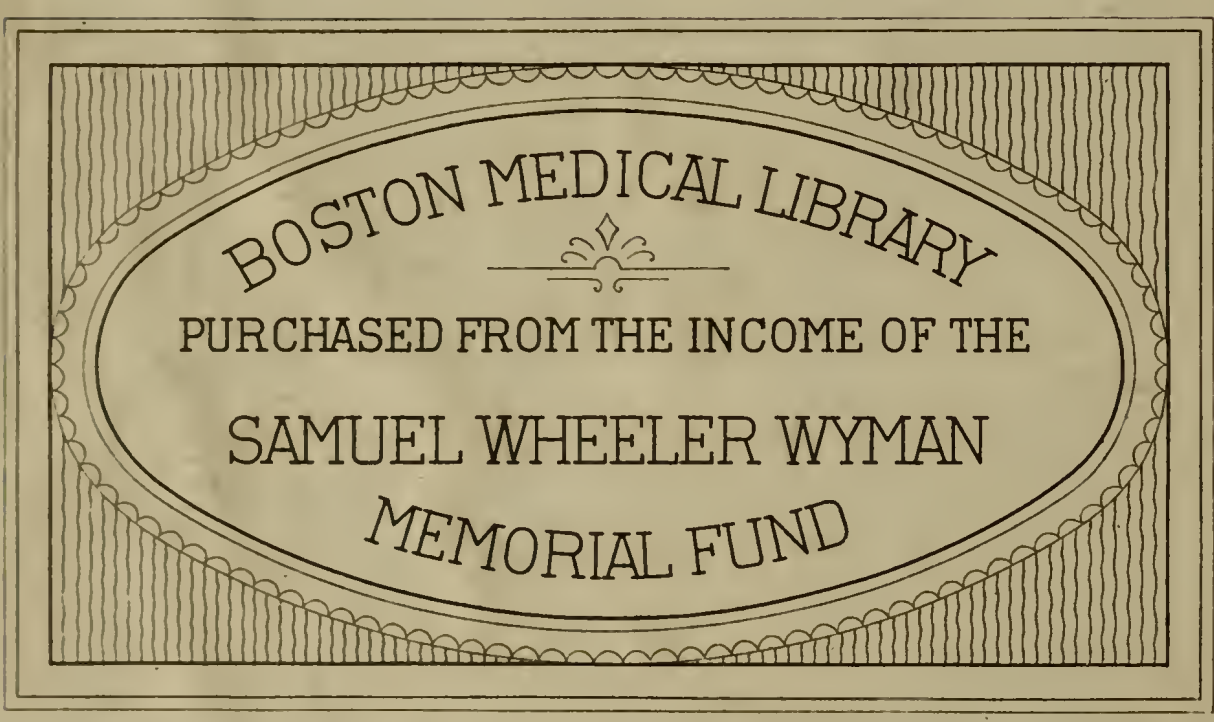






\title{
DIE ENTSTEHUNGSWEISE
}

DER

\section{DOPPELMISSBILDUNGEN}

BEI DEN

\section{HÖHEREN WIRBELTHIEREN}

VON

\begin{abstract}
C
DR. LEO GERLACH,

a. o. PROFESSOR DER ANATOMIE UND PROSECTOR AN DEM ANATOMISCHEN INSTITUT DER UNIVERSTTÄT ERLANGEN.
\end{abstract}

MIT NEUN TAFELN.

STU'T'I'GAR'T'.

VERLAG VON FERDINAND ENKE.

1882. 

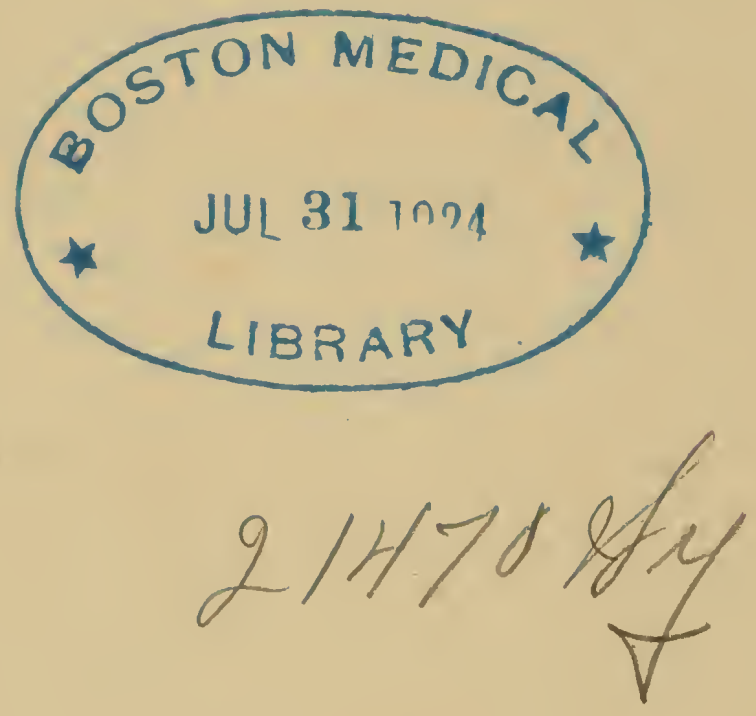

J. 


\section{HERRN}

\section{CAMILLE DARESTE \\ PROFESSOR DER EMBRYOGENIE AN DER ÉCOLE DE MÉDECINE IN PARIS}

IN VORZÜGLICHSTER VEREHRUNG UND HOCHACHTUNG

GEWIDMET

VOM VERFASSER. 



\section{Vor w ort.}

In der vorliegenden Monographie ist der Versuch gemacht worden, für die höheren Vertebraten die Grundprincipien einer Entwicklungsgeschichte der Doppelmissbildungen festzustellen. Vor wenigen Jahren noch wäre ein solches Unternehmen wegen des Fehlens der hierzu nöthigen Vorbedingungen unausführbar gewesen. Die teratologische Literatur ist der Natur der Sache gemäss vorwiegend eine casuistische; man legte bei der Veröffentlichung der beobachteten Deformitäten das Hauptgewicht auf die anatomische Beschreibung, und nur beiläufig wurde der muthmasslichen Entstehungsweise gedacht. Bei den Doppelmissbildungen pflegte das Letztere darin zu bestehen, dass dieselben je nach dem Standpunkte des Autors genetisch nach der Spaltungs- oder Verwachsungstheorie erklärt wurden. Zwar sind auch hie und da Doppelbildungen aus frühen embryonalen Stadien bekannt geworden, allein dieselben blieben nur vereinzelt und auf die Classe der Vögel beschränkt; für die Säugethiere und den Menschen existiren bis heute noch keine derartigen Befunde.

Eine entwicklungsgeschichtliche Behandlung der Doppelmonstra wäre daher auf die wenigen Fälle, welche bei Vögeln beobáchtet worden waren, angewiesen gewesen. Die Schlussfolgerungen, die man allenfalls trotz ihrer geringen Anzahl aus diesen Fällen in Bezug auf die Genese der Doppelmissbildungen hätte ziehen können, konnten jedoch nur für die Vögel Geltung beanspruchen; zu einer Erklärung der mannigfachen Formen der Doppelmonstra, wie sie bei dem Menschen und den Säugethieren vorkommen, waren sie nicht zu verwenden, da nach dem damaligen Stande unserer Kenntnisse die Ontogenie der Mammalia und die der Vögel rücksichtlich der Anlage des Embryo zu grosse Unterschiede darzubieten schienen.

Auch jetzt noch stellen sich den Untersuchungen, welche über die Entstehungsweise der Mehrfachbildungen angestellt werden, beträchtliche Hindernisse in den Weg; doch sind dieselben Dank den werthvollen Arbeiten neuerer Forscher, durch welche die angedeuteten Schwierigkeiten zum grossen Theile beseitigt wurden, nicht mehr unüberwindlich. Der Mangel an friihzeitigen Mehrfachbildungen ist gegenwärtig nicht mehr so fühlbar, da zu den wenigen älteren Fällen ein ansehnlicher Zuwachs neuer Beobachtungen hinzugekommen ist. Er lässt sich in Folge dessen das zu Gebote stehende entwicklungs- 
geschichtliche Material, wenn es auch noch lange nicht in der wünschenswerthen Fülle vorhanden ist, doch für das Studium der Teratogenie sämmtlicher Hauptformen der Doppelmissbildungen nutzbringend verwerthen. Bei Weitem die Mehrzahl der jüngst beobachteten Fälle hat Dareste in seinem inhaltsreichen Werke „La Production artificielle des Monstruosités" (Paris 1877) erläutert und abgebildet; ausserdem sind durch Rauber und Ahlfeld eine Reihe frühzeitiger Doppelbildungen bekannt geworden.

Auf die Erkenntniss der Bildungsweise der mehrfachen Monstra mussten ferner die neueren Errungenschaften auf dem Gebiete der normalen Entwicklungsgeschichte der höheren Vertebraten höchst vortheilhaft einwirken. Ich denke hier zunächst an die fruchtbringenden Untersuchungen von Hensen und Kölliker, durch welche anf die bei der Anlage und Ausbildung des Säugethierembryo obwaltenden Entwicklungsvorgänge ein helles Licht gefallen ist. Nicht minder sind auch unsere Kenntnisse über die Ontogenie der Vögel nach manchen Richtungen hin erweitert worden. In Folge dieser Fortschritte der normalen Embryologie konnte auch die vergleichende Entwicklungsgeschichte eine grössere Ausdehnung erlangen. Wir sind jetzt in der Lage gerade diejenigen ontogenetischen Processe, deren abnormer Verlauf bei Vögeln nachweislich das Zustandekommen einer Doppelmissbildung nach sich zieht, wie beispielsweise die Anlage und Ausbildung des Primitivstreifens der Chorda dorsalis etc., bei Vögeln und Säugethieren einer eingehenderen vergleichenden. Prüfung zu unterziehen. Von dem Grade der Uebereinstimmung;, den in dieser Hinsicht die genannten Thierclassen aufweisen, wird es abhängen, ob auch die Doppelbildungen bei beiden in der gleichen Weise auftreten. Die letztere Frage kann nur durch die normale Entwicklungsgeschichte eine prompte und präcise Beantwortung finden.

Wie sehr die normale Ontogenie das dunkle Gebiet der Teratogenie zu erhellen im Stande ist, ist neuerdings durch die trefflichen Untersuchungen Rauber's klar zu Tage getreten, welcher die Entstehungsweise der Doppelmissbildungen von den Gesichtspunkten der vergleichenden Embryologie aus zu erklären suchte, indem er sämmtliche Wirbelthiere in den Kreis seiner Betrachtungen zog. Auf diese Weise gelangte Rauber zu folgenschweren Resultaten, welche die Unhaltbarkeit der überkommenen Theorien der Spaltung und Verwachsung darthun mussten. Seine geistvolle und scharfsinnige Darstellung eröffnet ein Verständniss für die pathologische Embryologie der Wirbelthiere, wenn ihr auch auf der anderen Seite der Vorwurf einer zu weit gehenden Verallgemeinerung nicht ganz erspart bleiben kann.

Bei Gelegenheit meiner Untersuchungen über die normale Entwicklung des Hühnchens in der ersten Zeit der Bebrütung spielte mir ein glücklicher Zufall eine Doppelbildung in 'die Hände, welche sich in einem iiberaus frühen Stadium befand, indem ausser den beiden Primitivstreifen in der Area pellucida noch keine weiteren Bildungen aufgetreten waren. Dieselbe gab mir die Veranlassung mich nach ähnlichen Fällen in der Literatur umzusehen, was mich wiederum \%u einem eingehenderen Studium der neueren teratologischen Selıriften führte. Unter diesen fesselte mich insbesondere die Lectüre des genannten Werkes von Dareste, dessen Erfolge auf dem Gebiete der experimentellen Erzeugung von Missbildungen mir den Gedanken nahe legten, in etwas anderer 
Weise, als es bisher versucht worden ist, die künstliche Herstellung von Doppelmissbildungen in Angriff zu nehmen.

Es war anfänglich meine Absicht, die Ergebnisse dieser Experimente, über welche ich bereits kurz berichtet habe (Sitzungsber. der Erlanger ‘physik. med. Societät, 13. Heft 1880/81), sowie das erwähnte Doppelhühnchen, das wegen seiner frühen Entwicklungsstufe für die Erkenntniss der ersten Anlage der Mehrfachbildungen von dem grössten Interesse ist, zum Gegenstand zweier gesonderter Publicationen zu machen. Bei der Ausführung der beiden geplanten Arbeiten stellten sich jedoch zwischen ihnen so vielfache Wechselbeziehungen und damit eine so unverkennbare Zusammengehörigkeit heraus, dass es mir geboten schien, mein ursprüngliches Vorhaben aufzugeben und beide in den Rahmen einer grösseren einheitlichen Untersuchung einzufügen. Dass dieselbe keinen Anspruch darauf erheben kann, den ungemein vielseitigen und umfangreichen Stoff erschöpfend behandelt zu haben, dessen bin ich mir wohl bewusst.

Immerhin dürfte die von mir vorgenommene Zusammenstellung aller bekannt gewordenen Doppelbildungen aus früher Entwicklungszeit, sowie die Beigabe von Copien ihrer Originalabbildungen den Vortheil gewähren, dass das vorhandene Material ohne viele Mühe überblickt und beurtheilt werden kann. Neu beobachtete Fälle werden ferner leicht an der ihnen zukommenden Stelle untergebracht werden können.

In soweit meine Darstellung die Genese der Doppelmissbildungen, sowie deren künstliche Production betrifft, wird man an dieselbe keinen zu strengen Massstab anlegen dürfen. In Bezug auf Ersteres möchte ich daran erinnern, dass es schon Schwierigkeiten genug verursacht, bei einer Thierform, deren verschiedene Entwicklungsstadien leicht in beliebiger Menge zu beschaffen sind, sich über den allmähligen Aufbau der Embryonalanlage eine richtige Vorstellung zu bilden. Ungleich grössere Schwierigkeiten waren bei der Aufgabe, die ich mir gestellt hatte, zu überwinden; denn ich hatte einerseits nicht nur ein Endstadium der Entwicklung in Betracht zu ziehen, sondern alle die mannigfachen Formen der Doppelmissbildungen zu berücksichtigen, andererseits waren die Embryonalstadien dieser einzelnen Formen nur sehr spärlich vertreten, ja sie fehlten theilweise gänzlich, und es mussten diese Lücken durch Combination unter Beihülfe der normalen Entwicklungsgeschichte ausgefüllt werden.

Was endlich die künstliche Production von Doppelmonstrositäten anlangt, so befindet sich dieselbe noch auf einer zu niederen Stufe, als dass zur Zeit schon erheblichere Resultate zu erwarten sein dürften. Doch steht zu hoffen, dass, wenn die nöthigen Vorarbeiten einmal beendet sind, und dadurch eine Summe von Erfahrungen gewonnen ist, dann auch mit einer gewissen Regelmässigkeit durch bestimmte experimentelle Störungen der normalen Entwicklung Axenverdoppelungen hervorgerufen werden können.

Erlangen, den 26. April 1882

L. Gerlach. 


\section{Inhaltsverzeichniss.}

Einleitung . . . . . . . . . . . . . . . . . . . . . . . . . . . 1

Normale Entwicklung der höheren Vertebraten in der ersten Zeit der Embryonalbildung . . . . . . . . . . . . . . . . . . . . . . 6

Neue Fälle frühzeitiger Doppelbildungen des Hühnchens . . . . . . . . . . . 29

Die Anlage zweier Primitivstreifen in einem Fruchthofe. Unter welchen Umständen kann dieselbe zur Genese von Doppelmissbildungen führen, und welche Formen der letzteren kommen hier in Frage? . . . . . . . . . . . . . . . 34

Zusammenstellung der bisher bekannt gewordenen Fälle frühzeitiger Doppelbildungen bei den höheren Vertebraten . . . . . . . . . . . . . . . . . . 42

Vergleichung, Eintheilung und Epikrise der im vorhergehenden Capitel angeführten

Fälle . . . . . . . . . . . . . . . . . . . 56

Experimentelle Untersuchungen . . . . . . . . . . . . . . . . . . . . 90

Verwachsung oder Spaltung? . . . . . . . . . . . . . . . . . . . 137

Die Theorie der Radiation. . . . . . . . . . . . . . . . . . . 175

Schlussbetrachtungen . . . . . . . . . . . . . . . . . . 218

Tafelerklärungen . . . . . . . . . . . . . . . . . . . . 227 


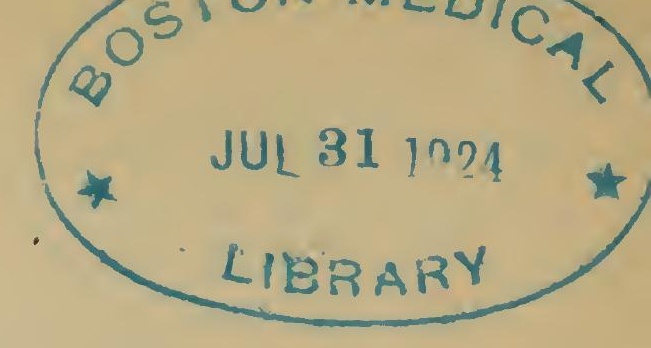

\section{Einleitung.}

Die Lehre von der Entstehungsweise der Missbildungen oder die Teratogenie und mit ihr die gesammte Teratologie steht in inniger unzertrennbarer Verbindung mit der normalen Entwicklungsgeschichte. Erst seitdem diese hergestellt war, konnte der erstgenannten Disciplin eine wissenschaftliche Behandlung zu Theil werden. Es waren die grossen Errungenschaften C. F. Wolff's auf dem Gebiete der normalen Embryogenie (1.759), welche auf die bis zu dieser Zeit rein speculativen Anschauungen der Gelehrtenwelt über das Werden und Wesen der Missbildungen reformirend einwirkten; ferner musste der mächtige Aufschwung der Entwicklungsgeschichte in dem 2. und 3. Jahrzehent unseres Jahrhunderts, den wir den bahnbrechenden Untersuchungen Pander's (1817) und C. E.v. Baer's (1828) verdanken, nothwendiger Weise auch auf die Teratogenie einen fördernden Einfluss ausüben, und jene alten Ansichten vollständig über Bord werfen. So hat die aufblühende Entwicklungsgeschichte den Anstoss gegeben, dass die Teratologie nach und nach eine exactere wissenschaftliche Grundlage erhielt. Man hatte erkannt, dass auch die Missbildungen denselben Gesetzen der Entwicklung unterliegen, wie der regelrecht gestaltete Organismus, indem erstere dadurch ins Leben treten, dass in irgend einer Zeit der Embryogenese durch gewisse, wenn auch noch unbekannte Ursachen der normale Entwicklungsgang eine Störung erleidet, welche ihrerseits wiederum die Entwicklungsgesetze modificirend beeinflussen muss. Damit hatte natürlich die teratologische Forsehung einen wichtigen Fingerzeig erhalten. Ihre Aufgabe musste fortan darin bestehen, die Monstrositäten von den Gesichtspunkten der normalen Entwicklung aus zu beurtheilen; es galt festzustellen, in welcher Embryonalzeit und in welcher Weise die Abweichung von der regulären Entwicklung aufgetreten ist, und welche Folgen diese bezüglich der weiteren Gestaltung des Organismus nach, sich ziehen musste. Ausserdem war es geboten, die Ursachen zu ergründen, welche jenes Abweichen veranlassen können; hierüber war sowohl aus der Beschaffenheit der einzelnen Missbildungen selbst, als auch aus den begleitenden Nebenumstïnden Aufschluss zu erhalten. Was die letzteren betrifft, so hatte man auf das Verhalten der Eihüllen, auf die Störungen, die bei Zwillingsschwangerschaften eintreten können, u. s. w. Acht zu geben. 
Durch die nach den bezeichneten Richtungen hin angestellten Untersuchungen ist denn auch eine ansehnliche Erweiterung unserer Kenntnisse erreicht worden. Wir sind über eine Reihe von Ursachen, welche zu Deformitäten Veranlassung geben können, aufgeklärt worden. Auch das zeitliche Eintreten der zu einer Monstrosität führenden Abweichung der normalen Embryonalbildung ist für verschiedene Arten derselben mit annähernder Genauigkeit festgestellt worden. Schliesslich hat man sich auch auf Grund der regulären Bildungsvorgänge die allmählige Gestaltung der Missbildungen in vielen Fällen zurecht legen können.

In Allgemeinen jedoch ist unser Wissen in Betreff der genannten Punkte noch ein sehr lückenhaftes, was sich aus den grossen Schwierigkeiten, mit denen die teratologische Forschung zu kämpfen hat, hinreichend erklärt. Die Objecte, mit denen sich dieselbe befasst, sind in der übergrossen Mehrzahl bereits gänzlich oder nahezu ausgebildete Missbildungen, welche beim Menschen und den Säugethieren entweder, was seltener vorkommt, als Frühgeburten, oder erst nach vollständig abgelaufener intrauteriner Entwicklungszeit zur Beobachtung gelangen. Diese Fälle stellen demnach die Endproducte der abnorm vor sich gegangenen Entwicklung dar; die Anfangs- und Zwischenstadien entziehen sich der objectiven Wahrnehmung, und es blieb darum dem Scharfsinn der Teratologen anheimgestellt, sich das Aussehen und die Gestalt der fehlenden Stadien geistig zu vergegenwärtigen. Damit. aber war der Individualität der einzelnen Forscher ein zu grosser Spielraum gelassen, was unausbleiblich zu Meinungsverschiedenheiten unter denselben führen musste; es war der Vermuthung und der Hypothese Thür und Thor geöffnet, Theorien und Gegentheorien wurden aufgestellt, die sich heftig befehdeten und über deren Werth wegen der Unmöglichkeit objectiver Beobachtung endgültig nicht entschieden werden konnte.

In dieser Nothlage war es mit Freuden zu begrüssen, dass von Seiten einiger Gelehrten ein Ausweg in sofern gefunden wurde, als dieselben, statt der für die Erforschung der fraglichen Vorgänge unzugünglichen Süugethiere, aus der Classe der Vögel das nöthige Untersuchungsmaterial zu erlangen suchten. Dasselbe Object, welches der Erkenntniss der normalen Entwicklungsgeschichte so wesentliche Dienste geleistet hat, sollte auch der Teratogenie zu Gute kommen. Es gebührt Panum das Verdienst, darauf aufmerksam gemacht zu haben, dass in solchen Eiern, die während der Brütung abgestanden waren, in der Regel Missbildungen anzutreffen seien. Da das Absterben der Eier in mangelhaft construirten Brüteapparaten eine hä̈fige Erscheinung ist, so musste die Untersuchung solcher Eier eine grosse Menge von Deformitäten zu Tage fürdern. Ferner gelang es Panum, nachzuweisen, dass die in faulen Eiern gefundenen Entwicklungsanomalien eine Folge von 'I'emperaturschwankungen seien,' denen während der Bebrütung die Eier ausgesetzt waren. Dadurch war ein Mittel gegeben, monströse Bildungen in beliebiger Menge willkührlich hervorzurufen. Auf diese Weise crhiclt Panum eine grosse Menge von Missbildungen, die er zum Theile noch lebend antraf, und unter denen die mannigfachsten Deformitïten in verschiedenen Entwicklungsstadien vertreten waren. Dieselben bildeten ein sehr werthvolles Untersuchungsmaterial, an welchem sich das erste Auftreten und 
die allmählige Ausbildung einer Reihe von Missbildungen objectiv verfolgen liess.

Auch auf anderem Wege, als durch zeitweise Abänderung der normalen Brütetemperatur, kann die Entwicklung künstlich gestört, und dadurch Veranlassung zur Entstehung von Missbildungen gegeben werden. Die Versuche dieser Art, durch welche die den Missbildungen zu Grunde liegenden ursächlichen Momente unserer Erkenntniss bedeutend näher gerückt wurden, reichen bis zum Anfang dieses Jahrhunderts zurück. In den zwanziger Jahren wurden sie von E. Geoffroy Saint-Hilaire wieder in grösserem Umfange aufgenommen, und seit dieser Zeit haben sich in Frankreich eine Anzahl von Gelehrten mit den gleichen Untersuchungen beschäftigt. Unter diesen nimmt Camille Dareste die erste Stelle ein, dessen Resultate wohl das Beste darstellen, was auf diesem Gebiete geleistet worden ist; denn im Gegensatz zu anderen Forschern, welche auf den gleichen experimentellen Eingriff hin bald diese, bald jene Deformität erzielten, hat Dareste es zu Wege gebracht, mit grosser Regelmässigkeit die gleichen Bildungsanomalien der Keimhaut zu erhalten, wenn er bei Bebrütung der Eier bestimmte Abänderungen der normalen Entwicklungsbedingungen vornahm.

Abgesehen von denjenigen Missbildungen, früher Embryonalstadien, welche in abgestandenen Eiern, oder nach künstlichen Entwicklungsstörungen gefunden wurden, sind solche auch in grösserer Anzahl bei Gelegenheit der vielfachen embryologischen Untersuchungen, welche am Vogelei ausgeführt worden sind, zufällig beobachtet worden. Unter den letzteren befindet sich auch eine Reihe von Doppelmissbildungen, welche in Bezug auf ihre Form und auf ihre Entwicklungszeit sich verschieden verhalten. Da es bisher trotz mehrfacher Versuche noch nicht gelungen ist, ganz sichere Methoden zum Behufe künstlicher Erzeugung von Doppelmissbildungen $\cdot z u$ ermitteln, ja selbst vor meinen eigenen Untersuchungen nach experimentellen Abänderungen der normalen Entwicklungsbedingungen meines Wissens bis jetzt noch keine unzweifelhafte Axenverdoppelung angetroffen worden ist, so sind die erwähnten Fïlle für die Erforschung der Entstehungsweise der Doppelmonstra von ganz besonderem Werthe.

Wenden wir uns nun zu der Frage, ob frühzeitige Missb̧ildungen der Vögel einen wirklichen Ersatz für die bei den Säugethieren und dem Menschen bis jetzt noch vollständig fehlenden Monstrositäten aus gleich frühen Stadien darbieten können, d. h. ob es gestattet ist, die hinsichtlich der Entstehung;weise derselben bei Vögeln erhaltenen Resultate auch auf die Sängethiere und den Menschen zu übertragen. Die Beantwortung dieser Frage wird für diese Formen der Missbildungen eine leichtere sein, für jene dagegen grössere Schwierigkeiten verursachen. Es wird dies wesentlich von dem Grade der Uè̄ereinstimmung abhängen, welche bei Vögeln und Sïugern diejenigen Organe oder Körpertheile, welche den Sitz der betreffenden Deformität bilden, in ihrer Entwicklung aufweisen. So wird z. B., da bei beiden die Wirbelsïule und das Medullarrohr wesentlich in der gleichen Weise zur Ausbildung gelangen, unbedenklich angenommen werden dürfen, dass auch die Anomalien derselben, wie die Spina bifida sammt den sie häufig begleitenden Abnormitäten des Hirnes und Rückenmarks bei Süugern und Vögch in der nämlichen 
Weise entstehen. Das Gleiche gilt von der Sympodie und vielen anderen monströsen Formen.

$\mathrm{Zu}$ denjenigen Missbildungen, bei denen es weniger leicht ist, eine Entscheidung darüber zu treffen, ob die Genese bei den beiden höchsten Vertebratenclassen auf dieselbe Art sich vollzieht, gehören die Axenverdoppelungen. Da dieselben bereits in der ersten Zeit der Entwicklung in Erscheinung treten, so wird man die Anfangsstadien der Embryonalbildung bei den Vögeln und den Säugern auf ihre Uebereinstimmung hin zu prüfen haben. Leider bieten gerade die Entwicklungsvorgänge, welche dem Auftreten der Embryonalanlage zu Grunde liegen, der embryologischen Forschung ganz besondere Schwierigkeiten dar, was zur Folge hatte, dass sie von den einzelnen Autoren in sehr verschiedener Weise aufgefasst worden sind. So wurden, um nur Eines anzuführen, über die Bildung und die Bedeutung des Primitivstreifens der Vögel die abweichendsten Ansichten laut. In den letzten Jahren hat jedoch auch auf diesem Gebiete eine Klärung und Läuterung sich angebahnt, indem die neueren Beobachter, welche im Besitze unserer jetzigen vervollkommneten technischen Hülfsmittel die erste Entwicklung der Vögel und Säuger bearbeitet haben, zu Resultaten gelangten, welche unter sich eine höchst erfreuliche Uebereinstimmung zeigen. Dadurch sind erst die nöthigen entwicklungsgeschichtlichen Grundlagen geschaffen worden, auf die hin eine eingehendere Vergleichung der ersten Embryonalstadien bei den höchst stehenden Vertebratenclassen vorgenommen werden kann.

In der Erwägung, dass nur dann ein Verständniss für die Genese der Doppelmissbildungen zu gewinnen ist, wenn man mit den Entwicklungsvorgängen, welche in der Norm bei der Anlage eines Einzelembryo sich vollziehen, genügend vertraut ist, habe ich eine kurze Darstellung der normalen Entwicklung der Vögel und der Säugethiere in den ersten Embryonalstadien an die Spitze unserer Betrachtungen gestellt. Im Anschluss an dieselbe werden die beiden 'Thierclassen rücksichtlich der in Betracht kommenden frühen Entwicklungserscheinungen einem Vergleiche unterstellt, welcher, wie ich jetzt schon bemerken will, ergab, dass zwischen beiden eine grosse Uebereinstimmung existirt. Dem entwicklungsgeschichtlichen Capitel reihen sich die weiteren Abschnitte meiner Untersuchung in folgender Weise an. Nach einer vorausgeschickten Beschreibung einiger neuer Fälle frühzeitiger Doppelbildungen des Hühnchens wird die Anlage zweier Primitivstreifen in einem Fruchthofe, sowie deren eventuelle Folgen eingehend besprochen. In dem folgenden Capitel habe ich sämmtliche bei Vögeln beobachtete Mehrfachbildungen früher Stadien nach Massgabe ihres Alters in geordneter Reihenfolge zusammengestellt. Daran schliesst sich der wichtigste Theil meiner Arbeit an, welcher in der Analyse der eben genannten Fïlle besteht, indem an der Hand derselben die Entstehungsweise der einzelnen Formen der Doppelmissbildungen erläutert wird. Der nächste Abschnitt handelt von der künstlichen Production der Missbildungen im Allgemeinen, über die experimentellen Versuche, welche die Herstellung von Axenverdoppelungen bezweckten, sowie über meine eigenen nach dieser Richtung hin unternommenen Experimente. Sodann wurde der einzelnen Theorien gedacht, welche über die Genese der Doppelmonstra aufgestellt worden sind. Nach einer historisch gehaltenen 
Uebersicht über die Wandlungen, welche sowohl die Verwachsungs-, als die Spaltungstheorie im Laufe der Zeit durchzumachen hatte, wird die eine, wie die andere kritisch beleuchtet, wobei gezeigt wird, dass keine der beiden Theorien den thatsächlichen Bildungsvorgängen, durch welche die Axenverdoppelungen zu Stande kommen, genügend Rechnung trägt.

Bei der Erörterung der Rauber'schen Radiationstheorie musste etwas weit ausgeholt werden, wail dieselbe nur auf vergleichend embryologischer Grundlage verständlich und in ihrer vollen Bedeutung gewürdigt werden kann. Es musste desshalb auch die Entwicklung der niederen Wirbelthierclassen Berücksichtigung finden.

Den Schluss bilden einige allgemeinere Betrachtungen, sowie eine $\mathrm{Zu}$ sammenstellung der hauptsächlichsten Resultate. 


\title{
Normale Entwicklung der höheren Vertebraten in der ersten Zeit der Embryonalbildung.
}

\author{
I. V ̈̈ g e l.
}

Unter den Vögeln ist die Ontogenie des Hühnchens am meisten und vollkommensten studirt worden. Ueber die am ersten Tage der Bebriitung stattfindenden Entwicklungsvorgänge stehen mir eigene Erfahrungen zu Gebote, indem ich mich in den letzten Jahren vorwiegend mit Untersuchungen über diesen Gegenstand beschäftigt habe. Die Ergelunisse derselben bilden die Grundlage zu der folgenden Beschreibung ${ }^{1}$ ), bei der ich, um sie nicht allzusehr auszudehnen, günzlich davon absehen werde, die Controversen, welche in Bezug auf die Blätterbildung etc. zwischen den einzelnen Forschern bestehen, zu berühren. Hiezu wären sehr weitgehende Auseinandersetzungen nöthig, welche nicht in meiner Intention liegen, da hier eben nur ein kurzes übersichtliches Bild über die Anfangsstadien der Embryogenese des Hühnchens entworfen werden soll. Ich bemerke jedoch, dass in der vielbestrittenen Frage der Keimblätterbildung der neueste Autor auf diesem Gebiete, Koller ${ }^{2}$ ), in den wesentlichsten Puncten mit mir übereinstimmt.

Die Keimhaut oder das Blastoderma des gelegten unbebrüteten Hühnereies ist eine rundliche Scheibe, deren Durchmesser im Mittel eine Lünge von $3,5 \mathrm{Mm}$. besitzt. Bei der Betrachtung von oben unterscheidet man einen mittleren rundlichen durchsichtigen Theil, und eine denselben ringförmig umgebende undurchsichtige Zone. Der erstere wird Area pellucida oder Mittelscheibe (Rauber), die letztere Area opaca, Ringgebiet (His), Keimring (Rauber), genannt. Die Area pellucida stellt den dünneren, das Ringgebiet den dickeren 'T'heil der Keimscheibe dar. Wenn man ein unbebrütetes Ei nach Eröffnung der Schale so vor sich hinlegt, dass der stumpfe Eipol nach links, der spitze nach rechts sicht, und sich die Keimhaut durch eine von Eipol zu Eipol gehende Linie in zwei halbkreisförmige Hälften zerlegt denkt, so kann man in Rücksicht auf die spätere Lage des Embryo dic dem Beob-

1) Dieselbe bildet zum Theil eine Reproduction meiner vorlänfigen Mittheilung im biologrischen Centralblatte Nr. 1, Bd. 1: "Ueher die entodermale Entstehungsweise der Chorda dorsalis".

$\left.{ }^{2}\right)$ C. Koller, Untersuchungen ïber die Blitterbildung im Hühnerkeim. Arehiv füir mikroskop. Anatomic Bd. 20, jatg. 174, 1881. 
achter zugekehrte Hälfte als die hintere, die andere als die vordere Hälfte der Keimhaut bezeichnen. Die Area pellucida oder die Mittelscheibe setzt sich nun, wenn man die so erläuterten Begriffe von vorne und hinten zu Grunde legt, mit ihrem hinteren Rande scharf gegen das Ringgebiet ab, während vorne die Grenzen zwischen beiden häufig etwas verwischt sind.

Die Keimhaut ruht mit ihrem Ringgebiete unmittelbar dem weissen Dotfer auf, während die Area pellucida von demselben durch eine mit Flüssigkeit erfüllte Höhle, die Furchungshöhle, geschieden ist. Diesem Lageverhältniss, zusammengehalten mit der geringen Dicke der Area pellucida, verdankt dieselbe ja bekanntlich den Namen des durchsichtigen Fruchthofes.

Der histologische Aufbau der Keimhaut ist nur auf Durchschnitten ersichtlich. An denselben bemerkt man, dass sich die Keimscheibe aus zwei Zellenschichten zusammensetzt, einer oberen, oder dem Ektoderm, und einer unteren, oder dem Entoderm. Die Zellenlage des Ektoderms besteht in den mittleren Theilen der Area pellucida, wo sie am dicksten ist, aus hohen Cylinderzellen, die gegen den Rand des Ringgebietes zu niedriger werden. Im Bereiche des letzteren besteht das obere Keimblatt nur aus einer Schichte cubischer Zellen. Das Entoderm, oder das untere Keimblatt, zeigt in den einzelnen frisch gelegten Eiern sehr merkliche Verschiedenheiten in seiner Ausbildung, woraus hervorgeht, dass die Zeit des Ablegens der Eier in der Entwicklung der Keimscheibe keinen bestimmten Abschnitt bildet, indem zu dieser Zeit die letztere, und zwar hauptsächlich deren Entoderm bereits mehr oder weniger ausgebildet sein kann. Im Allgemeinen lässt sich behaupten, dass in der hinteren Hälfte des Blastoderma das untere Keimblatt immer weiter in seiner Entwicklung gediehen ist, als in der vorderen. In den hinteren Bezirken der Area pellucida bildet das Entoderm meistens schon eine continuirliche Zellschichte, welche je nach dem Grade der Ausbildung dieses Blattes nach vorne zu bald früher, bald später aufhört; von nun an wird die-Stelle des letzteren von einer Reihe unregelmässig angeordneter 'Zellhaufen eingenommen, welche dem Ektoderm dicht anliegen, und, da sie nicht fest zusammenschliessen, eine vielfach durchbrochene Platte darstellen. Im Inneren dieser Haufen, sowie auch in den hinteren Theilen des Entoderms stösst man vielfach auf grössere und kleinere Furchungskugeln. Dieselben finden sich auch oft zu mehreren neben einander gelegen oberhalb des bereits zu einer zusammenhängenden Zellschichte ausgebildeten Entoderms, und liegen dann zwischen den beiden Keimblättern. Ich habe diese intermediären Furchungskugeln, wie ich im Voraus bemerken will, auch noch bei 8-10 Stunden bebrüteten Keimhäuten, an denen beicits der Primitivstreif aufgetreten war, angetroffen. Auch inter dem Entoderm im Innern der Furchungshöhle, sowie auf dem Boden derselben liegend, kommen viclfach solche Furchungskugeln vor.

Innerhalb des Ringgebietes ist das Entoderm ungleich dicker, als in der Arca pellucida. Es besteht hier aus mehreren Lagen rundlicher Zellen von verschiedener Grösse, die meistens stark granulirt sind. Diese ringförmige Verdickung des Entoderms in der Area opaca, mit welcher dasselbe auf dem weissen Dotter aufruht, pflegt man. als Randwulst des unteren Keimblattes zu bezeichnen. Auf Durchschnitten beobachtet man eine glänzende saumförmige Linie, wclche den Randwulst von dem darunter gelegenen Dotter 
trennt. Im Bereiche der Area pellucida scheidet diese Linie die Furchungshöhle von dem weissen Dotter. Gegen die Peripheric der Keimscheibe zu wird der Randwulst und damit die gesammte Keimhaut wieder etwas dünner. In vielen Fällen ist der Randwulst im hintersten Abschnitte des Ringgebietes etwas stärker entwickelt. Schliesslich ist hervorzuheben, dass die Zellen des Randwulstes überall dem Ektoderm fest angelagert erscheinen, was sich auch im Anfange der Bebruitung unverändert erhält, während in der Area pellucida das Entoderm, da, wo es bereits zu einer continuirlichen Zellenschichte geworden ist, nicht so dicht dem Ektoderm anliegt; vielmehr lassen sich auf Durchschnitten bereits die ersten Spuren eines spaltförmigen Raumes zwischen beiden Keimblättern erkennen, welcher in den ersten Brütestunden immer deutlicher zu Tage tritt.

Ich gehe nun über zu den Veränderungen, welche sich in Folge der Bebrütung in der Keimhaut einstellen. Hier ist zunächst der fortschreitenden Entwicklung des Entoderms zu gedenken, welches in der Area pellucida sich immer mehr zu einer ununterbrochenen, aus einer einzigen Lage platter Zellen bestehenden Schichte ausbildet, die durch den bereits erwähnten, sich immer mehr ausdehnenden spaltförmigen Raum von dem Ektoderm getrennt ist. Im Flächenbilde stellt sich gegen die 4.-5. Stunde im durchsichtigen Fruchthof eine rundliche Trübung ein, deren Grenzen nicht scharf ausgeprägt sind. Dasselbe ist das von Dursy ${ }^{1}$ ) zuerst naturgetreu abgebildete Embryonalschild, welches der Ausdruck einer etwas stärkeren Verdickung der centralen Theile des Ektoderms ist. Das Embryonalschild fällt zusammen mit einer kuppenförmigen Prominenz der Area pellucida, welche an frischen Keimhäuten, nachdem sie vom Dotter losgelöst sind, sehr leicht zu erkennen ist und bei der Erhärtung so häufig in der Mitte des hellen Fruchthofes zur Bildung von kleinen Fïltchen Veranlassung gibt. Was die Lage der Kuppe anlangt, so ist dieselbe keine ganz regelmässige, indem das Embryonalschild entweder mehr central oder excentrisch liegen kann, indem es nüher an den hinteren Rand der Area pellucida heranrückt.

Auch im Ringgebict treten Veränderungen auf, doch betreffen diese fast ausschliesslich den hintersten Abschnitt desselben. Hier kommt es im Gegensatz zu dem gegenüber gelegenen vordersten Abschnitt der Area opaca zu einer Verdickung der Keimhaut, welche in einer Vermehrung der entodermalen Zellen ihren Grund hat. An einer Stelle jedoch betheiligt sich an derselben auch das Ektoderm. Diese Stelle, deren Umfang kein sehr grosser ist, reicht nach vorne ziemlich nahe an den hinteren Rand der Area pellucida heran. Es besteht hier eine kurze Strecke weit das Ektoderm aus 2-3 Lagen von Zellen; diese sind dicht zusammengedrängt und fürben sich durch Pikrocarmin intensiv roth, was sie von den unter ihnen befindlichen granulirten Mesodermzellen scharf trennt. Nach hinten und vorne zu geht diese Ektodermverdickung, allmählig dünner werdend, continuirlich in die angrẹnzenden Theile des oberen Keimblattes über, welche nur eine einschichtige Lage von Kellen darstellen. Ich glaube kaum zu irren, wenn ich die in Rede stehende Verdickung auf eine locale Wucherung der Zellen des oberen Keimblattes 
zurïckführe. Dieselbe scheint rasch nach beiden Seiten entlang dem hinteren Rande der Area pellucida fortzuschreiten, wodurch eine kleine Sichel entsteht, deren Hörner abgerundet enden. Die Sichel, deren seitliche Ausdehnung sehr variirt, liegt im Bereich des Ringgebietes, grenzt aber nach vorne, wenn auch nicht immer, doch meistens an den durchsichtigen Fruchthof. Sie ist, wie aus dem Gesagten hervorgeht, der optische Ausdruck einer localen Verdickung des Ektoderms, welches in Folge davon an dieser Stelle etwas nach oben prominirt. Etwa gegen die 6.-7. Brütestunde hat die Sichel auch nach vorne einen Fortsatz abgeschickt, der in die Area pellucida eingetreten ist; derselbe ist an seinem vorderen Ende verschmälert, während er hinten am Rande der Area pellucida, wo er in die Sichel übergeht, viel breiter wird, so dass er im Flächenbilde als ein kleines Dreieck erscheint, dessen Basis mit dem hinteren Rande der Area pellucida zusammenfällt, dessen abgerundete Spitze nach vorne sieht und bereits bis in das Embryonalschild hinein vorgedrungen ist; die Seitenränder des Dreiecks treten nur selten schärfer hervor (Fig. 1, Taf. I). Das Bild des Dreiecks verschwindet jedoch sehr rasch wieder, indem der von der Sichel abgehende Fortsatz, die Medianlinie einhaltend, sich nach vorne zu verlängert und immer weiter in die Area pellucida und in derén Embryonalschild hineinwächst. Die Kuppe des letzteren wird durch denselben an der betreffenden Stelle niedergedrückt und es erscheint nun das Embryonalschild unter dem Bilde einer Falte, welche einen nahezu kreisförmigen Bogen bildet, der um den vorderen Theil des Sichelfortsatzes herumgelegt ist. Dieser geht nun nach und nach in den Primitivstreifen über, dessen Bildung in gleicher Weise, wie die der Sichel, auf eine gegen das Entoderm zu gerichteten Wucherung des Ektoderms zurückzuführen ist, oder was dasselbe sagen will, Primitivstreifen und Sichel sind verdickte Stellen des oberen Keimblattes. Im Flächenbilde stellen beide zusammen eine ankerartige Figur dar (Fig. 2, Taf. I), die immer deutlicher hervortritt, damit der Verlängerung des Primitivstreifens eine Reduction des unter der Sichel liegenden Entodermbezirkes einhergeht. Das untere Keimblatt verdünnt sich an dieser Stelle zu einer einzelligen Lage und da diese sich gleichzeitig vom weissen Dotter abhebt, so wird dadurch die Furchungshöhle nach hinten zu ausgedehnt, und die Area pellucida auf Kosten des Ringgebietes um ein kleines Stück vergrössert (Zuwachsstück, His), wodurch sie eine birnförmige Gestalt erhält.

In dem Zuwachsstück ist die Sichel gelegen; sie muss, wenn die Verdünnung des Entoderms nicht über dem hinteren Rand der Sichel hinausgegangen ist, nach rückwärts zu an das Ringgebiet unmittelbar anstossen, im anderen Falle dagegen sind beide durch eine schmale, der Area pellucida àngehörige Zone geschieden und es erscheint dann die ankerförmige Verdickung des Ektoderms gänzlich im Innern des durchsichtigen Fruchthofes.

In dem Primitivstreifen tritt bald eine rinnenförmige Einsenkung auf, die Primitivrinne, deren Anfänge nach Koller ${ }^{1}$ ) bereits mit der Bildung der Sichel zusammenfallen, in der sie als Sichelrinne zuerst auftreten soll. Ob cine Sichelrinne in allen Fällen sich bildet, scheint mir jedoch sehr zweifelhaft, da bei dem ausgebildeten Primitivstreifen die Primitivrinne in Bezug auf 
ihre Ausdehnung sehr viclen individnellen Verschiedenheiten unterworfen ist. Bald ist sie nur kur und nimmt nicht die ganze Länge des Primitivstreifens ein, bald ist sie sehr seicht, kann einmal oder mehrfach unterbrochen sein, bald ist sie wiederum sehr tief. Nach meinem Dafürhalten ist eine Sichelrinne ursprünglich nur dann vorhanden gewesen, wenn auch noch bei dem ausgebildeten Primitivstreifen sich die Sichel noch erhalten hat, indem das hintere Ende des Letzteren, sowie die Primitivrinne schliesslich in zwei kurze Schenkel auseinandergeht (Fig. 3, 'Taf. I). Dic Primitivrinne theilt den Primitivstreifen in zwei Längshälften, die als Primitivwälle bezeichnet werden. Gegen die 12.-14. Stunde der Bebriitung, bis zu welcher der Primitivstreifen fortwihhrend an Lüinge gewinnt, hat derselbe seine vollendete Ausbildung crreicht (Fig. 3, Taf. I) und wïchst von nun an nicht mehr nach vorne weiter.

Wïhrend des Auftretens und der Vervollkommnung des Primitivstreifens hat sich die gesammte Keimhaut nach der Peripherie zu langsam ausgedehnt und umwächst, wïhrend sich die zu schildernden Entwicklungsvorgänge in dem durchsichtigen Fruchthofe abspielen, nach und nach den ganzen Dotter.

Un verständlicher zu sein, habe ich bisher die Entwicklung des Primitivstreifens im Zusammenhange erörtert, ohne auf andere sich gleichzeitig einstellende Veränderungen im Blastoderm Rücksicht zu nehmen, was ich jetzt nachholen muss. Diese beruhen in dem Auftreten und der Aușbreitung des mittleren Keimblattes oder des Mesoderm, dessen Entwicklung mit dem Escheinen der Sichel beginnt. Die Zellen derselben vermehren sich alsbald sehr stark, so dass die Sichel sowohl auf Kosten der unter ihr gelegenen, sich immer mehr verdünnenden Entodermtheile centralwïrts, d. h. nach unten zu in die Dicke wächst, als auch in den Stand gesetzt wird, nach vorne, sowie nach rückwärts Zellen abzugeben. Die von der Sichel nach rückwïrts auswachsenden Z Zellen verhalten sich ähnlich, wie die Zellen der Sichel selbst. Sic sind fest an einander gedrïngt und bilden fürs Erste eine einschichtige Lage, die sich zwischen Ektoderm und Entoderm des Ringgebietes einschiebt. Dieselbe tritt auf Längsdurchschnitten durch Keimh:iute der betreffenden Stadien deutlich hervor, im Flichenbilde dagegen ist sie weniger gut zu erkennen.

Diejenigen Zellen, welche aus der Sichel nach vorne zu austreten, gelangen jederseits von dem Sichelfortsat\% innerhalb der Area pellucida in den spaltförmigen Raum zwischen dem oberen und unteren Keimblatt und haben hier Plat\%, sich etwas weiter von einander zu entfernen; sie sind darum viel lockerer zusammengefügt.

Die gleichen Vorgïnge, wie hei der Sichel, wiederholen sich in successiver Reihenfolge auch bei dem Primitivstreifen; denn auch dieser ist ja nichts weiter, als eine Ektodermverdickung; überall da, wo diese bereits eine gewisse Stïrke erlangt hat, beginmen Zellen derselben seitwairts zwischen die beiden Keimbläter einzuwachsen. Indem sie sich mit den von der Sichel abstammenden Zellen zu einer intermediairen Zellenlage vereinigen, entsteht das mittlere Keimblatt. Aus der Bildungsweise desselben geht mit Nothwendigkeit hervor, dass es im Unfange der Sichel, sowie längs des Primitivstreifens mit dem oberen Keimblatt, von dem aus es cryengt wird, zusammenhïingen muss. Die Ausdehnung der Sichel ist viel kleiner, als die des Primitivstreifens. Daraus 
folgt, dass jene nur in der ersten Zeit, wenn dieser noch nicht sehr weit gediehen ist, für die Mesodermentwicklung in Betracht kommt; später erfolgt die weitere Anlage desselben fast ausschliesslich von dem Primitivstreifen aus. In manchen Fällen ist die Betheiligung der Sichel an der Bildung des mittleren Keimblattes auch von vorneherein schon eine sehr minimale; dies gilt für diejenigen Keimhäute, bei denen die Sichel, wie ich es nicht allzuselten beobachtet habe, nur eine äusserst geringe seitliche Ausdehnung erlangte, was in späteren Stadien an der nur schwachen Anschwellung des hinteren Endes des Primitivstreifens zu erkennen ist.

Da die Ausbildung des Primitivstreifens von hinten nach vorne zu fortschreitet, so werden dem entsprechend diejenigen Mesodermzellen, welche von der Sichel und dem hinteren Abschnitte des Streifens abstammen, indem sie zwischen den beiden anderen Keimblättern immer weiter nach aussen vordringen, eher das Ringgebiet erreichen müssen, als die von dem vorderen Abschnitte des Streifens aus wuchernden Mesodermzellen. Am besten kann man dieses Verhalten erkennen, wenn man eine Schnittreihe durchsieht, in welche der Quere nach eine Keimscheibe zerlegt ist, deren Primitiustreifen noch keine ausgesprochene Rinne zeigt, also etwa in der Mitte seiner Entwicklung steht. Die durch den vordersten Theil des Primitivstreifens gehenden Schnitte zeigen nur eine nach unten zu verdickte Stelle des Ektoderms; erst bei den durch das mittlere Drittheil fallenden Schnitten sind seitlich an dieser verdeckten Stelle flügelförmige Anhänge zu erkennen, welche eine kurze Strecke weit zwischen das obere und untere Keimblatt eindringen; dieselben entsprechen den Durchschnitten durch das im Entstehen begriffene Mesoderm. Je weiter nun die Schnitte nach hinten rücken, eine desto grössere Länge erreichen nach beiden Seiten hin die Mesodermanhänge des Primitivstreifens. Schliesslich erkennt man an den durch die hintersten Theile der Area pellucida gehenden Schnitten, dass das Mesoderm sich bereits bis in die Area opaca hinein vorgeschoben hat.

Im Flächenbilde muss in diesem Entwicklungsstadium derjenige Theil der Keimhaut, welcher bereits ein Mesoderm enthält, als ein annähernd gleichschenkliches Dreieck erscheinen, dessen abgerundete Spitze von dem Kopfende des Primitivstreifens eingenommen wird, und dessen Grundlinie bereits in das Ringgebiet hineinfällt, jedoch nicht gerade, sondern nach hinten convex ist, während die beiden Seitenlinien gleichfalls als leicht gebogene Linien zu Tage treten, deren Concavität nach vorne und aussen gerichtet ist (Fig. 2, Taf. I).

Die weitere mit der allmähligen Ausbildung des Primitivstreifens einhergehende Ausdehnung des Mesoderms schreitet nach hinten unter dem Ektoderm des Ringgebietes nur langsam fort; verhältnissmässig rasch breitet es sich dagegen seitlich von dem Primitivstreifen in der Area pellucida ans, indem die Mesodermzellen sich rasch vermehren und auch in der mittleren Querzone der gesammten Keimhaut bis in das Ringgebiet hinein vordringen. Die Figur, unter welcher um die 12.-14. Brütestunde nach vollständiger Entwicklung des Primitivstreifens das mittlere Keimblatt im Flächenbilde erscheint, kann man sich am besten construiren, wenn man dieselbe als ein Halboval auffasst, welches dadurch entsteht, dass man von einem Oval sich 
die eine Hälfte durch einen im kleineren Durchmesser desselben geführten Schnitt losgetrennt denkt (Fig. 3, Taf. I).

In unserem Falle ist nun das Halboval so gestellt, dass die der Halbirungslinie entsprechende Gerade nach vorne, die Bogenlinie desselben mit ihrem am meisten convexen Theil nach rückwärts gerichtet ist; die Bogenlinie fällt bereits durchaus in das Ringgebiet. Auch darf man sich die vordere Grenzlinie nicht als eine vollständige Gerade vorstellen, sondern sie ist in der Medianlinie durch das Kopfende des Primitivstreifens nach vorne etwas vorgebuchtet.

Nach der Ausbildung des Primitivstreifens fallen nun die weiteren Entwicklungsvorgänge vorwiegend in das vor dem letzteren liegende Gebiet der Area pellucida. Bei der Betrachtung von Flächenbildern solcher Keimhäute, welche dieser Phase der Entwicklung angehören, lässt sich leicht beobachten, wie von dem etwas anschwellenden Kopfende des Primitivstreifens ein sich nach vorne immer mehr verlängernder Fortsatz abgeht, der die Medianlinie cinhält. Kölliker hat denselben Kopffortsatz des Primitivstreifens genannt. Von Interesse ist das Verhalten desselben zu dem Embryonalschild. Schon durch den nach vorne sich verlängernden Primitivstreifen ist die Bogenfalte des Embryonalschildes länglich ausgezogen worden; ihre bisherige rundliche Umgrenzung aufgebend, geht sie in eine ovale Form über, die sich, wenn der Kopffortsatz entsteht und sich nach vorne verlängert, immer mehr streckt (Fig. 4 u. 5, Taf. I). Zu gleicher Zeit flacht sich die Falte immer mehr ab, wodurch die äusseren Grenzen des Embryonalschildes allmählig verwischt werden. Nur in seltenen Fällen sind dieselben so gut zu erkennen, wie bei der durch Fig. 5 Taf. I bildlich wiedergegebenen 16 Stunden bebrüteten Keimhaut. Hier grenzt sich das Oval des Embryonalschildes allseitig auf das Deutlichste ab. Die Längsaxe desselben nimmt der vordere Theil des Primitivstreifens, sowie der Kopffortsatz ein, welcher nach vorne zu sich dreieckig verbreitert und hier auch nicht mehr scharf seitlich begrenzt ist; er reicht bis nahe an das vordere Ende des Ovals heran.

Der Kopffortsatz des Primitivstreifens ist nun keineswegs, wie friiher allgemein für das Hühnchen behauptet wurde, eine Mesodermbildung, sondern er kommt, wie ich gezeigt habe ${ }^{1}$ ), durch eine leistenförmige Verdickung des Entoderms zu Stande. Im Querschnitt erscheint dieselbe unmittelbar vor dem Primitivstreifen spindelförmig; nach vorne zu wird diese Spindel allmählig breiter, indem die Uebergangsstelle derselben in die angrenzenden dünnen Entodermberirke sich immer mehr verwischt. Sehr instructiv sind mediane Längsschnitte, welche durch den Primitivstreifen und den Kopffortsatz gelegt sind. Wenn dieselben dünn genug ausgefallen sind, so lassen sie in der Nähe des Kopfendes des Primitivstreifens eine schiefe Linie erkennen, welche die Zellen des letzteren von dem Kopffortsatze trennt. Hinter der Grenzlinie ist das Entoderm dünn und nur lose mit den Zellen des Primitivstreifens verbunden, bereits unter ihr beginnt sich das erstere zu dem Kopffortsatze zu verdicken und behiilt sodann nach vorne zu die gleiche Stärke bei, un sich erst am vorderen Ende des Kopffortsatzes langsam wieder bis zur normalen Dicke des Ento-

1) I. Gerlach, Ueber die entodermale Entstehungsweise der Clorda dorsalis I. c. 
derms zu verschmälern. Mit anderen Worten, es scheidet auf solchen medianen Längsschnitten jene schiefe Grenzlinie eine Verdickung des Ektoderms (Primitivstreif) von einer Verdickung des Entoderms (Kopffortsatz).

Was das Mesoderm anlangt, so fällt dessen weitere Ausbreitung, nachdem der Kopffortsatz aufgetreten ist, nicht direct vor den Primitivstreifen, sondern dasselbe wuchert seitlich von der Mittellinie in den vor dem Primitivstreifen gelegenen Abschnitt der Area pellucida weiter nach vorne und aussen und ist in der Nähe des Ringgebietes am stärksten, während es medianwärts schwächer wird. Die Figur, unter der es, wenn der Kopffortsatz noch nicht sehr lang ist, im Flächenbilde erscheint, ist die eines gestreckten Kartenherzens, dessen stark abgerundete Spitze nach hinten sieht, während unmittelbar vor dem Primitivstreifen der Einschnitt des Herzens liegt, welcher zum Theil von dem Kopffortsatz ausgefüllt wird (Fig. 4). Je weiter der Kopffortsatz und die beiden Seitentheile des Mesoderms nach vorne wachsen, desto mehr nähern sich gegenseitig successive die Ränder des erwähnten Einschnittes (Fig. 5), indem das mittlere Keimblatt medianwärts gegen den Kopffortsatz zu wuchert und sich mit seinen Zellen dicht an denselben anlegt. Aus dem Gesagten ergibt sich, dass in der Region der Area pellucida, welche den Primitivstreifen enthält, die Ausdehnung des Mesoderms eine centrifugale ist, während sie in dem vor dem Primitivstreifen gelegenen Bezirke auch centripetal vor sich geht.

Mit der Entwicklung des Kopffortsatzes, sehr häufig aber schon vor derselben, bildet sich in dem vordersten 'Theile des durchsichtigen Fruchthofes eine bogenförmige Verdickung der Keimhaut aus. Dieselbe ist unter dem Namen der vorderen Amnionfalte (vordere Aussenfalte, $\mathrm{His}$ ) bekannt. Nach meinen Untersuchungen jedoch steht dieselbe zur Amnionbildung nur in indirecter Beziehung. Sie kommt dadurch zu Stande, dass sich von dem vorderen Theile des Randwulstes eine kleine Zone abspaltet. Dies geschieht in der Weise, dass sich vor der abzuspaltenden bogenförmigeń Zone der Randwulst innerhalb eines schmalen ebenfalls bogenförmigen Streifens zu einer einschichtigen platten Zellenlage verdünnt. Dadurch wird sowohl die verdünnte Stelle, als der abgespaltene Theil des Randwulstes in dem durchsichtigen Fruchthof mit einbezogen, so dass der letztere nach vorne zu vergrössert wird. Die vordere Amnionfalte selbst besteht sonach aus Zellen des Randwulstes; dieses Zellenmaterial ist offenbar dazu bestimmt, der weiteren Lüngenausdehnung des vorderen Theiles der Area pellucida Vorschub zu leisten. Dass dieses Material schon vor der Bildung einer richtigen Amnionfalte allmählig aufgebraucht wird, geht aus dem Umstand hervor, dass die sogenannte vordere Airnionfalte sehr bald nach ihrem Auftreten Unterbrechungen erleidet, indem offenbar an den betreffenden Stellen die Substanz der in Rede stehenden Bildung auf eine einzige platte Zellenlage reducirt wird.

Die weiteren Entwicklungsvorg̈̈nge, wèlche wir zu verfolgen haben, betreffen hauptsächlich den Kopffortsatz, sowie das ihn umgebende lïnglich ausgezogene Embryonalschild. Mit dem fortschreitenden Lüngenwachsthum des ersteren streckt sich auch das letztere immer mehr. Schon oben wurde erwähnt, dass die Bogenfalte des Embryonalschildes`sich allmählig abflacht. Dies ist besonders in ihrem hintersten Abschnitte der Fall, welcher jederseits 
neben dem vorderen Theile des Primitivstreifens gelegen ist. In diesem Abschnitte ist auch die Streckung des Embryonalschildes eine nur geringe; diese fällt fast ausschliesslich vor'den Primitivstreifen, wesshalb hier auch das Embryonalschild eine stärkere Verschmälerung erleidet (Fig. 6, Taf. I). In gleicher Zeit tritt am vorderen Ende des Embryonalschildes eine Veränderung auf, welche die Bildung der Kopfdarmhöhle einleitet. Ich muss hier an eine frühere Angabe erinnern, wonach der Kopffortsatz schon bald nach seinem Auftreten eine Verbreiterung seines vorderen Endtheiles zeigt. Dieselbe ist von dreieckiger Form und es geht die in der Medianlinie liegende Spitze des Dreiecks nach rückwärts continuirlich in den geradlinigen Theil des Kopffortsatzes über (vgl. Fig. 5, Tafel I). Diese nicht scharf zu bezeichnende Uebergangsstelle ist für den Anfang der Entwicklung der Kopfdarmhöhle von Bedeutung. Wenn Kopffortsatz und Embryonalschild eine gewisse Länge erreicht haben, so senkt sich von der genannten Stelle nach hinten zu die Keimhaut in der Medianlinie ventralwärts ein. Es entsteht so ein nach dem Dotter zu gerichteter Kiel des Blastoderms, welcher vorne ziemlich scharf begrenzt ist, und nach rückwärts sich allmählig abflacht.

Ueber die Lage dieses Kieles erhält man am besten Aufschluss, wenn man die in den betreffepden Bildungsstadien befindlichen Keimhäute von der Ventralseite aus betrachtet. Theilt man die Strecke von dem hinteren Ende des Kopffortsatzes an bis zu der Stelle, wo er in jene dreieckige Verbreiterung ïbergeht, in zwei Hälften, so ist der Kiel nur in der vorderen deutlich ausgeprägt, in der hinteren Hälfte ist er schon sehr flach geworden, und unmittelbar vor dem Primitivstreifen fast ganz verschwunden. Gleichzeitig mit der Bildung des Kieles muss die Bogenfalte des Embryonalschildes, welche sich sowohl zu beiden Seiten als auch vor dem Kopffortsatz bedeutend abgeflacht hatte, und darum kaum mehr zu bemerken war, im vordersten Theile des Schildes wieder verstärkt zum Ausdruck kommen. Da diese sich hier dorsalwïrts über das Nivean der Keimhaut erhebt, so muss sie von der ventralen Seite aus betrachtet, als eine Furche erscheinen, und zwar von der Form eines Hufeisens. Sie besteht demnach aus zwei Längsfurchen, welche durch eine kurze quere Verbindungsfurche, die im Bogen um das vordere Ende des Kieles herumgeht, mit einander zusammenhïngen. Nach hinten zu verlieren sich die beiden Furchen ebenso, wie der Kiel, ziemlich rasch in dem Niveau der Keimhaut.

Von der vorderen Querfurche geht die Bildung der Kopfdarmhöhle aus. An dieser Stelle besteht die Keimhaut zuerst nur aus dem Ektoderm und dem dreiseitig verbreiterten Ende des Kopffortsatzes; das Mesoderm ist hier noch nicht bis in die nächste Nähe der Medianlinie vorgedrungen. Dadurch erklïrt es sich, wesshalb die Kopfdarmhöhle in ihren ersten Anfüngen nur eine zweischichtige Wand besitzt; diese besteht nur aus einem sehr verdickten Entoderm und dem Ektoderm. Das mittlere Keimblatt wandert erst spiiter von der ventralen Seite aus ein.

Mustert man eine in diesem Stadium befindliche Keimhaut von der dorsalen Seite aus (Fig. 6, 'Taf. I), so füllt die faltenförmige Erhebung des embryonalen Kopfendes am meisten in das Auge. Da diese ja die Gestalt eines Hufeisens besitzt, so können wir ebenfalls zwei Lïngsfalten und eine 
bogenförmige Querfalte unterscheiden. Die letztere ist unter dem Namen der Kopffalte bekannt. Die beiden Längsfalten sind nichts Anderes, als die vorderen Theile der Rückenwülste, welche die vorne sehr tiefe Medullarrinne oder Rückenfurche zwischen sich fassen. Nach hinten zu werden Rückenrinne und Medullarwülste immer flacher; die letzteren sind aber auch hier schon deutlich zu erkennen, da ihre Ränder gegenüber den angrenzenden Theilen der Keimhaut sich bereits etwas erhoben haben, was durch die allmählige Dickenzunahme der unter ihnen liegenden Mesodermtheile bedingt ist. Die Kückenwülste fassen mit ihren hinteren Enden den vorderen Theil des Primitivstreifens ein, sie sind hier etwas breiter, da, wie wir wissen, dieser Abschnitt des Embryonalschildes sich nicht sehr gestreckt, und darum auch nur wenig sich verschmälert hat.

Es hat sich demnach aus dem Ektoderm des ursprünglichen Embryonalschildes die Rückenplatte gebildet, worunter wir jenen Theil des Ektoderms der Area pellucida verstehen, der sich in dem Bereiche der Rïckenfurche befindet, und der von den Rändern der Medullarwülste seitlich begrenzt wird. Den mit der Rückenplatte sich deckenden Bezirk' der gesammten Keimhaut können wir mit His als Stammeszone bezeichnen. In ihrer Umgrebung, abgesehen von dem vor der Kopffalte liegenden Theil der Keimhaut, wo diese nur zweiblätterig ist, hebt sich eine zweite Zone ab, die Parietalzone, welche bis zu dem hinteren Ende des Primitivstreifens reicht. Sie ist der Ausdruck einer etwas stärkeren Mesodermeinlage, als die der peripheren Bezirke der Area pellucida ist, welche man die Aussenzone nennen kann. Innerhalb der letzteren ist das Mesoderm am schwächsten entwickelt. Im Bereich der Area opaca können wir ebenfalls einen Bezirk unterscheiden, in welchem das Mesoderm bereits vorhanden ist, das nur in den vorderen Theil des Ringgebietes sich noch nicht eingeschoben hat. Der Bezirk der Area opaca, welcher bereits das mittlere Keimblatt enthält, stellt die künftige Area vasculosa dar.

Kehren wir nun zu der Rückenfurche zurück, so finden wir unter dem Boden derselben, die Medianlinie einhaltend, den Kopffortsatz, oder wie wir jetzt schon sagen müssen, die Chorda dorsalis; nur im hintersten Theile der Rückenfurche liegt an deren Boden das vordere Ende des Primitivstreifens. Mit dem Lungenwachsthum des Kopffortsatzes geht einher eine Verschmälerung seines spindelförmigen Querschnittes; derselbe wird allmählig rundlich und zwar am frühesten im hinteren Theile des Kopffortsatzes, was dann weiter nach vorne zu fortschreitet; zu gleicher Zeit mit dem Rundlichwerden der Chorda löst sie sich allmählig von dem Entoderm ab. Es entsteht so ein cylindricher Chorda-Strang, welcher zuerst einen etwas grösseren Durchmesser hat, als in den darauf folgenden Stadien, weil mit dem Lüngenwachsthum der Chorda eine Verschmälerung derselben mit einher geht. Das Rundlichwerden der Chorda geht ferner parallel mit einer stärkeren Ausbildung der neben ihr liegenden Mesodermtheile; dieselben sind zuerst im vorderen Abschnitte der Medullarwülste noch sehr dünn, hinten dagegen schon dicker, wo sie sich auch an der Grenze zwischen Stammes- und Parietalzone von den Seitentheilen des Mesoderm zuerst trennen, und damit zu den Urwirbelplatten werden. Die ersten Querspalten in den letzteren, und somit die ersten 
Urwirbel treten unmittelbar vor dem Kopfende des Primitivstreifens auf. In der Fig. 6, Taf. I ist die Lage des ersten Urwirbelpaares angedeutet.

Sind die Medullarwülste und damit die Medullarfurche angelegt, was gegen die 20.-22. Stunde des ersten Brütetages vollendet ist, so ist ein Entwicklungsstadium erreicht, in welchem sowohl das animale als das vegetative Rohr in der Anlage vorhanden sind. Ersteres wird durch die Medullarfurche repräsentirt, die Bildung des letzteren wird durch das Auftreten der Kopfdarmhöhle eingeleitet, deren erste Anfänge vorhin näher beschrieben worden sind. In der Chorda haben wir einen Vorläufer der Wirbelsäule, welcher sich zwischen animale und vegetative Röhre einschiebt, und welcher die embryonale Längsaxe einnimmt. Auch eine Eintheilung in die späteren Körperregionen ist theilweise angedeutet, indem der hintere Theil der Stammeszone, welcher den Primitivstreifen enthält, sich zu der späteren Beckenregion entwickelt, die vorderen Abschnitte sich dagegen zu den Rumpf- und Kopftheilen ausbilden. Aus diesen Gründen erscheint es mir zweckmässig, das in Rede stehende Entwicklungsstadium zur zeitlichen Abgrenzung der Entwicklungsvorgänge zu verwerthen. Wenn dasselbe erreicht ist, so ist die Ontogenie bis zu einem gewissen Abschlusse gelangt, und es empfiehlt sich desshalb, bis zu dem genannten Stadium den sich entwickelnden Organismus als Embryonalanlage zu bẻzeichnen, da bis zu dieser Zeit die in der Keimhaut ablaufenden Veränderungen darauf hinzielen, die Bildung des Nerven- und Eingeweiderohres anzubahneñ. Sobald jedoch die Rückenfurche vollendet und die Kopfdarmhöhle in ihren ersten Anfängen vorhanden ist, wird man mit vollem Rechte schon von einem Embryo sprechen dürfen, denn von nun an bestehen die weiteren Entwicklungserscheinungen hauptsächlich in einer weiteren Ausbildung und Vervollkommnung der bereits existirenden Organanlagen. Ich werde daher in den folgenden Betrachtungen unter Bezugnahme auf die soeben erörterte Entwicklungsgrenze zwischen Embryonalanlage und Embryo unterscheiden.

Die wichtigsten Bildungsvorgänge in der Keimhant, welche wir bisher besprochen haben, und die durch die Figuren 1-6, Taf. I repräsentirt werden, lassen sich folgendermassen kurz zusammenfassen: Auftreten des Embryonalschildes, Entstehung des Primitivstreifens, Einwachsen desselben in das Embryonalschild, Ausbildung des Kopffortsatzes, Umformung des Embryonalschildes in die Stammeszone durch Ausbildung der Kopffalte und der Rückenwiilste, Uebergang des Kopffortsatzes in die Chorda.

Hinsichtlich der weiteren Entwicklung des Embryo's, welche dessen fortschreitendes Längenwachsthum, den Schluss der Medullarrinne, die Vervollkommnung der Kopfdarmhöhle, die Genese des Herzens etc. betreffen, verweise ich auf die entwicklungsgeschichtlichen Handbücher von Kölliker und Balfour, da es nicht in meiner Absicht liegt eine detaillirte Schilderung dieser Vorgänge zu geben. Für die folgenden iiber die Entstehung der Doppelmissbildungen anzustellenden Betrachtungen sind hauptsïchlich die ersten Entwicklungsstadien von Belang, die späteren dagegen von weit geringerer Bedeutung. Ich beschränke mich desshalb an dieser Stelle darauf, an der Hand der Fig. 7, 'Taf. I, in welcher ich cine Keimhant vom Ende' des ersten Brütetages abgebildet habe, das Fortschreiten der Entwicklung kurz zu 
erläutern. Vergleicht man diese Abbildung mit Fig. 6, Taf. I, so stellt sich heraus, wie das Längenwachsthum des Embryo einzig und allein in den vor dem Primitivstreifen gelegenen Abschnitt fällt. Das hintere Ende der Medullarrinne, an deren Boden der vordere Theil des Primitivstreifens liegt, hat sich nur wenig verändert. Die Streckung des Embryo in seinen mittleren Theilen ist besonders gut an der hier eingetretenen Verschmälerung ersichtlich. In Folge derselben musste das Kopfende weiter nach vorne rücken, und wir sehen desshalb, wie dieses bereits sich über die Keimhaut beträchtlich erhoben hat und wie durch sein Wachsthum nach vorne zu die Kopfdarmhöhle zugleich sich verlängern muss. Dieselbe stellt nun eine nach vorne und dorsalwärts gerichtete blind endigende Ausstïlpung der Keimhaut dar, die unter das vordere Ende der Medullarrinne zu liegen kommt, und welche sich ihrer Entstehungsweise gemäss nach hinten und ventralwärts öffnen muss; diese Oeffnung heisst die vordere Darmpforte. Das Medullarrohr hat sich im vorderen Embryonalabschnitt schon theilweise geschlossen; sein vorderes Endstuick ist jedoch noch offen, doch ist an demselben bereits die Verbreiterung ausgesprochen, welche zur Genese des ersten Hirnbläschens führt. In der schmäleren mittleren Region des Embryo ist unter der Medullarfurche die Chorda zu erkennen, neben ihr eine Anzahl von Urwirbeln. Der hinterste Theil. der Medullarfurche, an deren Boden der Primitivstreifen immer undeutlicher wird, entspricht der Gegend des späteren Sinus rhomboidalis. Der Embryo ist mit Ausnahme seines Kopfendes seitlich von der Parietalzone umgeben, die nur in der mittleren Embryonalregion etwas schwächer ausgebildet ist. Nach aussen von derselben folgt die Aussenzone. Auch das Mesoderm hat sich innerhalb der Area opaca ansehnlich ausgebreitet; nur der unmittelbar vor der Area pellucida liegende Abschnitt der ersteren enthält noch kein mittleres Keimblatt. Vor dem Kopfende des Embryo befindet sich die vorderc Amnionfalte; die Bildung des Herzens leitet sich ein.

Ein besonderes Interesse bietet schliesslich das Verhalten des Primitivstreifens während und nach der Ausbildung der Medullarfurche dar. Hierüber gibt ein Vergleich der Figuren 3-7, Taf. I Aufschluss. Seine grösste Längenausdehnung besitzt derselbe in dem Entwicklungsstadium der Fig. 4, in welchem der Kopffortsatz noch klein ist. Wenn der letztere sich jedoch nach vorne zu verlängert, so tritt eine allmählige Verkürzung des Primitivstreifens ein. Kurz nachdem sich die Rückenfurche gebildet hat, besitzt dic Chorda ungefähr die gleiche Länge mit dem Primitivstreifen; bald wird der letztere in Folge des raschen Embryonalwachsthums und der gleichzeitig dainit eīihhergehenden allmähligen Verkürzung des Streifens von der Chorda immer mehr an Länge übertroffen, (Fig. 7). Mit dem Auftreten der Rückenfurche stellt sich eine Anschwellung des vorderen Endes des Primitivstreifens ein, (Schwanzanschwellung, Dursy). Die Genese derselben denke ich mir: in der folgenden Weise. Die Chorda ist cingeschaltet zwischen die Kopffalte und das vordere Ende des Primitivstreifens. Wiichst dieselbe in die Länge, so werden durch den Wachsthumsdruck, der hiebei sich geltend macht, die beiden genannten Bildungen aus einander geschoben werden müssen. Dic Kopffalte, die sich bald nach vorne umlegt, sowie das gesammte Kopfende wird dadurch immer melı noch vorne gedrïingt werden müssen; anch zur 
Verkürzung des Primitivstreifens wird das Läng’enwachsthum der Chorda beitragen, und zwar in der Weise, dass sein vorderes Ende in sagittaler Richtung stark comprimirt wird, was zur Bildung der Schwanzanschwellung führt.

Was die weiteren Schicksale des Primitivstreifens anbetrifft, so ist zwischen dem vorderen Theil desselben, welcher an dem Boden der Rückenfurche liegt, und dem hinteren Abschnitt, der in die Parietalzone fällt, zu unterscheiden. Die erstere Abtheilung des Streifens wird dem Beckenende des Embryo einverleibt, und über ihr kommt der Sinus rhomboidalis zu liegen; der hintere Abschnitt des Primitivstreifens bildet sich immer mehr zurück, verdünnt sich unter dem Schwinden der Primitivrinne immer mehr und schliesslich ist er im Flächenbilde überhaupt nicht mehr zu erkennen.

\section{Säu g ethi er e.}

Unsere Kenntnisse iiber die ersten Stadien der Embryonalentwicklung der Sängethiere sind trotz vielfacher Untersuchungen noch lange nicht bis zu dem Grade der Vollkommenheit gediehen, dass sie den für die Bildung der Vogelembryonen gewonnenen Erfahrungen an die Seite zu stellen wären. Daran ist der Umstand Schuld, dass nicht nur die Untersuchung selbst, sondern die Beschaffung des nöthigen Materials mit viel grösseren Schwierigkeiten verknüpft ist, als bei den Vögeln. Da bei den letzteren die Entwicklung ausserhalb des mütterlichen Organismus stattfindet, so kann man dieselbe nach Belieben beginnen lassen, indem man die Eier der Brutwärme aussetzt. Der Anfang der Bebrütung stellt somit den Zeitpunct dar, in welchem die Veränderungen der Keimhaut sich einleiten, die zum Auftreten der Embryonalanlage führen. Die Entwicklungsdauer, d. h. das Alter der Embryonen datirt von diesem Zeitpuncte an, und es entspricht der Grad der Ausbildung der Embryonen der Länge der Bebrütung. Man kann somit leicht bestimmte Entwicklungsstadien erhalten, wenn man die Eier zur richtigen Zeit aus dem Brütofen herausnimmt. Bei den Säugethieren dagegen haben wir keine so präcisen Anhaltspuncte, um die Entwicklungsdauer zu bestimmen; bei ihmen schreitet im Gegensatz zu den Vögeln die Entwicklung ununterbrochen fort, da sie sich ja im Inneren des Thierkörpers vollzieht. Ihr Anfang füllt somit mit der Befruchtung zusammen, deren zeitliches Eintreten wir nicht ermitteln können. Von dem Acte der Begattung ist sie selbst bei den Eiern der gleichen Ovulationsperiode durch ein variables Zeitintervall getrennt, und dies ist die Ursache, wesshalb wir bei einem Thiere, welches einige Zeit nach der Copulation getödtet wurde, die dem Uterus entnommenen Eier nicht gleich weit entwickelt vorfinden.

Wir können somit bei unserer Unkenntniss über die Zeit der Befruchtung die Entwicklungsperiode der im Inneren des Uterus befindlichen Fier nur approximativ schätzen und wissen nicht genau, welche Entwicklungsstadien wir antreffen werden, wenn wir nach Ablauf einer gewissen von dem Momente der Begattung an \%u rechnenden \%eit die 'Thiere tödten und die im Uterus enthaltenen Eier untersuchen. Stellt man sich daher die Aufgabe, eine ganz bestimmte Phase der Embryogenese genauer zu studiren, so wird man eine grosse Anzahl von Thieren opfern muissen, um recht viele Eier von der beab- 
sichtigten Entwicklungsstufe zu erhalten, unter denen womöglich die gleichen Entwicklungsstadien mehrfach vertreten sind. Letzteres ist besonders aus dem Grunde äusserst wünschenswerth, weil sehv viele individuelle Verschiedenheiten namentlich in der ersten Zeit der Embryonalbildung vorkommen. Ueber dieselben wird man nur dann einen Ueberblick gewinnen können, wenn der Untersuchung ein verhältnissmässig reiches Beobachtungsmaterial zu Gebote steht.

Wohl mancher von den Autoren, welche über die erste Entwicklung des Säugethierembryo geschrieben haben, mag in Bezug auf sein Untersuchungsmaterial etwas knapp bestellt, und darum nicht in der Lage gewesen sein, einmalige Beobachtungen revidiren zu können. Nur so erkläre ich mir die in vielen und wichtigen Puncten so weit aus einander gehenden Angaben und Ansichten, welche das Studium der in Rede stehenden Entwicklungsvorgänge für Jeden, der sich nicht selbst mit der Sache näher befasst hat und nach eigener Erfahrung urtheilen kann, höchst merquicklich machen müssen.

Unter den Säugethieren ist es das Kaninchen, über dessen Entwicklung wohl die meisten Beobachtungen vorliegen. Aus der Rëihe der ïlteren Arbeiten über diesen Gegenstand hebe ich die classischen Untersuchungen Bischoff's ${ }^{1}$ ) hervor. In den letzten Jahren hat E. v. Beneden bei dem Kaninchen die Furchung und Blätterbildung genauer studirt ${ }^{2}$ ), ferner haben Hensen ${ }^{3}$ ) und Kölliker ${ }^{4}$ ) sich sowohl mit dem gleichen Gegenstande, als auch mit dem Aufbau des Embryonalleibes vom Kaninchen eingehend beschäftigt, und sind zu Resultaten gelangt, deren Uebereinstimmung in Anbetracht der grossen Schwierigkeiten, mit denen die Untersuchung zu kämpfen hat, ungemein wohlthuend berühren muss. Insbesondere ist es $\mathrm{Kölliker,} \mathrm{welcher}$ iiber die ersten Entwicklungsvorgänge des Kaninchens in seinem Lehrbuche ein überaus klares und anschauliches Bild entwirft. Mir selbst stehen hieriuber nur vereinzelte Beobachtungen zur Verfügung und es wird daher die folgende Schilderung hauptsächlich auf den Angaben von Kölliker und Hensen basiren. Da das Handbuch Kölliker's eine Reihe von Abbildungen enthält, welche die Embryonalanlage des Kaninchens in verschiedenen Stadien illustriren und da dasselbe wegen seiner weiten Verbreitung für Jedermann leicht zugänglich ist, so habe ich es für überflïssig gehalten, Copien dieser Figuren Kölliker's meiner Monographie beizugeben, und werde daher bei der Beschreibung der einzelnen Stadien auf die genannten Abbildungen verweisen.

Indem ich die Furchung des Kanincheneies und die darauf folgende Ausbildung der Keimblase übergehe, beginne ich bei einem Stadium, welches ètwa am 7. Tage nach der Begattung erreicht wird. Un diese Zeit besit\%t die Keimblase, deren Wand von der Zona pellucida etwas abstelit, cine linng-

1) Bischoff, Entwicklungsgeschichte rles Kanincheneies. 1842.

2) E. v. Beneden, Recherches sur l'embryologie des mammilères. Ia lonmaliom des feuillets chez le Lapin. Archives de Biologic T. I, pag. 136, 1880.

${ }^{3}$ ) Hensen, Beobachtungen ïber die Befrnchtung und Entwicklung des Kaninehrus und Meerschweinchens. Zeitschxift für Anatomie mol EntwickTungsegeschichıte Bil. I, pisg. 21:; und $35.3,1875 / 76$.

4) Kölliker, Entwicklungsgeschichte des Mensehen und der höhrorn Thicre. 1879. Siehe auch: '/oolog. Anzeiger $\mathrm{Nr}$. 61 n. 62, 1880. 
lich runde Form, und an einer Stelle zeigt dieselbe einen rundlichen weisslichen Fleck, den Embryonalfleck. Die von Kölliker in Fig. 150 und 151 abgebildete Keimblase, welche diesem Stadium angehört, hatte eine Länge von 3,47 Mm. und eine Breite von 2,85 Mm. Der Embryonalfleck zeigte einen Durchmesser von 0,57 Mm. Was die Zusammensetzung der Keimblase anlangt, so besteht dieselbe aus einer äusseren Zellenlage, dem Ektoderm, dessen Innenfläche zum Theil von einer zweiten Zellenlage, dem Entoderm überzogen wird. Die Wand der Keimblase ist demnach theils doppelblätterig, theils noch einschichtig ${ }^{1}$ ). Der Embryonalfleck nimmt die Mitte des doppelblätterigen Theiles der Keimblase ein. Betrachtet man die Stelle des Embryonalfleckes als den einen Pol der Keimblase, so erstreckt sich das Entoderm nur auf die eine Polhälfte des Eies, indem es um die genannte Entwicklungszeit erst bis zu dem Aequator der Keimblase vorgedrungen ist. Später umwächst es allmählig die Höhlung der Keimblase vollständig, worauf diese durchaus aus zwei Keimblättern besteht. Dieselben stellen einschichtige Zellenlagen dar; das Entoderm setzt sich aus mehr platten Zellen zusammen, und ist desshalb sehr dïnn; die Zellen des Ektoderms sind etwas höher. An einer Stelle jedoch 'findet man statt der niedrig cubischen Zellen des Ektoderms höhere, cylinderförmige Zellen, und diese Stelle deckt sich mit dem Embryonalfleck. Derselbe hebt sich nur dadurch von seiner Umgebung ab, dass innerhalb seines Bezirkes die Ektodermzellen an Höhe nahezu um das Dreifache die sonstigen Zellen des äusseren Keimblattes übertreffen. Das Entoderm dagegen verhält sich im Bereiche des Embryonalfleckes ebenso, wie an anderen Orten. Es ist demnach der Embryonalfleck nichts Anderes, als eine verdickte Stelle des äusseren Keimblattes. Aus einer Zeichnung Bischoff's (Fig. 42 C), welche eine Seitenansicht des Embryonalfleckes darstellt, sowie aus dem von Kölliker (Fig. 152) abgebildeten Durchschnitt durch denselben scheint mir hervorzugehen, dass der Embryonalfleck eine leichte kuppenförmige Vorwölbung der Keimblase bildet. Auch die Figur 17B Hensen's, welche ein etwas älteres Entwicklungsstadium wiedergibt, zeigt deutlich ein solches Verhalten.

Die nächstfolgende Veränderung, welche die Keimblase erleidet, beruht auf einer Vergrösserung des Embryonalfleckes; derselbe streckt sich in die Länge und nimmt allmählig eine birnförmige Gestalt an. Gleichzeitig dehnt sich, wie schon erwähnt, das Entoderm immer mehr über die andere Polhälfte der Keimblase aus. Der Uebergang des runden in den birnförinigen Embryonalfleck bedarf noch einer genaueren Untersuchung, welche darüber zu entscheiden haben wird, ob die Vergrösserung desselben dadurch zu Stande kommt, dass an einer Stelle die an den Fleck anstossenden Zellen des Ektoderms suceessive ebenfalls cylinderförmig werden, oder ob, wie v. Beneden ${ }^{2}$ )

1) Diese Angabe entspricht jedoch in sofern nicht ganz dem richtigen Sachverhalt, als im Berirke des Embryonalfleckes zur Zeit seines Auftretens und anch noch in den nächstfolgenden lintwicklungsstadien der Aussenfläche des Ektoderms eine ans sehr platten Zellen bestehende Deckschichte anfliegt. Dieselbe ist von Rauber (Sitzungsberichte der naturf. Gesellschalt zu Leipzig 2. Jahrg., 1875) zuerst beobachtet worden. Nach den Untersuchungen Kölliker's schwindet jedoch diesclbe verhithtnissmässig rasch, und dies ist dè Grund, wesshalb ich im 'Texte derselben keine brwähnung gethan habe.

2) 1. c. jitg. 186 . 
befürwortet, ein halbmondförmiger Bezirk der Umgebung eine Verbindung mit dem Embryonalfleck eingeht, wodurch derselbe eine Art von Zuwachsstück erhalten würde. Ich bemerke, dass v. Beneden angibt, dass innerhalb dieses Halbmondes zwischen Ektoderm und Entoderm eine mittlere Zellenlage vorkomme, während die vor demselben gelegene kreisförmige Region des Embryonalfleckes nur aus zwei Keimblättern bestehe. Die von v. Beneden als Halbmond bezeichnete Region kann man als den hinteren Bezirk des Embryonalfleckes auffassen, da in demselben die ersten Spuren des Primitivstreifens sichtbar werden. Dieselben erscheinen als eine die hinterste Stelle des Embryonalfleckes einnehmende rundliche Trübung, die nicht sehr scharf umgrenzt ist und welche nach vorne sich allmählig verlängert, so dass das ganze Gebilde in einem gewissen Stadium eine keulenförmige Gestalt darbietet, deren breiteres Ende, nach hinten sieht und bis an den Rand des Fleckes reicht, dessen vorderer Theil sich verschmälert und schliesslich ohne scharfe Grenze aufhört. Kölliker hat einen Embryonalfleck dieses Stadiums in seiner Fig. 157 wiedergegeben; das betreffende Ei besass eine Länge von $5 \mathrm{Mm}$, der Embryonalfleck eine solche von 1,61 Mm. Ein ähnliches Stadium kam mir selbst zur Beobachtung, und es schien mir schon bei der Untersuchung der frischen Keimblase ein hinterer halbmondförmiger Theil von dem vorderen kreisförmigen Bezirk des Embryonalfleckes sich, wenn auch nicht sehr deutlich, abzuheben. Nach sorgfältiger Erhärtung der Keimblase war sogar eine sehr scharfe Grenze zwischen beiden aufgetreten, indem der vordere kreisförmige Abschnitt stark prominirte.

Hensen bildet in seiner Fig. 17 A einen auf der gleichen Entwicklungsstufe befindlichen Embryonalfleck ab und hat denselben später auch in Längsschnitte zerlegt. Dadurch gelang es ihm nachzuweisen, dass im Bereiche der als Halbmond bezeichneten Stelle des Embryonalfleckes eine mittlere mit dem Ektoderm zusammenhängende Zellenlage, das im Entstehén begriffene Mesoderm, zwischen den beiden anderen Keimblättern aufgetreten ist (Fig. 19 der Hensen'schen Abhandlung). Es fällt somit die Bildung des mittleren Keimblattes mit dem Auftreten des Primitivstreifens zusammen. Das erstere steht nach Kölliker, der die erste Anlage des Primitivstreifens auch auf Querschnitten untersuchte, genetisch in keiner Beziehung zu dem Entoderm, sondern stammt allein von dem Ektoderm ab. Ganz in der gleichen Weise, wie beim Hühnchen, tritt der Primitivstreifen als eine Verdickung oder Wucherung des Ektoderms auf und von demselben aus entwickelt sich das mittlere Keimblatt.

Auch das weitere Vordringen des Primitivstreifens gegen die Mitte des Embryonalfleckes und das Auftreten der Primitivrinne erfolgt den Angaben Kölliker's zufolge ganz ebenso wie bei dem Hühnchen. Während dieser Vorgänge nimmt der Embryonalfleck etwas an Länge zu. Bei einer Keimblase, deren Embryonalfleck 1,73 Mm. lang war (Fig. 158), fand Kölliker bereits einen gut ausgebildeten, mit Primitivrinne versehenen Streifen von 0,85 Mm. Länge und 0,22 Mm. Breite. Sein vorderes Ende lag ungefähr in der Mitte des Embryonalfleckes.

Bei etwas weiter entwickelten Eiern bemerkt man um den Embryonalfleck eine allmählig sich ausdehnende, nicht scharf ungrenzte ringförmige Zone, welche man als den sich bildenden Gefiisshof oder die Area vasculosa 
ansprechen muss. Derselbe kommt nach der Ansicht Kölliker's dadurch zu Stande, dass das von dem Primitivstreifen aus zwischen die beiden anderen Keimblätter peripherwärts vordringende Mesoderm über den Embryonalfleck hinauswächst. Näheres über die Art der Ausbreitung des Mesoderms, besonders in der vor dem Primitivstreifen gelegenen Hälfte des Embryonalfleckes, ist bis jetzt noch nicht bekannt; doch lassen die Zeichnungen Kölliker's wie die Hensen's erkennen, dass der Embryonalfleck in dem sich bildenden Getässhof excentrisch gelegen ist, indem er bis nahe an den vorderen Rand des letzteren heranreicht, während das hintere Ende des Primitivstreifens von dem hinteren Rand der Area vasculosa beträchtlich entfernt ist. Es erinnert dieses Lageverhältniss des Gefässhofes zum Primitivstreifen an das Auswachsen des Mesoderms bei dem Hühnchen, wo dasselbe in der ersten Zeit ja auch hinter dem Primitivstreifen am weitesten in die Arca opaca hinein vorgedrungen erscheint ${ }^{1}$ ).

Ist die Bildung des Primitivstreifens vollendet, so tritt vor demselben eine rinnenförmige Einsenkung auf, die Rückenfurche, zu deren Seiten sich die Medullarwiilste immer mehr erheben. Die letzteren verlängern sich auch nach hinten zu, so dass sie das vordere Ende des Primitivstreifens, wie aus der Fig. 161 Kölliker's ersichtlich, seitlich umschliessen. Das vordere Ende des Primitivstreifens verdickt sich mit der Ausbildung der Rückenfurche immer mehr und stellt so den Endwulst oder den Knoten des Primitivstreifens (Hensen) dar. Ferner zerfällt der Embryonalfleck, der nach Kölliker und Hensen die gesammte Embryonalanlage vorstellt, in eine mittlere Stammeszone und in eine dieselbe umgebende Parietalzone. Die Stammeszone ist zuerst nur in dem vorderen und mittleren Theile der Embryonalanlage deutlich begrenzt und hat die gleiche Ausdehnung, wie die Medullarplatte, d. h. derjenige Theil des Ektoderms, welcher am Boden der Rückenfurche liegt, und aus dem späterhin das Medullarrohr sich bildet. Die Parietalzone ist ebenfalls nur in ihrem vorderen Theile scharf begrenzt und zeigt zu beiden Seiten der Kopfgegend an ihrem Rande eine dunkle Stelle, welche die erste Andeutung der doppelten Herzanlage repräsentirt. Zur Zeit des Auftretens der beiden Zonen ist die nach vorne zu sich ausdehnende Embryonalanlage nahezu $3 \mathrm{Mm}$. lang gewor-. den (siehe Fig. 163 der Kölliker'schen Entwicklungsgeschichte). Sie besitzt eine bisquitförmige Gestalt; ihre schmälste Region fällt nicht weit vor den Primitivstreifen. An dieser Stelle treten in der Stammeszone auch die ersten Urwirbel auf, welche so ziemlich die Mitte der gesammten Embryonalanlage einnehmen. Je mehr der vor dem Primitivstreifen gelegene 'Theil der Embryonalanlage unter allmähliger Vermehrung der Urwirbelpaare in die Lünge

1) Berrits nach Abschluss moines Manuscriptes crhielt ich duch die Freundlichlicit des Verlassers die neneste Arlocit Kölliker's über die Entwicklnng der Keimblitter des Kaninchens zugesehickt. (Festschrift zur Feicr des 300jährigen Bestehens der Universilait IViir\%lurg.) Auch Kölliker macht (pag. 42 u. 43 des Separatabdruckes) auf die Aehulichkoit anlincrksan, welche in einem gewissen Entwicklungsstadium das Flächenbild des Mesuderms des Kaninchens mit dem des Hiilnehens anfweist. Anch die $\Lambda$ bloildungen, welche K. von den costen Entwicklungsstatien des Kaninchens gibt (Fig. 1-10), erinnern sehr an das Aussehen der nir vorliegenden Keimhaiute des Hiihnchens aus den entspreclienden Starlien. 
wächst, desto mehr verkürzt sich sowohl absolut wie relativ der Primitivstreifen selbst. Derselbe scheint, wie ein Vergleich der Kölliker'schen Figuren 163, 164 und 165 lehrt, sich in dem einen Falle schneller, in dem anderen langsamer zurückzubilden. Besonders möchte ich auf den Primitivstreifen der Fig. 164 aufmerksam machen, dessen Gestalt mir dafür zu sprechen scheint, dass auch bei dem Kaninchen in einem gewissen Stadium der Primitivstreifen eine ankerförmige Form besitzen kann.

Nachdem ich vorstehend einen Ueberblick über die erste Entwicklung des Kaninchenembryo gegeben habe, möchte ich auf die Genese der Ruickenfurche noch etwas näher eingehen. Leider ist die Ausbreitung des mittleren Keimblattes in dem vor dem Primitivstreifen liegenden Abschnitte des Embryonalfleckes, welche bei der Ausbildung der Rückenfurche eine wesentliche Rolle spielt, noch nicht genügend erforscht. Nach Hensen soll das Mesoderm kurz nach seinem Auswachsen von seiner Bildungsstätte aus im Bereiche des ganzen Embryonalfleckes sich náchweisen lassen, später jedoch in der Medianlinie unter der Medullarrinne fehlen, indem hier die Chorda aus dem Entoderm sich entwickle. Nach Kölliker dagegen soll sich die Chorda dorsalis aus dem Mesoderm entwickeln, da man sie nach hinten bis in den Endwulst des Primitivstreifens verfolgen könne. Die Querschnitte, welche Kölliker von einem etwas älteren Kaninchenembryo abbildet, der bereits 7 Urwirbelpaare, jedoch eine noch überall offene Rückenfurche besass, und die er hauptsächlich für seine Anschauung verwerthet, können meines Erachtens auch in anderer Weise gedeutet werden. Mir scheint der Umstand, dass in den betreffenden Durchschnitten (Fig. 194-197) das Entoderm unter der nicht sehr hohen, aber stark seitlich verbreiterten Chorda ungemein verdünnt ist, für eine eben stattgefundene Loslösung der Chorda von dem unteren Keimblatte zu sprechen, da sich diese Erscheinung in anderer Weise nicht gut erklären lässt. Von einem etwas jüngeren Embryo mit nur drei Urwirbeln hat dagegen Hensen eine Reihe von Querschnitten abgebildet (Fig. 37-42), die eine so grosse Aehnlichkeit mit den Querschnittsbildern haben, welche ich von einem Hïhnerembryo, bei dem die Rückenfurche gebildet, jedoch noch keine Urwirbel aufgetreten waren, erhalten habé, dass es mir nicht zweifelhaft ist, dass auch bei dem Kaninchen die Chorda aus dem Entoderm entsteht; nur scheint sowohl ihre Anlage als ihre Abschnürung von dem unteren Keimblatt später stattzufinden, wie bei dem Hühnchen. Ob Hensen's Angaben sich bestätigen werden, dass Anfangs unter der Riickenfurche ein Mesoderm vorhanden ist, oder nicht, muss die Zukunft lehren; im letzteren Falle würde die Rïckenfurche in der Weise entstehen, dass in der vorderen Verlängerungslinic des Primitivstreifens das Ektoderm dem Entoderm angelagert bleiben würde, während es zu beiden Seiten dieser Linie durch das vorwachsende Mesoderm abgedrängt und etwas emporgehoben würde, wodurch die Medullarwiilste im Flächenbilde zum Ausdruck kommen müssen. Dic letztgenannte Annahme hat nach meinen bei dem Hühnchen gewonnenen Erfahrungen sehr viel Wahrscheinlichkeit für sich. Mit dem Auftreten der Urwirbel stellt sich dann eine am Endwulste des Primitivstreifens beginnende, von hinten nach worne unter der Medullarrinne fortschreitende Verdickung des Entoderms ein, eine Bildung, welche dem Kopffortsatze des Hühnchens homolog ist und von diesem sich nur dadurch 
unterscheidet, dass sie eben später zu Stande kommt und demgemäss auch erst später in die Chorda sich umbildet. Dass jedoch ausnahmsweise auch schon früher ein Kopffortsatz beim Kaninchen auftreten kann, scheint mir aus zwei Abbildungen Hensen's geschlossen werden zu dürfen. In dessen Fig. 25 C, die einen Embryonalfleck von 2,75 Mm. Länge, welcher eine deutliche Rückenfurche, aber noch keine Urwirbel besass, im Flächenbilde darstellt, sieht man ganz deutlich von dem Knoten des Primitivstreifens nach vorne einen Streifen abgehen, der nur als Kopffortsatz aufgefasst werden kann. Auch die Fig. 36 Hensen's, welche einen medianen Sagittalschnitt durch einen Embryonalfleck von 3,36 Mm. Länge, bei dem auch noch keine Urwirbel aufgetreten waren, wiedergibt, zeigt vor dem Knoten eine Verdickung des Entoderms, welche ganz und gar meinen Längsschnitten durch den Kopffortsatz des Hühnchens entspricht.

Hat sich vor dem Primitivstreifen die Rückenfurche angelegt, so verlängert sich dieselbe rasch, sowohl nach vorne, als auch nach hinten zu. Ersteres ist durch das Längenwachsthum der vor dem Primitivstreifen gelegenen Abtheilung des Embryonalfleckes bedingt; die Verlängerung nach rückwärts, welche bald beendet ist, kommt dadurch zu Stande, dass auch neben dem vorderen Theil des Primitivstreifens das Mesoderm sich verdickt, wodurch an dieser Stelle Erhebungen entstehen, welche die Fortsetzung der Medullarwiilste bilden und von denen das Kopfende des Primitivstreifens seitlich umschlossen wird. Dasselbe kommt dadureh auf den Boden des hintersten Abschnittes der Rückenfurche zu liegen und scheint im Flächenbilde rascher zu verschwinden als das hintere, nicht umschlossene Stück des Primitivstreifens. Hinsichtlich des Verhaltens des letzteren zur Rückenfurche, sowie zur Stammes- und Parietalzone, ist weder aus den leider etwas klein gehaltenen Zeichnungen Hensen's, noch aus den Abbildungen Kölliker's eine klare Uebersicht zu gewinnen. Dies hat hauptsächlich darin seinen Grund, dass der Primitivstreifen in Betreff seiner Rückbildung sich bei, den einzelnen Embryonen sehr verschieden verhält; bald ist er im Flächenbilde schon schr frühzeitig bis auf einen geringen, hinter der Medullarrinne liegenden Rest verschwunden (siehe Kölliker's Fig. 163), bald erhält er sich länger, wie die Fig. 164 der Entwicklungs-. geschichte Kölliker's lchrt; die letztere Abbildung lässt unzweifelhaft erkennen, dass ein 'Theil des Primitivstreifens in die Stammeszone, ein anderer in die Parietalzone fällt. Vor dem vordersten Ende des Primitivstreifens, dem Endwulste, bemerkt man am Boden der Rückenfurche jedoch nichts mehr, während bei einem älteren Embryo mit 7 Urwirbeln (Fig. 170) die anderen Theile des Streifens bereits verschwunden sind und allein der Endwulst noch sichtbar ist.

Was die vorderen, in der ersten /ceit sehr abgeflachten Enden der Rüickenwülste anbetrifft, so reichen diesclben so weit nach vorne, wie die Stammeszone der Embryonalanlage; sie sind nicht durch eine so ausgesprochene Querfalte verbunden, wie es beim Hühnchen durch die Kopffalte bewirkt wird und darum hört auch die Medullarrinne nach vorne zu meistens ohne scharfe Grenze auf; eine $\Lambda$ rt von Kopffalte scheint sich erst dann einzustellen, wenn der Embryo, dessen Länge unterdessen auf $4 \mathrm{Mm}$. und darüber angewachsen ist, mit seinem Kopfende sich etwas über das Niveau der Keimblase zu erheben 
beginnt und damit die Bildung des Vorderarms sich einleitet (siehe Fig. 166 Kölliker's).

Ich beschränke mich darauf, in dem Vorhergehenden die ersten Entwicklungsvorgänge des Kaninchens, welche zur Ausbildung der Embryonalanlage führen, geschildert zu haben. Die weitere Entwicklung des Kaninchenembryo besteht zunächst in der Vermehrung der Urwirbel, der allmähligen Vereinigung zweier Herzanlagen zu einem gemeinsamen Herzen, dem Schluss des Medullarrohres; dann folgt die Genese des Vorder- und Enddarmes des Amnions etc.; auf die Entstehungsgeschichte dieser Organe kann ich begreiflicher Weise hier nicht eingehen. Dies würde die dem entwicklungsgeschichtlichen Abschnitte dieses Buches gesteckten Grenzen weit überschreiten und würde ausserdem für die Teratogenie der Doppelmissbildungen keinen besonderen Werth haben, für welche fast ausschliesslich die erörterten Entwicklungsstadien in Betracht kommen.

Es sei mir schliesslich gestattet, die beiden höchststehenden Vertebratenclassen, die der Vögel und der Säugethiere, hinsichtlich der Entstehungsweise der Embryonalanlage einem Vergleiche zu unterziehen. Es kann nicht geleugnet werden, dass die Ontogenie der beiden Classen in den soeben geschilderten Entwicklungsphasen die grösste Uebereinstimmung zeigt und nur in unwesentlichen Puncten Unterschiede erkennen lässt.

Sobald die beiden ersten Keimblätter, das Ektoderm und das Entoderm, hinreichend ausgebildet sind, schen wir die ersten Spuren der Embryonalanlage auftreten; es stellt sich innerhalb eines rundlichen Bezirkes eine durch Erhöhung der Ektodermzellen verursachte Verdickung des oberen Keimblattes ein. So entsteht das Embryonalschild der Vögel, der Embryonalfleck der Säuger, welche auch darin sich ähnlich verhalten, dass beide etwas kuppenförmig prominiren. Hierauf kommt es mit der Bildung des Primitivstreifens zur Entwicklung des mittleren Keimblattes. Bei den Vögeln liegt die Stelle, von der die Genese des Primitivstreifens ausgeht, hinter dem Embryonalschild; vielleicht lehren spätere Untersuchungen, dass auch bei den Säugern die Bildung des Primitivstreifens an einer ursprünglich ausserhalb des rundlichen Embryonalfleckes gelegenen Stelle der Keimblase beginnt, die jedoch dessen hinterer Peripherie eng anliegt und später in denselben einbezogen wird. Auf ein derartiges genetisches Verhältniss deutet der von v. Beneden beschriebene und auch von mir beobachtete Halbmond hin. Für die Bildung der Embryonalanlage ist übrigens die Lage des Punctes, von dem aus der Primitivstreifen sich entwickelt, von mehr untergeordnetem Belang. Darin stimmen die Vögel mit den Säugern wieder vollständig überein, dass der Primitivstreifen als lineare Verdickung des Ektoderms in dem Embryonalschild, resp. Embryonalfleck gegen dessen Mitte zu immer weiter vordringt und dass währenddem von dem Primitivstreifen aus das Mesoderm zwischen die beiden anderen Keimblätter hineinwächst; ebenso erfolgt die weitere Ausbildung des Primitivstreifens, das Auftreten der Primitivrinne bei beiden Thierclassen ganz gleichmïssig. Hat der Primitivstreifen, wenn ich so sagen darf, dem Bezirk der Embryonalanlage das mittlere Keimblatt zugeführt, so fallen die weiteren Entwicklungsvorgïnge vor das Kopfende des Primitivstreifens. In der bezeichneten Region streckt sich 
das Embryonalschild, resp. der Embryonalfleck. Ich werde für beide von nun an der leichteren Beschreibung halber einen gemeinsamen Namen gebrauchen, indem ich das eine wie den anderen als Embryonalzone bezeichnen will. Es erfolgt zu beiden Seiten der vorderen Verlängerungsliniè des Primitivstreifens eine allmählige Erhebung der Embryonalzone in Gestalt von länglichen, zuerst sehr flachen Längswiilsten. Dieselben, an deren langsam zunehmender Erhöhung das nach vorne auswachsende Mesoderm wesentlichen Antheil nimmt, stellen die Medullarwülste dar; die zwischen ihnen befindliche Rinne ist die Medullarfurche. Unter dem Boden der letzteren besteht die Embryonalzone nur aus zwei Keimblättern, in dem das Mesoderm vor dem Primitivstreifen nur seitlich von der Medianlinie sich ausbreitet, diese selbst jedoch frei lässt. Wahrscheinlich ist daran zum Theile jene unter dem Boden der sich bildenden Medullarrinne sich einstellende Entodermverdickung Schuld, aus der sich die Chorda dorsalis entwickelt; bei den Vögeln tritt die in Rede stehende Entodermverdickung als Kopffortsatz schon sehr frühe auf, in einer Zeit, in welcher die Medullarwülste noch sehr flach sind, während bei den Säugern dieselbe erst etwas später sich einstellt.

Während des allmähligen Tängenwachsthums der Embryonalzone, welches vorwiegend deren vordere Hälfte betrifft, treten auch die Medullarwülste seitlich von dem vorderen Ende des Primitivstreifens deutlicher auf; sie umfassen seitlich ein Stück desselben, welches in Folge dessen auf den Boden der Medullarfurche zu liegen kommt, die jedoch an der bezeichneten Stelle fürs Erste noch ziemlich flach ist. Späterhin, wenn der hintere Theil der Rückenfurche sich mehr und mehr vertieft, erscheint das am Boden derselben gelegene vordere Stück des Primitivstreifens deutlicher gegen den hinteren Abschnitt desselben abgegrenzt; das Kopfende des Streifens ist am Boden der Rückenfurche bei den Vögeln als Endwulst noch verhältnissmässig lange erkennbar, während der nicht von den Medullarwülsten umschlossene Theil des Primitivstreifens im Flächenbilde zicmlich rasch verschwindet.

Gleichzeitig mit der fortschreitenden Ausbildung der Rückenfurche, d. h. mit der zunehmenden Erhebung der Medullarwülste, welche durch eine Verdickung des unter ihnen liegenden Mesoderms bewirkt wird, tritt eine Stammeszone und Parietalzone immer deutlicher hervor. Die erstere umfasst den Bezirk der Medullarwiilste und reicht daher in der ersten Zeit nach beiden Seiten hin so weit, wie die Medullarplatte, d. h. jener verdickte Abschnitt des Ektoderms, welcher den Boden der Rückenfurche bildet und aus dem sich später das Medullarrohr aufbaut. Die seitliche Grenze der Stammeszone, von der die sich erhöhenden Kanten der Medullarwülste späterhin medianwärts immer mehr abriicken, um sich entgegen zu wachsen und den Schluss des Medullarrohres zu bewerkstelligen, füllt ferner zusammen mit dem lateralen Rande der Urwirbelplatten, welche ja der Ausdruck der unter den Medullarwiilsten verdickten Mesodermleisten sind. Die Stammeszone ist aussen umgeben von der Parietalzone, deren Mesodermeinlage diinner ist als die der ersteren, jedoch dicker als die des angrenzenden Theiles des Blastoderma.

Es entsteht nun die Frage, wic verhiilt sich genetisch die Stammes- und Parietalzone zu der Embryonalzone, d. h. zu dem ursprünglichen Embryonalschild der Vögel, dem Embryonalfleck der Säuger? Es handelt sich hier um 
die Alternative: entweder geht aus der Embryonalzone sowohl Stammes-wie Parietalzone hervor, oder nur die erstere, indem die letztere aus den umgebenden Theilen des Blastoderma sich bildet. Die Meinungen der Forscher gehen über diesen Punct aus einander und es sind sowohl für die Vögel, als für die Siiugethiere beide Möglichkeiten befürwortet worden. Die von mir vertretene Ansicht, dass bei dem Hühnchen die Embryonalzone ganz allein in der Stammeszone aufgehe, steht der Anschaung der meisten anderen Autoren gegenüber, wonach sich aus der ersteren sowohl Stammes- als Parietalzone herausbilden sollen. Das Gleiche ist von Kölliker und Hensen auch für das Kaninchen angegeben worden, während sich, wie ich aus einem Citate Hensen's ersehe, Prevost und Dumas ${ }^{1}$ ) dahin ausgesprochen haben, dass bei den Säugern aus dem Embryonalfleck die Medullarplatte, mit deren Ausbreitung in der ersten Zeit ja die Stammeszone zusammenfällt, hervorgehe.

An und für sich kommt, wie ich glaube, der in Rede stehenden Streitfrage keine allzu grosse Wichtigkeit zu. Wegen der nur unbestimmten Abgrenzung, welche besonders bei den Vögeln die Embryonalzone Anfangs zeigt, indem das zu derselben verdickte Ektoderm ganz allmählig in die periphere dünnere Ektodermzone der Area pellucida übergeht, ist dem subjectiven Urtheil, bis wie weit man das Embryonalschild peripherwärts reichen lassen will, ein grosser Spielraum gelassen. Dadurch erklärt sich auch die Verschiedenheit der Ansichten in der zu erörternden Frage. Jedenfalls dürfte es keinem Zweifel unterliegen, dass in Hinsicht auf das Zustandekommen der Stammesund Parietalzone die beiden höchststehenden Vertebratenclassen das gleiche Verhalten zeigen. So möchte ich denn auf Grund meiner Beobachtungen beim Hülnchen der Anschauung von Prevost und Dumas beipflichten und fasse meine Ansicht über den fraglichen Punct folgendermassen zusammen:

Bei den Vögeln und bei den Säugern geht die Embryonalzone, welche in Folge einer Verdickung des Ektoderms in Erscheinung tritt, lediglich in die Stammeszone der Embryonalanlage über. Die Parietalzone ist eine secundäre Bildung, welche im Flächenbilde dadurch zum Ausdruck kommt, dass innerhalb der unmittelbaren Umgebung der Embryonalzone das Mesoderm sich gegenüber den peripheren Theilen der Keimhaut etwas verdickt. Das Ektoderm der ursprünglichen Embryonalzone wird zur Medullarplatte und aus ihm geht das Centralnervensystem hervor. Damit ist ausgesprochen, dass späterhin mit dem allmähligen Schluss des Medullarrohres die Ektodermzellen der Parietalzone medianwärts in das Gebiet der Stammeszone vorrïcken, deren ganze Ausdehnung sie schliesslich einnehmen, 'wenn das Medullarrohr sich geschlossen hat und damit die hohen Cylinderzellen der ursprünglichen Embryonalzone von der Oberflïche verschwunden sind. Es beginnt daher streng genommen die Bildung des Embryo mit der Anlage des Centralnervensystems, welche von dem-verdickten Ektoderm der Fmbryonalzone dargestellt wird.

Dies möchte ich jedoch nicht so aufgefasst wissen, als ob ich unter den ersten Entwicklungsvorgängen die Erhöhung der Ektodermzellen in der Em-

1) Prevost und D n mas, De la génération dans les Mammifìres. Anniles des sciences naturelles Tom. III (e 2). 
bryonalzone als den bedeutsamsten Process hinstellen wollte. Unstreitig viel wichtiger als dieser ist für das Zustandekommen der Embryonalanlage die Bildung des Primitivstreifens. Erst der letztere bahnt in der vorher höchst unbestimmt gehaltenen Embryonalzone, welche sich bisher nur wenig von ihrer Umgebung unterschieden hatte, den Aufbau des Embryo an. Abgesehen davon, dass mit dem Eindringen des Primitivstreifens die Embryonalzone das Mesoderm erhält, also dreiblätterig wird, leitet der Primitivstreifen die bilaterale Symmetrie des Organismus ein, indem er und seine vordere Verlängerungslinie, in welcher der Kopffortsatz sich entwickelt, die mediane Längsaxe der Embryonalanlage darstellt. Damit ist auch die Richtung angegeben, in welcher die Embryonalzone sich verlängern muss, und so sehen wir denn, wie deren Ektoderm unter allmähliger Ausbildung der Rückenfurche und Rückenwülste nach und nach eine schärfere seitliche Abgrenzung gewinnt, um als Medullarplatte fuir die Bildung des Medullarrohres Verwendung zu finden.

Diesen Betrachtungen zufolge können wir der Embryonalzone nur in sofern Werth beilegen, als durch deren Erscheinen die Stelle der Keimhaut bezeichnet wird, wohin die Embryonalanlage zu liegen kommt. Der Anstoss zur Bildung der letzteren geht jedoch allein von dem Primitivstreifen aus.

Da nun, wie wir wissen, der Primitivstreifen immer gegen die Mitte der Embryonalzone vordringt, so ist es höchst wichtig, die Stelle zu kennen, wo die Bildung desselben beginnt. Für die Säugethiere lassen sich hierüber keine genaueren Angaben machen; dagegen ist uns für die Keimscheibe des Vogeleies bekannt, dass diejenige in das Ringgebiet fallende Stelle, an welcher die Sichel des Primitivstreifens sich zu bilden beginnt, eine ganz bestimmte Lage im Gesammtei einnimmt. Wir können darum auch im Voraus die Längsaxe der Embryonalanlage bestimmen, man braucht nur die genannte Stelle mit dem Centrum der Embryonalzone durch eine Linie zu verbinden. Es wurde friiher auseinandergesetzt, wie Sichel und Primitivstreifen durch eine Wucherung der Ektodermzellen entstehen. Man wird daher mit grosser Wahrscheinlichkeit annehmen dürfen, dass diejenige Stelle, an der jene Wucherung ihren Anfäng nimmt, sowie die Keimhautbezirke, in denen dieselbe fortschreitet, bezüglich ihrer Lage- und sonstigen Verhältnisse sich der für die Theilung und Vermehrung der Zellen günstigsten Bedingungen zu erfreuen haben. 


\section{Neue Fälle frühzeitiger Doppelbildungen des Hühnchens.}

I.

Der seiner Entwicklungszeit nach früheste Fall der mitzutheilenden Doppelbildungen (Fig. 1, Taf. III) stammt aus einem Hühnerei, welches 20 Stunden bebriitet worden war. An dem frischen Präparate konnte man in dem birnförmigen durchsichtigen Fruchthofe den Primitivstreifën, der seine gewöhnliche Stelle einnahm, gut unterscheiden; von einem Kopffortsatze, sowie von einer Medullarrinne, deren Anlage in der 20. Stunde des ersten Brütetages in der Norm bereits vollendet ist, war nichts zu bemerken. Dagegen fiel ein zweiter feiner weisslicher Streifen auf, welcher, von dem linken vorderen Ende des durchsichtigen Fruchthofes ausgehend, in denselben einstrahlte und sich bis zu der vorderen Verlängerungslinie des eigentlichen Primitivstreifens verfolgen liess.

Nach der sorgfältig vorgenommenen Erhärtung der Keimhaut stellte es sich nun heraus, dass dieser weissliche Streifen einen zweiten Primitivstreifen darstellte. Somit waren in einer gemeinsamen Area pellucida zwei Primitivstreifen vorhanden und es handelte sich um eine sehr frühe Doppelbildung, wodurch sich auch die retardirte Entwicklung der Embryonalanlagen erklärte. Von den beiden Primitivstreifen will ich den an der normalen Stelle befindlichen von nun an einfach als "hinteren", den anderen wegen seiner Lage zum ersten als „linken vorderen" bezeichnen.

Der hintere Primitivstreifen besass eine Länge von 1,8 Mm. und war entschieden besser entwickelt als der linke vordere, der nur 1,6 Mm. lang war. Mit ihren centralen oder Kopfenden waren die beiden Streifen in das Embryonalschild hinein vorgedrungen, welches von der dunkleren Randzone des durchsichtigen Fruchthofes sich nur schwach abhebt. Die Entfernung zwischen den Kopfenden der beiden Streifen beträgt $0,4 、 \mathrm{Mm}$.

Die Primitivrinne hatte sich bei beiden bereits ausgebildet und war besonders in den leicht verbreiterten Kopfenden sehr deutlich wahrzunehmen; in den übrigen Abschnitten der beiden Primitivstreifen war sie bei dem hinteren entschieden besser ausgesprochen als bei dem linken vorderen. Das mittlere Keimblatt hatte sich ebenfalls schon und zwar von jedem der beiden Primitivstreifen aus entwickelt. Das von dem hinteren abstammende Mesoderm erschicn besser abgegrenzt als das dem linken vorderen angehörende, welches jedoch 
dem Anscheine nach eine etwas grössere Flächenausdehnung erlangt hatte. Die zwei ihrem Ursprunge nach verschiedenen mittleren Keimblätter, welche beide mit einem kleinen Theile innerhalb der Area opaca lagen, hatten sich noch an keiner Stelle berührt, sondern die einander zugekehrten Ränder liessen noch einen kleinen Bezirk des durchsichtigen Fruchthofes zwischen sich, dessen Keimhaut nur aus Ektoderm und Entoderm bestand.

Bezüglich der Masse der birnförmigen Area pellucida ist noch zu erwähnen, dass der längere Durchmesser derselben eine Länge von 3,2 Mm. zeigte; ihre grösste Breite bemass sich auf 2,7 Mm. Der Durchmesser der gesammten Keimhaut betrug $7 \mathrm{Mm}$.

II.

Der zweite von mir beobachtete Fall einer Zwillingsbildung (Taf. II) fällt in eine spätere Periode der Entwicklung; das betreffende Ei war am 4. Tage aus dem Briitofen herausgenommen worden; nach Eröffnung der Schale waren sofort zwei Embryonen, welche innerhalb eines Gefässhofes lagen, deutlich sichtbar. Ihre Herzen waren noch in voller Thätigkeit und pulsirten, soweit ich es feststellen konnte, nicht ganz isochron.

Hinsichtlich der Lagebeziehungen der beiden Zwillinge ist zu bemerken, dass der eine mit seiner Längsaxe in den kurzen Durchmesser des Eies zu liegen kam und in dem hinteren Theil des durchsichtigen Fruchthofes sich befand, während der andere Zwilling vor dem Kopfende des ersteren, mehr in der Richtung des grösseren Durchmessers des Eies gelegen war; sein hinteres Körperende war nach links, sein Kopfende nach rechts gewendet. Die Embryonen zeigten sonach, was sich nach der Erhärtung der Keimhaut noch deutlicher herausstellte, ganz die gleiche Anordnung, wie die beiden Primitivstreifen des vorigen Falles, sowohl in ihren gegenseitigen Lagebezichungen, als in ihrem Lageverhältniss zum Gesammtei. Aus diesem Grunde werde ich in der Folge den einen Embryo ebenfalls in Kürze als „hinteren", den anderen als , linken vorderen" anführen.

Durch das Vorhandensein von zwei Embryonen hatte sich die Form der Area pellucida beträchtlich verändert. Während der hintere Abschnitt derselben nicht aussergewöhnlich vergrössert war, hatte sich ihr vorderer Theil, der den linken vorderen Embryo enthielt, stark verbreitert.

Dic beiden Embryonen waren vollkommen normal gebildet und in ihrer Entwicklung gleich weit vorgeschritten, wenigstens liessen sie beziiglich ihrer Körperlïnge nur einen unbedeutenden Unterschied erkennen; die des hinteren belief sich auf $6 \mathrm{Mm}$; der linke vordere war um ein Unbedeutendes grösser, er besass eine Lünge von 6,3 Mm. Für ihr Alter waren jedoch die beiden Zwillinge entschieden in ihrer Ausbildung zurück, indem sie ihrer Grösse und sonstigen Formbeschaffenheit nach normalen Einzelembryonen vom dritten Brütctage entsprachen. Bei beiden war bereits die Kopf- und Nackenkriimmung ausgeprïgt, die Beckendarmhöhle soeben angelegt. Ferner waren schon die Hemisphiirenblïschen entwickelt, ebenso die Kiemenbögen. Die Linse war in der Bildung begriffen und man konnte darum sehr schön die Linsengrübchen wahrnehmen. Hinsichtlich ihrer Lagerung auf der Keimhaut verhielten sich 
die beiden Embryonen nicht gleich; der hintere hatte sich mit seinem Kopfende auf die linke Seite, der linke vordere dagegen auf seine rechte Seite gelegt. Es hatte daher der hintere die normale, der linke vordere die anormale Kopflage eingenommen. Weder von einer vorderen noch von einer hinteren Amnionfalte war in dem Fruchthofe etwas zu bemerken.

Ein besonderes Interesse dürfte dem vorliegenden Falle das gegenseitige Lageverhältniss der Köpfe beider Embryonen verleihen. Es erscheint nämlich die Mittelhirngegend des hinteren Embryo an die Nachhirngegend des anderen Zwillings so fest angedrückt, dass ich zuerst glaubte, es lüge zwischen beiden an der bezeichneten Stelle eine Verwachsung vor. Allein ich konnte mich von dem Gegentheile leicht überzeugen, indem ich die beiden Köpfe durch einen kleinen untergeschobenen Spatel vorsichtig von dem Fruchthofe abzuheben suchte, wobei sie sofort aus einander wichen.

Ich gehe nun zu dem Verhalten der Gefässe der Keimhaut uiber. Die Area vasculosa, nach aussen durch die Vena terminalis abgeschlossen, hatte bereits eine ziemliche Ausdehnung erlangt. Sie besass einen Durchmesser von 19,5 Mm.

Die Herzen beider Embryonen waren gut ausgebildet und trieben das Blut durch die Omphalomesenterialarterien in den gemeinschaftlichen Gefässhof. Die genannten Arterien waren jedoch nur bei dem hinteren Embryo gleichmässig entwickelt; der linke vordere Embryo besass nur eine linke gut ausgebildete Arteria omphalomesenterica, die rechte dagegen war entweder nur rudimentär angelegt oder bereits zurückgebildet; sie hatte ein sehr schwaches Caliber und verlor sich, in kleine Aeste zerspalten, bereits innerhalb des durchsichtigen Fruchthofes. Der Rückfluss des venösen Blutes zu den beiden Herzen wurde hauptsächlich durch drei grössere Venenstämme vermittelt, von denen der eine, welcher bis zu der Vena terminalis sich verfolgen liess, unter das Kopfende des linken vorderen Embryo trat und in die Vena omphalomesenterica desselben einmündete, nachdem er vorher noch einige Seitenvenen zu dem anderen Embryo abgeschickt hatte. Es wurde also durch die genannte Vene, welche wohl als Vena vitellina anterior aufzufassen ist, den beiden Embryonen von den ihren vorderen Körperenden näher gelegenen Theilen des Gefässhofes aus das Blut zugeführt. Ausserdem nahm die Vena omphalomesenterica eines jeden Embryo eine von rückwärts kommende Vene auf, die der Vena vitellina posterior einer Area vasculosa entsprechen würde, welche nur einen Einzelembryo enthielte. Nur war in unserem Falle die Anordnung dieser Vene in sofern eine andere, als dieselbe auf der rechten Seite einès jeden der beiden Zwillinge verlief und sich darum mit der rechten Arteria omphalomesenterica kreuzen musste. Es ist schliesslich noch bezüglich der Venenvertheilung zu bemerken, dass die venösen Abschnitte der beiden Herzen noch durch eine Vene direct mit cinander verbunden waren, welche gerade unter der Berührungsstelle der beiden Embryonen von dem einen zum anderen ging und darum nur bei Betrachtung der unteren Keimhautfliiche zu sehen ist. 
III.

Der Beschreibung der beiden vorstehenden Fälle füge ich die eines dritten Doppelembryo an, welcher eine beim Hühnchen seltener beobachtete Form von Doppelbildung repräsentirt. Während in den beiden anderen Fällen zwei vollständig getrennte Componenten der Zwillingsbildung vorlagen, handelt es sich hier um zwei nur in der mittleren Körperregion und den Kopfenden gesonderte Embryonen, welche in ein einheitliches hinteres Körperende auslaufen. Es ist demnach die Doppelbildung als eine Duplicitas anterior aufzufassen. Dieselbe wurde einem 48 Stunden bebrüteten Eie entnommen; sie kam schon vor vielen Jahren meinem Vater zur Beobachtung, welcher das Präparat mit Carmin färbte und in Canadabalsam einschloss. Da ich nun über das Verhalten des Schwanzendes an dem aufgehellten Präparate nicht ins Reine kam, habe ich dasselbe auf längere Zeit in Chloroform gelegt; darin löste sich der Balsam langsam auf, so dass schliesslich das Deckgläschen abfiel, und das Object selbst frei wurde. Dasselbe wurde sodann in Alcohol gebracht und in demselben bei auffallendem Lichte betrachtet und abgezeichnet (Fig. 2, Taf. III). Später habe ich die Keimhaut in Glycerin eingeschlossen. Leider hat das Präparat unter diesen verschiedenen Manipulationen gelitten, indem einige periphere Stellen etwas abbröckelten, und auch die Area pellucida einen kleinen Einriss erhielt; jedoch wurde der beabsichtigte Erfolg vollkommen erreicht, indem bei auffallender Beleuchtung sich die Reliefverhältnisse der Dorsalfläche sehr gut erkennen liessen.

Die beiden Embryonen, deren Vorderkörper hinsichtlich seiner Ausbildung etwa der 30.-36. Briutestunde der normalen Entwicklung eines Einzelembryo entspricht, zeichnen sich durch ihre kurze gedrungene Gestalt aus. Ich habe ihre Länge mit der von Einzelembryonen, welche sich in den bezeichneten Entwicklungsstadien befanden, verglichen und es hat sich dabei herausgestellt, dass letztere nahezu die doppelte Körperlänge zeigten, wie die beiden Zwillingsembryonen des in Rede stehenden Falles.

Dieselben sind innerhalb einer 1,5 Mm. langen Strecke von einander getrennt, das gemeinschaftliche hintere Körperende betrïgt 1,1 Mm., ihre Gesammtlïnge beliiuft sich demnach auf 2,6 Mm. Der rechte der beiden ist viclleicht um ein Minimum kürzer als der andere; auch ist er gegen den linken Zwilling in der Entwicklung ein wenig zurück.

Bei beiden Embryonen zeigt das Hirnrohr bereits eine Gliederung in die Hirnblïschen. Von dem Vorderhirnbläschen sind die Augenblasen eben in der Abschnürung begriffen; auch das mittlere Hirnbläschen tritt schon deutlich hervor, während das dritte Hirnbläschen am wenigsten gut abgegrenzt erscheint. An dem Vorderhirn des rechten Embryo ist noch durch eine kleine Vorwölbung nach vorne die Stelle kenntlich, wo das Hirnrohr sich zuletzt geschlossen hat. Innerhalb des gesonderten Körperabschnittes ist das Medullarrohr bei beiden Embryonen geschlossen; neben demselben liegen die Urwirbelpaare. Kur\% nach der Vereinigung der beiden Embryonen zu einem gemeinsamen Endabschnitte beginnt das Medullarrohr eines jeden dorsalwairts zu klaffen; die Ränder der früheren Medullarrinnen weichen aus einander und 
bald gehen die beiden Medullarrohre in eine gemeinsame sehr verbreiterte und flache Medullarfurche über. Die letztere ist seitlich von Medullarwülsten begrenzt, welche nach rückwärts allmählig niedriger werden, um schliesslich ohne scharfe Grenze in dem anstossenden Bezirk der Area pellucida überzugehen. Von einem Primitivstreifen, oder von dessen Rinne liess sich nichts mehr wahrnehmen.

Die Ventralansicht des Präparates liess schon die vordeṛe Darmpforte, welche in den Vorderdarm führt, bei beiden Zwillingen erkennen. Eine Beckendarmhöhle hatte sich noch nicht gebildet; dagegen ist ungefähr in der Mitte des gemeinsamen Körperabschnittes, unter der Medullarfurche liegend, ein querer Wulst sichtbar, den ich als eine pathologische Zellenwucherung der Keimhaut in der Gegend des früheren Primitivstreifens auffassen möchte.

Bei beiden Embryonen hat sich bereits ein Herz gebildet; doch ist das des linken etwas mehr entwickelt, als das des rechten. Bei dem ersteren zeigt der Herzschlanch schon eine kleine Ausbiegung nach links; bei dem letzteren ist er noch vollkommen gerade; auch die beiden Venae omphalomesentericae sind bei beiden Embryonen schon erkennbar, lassen sich dagegen noch nicht in den durchsichtigen Fruchthof hinein verfolgen:

Der Gefässhof ist im Entstehen begriffen; die Vena terminalis ist zwar noch nicht vorhanden, doch deren Stelle schon markirt. Der durchsichtige Fruchthof besitzt eine längliche Form; er ist vorne breiter, in seinem hinteren Theile schmäler. Eine Amnionfalte ist noch nicht aufgetreten. 


\section{Die Anlage zweier Primitivstreifen in einem Fruchthofe. Unter welchen Umständen kann dieselbe zur Genese von Doppelmissbildungen führen, und welche Formen der Letzteren kommen hier in Frage?}

Die bei den höheren Wirbelthieren bekannt gewordenen frühzeitigen Doppelbildungen, welche in den beiden folgenden Capiteln dieser Monographie ausführlicher behandelt werden sollen, lassen sich bis auf eine verschwindend kleine Anzahl von Fällen genetisch auf das Vorhandensein von zwei Embryonalanlagen, resp. Primitivstreifen in einem einzigen Fruchthofe zurückführen. Die Entstehungsweise der letzteren ist bisher noch nicht ganz aufgeklärt worden, indem über dieselbe die Anschauungen der einzelnen Forscher auseinandergehen. Auf die verschiedenen Ansichten, welche über den Bildungsmodus der Mehrfachbildungen laut wurden, werde ich später eingehender zu sprechen kommen; vorerst möchte ich mich auf die Erörterung derjenigen Doppelbildungen beschränken, welche sich auf einer so frühen Entwicklungsstufe befinden, dass die Embryogenese noch nicht über das Stadium der Ausbildung zweier Primitivstreifen in einer Area pellucida hinausgegangen ist.

Ihrer Zahl nach sind es nur zwei, indem in der Literatur nur eine einzige Beobachtung einer Doppelbildung verzeichnet ist, welche, in Bezug auf ihre frühe Entwicklungsphase, dem ersten meiner Fälle an die Seite gestellt werden kann. Dieselbe ist von Allen 'Thomson ${ }^{1}$ ) an einem Hühnerei gemacht worden, welches 16-18 Stunden bebrütet worden war. Ich habe die Abbildung dieses wichtigen Falles in Fig. 1, Taf. IV wiedergegeben. Man bemerkt in derselben, dass der nach vorne abgerundete durchsichtige Fruchthof nach hinten zu in zwei kleine Spitzen ausläuft, vou denen eine jede das hintere Ende je eines der beiden Primitivstreifen enthält; die letzteren, deren Länge etwa $2 \mathrm{~mm}$ beträgt, verlaufen in leichtem Bogen nach vorne zu. Die beiden Bögen der Primitivstreifen wenden ihre Convexität einander zu und sind ferner so angeordnet, dass ihre gleich weit nach vorne reichenden Kopfenden näher an einander liegen, als ihre hinteren Enden.

Wie man sieht, gehört die von Allen Tlıomson beschriebene Doppelbildung fast ganz der gleichen frühen Entwicklungsphase an, wie die von mir beobachtete. Die beiden Fälle dürften, da sie alle anderen Doppelbildungen der höheren Wirbelthiere, von denen wir Kenntniss haben, hinsichtlich ihres

1) Allen Thomson, The London and Edinburgh Honthly Journal 1844, pag. 479. 
frühen Entwicklungsstadiums weit übertreffen, in erster Linie dazu berufen sein, die Anlage einer Mehrfachbildung aufzukiären. Da nun, wie schon erwähnt, die Meinungen, welche von Seiten der verschiedenen Autoren in Betreff der Genese der Mehrfachbildungen, beziehungsweise Doppelmissbildungen geäussert wurden, sehr von einander abweichen, ja sich vielfach geradezu direct gegenüberstehen, so werden sich die beiden Fälle auch mit Vortheil zur Prüfung der einzelnen Anschauungen verwenden lassen, und es steht $\mathrm{zu}$ erwarten, dass sich aus einem Vergleiche derselben Schlussfolgerungen ergeben werden, welche über den Werth und die Haltbarkeit dieser verschiedenen Ansichten endgültig entscheiden dürften.

Sucht man sich unter Berücksichtigung der verschiedenen über die Entstehungsweise der Doppelbildungen aufgestellten Theorien für die beiden vorliegenden Fälle die Anlage der zwei Primitivstreifen in einer Area pellucida zurecht zu legen, so wird man zu der folgenden Alternative gelangen. Entweder ist jeder der beiden Primitivstreifen für sich entstanden, oder dicselben stammen aus einer einheitlichen Anlage, die in zwei Hälften zerfiel, welche von einander abrückten und sich währenddem zu zwei völlig ausgebildeten Primitivstreifen entwickelten.

Die letztgenannte Möglichkeit ist conform mit den Anschauungen von Ahlfeld ${ }^{1}$ ), der sowohl durch kritische Sichtung des bereits vorhandenen Materials, als auch durch die Beschreibung einiger neuer Fälle von frühzeitigen Doppelbildungen unsere Kenntnisse über deren Bildungsweise gefördert hat. Ahlfeld verlegt die Spaltung der Embryonalanlage in eine ungemein frühe Zeit. „Es steht fest, dass die Spaltung einer gemeinsamen Anlage nicht mehr stattfinden kann, sobald die Primitivrinne gebildet ist, sobald die Blättertheilung beginnt. Der Zustand des Eies ist für die Theilung günstig, wo nach Beendigung des Furchungsprocesses sich das Bildungsmaterial undifferenzirt an einer Stelle der Keimblase angehäuft hat. Wenn in dieser Keimscheibe die Spaltung Fortschritte gemacht hat, dann ist hiermit auch der Anfangspunct für eine nachfolgende Drehung der durch Spaltung entstandenen beiden Axen gegeben" ${ }^{2}$ ).

Nach dieser Auffassung müsste die Spaltung der Anlage des Primitivstreifens in eine Entwicklungsphase fallen, in welcher derselbe im Flïchenbilde entweder dreieckig erscheint, oder bereits etwas länglich geworden ist. Ahlfeld nimmt dann weiter an, dass nach der Spaltung die zwei Hälften zu zwei Streifen sich entwickeln sollen. Diese entfernen sich allmählig von einander, und zwar soll dabei eine Drehung stattfinden, welche eine Axenverschiebung bewirke. Die Drehung denkt sich A. in der Weise, dass die beiden Streifen mit ihrem einen Ende genähert blieben, während sie mit dem anderen immer weiter von einander abriicken. Auch nach vollendeter Ausbildung der Primitivstreifen könne die durch Drehung verursachte Verschiebung der Längenaxen der beiden Embryonalanlagen noch eine Zeit lang andauern. „Die Möglichkeit, dass sich die Axen gegenseitig in ihrer Lage verändern, hört auf,

1) Ahlield, Beiträge \%ur Lehre von den Zwillingen. Arehiv tär Gynätiologie Bd. 9, 1876 , pag. 196.

2) 1. c. pag. 213. 
wenn die Gefässe des Fruchthofes sich ausbreiten. Von der Zeit an verwachsen die Fruchtanlagen mit einander in der Lage, welche sie zur Zeit gerade einnehmen" 1).

Wenn man nach der Ahlfeld'schen Hypothese den von Allen Thomson beschriebenen Fall sich genetisch zu erklären sucht, so macht dies keine Schwierigkeit, und es lïsst sich sehr gut die veränderte Gestalt des durchsichtigen Fruchthofes darauf zurückführen, dass die beiden Primitivstreifen sich gerade in der Drehung befinden. Ihre beiden hinteren Enden divergiren immer mehr von einander, und dadurch kommt es zu einer Verbreiterung des hinteren Theiles der Area pellucida. Während demnach der Allen Thomson'sche Fall für die Ansicht Ahlfeld's sich verwerthen lässt, kann die von mir beschriebene Doppelbildung meiner Meinung nach unmöglich durch die Hypothese einer frühen Spaltung der Embryonalanlage ihre Erklärung finden. Dieselbe liefert vielmehr, wie ich glaube, den unwiderlegbaren Beweis einer gesonderten Anlage der beiden Primitivstreifen. Fürs Erste dürften gegen die Möglichkeit der Spaltung einer einheitlichen Anlage mit darauffolgender Drehung, unter zunehmender Divergenz der hinteren Enden beider Streifen, die folgenden Argumente sich anführen lassen. Zunächst ist die Form des durchsichtigen Fruchthofes eine dem Entwicklungsstadium der Primitivstreifen entsprechende, vollkommen normale. Eine so regelmässige Beschaffenheit könnte die Area pellucida nicht gut besitzen, wenn eine Drehung der sich entwickelnden Primitivstreifen vorausgegangen wäre; auch verlaufen die letzteren völlig geradlinig, was ebenfalls gegen eine stattgehabte Drehung spricht. Ferner hat sich von jedem der beiden Streifen aus ein Mesoderm gebildet. Würden dieselben ursprünglich neben einander gelegen und sodann allmählig gewandert sein, so müssten die beiden mittleren Keimblätter, deren Anlage und Ausbreitung der Genese der Streifen selbst auf dem Fusse folgt, nothwendiger Weise continuirlich in einander übergehen. Sie sind jedoch noch vollständig von einander getrennt und wachsen sich erst entgegen. Endlich dürfte die kurze Zeit der Bebrütung sich kaum mit der Annahme vereinigen lassen, dass die beiden Streifen früher einmal dicht neben einander lagen. Gibt man nämlich sowohl für den Fall Allen Thomson's wie für den meinigen ein Auseinanderrücken der beiden Primitivstreifen zu, so ist in Anbetracht der bei beiden nahezu gleichen Brütedauer nicht einzusehen, warum in dem einen Falle die beiden Streifen sich nicht um die gleiche, sondern um eine weit grössere Strecke von einander entfernt haben, wie in dem anderen.

Es ist somit schon aus den angeführten Gründen die von mir beschriebene Doppelbildung mit der Spaltungshypothese Ahlfeld's unvereinbar. Auf der anderen Seite lehrt ein Blick auf die normale Entwicklungsgeschichte, dass es sich hierbei um ein gesondertes Auftreten von zwei Primitivstreifen handelt; denn die Keimhaut wiirde, wenn man sich einen von den beiden Streifen entfernt denkt, ein fast ganz normales Aussehen darbieten. Dies ist ein sicheres Zeichen dafür, dass der eine Streifen mit dem anderen bisher noch in keine Collision gerathen ist, sowie dass eine früher bestandene grössere Nïhelage und ein anfünglicher Zusammenhang der beiden Streifen von der Hand zu 
weisen ist. Es haben sich vielmehr die beiden Streifen vơn verschiedenen Punkten des Ringgebietes aus entwickelt, sie haben der Norm entsprechend je ein Mesoderm aus sich auswachsen lassen und sind, während die Primitivrinne sich bildete, bis in das Embryonalschild der Area pellucida hinein vorgedrungen.

Auch der Allen Thomson'sche Fall erklärt sich viel ungezwungener durch die Annahme einer gesonderten Anlage der beiden Primitivstreifen, als nach der Spaltungstheorie. Es sind eben hier (Fig. 1, Taf. IV) von zwei nicht allzu entfernten Stellen des Ringgebietes aus die zwei Primitivstreifen in die Area pellucida eingewachsen; dieselbe hat an zwei den hinteren Enden der beiden Streifen entsprechenden Stellen je ein Zuwachsstück erhalten, wodurch ihre ursprünglich runde Form verändert wurde und die beiden kleinen zackigen Ausläufer entstanden. Dass die zwei Primitivstreifen und zwar vorwiegend mit deren hinteren Abschnitten sich etwas von einander entfernt haben, wodurch ihr bogenförmiger Verlaut verursacht wurde, darin stimme ich mit Ahlfeld völlig überein; nur scheint mir daran kein Druck von oben Seitens der Dottermembran, sondern vielmehr die von jedem Primitivstreifen ausgehende Entwicklung eines Mesoderm Schuld zu sein. Die beiden. mittleren Keimblätter, welche von den hinteren Enden des Primitivstreifens zuerst und dann erst successive von den vorderen Abschnitten derselben nach beiden Seiten hin auswachsen, werden bald zwischen den beiden Streifen zusammentreffen und vermöge der ihnen zukommenden Wachsthumsenergie die letzteren aus einander drängen müssen, was zuerst an deren hinteren Enden beginnt und hier auch am ergiebigsten sich vollziehen wird.

Es sind somit nach meiner Ansicht die in Rede stehenden beiden frühesten Fälle einer Doppelbildung genetisch darauf zurückzutühren, dass an zwei Stellen die Anlagen der Primitivstreifen aus dem Ringgebiet in die Area pellucida eingewachsen sind; ferner lässt sich aus ihnen schliessen, dass die Distanz zwischen diesen beiden Stellen eine verschiedene sein kann; in dem Falle von Allen Thomson ist dieselbe eine geringe, in dem meinigen eine beträchtliche. Hiermit im engsten Zusammenhange steht begreiflicher W eise die spätere Stellung der beiden Primitivstreifen zu einander oder, was das Gleiche sagen will, die der Längsaxen der Embryonalanlagen. Liegen die Stellen, von wo aus die Primitivstreifen in die Area pellucida einstrahlen, wahe an einander, so werden diese, da sie bei ihrem weiteren Vordringen doch mehr oder weniger dem Mittelpuncte des Fruchthofes zustreben, später so gestellt sein, dass sie, resp. ihre linearen Verlängerungen einen spitzen Winkel mit einander bilden. Dieser Winkel wird mit der zunehmenden Entfernung jener Stellen von einander immer mehr sich vergrössern und schliesslich, wenn derselbe auf $180^{\circ}$ gestiegen ist, werden die an zwei opponirt gelegenen Stellen eindringenden Primitivstreifen sich in einer geraden Linie entgegenwachsen.

Die vorgetragene Auffassung steht in vollkommenem Einklang mit einer vor wenigen Jahren von Rauber über die Genese der Mehrfachbildungen aufgestellten Theorie ${ }^{1}$ ), welche dieser Forscher wegen der radienförmigen Anordnung der auftretenden Embryonalanlagen Radiationstheorie nannte.

$\left.{ }^{1}\right)$ Rather, Die 'Theorien der excessiven Monstra. Virchow's Arehiv Bd. 71. 1877. 
Rauber hat diese Theorie in einer sowohl die normale Entwicklung der Wirbelthiere, als auch die bisher beobachteten Formen frühzeitiger Mehrfachbildungen berücksichtigenden Abhandlung in überaus klarer und anschaulicher Weise begründet und durchgeführt. Auf die Differenzpuncte zwischen seinen Anschauungen und den meinigen werde ich späterhin noch in einem besonderen von der Rauber'schen Theorie handelnden Capitel eingehender zu sprechen kommen.

Schon bei der Beschreibung des zweiten der von mir beobachteten Fälle wurde darauf hingewiesen, dass die beiden Embryonen bezüglich der Stellung ihrer Längsaxen die gleiche Anordnung zeigen, wie die Primitivstreifen in meinem ersten Falle. Daraus ergibt sich auch die gleiche Entstehungsweise der beiden Doppelbildungen. Bei beiden hat sich die Anlage der zwei Embryonen dadurch eingeleitet, dass je zwei Primitivstreifen von identischen Stellen des Ringgebietes aus in das Innere einer gemeinsamen Area pellucida vordrangen, wobei sie auch eine so ziemlich gleiche Richtung einhielten. In beiden Fällen ist es ferner für die eine Embryonalanlage die normale Stelle, für die andere die linke vordere abgerundete Seitenecke der später birnförmigen Area pellucida, von wo aus das Einwachsen stattfand. Aus den genannten Grïnden halte ich mich für berechtigt, die beiden Fälle als verschiedene Stadien der gleichen Entwicklungsform einer Doppelbildung aufzufassen. Es scheint mir darum von Interesse, die beiden Keimhäute einem genaueren Vergleiche zu unterziehen, in der Erwartung, dass aus demselben sich Anhaltspuncte ergeben werden, welche hinsichtlich der Wachsthumsvorgänge von Doppelbildungen in den ersten Tagen der Bebrütung Folgerungen gestatten.

Hält man die beiden Zwillingsbildungen (Taf. II u. Fig. 1, Taf. III) neben einander, so wird man sich zunächst die Frage vorlegen müssen, in welcher Weise das Embryonalschild, wenn zwei Primitivstreifen in dasselbe einwachsen, den veränderten Verhältnissen Rechnung trägt. Der Umstand, dass sich in dem älteren meiner Fälle die beiden Embryonen noch nicht vereinigt haben, beweist, dass aus dem Embryonalschild unter solchen Umständen die Stammeszonen von zwei Embryonalanlagen sich herausbilden können, indem jeder der beiden Primitivstreifen einen Theil des gemeinschaftlichen Embryonalschildes für sich in Anspruch nimmt und diesen in der Art beeinflusst, dass zwei gretrennte Medullarrinnen entstehen, die, wenn der dazwischen liegende 'L'heil des Schildes sich ausdehnt, aus cinander rücken werden. Wie ich früher aus einander gesetzt habe, stellt das Embryonalschild Anfangs einen noch sehr wenig differenzirten Bestandtheil der Area pellucida dar; es kann daher nicht Wunder nehmen, wenn bei Zwillingsbildungen dasselbe an gewissen Stellen eine stärkere Flächenausdehnung zeigt, wodurch es in zwei Abtheilungen für je einen Primitivstreifen ausgezogen wird.

Als ein zweites Ergebniss, zu dem ein Vergleich meiner beiden Fälle führt, ist die übrigens auch schon durch anderweitige Beobachtungen festgestellte 'T'hatsache namhaft zu machen, dass die beiden in einer Area pellucida eingeschlossenen Embryonen, solange sie sich nicht durch allzunahe Lagerung oder durch directes Aufeinandertreffen in ihrer Ausbildung stören, in durchaus normaler Weise sich weiter entwickeln können. So mag in der 
älteren der beiden Doppelbildungen die Entwicklung der beiden Embryonen, abgesehen von dem Ausbleiben der Amnionfalten, bis zur Bildung der Herzen und des Gefässhofes normal fortgeschritten sein; dann aber trat bei beiden eine Verschiedenheit auf; der Herzschlauch des linken vorderen Embryo bog anormaler Weise bei seiner Wachsthumsverlängerung nach links ab, so dass die Herzschlinge nicht rechts, sondern links von dem embryonalen Körper zu liegen kam. Ebenso bildete sich die rechte Arteria omphalomesenterica dieses Embryo nicht hinreichend aus. An beiden Dingen ist die Nähe des anderen Embryo Schuld, worin wir auch wohl die Ursache zu erblicken haben, dass bei der Ausbildunge der Kopfkrümmung der erstgenannte Embryo sich statt mit der linken, mit der rechten Seite auf die Keimhaut auflegte.

Einen weiteren Rückschluss gestatten ferner die beiden Keimhäute in Bezug auf die Ausdehnung des durchsichtigen Fruchthofes. Die Vergrösserung desselben geht nicht allein appositionell vor sich (Einbeziehung der beiden Zuwachsstiicke), sondern es muss auch ein intussusceptionelles Wachsthum angenommen werden. Erwägt man nämlich die geringe Entfernung zwischen den Kopfenden der beiden Primitivstreifen, wie sie bei der jüngeren meiner beiden Doppelbildungen zu beobachten ist (Fig. 1, Taf. III), so müsste in diesem Falle, wenn die Distanz zwischen jenen sich nicht bei der fortschreitenden Entwicklung vergrössern würde, sehr bald der Kopffortsatz des unteren Primitivstreifens auf den des linken vorderen stossen und dadurch eine Entwicklungsstörung verursacht werden, welche ihrerseits wiederum die Bildung von zwei vollkommen getrennten Medullarrinnen verhindern würde. Da dies nun bei den Embryonen meines älteren Falles nicht eingetreten ist, so folgt daraus eine länger andauernde intussusceptionelle Ausdehnung des zwischen den beiden je einem Primitivstreifen zugehörigen Abtheilungen des Embryonalschildes gelegenen Keimhautbezirkes. Dass derselbe ursprünglich ebenfalls dem gemeinsamen Embryonalschild angehörte, ist bereits erwähnt worden. Diese Ausdehnung scheint späterhin, wenn die Kopfenden der beiden Embryonen sich aús dem Niveau des Fruchthofes erheben, mit deren Längenwachsthum nicht mehr lange gleichen Schritt halten zu können; wenigstens ist dies für die ältere der beiden in Rede stehenden Doppelbildungen anzunehmen, deren Embryonen mit ihren Köpfen sich eng an einander gelegt haben, was in Anbetracht des relativ frühen Entwicklungsstadiums der beiden Zwillinge aller Wahrscheinlichkeit in kürzester Frist zu einer Verwachsung geführt haben wïrde. Dadurch würde voraussichtlich schon in den nächsten Tagen, falls die Bebrütung fortgesetzt worden wäre, eine kraniopage Doppelmissbildung zu Stande gekommen sein. Das Fehlen des Amnion würde jedoch die vollständige Ausbildung der Allantois beeinträchtigt haben, wesshäib die beiden Embryonen späterhin hätten absterben müssen; doch dürften sich dieselben immerhin bis in die Mitte der Brütezeit am Leben haben erhalten können, da wir durch Dareste wissen, dass Hühnerembryonen mit vollständigem Amnionmangel oft noch am 13. Tage der Bebrütùng lebend angetroffen werden ${ }^{1}$ ).

Wir haben somit für den älteren meiner beiden Fälle wahrscheinlich machen können, dass die beiden Embryonen desselben sich zu einer Doppelmissbildung hätten vereinigen müssen. Es wirft sich hierbei die Frage auf, ob

1) Dareste, Sur l'absence totale de l'amnios dans les embryous de poule. Comptes rendus T. 88, Nr. 25, pag. $1329-1332$. 
alle in einer Keimscheibe zur Entwicklung kommenden Zwillingsembryonen zu einer Monstrosität zusammenwachsen müssen. Für die Vögel ist diese Frage zu bejahen. Es haben Panum ${ }^{1}$ ) und Dareste ${ }^{2}$ ) darauf aufmerksam gemacht, dass zwei auf einem Dottér sich gleichmässig entwickelnde Embryonen schliesslich am Ende der Bebrütung, wenn der gemeinschaftliche Dottersack von beiden in die Leibeshöhle eingezogen wird, am Nabel mit einander verwachsen müssen. Js. Geoffroy Saint-Hilaire ${ }^{3}$ ) hat eine solche Missbildung O mphalopagen" genannt. Das Zustandekommen von Omphalopagen ist jedoch durch die bei der Entwicklung der Vögel gegebenen Verhältnisse bedingt. Bei den Säugern findet eine vollständige Trennung des Darmrohres vom Nabelbläschen statt, wesshalb hier zwei aus einem Eie entstandene Zwillinge sich vollständig von einander trennen können.

Die am Ende der Briitezeit stattfindende Vereinigung von zwei auf einem Dotter sich entwickelnden Embryonen zu einer omphalopagen Missbildung stellt demnach eine besondere Eigenthümlichkeit der Vögel dar. Wir können darum von derselben hier absehen und haben vielmehr zu untersuchen, ob und unter welchen Umständen in der ersten Zeit der Entwicklung die Vereinigung von zwei in einer gemeinsamen Area pellucida auftretenden Embryonalanlagen, resp. Embryonen stattfindet und welche Arten von Doppelmissbildungen daraus resultiren.

A priori ist anzunehmen, dass die beiden Componenten einer Doppelbildung sich so lange gesondert entwickeln werden, als sie sich gegenseitig in ihrer weiteren Ausbildung nicht stören. Eine solche Störung kann aber direct oder indirect erfolgen. Die indirecten Störungen können sehr mannigfacher Art sein. Sie treten jedoch nicht in den ersten Stadien der Embryonalbildung auf, sondern äussern sich meistens erst später. In der Mehrzahl der Fälle beruhen sie auf einer ungleichen Entwicklung der beiden Zwillinge, die für den schwächeren verhängnissvoll wird. Der letztere wird in Folge des Zusammenhanges der Blutgefässe beider Embryonen allmählig von dem stärkeren, der eine kräftigere und ausgedehntere Blutcirculation entfalten kann, gewissermassen unterjocht und es kann hierauf zu verschiedenen Missbildungen kommen. Legt man dabei die bei den Vögeln obwaltenden Verhältnisse zu Grunde, so kann der schwächere Embryo, dessen Entwicklung schliesslich sistirt, bei Einziehung des Dotters in die Bauchhöhle in das Innere des stärkeren Zwillings gelangen und wird dann einen Foetus in foetu darstellen; bei den Säugethieren jedoch können durch indirecte Entwicklungsstörung ausser den verschiedenartigsten parasitären Zwillingsmissbildungen auch Acardiaci neben normalen Embryonen zur Entwicklung gelangen, wie dies unlängst Ahlfeld ${ }^{4}$ ) des Näheren auseinandergesetzt hat.

Während die indirecten Entwicklungsstörungen, die für unsere Betrachtungen nur ein geringes Interesse haben, meistens erst dann eintreten, weun beide Embryonen bereits eine gewisse Ausbildung erreicht haben, können sich die directen schon in den allerersten Stadien der Embryonalanlage einstcllen. Dieselben

\footnotetext{
') Panum, Intersuchungen üher die Fntstehung der Missbildungen pag. 248.

$\left.{ }^{2}\right)$ Dareste, Production artificielle des monstruosités pag. 296.

${ }^{3}$ ) Js. Geofiroy Saint-Hilaire, 'Traité de tératologie 'T. III, pag. 107.

4) Ahlfeld, Beiträge zur Lehre von den \%willingen. VI. Die Entstehnng der Acardiaci. Archiv liir Gynakolorgic BA. XIV. pag. 321.
} 
beruhen darauf, dass in relativ früher Entwicklungszeit den beiden Embryonen zu ihrer normalen Fortbildung nicht genïgend Platz bleibt, indem durch den einen Zwilling dem anderen der nöthige Raum weggenommen wird, oder sie sich vielleicht beide gegenseitig im Wege stehen; sie werden darum schliesslich auf einander treffen müssen und sich dadurch in ihrer weiteren normalen Entwicklung beeinträchtigen. Wir wissen aus den früheren Darlegungen, dass bei dem Auftreten von zwei Primitivstreifen dieselben von verschiedenen Stellen der Peripherie aus mehr oder weniger gegen das Centrum der Area pellucida vordringen. Durch dieses Vorwachsen müssen sich die Kopfenden der Primitivstreifen immer mehr nähern. Entwickeln sich vor den letzteren noch die Kopffortsätze und die Medullarrinnen, wobei sich die Embryonalanlage immer weiter nach vorne verlängert, so muss ein schliessliches Zusammentreffen der vorderen Körperenden beinahe unvermeidlich erscheinen. Trotzdem kann es unseren Erfahrungen zufolge vorkommen, dass beide Embryonen getrennt bleiben; dann aber muss sich der zwischen den genäherten Kopfenden der beiden Zwillinge liegende Abschnitt der Keimhaut in einer dem Wachsthum derselben äquivalenten Weise ausdehnen, und zwar muss dies so lange andauern, bis die Zwillinge sich vollkommen aus dem Niveau der Keimhaut erhoben haben und in der Amnionflüssigkeit sich frei bewegen können; um diese Zeit ist eine Verwachsung kaum mehr zu befürchten. In den meisten Fällen jedoch wird jene Ausdehnung des Fruchthofes entweder gänzlich unterbleiben, oder nur kurze Zeit andauern und es wird zu einer Vereinigung der Embryonen kommen müssen. Dieselbe kann nur in geringer Ausdehnung erfolgen oder grössere Dimensionen annehmen, worüber in den späteren Capiteln dieses Buches ausfïhrlicher berichtet werden .wird; an dieser Stelle sei nur bemerkt, dass es hauptsächlich zwei Puncte sind, welche auf die mehr oder minder weit gehende Vereinigung zweier Zwillinge von Einfluss sind; erstens die ursprüngliche Längenanordnung der beiden Embryonalanlagen und zweitens die Zeit des Zusammentreffens der letzteren. Je früher dieses stattfindet, eine desto vollständigere Fusion wird erfolgen. Bei den meisten Doppelbildungen werden die beiden Momente zusammenfallen, d. h. diese oder jene Stellung der Embryonalanlagen involvirt eine mehr oder minder frühzeitige Vereinigung der beiden Componenten einer Doppelbildung.

Aus den angestellten Betrachtungen darf im Allgemeinen gefolgert werden, dass in dem Vorhandensein von zwei Primitivstreifen in einem gemeinsamen durchsichtigen Fruchthofe ein prädisponirendes Moment für die Genese solcher Doppelmissbildungen erblickt werden muss, welche bei getrennten hinteren Leibesenden innerhalb ihrer vorderen oder mittleren Körpertheile-eine verrschieden hochgradige Vereinigung aufweisen. Es werden sonach Doppelmonstra resultiren, welche, um die von Förster in seinem Buche über die Missbildungen gebrauchten Bezeichnungen ebenfalls anzuwenden, in die Classe der Terata anadidyma (Duplicitas posterior) und anakatadidyma einzureihen sind.

Mit dieser Schlussfolgerung, zu der wir vorerst mehr theoretisch und hauptsächlich gestiitzt auf die Vorgänge der normalen Entwicklung grelangten, stimmen, wie ich jetzt schon erwähnen will, die Beobachtungen frülıcitiger Doppelmissbildungen, bei denen noch zwei ursprünglich getrennte Embryonalanlagen nachweisbar sind, vollständig überein. 


\section{Zusammenstellung der bisher bekannt gewordenen Fälle frühzeitiger Doppelbildungen bei den höheren Vertebraten.}

Die bei menschlichen und Säugethier-Embryonen gemachten Befunde von Doppelbildungen betreffen leider kein so frühes Entwicklungsstadium, wie wir es bedürfen, um über das Zustandekommen derselben Aufschluss zu erhalten. Man ist somit auf die Classe der Vögel beschränkt, aus welcher uns ein verhältnissmässig reiches Material von Beobachtungen frühzeitiger Mehrfachbildungen zu Gebote steht. Dieselben sind bereits von Ahlfeld und Rauber in deren oben citirten Abhandlungen zusammengestellt worden. Seit dem Erscheinen derselben sind jedoch in beträchtlicher Anzahl weitere, theilweise sehr wichtige Fälle mitgetheilt worden, welche wir zum Theile Rauber, zum grössten Theile aber Dareste verdanken, dessen Buch eine wahre Fundgrube von hierher gehörigen Beobachtungen darstellt. Es scheint mir desshalb nöthig, nochmals über die einschlägigen Fälle kurz zu referiren, damit das gesammte vorliegende Material übersehen werden kann. Ich werde dabei die einzelnen Fälle nicht, wie es von moinen Vorgängern geschah, nach der Zeit der Publication ordnen, sondern dieselben unter Bezugnahme auf die Zeit ihrer Entwicklung auf einander folgen lassen, indem ich mit den auf den frühesten Bildungsstadien befindlichen Doppelbildungen beginne und dann successive zu denjenigen Doppelembryonen übergehe, welche späteren Entwicklungsphasen angehören.

Der Ausführung dieses Vorhabens stellen sich jedoch einige Schwierigkeiten in den Weg. Während von den anderen Autoren fast ausnahmlos die Brïtedauer der Eier, aus denen die Doppelbildungen stammen, angegeben wurde, hat Dareste, dem gerade von allen anderen Forschern die meisten Mehrfachbildungen zu Gesicht kamen, zu meinem Bedauern es unterlassen, in seinem Buche derartige Angaben zu machen; auch die Beschreibung, welche Dareste über die betreffenden Fälle gibt, beschränkt sich nur auf kurze, zur Erläuterung der Abbildungen dienende Bemerkungen. Ich räume gern ein, dass durch eine gut ausgeführte Zeichnung eine eingehendere Beschreibung des Falles theilweise überflüssig gemacht wird, da man durch eine solche über das Entwicklungsstadium, die Form und die Anordnung der Embryonen sofort orientirt wird; allein trotzdem scheinen mir nähere Angaben über die Dauer der Bebrütung, das Alter, die Ausbildung der Organe Seitens des verdienstvollen französischen Forschers äusserst wünschenswerth. Bei der folgenden 
Aufführung der einzelnen Doppelbildungen habe ich mir nun bezüglich der Dareste'schen Fälle so geholfen, dass ich zu den kurzen Bemerkungen Dareste's noch diejenigen, Data über die Beschaffenheit der Embryonen und deren Organe hinzufügte, welche sich aus den betreffenden Zeichnungen mit Sicherheit ergaben. Bei dem Einordnen dieser Fälle in die Reihe der ïbrigen konnten bei dem Mangel jeglicher Zeitangaben für mich ebenfalls nur die Abbildungen bestimmend sein. Dadurch musste nothwendiger Weise die Einreihung der Dareste'schen Fälle bis zu einem gewissen Grade eine willkührliche werden, da es ja in zweifelhaften Fällen meinem Ermessen anheim gestellt war, der bezüglichen Doppelbildung diese oder jene Stelle in der Reihe anzuweisen.

Von der Ansicht ausgehend, dass Abbildungen der einzelnen Doppelbildungen nicht nur für deren Schilderung erforderlich, sondern auch für eine vergleichende Prüfung derselben geradezu unentbehrlich sind, bin ich dem Beispiele Ahlfeld's gefolgt und habe mir die Mühe genommen, für sämmtliche Fälle Copien der von den einzelnen Autoren ihren Abhandlungen beigegebenen Zeichnungen anzufertigen. Es gewährt dies eine leichtere Uebersicht über das vorliegende Beobachtungsmaterial und hat ferner den Vortheil, dass ich späterhin, wenn die Schlussfolgerungen, zu denen dieser oder jener-Fall berechtigt, erörtert werden, nur auf die Abbildung desselben zu verweisen brauche, wodurch sonst unvermeidliche Wiederholungen unnöthig werden.

Bevor ich nun über die beobachteten Doppelbildungen der Reihe nach referire, möchte ich noch auf einen Punct aufmerksam machen. Der alte Streit, ob die Doppelmissbildungen sich durch das Verwachsen von Embryonen bilden, welche von zwei Eiern sich ableiten, oder solcher, die aus einem einzigen Eie stammen, kann wohl heutzutage als zu Gunsten der monovistischen Theorie beigelegt betrachtet werden. Eine andere Frage dagegen ist es, ob die beiden Componenten einer Doppelbildung immer in nächster Nähe, d. h. unter Bezugnahme auf die für die Vögel geltenden Verhältnisse in einem gemeinsamen durchsichtigen Fruchthofe sich anlegen, oder ob sie vielleicht auch in grösserer Entfernung von einander in zwei verschiedenen Areae pellucidae ihre Entwicklung beginnen können. Letzteres steht nach den allerdings nur vereinzelten Beobachtungen, welche hier in Betracht kommen, meines Erachtens ausser allem Zweifel. So ist von Panum und später von Dareste das Vorkommen von zwei ursprünglich getrennten Keimhäuten constatirt worden; ferner weisen mehrere theils von Dareste, theils von Reichert und Rauber mitgetheilte Fälle von Doppelbildungen unzweideutig darauf hin, dass bei den betreffenden Eiern zwei Areae pellucidae, eingeschlossen in eine gemeinsame Area opaca, vorhanden gewesen sein müssen.

Leider sind jedoch derartige Beobachtungen noch nicht sehr zahlreich und es lässt sich aus ihnen nicht mit Gewissheit erkennen, ob in den Fällen, in welchen innerhalb zweier von einem gemeinsamen Ringgebiete umschlossenen Areae pellucidae die beiden Embryonalanlagen auftreten, dieselben in der ersten Entwicklungszeit bis zu dem Grade sich nähern können, dass sie mit einander zu einer Doppelmissbildung sich vereinigen. Aus diesem Grunde habe ich von den in zwei getrennten durchsichtigen Fruchthöfen sich entwickelnden Doppelbildungen Abstand genommen und habe in der nachstehenden Zusammenstellung nur diejenigen Fälle berücksichtigt, aus deren 
Beschreibung und Abbildung hervorging, dass die beiden Zwillinge einer gemeinschaftlichen Area pellucida angehörten.

Fall 1. Allen Thomson ${ }^{1}$ ).

Hühnerei, 16-18 Stunden bebrütet. Taf. IV, Fig. 1.

Ueber dasselbe wurde bereits früher referirt.

Fall 2. Gerlach. (Der erste der von mir beschriebenen Fälle.)

Hühnerei, 20 Stunden bebrütet. Taf. III, Fig. 1.

Fall 3. von Baer ${ }^{2}$ ).

Hühnerei, noch nicht 24 Stunden bebrütet. Taf. IV, Fig. 2.

Dieser Fall ist. leider nur sehr ungenügend beschrieben, da v. Bär das betreffende Präparat, welches ihm verloren gegangen war, nur nach der Erinnerung schilderte. Da er angibt, dass der vordere Abschnitt der Embryonalanlage ungetheilt gewesen sei, die Chorda dorsalis sich jedoch nach rückwärts in zwei Schenkel gespalten habe, so muss angenommen werden, dass der Embryo ein frühes Stadium einer Duplicitas posterior darstellte.

Fall 4. Dareste ${ }^{3}$ ).

Hühnerei, Brütedauer unbekannt. Taf. IV, Fig. 3.

„Blastoderme présentant les débris d'un monstre double parasitaire. Il y avait deux têtes: une complète et une autre beaucoup plus petite. C'était très probablement un hétérodyme. La désorganisation ne m'a pas permis de l'étudier d'une manière plus complète; mais l'extrême rareté de ce type de monstruosité double m'engage à le publier. Je n'en ai pas encore observé d'exemples vivants. Grossi six fois."

Wie aus vorstehender Notiz zu entnehmen, stammte die vorliegende Doppelmissbildung aus einem Ei, bei dem die Entwicklung schon sehr frühe sistirte, und das erst später eröflnet und untersucht worden war. So viel geht jedoch aus der Zeichnung Dareste's mit Sicherheit hervor, dass es sich um ein Entwicklungsstadium handelt, das etwa der 12. Stunde des ersten Tages bei normaler Entwicklung entspricht. Es würde daraus zweifelsohne bei der weiteren Ausbildung eine Duplicitas anterior mit ungleicher Entfaltung der beiden Componenten entstanden sein, da die eine der beiden Medullarfurchen, welche sich nach vorne von einem gemeinsamen mit Primitivrinne versehenen Primitivstreifen entwickelt haben, breiter und stärker angelegt ist, als die andere. Dass das äusserst werthvolle Präparat leider so spạt erst zur Untersuchung $\mathrm{kam}$, so dass Dareste nicht mehr in der Lage war, dasselbe genauer zu studiren, ist sehr zu bedauern, da gerade ein so frühes Studium vorderer Verdoppelung die Anlage einer solchen Missbildung unzweideutig nachweisen müsste.

Fall 5. Reichert ${ }^{4}$ ).

Hühnerei, vom zweiten Tage der Bebrütung ${ }^{5}$ ). Taf. IV, Fig. 4.

Die beiden Embryonen liegen in einer Linie, mit den Kopfenden einander «ugekehrt. An den Berührungsstellen der Kopfenden war eine Verschmelzung nicht

') Allen Thomson, The London and Edinburgh Monthly Journal 1844, pag. 479.

$\left.{ }^{2}\right)$ Mémoires de l'Académie de St. Petersbourg. V1. Série. Tom. IV, 1845.

${ }^{3}$ ) Dareste, Recherches sur la production artificielle des monstruosités. Paris 1877. Tal. XVI, Fig. 7.

$\left.{ }^{4}\right)$ Archir fïl Anatomie u. Physiologie 1864, Tuf. XVIII, Fig. 4.

$\left.{ }^{5}\right)$ Es scheint mir diese Zeitangabe, welche sich in den Erklïrungen der Abbildungen findet, für den betreffenden Dropelembryo zutreffender, als die Angabe Reichert's im Texte, wonach das Ei erst am Ende des dritten Tages zur Untersuchung gekommen wäre. 
vorhanden. Rückenfurche noch vollständig offen; die Rückenwülste, welche vorne bei jedem Embryo durch eine Kopffalte mit einander verbunden sind, baben sich in ihrem vorderen Theile schon ziemlich stark entwickelt. Herzanlage fehlt noch. Kopfdarmhöhle in den ersten Anfängen vorhanden.

Die Area pellucida ist länglich und schmal, nur in ihrer Mitte in der Höhe der Kopfenden beider Embryonen erscheint sie seitlich etwas in die Breite gezogen.

Der Gefässhof hat eine längliche elliptische Form; die kurze Axe der Ellipse fällt zwischen die Kopfenden der beiden Zwillinge.

Fall 6. Rauber ${ }^{1}$ ).

Hühnerei, 36 Stunden bebrütet. Taf. IV, Fig. 5.

Beide Embryonen grenzen mit ihren vorderen Enden an einander, die Schwanzenden sind von einander abgewendet. Thre Längsaxen bilden einen Winkel von $120^{\circ}$. Der eine Embryo ist weiter entwickelt, als der andere, dessen Ausbildung durch den ersten im Kopftheile gehemmt wurde.

Der stärkere Zwilling besitzt eine noch überall offene Rückenfurche, welche sich im Kopftheile normal verhält; 5-6 Urwirbel sind bereits aufgetreten. Hinter der Medullarfurche befindet sich der Primitivstreifen mit der Primitivrinne; das Ende desselben ist gekrümmt und stösst an die Area opaca an. Der. Vorderdarm eben angelegt, dagegen ist von dem Herzen noch nichts zu bemerken.

Der schwächere Embryo besteht aus einem Primitivstreifen mit Primitivrinne, an welchen sich nach vorne zu eine anormal tiefe Medullarfurche, die seitlich von den Rückenwülsten begrenzt ist, anschliesst; dieselbe reicht bis zu dem Kopfende des stärkeren Embryo. Vorderdarm fehlt, natürlich auch das Herz.

Die Area pellucida bildet ein, sehr flaches gleichschenkliches Dreieck mit abgerundeten Winkeln und eingebogenen Seitenlinien. Die Grundlinie, d. h. die längste Seite des Dreiecks sieht nach rechts. Der Gefässhof annähernd normal; der Sinus terminalis in der Bildung begriffen.

\section{Fall 7. Ahlfeld ${ }^{2}$.}

Hühnerei, 36 Stunden bebrütet. Taf. IV, Fig. 6 .

Der $3,0 \mathrm{~mm}$ lange Embryo erscheint am hinteren Körperende gespalten; die Spaltung beginnt 2,2 mm von dem gemeinsamen Kopfende entfernt. Die Entfernung beider Schwanzspitzen beträgt 2,25 $\mathrm{mm}$.

Es finden sich 4 Reihen Urwirbel neben einander; jede Reihe besteht aus 5 Urwirbeln; die beiden inneren Reihen liegen etwas höher; von ihrem hinteren Ende geht, die Medianlinie einhaltend, ein feiner Strang nach hinten zu ab, der bis zum Rande des Fruchthofes sich verfolgen lässt; derselbe ist nach A. zum 'Theil als Amnion aufzufassen, dessen Kopfscheide sich ebenfalls schon entwickelt hat ${ }^{3}$ ).

Das Medullarrohr noch überall offen; es erscheint in seinem vorderen Theile auffallend breit und theilt sich in der Höhe der vorderen Urwirbel. In der Urwirbel-

1) Morphologisches Jahrbuch Bd. VI, 1880, Taf. X, Fig. 26 a u. b.

2) Archiv für Gynäkologic Bd. 9, 1876, Taf. VI, Fig. 22.

$\left.{ }^{3}\right)$ Ahlfeld sagt über das in Rede stehende Gebilde Folgendes: "Der schon oben erwähnte Strang wird Anlangs gebildet aus der Kante der schräg gegen einander gerichteten inneren Wirbelplatten. Er setzt sich aber anch noch tort an der Stelle, wo die Wirbelplatten mit den sich trennenden Schwamzenden abweichen. Vou da ans halte ich ihn für das sich erhebente Amnion. An seinem letzten Theile, wo er mit der Umgebung des Fruchthofes, dem Keimwalle, in Beriihrung steht, verbreitert er sich wesentlich, so dass er Init einel breiten Basis ohne deutliche Abgrenzung in den Keimwall iibergehı." 
gegend verlaufen die beiden stark eingeengten Medullarrinnen parallel neben einander, um sodann unter einem Winkel von etwa $120^{\circ} \mathrm{zu}$ divergiren.

Das Herz ist noch nicht vorhanden, dagegen sind die Blutinseln schon aufgetreten. Die Area pellucida annähernd oval, mit einer kleinen Ausbuchtung nach links und hinten versehen.

Fall 8. Gerlach. (Der dritte der von mir beschriebenen Fälle.) Hühnerei, 48 Stunden bebrütet. Taf. III, Fig. 2.

\section{Fall 9. von Baer ${ }^{1}$.}

Hühnerei, 52-54 Stunden bebrütet. Taf. IV, Fig. 7.

Die beiden Embryonen, deren Längsaxen in einer Linie liegen, kehren ihre Schwanzenden von einander ab; mit ihren Köpfen sind sie verwachsen. Der gemeinsame Kopf erhebt sich merklich aus der Ebene der Keimhaut, und ist nach einer Seite übergebogen. Das Medullarrohr ist bei beiden Embryonen überall geschlossen; neben ihm befinden sich die Urwirbelreihen.

Es existiren zwei Herzen, von denen das eine mehr ausgebildet ist, als das andere; an den beiden Schwanzenden scheint eine eben auftretende Amnionbilduing vorzuliegen; am Kopfe dagegen fehlt eine solche.

Die Area pellucida hat die Gestalt eines Kreuzes, dessen längere Arme in der Queraxe des Eies, die kürzeren in dessen Längsaxe liegen; in der Höhe der letzteren befinden sich die vereinigten Kopfenden der Zwillinge, deren übrige Körperabschnitte in den langen Schenkeln des Kreuzes liegen. Die verwachsenen Köpfe waren nach dem spitzen Eipol hin abgebogen.

\section{Fall 10. Dönitz ${ }^{2}$.}

Hühnerei, 3 'Tage bebrütet. 'Taf. IV, Fig. 8.

Die mit ihren Kopfenden einander zugekehrten Zwillinge lagen quer zu der Längsaxe des Eies. Der eine Embryo ist etwas länger, als dęr andere; bei beiden hat sich das Medullarrohr mit Ausnahme seines hinteren Abschnittes geschlossen. Die vorderen Hirnbläschen der beiden Embryonen hängen mit einander zusammen. Ob ihre Hohlräume communiciren, lässt sich nicht entscheiden; die beiderseitigen mittleren und hinteren Hirnblïschen erscheinen ventralwärts stark eingeknickt; diesen Knickungen unterliegt an den betreffenden Stellen auch die Chorda dorsalis. Der schwächere Embryo besitzt 9, der stärkere 12 Paar Urwirbel. Die Darmrinne ist bei beiden noch sehr seicht.

Die Herzen sind nur rudimentär angelegt; die Stämme der Arteriae und Venae omphalomesentericae lassen sich nicht deutlich nachweisen. Von dem Amnion ist noch nichts zu bemerken.

Die Area vasculosa oval; Blutpuncte sind in derselben nicht deutlich sichtbar. Die Area pellucida hat die Gestalt eines Kreuzes, dessen lange Schenkel schmal, dessen kürzere, in deren Region die Kopfenden liegen, ausserordentlich breit sind.

\section{Fall 11. Dareste ${ }^{3}$ ).}

Hühnerei, Brütedauer unbekannt. 'Taf. IV, Fig. 9.

„Nonstre double monosomien. Corps unique; terminé par deux têtes soudées dans leur région inférieure. ("était un iniodyme. Grossi quatre fois."

') Mémoires de l'A cadémie de St. Petersbourg. VI. Série. 'Tom. IV, 1845; und Meckel's Archiv für Anatomie und Physiologie 1827, pag. 576.

$\left.{ }^{2}\right)$ Reichert's und Du Bois-Reymond's Archiv 1866, 'Taf. XIII.

3) 1. c. Taf. $X V$, Fig. 5 . 
- Dieser Bemerkung lässt sich der beigegebenen Abbildung zu Folge noch beifügen, dass das Medullarrohr etwa in der Höhe der vorderen Darmpforte nach vorne hin in zwei Abtheilungen ausläuft, welche mit kleinen Anschwellungen vorne endeten. Die Kopfanlage zeigte durch einen seichten vorderen Einschnitt eine Trennung in zwei Hälften. Es haben sich nur zwei Gehörgrübchen entwickelt, ebenso ist nur ein Herz zur Ausbildung gelangt. Die vordere Amnionfalte deckt bereits das vordere Drittheil des Embryo; die hintere hat sich ebenfalls schon angelegt.

Fall 12. Dareste ${ }^{1}$ ).

Hühnerei, Brütedauer unbekannt. Taf. V, Fig. 1.

„Monstre à corps unique, et à têtes doubles, mais soudées. Deux gouttières longitudinales, avec trois rangs de prévertèbres. Cœur simple, mais présentant des traces bien évidentes de dualité. Grossi six fois."

Ausser den bereits bemerkten Eigenthümlichkeiten dieser Duplicitas anterior lässt die Zeichnung noch erkennen, dass die beiden Medullarrohre erst an der Stelle des hinteren Körperendes, an welcher die Urwirbel aufhören, sich zu einem gemeinsamen, nur noch kurzen Stücke vereinigen. Die mittlere Reihe der Urwirbel liegt zwischen den beiden Medullarrohren. Jedes der letzteren zeigt bereits eine beginnende Abschnürung der Augenblasen. Es haben sich nur zwei Labyrinthgrübchen angelegt; jedes derselben liegt lateral von je einem der beiden Nervenrohre.

\section{Fall 13. Reichert ${ }^{2}$ ).}

Gänseei, 3 Tage bebrütet. Taf. V, Fig. 2, A u. B.

Der Entwicklungszustand dieser Doppelbildung entspricht einem normalen Embryo nach 48stündiger Bebrütung. 'Es handelt sich nach R. um zwei dicht neben einander gelegene Embryonen, deren Rücken und Bauchflächen nach gleichen Richtungen hin gewendet sind. Nur der Kopf und das wenig entwickelte Schwanzende beider Embryonen sind völlig getrennt; im übrigen Theile sind dieselben seitlich der Länge nach eng verwachsen und vereinigt.

Das Medullarrohr ist in der Kopf- und Halsgegend, sowie im Schwanzende doppelt und hier auch schon geschlossen. Im übrigen Körpertheile ist die Rückenfurche noch offen und gemeinschaftlich; doch ist eine Trennung durch eine mediane Längsleiste angedeutet, die nach hinten zu sich abflacht. Etwas seitlich von dieser Leiste liegen die beiden Chordae dorsales, ziemlich nahe an einander; dieselben verlaufen nicht ganz parallel, indem sie vorne eine, wenn auch nur um ein Minimum grössere. Entfernung zwischen sich lassen, als hinten.

Die drei Hirnbläschen haben sich in den beiden Kopftheilen bereits angelegt; die Augenblasen sind in der Abschnürung begriffen; die Ohrgrübchen sind schon aufgetreten, jedoch im Ganzen nur zwei, indem sie an den einander zugewendeten Seiten der beiden Köpfe sich nicht ausgebildet haben.

- Die Darmrinne ist in ihrem mittleren Theile gemeinschaftlich; sie setzt sich nach vorne und hinten in zwei Kopfdarm- und Beckendarmhöhlen fort; die letzteren sind noch sehr klein.

Die zwei Herzen, von denen ein jedes einen Rulbus aortae besitzt, sind seitlich mit einander verwachsen.

Die Area pellucida ist bisquitförmig, ihre vordere Verbreiterung ist etwas grösser, als die hintere. Die Area vasculosa besitzt eine normale Beschaffenheit; die Vena terminalis hat sich noch nicht ausgebildet.

1) 1. c. 'T'af. XVI, Fig. 5 1. 6.

$\left.{ }^{2}\right)$ Archiv für Anatomie und Physiologie 1864, Taf. XVII, Fig. 1, 2 u. 3. 
Fall 14. Rauber ${ }^{1}$ ).

Hühnerei, 80 Stunden bebriitet. Taf. V, Fig. 3.

Die beiden Embryonen liegen Kopf an Kopf; ihre Schwanzenden sind von einander abgewendet: sie sind weniger entwickelt, als es der gleichen Brütedauer bei normalen Einzelembryonen entspricht. Der eine ist schwächer, als der andere; ihre Längsaxen bilden mit einander einen stumpfen Winkel.

Bei beiden Embryonen sind die Medullarrohre völlig gesehlossen, ferner haben sich Urwirbel in grösserer Anzahl gebildet. Beide Köpfe sind in ihrer Form deutlich alterirt; der des stärkeren überdeckt theilweise den des schwächeren. Das Hirnrohr des schwächeren ist $z u$ einer Platte comprimirt; Augenblasen sind nicht vorhanden, dagegen haben sich bei beiden Zwillingen die Ohrgrübchen gebildet.

Die Vorderdarmhöhle fehlt. Zwei Herzanlagen von schlingenförmiger Gestalt liegen rechts und links von den Köpfen.

Die Amnionbildung hat sich für den Kopf des stärkeren Embryo in der Art eingeleitet, dass der Kopf des schwächeren in die noch kurze Kopfkappe des Amnion einbezogen wurde.

Die Area vasculosa, sowie der Sinus terminalis ist bereits vorhanden. Der durchsichtige Fruchthof ist kreuzförmig ${ }^{2}$ ) und besteht aus zwei langen und zwei kurzen Armen.

\section{Fall 15. Ahlfeld ${ }^{3}$ ).}

Hühnerei, etwa 90 Stunden bebrütet. Taf. V, Fig. 4.

Zwei deutlich von einander geschiedene Embryonen von 4,0 und 4,6 mm Länge. Die Kopfenden liegen dicht neben einander, die Scbwanzenden von einander entfernt. Die Vorderhirnbläschen der beiden Zwillinge sind durchaus geschlossen; ihre Wände berühren sich jedoch und sind vielleicht mit einander verwachsen. In Folge der Erhebung der Kopfenden über das Niveau des Fruchthofes ist bei beiden Embryonen eine Umbiegung der Lïngsaxen in der Gegend der sich bildenden Medulla oblongata aufgetreten, so dass von dieser Stelle an die vorderen Theile der Medullarrohre eine kurze Strecke weit parallel verlaufen. Die Gehörgrübchen sind bei beiden gut ausgebildet. Neben jedem Medullarrohre liegen etwa 24 Urwirbel. Das zwischen den beiden Kopfenden gelegene Her\% ist gemeinschaftlich und stellt einen lïnglichen Sack dar.

Die Kopfscheide des Amnion bedeckt die beiden Kopftheile der Embryonen; die hinteren Enden derselben besitzen ihre besonderen Amnionfalten.

Der durchsichtige Fruchthof ist annähernd dreiseitig; in der abgerundeten Spitze des Dreiecks liegen die beiden Köpfe, in den Seitenwinkeln der Grundlinie die Sichwanzenden der Fmbryonen.

\section{Fall 16. Ahlfeld ${ }^{4}$.}

Hühnerei, Brütedauer mbekannt. Taf. V, Fig. 5.

Zwei mit den Köpfen vereinigte Embryonen, von denen der linke eine Lüinge von 7,8 , dur rechte eine solche von $6,2 \mathrm{~mm}$ besit\%t. Sowohl die verwachsenen Küpfe

3) Virrlaw's Archiv Ba. 71, 1877, Tatr. VIII, Fig. 34.

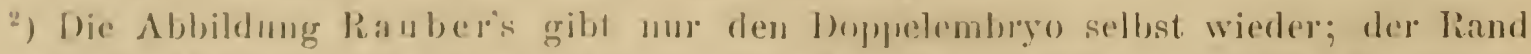
der Ara pellucida ist nicht mit eingezeichnet worden. wesshalb anch bei der Reproduction dieser bignr die Gernzen des durchsichtigen Fruchthofes nicht scharl angedentet werden konnten.

$\left.{ }^{3}\right)$ Arehiv für Gynäkologie Bd. 9, 1876, Tat. VI, Fïg. 21.

4) 1. e. Tat: V1. Figg. 2:3. 
als die Schwanzenden haben sich beträchtlich über das Niveau der Keimhaut erhoben. Zwischen den Halstheilen der beiden Zwillinge liegt das gemeinsame Herz; die grossen Gefässe des Fruchthofes sind stark entwickelt; sie treten seitwärts zu den Körpern der Zwillinge.

Beide Embryonen sind von einem Amnion umgeben. Die Area pellucida hat die Gestalt eines Rhomboïds mit abgerundeten Ecken.

\section{Fall 17. Dareste ${ }^{1}$ ).}

Hühnerei, Brütedauer unbekannt. Taf. V, Fig. 6.

„Monstre double. Union par les têtes. Corps parallèles. Existence de deux anses cardiaques très-inégales. Celle, qui est en dehors des têtes beaucoup plus développée, que celle qui est en dedans, et qui se perd dans les lacunes de l'aire transparente. Ces deux cœurs battaient sur du sang complétement incolore. Grossi trois fois."

Aus der Zeichnung dieses Falles lässt sich, abgesehen von den schon gemachten Angaben, nur noch Weniges ersehen. Der Schluss des Medullarrohres hat sich bei beiden Embryonen nach rückwärts fortschreitend schon nahezu durchaus vollzogen; nur in der Gegend des Sinus rhomboïdalis scheint das Medullarrohr dorsalwärts noch etwas zu klaffen. Im mittleren und hinteren Kopftheile sind beide Embryonen gleich weit in der Entwicklung fortgeschritten; die Verwachsung scheint sich nur auf die vorderste Partie des Kopfes, d. h. auf die beiden primären Vorderhirne zu beschränken; das zweite und dritte Hirnbläschen ist bei jedem der Zwillinge gesondert vorhanden.

Der durchsichtige Fruchthof hat Aehnlichkeit mit einem gothischen Fenster; der Spitze desselben genähert liegen die Kopfenden der beiden Embryonen.

Fall 18. Gerlach. (Der zweite der von mir beschriebenen Fälle.) Hühnerei, vom 4. Tage der Bebrütung. Taf. II.

\section{Fall 19. Dareste ${ }^{2}$ ).}

\section{Hühnerei, Brütedauer unbekannt. Taf. V, Fig. 7.}

„Céphalopage. Deux embryons joints ensemble par le vertex. Les yeux ne sont qu'incomplétement développés, et ne présentaient pas de pigment. Les anses cardiaques sont sorties à la droite de deux embryons. Amnios très-incomplétement formé, et présentant une très-large ouverture. Grossi deux fois."

Die beiden Embryonen scheinen gleich stark gewesen zu sein; sie liegen mit ihren Längsaxen in einer Linie, welche nur an der Stelle der beiden mit den Scheiteln verwachsenen Köpfe nach der einen Seite schlingenförmig ausgebogen erscheint. Die beiden Zwillinge sind schon ziemlich weit entwickelt, indem der Schwanzhöcker ausgebildet, sowie die Anlage der 4 Extremitäten bereits zu erkennen ist.

Der durchsichtige Fruchthof ist länglich oval und besitzt eine der Ausbiegung der Kopfenden entsprechende Ausbuchtung nach der gleichen Seite hin; der Gefässhof ist von rundlicher Form, der Sinus terminalis gut ausgebildet.

\section{Fall 20. Dareste ${ }^{3}$ ).}

\section{Hühnerei, Brütedauer unbekannt. Taf. V̀, Fig. 8.}

"Monstre sycéphalien, vu par la face inférieure. 'T'ête unique affectée d'omphalocéphalie. On voit les deux cœurs des deux côtés de la tête. Grandeur naturelle."

1) 1. c. 'Taf. $X V$, Fig. 4.

$\left.{ }^{2}\right)$ 1. c. Taf. $X V$, Fig. 1.

$\left.{ }^{3}\right)$ 1. c. Taf. $X V$, Fig. 2. 
Die bejden Embryonen scheinen so ziemlich dem gleichen Entwicklungsstadium anzæxpehören, wie die des vorigen Falles. Schwanzhöcker, sowie die Anlagen der Extremitäten sind bereits entwickelt. Die Längsaxen der beiden Embryonen bilden nahezu einen rechten Winkel mit einander.

LIBRAR Der durchsichtige Fruchthof besitzt die Gestalt eines Dreiecks mit abgerundeten Winkeln. Der Gefässhof ist rundlich; die Arteriae omphalomesentericae sind bei beiden Embryonen gut ausgeprägt, ebenso der Sinus terminalis.

\section{Fall 21. Dareste ${ }^{1}$.}

\section{Hühnerei, Brütedauer unbekannt. Taf. VI, Fig. 1.}

"Monstre double, dont les sujets composants sont unis latéralement par les régions cervicales et les têtes. Je suppose, que e'était un hémipage en voie de formation. Existence d'un pli céphalique unique au-dessus de la tête, de deux plis caudaux aux extrémités du corps. Grossi deux fois."

Die Abbildung gibt nur über Weniges noch Auskunft, was nicht bereits in der vorstehenden Note enthalten wäre. Die beiden Embryonen scheinen gleich weit entwickelt. Ihre Längsaxen bilden einen rechten Winkel mit einander; das Kopfende des einen Embryo ist rechtwinklig zu dessen übrigen Körper umgebogen; der andere Embryo weist ein derartiges Verhalten nicht auf.

Die Area pellucida ist dreiseitig; die Winkel sind abgerundet, die Seiten etwas eingezogen, und zwar am meisten die zwischen den beiden Schwanzenden der Embryonen gelegenen Seite.

\section{Fall 22. Dareste ${ }^{2}$.}

\section{Hühnerei, Brütedauer unbekannt. Taf. VI, Fig. 2.}

„Trois jumeaux bien conformés, développés sur un blastoderme unique et provenant par conséquent d'une cicatricule unique. Ils sont déjà retournés et présentent à leur extrémité caudale un pli caudal, commencement d'un capuchon caudal. Ces plis se seraient soudés pour former un amnios unique. Grossis presque deux fois."

Dieser Fall ist von dem höchsten Interesse, da die Ausbildung von ganz gleichmässig entwickelten Drillingen in einer Keimhaut vor Dareste noch niemals beobachtet worden ist $^{3}$ ). Was ihre Anordnung betrifft, so liegen zwei davon mit ihrer Längsaxe in einer Linie, zu welcher die des dritten annähernd rechtwinklig gestellt ist. Alle drei Embryonen, welche bereits Scheitel- und Nackenkrümmung zeigen, liegen mit dem Kopfende auf der linken Seite. Verwachsen scheinen die Köpfe noch nicht zu sein; dies würde, wenn es der Fall gewesen wäre, Dareste wohl hinzugefügt haben.

Die Gestalt des durchsichtigen Fruchthofes ist sehr unregelmässig; sie ist am ehesten wohl mit einem Dreieck mit mehrfach ein- und ausgebuchteten Seiten zu vergleichen. Die Area vasculosa ist rundlich; der Sinus terminalis gut ausgesprochen. Jeder Embryo hat zwei Arteriae und eine Vena omphalo mesenterica.

1) 1. c. Taf. $X V$, Fig. 3.

2) 1. c. Taf. XIV, Fig. 4.

${ }^{3}$ ) Einen ähnlichen Fall scheint Mo r rigia (Tre embrioni di Gallina. Atti della R. Acead. dei Lincei 1878/79, Transunti III, Marzo 1879) beschrieben zu haben. Leider konnte ich mir dessen Abhandlung im Original nicht versehaffen, wesshalb ich die von ihın beobachtete Dreifachbildung nicht unter die Zahl der zusammenzustellenden Fälle aufnehmen konnte. Soviel ich aus dem mir vorliegenden kurzen Referate ersah, handelte es sich um $76 ;$ Stunden alte Drillinge, welche in ein Blastoderma eingeschlossen waren. 
Fall 23. Dareste ${ }^{1}$ ).

Hühnerei, Brütedauer unbekannt. Taf. VI, Fig. 3.

"Deux embryons jumeaux sur un blastoderme unique. Ils sont bien conformés, et placés l'un et l'autre dans une situation telle qu'ils n'auraient pu se souder autrement que par leurs annexes. Grandeur naturelle."

Die beiden Embryonen laufen mit ihren Vorderkörpern von der Gegend der vorderen Extremitäten an, die der eine schon deutlich erkennen lässt, annähernd parallel; der übrige Körperabschnitt ist bei dem einen nach links, bei dem auderen nach rechts abgebogen. Die Kopfenden haben sich bereits in ihren Längenaxen gedreht und wenden beide ihre linke Seite dem Dotter zu.

Der durchsichtige Fruchthof ist unregelmässig geformt; der Gefässhof dagegen ist rundlich; die Arteriae omphalo mesentericae eines jeden Embryo sind gut ausgebildet.

\section{Fall 24. Rauber ${ }^{2}$ ).}

Hühnerei, $4^{1 / 2}$ Tage bebrütet. Taf. VI, Fig. 4.

Die Entwicklungsstufe der beiden Embryonen entspricht dem dritten bis vierten Tage der Bebrütung eines normalen Einzelembryo. Ihre Köpfe und Hälse sind mit einander verschmolzen; die übrigen Körperabschnitte weichen unter einem Winkel von etwa $120^{\circ}$ aus einander; ihre Dorsalseite ist nach oben gekehrt. Der gemeinsame, stark prominirende Kopftheil beider Embryonen zeigt weder Augenanlagen noch Nasengrübchen, auch keine Mundöffnung; dagegen auf der einen Seite drei noch offene Kiemenspalten. Der Hals des einen Embryo geht bogenförmig in den Kopftheil über, der des zweiten Embryo verläuft gerade.

Zwei Herzen; dagegen ist nur eine Darmpforte vorhanden, welche aufwärts und abwärts von je einem Herzen umsäumt wird.

Das Amnion bildet um beide Embryonen eine ringförmige Falte, welche bereits den vorderen Abschnitt des gemeinsamen Kopfes und das Schwanzende des einen Embryo überdeckt.

\section{Fall 25. Allen Thomson ${ }^{3}$ ).}

Gänseei, 5 Tage bebrütet. Taf. VI, Fig. 5.

Die beiden gleich grossen Embryonen wenden ihre Schwanzenden von einander ab; ihre Axen liegen in der Längsaxe des Eies. Thre Länge vom Hinterhaupt bis zum Schwanzende gemessen beträgt $8 \mathrm{Mm}$. Beide Köpfe haben sich über das Niveau der Keimhaut erhoben, die Schwanzenden noch nicht. Die Köpfe sind gut ausgebildet, mit Kiemenbögen versehen; sie sind nicht mit einander verwachsen, doch liegen sie neben einander. Die Abbildung Thomson's stellt die Köpfe in etwas anderer Lage dar; dieser zu Folge waren die Köpfe nicht neben einander, sondern über einander gelagert; die rechte Seite des einen Kopfes ruht auf der rechten Seite des anderen in der Art auf, dass die beiden Gesichter so ziemlich nach derselben Richtung hin gewendet sind. Die beiden Köpfe sind von einer gemeinsamen Kopfkappe des Amnions bedeckt. Unter den Kiemenbögen liegt ein gemeinsames Herz. Die Extremitätenanlagen sind bereits sichtbar.

1) 1. e. Taf. XIV, Fig. 1.

$\left.{ }^{2}\right)$ Morphologisches Jahrbuch Bd. VI, 1880, Taf. X, Fig. 27.

${ }^{3}$ ) The London and Edinburgh Monthly Journal 1844. Leirler habe ich mir die Schrift 'Thomson's, trutzdem ich bei mehreren Bibliotheken anfragte, nicht verschaffen können. Ich gebe daher die Schilderung dieses Falles nach dem Ahlfeld'schen kurzen Referate und den Bemerkungen Dareste's ïber denselben. 
Die Form der Area pellucida ist eine kreuzförmige mit fast gleich grossen 4 Schenkeln, die alle spitz auslaufen.

Fall 26. Dareste $^{1}$ ).

Hühnerei, Brütedauer unbekannt. Taf. VI, Fig. 6.

"Monstre double par union latérale. Les têtes à régions cervicales séparées. Corps unis latéralement. Trois membres supérieurs et trois membres inférieurs. Ceux de ces membres qui occupent la ligne médiane appartiennent par moitié à chacun des sujets composants. C'était probablement un xiphodyme en voie de formation. Grossi quatre fois."

Die Entwicklung der beiden Embryonen entspricht etwa dem Anfang des 4. Brütetages bei einem normal gestalteten Einzelembryo. Bei der Drehung der Köpfe um ihre Längsaxe haben sich dieselben beide mit ihrer linken Seite auf die Keimhaut aufgelegt. Der rechte Embryo erscheint etwas kürzer, da seine Nackenkrümmung deutlich ausgesprochen ist, als der linke, dessen Nackenkrümmung sich wegen der Nachbarschaft des anderen Embryo bis jetzt noch nicht hatte ausbilden können.

\section{Fall 27. Dareste ${ }^{2}$ ).}

Hühnerei, Brütedauer unbekannt. Taf. VI, Fig. 7.

„Monstre double; union des têtes, par les vésicules cérébrales antérieures. Une seule face présentant deux yeux rudimentaires et réduite à des taches de pigment. Deux allantoïdes. Deux cœurs inégaux. Déradelphe. Grossi trois fois."

In diesen Angaben Dareste's ist bereits alles Wesentliche enthalten, was der vorliegende Fall, soweit derselbe aus der Abbildung zu beurtheilen ist, darbietet.

\section{Fall 28. Dareste ${ }^{3}$ ).}

Hühnerei, Brütedauer unbekannt. Taf. VI, Fig. 8 A u. B.

„Monstre double. Union des têtes par les vésicules centrales antérieures. Deux faces appartenant par moitié à chacun des sujets composants. Une face complète, mais avec deux yeux rudimentaires et une bouche. Une face incomplète avec un œil unique. Une seule allantoïde. Un cœur double à l'extérieur du côté de la face complète. Iniope. Grossi trois fois."

Auch bezüglich dieser Doppelbildung kann ich aus der Abbildung nichts von Bedeutung entnehmen, was den Angaben Dareste's noch hinzuzufügen wïre.

In die Reihe der vorstehenden 28 Fälle habe ich die von Wolff ${ }^{4}$ ) und Panum ${ }^{5}$ ) beobachteten Doppelbildungen, obwohl sie einer nur wenig älteren Entwicklungsphase angehören, wie die zuletzt angeführten Fälle, dennoch nicht aufgenommen, weil bei beiden die zwei Embryonen sich bereits von der Keimhaut vollständig abgeschnürt hatten und ihre ursprüngliche Anordnung in der Keimscheibe, da sie keine Verwachsung mit einander eingegangen sind, nicht mehr erkennen lassen. Auch einen von Schrohe ${ }^{6}$ ) mitgetheilten Fall habe

1) 1. c. Tar. $X V$, Fig. 6.

$\left.{ }^{2}\right)$ 1. c. Taf. XVI, Fig. 1 น. 2.

$\left.{ }^{3}\right)$ 1. c. Taf, XVI, Fig. 3 u. 4.

${ }^{4}$ ) C. F. Wolff, Ovum simplex gemelliferum. Novi Commentarii Acad. imp. Petropol. Tom. XIV, pag. 456, Taf. XI, Fig. 1. 2 und 3.

$\left.{ }^{5}\right)$ P anum, Untersuchungen über die Entstehung der Missbildungen. Taf. XII, Fig. 1,

B) Schrohe, Untersuchungen über den Einfluss mechanischer Verletzungen auf die Entwicklung des Embryo. Dissert. Giessen 1862. Taf. II, Fig. 10. 
ich unerwähnt gelassen, da mir keineswegs festzustehen scheint, dass derselbe, wie Schrohe meint, als eine wirkliche Doppelbildung anzusehen sei. Meine Meinung über diesen Fall geht, wie in einem späteren Capitel noch genauer auseinandergesetzt werden wird, vielmehr dahin, dass derselbe nur eine scheinbare Verdoppelung vorstellt, welche in Folge der experimentellen Durchtrennung der Keimscheibe des betreffenden Eies auftrat. Auch dann, wenn in dem Schrohe'schen Falle eine wirkliche Doppelbildung vorliegen würde, könnte derselbe für unsere Betrachtungen keine Verwerthung finden, da durch die Läsion der Keimhaut und deren Folgezustände die ursprüngliche Lage der Embryonen nothwendiger Weise eine Veränderung hätte erleiden müssen.

Dagegen dürfen meines Erachtens zwei andere Fälle nicht mit Stillschweigen übergangen werden; bei beiden handelt es sich um Drillinge auf einem einzigen Eidotter; jedoch lagen die drei Embryonen nicht in einer gemeinsamen Area pellucida, sondern in zwei, indem die eine derselben nur einen, die andere die beiden anderen Embryonen enthielt. Es ist somit bei beiden Fällen das Vorkommen von Zwillingen innerhalb eines einzigen durchsichtigen Fruchthofes dadurch complicirt, dass ausserdem, und zwar in der unmittelbaren Nachbarschaft dieses einen Fruchthofes, sich ein zweiter auf. dem Dotter vorfand, der ebenfalls einen Embryo einschloss. Die eine der beiden Beobachtungen ist von Dareste, die andere, welche ein sehr frühes Stadium repräsentirt, von Rauber gemacht worden. Es scheint mir geboten, im Anschluss an die bereits angeführten Fälle auch dieser beiden Mehrfachbildungen in einem kurzen Referate zu gedenken.

\section{Fall 29. Dareste ${ }^{1}$ ).}

Hühnerei, Brütedauer unbekannt. Taf. VI, Fig. 9.

"Trois embryons développés sur deux blastodermes différents, et qui laissaient encore voir la ligne de jonction. Sur l'un des blastodermes on voit deux embryons inégalement développés; l'un est complet et présente une anse cardiaque à droite; l'autre, plus petit, ne présente pas de cœur. L'embryon développé seul sur l'autre blastoderme est développé d'une manière normale, et présente une anse cardiaque sortie à droite. Grossi trois fois."

Der die zwei Embryonen enthaltende Fruchthof hat eine längliche Gestalt. Seine Area pellucida ist dreiseitig. Die beiden Zwillinge in derselben wenden ihre Schwanzenden von einander ab. Ihre Kopfenden sind an einander vorbei gewachsen, lassen jedoch eine beträchtliche Distanz zwischen sich; bei beiden scheint das Medullarrohr grösstentheils geschlossen zu sein; die drei Hirnbläschen sind schon angelegt.

Der andere Fruchthof ist mehr dreiseitig mit abgerundeten Ecken. Er legt sich nur mit einer der beiden Längsseiten dem ersten Fruchthofe an. Sein Embryo wird von einer länglichen Area pellucida ziemlich enge umschlossen und wendèt das vordere Ende dem schwächeren der beiden anderen Embryonen entgegen; auch bei ihm sind bereits die Gehirnbläschen aufgetreten.

Fall 30. Rauber ${ }^{2}$ ).

Hühnérei, 21/2 Tage bebrütet. Taf. VI, Fig. 10.

Die drei Embryonen liegen in zwei an einander grenzenden Areae pellucidae; die Trennungslinie zwischen denselben verbreitert sich beiderseits zu einem dreieckigen

1) 1. c. Taf. XIV, Fig. 5 .

$\left.{ }^{2}\right)$ Morphologisches Jahrbuch Bd. V, 1879, Taf. XII, Fig. 1, 2 u. 3. 
Feld, das an die Area opaca anstösst. Histologisch besteht diese Trennungslinie sammt ihren dreieckigen Verbreiterungen aus einem gleich beschaffenen Ektoderm, wie in den übrigen nicht embryonalen Bezirken des durchsichtigen Fruchthofes, dagegen ist an den genannten Orten das, Mesoderm nur spurenweise vorhanden, und statt der platten Zellen des Entoderms findet sich eine einschichtige Lage grossblasiger Dottersackepithelien.

Der grössere der beiden durchsichtigen Fruchthöfe enthält zwei Embryonen; sein vorderer Abschnitt, in dem die beiden neben einander gelegenen Kopfenden der Zwillinge sich befinden, hört rundlich auf, während sein hinterer Bezirk, entsprechend den divergirenden Schwanzenden der Embryonen, in zwei nicht ganz gleich lange Schenkel ausläuft. Die beiden Embryonen liegen mit ihrer Längsaxe bis zum Anfang des Primitivstreifens, der an seiner Rinne erkenntlich ist, dicht neben einander und verlaufen so ziemlich parallel. Die Divergenz beginnt erst am vorderen Ende der Primitivstreifen, welche unter einem Winkel von fast $90^{\circ}$ aus einander weichen. Von der Divergenzstelle aus verläuft gerade nach hinten, sich demnach von den zwei Primitivstreifen gleich weit entfernt haltend, ein Zwischenwulst, welcher vorne etwas schmäler ist und nach hinten zu sich leicht verbreitert. Derselbe kommt, wie Durchschnitte lehren, in Folge einer an den bezeichneten Stellen befindlichen Mesodermverdickung zum Ausdruck, welche am meisten in dem hintersten Theile der Area pellucida entwickelt ist und hier sogar eine kleine Höhlung einschliesst. Nach der Fig. 9 Rauber's scheint es mir höchst wahrscheinlich, dass diese Höhlung dadurch entstand, dass an dem betreffenden Orte der Zwischenwulst zuerst eine ventralwärts vorspringende, kleine longitudinale Falte bildete, worauf späterhin die beiden Lamellen der Falte an ihrer Abgangsstelle von dem horizontal ausgebreiteten Mesoderm mit einander sich vereinigten.

Was das Entwicklungsstadium der beiden Embryonen anlangt, so war das Medullarrohr noch durchaus offen; die Medullarrinne war in ihrem hinteren Theile - die Medullarwülste hatten das vordere Ende der Primitivrinne seitlich schon umfasst - noch sehr flach; nach vorne zu wurde sie immer tiefer, besonders im Kopftheile, wo sie besonders bei dem einen Zwilling stark comprimirt erschien. Die Kopftheile beider Embryonen waren durch eine tiefe Zwischenrinne von einander getrennt, welche nach hinten zu sich abflachte, vorne jedoch um jede der beiden Kopfanlagen herum, welche schon aus dem Niveau der Keimhaut herausgetreten waren, in die Seitenrinne der beiden Embryonen überging.

Die Chorda ist bei beiden Zwillingen gut ausgebildet; seitlich von derselben sind etwa je 12 Urwirbelpaare aufgetreten. Jeder der zwei Embryonen besitzt einen eigenen Vorderdarm, welcher zur Chorda asymmetrisch gelagert ist. Zu beiden führt jedoch eine gemeinsame vordere Darmpforte.

Von einem Herzen ist bei beiden Embryonen noch nichts wahrzunehmen, weun wir von einer Verdickung der Darmfaserplatte absehen, welche in den Seitenrändern der gemeinsamen vorderen Darmpforte gelegen ist, und die erste Andeutung des künftigen Herzens darstellt.

Vor den Köpfen der beiden Zwillinge erhebt sich eine gemeinschaftliche vordere Amnionfalte.

An das vordere Ende der soeben besprochenen grösseren $\Lambda$ rea pellucida schliesst sich die zwoite kleinere an, in welcher der dritte Embryo liegt. Die beiden durchsichtigen Fruchthöfe, zwischen welche die schon erwïhnte Trennungslinie sich einschicbt, stossen unter einem nach rechts offenen Winkel von ungeführ $115^{\circ}$ auf einander. Den gleichen Winkel bildet auch die Längsaxe dieses dritten Embryo zu der vorderen Verlängerungslinie des Zwischenwulstes. Mit seinem vorderen Ende 
erscheint der dritte Embryo den Köpfen der beiden anderen zugekehrt; sein abgewendetes hinteres Körperende reicht bis an die Area opaca heran.

Die Entwicklung dieses dritten Componenten der Drillingsbildung ist ungleich weiter vorgeschritten, als die der beiden anderen. Zwar ist auch bei ihm das Medullarrohr noch an keiner Stelle geschlossen, doch haben sich die Ränder der Medullarwülste schon sehr genähert. Der Primitivstreifen ist ebenfalls noch zu sehen, aber er ist schon bedeutend reducirt.

Neben der Chorda sind bereits 10 Urwirbel zu zählen. Der Vorderdarm ist schon ausgebildet; die vordere Darmpforte verhält sich normal. Die Herzentwicklung ist in den ersten Stadien begriffen.

Was die gesammte Keimhaut betrifft, so hatte deren Rand den Aequator der Dotterkugel nur um Weniges, bereits überschritten. Der Dotterhof zeigte eine normale Beschaffenheit. Der Gefässhof erschien durch die Anlage der Vena terminalis deutlich nach aussen abgegrenzt. Bezüglich seiner Form war derselbe jedoch nicht kreisförmig oder oval, sondern er war mit einem Abschnitte, welcher den grössten Theil des kleineren durchsichtigen Fruchthofes enthielt, schief ausgezogen.

Ich habe absichtlich bei der Schilderung der Rauber'schen Drillingsbildung etwas länger verweilt. Dazu veranlasste mich einerseits die ungemein anschauliche und gründliche Beschreibung dieses Falles, welcher sich vorzugsweise auf Durchschnitte stützt, deren Abbildungen für den Leser äusserst instructiv sind, andererseits aber auch der Umstand, dass der Rauber'sche Tripelembryo einer sehr frühen Entwicklungszeit angehört. Ausserdem musste ich die eben besprochene Mehrfachbildung auch desshalb eingehender behandeln, weil sie mir Belege für eine von mir vertretene Anschauung zu bringen scheint, nach welcher zwei ursprünglich dicht neben einander in die Area pellucida einstrahlende Primitivstreifen im Laufe ihrer ferneren Ausbildung durch die Wachsthumsenergie des zwischen ihnen gelegenen Mesodermbezirkes bis zu einem gewissen Grade auseinandergedrängt werden können. Ich werde mich später mit diesen Fragen noch eingehender zu befassen haben. 


\section{Vergleichung, Eintheilung und Epikrise der im vorher- gehenden Capitel angeführten Fälle.}

In einem der früheren Abschnitte ist der Nachweis erbracht worden, dass zwei in einer gemeinsamen Area pellucida auftretende Embryonalanlagen dadurch zu Stande kommen, dass von zwei Stellen der Peripherie aus je ein Primitivstreifen in den durchsichtigen Fruchthof einwächst. Nimmt man diese Thatsache bei einer kritischen Sichtung des mitgetheilten Materials, sowie bei einem Vergleiche der einzelnen Fälle zum Ausgangspunct, so gelangt man zu dem Ergebniss, dass mit Ausnahme des 4., 8., 11. und 12. Falles, sowie der Dareste'schen Drillingsbildung bei sämmtlichen übrigen ursprünglich zwei gesonderte Primitivstreifen in einer einzigen Area pellucida zur Ausbildung gekommen sind. Bei den jüngeren Stadien dieser Doppelbildungen sind, wie die Abbildungen lehren, die Primitivstreifen noch erkennbar; in den übrigen Fällen, welche einer späteren Entwicklungsphase angehören, haben sie sich bereits zurückgebildet; doch kann aus entwicklungsgeschichtlichen Gründen darüber kein Zweifel bestehen, dass dieselben ursprünglich vorhanden gewesen sein müssen, denn es ist ja bekannt, dass die Chorda und das Medullarrohr sich vor dem Primitivstreifen anlegt. Wo man daher zwei Medullarrohre oder zwei Chordae dorsales in einem gemeinsamen durchsichtigen Fruchthofe antrifft, da müssen auch einst zwei Primitivstreifen existirt haben. Dies in Abrede stellen zu wollen, würde damit gleichbedeutend sein, bei einem älteren Einzelembryo die frühere Existenz von dessen Primitivstreifen zu negiren.

Wie sich die vorderen Enden der beiden in einer Area pellucida vorhandenen Embryonen verhalten, ist für diese Frage vollkommen gleichgültig. $\mathrm{Ob}$ die vor den beiden Primitivstreifen auftretenden Embryonaltheile in ihrer weiteren Ausbildung sich gegenseitig stören, mit einander verwachsen oder getrennt bleiben, diese Eventualitäten entscheiden sich erst in einer späteren Zeit und haben darum mit vorausgegangenen Entwicklungsperioden, in welche die Anlage der Primitivstreifen füllt, nichts zu thun.

Der Umstand, dass die Entwicklung des Embryo immer nach vorne zu strebt, indem sich bei Weitem der grösste Theil des embryonalen Körpers vor dem Primitivstreifen anlegt, wodurch die Längsaxe der Embryonalanlage in die vordere Verlängerungslinie des Primitivstreifens zu liegen kommt, ist für unsere Betrachtungen von der grössten Wichtigkeit. Denn es ist uns dadurch ein Mittel in die Hand gegeben, die Lage und Stellung der einstigen Primitiv- 
streifen aus der Richtung der Längsaxen beider Embryonen' auch in einer relativ späten Entwicklungszeit, wenn die Primitivstreifen schon verschwunden sind, noch mit annähernder Genauigkeit zu bestimmen.

Wenn man von diesen Gesichtspuncten ausgehend die vorliegenden Fälle sichtet, so lassen sich sämmtliche Doppelbildungen mit Ausnahme der vier erwähnten Fälle (4., 8., 11., 12.) und dem Dareste'schen Tripelembryo am besten in folgende drei Gruppen bringen.

Die erste derselben umfasst diejenigen Mehrfachbildungen, bei denen die Längsaxen beider Embryonalanlagen neben einander - worunter ich sowohl eine rein parallele, als eine nach vorne schwach convergente oder schwach divergente Stellung verstehe - verlaufen. Die beiden Primitivstreifen strahlten von nahe gelegenen Stellen der Peripherie aus und demnach im Anfange spitzwinklig in die Area pellucida ein.

In die zweite Gruppe gehören die Fälle, bei denen die Längsaxen beider Fruchtanlagen, resp. ihre vorderen Verlängerungslinien einen rechten oder stumpfen Winkel bilden; die gleiche Anordnung zeigten früher die beiden Primitivstreifen.

Der dritten Gruppe endlich fallen diejenigen Doppelbildungen zu, bei denen die beiden Embryonalanlagen in einer Linie liegen und zwar mit einander zugekehrten Kopfenden und abgewendeten Schwanzenden; die beiden Primitivstreifen drangen von diametral gegenübergestellten Orten der Peripherie aus, also unter einem Winkel von $180^{\circ}$ in die Area pellucida ein. Ich will diese Anordnung Oppositionsstellung der Primitivstreifen nennen.

Diesen drei Gruppen schliessen sich als vierte die Fälle 4, 8, 11 und 12 an, bei denen eine in ihrem hinteren Abschnitt. einfache Embryonalanlage in zwei nach vorne divergirende Theile auseinandergeht.

Es sollen diese vier Gruppen der Reihe nach besprochen werden.

I.

Doppelbildungen, deren Primitivstreifen in geringer Entfernung von einander in die Area pellucida einstrahlten und daher Anfangs unter einem spitzen Winkel nach vorne convergirten. Die embryonalen Längenaxen verlaufen neben einander.

In diese Gruppe fügen sich ohne Schwierigkeit die folgenden Fälle ein:
1) Allen Thomson Fig. 1, Taf. IV.
7) Ahlfeld
Fig. 6, Taf. IV.
13) Reichert
Fig. 2, A und B, Taf. V.
17) Dareste
Fig. 6, Taf. V.
26) Dareste
Fig. 6, Taf. VI.

Ferner gehört in dieselbe der Fall 30, von Rauber (Fig. 10, Taf. VI), der zwar eine Dreifachbildung darstellt, jedoch eine aus zwei Areae pellucidae bestehende; hier ist natürlich nur der eine der beiden durchsichtigen Fruchthöfe gemeint, welcher die beiden Embryonen enthält.

Von diesen sechs Doppelbildungen wollen wir nun Fall 1, 7 und $30 \mathrm{zu}$ erst erörtern, da sie die drei frühsten Entwicklungsstadien repräsentiren. Bei 
der Doppelbildung Allen Thomson's (1), welche bereits oben besprochen wurde, sind nur die Primitivstreifen vorhanden; bei dem Fall Rauber's (30) sind dieselben ebenfalls noch deutlich wahrzunehmen. Für den Ahlfeld'schen Fall (7) wird zwar das Vorhandenséin der beiden Primitivstreifen nicht besonders angegeben, doch glaube ich in der einen bei stärkerer Vergrösserung gezeichneten Abbildung dieses Falles, die Ahlfeld seiner Abhandlung beigegeben hat, die Primitivstreifen mit ihren heller gehaltenen Rinnen erkennen zu diurfen; jedenfalls sind in einem Stadium, in welchem sich erst vier bis fünf Urwirbelpaare gebildet haben, die Primitivstreifen noch nicht geschwunden, und einem solchen gehört die Ahlfeld'sche Doppelbildung an.

Bei einer genaueren Betrachtung der drei genannten Fälle muss es im höchsten Grade überraschen, dass die beiden Primitivstreifen in übereinstimmender Weise das gleiche anormale Verhalten zeigen. Sie sind nicht geradlinig, sondern verlaufen bogenförmig, und zwar mit einander entgegengerichteter Convexität. Sieht man näher zu, so wird man bemerken, dass die grösste Biegung des Bogens in den vorderen Abschnitt der beiden Streifen fällt.

Diese auffallende Anordnung der beiden Primitivstreifen drängt zu der Frage, wie man sich das Zustandekommen derselben zu erklären habe. Meines Erachtens kann es sich nur um die folgende Alternative handeln. Entweder sind die beiden Streifen nicht geradlinig eingewachsen, sondern sind, nachdem sie sich bis auf eine gewisse Distanz genähert haben, aus der bis dahin eingehaltenen Richtung nach vorne umgebogen, oder es ist durch eine ungleichmässige Verschiebung der einzelnen Theile der beiden Streifen aus ihrer ursprünglichen radiären Lage die Krümmung derselben verursacht worden. Nach der ersten Annahme haben die Primitivstreifen von Anfang an die gleichen Stellen der Keimhaut eingenommen und unverändert beibehalten. Es würde somit der verhältnissmässig grössere Abstand zwischen ihren peripheren Enden von jeher der gleiche gewesen sein. Die zweite Annahme befürwortet eine Inconstanz der Lage; ihr zufolge sind die beiden Streifen von näher aneinandergelegenen Stellen der Peripherie aus in die Area pellucida vorgedrungen, haben aber schon, ehe sie ihre ganze Länge erreicht, also noch während ihres Wachsthums nach vorne zu mit ihren hinteren Enden angefangen, sich von einander zu entfernen. Dieses Auseinanderrücken schreitet in stetig abnehmendem Masse nach vorne zu weiter, so dass die vorderen Enden der beiden Streifen im Vergleich zu den hinteren nur wenig von einander nach beiden Seiten hin abgedrïngt werden.

Prüft man die beiden Annahmen auf ihre Wahrscheinlichkeit, so kann für die erstere, wie ich glaube, kaum ein überzeugendes Argument angeführt werden. MIan sucht vergebens nach einer Ursache, warum die beiden Primitivstreifen, noch ehe sie aufeinandergetroffen sind, ihre geradlinige Bahn verlassen sollten. Dagegen scheint mir die zweite Erklïrung des bogenförmigen Verlaufes, welche eine Verschiebung der Primitivstreifen aus ihrer ursprünglichen Lage supponirt, sich sehr gut begründen zu lassen.

Schon in einem früheren Capitel habe ich darauf lingewiesen, dass unter gewissen Umständen das sich entwickelnde Mesoderm eine Lageveränderung zweier in einer Keimhaut liegender Primitivstreifen bewirken könne. Ich glaube kaum zu irren, wenn ich die in den genannten drei Fiallen von Doppel- 
bildungen vorliegende Krümmung der Primitivstreifen dem Wachsthum des mittleren Keimblattes zuschreibe. Nach meiner Auffassung sind bei sämmtlichen drei Fällen die Primitivstreifen von ziemlich nahe gelegenen Stellen des Keimringes aus in die Area pellucida eingewachsen. Die weiteren Entwicklungsvorgänge denke ich mir in folgender Weise. Jeder der beiden Primitivstreifen wird radiär einstrahlen; da nun nach unserer Voraussetzung ihre hinteren Enden nur durch einen kleinen Zwischenraum getrennt sind, so werden sie nach vorne in nur geringem Grade convergiren, nehmen wir an, unter einem Winkel von $20-30^{\circ}$. Von jedem der beiden Primitivstreifen aus wird sich, wenn dieselben eine gewisse Länge erreicht haben, je ein Mesoderm entwickeln, das seitlich von jedem Streifen in einer zu dessen Verlauf senkrechten Richtung weiterwuchert. Das Auswachsen des Mesoderms aus dem Primitivstreifen beginnt, wie wir wissen, an dessen hinterem Ende. Bei der nahen Lage der zwei Streifen kann es nicht lange dauern, bis zwischen denselben die beiden sich in diesem Abschnitte des Blastoderms fast direct entgegenwachsenden mittleren Keimblätter aufeinandertreffen müssen. Es wird so zu einer Vereinigung der letzteren kommen müssen und zwar zuerst im hinteren Theile des Fruchthofes, weil ja hier die Bildung des Mesoderms am frühesten begonnen hat und dasselbe darum auch seitlich von den beiden Streifen am weitesten vorgedrungen sein kann. Nach und nach wird aber auch nach vorne zu das Zusammenfliessen der beiden Mesodermata fortschreiten. Gleichzeitig aber wird in Folge der fortgesetzten Vermehrung der Mesodermzellen das vereinigte mittlere Keimblatt zwischen den hinteren Enden der Primitivstreifen bestrebt sein, sich auszudehnen; dies kann es aber nur dann thun, wenn es die beiden Streifen nach beiden Seiten hin vermöge seiner Wachsthumsenergie auseinanderdrängt. Die Keimhaut hat in dieser frühen Entwicklungszeit noch nicht die genügende Festigkeit angenommen; sie ist noch dehnbar und nachgiebig und wird darum der Verschiebung der beiden Primitivstreifen im Anfange noch keinen erheblichen Widerstand entgegen setzen können. Auch das Auseinanderrücken der beiden Primitivstreifen wird nach vorne zu fortschreitenmüssen, bis schliesslich auch die vorderen Enden derselben etwas von einandergedrängt werden. Allein während dies geschieht, wird das Blastoderm durch die Ausbreitung des mittleren Keimblattes in den lateralen Bezirken der Keimhaut einen immer festeren Zusammenhalt gewinnen und die Primitivstreifen werden sich immer schwerer auseinanderdrängen lassen, bis schliesslich die Wachsthumsenergie des betreffenden Mesodermtheiles nicht mehr ausreicht, den Widerstand zu überwinden. Von diesem Zeitpuncte an werden die beiden Streifen ihre Lage beibehalten.

- Da nun in der ersten Zeit, wenn die hinteren Abschnitte der Primitivstreifen von einander abrücken, dieses Auseinanderschieben intensiver vor sich geht, während später die vorderen Enden aus den genannten Gründen nur wenig mehr aus ihrer ursprünglichen Lage lateralwärts gedrängt werden können, so muss in Folge dieser ungleichmïssig stattfindenden Lageveränderung nothwendiger Weise eine bogenförmige Krümmung der beiden Primitivstreifen resultiren.

Indem ich es vorlïufig verschiebe, für meine sōeben geschilderte Auffassung weitere Belege beizubringen, möchte ich noch darauf aufmerksam 
machen, wie dadurch, dass auch die vorderen Enden der Primitivstreifen etwas auseinandergedrängt werden, die vor diesen sich entwickelnden Chordae dorsales gleichfalls in grössere Entfernung von einander gebracht werden. Würden bei der Verschiebung die vorderen Enden der Streifen stehen bleiben, während ihre übrigen Abschnitte mit einer nach rückwärts zunehmenden Stärke von einander abrücken, d. h. würde eine Drehung der beiden Streifen in der Ebene der Keimhaut stattfinden, so müsste diese nicht nur die Streifen selbst, sondern auch die in deren vorderer Verlängerungslinie entstehenden Chordae dorsales convergenter zu einander stellen. Letztere würden dann bei ihrem nach vorne zu fortschreitenden Wachsthum in Bälde aufeinandertreffen müssen. Sind jedoch die vorderen Enden der Primitivstreifen, wie wir es bei dem Allen Thomson'schen Fall sehen, etwas von einander entfernt worden, so können sich die Chordae dorsales später parallel zu einander stellen, ja sogar etwas divergiren. Der dieselben trennende Abschnitt der Keimhaut wird dann ein um so grösserer sein, je weiter das mittlere Keimblatt die vorderen Enden der Primitivstreifen noch hat auseinanderdrängen können; ich habe Grund, zu vermuthen, dass die durch die erörterte Wirkung des Mesoderms zu Stande kommende Distanz der beiden Chordae zuweilen eine recht beträchtliche werden kann.

Auf der anderen Seite scheint unter gewissen Umständen das Mesoderm es nicht ganz zu Wege bringen zu können, die Kopfenden der Primitivstreifen bis zur Parallelstellung der späteren Chordae auseinanderzuschieben. Wahrscheinlich sind in solchen Fällen die Primitivstreifen anfänglich unter einem etwas grösseren Winkel, d. h. von Stellen aus eingestrahlt, welche um einige Grade mehr von einander ablagen, als wir es oben angenommen haben. Es hat sich darum das Zusammenfliessen der beiden mittleren Keimblätter, von denen ein jedes zwischen den Primitivstreifen bei seinem Auswachsen einen weiteren Weg zurückzulegen hatte, erst in einer etwas fortgeschritteneren Entwicklungsphase vollziehen können, was wiederum zur Folge haben musste, dass die Lageverschiebung der beiden Streifen erst später beginnen konnte. Als dieselbe sich bis zu den Kopfenden der letzteren fortgepflanzt hatte, waren die Widerstände schon zu gross, um hier noch ein nennenswerthes Auseinanderrücken zu gestatten. Es werden darum unter solchen Verhältnissen nư die von vorneherein schon entfernteren hinteren Abschnitte der Primitivstreifen noch weiter auseinandergedrängt, so dass schlieslich ihre peripheren Enden, wie bei dem Ahlfeld'schen Falle, um noch mehr als $90^{\circ}$ von einander abstehen können; die vor den Kopfenden der Streifen auftretenden Chordae aber werden spüterhin nach vorne in geringem Grade convergiren müssen.

Aus dem Gesagten geht weiterhin hervor, welche wichtige Rolle dem mittleren Keimblatt bei der Genese der verschiedenen Formen von Doppelmissbildungen, die in unsere Gruppe gehören, meiner Auffassung nach zufällt. Denn je nachdem dasselbe im Stande ist, die vorderen Enden der Primitivstreifen von einander zu entfernen, wird es indirect bald diese, bald jene Stellung der später auftretenden Chordae dorsales veranlassen müssen. Von der Anordnung der letzteren hängt aber, wie wir weiter unten sehen werden, die Art der schliesslich resultirenden Doppelmissbildung ab.

Die Lageverschiebung der spitzwinklig einstrahlenden Primitivstreifen 
und der dadurch bedingte bogenförmige Verlauf der letzteren ist demnach meiner Anschauung zu Folge ein Werk des mittleren Keimblattes und zwar verursacht durch die Wachsthumsenergie, welche der Theil des Mesoderms entfaltet, der zwischen den beiden Streifen gelegen ist. Auf dieser Voraussetzung beruhen meine späteren Darlegungen über den Bildungsmodus der hier in Betracht kommenden Fälle von Doppelmissbildungen, welche sich sämmtlich nach der von mir ausgesprochenen Annahme in durchaus befriedigender und ungezwungener Weise genetisch erklären lassen. Meine Ansicht über deren Entstehungsweise wird ferner dadurch eine nicht zu unterschätzende Stütze erhalten, wenn sich für die Wachsthumsenergie des betreffenden Mesodermbezirkes ein directer Beweis erbringen lässt.

Einen solchen Beweis glaube ich nun führen zu können mit Hülfe der beiden obengenannten Fälle von Ahlfeld und Rauber (7 und 30). Bei beiden ist es zwischen den zwei Primitivstreifen zur Entwicklung eines länglichen strangförmigen Wulstes der Keimhaut gekommen, welcher in seinem Verlaufe sich von den beiden Primitivstreifen gleich weit entfernt hält und nach rückwärts sich etwas verbreiternd bis zur Area opaca reicht. In Anbetracht der sonstigen Congruenz der beiden Fälle kann man kaum zweifeln, dass es sich um ein homologes Gebilde handelt, welches in der gleichen Weise zu Stande gekommen ist. Ahlfeld hält den in Rede stehenden Wulst zum Theil für das sich erhebende Amnion, führt jedoch für diese Auffassung keine Gründe an; es hat sich zwar in dem bezüglichen Falle bereits eine Kopfscheide erhoben, dagegen beobachtet man hinter dem Schwanzende und an der Aussenseite der beiden Embryonalanlagen noch keine Amnionfalten, wesshalb es unwahrscheinlich ist, dass zwischen den hinteren. Enden der Embryonen eine solche bereits aufgetreten sein sollte. Rauber dagegen hat das fragliche Gebilde, welches er Zwischenwulst nennt, auf Durchschnitten untersucht und uns dadurch über seine wahre Natur aufgeklärt. Es hat sich herausgestellt, dass derselbe der Ausdruck einer länglichen Verdickung des Mesoderms ist, welche in ihren hinteren breiteren Partien sogar eine kleine Höhlung einschliesst. Augenscheinlich ist diese Höhlung dadurch entstanden, dass das Mesoderm im hinteren Bezirke des Fruchthofes eine längliche Falte und zwar ventralwärts gegen den Dotter zu getrieben hat, deren beide Schenkel später an ihrer Abgangsstelle vón dem übrigen Mesoderm mit einander verwachsen sind ${ }^{1}$ ). Berücksichtigt man die offenbar nur kurz dauernde Existenz des Zwischenwulstes, sowie den Umstand, dass derelbe in keiner Weise für die Entwicklung der beiden Embryonen selbst von Bedeutung sein kann, so bleibt nur eine einzige Erklärung desselben möglich. In dem zwischen den beiden Primitivstreifen liegrenden Abschnitt der Keimhaut haben die sich durch fortgesetzte Zelltheilungen mehrenden Elemente des Mesoderms keinen Platz, um, wie bisher, in einer Fläche ausgebreitet bleiben zu können, wesshalb es zur Erhebung einer Falte kommen muss. Der betreffende Mesodermabschnitt ist seitlich, wie gesagt, von den beiden Primitivstreifen begrenzt, welche sich von einer bestimmten Entwicklungsphase an wegen des festeren Zusammenhaltens und

$\left.{ }^{1}\right)$ Cfr. den von Rauber abgebildeten Querschnitt Fig. 9, Taf. XIII im 5. Bande des Morphologischen Jahrbuches. 
grösseren Unnachgiebigkeit, welche das Blastoderm allmählig erlangt hat, nicht mehr von ihrem Platze entfernen lassen. Es kann darum nicht ausbleiben, dass der seitlich durch die beiden Primitivstreifen eingeengte und an seiner weiteren Ausbreitung behinderte Mesodermbezirk eine Falte treiben muss. Dass er dies gerade in der Vereinigungslinie der ursprünglich getrennten, von je einem Primitivstreifen abstammenden mittleren Keimblätter vollführt, halte ich für ein bedeutungsvolles Moment. Ferner scheint mir erwähnenswerth, dass die Falte in ihrem hinteren Theile stärker zur Entwicklung kommt, während sie nach vorne nach und nach sich abflacht, um schliesslich in eine leistenförmige Verdickung des Mesoderms überzugehen, welche sich bald gänzlich verliert.

Mit dieser Interpretation des Zwischenwulstes ist zugleich ausgesprochen, dass das Auftreten desselben zeitlich mit der Beendigung des Auseinanderrückens der beiden Primitivstreifen zusammenfällt. Es wird daher bezüglich der Grösse des Abstandes, welcher den die Mittellinie zwischen beiden Streifen einnehmenden Zwischenwulst von jedem derselben trennt, darauf ankommen, wie weit die Primitivstreifen schon von einander abgerückt waren, als das mittlere Keimblatt nicht mehr im Stande war, sie noch weiterauseinanderzudrängen.

Haben die Primitivstreifen der in Rede stehenden Doppelbildungen unter den erörterten Begleiterscheinungen ihre volle Entwicklung erlangt, so kommt es vor jedem derselben zur Bildung eines Kopffortsatzes. Dieser wird sich nach der Richtung hin entwickeln müssen, nach welcher das Kopfende seines Primitivstreifens gewendet ist. Es werden daher die beiden Kopffortsätze, aus denen die Chordae hervorgehen, je nach dem Verhalten der Kopfenden beider Streifen convergiren oder divergiren oder parallel gestellt sein (siehe die schematischen Figuren 1-4, Taf. VII). Wir haben nun zu prüfen, welche Formen von Doppelmissbildungen sich aus diesen verschiedenen Anordnungen ableiten.

I. Convergenzstellung der beiden Chordae. Als Repräsentanten dieser in der schematischen Fig. 1, Taf. VII wiedergegebenen Anordnung führe ich den Ahlfeld'schen Fall (7) an. Hier hat zweifellos eine zweifache Chordae dorsalis vorgelegen, da vier Reihen von Urwirbeln vorhanden waren. Die Entfernung zwischen den hinteren Abschnitten der Chordae war zwar keine allzugrosse, aber doch eine genügende, um hier zwei Medullarrinnen zur Ausbildung gelangen zu lassen, während vorne die beiden Chordae so nahe neben einander verliefen, dass dieselben unter den Boden einer gemeinsamen, wenn auch etwas breiteren Medullarfurche zu liegen kamen. Wir begegnen hier einem wichtigen Gesetze, das wir bei sämmtlichen nachher zu besprechenden Fällen bestätigt finden werden. Dasselbe lässt sich in der Weise ausdrücken, dass an allen Stellen, innerhalb derer die beiden Chordae dorsales sich auf eine gewisse Distanz nahe kommen, die Rückenfurche einfach zur Ausbildung gelangt. Die maximale Entfernung zwischen den beiden Chordae, innerhalb welcher dieselben von den Wülsten einer gemeinsamen Rückenfurche seitlich umfasst werden können, werde ich von nun an des kürzeren Ausdruckes wegen als Copulationsnähe, den dabei stattfindenden Vorgang selbst, durch welchen zwei Embryonalanlagen streckenweise zu einem einheitlich sich ent- 
wickelnden Körperabschnitt zusammengeschlossen werden, als Copulation bezeichnen.

Bei der Ahlfeld'schen Doppelbildung sind die beiden convergirenden Chordae in ihrem Verlaufe nach vorn schon ziemlich frühe bis zur Copulationsnähe an einander herangerückt, so dass ein beträchtlicher Abschnitt der Medullarrinne einfach sich gestalten musste. Daraus geht hervor, dass der betreffende Fall die Anlage zu einer Duplicitas posterior darstellt.

Lägen die vorderen Enden der Primitivstreifen etwas entfernter von einander, so würden bei einer gleichen Convergenz die Chordae erst später die Copulationsnähe erreichen, und es würde der gemeinsame Abschnitt der Medullarrinne ein kürzerer werden müssen. Die resultirende Duplicitas posterior würde einen höheren Grad aufweisen, wie im Ahlfeld'schen Falle. Denkt man sich die vorderen Enden der Primitivstreifen immer weiter von einander nach den Seiten hin entfernt, so wird schliesslich ihr Abstand so gross werden, dass die convergirenden Chordae an keiner Stelle mehr bis zur Copulationsnähe sich naherücken. Doss Gleiche muss auch bei einer etwas geringeren Distanz zwischen den Kopfenden der Primitivstreifen eintreten, wenn diese so gestellt sind, dass die Chordae weniger convergiren, als bei der Ahlfeld'schen Doppelbildung. In allen diesen Fällen, in denen die Chordae an keinem Orte bis zur Copulationsnähe an einander herangetreten sind, wird die normale Entwicklung der beiden Embryonalanlagen zur Zeit des Auftretens der Rückenfurche noch nicht beeinträchtigt werden.

II. Divergenzstellung der beiden Chordae. Leider steht uns für diese Verlaufsrichtung der Chordae keine so frühzeitige Doppelbildung zu Gebote, wie bei der eben besprochenen Anordnung. Doch gehört zweifellos hierher der Reichert'sche Fall (13). Die schwache Divergenz der Chordae lässt sich besser an der Abbildung Reicher t's erkennen, welche den Embryo von der Ventralseite aus darstellt (Fig. 2B, Taf. V), als an der anderen Zeichnung, welche eine dorsale Ansicht wiedergibt (Fig. 2A, Taf. V). Die beiden Primitivstreifen sind, entsprechend der vorgerückten Entwicklungszeit, nicht mehr wahrzunehmen; doch lässt sich mit Sicherheit aus der Divergenz der Schwanzenden folgern, dass dieselben die oben eingehender erörterte Lageveränderung durchmachen mussten. In einem früheren Entwicklungsstadium mag die Reichert'sche Doppelbildung ungefähr so ausgesehen haben, wie die schematische Fig. 2, Taf. VII. Die beiden Chordae verliefen vor den Kopfenden der Primitivstreifen eine ansehnliche Strecke weit innerhalb der Copulationsnähe; erst in ihren vorderen Abschnitten hatten sie sich in Folge ihres divergenten Verlaufs so weit von einander entfernt, dass hier die Anlage von zwei Medullarfurchen nöthig ward, während in der mittleren Körperregion die Rückenfurche einfach sich anlegen konnte. Wir haben daher in dem Reichert'schen Falle ein wenn auch noch nicht überall geschlossenes Medullarrohr, welches nach vorne und nach hiñten in zwei Schenkel ausläuft. Es handelt sich demnach um ein sehr frühes Stadium eines Monstrum a superiore et inferiore parte duplex, welches in der mittleren Körpergegend durch ein einfaches Rückenmark und vermuthlich auch einfache Wirbelsäule charakterisirt ist.

Je stïrker die beiden Chordae divergiren, desto früher werden sie aus 
dem Bereich der Copulationsnähe herauskommen, desto kürzer wird in Folge dessen der einfache Abschnitt der Medullarrinne sein. Liegen die vorderen Enden der Primitivstreifen so weit von einander ab, dass selbst die hinteren Theile der divergirenden Cordae nícht mehr in die Copulationsnähe kommen, so werden zwei vollkommen gesonderte Medullarfurchen sich anlegen müssen.

III. Parallelstellung der beiden Chordae. Auch bei dieser Anordnung gilt das oben ausgesprochene Gesetz, dass überall da, wo die Chordae nicht bis zur Copulationsnähe aneinanderrücken, das Medullarrohr doppelt auftreten muss. Daraus ergeben sich die zwei Eventualitäten, welche bei Parallelstellung der beiden Chordae eintreten können, von selbst. Entweder bleiben die parallelen Chordae ausserhalb der Copulationsnähe, dann werden zwei getrennte Medullarfurchen sich anlegen (schematische Fig. 4, Taf. VII), oder sie verlaufen so nahe neben einander, dass sie unter den Boden einer gemeinsamen Rückenfurche zu liegen kommen (schematische Fig. 3, Taf. VII).

Als hierher gehörige Fälle nenne ich die von Dareste mitgetheilte Doppelbildung (17) und den Rauber'schen Fall (30). Die erstere (Fig. 6, Taf. V) zeigt einen beträchtlichen Zwischenraum zwischen den beiden Embryonen. Es müssen daher zwei durchaus gesonderte Rückenfurchen sich angelegt haben, wogegen die Vereinigung der beiden Kopfenden keineswegs angeführt werden darf, denn diese kann in Anbetracht der Entfernung der beiden Embryonen erst in einer späteren Entwicklungszeit erfolgt sein. Der Umstand, dass in dem vorliegenden Falle die Chordae leichtgebogen verlaufen, scheint mir ebenfalls nicht gegen deren ursprüngliche Parallelstellung zu sprechen, indem dies durch das Längenwachsthum der beiden Embryonen, deren Kopfenden in Folge ihrer Verwachsung gezwungen sind, in einer bestimmten Nähelage zu bleiben, sich leicht erklärt.

Auch in dem einen früheren Stadium angehörigen Rauber'schen Falle (Fig. 10, Taf. VI) verlaufen die beiden Chordae resp. die Medullarrinnen nicht ganz geradlinig. Trotzdem glaube ich, dass diese Doppelbildung hier unterzubringen ist, da die Kopffortsätze, wie aus dem hinteren Theil der Chordae noch ersichtlich ist, wenigstens eine Zeit lang parallel nach vorne sich entwickelt haben müssen; es ist darum die leichte Krümmung der linken Rückenfurche wohl ebenfalls als eine secundäre Erscheinung zu betrachten ${ }^{1}$ ).

Die beiden genannten Fälle zeigen, wie die Entfernung zwischen den zwei Medullarrinnen eine verschiedene sein kann; in dem ersteren musste sie eine verhältnissmässig grosse gewesen sein, während in der $\mathrm{R}$ a uber'schen Mehrfachbildung die beiden Rückenfurchen ziemlich nahe neben einander verlaufen. Eine solche Doppelbildung, deren Chordae unter einer gemeinsamen Medullarrinne liegen, ist zwar bis jetzt noch nicht bekannt geworden; doch kann ein derartiges Vorkommen, welches ebenfalls zu einer Duplicitas posterior, wenn auch nur geringen Grades, Veranlassung geben müsste, nicht in Abrede

1) Die geringe Biegung der Längsaxen der beiden Embryonen wird meiner Meinung nach durch die vor den Kopfenden sich erhebende vordere Amnionfalte verursacht. Indem diese die beiden Köpfe nach und nach überwächst, bringt sie eine Annäherung und zuweilen sogar eine Verwachsung derselben zu Stande; mit dem Aneiuanderrïcken der beiden Kopfenden werden sich die bisher geradlinigen medianen Längenaxen etwas krümmen inüssen. 
gestellt werden, da sich dasselbe eng an die Fälle von Ahlfeld und Reichert anschliessen würde, bei denen die Chordae ja nur wenig von der Parallelstellung abweichen.

Fassen wir das Gesagte nochmals kurz zusammen. Für die Form der schliesslich resultirenden Doppelmissbildung ist die Anordnung der Kopffortsätze, resp. der Chordae dorsales von grosser Bedeutung. Liegen dieselben an einer mehr oder minder ausgedehnten Stelle ihres Verlaufs innerhalb der Copulationsnähe, so wird längs derselben ein einfaches Medullarrohr und späterhin wohl auch eine einfache Wirbelsäule entstehen müssen. Was den Grad dieser Monstra mit partieller Axenverdoppelung anlangt, welcher sich durch das Verhältniss des einfachen zu dem doppelt vorhandenen Abschnitte der Wirbelsäule bestimmt, so ist hierfür die Verlaufsrichtung der sich entwickelnden Chordae ausschlaggebend. Aus einer stärkeren oder geringeren Convergenzstellung muss eine mehr oder minder ausgedehnte Duplicitas posterior, aus einer stärkeren oder geringeren Divergenzstellung eine mehr oder minder hochgradige Duplicitas a posteriore et anteriore parte sich ableiten, während ein innerhalb der Copulationsnähe bleibender paralleler Verlauf der beiden Chordae nur eine geringgradige Duplicitas posterior nach sich ziehen wird.

Halten sich jedoch die Chordae in ihrer gesammten Länge ausserhalb der Copulationsnähe, so ist es fast ohne alle Bedeutung, ob die beiden Chordae schwach convergiren oder divergiren, oder parallel verlaufen. In älteren Entwicklungsstadien nach Schwinden der Primitivstreifen wird man die ursprüngliche Stellung derselben, da die Längsaxen in Folge verschiedener Entwicklungsvorgänge ihre anfänglich vollkommen geradlinige Richtung bald aufgeben, kaum mehr mit Sicherheit bestimmen können. In allen diesen Fällen aber, bei denen zwei gesonderte Rückenfurchen auftreten, wird es auch zur Ausbildung von zwei Wirbelsäulen kommen müssen. Von der Entfernung zwischen den beiden Rückenfurchen, sowie der späteren Nervenröhren und der sich ausbildenden Wirbelsäulen, welche eine verschiedene sein kann, wird es abhängen, ob die beiden Embryonen seitlich mit einander in Verbindung treten.

Aus diesen Betrachtungen ergibt sich weiterhin, dass das spätere Verhalten der Wirbelsäulen einer Doppelmissbildung nach dem Auftreten der Rückenfurchen bereits entschieden ist. Für eine in diesem Stadium befindliche Doppelbildung würde man es vorausbestimmen können, ob deren Componenten durchaus verdoppelte Wirbelsäulen aufweisen werden, oder ob eine stellenweise einfache Wirbelsäule zur Ausbildung kommen wird. Es scheint mir daher zweckmässig, das Stadium der fertig angelegten Medullarrinne als zeitliche Grenze festzusetzen und die zwischen zwei Embryonalanlagen und «wei Embryonen stattfindenden Vereinigungen auseinanderzuhalten ${ }^{1}$ ). Die zwischen ersteren zu Stande kommenden Vereinigungen will ich primäre, die zwischen letzteren sich einstellenden secundäre nennen. Die Folgen der primären Vereinigung bestehen darin, dass das Azenskelett des späteren Doppel-

$\left.{ }^{-1}\right)$ Es ist hier daran zu erinnern, dass in dem entwicklungsgeschichtlichen Capitel dieses Buches zwisehen Embryonalanlage und Embryo unterschieden wurde. Im Stadium der Embryonalanlage befindet sich der sich entwickelnde Organismus so lange, bis sich die Rückenfurche völlig ausgebildet hat. Sobald dies geschènen, ist er als Embryo zu bezeichnen. 
embryo an einer Stelle wenigstens ein einfaches ist, während die in Folge secundärer Vereinigung entstandenen Doppelmissbildungen durch zwei völlig gesonderte Wirbelsäulen sich kennzeichnen, ausserdem aber eine verschieden hochgradige Fusion der seitlichen Rumpftheile, d'er Extremitäten, der Köpfe aufweisen können.

Nachdem die in Folge der primären Vereinigung auftretenden Formen von Doppelmissbildungen besprochen sind, scheint mir hier der geeignete Ort, eine Frage einzuschalten, zu welcher der dritte der in unserer Zusammenstellung angeführten Fälle Veranlassung gibt. Derselbe wurde von C. E. v. Baer leider nur ungenügend und aus der Erinnerung beschrieben. v. Baer gibt an, dass in dem betreffenden Falle die Chorda dorsalis sich nach hinten in zwei Aeste gespalten habe. Es handelt sich um ein 24 Stunden bebrütetes Hühnerei, also um ein Entwicklungsstadium, in dem die beiden Primitivstreifen noch unverkürzt erhalten gewesen sein mussten. Bei der Deutung des v. Baer'schen Falles sind zwei Möglichkeiten in das Auge zu fassen. Entweder haben die Kopfenden der beiden Primitivstreifen, deren hintere Enden wohl von Anfang an etwas weiter von einander abstanden, an der Lageverschiebung so gut wie keinen Antheil genommen und lagen darum nach vollendeter Ausbildung der Primitivstreifen so dicht neben einander, dass sich vor ihnen nur ein einziger Kopffortsatz ausbildete, oder es sind zwei stärker couvergirende Kopffortsätze zur Entwicklung gekommen, welche in ihrem weiteren Wachsthum nach vorne bald auf einander trafen und sich zu einem gemeinsamen Stücke vereinigten, das dann nach Analogie der Resultirenden des Kräfteparallelogramms direct nach vorne weiter wachsen musste. Die beiden Möglichkeiten, von denen jedoch mir die erstere mehr zusagt, wie die letztere, müssen zugegeben werden; sie bleiben jedoch so lange Möglichkeiten, bis durch glückliche Beobachtung hierher gehöriger frühzeitiger Doppelbildungen der v. Baer'sche Fall nicht mehr der Genossen entbehrt. Der Letztere allein kann schon aus dem Grunde nicht zu einer Entscheidung der vorliegenden Frage Verwerthung finden, da die Abbildung v. Baer's (Fig. 2, Taf. IV) die denkbar einfachste ist und man darum nicht in der Lage ist, iiber das Aussehen dieser Doppelbildung sich eine klare Vorstellung zu bilden.

Bevor ich zu der secundären Vereinigung zweier Embryonen übergehe, möchte ich noch eine Bemerkung einfügen. Bei den bisherigen Erörterungen der primären Vereinigung wurde stillschweigend vorausgesetzt, dass sich die beiden Componenten einer Doppelbildung gleichmässig weiter entwickeln. Das Gleiche gilt auch für die nun zu besprechenden secundären Verwachsungen. Da die Intention meiner ganzen Darstellung hauptsächlich darauf gerichtet ist, leitende Gesichtspuncte zu geben, nach denen man sich die Doppelmissbildungen genetisch zurecht legen könne, so wäre es ein eben so zweckloses, als verfehltes Unternehmen, wollte ich dic mannigfachen Eventualitäten berücksichtigen, welche eintreten, weun in Folge unbekannter pathologischer Verhältnisse der Keimhaut einer der beiden Embryonen bereits in der ersten Entwicklungszeit in seiner Ausbildung zurückbleibt. Ich werde daher Doppelembryonen von ungleicher Entwicklung nur beiläufig in den Kreis meiner Betrachtungen ziehen und glaube um so mehr dazu berechtigt zu sein, als nur bei sehr wenigen der mitgetheilten Fälle eine auffallende Ungleichheit in der Ausbildung der beiden Embryonen bemerklich ist. 
Die secundäre Vereinigung oder Verwachsung zweier mit ihrer Längsaxe schwach convergent, parallel oder schwach divergent gestellter Embryonen wird, wie bereits früher im Allgemeinen ausgeführt wurde, dann eintreten müssen, wenn dieselben sich gegenseitig den Raum wegnehmen, dessen ein jeder von ihnen zu seiner normalen Weiterentwicklung benöthigt ist. Man hat hier zwei Momente zu unterscheiden: 1) die Grösse der Entfernung zwischen beiden und 2) das Wachsthum und Ausdehnungsvermögen des zwischen beiden Embryonen befindlichen Keimhautbezirkes. So lange, als letzteres mit der Volumvergrösserung der beiden sich entwickelnden Embryonen proportional einhergeht, werden dieselben in gehöriger Entfernung von einander gehalten und eine Verwachsung wird vermieden werden. Ich habe bereits bei Gelegenheit eines Vergleiches der beiden ersten der von mir beschriebenen Doppelbildungen darauf hingewiesen, wie der Umstand, dass die Köpfe der Embryonen meines zweiten Falles nicht schon längst mit einander verwachsen sind, nur darin seine Erklärung findet, dass der zwischen ihnen liegende Keimhautbezirk sich entsprechend dem Wachsthum und der Vergrösserung der Embryonalkörper ausgedehnt haben muss. Ich glaube das gleiche Verhalten auch für die in Rede stehenden Doppelbildungen in in Anspruch nehmen zu dürfen. Einen Beleg für diese Auffassung erblicke ich in einem Falle von Dareste (Fall 17; Fig. 6, Taf. V), bei dem die parallel verlaufenden Körper beider Embryonen um ein ansehnliches Stück seitlich von einander abgerückt sind, aber trotzdem noch nicht weit genug, um eine Verwachsung der beiden Köpfe hintanzuhalten.

Wenn daher auch eine intussusceptionelle Ausdehnung des zwischen den beiden Embryonen liegenden Keimhautbezirkes mit einiger Sicherheit angenommen werden darf, so scheint dieselbe jedoch meistens hinter der weiteren Ausbildung der beiden Embryonen bald zurückzubleiben, um schliesslich ganz aufzuhören. Es sind demnach die beiden Embryonen derjenigen Doppelbildungen am meisten und längsten gegen eine Verwachsung gesichert, deren Kopffortsätze, resp. Chordae von Anfang an schon weiter von einander sich entwickelt haben. War der die beiden Chordae trennende Zwischenbezirk der Keimhaut schon in den ersten Bildungsstadien derselben verhältnissmässig. breit, so kann vielleicht sein geringes intussusceptionelles Wachsthum genügen, um eine Verwachsung der beiden Embryonen zu hindern. Je schmäler dagegen dieser Zwischenbezirk war, desto früher steht eine secundäre Vereinigung zu erwarten, welche, je früher sie eintritt, zu einer desto intensiveren Verschmelzung führen muss. Das soeben Erörterte lässt sich auch folgendermassen ausdrücken. Die Zunahme der Entfernung, innerhalb welcher die beidèn Chordae sich entwickeln, involvirt eine um so spätere und darum weniger tiefgehende Verwachsung beider Embryonen.

Was die Art und Ausdehnung der Verwachsung der mit ihren Längsaxen vollständig oder nahezu parallel verlaufenden Zwillingsembryonen anlangt, so kann dieselbe in einer Vereinigung der seitlichen Rumpftheile oder der Köpfe bestehen, ferner kann an beiden Stellen eine Verbindung stattfinden.

Eine Verwachsung der beiden Köpfe beobachten wir in der mehrfach erwähnten Dareste'schen Doppelbildung (Fall 17, Fig. 6, Taf. V), welche um so bemerkenswerther ist, als ja die mittleren Körpertheile nach Dareste's 
Angabe parallel stehen, und aus der betreffenden Abbildung ersichtlich ist, dass die Kopfenden der beiden Embryonen in der ersten Zeit nicht allzu nahe an einander gelegen sein können. Den Grund der uns auffälligen Verwachsung der Köpfe glaube ich in dem Vorhandensein einer gemeinschaftlichen vorderen Amnionfalte suchen zu müssen, welche, wie auf der Daresteschen Zeichnung angedeutet, die vereinigten Kopfenden schon etwas überdeckt. Diese Vermuthung erhält durch die Rauber'sche Doppelbildung (Fall 30) eine Stütze. Auch hier ist vor den Kopfenden der beiden Zwillingsembryonen eine vordere Amnionfalte im Auftreten begriffen, und auch hier liegen die vorderen Enden der beiden Zwillinge dicht neben einander, während ihre übrigen Körperabschnitte bis zum Kopfende der Primitivstreifen nahezu parallel verlaufen.

Eine Doppelbildung, bei der sich eine secundäre Vereinigung der seitlichen Körpertheile einstellte, liegt in Fall 26 (Fig. 6, Taf. VI) vor, den wir ebenfalls Dareste verdanken. Hier waren die beiden Embryonen seitlich bis zum Auftreten der Extremitätenstummel gänzlich getrennt geblieben; erst als die einander zugekehrten Extremitätenpaare länger wurden, stiessen sie auf einander, und es trat eine Verwachsung ein. Dieselbe würde bei einer noch grösseren Nähe der beiden Embryonen schon früher haben erfolgen müssen. Die beiden Köpfe der betreffenden Doppelmissbildung sind dagegen getrennt; eine vordere Amnionfalte scheint der Zeichnung nach nicht zur Ausbildung gekommen zu sein.

Eine Verwachsung der Köpfe und der vorderen Rumpftheile zeigen die Fälle 27 und 28 (Fig. 7 und 8, Taf. VI), die auch wiederum von Dareste beobachtet worden sind. Die zwei Doppelbildungen befinden sich zwar schon in einem relativ späten Entwicklungsstadium, indem bei beiden die Abschnürung der Embryonen von der Keimhaut schon ziemlich weit gediehen ist. Es war ihnen desshalb möglich, sich in der Amnionflüssigkeit zu bewegen und sie hatten so ihre ursprüngliche Lage etwas verändern können. Aus diesem Grunde ist es schwierig zu bestimmen, ob die beiden Fälle in die erste oder vielleicht in die zweite Gruppe einzureihen sind, da die nicht verwachsenen Körpertheile aus den genannten Gründen keine Anhaltspuncte darbieten. In dem Umstand jedoch, dass nicht nur die Köpfe, sondern auch ein beträchtlicher Theil der übrigen Körperabschnitte sich vereinigt haben, liegt meiner Auffassung nach ein Kriterium, das mehr für ihre Zugehörigkeit zu der ersten Gruppe in das Gewicht fällt. In dem Falle 28 ist noch ein drittes dorsalwärts gekehrtes Auge zur Ausbildung gekommen. Daraus geht hervor, dass die beiden Köpfe zur Zeit ihrer Vereinigung sich die Seitengegenden nicht direct zuwendeten, sondern es müssen die vorderen Embryonaltheile schon in der Drehung um ihre Längenaxe begriffen gewesen sein; jedoch suchten sie sich nicht mit der gleichen Seite auf den Dotter aufzulegen, wie im Falle 26, sondern mit entgegengesetzten, so dass sie mit den späteren Stirngegenden an einander zu liegen kamen, was zu einer Verwachsung der Vorderhirnbläschen führen musste. 
II.

Doppelbildungen, bei denen die Längenaxen beider Embryonalanlagen, resp. ihre linearen Verlängerungen einen rechten oder stumpfen Winkel bilden.

Dieser Gruppe gehören die folgenden Fälle an:
2) Gerlach Fig. 1, Taf. III.
6) Rauber Fig. 5, Taf. IV.
14) Rauber Fig. 3, Taf. V.
15) Ahlfeld Fig. 4, Taf. V.
16) Ahlfeld Fig. 5, Taf. V.
18) Gerlach Taf. II.
20) Dareste Fig. 8, Taf. V.
21) Dareste Fig. 1, Taf. VI.
23) Dareste Fig. 3, Taf. VI.
24) Rauber Fig. 4, Taf. VI.

Diesen Beobachtungen schliesst sich die Dareste'sche Dreifachbildung (Fall 29, Fig. 9, Taf. VI) an, indem der eine der beiden durchsichtigen Fruchthöfe, welcher zwei Embryonen enthält, die geforderte Anordnung der Längenaxen der letzteren aufweist. Doch scheint es gerathen, von diesem Falle gänzlich abzusehen, da in Folge der Anlagerung eines zweiten nur einen Embryo einschliessenden Fruchthofes der erste keine normale Beschaffenheit besitzt, und auch die Embryonen desselben ungleich entwickelt sind.

Der von den übrigen 10 Fällen seiner Entwicklungszeit nach früheste ist die von mir beschriebene Doppelbildung (Fall 2), welche, wie oben eingehender geschildert wurde, zwei Primitivstreifen erkennen lässt, die unter einem stumpfen Winkel in die Area pellucida eingedrungen sind. Es liegt im Rückblick auf das Verhalten der spitzwinklig einstrahlenden Primitivstreifen die Frage nahe, ob auch bei recht- oder stumpfwinkliger Stellung derselben das mittlere Keimblatt, wenn es sich ausbreitet, eine Lageverschiebung der beiden Streifen verursachen könne? Bei der eben genannten Anordnung der beiden Streifen, deren periphere Enden eine bedeutende Entfernung zwischen sich lassen, wird es begreiflicher Weise erst vièl später zu einer Vereinigung der zwei von je einem Streifen aus sich entwickelnden mittleren Keimblätter kommen können. Die Abbildung meines Falles (Fig. 1, Taf. III) zeigt auf das deutlichste, wie sich die beiden Mesodermata noch nicht vereinigt haben, und zwar in einer Zeit, in welcher die Primitivstreifen bereits nahezu vollendet sind und das Auftreten der Kopffortsätze unmittelbar bevorsteht. Ferner ist zu bemerken, dass sich die beiden mittleren Keimblätter nicht direct entgegenwachsen, wie dies bei spitzwinkliger Stellung der beiden Streifen geschieht. Aus diesen Gründen lege ich einer etwaigen geringen Lageverschiebung der beiden Streifen', welche durch die sich ausbreitenden Mesodermata vielleicht in einzelnen Fällen bewirkt wird, keine sonderliche Bedeutung bei. Jedenfalls ist sie nicht im Stande, auf die gegenseitige Lagebeziehung der Chordae irgend einen Einfluss auszuüben, wie wir es bei den Föllen der ersten Gruppe anzunehmen gezwungen waren. Um diese Wirkung haben zu können, miisste 
die Lageverschiebung in einer Entwicklungsphase beginnen, welche der nahezu vollendeten Ausbildung der Primitivstreifen, wie sie Fall 2 zeigt, noch vorausgeht. Vereinigen sich jedoch, die beiden mittleren Keimblätter erst in einer späteren Zeit der Entwicklung, so werden höchstens die peripheren Enden der Streifen noch etwas auseinandergetrennt werden können; dadurch wird zwar auch eine leichte Krümmung derselben verursacht; allein dieselbe wird mehr in die hinteren Abschnitte der Streifen fallen müssen. Eine derartige Biegung zeigen in dem Ra uber'schen Falle 6 (Fig. 5, Taf. IV) die beiden Primitivstreifen. Hier ist vermuthlich die Vereinigung der beiden mittleren Keimblätter schon relativ frühe erfolgt, so dass die hinteren Abschnitte der Streifen noch etwas nach entgegengesetzten Richtungen hin abgebogen werden konnten. Die vorderen Stïcke der Primitivstreifen gaben jedoch ihren geradlinigen Verlauf nicht auf und liegen darum in einer Linie mit den vor ihnen befindlichen Rückenfurchen.

Die mehr oder weniger stumpfwinklige Stellung der beiden Embryonalanlagen bringt es mit sich, dass sie bei ihrer nach vorne zu gerichteten Wachsthumsverlängerung zuerst mit den Kopfenden auf einander treffen müssen. In Bezug auf die Intensität und die Zeit des Eintretens der Verwachsung gilt natürlich auch hier der mehrfach ausgesprochene Grundsatz, dass die Vereinigung um so hochgradiger sich gestaltet, je frühzeitiger sie beginnt. Bei keinem der in unsere Gruppe gehörigen Fälle ist es ersichtlich, dass die Verbindung der beiden Zwillinge schon vor der vollendeten Ausbildung der Medullarrinne eingetreten ist; es scheint demnach eine primäre Vereinigung, wie wir sie bei der ersten Gruppe kennen gelernt haben, nicht stattzufinden.

Auch bezüglich der Art und Ausdehnung der secundären Vereinigung zeigen die einzelnen Fälle beträchtliche Verschiedenheiten. Wenn die Kopfenden der beiden Embryonen in Folge ihrer hauptsächlich nach vorne gerichteten Verlängerung früher oder später - je nach dem Verhalten des zwischen ihnen befindlichen Keimhautbezirkes, welcher sich, wie bereits des Genaueren ausgeführt wurde, längere oder nur kürzere Zeit und in verschieden hohem Grade ausdehnen kann - zusammentreffen, so hängt die Art und Weise der Vereinigung vorwiegend von dem Umstande ab, ob um diese Zeit die beiden Embryonen in ihrer Entwicklung gleich weit fortgeschritten sind oder nicht. Im ersteren Falle werden die gegenseitigen Störungen in der weiteren Ausbildung von annähernd gleicher Intensität sein, in dem letzteren jedoch wird der weiter ausgebildete, stärkere Embryo eine geringere Störung erleiden, als der andere.

Befassen wir uns zunächst mit der letztgenannten Eventualität. Von den hier in Betracht kommenden Fällen sind es nur zwei, der Fall 6 (Fig. 5, Taf. IV) und der Fall 14 (Fig. 3, 'Taf. V), beide von Rauber beobachtet, welche eine auffallend ungleiche Ausbildung der beiden Embryonen aufweisen. Die beiden Doppelbildungen, deren Embryonen ganz die gleiche Anordnung der Längenaxen zeigen, haben auch sonst viel Aehnlichkeit mit einander; nur ist die Entwicklungszeit, in welcher die Kopfenden der Embryonen aufeinandertrafen, bei beiden eine verschiedene gewesen. Im Falle 6 fand dies offenbar in einem früheren Entwicklungsstadium statt, als im Falle 14. Bei der ersteren Doppelbildung ist das Kopfende des stïrkeren Embryo, wie es scheint, noch kaum in seiner Ausbildung beeinträchtigt worden; dagegen hat das des schwächeren eine um so ansehnlichere Störung erlitten. Dass auch 
bei diesem die Medullarfurche vordem sich regelrecht angelegt hat und demnach eine Kopffalte vorhanden gewesen sein muss, darf mit Sicherheit aus der Entfernung zwischen den Kopfenden der beiden Primitivstreifen gefolgert werden. Die Kopffalte des schwächeren Embryo kam jedoch dem vorwachsenden Kopfe des stärkeren Zwillings in den Weg, wurde von ihm niedergedrückt und dadurch an ihrer weiteren Entwicklung gehindert, während der hintere Theil der Rückenfurche verschont blieb, und sich darum normal verhält. Das Schicksal dieser Doppelbildung würde voraussichtlich darin bestanden haben, dass das vordere Ende des allmählig absterbenden schwächeren Embryo in die Bildung der vorderen Amnionfalte des stärkeren Zwillings mit einbezogen worden wäre.

Der andere Rauber'sche Fall (14) repräsentirt ein älteres Stadium; er lässt ebenfalls eine ungleiche Entwicklung der Kopfenden beider Zwillinge erkennen, indem der kräftigere eine entschieden geringere Missgestaltung des Kopfendes zeigt, als der schwächere, dessen Hirnrohr offenbar durch den wachsenden Kopf seines Genossen zu einer Platte comprimirt worden war. Bei dieser Doppelbildung hat die Entwicklung der für den stärkeren Embryo bestimmten vorderen Amnionfalte nach den Angaben Rauber's bereits begonnen und zwar in der Art, dass der Kopf des schwächeren Embryo die kurze Kopfkappe des Amnion mit construiren hilft.

Es lässt sich somit aus den beiden Rauber'schen Fällen entnehmen, dass bei ungleicher Ausbildung der Embryonen zur Zeit des Zusammentreffens derselben die Vereinigung beider mehr indirect, durch das Amnion, vermittelt wird. Die schwächeren Zwillinge in den beiden Fällen werden voraussichtlich immer mehr in ihrer Entwicklung zurückbleiben; der des Falles 6 wird bald absterben müssen, da die Bildung des Vorderdarms ausgeblieben und damit auch die des Herzens unmöglich geworden ist. Hingegen kann der schwächere Embryo des Falles 14, der ein Herz bereits besitzt, noch längere Zeit am Leben sich erhalten; er kann möglicher Weise eine Allantois entwickeln, deren Gefässe vielleicht mit den Allantoisgefässen des stärkeren Zwillings in Communication treten, was schliesslich zur Genese eines Allantoisparasiten führen würde.

Die secundäre Verwachsung zweier gleich weit entwickelter Componenten einer Doppelbildung, zu der ich nun komme, möchte ich an der Hand zweier Beobachtungen, des Ahlfeld'schen Falles 16 (Fig. 5, Taf. V) und des Rauber'schen Falles 24 (Fig. 4, Taf. VI), besprechen. Soweit es die Abbildung des ersteren Falles erkennen lässt, ist derselbe der Entwicklungszeit nach der frühere, da es bei beiden Embryonen noch nicht zur Anlage der Extremitäten gekommen ist; er zeigt jedoch mit der Rauber'schen Doppelbildung eine so grosse Uebereinstimmung, dass beide gemeinsam erörtert werden können. In den beiden Fällen muss, es zu einer sehr frühen Zeit, vielleicht schon bei der Schliessung des vorderen Hirnrohres, zu einer Verwachsung der zwei Köpfe gekommen sein. Daraus entstand ein für die äussere Betrachtung gemeinschaftlicher Kopftheil, während im übrigen Körper die beiden Zwillinge normal gebildet waren; der in beiden Fällen missgestaltete gemeinsame Kopf entspricht hinsichtlich seiner Grösse insofern der Entwicklungsstufe der beiden Zwillinge, als er, den Zeichnungen nach zu urtheilen, 
ungefähr die doppelte Volumsgrösse aufweist, welche dem Kopfe eines in dem gleichen Stadium befindlichen normalen Einzelembryo zukommt. Man kann aus diesen Fällen den Schluss ziehen, dass die gegenseitige Störung in der Entwicklung des Kopfes sich auf beide Embryonen ziemlich gleichmässig vertheilte, indem durch dieselbe dis Bildung der Augenanlage, der Nasengrübchen etc. bei beiden Zwillingen hintangehalten wurde.

Im Anschluss an die beiden vorstehenden Beobachtungen möchte ich den von Dareste mitgetheilten Fall 20 (Fig. 8, Taf. V) besprechen, da in demselben nach der kurzen Notiz dieses Autors ebenfalls ein beiden Embryonen gemeinsamer Kopf existirte. Soviel aus der Zeichnung zu ersehen, ist jedoch bei beiden Zwillingen eine Kopfkriummung schon eingetreten, woraus man schliessen könnte, dass nur die vorderen Kopftheile gemeinsam seien, und die Verschmelzung erst eingetreten wäre, nachdem sich die Embryonen bereits anschickten, ihren Kopf auf die Seite zu legen. Da dies nun nicht bei beiden in der gleichen Weise geschah, indem die Köpfe sich auf verschiedene Seiten legten, konnten die Vordertheile derselben in Berührung kommen und verwachsen. Inwieweit diese Vermuthung gerechtfertigt ist, lässt sich nicht mit Bestimmtheit sagen, da die in sehr kleinem Massstabe ausgefïhrte Abbildung Dareste's, sowie seine nur kurze Erläuterung dieses Falles nicht hinreichen, um sich über denselben ein genaueres Urtheil bilden zu können.

Ein grosses Interesse bietet der von Ahlfeld beobachtete Fall 15 (Fig. 4, Taf. V) dar. Leider macht dieser Autor keine Angaben über das Verhalten des Vorderdarms beider Embryonen, und doch ist gerade dieser Punct für die Erklärung der Entwicklungsvorgänge, welche zu der Bildung eines gemeinschaftlichen Herzens führten, von besonderer Wichtigkeit. Ich lege mir das Zustandekommen der betreffenden Missbildung folgendermassen zurecht, will jedoch zugleich bemerken, dass meine Auffassung, welche nur auf der Ahlfeld'schen Abbildung und den wenigen im Texte beigefügten erläuternden Bemerkungen dieses Forschers basirt, keinen Anspruch auf eine durchaus richtige Deutung dieses Falles erheben kann.

Aus der Existenz eines gemeinsamen Herzens schliesse ich auf einen urspriinglich einfachen Vorderdarm. Das Zustandekommen eines solchen ist aber nur dann möglich, wenn die Kopftheile beider Embryonen kurz nach Auftreten der Kopffalte eng neben einander lagen. Daraus folgt wiederum, dass die beiden Medullarrinnen, nachdem sie mit ihren Kopffalten aufeinandergetroffen waren, ihre bisherige Wachsthumsrichtung aufgegeben haben, indem sie, ohne seitlich zu verschmelzen, parallel neben einander sich weiter entwickelten und zwar in einer Richtung, welche die Resultirende aus den von beiden früher eingehaltenen Verlaufsrichtungen darstellt. Während das Hirnrohr sich allmählig schloss, kam es vor dem gemeinsamen Vorderdarm zur Bildung des Herzens, und sodann fand um das gemeinschaftliche Herz eine allmählige Drehung der beiden Köpfe in ihren Längsaxen statt. Der eine drehte sich nach links, der andere nach rechts. In Folge dieser Bewegung riickten dic beiden Hirnrohre von einander ab, so dass das Herz, welches sie früher bedeckt hatten, von obenher sichtbar werden musste; die Hirnrohre selbst aber wenden nun die Seiten nach oben und unten, die Dorsalflïchen sind von einander abgewendet, dagegen sind ihre Ventralflächen dem gemein- 
schaftlichen Herzen zugekehrt. Ob eine Theilung des Vorderdarms bei der Drehung stattgefunden hat, kann Jemand, dem das Präparat nicht selbst vorgelegen, kaum entscheiden. In Folge der Drehung müssen die ventralwärts wachsenden vorderen Hirntheile direct aufeinanderstossen und schliesslich verschmelzen. Die Art der Vereinigung der beiden Embryonen mittelst der Herz- und Kopfgegend lässt deutlich erkennen, welche Monstrosität aus der.Ahlfeld'schen Doppelbildung entstanden sein würde. Letztere stellt zweifelsohne die Anlage eines Cephalo-thoracopagus dar.

Während wir bei der eben erörterten Doppelmissbildung eine seitliche Verschmelzung der eine Zeit lang neben einander sich entwickelnden Kopftheile ausschliessen mussten, zeigt im Gegensatz hierzu der Dareste'sche Fall 21 (Fig. 1, Taf. VI) eine derartige Vereinigung. Offenbar sind auch hier die Embryonen dadurch, dass sie mit den Köpfen aufeinandertrafen, von ihrer ursprünglichen Wachsthumsrichtung abgelenkt worden; die Kopfund Halsgegenden der beiden Zwillinge kamen neben einander zu liegen und - sind seitlich verwachsen. Nach der Abbildung scheint der eine Embryo, vielleicht weil er etwas stärker war und unter besseren Existenzbedingungen sich befand, als der andere, weniger von der ursprünglichen Richtung mit seinem vorderen Ende abgewichen zu sein, als jener.

Auch die Dareste'schen Fälle 27 und 28 (Fig. 7 und 8, Taf. VI) müssen hier Erwähnung finden, da sie vielleicht 'in die zweite Gruppe gehören. Bei beiden erstreckt sich die Vereinigung weiter nach rückwärts, als in dem eben besprochenen Falle 20. Dies war für mich der Grund, sie in der ersten Gruppe mit anzuführen, allerdings unter einer gewissen Reserve; denn da die beiden Fälle ein älteres Entwicklungsstadium repräsentiren, in welchem die hinteren Körpertheile sich schon frei in der Amnionhöhle bewegen konnten, so lässt sich die ursprüngliche Anordnung ihrer Längsaxen unmöglich mehr feststellen.

Dagegen ist unstreitig in unsere Gruppe die zweite der von mir beschriebenen Doppelbildungen (Fall 18, Taf. II) einzureihen. Eine Verwachsung ist zwar in diesem Falle noch nicht erfolgt, doch, wie aus der Lage der beiden Embryonen hervorgeht, unmittelbar bevorstehend. Ich kann über diesen Fall hier hinweggehen, weil er bereits früher eine eingehendere Erörterung gefunden hat.

Zum Schlusse möchte ich die Dareste'sche Doppelbildung (Fall 23 Fig. 3, Taf. VI) noch anführen. Dieselbe gehört zwar auch einer schon etwas späteren Entwicklungszeit an, lässt jedoch noch deutlich die Anordnung der beiden Embryonen, d. h. ihre stumpfwinklige Stellung zu einander erkennen. Wie aus der Abbildung Dareste's zu ersehen ist, sind die hinteren Körperenden beider Embryonen noch in der Keimhaut fixirt und konnten ihre Lage noch nicht ändern. Auch hier ist. die Längsaxe der beiden '/willinge keine geradlinige geblieben; sie mussten ebenfalls, nachdem sie aufeinandergetroffen waren, ihre ursprüngliche Wachsthumsrichtung aufgeben, und darum bilden ihre vorderen Abschnitte mit den Hinterkörpern einen Winkel. Einen hauptsächlichen Unterschied jedoch, welcher diese Doppelbildung gegenüber den bisher besprochenen auszeichnet, erblicke ich in dem Umstand, dass trotz der grossen Nähe, in welche die beiden Embryonen zeit- 
weise kamen, eine Verwachsung gänzlich unterblieben ist, und eine solche, worin ich Dareste beipflichte, auch nicht mehr zu erwarten ist. Auch ist bei diesem Falle noch zu erwähnen, dass die beiden Zwillinge die Köpfe mit der gleichen Seite auf die Keimhaut auflegten; auf diese Weise wurde eine Berührung und eventuelle Verwachsung der Vorderhirne unmöglich. Es liefert der in Rede stehende Fall ferner den Beweis, dass auch bei einer ursprünglich stumpfwinkligen Stellung der Chordae, resp. der Embryonalaxen eine Verwachsung der zwei Componenten einer Doppelbildung nicht einzutreten braucht.

Die Ergebnisse, zu welchen uns die Betrachtung derjenigen Doppelembryonen führte, die sich von zwei stumpfwinklig zu einander gestellten Primitivstreifen ableiten, lassen sich kurz zusammenfassen. Es sollen dabei nur diejenigen Doppelbildungen Berücksichtigung finden, deren Componenten annähernd gleich weit entwickelt sind. Durch die Anordnung der Längsaxen ist es bedingt, dass die beiden Embryonen in ihrem Wachsthum nach vorne bald aufeinanderstossen müssen. Sie werden dadurch von ihrer bisherigen Wachsthumsrichtung abgelenkt. Findet alsbald nach dem Zusammentreffen eine Vereinigung statt, so kann es zur Bildung eines gemeinsamen, äusserlich einfachen, missgestalteten Kopfes kommen. Im anderen Falle entwickeln sich die beiden Kopfenden neben einander weiter und können dabei seitlich in höherem oder geringerem Grade mit einander verwachsen, oder sie können getrennt bleiben. Sind sie noch zu der Zeit von einander gesondert, in welcher die Kopfenden sich um ihre Längsaxen drehen und sich mit der einen Seite auf den Dotter legen, so kann es zu einer Verwachsung der Vorderhirne kommen, die sich mit einer Vereinigung der späteren Brustgegenden compliciren kann. Es ist daraus ersichtlich, dass aus einer stumpfoinkligen Stellung der Primitivstreifen die höheren Grade der Duplicitas posterior resultiren müssen.

Ehe ich zur nächsten Gruppe übergehe, möchte ich noch auf eine Frage zu sprechen kommen, welche bei einem Vergleiche der einzelnen Fälle der zweiten Gruppe sich aufwerfen muss. Sie betrifft das Lageverhältniss der beiden Embryonen einer Doppelbildung im Gesammtei und deren Beziehungen zu der normalen Lagerungsstätte eines Einzelembryo. Es lässt sich leicht die Möglichkeit vorstellen, dass einer der beiden Zwillinge in den ersten Entwicklungsstadien die Lage einnimmt, welche, falls die Keimscheibe nur einem Embryo zugehörte, diesem zukommen würde. Wir wissen aus der Entwicklungrgeschichte, dass ein Finzelembryo in der Norm sich Anfangs immer senkrecht zur Längsaxe des Vogeleies entwickelt, und dass der Primitivstreifen in diejenige Hälfte der Area pellucida zuerst einstrahlt, welche einem Beobachter zugekehrt ist, wenn das vor ihm liegende Ei den stumpfen Pol nach links, den spit\%en Eipol nach rechts wendet. Daraus ergibt sich eine ganz bestimmte Lagerung des Embryo, sowohl in der Area pellueida, als im Gesammtei. Es wird zweckmässig sein, dieser Lage einen kurzen passenden Namen zu geben. Ich will sie daher als $\mathrm{N}$ ormalstellung bezeichnen.

Es wird sich daher darum handeln müssen, zu untersuchen, ob in den einzelnen hierher gehörigen Fällen einer der beiden Zwillingsembryonen die 
Normalstellung innegehabt habe. Sichere Aufklärung über diesen Punct wird man nur für diejenigen Doppelbildungen erhalten können, deren Beschreibung von Seiten der betreffenden Autoren Angaben über das Lageverhältniss der Embryonen zur Längsaxe des Eies beigefügt worden sind. Es ist sehr begreiflich, dass von den meisten Beobachtern auf diese Fragen, da man ihnen keinen besonderen Werth beilegte, keine Rücksicht genommen worden ist, und darum Angaben nach der erörterten Richtung hin meistens unterblieben sind. Meiner Ansicht nach sind jedoch diese Fragen nicht so ganz bedeutungslos und ich war daher froh, dass ich über die Lage der Embryonen in den von mir beschriebenen Fällen, als ich in meinen Notizen nachsah, die nöthigen Bemerkungen vorfand. Bei diesen zwei Doppelbildungen, deren Componenten die gleiche Anordnung zeigten, war es bei beiden der „hintere", welcher die Normalstellung einnahm. Denkt man sich in beiden Fällen den ᄁlinken vorderen" Componenten weg, so würde der restirende andere Embryo hinsichtlich seiner Lage im Fruchthofe und im ganzen Ei normale Verhältnisse darbieten. Es scheinen sonach die zwei Componenten bei beiden Doppelbildungen nicht ganz gleichwerthig zu sein, ein Verhalten, welchem ich dadurch Ausdruck verleihen möchte, dass ich für den frühèr als „hinteren“ bezeichneten Zwilling der beiden Doppelbildungen den Namen ${ }_{\pi} \mathrm{Stamm-}$ embryo" vorschlage, während der , linke vordere" als accessorischer Embryo bezeichnet werden soll.

$\mathrm{Ob}$ auch bei den anderen .Doppelbildungen unserer Gruppe ein Unterschied zwischen einem Stammembryo und einem accessorischen Embryo gemacht werden darf, ist nicht mehr mit Sicherheit festzustellen, da Angaben über die Lage der Embryonen im Ei bei allen anderen Fällen nicht vorliegen. Dass jedoch bei den meisten Doppelbildungen einer der beiden Componenten als Stammembryo anzusprechen ist, scheint mir sehr wahrscheinlich. Es liegt aus teleologischen Gründen die Annahme nahe, dass die Normalstellung des Primitivstreifens eines Einzelembryo für dessen weitere Entwicklung die günstigsten Chancen darbietet. Wenn nun bei Doppelbildungen einer der beiden Componenten während der ersten Entwicklungszeit in seiner Ausbildung zurückbleibt oder sich auffallend anormal verhält, so wird man daraus schliessen müssen, dass derselbe sich unter ungünstigeren Existenzbedingungen befindet als der andere; man wird mit einer gewissen Wahrscheinlichkeit dann den ersteren als accessorischen, den letzteren als Stammembryo betrachten dürfen. Sehr deutlich tritt die ungleiche Ausbildung der beiden Componenten in den Rauber'schen Fällen 6 und 14 (Fig. 5, Taf. IV und Fig. 3, Tafel V) zu Tage. Fasst man den stärkeren als Stammembryo, den schwächeren als accessorischen auf, so steht man vor einer anderen Anordnung der beiden Embryonen, als sie bei den von mir beobachteten zwei Doppelbildungen bemerklich ist. Hier wie da bilden die beiden Embryonen so ziemlich einen gleich grossen stumpfen Winkel; bei den Rauber'schen Fällen ist derselbe jedoch nach rechts offen, während er bei den meinigen sich nach links öffnet. Dass dieser Unterschied davon abhängt, welchen Componenten der Doppelbildung man als den hinteren oder den Stammembryo betrachtet, bedarf keiner weiteren Auseinandersetzung.

Auch bei den meisten anderen, in späteren Entwicklungsstadien befindlichen 
Doppelbildungen macht sich eine wenn auch nur geringe Verschiedenheit in der Ausbildung der beiden Zwillinge geltend. Wenn die vorderen Enden der Rückenfurchen aufeinandergetroffen sind und das Wachsthum derselben eine andere Richtung einschlägt, so wird sich jedenfalls der stärkere Embryo weniger von seiner bisherigen Bahn abbringen lassen, als der andere; der erstere wird daher später eine geringere Biegung seiner Längsaxe aufweisen müssen. Fasst man diesen Voraussetzungen zu Folge die stärkeren Componenten als hintere oder Stammembryonen auf, so würden sich, wenn man dieses Verhalten durch die Richtung ausdrückt, nach der sich der Winkel der beiden embryonalen Längenaxen öffnet, die einzelnen Fälle folgendermassen classificiren lassen. Es würde im Falle 16 und 21 dieser Winkel sich nach rechts, im Falle 24 sich nach links hin öffnen. Bei den noch restirenden Doppelbildungen, Fall 15, 20 und 23, hält es schwer, da jegliche Anhaltspuncte fehlen, die Wahl zu treffen, welchen der beiden Zwillinge man für den Stammembryo erklären soll. In den drei Fällen sind die beiden Embryonen gleich entwickelt und dass im Falle 15 und 20 einer der beiden sich anormaler Weise mit der falschen Kopfseite auf den Dotter gelegt hat, ist ein zu ungenügendes Kriterium, als dass es Berücksichtigung finden könnte. Die Möglichkeit, dass keiner der beiden Componenten den Stammembryo darstellt; indem dieselben sich vielleicht in gleich weiter Entfernung von der Normalstellung entwickelt haben, ist gerade für die genannten drei Fälle in erster Linie offen zu lassen.

\section{III.}

Doppelbildungen, bei denen die beiden Embryonalanlagen in eine Linie zu liegen kamen, und zwar mit zugekehrten Kopfenden und abgewendeten Schwanzenden. Oppositionsstellung der Primitivstreifen.

Dieser Gruppe fügen sich die nachstehenden Fälle ein:
5) Reichert
Fig. 4, Taf. IV.
9) v. Baer
Fig. 7, Taf. IV.
10) Dönitz
Fig. 8, Taf. IV.
19) Dareste
Fig. 7, Taf. V.
25) Allen 'Thomson Fig. 5, Taf. VI.

Die fünf Fälle repräsentiren verschieden weit auseinanderliegende Entwicklungsstadien (vom zweiten bis fünften 'Tage der Bebrütung). Bei keinem derselben ist es zu einer Vereinigung vor der Ausbildung der Medullarrinne gekommen, so dass mit Ausnahme der Reichert'schen Beobachtung, bei welcher die Einbryonen sich überhaupt noch nicht vereinigt haben, in allen anderen Fällen eine secundäre Verwachsung stattgefunden haben muss.

Sehr instructiv ist der frühste von $R$ eichert beschriebene Fall dieser Gruppe (Fig. 4, 'Taf. IV). Die vorderen Enden der Embryonen sind bereits einander so nahe gekommen, dass die Kopffalten sich berühren; zu einer Vereinigung ist es noch nicht gekommen. Erwägt man, dass der Primitivstreifen bei der normalen Entwicklung eines Embryo bis tief in die vordere Hälfte der Area pellucida vordringt, so folgt hieraus, dass in unserem Falle der durchsichtige Fruchthof, in welchem zwei Primitivstreifen sich direct 
entgegenkamen, eine bedeutende Ausdehnung der Länge nach erlitten haben musste, denn sonst hätten die Primitivstreifen schon längst aufeinander stossen müssen und die Medullarrinnen hätten sich nicht anlegen können. Die Längenzunahme der Area muss aber nach vollständiger Ausbildung der beiden Streifen noch eine Zeit lang angedauert haben, denn sonst würden die Kopffortsätze aufeinander getroffen sein und das Auftreten der Kopffalte wäre unmöglich geworden. In Folge der starken Längenausdehnung der Area pellucida erhielt dieselbe die eigenthümliche Kreuzesform, welche wir bei allen in die dritte Gruppe gehörigen Fällen mehr oder minder ausgesprochen vorfinden.

Dass die Verwachsung der Kopfenden beider Embryonen unmittelbar bevorstand, kann kaum in Abrede gestellt werden. Es würde zu einer Vereinigung der vorderen Hirnbläschen gekommen sein, und damit schliesslich zu einer kraniopagen Doppelmissbildung.

Der Fall 9, welchen v. Baer beschrieb (Fig. 7, Taf. IV), befindet sich in einer etwas späteren Entwicklungsphase; es ist jedoch nicht zu bezweifeln, dass diese Doppelbildung in einem früheren Bilduugsstadium ganz das gleiche Aussehen dargeboten habe, wie der Reichert'sche Doppelembryo. Was bei dem letzteren zu erwarten stand, ist hier bereits seit einiger Zeit eingetreten; die Kopfenden beider Embryonen sind in Folge ihrer directen Oppositionsstellung an den Berührungsflächen verwachsen, und bei dem weiteren Wachsthum musste sich der vereinigte Kopf nach einer Seite hin überbiegen; jedoch kann dies der Zeichnung nach erst vor Kurzem geschehen sein, da die Abweichung von der Linie der Längenaxen beider Embryonen noch keine sehr grosse ist. Die kreuzförmige Gestalt der Area pellucida dieser Doppelbildung ist eine sehr gleichmässige.

Auch bei der durch Dönitz bekannt gewordenen Zwillingsmissbildung (Fall 10, Fig. 8, Taf. IV) ist es zu einer Verschmelzung der sich direct gegenüberstehenden Kopfenden der zwei Embryonen gekommen; die vorderen Hirnbläschen wurden dadurch mit einander in Verbindung gebracht; ob mit oder ohne nachherige Communication ihrer Hohlräume, liess sich nicht feststellen. Während aber in dem vorhergehenden Fall die wachsenden Hirntheile beider Zwillinge seitwärts aus der Linie der Längsaxen ausbogen, fand bei dem Dönitz'schen Falle diese Ausbiegung hauptsächlich ventralwärts statt und zwar in der Gegend der mittleren und hinteren Hirnbläschen. Dass durch ein derartiges Verhalten eine weit grössere Verunstaltung des Kopfes veranlasst werden muss, wie im vorigen Fall, liegt auf der Hand.

$\mathrm{Zu}$ welchen Veränderungen eine Verwachsung der beiden vorderen Hirnbläschen späterhin führen kann, zeigt die sehr beachtenswerthe von Dar este mitgetheilte Doppelbildung (Fall 19 Fig. 7, Taf. V). Die beiden Componenten derselben, welche sich in einem früheren Stadium ähnlich wie die verwachsenen Zwillinge des Reichert'schen Falles verhalten haben mussten, haben sich nach der Vereinigung ihrer Vorderhirne in den übrigen Körperabschnitten mit Ausnahme der Kopftheile normal weiter entwickelt; es ist bei ihnen schon . ein Schwanzhöcker, sowie die Anlage der vier Extremitäten zur Ausbildung gelangt. Es ist nun von Interesse, zu untersuchen, wie sich die verwachsenen Köpfe bei der Drehung der Kopfenden um ihre Längsaxen, ein Stadium, welches die beiden Embryonen bereits hinter sich hatten, verhielten. Da die 
Herzschlinge auf der rechten Seite eines jeden der beiden Embryonen liegt, so ist daraus zu ersehen, dass die hinteren Kopftheile normaliter mit ihrer linken Seite auf dem Dotter aufruhen.' Die vorderen Hirnbläschen sind jedoch beide in Folge ihrer Verwachsung nach der gleichen Seite hin von der Linie der Embryonalaxen abgewichen. Es musste daher bei dem einen Embryo das Vorderhirn nahe an die Herzschlinge desselben zu liegen kommen, während es bei dem anderen Embryo sich von dem ihm zugehörigen Herzen entfernt hat. Bei dem letzteren ist also eine grössere Abweichung von der Norm zu constatiren, als bei dem ersteren, der wahrscheinlich der stärkere war und desshalb den Auschlag gab, als in Folge des embryonalen Längenwachsthums ein Ausbiegen aus der Linie der Embryonalaxen eintreten musste. Da nun nach den Angaben Dareste's die Augen nur unvollkommen entwickelt waren, wie denn überhaupt die Abbildung dieses Falles eine nur sehr geringe Seitenausdehnung der vorderen Hirntheile erkennen lässt, so ist daraus zu folgern, dass der Cephalopagus, welcher aus der vorliegenden Doppelbildung entstanden wäre, monströse Defecte an den beiden verwachsenen Köpfen aufgewiesen haben würde.

Die letzte Zwillingsbildung, mit der unsere Gruppe abschliesst, ist der von Allen Thomson beschriebene Fall 25 (Fig. 5, Taf. VI). Am meisten müssen bei diesem Doppelembryo zwei Erscheinungen auffallen; erstens das Fehlen einer Verwachsung zwischen den beiden Köpfen und zweitens das gemeinschaftliche Herz. Es ist mir dieser Fall hinsichtlich seiner Genese von sämmtlich bisher besprochenen bei Weitem am unklarsten geblieben, und ich sehe nur eine Möglichkeit, wie man sich die genannten beiden Erscheinungen allenfalls erklären könnte. Es wäre denkbar, dass die Kopfenden der beiden Embryonalanlagen zwar in Oppositionsstellung zu einander standen, dass sie sich jedoch nicht ganz direct entgegenkamen, sondern dicht an einander vorbeigewachsen sind; so konnte es geschehen, dass in der Zeit, in welcher die Anlage der beiden Herzen erfolgte, deren Bildungsstätten dicht neben einander gelegen waren, was zur Entstehung eines verbreiterten gemeinsamen Herzens führte. Falls die eben ausgesprochene Vermuthung dem wirklichen Sachverhalt entsprechen würde, könnte man streng genommen die Allen Tho m s on'sche Doppelbildung nicht der dritten Gruppe zuzählen, da die beiden Embryonalanlagen nicht genau in eine Linie fielen. Immerhin würde sie aber dieser Gruppe am nächsten stehen. Voraussichtlich würde sich aus der Allen Thomson'schen Doppelbildung ein Thoracopagus entwickelt haben; in den vier anderen Fällen ist die Prognose auf eine cephalopage Doppelmissbildung zu stellen. Dass die Verunstaltungen, welche aus einer Verwachsung der vorderen Hirnbläschen entstehen, mehr oder minder tief greifende sein können, lehrt ein Vergleich zwischen Fall 10 und Fall 19. Auf der anderen Seite wäre es nicht unmöglich, dass ausnahmsweise die Verwachsung der vorderen Hirntheile sich erst relativ spät einstellen kann, in welchem Falle die Vereinigung der beiden Embryonen eine mehr oberflächliche bleiben würde. Vielleicht ist in dieser Weise eine bereits dem Ende der Bebrütung nahe Doppelmissbildung einer Ente entstanden, welche Dareste beobachtete und fuir einen Métopage erklärte. Ich habe diesen Fall in Fig. 11, 'Taf. VI wiedergegeben. Allem Anscheine nach sind hier die beiden in Oppositionsstellung befindlichen Embryonen, indem der zwischen 
ihren Kopfenden liegende Keimbautbezirk sich sehr stark ausdehnte, erst mit einander verwachsen, nachdem die Hemisphärenbläschen sich ausgebildet hatten. Aus diesem Grunde haben die beiden Köpfe keine merkliche Verkümmerung erlitten.

Im Gegensatz zu den Doppelbildungen der zweiten Gruppe liegen für die Fälle 9 und 10 unserer Gruppe bestimmte Angaben über das Lageverhältniss der Embryonalaxen zu den Durchmessern des Eies vor. In beiden Fällen lagen die Embryonen in der Queraxe des Eies. Daraus geht hervor, dass einer derselben als Stammembryo anzusprechen ist. Da in dem v. Baerschen Fall die beiden Zwillinge gleich weit entwickelt sind, wird nicht zu entscheiden sein, welcher von ihnen den Stammembryo darstellt. Dagegen wird der stärkere Component der Dönitz'schen Doppelbildung aus den oben erörterten Gründen wohl als Stammembryo aufzufassen sein.

Eine gegentheilige Angabe, wonach die beiden Embryonen in der Längsaxe des Eies gelegen haben sollten, hat Allen Thomson für seinen Fall gemacht. Wie schon bemerkt, gehört jedoch derselbe nicht eigentlich in die dritte Gruppe; andererseits aber stimmt, worauf auch Ahlfeld aufmerksam machte, mit dieser Angabe nicht ganz die Abbildung Allen Thomson's überein, indem dieser zu Folge die Linie der Embryonalaxen den langen Durchmesser des Eies unter einem spitzen Winkel schneidet.

Die Uebereinstimmung in der Lage der Embryonen, welche die Fälle 9 und 10 aufweisen, dürfte kaum eine zufällige sein; ich neige mich der Ansicht zu, dass die gleiche Anordnung zu den Eiaxen auch in den Fällen 5 und 19 bestanden habe.

Es scheint mir zweckmässig, nach der Erörterung der drei Gruppen, deren Doppelbildungen sich auf zwei in die Area pellucida vorgedrungene Primitivstreifen zurückführen lassen, die wichtigsten Ergebnisse zusammenzufassen, zu denen wir bei der Prüfung und Vergleichung der einzelnen Fälle gelangten.

Was zunächst die einzelnen Formen der Doppelmonstra anbetrifft, welche sich aus den angeführten Fällen entwickelt haben würden, so ist für sämmtliche eine künftige Duplicitas anterior, welche für sich allein, ohne mit einer Duplicitas posterior complicirt zu sein, bestehen würde, auszuschliessen. Alle anderen Formen der Axenverdoppelungen lassen sich jedoch für die einzelnen Fälle theils mit Sicherheit, theils mit grosser Wahrscheinlichkeit im Voraus bestimmen.

Hinsichtlich der Art der Verbindung zweier in einem Fruchthofe sich entwickelnder Zwillinge hat es sich herausgestellt, dass zwischen einer primären und secundären Vereinigung unterschieden werden müsse. Die erstere führt zu einer Doppelmissbildung, welche innerhalb einer längeren oder kürzeren Strecke eine einfache Wirbelsäule besitzt, während die letztere diejenigen Formen der Zwillingsmonstra bedingt, welche zwei durchaus getrennte Wirbelsäulen zeigen. Die Köpfe der durch secundäré Verwachsung zu Stande kommenden Missgeburten können entweder durchaus getrennt oder äusserlich einfach sein. 
Nur bei der ersten Gruppe war eine primäre Vereinigung nachweisbar, welche je nach der Stellung der Chordae zu einander entweder einen einfachen vorderen Abschnitt der Wirbelsäule (natürlich dann auch einen einfachen Kopf) der resultirenden Missbildung zur Folge hatte, oder es lag der einfache Theil der Wirbelsäule mehr in der mittleren Körpergegend, der Beckenregion genähert; es handelte sich mit anderen Worten um ein Monstrum a posteriore et anteriore parte duplex.

Die secundäre Vereinigung äusserte sich in Bezug auf die Form der resultirenden Missbildung bei den der ersten Gruppe zugehörigen Fällen in der Weise, dass ein Zusammenhang der beiden Embryonen mit den mittleren Körpergegenden oder mit den Köpfen oder mit beiden zugleich erfolgte. Die Fälle der zweiten Gruppe liessen ebenfalls Entwicklungsstadien der höheren Grade der Duplicitas posterior erkennen, während uns die der dritten Gruppe den höchsten Grad der Duplicitas posterior, den Cephalopagus, in verschiedenen Stufen der Ausbildung vorführten.

In Betreff des Lageverhältnisses der beiden Embryonen einer Zwillingsbildung zu den Axen des Eies ergaben sich einige nach meinem Ermessen nicht unwichtige Resultate. Bei den Fällen der zweiten und dritten Gruppe deuten fast ausnahmslos die diesbezüglichen Angaben, wenn sie auch nur spärliche sind, darauf hin, dass einer der beiden Zwillinge die Lage in der Keimhaut und im Ei angenommen hat, welche bei der normalen Entwicklung eines Einzelembryo dieser inne hat. Wir nannten diese Lage Normalstellung und bezeichneten den einen der beiden Zwillinge, der dieselbe einnimmt, als Stammembryo, den anderen als accessorischen Embryo. Dieser Untersehied zwischen den beiden Componenten einer Zwillingsbildung lässt sich begreiflicher Weise nur bei den Fällen der zweiten und dritten Gruppe durchführen; bei den Doppelbildungen der ersten Gruppe, deren Componenten neben einander liegen, ist keiner von beiden der Stammembryo. Vermuthlich liegt die Stelle der Keimhaut, die dem létzteren zukommen würde, in der Mitte zwischen den neben einander gelagerten Embryonen.

Da nun die beiden Componenten der zur ersten Gruppe gehörenden Zwillingsbildungen meistens ziemlich nahe aneinandergelegen sind, so befinden sich beide, wenn die eben geäusserte Vermuthung das Richtige trifft, in der gleichen unmittelbaren Nähe von der Normalstellung. Es ist eine auffallende Erscheinung, dass bei sämmtlichen Fïllen der ersten Gruppe die beiden Zwillinge in der Entwicklung gleichen Schritt gehalten haben. Dieselbe stimmt sehr gut zu der obigen Hypothese; denn, wenn die Normalstellung des Embryo die für dessen Ausbildung günstigste Lage darstellt, so müssen zwei Embryonen, die in der gleichen Entfernung seitwärts von der Normalstellung liegen, auch unter ganz den gleichen Entwicklungsbedingungen sich befinden. Völlig anders liegt die Sache bei den Doppelbildungen der zweiten und dritten Gruppe, bei denen wir einen accessorischen und einen Stanmembryo unterscheiden können. Hier ist jedenfalls der Stammembryo dem anderen gegenüber im Vortheil, was sich besonders dann documentiren muss, wenn die beiden Embryonen in Collision mit einander gerathen. Wir konnten daher bei diesen Gruppen mehrmals eine ungleiche Ausbildung der beiden Embryonen beobachten. 
Es erübrigt mir noch, die Häufigkeit dieser oder jener Anordnung der beiden Embryonen im Fruchthofe zu erörtern. Die meisten Repräsentanten zählt die zweite Gruppe, woraus ersichtlich ist, dass die stumpfwinklige Stellung der Embryonalaxen unter den bekannt gewordenen Doppelbildungen prävalirt. Die Grösse des stumpfen Winkels schwankt zwischen $90^{\circ}$ und $130^{\circ}$. Man kann sich wohl am besten diese Anordnung vergegenwärtigen, wenn man sich eine Doppelbildung dieser Art etwa am Ende des ersten Brütetages vorstellt, bei welcher der eine Component die Normalstellung inne hat; ist nun am hintern Ende des Primitivstreifens des Stammembryo ein. Zuwachsstück zu der Area pellucida getreten und diese dadurch birnförmig geworden, so wird der Primitivstreifen des anderen Embryo von einer der oberen abgerundeten Ecken aus, entweder von rechts oder von links, in die birnförmige Area pellucida hinein sich erstrecken. Ist derselbe von links eingestrahlt, so liegt eine Doppelbildung vor, wie sie Fig. 1, Taf. III darstellt; aus dieser Zeichnung lässt sich leicht das Bild eines gleich frühen Stadiums einer Doppelbildung construiren, bei welcher der accessorische Primitivstreifen von rechts aus in den durchsichtigen Fruchthof eindringt. An den beiden abgerundeten oberen Ecken der birnförmigen Area pellucida wird sich daher entweder rechts oder links das zweite Zuwachsstück ansetzen, wodurch die birnförmige Form mehr in den Hintergrund treten muss. Dass die besagten Stellen ganz besonders bevorzugt sind, $d$. $h$. dass von ihnen aus am häufigsten die Primitivstreifen der accessorischen Embryonen in den durchsichtigen Fruchthof eindringen, erhellt in ganz besonders anschaulicher Weise durch die einzige bekannt gewordene Drillingsbildung, deren Componenten in einer gemeinsamen Area pellucida eingeschlossen sind (Fig. 2, Taf. VI). Dieselbe ist von Dareste beobachtet worden, und besteht aus drei normal gebildeten, wie es scheint, nicht verwachsenen Embryonen. Der durchsichtige Fruchthof dieser Keimhaut lässt noch deutlich die frühere Birnform erkennen. Derselbe dürfte in einem Entwicklungsstadium, in welchem die drei Primitivstreifen nahezu ausgebildet waren, ein Bild dargeboten haben, wie man es erhält, wenn man sich in den durchsichtigen Fruchthof der Fig. 1, Taf. III noch einen dritten von rechts hervorgedrungenen Primitivstreifen eingezeichnet denken würde. Dieses Bild würde viel Aehnlichkeit mit der schematischen Figur darbieten, welche Rauber zur Illustration seiner Radiationstheorie in mehreren seiner Abhandlungen abgebildet hat ${ }^{1}$ ). Von den drei Componenten des Dareste'schen Tripelembryo halte ich diejenigen beiden Embryonen für die accessorischen, welche so ziemlich in einer Linie verlaufen; auf der letzteren steht die Längsaxe des Stammembryo senkrecht. Wegen der vorhandenen zwei accessorischen Embryonen sind die ursprünglichen oberen abgerundeten Ecken der Area pellucida, nachdem sich an dieselben je ein Zuwachsstück angesetzt hatte, durch die darauf folgende quere Ausdehnung des durchsichtigen Fruchthofes ziemlich weit von einander entfernt worden.

Nächst der stumpfwinkligen Stellung der Embryonalanlagen scheint die häufigste Anordnung diejenige zu sein, bei welcher-die beiden Zwillinge mit

1) Ich habe dieselbe in Fig. 6, Taf. VII wiedergegeben. 
ihren Längsaxen neben einander - sei es parallel, sei es unter schwacher Convergenz, sei es unter leichter Divergenz - verlaufen; es sind dies demnach die Vertreter der ersten Gruppe.

Bei Weitem in der Minderzahl befinden sich endlich die der dritten Gruppe angehörenden Fälle, indem bei den Doppelbildungen die Oppositionsstellung der Embryonalanlagen offenbar ein relativ seltenes Vorkommniss darstellt.

Ehe ich zur vierten Gruppe übergehe, möchte ich noch zuvor das Verhalten des Amnions bei den bisher beobachteten Mehrfachbildungen zum Gegenstand einer kurzen Betrachtung machen. Stellt man die Abbildungen der einzelnen Fälle neben einander, so gelangt man bei deren Besichtigung zu den folgenden zwei Resultaten:

1) Bei Mehrfachbildungen findet die Anlage und Ausbildung des Amnions in einer spätern Entwicklungszeit statt, als wie bei einem Einzelembryo.

2) Für die Componenten einer monoarealen ${ }^{1}$ ) Mehrfachbildung entwickelt sich in allen Fällen ein gemeinsames Amnion.

Was das späte Auftreten des Amnion betrifft, so lässt sich dies mit am besten an der Allen Thomson'schen Doppelbildung (Fall 25, Fig. 5, Taf. VI) veranschaulichen. Das betreffende Ei wurde bereits fünf Tage bebrütet und noch hat die Kopfscheide des Amnions nicht einmal ganz die beiden Köpfe überdeckt; eine hintere Amnionscheide ist überhaupt noch nicht sichtbar. Auch in dem von mir beschriebenen Falle 18 (Taf. II) muss der Mangel einer Amnionanlage auffallen; es scheint zweifelhaft, ob es überhaupt noch zur Bildung eines solchen gekommen wäre.

Das für alle Componenten einer Mehrfachbildung gemeinschaftliche Amnion legt sich nach dem Grundsatze an, dass die benachbarten oder miteinander verwachsenen Embryonalenden, falls sie nicht in der Mitte des Fruchthofes liegen, nur eine einzige Amnionfalte erhalten, während die von einander entfernten Embryonalenden von je einer besonderen Amnionscheide überdeckt werden. So sehen wir z. B. bei dem eben citirten Allen Thomson'schen Falle eine gemeinsame Kopfscheide der beiden Köpfe; das Gleiche beobachten wir in dem Dareste'schen Falle 21, Fig. 1, Taf. VI, wo ebenfalls die beiden mit einander vereinigten Köpfe nur von einer Kopfscheide überwachsen werden, während hinter den von einander abstehenden Schwanzenden sich je eine Amnionfalte zu erheben beginnt. Selr instructiv ist das Verhalten der Amnionfalten bei dem Dareste'schen 'Tripelembryo (Fig. 2, 'Taf. VI). Hier liegen die einander genäherten Köpfe mehr in der Mitte des Fruchthofes, erhalten demnach vorerst keine Amnionumhüllung; dagegen sehen wir hinter jedem der drei Schwanzenden Amnionfalten auftreten, die sich bei ihrer weitern Entwicklung vereinigt haben würden, sodass die drei Embryonen späterhin von einem einzigen grossen Amnionsack umschlossen worden wären. Eine bereits fortgeschrittenere Amnionbildung zeigen die Fälle 19 und 24 (Fig. 7, 'Taf. V und Fig. 4, 'I'af. VI). Die einzelnen Amnionfalten sind zu einer einzigen Ringfalte confluirt, die eine Oeffnung umrandet, welche in die

1) Die Entwicklıng zweier Embryonen in einer gemeinsamen Area pellucida ist als eine monoareale zu bezeichnom. 
Amnionhöhle führt. Diese Oeffinung wird um so kleiner werden, je weiter sich das Amnion entwickelt und wird sich endlich an einer Stelle, dem Amnionnabel, vollständig schliessen müssen.

\section{IV.}

Doppelbildungen, welche auf Embryonalanlagen zurückzuführen sind, die einen gemeinschaftlichen, einheitlichen hinteren Abschnitt besitzen, während sie nach vorne in zwei gesonderte Embryonaltheile aus einander gehen.

Zu dieser Gruppe habe ich die noch restirenden vier Fälle zusammengefasst:
4) Dareste Fig. 3, Taf. IV.
8) Gerlach Fig. 2, Taf. III.
11) Dareste Fig. 9, Taf. IV.
12) Dareste Fig. 1, Taf. V.

In der Ueberschrift ist bereits der gemeinsame Character dieser Fälle präcisirt worden, woraus hervorgeht, dass dieselben Entwickiungsstadien von der gleichen Form der Doppelmissbildung darstellen, nämlich der Duplicitas anterior.

Während es mit Hülfe der früher besprochenen Fälle möglich war, die erste Anlage und Entstehungsweise für die anderen Formen der Doppelmissbildungen wenigstens in den wesentlichsten Puncten festzustellen, so befinden wir uns der Duplicitas anterior gegenüber in einer weniger günstigen Lage. Einmal stehen uns nur die wenigen Fälle zu Gebote, und zweitens ist gerade der Fall 4 der seiner frühen Entwicklungsstufe halber geeignet wäre, die erste Anlage der in Rede stehenden Monstrositäten aufzuklären, nur mit grosser Vorsicht zu verwerthen. Es bleibt daher nichts übrig, als die Möglichkeiten, welche für das Zustandekommen der Duplicitas anterior angeführt werden können, an der Hand der einzelnen Fälle auf ihre Wahrscheinlichkeit hin zu prüfen, um vielleicht so per exclusionem dem richtigen Bildungsmodus auf die Spur zu kommen. Ich werde dabei nicht umhin können, die beiden hypothetischen Vorgänge, welche von Seiten der Teratologen für die genetische Erklärung der Doppelmissbildungen in den Vordergrund gestellt zu werden pflegen, nämlich die Spaltung und Verwachsung, zur Sprache zu bringen. Bei den anderen Gruppen konnten wir von denselben, uns an das thatsïchliche Material haltend, gänzlich absehen. Allerdings muss es nach unseren dort gemachten Erfahrungen, denen zu Folge für die Entstehungsweise der übrigen Doppelmissbildungen, sowohl eine Spaltung als eine Verwachsung worunter im üblichen Sinne eine Verschmelzung früher doppelt vorhandener Embryonaltheile zu einem einheitlichen verstanden wird - auszuschliessen waren, von vorne herein schon als höchst problematisch erscheinen, dass derartige Vorgänge allein bei der Genese einer Duplicitas anterior obwalten sollten. Allein es wäre meiner Ansicht nach unerlaubt, bloss auf diese Analogie hin bei unserer Gruppe, deren Doppelbildungen uns eben nicht die zur Erkenntniss der Bildungsgeschichte vorderer Verdoppelungen wünschenswerthen positiven Anhaltspuncte an die Hand geben, die Spaltung und Ver- 
wachsung als völlig unmöglich zu erachten und desshalb über sie mit Stillschweigen hinwegzugehen.

Ueberblickt man nun die vorliegenden vier Doppelbildungen unserer Gruppe, so überzengt man sich, dass eine Duplicitas anterior bereits in sehr früher Entwicklungszeit sich anlegen muss; denn so viel lässt der Fall 4 (Fig. 3, Taf. IV) mit Sicherheit erkennen, dass es sich dabei um zwei Medullarfurchen handelt, welche nach hinten convergirend in einen unpaaren Theil der Embryonalanlage auslaufen. Dass die Rinne in dem unpaaren hinteren Theil entweder die ganze oder nur einen Abschnitt der Primitivrinne darstellt, darüber kann für denjenigen, der mit der Entwicklungsgeschichte des Hühnchens auch nur einigermassen vertraut ist, kein Zweifel existiren. Es steht daher fest, dass in der Y-förmigen Embryonalanlage der hintere unpaare Schenkel ganz oder theilweise dem Primitivstreifen zukommt, während die vorderen paarigen Schenkel von zwei spitzwinklig zu einander gestellten Medullarfurchen gebildet werden, deren jede mit einer Kopffalte vorne endet. Wo eine Rückenfurche existirt, da muss unter deren Boden auch eine Chorda dorsalis verlaufen. Daraus folgt wiederum unbestreitbar, dass in dem besagten Falle, da zwei Chordae vorhanden sind, auch zwei Kopffortsätze sich entwickelt haben mussten, denn es geht ja, wie wir aus der Entwicklungsgeschichte wissen, die Chorda unmittelbar aus jener Verdickung des Entoderms hervor, welche wir im Flächenbilde Kopffortsatz nennen. Leider lässt die Abbildung Dareste's nicht das Mindeste über das Verhalten der Chordae erkennen. Es muss daher unentschieden bleiben, ob unmittelbar vor dem vorderen Ende des Primitivstreifens schon zwei Kopffortsätze existirten, oder ob innerhalb einer kurzen Strecke ein einheitlicher Kopffortsatz vorlag, der etwas weiter vorne erst in zwei Schenkel aus einander lief.

Indem wir vorerst von der eben genannten Alternative gänzlich absehen, wollen wir untersuchen, auf welche Weise der Dareste'sche Fall entstanden sein kann. Es lässt sich dessen Bildung auf dreierlei Art erklären. Erstens nach der Verwachsungstheorie. Dieser zu Folge müsste man zwei ursprünglich vollkommen getrennte Embryonalanlagen annehmen, welche mit ihren Primitivstreifen sich vereinigt hätten. Man würde demnach an eine Verschmelzung zweier neben einander befindlicher Primitivstreifen zu einem einzigen denken müssen. Nachdem bereits bei der ersten Gruppe eingehend erörtert worden ist, dass zwei neben einander in die Area pellucida einstrahlende Primitivstreifen niemals sich gegenseitig bis zur allseitigen Berührung nahe kommen können, sondern vielmehr durch die Wachsthumsenergie des zwischen ihnen liegenden Mesodermbezirkes immer weiter aus einander gedrängt werden, so glaube ich davon Umgang nehmen zu können, nochmals diese Vorgänge zu schildern. Jedenfalls sind die an dem genannten Orte besprochenen Doppelbildungen von Ahlfeld (Fig. 6, Taf. IV) und von Rauber (Fig. 10, 'laf. VI) auch hier zu erwähnen, da sie beweisen, dass an ein Zusammenwachsen zweier Primitivstreifen zu einem einzigen nicht gedacht werden kann.

Zweitens könnte man auf die Dareste'sche Doppelbildung hinsichtlich ihrer Entstehung auch die Spaltungstheorie anwenden. Man müsste dann im Gegensatz zur. Verwachsung cine urspriunglich einheitliche Embryonalanlage 
annehmen, deren vorderer Theil sich nach kurzer Zeit des Bestehens secundär in zwei Hälften zertheilt habe. Verlegt man nun die Spaltung in eine Zeit, in welcher bereits eine ausgesprochene Medullarfurche, sowie eine Kopffalte existiren, so ist man gezwungen, weiter zu schliessen, dass nach erfolgter Spaltung jede der beiden Hälften sich alsbald eine zweite Hälfte zulege, damit die in der Bildung begriffene Duplicitas anterior zwei vollständige vordere Embryonaltheile aufweisen kann. Diese Ueberlegung reicht meines Erachtens hin, eine so späte Theilung der vorderen Embryonalanlage von der Hand zu weisen. Will man überhaupt eine Spaltung aufrecht erhalten, so muss man dieselbe in eine Zeit verlegen, in welcher zwar schon der Kopffortsatz des Primitivstreifens, aber noch nicht eine Medullarfurche aufgetreten ist; man müsste dann den ersteren durch Spaltung in zwei gleiche Bildungen zerfallen lassen, werche mit ihren vorderen Enden sich immer mehr von einander in der Keimhaut entfernen würden.

Die dritte Annahme endlich, nach der die Bildung einer embryonalen Duplicitas anterior, wie sie in dem $D$ areste'schen Falle gegeben ist, erklärt werden kann, hat jedenfalls den Vortheil vor der Spaltungstheorie voraus, dass sie viel einfacher und ungezwungener ist als diese. Wozu braucht überhaupt erst eine totale, einfache Embryonalanlage sich zu entwickeln, wenn ein Theil derselben sich später durch Spaltung verdoppeln soll? Da wir ja wissen, dass die Embryonalanlage von rückwärts nach vorne zu sich ausbildet, so lässt sich leicht vorstellen, dass die Entwicklung nach vorne bis zu einem gewissen Puncte und Zeitabschnitt regelrecht und in gerader Linie fortschreite, von da an aber ein Auseinanderweichen in zwei Schenkel eintrete, so dass die.bis zu dem betreffenden Zeitabschnitt noch nicht entwickelten Theile der Fruchtanlage gleich von vorneherein doppelt sich anlegen. Je nachdem das Auseinanderweichen in eine frühere oder spätere ontogenetische Zeit fällt, wird ein höherer oder geringerer Grad von vorderer Verdoppelung resultiren müssen. Diese Annahme des gabligen Auseinanderweichens der sich entwickelnden Embryonalanlage zur Erklärung der Genese einer Duplicitas anterior möchte ich der Spaltung und Verwachsung als "Bifurcation" gegenüberstellen.

Legt man eine Bifurcation zu Grunde, so würde die Dareste'sche Doppelbildung in der Weise entstanden sein, dass entweder statt eines Kopffortsatzes zwei vor dem Kopfende des Primitivstreifens sich entwickelt haben, oder dass der Kopffortsatz zuerst der Norm entsprechend eine kurze Strecke weit direct nach vorne gewachsen, dann aber in zwei unter spitzem Winkel divergirende Schenkel zerfallen sei. Es unterscheidet sich demnach für unsèren Fall die Bifurcation von der Spaltungstheorie hauptsächlich darin, dass sie im Gegensatz zu der letzteren die vollständige Ausbildung eines Kopffortsatzes, der sodann in zwei sich zertheilen solle, in Abrede stellt. Sie befürwortet vielmehr entweder eine sofortige Anlage von zwei Kopffortsätzen, oder ein mehr oder minder frühzeitiges Divergiren eines einzigen in zwei Schenkel.

Bekanntlich supponiren die Anhänger der Spaltungstheorie Kräfte, die sie meist nur in unbestimmter Weise definiren, von denen sie aber glauben, dass sie eine einheitliche Embryonalanlage ganz oder theilweise in zwei 
zu zerspalten im Stande sind. Gibt man nun das Dasein solcher Kräfte zu, so ist nicht einzusehen, wesshalb diese - ich will hier speciell den Darest'schen Fall in das Auge fassen - ihr Eingreifen hinausschieben sollten, bis der Kopffortsatz fertig gebildet ist. Diese Kräfte, falls sie wirklich existiren, werden sich zweifellos auch schon früher äussern, und werden den Kopffortsatz überhaupt nicht zur vollen Ausbildung gelangen lassen, sondern schon vorher die Entwicklung desselben in andere von der Norm abweichende Bahnen lenken.

Wie man siebt, müssen die soeben angestellten Betrachtungen, wenn man unter den drei Möglichkeiten, nach denen man sich die Genese einer Duplicitas anterior zurecht legen kann, nämlich der Verwachsung, der Spaltung und der Bifurcation, zu wählen hat, für die letztere entscheidend in die Wagschale fallen.

Nachdem wir uns somit für eine Bifurcation erklärt haben, wird unsere nächste Aufgabe darin bestehen müssen, die vier Fälle von embryonaler vorderer Verdoppelung, welche die vierte Gruppe bilden, vom Standpuncte des genannten Princips aus zu beleuchten. Dass die vier Doppelbildungen nicht alle zu dem gleichen Grade der Duplicitas anterior geführt haben würden, lehrt ein Vergleich der einzelnen Abbildungen, die wir von ihnen besitzen. Am Meisten wird der Unterschied zwischen dem Falle 11 und 12 (Fig. 9, Taf. IV und Fig. 1, Taf. V) auffallen müssen, indem der erstere eine in der Ausbildung begriffene vordere Duplicität geringeren Grades erkennen lässt, während in der Doppelbildung Fall 12 eine dritte mittlere Reihe von Urwirbeln aufgetreten ist, was auf einen höheren Grad der vorderen Verdoppelung hindeutet.

Da, wie schon oben angegeben, die Duplicitas anterior sich auf einen um so ausgedehnteren Körperabschnitt erstrecken muss, je früher die Bifurcation der Embryonalanlage eingetreten ist, so würde, wenn dieselbe bereits am Anfange der Einstrahlung des Primitivstreifens in das Embryonalschild der Area pellucida sich einstellen sollte, dies zur Entwicklung des höchsten Grades der besagten Doppelmissbildung führen müssen. Ich unterlasse es, die Frage, ob eine Bifurcation des Primitivstreifens überhaupt stattfindet, an diesem Orte eingehender zu discutiren, weil dazu die vorliegenden vier Fälle keine Anhaltspuncte geben. Es genüge, hier auf die Möglichkeit eines solchen Vorkommens hingewiesen zu haben; dass dasselbe in der That stattfinden kann, werde ich in einem späteren Capitel darzuthun suchen.

Die Bifurcation der in dem durchsichtigen Fruchthof nach vorne zu sich vervollkommnenden Embryonalanlage kann ferner nach Vollendung des Primitivstreifens dadurch zu 'Tage treten, dass vor dessen vorderem Ende zwei Kopffortsätze sich ausbilden, welche unter einem mehr oder weniger spitzen Winkel nach vorwärts divergiren. Die Zeit der ersten Anlage des Kopffortsatzes, wenn der Primitivstreifen seine völlige Entwicklung erreicht hat, scheint mir der günstigste Moment für die Bifurcation zu sein, da von diesem Zeitpunkte an das Entoderm, indem es den Kopffortsatz erzeugt, sich direct an der Bildung der Embryonalanlage betheiligt, welche bis dahin mehr dem Ektoderm zufiel, das ja mit der Bildung des Primitivstreifens die Embryogenese einleitete. 
Die letzte Entwicklungsphase endlich, innerhalb welcher eine Bifurcation noch stattfinden kann, fällt in die Zeit, während welcher der bereits angelegte Kopffortsatz nach vorne wächst, bis zu dem Auftreten der Kopffalte, womit die Medullarrinne vorne abschliesst. Es handelt sich also hier um ein Divergiren des Kopffortsatzes selbst, was zur Folge haben muss, dass an der gleichen Stelle die sich bildende Medullarfurche ebenfalls dichotomisch aus einander weicht. Je später nun eine Bifurcation des Kopffortsatzes erfolgt ist, desto länger wird der einheitliche Abschnitt desselben und desshalb auch die einfache Strecke der Medullarfurche werden müssen. Damit geht natürlich eine um so geringere Verdoppelung der vorderen Fruchtanlage einher.

Unter den 4 uns zu Gebote stehenden Fällen dieser Gruppe befindet sich, wie schon erwähnt, keiner, welcher sich für eine Bifurcation des Primitivstreifens verwerthen liesse. Bei sämmtlichen kommen nur die beiden anderen Eventualitäten in Frage. Am meisten für eine vollständig doppelte Anlage der beiden Kopffortsätze scheint mir der Dareste'sche Fall 12 zu sprechen, dessen Dorsalansicht Fig. 1, Taf. V wiedergibt. Der hinter den Urwirbeln gelegene, nur kurze einheitliche Endabschnitt dieser Doppelbildung scheint mir nach meinen Erfahrungen in der normalen Entwicklungsgeschichte von Einzelembryonen an der Stelle der Keimhaut zu liegen, welche früher von dem vorderen Theile des Primitivstreifens eingenommen wurde. Auch der Dareste'sche Fall 4 (Fig. 3, Taf. IV), sowie die von mir beschriebene Doppelmissbildung Fall 8 (Fig. 2, Taf. III) lassen sich sehr gut mit der Annahme vereinbaren, wonach unmittelbar vor dem Kopfende des Primitivstreifens die Bifurcation der Embryonalanlage sich eingestellt hat.

Dagegen scheint der Dareste'sche Fall 11 (Fig. 9, Taf. IV); der von allen vier Fällen den geringsten Grad vorderer Duplicität aufweist, auf eine erst sehr spät erfolgte Bifurcation des Kopffortsatzes hinzudeuten. Doch werde ich sogleich darauf zu sprechen kominen, dass die Genese desselben sich auch auf eine andere Weise und zwar ähnlich, wie die der drei übrigen Fälle erklären lässt.

Was den Divergenzwinkel, d. h. den Winkel anlangt, welchen die doppelt sich anlegenden Theile der Embryonalanlage mit einander bilden, so scheint derselbe in den vier Fällen ein verschiedener $\mathrm{zu}$ sein; er ist am grössten in dem Falle 8, etwas kleiner erscheint er in dem Falle 4, dann folgen Fall 12 und 11. Die Grösse des Divergenzwinkels ist für die seitliche Ausdehnung, welche die Verdoppelung gewinnt, von weitgehender Bedeutung. Es sind sonach für den höheren oder geringeren Grad der schliesslich resultirenden Missbildung zwei Momente bestimmend: 1) die Zeit der Bifurcàtion und 2) die Grösse des Divergenzwinkels.

Sehr klein muss der Divergenzwinkel bei der Dareste'schen Doppelbildung Fall 12 gewesen sein. Die beiden-Medullarrinnen kamen desshalb in geringe Entfernung neben einander zu liegen, und der sie trennende Zwischenraum nimmt nur sehr langsam nach vornehin an Breite zu. Bei der Bildung der Kopfdarmhöhle lagen daher die beiden Medullarfurchen so nahe an einander, dass es zuerst nur zur Anlage eines einzigen Vorderdarms kam, von dem aus allerdings bei dem späteren Wachsthum des Embryo nach vorwärts zwei Ausläufer sich entwickelten. Zu denselben führt, wie auf der einen Abbildung 
Dareste's, welche eine Ventralansicht vorstellt, deutlich zu sehen ist, nur eine einzige vordere Darmpforte. Mit der ursprünglich einheitlichen Anlage des Vorderdarms hängt auch der Umstand innig zusammen, dass sich nur e in Herz ausbildete.

Auch bei dem ebenfalls von Dareste mitgetheilten Falle 11 muss der Divergenzwinkel ein sehr kleiner gewesen sein. Da ungefähr erst in der Höhe der vorderen Darmpforte das Medullarrohr in zwei Schenkel sich verzweigt, so ist es begreiflich, dass auch nur ein Vorderdarm und ein Herz zur Ausbildung gelangen konnten. Voraussichtlich würde in diesem Falle die Verdoppelung nur den Kopf und zwar vorwiegend dessen dorsale Theile betroffen haben. Wenn man diese Dareste'sche Doppelbildung mit dem Reichert'schen Falle 13 (Fig. 2, Taf. V) vergleicht, so wird eine gewisse Aehnlichkeit der Kopftheile bei beiden Doppelbildungen nicht zu verkennen sein, wenn auch in dem Reichert'schen Fall sich die Verdoppelung etwas weiter nach hinten erstreckt, als in dem vorliegenden. Da nun bei der Reichert'schen Doppelbildung sich zwei durchaus getrennte Chordae dorsales nachweisen liessen, die schwach nach vorne divergirten und desshalb erst spät ausserhalb des Bereiches der Copulationsnähe kamen, so liegt der Gedanke nahe, dass es sich bei dem in Rede stehenden Falle vielleicht auch um eine doppelte Anlage der beiden Chordae handeln könne. Es müssten aber nach dieser Auffassung die beiden vor dem Kopfende des einheitlichen Primitivstreifens sich entwickelnden Kopffortsätze nur eine sehr schwache Divergenz gezeigt haben, so dass sie die grösste Strecke ihres Verlaufs innerhalb der Copulationsnähe verblieben und erst spät bis zu einem solchen Abstand von einander sich entfernten, der zur Bildung von zwei Medullarfurchen hinreichte. Es würde sich auf diese Weise auch der Umstand erklären lassen, dass in der Dareste'schen Doppelbildung der grösste Abschnitt des Medullarrohres einfach und nur dessen vorderster Theil doppelt vorhanden ist. Somit kann auch für diesen Fall, wie bei den übrigen drei Doppelbildungen dieser Gruppe angenommen werden, dass die Anlage der Duplicitas anterior unmittelbar nach der vollendeten Ausbildung des Primitivstreifens begonnen hat und demnach in eine sehr frühe Entwicklungszeit zurückdatirt.

Grösser wie in den beiden besprochenen Doppelbildungen ist der Divergenzwinkel bei Fall 4, noch grösser bei Fall 8. Wenn man die zwei Abbildungen des Falles 8 und des Falles 12 neben einander hält, so wird man die Beobachtung machen, dass bei dem letzteren die Strecke des zweifach vorhandenen Hirnrückenmarkrohres noch eine grössere ist wie im Falle 8, und trotzdem wird derselbe den Eindruck einer viel geringeren Monstrosität machen, wie die von mir beschriebene Doppelbildung Fall 8. Man kann hier so recht den Einfluss erkennen, welchen dic Grösse des Divergenzwinkels auf den Grad der resultirenden Doppelmissbildung ausüben muss. In dem Falle 12 ist eben darum, weil der Divergenzwinkel nur ein kleiner ist, der Abstand zwischen den beiden Medullarrohren ein nur geringer; es wurde schon darauf hingewiesen, wie aus diesem Grunde sich ein Anfangs einheitlicher Vorderdarm und nur ein Herz ausbilden konnte; auch nur zwei Gehörgrübchen haben sich anlegen können; die beiden mittleren fehlen. Mit absoluter Sicherheit ist zu sagen, dass bei einer Doppelmissbildung, wie die vorliegende, 
auch nur jederseits eine obere und untere Extremität zur Entwicklung kommen wird. An der schliesslich aus einem Bildungsstadium, wie es der Dareste'sche Fall zeigt, resultirenden Missgeburt würde, abgesehen von den zwei seitlich mit einander verwachsenen Köpfen, nur an der verbreiterten Halsgegend die Verdoppelung äusserlich zu erkennen sein.

Im Gegensatz zu der eben erörterten Doppelbildung bestand bei Fall 8 wegen des stärkeren Divergenzwinkels ein grösserer Abstand zwischen den beiden Medullarfurchen. Derselbe wird vielleicht noch etwas bedeutender gewesen sein, wie der, welcher die beiden Medullarrinnen im Fall 4 von einander trennt. In Folge dessen konnten sich getrennte Köpfe und Vorderkörper, ferner je eine Kopfdarmhöhle und je ein Herz entwickeln. Die Ohrgrübchen sind zwar noch nicht sichtbar, jedoch ist nicht daran zu zweifeln, dass sich binnen kurzem im Ganzen 4 würden ausgebildet haben. Auch würden vermuthlich 4 obere Extremitäten aufgetreten sein, sodass die Prognose des vorliegenden Falleś auf einen Dicephalus tetrabrachius zu stellen ist.

Ziehen wir nun das Facit aus dem, was über Fall 8 und 11 gesagt worden ist, so wird sich der Einfluss, welchen die Zeit der Bifurcation und die Grösse des Divergenzwinkels auf den Grad der resultirenden Duplicitas anterior ausübt, etwa folgendermassen präcisiren lassen:

Mit der Grösse des Divergenzwinkels nimmt die Trennung und damit die Selbstständigkeit der doppelt angelegten Abschnitte der Embryonalanlage zu. Die Länge der beiden letzteren hängt von der Zeit des Eintretens der Bifurcation $a b$; je früher dieselbe sich einstellt, desto länger müssen die doppelt auftretenden Embryonalabschnitte werden.

Die Tiefe des Spaltes, welcher die doppelt vorhandenen Theile einer embryonalen Duplicitas anterior trennt, wird um so bedeutender sein müssen, je früher die Bifurcation stattgehabt und je grösser der Divergenzwinkel ist.

Mit dem Wachsthum der Doppelbildung wird dieser Spalt begreiflicher Weise etwas seichter werden müssen, indem die sich vergrössernden Volumina der doppelt vorhandenen Körpertheile die tiefliegendsten Partien des Spaltes allmählig mehr und mehr ausfüllen müssen. 


\section{Experimentelle Untersuchungen.}

Die Thatsache, dass es innerhalb eines einzigen Fruchthofes zur Anlage von zwei Embryonen oder auch nur von doppelt sich bildenden Embryonaltheilen kommen kann, musste wegen ihrer eminenten Bedeutung stets von Neuem dazu auffordern, den dieser Erscheinung zu Grunde liegenden Ursachen nachzuspüren. Ist es ein übermässiger, dem $\mathrm{Ei}$ innewohnender Bildungstrieb, der zu dem Auftreten eines Doppelembryo führt, oder sind es von aussen her auf das Ei einwirkende Umstände, welche die Entwicklung nach der zur Genese einer Mehrfachbildung führenden Bahn hinlenken? - hierüber gehen die Ansichten der einzelnen Forscher auseinander.

Es ist nicht meine Absicht, an dieser Stelle diese verschiedenen Auffassungen eingehender zu erörtern; ich will mich hier darauf beschränken, eine kurze Uebersicht über den gegenwärtigen Stand der genannten Fragen zu geben.

Was diejenigen Theorien anlangt, welche die zu Doppelbildungen veranlassenden Momente auf besondere aussergewöhnliche Eigenthümlichkeiten des Eies zurückführen, so finden sich zwei Richtungen vertreten; nach der von Schultze befürworteten Theorie besitzt das Ei bereits vor der Befruchtung die Eigenschaften, welche nach der Furchung das Zustandekommen von zwei Embryonalanlagen nach sich ziehen sollen. Schultze stellt sich vor, dass das Vorhandensein von zwei Keimblïschen in einem. Ei die Anlage einer Mehrfachbildung zu Folge habe ${ }^{1}$ ).

In neuerer Zeit ist man dagegen mehr geneigt, in einem nicht ganz regulïren Befruchtungsvorgange die Ursache für die Genese eines Doppelembryo zu erblicken. Nach den bahnbrechenden Untersuchungen von $\mathrm{O}$. Hertwig ${ }^{2}$ ) und $\mathrm{Fol}^{3}$ ) scheint in der Norm nur ein einziges Spermatozoon die Befruchtung eines Eies vorzunehmen. Die beiden Forscher kamen zu dem gleichen Resultate, dass der Eintritt mehrerer Spermatozoen in ein Ei eine

$\left.{ }^{1}\right)$ B. Schultze, Ueber anomale Duplicität der Axenorgane. Virchow's Archiv Bd. 7, pag. 479, 1854.

$\left.{ }^{2}\right)$ O. Hertwig, Beiträge zur Kenntniss der Bildung, Befruchtung und Theihung des thierischen Eies. G e g en b a u r's Morpholog. Jahrbuch Bd. I, 1876, pag. 347 und Bd. III, pag. 1 und pag. 271.

3) H. Fol, Sur le commencement de l'hénogenie chez divers animaux. Archives des sciences phys. et anat. de la Bibl. univ. Revue suisse. Genève Tom. LVIII, Avril 1878. 
anormale Furchung und Entwicklung des Eies verursacht. Fol konnte an Eiern von Seesternen, welche von mehreren Samenfäden befruchtet wurden, die Entwicklung von monströsen Larven (z. B. Gastrulae mit doppelter Invagination) beobachten.

Was die zweite Ansicht betrifft, wonach die Anlage von Doppelmissbildungen erst nach der Befruchtung durch äussere Momente, die auf das Ei einwirken, veranlasst werde, so ist begreif licher Weise in dieser Beziehung der Vermuthung und Speculation ein grosser Spielraum gelassen, da man sich ja eine mannigfache Reihe von Ursachen denken kann, welche von aussen her auf die Entwicklung des Eies einen Einfluss ausüben können. Hauptsächlich sind es Einwirkungen von mehr mechanischer Natur, welche, wie man annahm, unter gewissen, allerdings noch völlig unerkannten Umständen die Entwicklung einer Doppelbildung zu Wege bringen sollten. Für derartige Vermuthungen sprachen unter Anderen die Erfahrungen von Valentin, welcher unter einer grossen Anzahl von Hechteiern, die unmittelbar nach ihrer Befruchtung mehrere Meilen in einem Topfe getragen und dadurch einer andauernden Erschütterung ausgesetzt worden waren, auffallend viele Doppelmissbildungen vorfand ${ }^{1}$ ). Neueren Datums sind die Untersuchungen von $\mathrm{Knoch}{ }^{2}$ ), welcher mittheilt, dass es $\mathrm{hmm}$ bei Eiern von Lachsen und Lachsforellen gelungen sei, durch häufigen Wechsel des Wassers und die dadurch hervorgerufene oftmalige Erschütterung frisch befruchteter Eier Doppelbildungen zu erzielen. Bei Eiern, die in ruhigem Wasser sich entwickelten, kamen dagegen nur wenige Doppelbildungen vor.

Bei Vögeln erblickte man gleichfalls in Erschütterungen, welche die Eier während ihrer Bebrütung - so z. B. bei häufiger Lageveränderung der Eier im Brutofen - treffen sollten, mechanische Ursachen, die der Genese von Doppelbildungen günstig wären.

Für die Säuger hat noch vor kurzer Zeit Ahlfeld ${ }^{3}$ ) sich dahin ausgesprochen, dass eine allzu starke Spannung der Zona pellucida über dem Fruchthof auf die Anlage der Frucht eine mechanische Einwirkung ausüben müsse, in Folge deren Doppelbildungen erzeugt werden sollten.

Die vorstehenden Beobachtungen und Vermuthungen lassen zur Genüge erkennen, wie wenig Thatsächliches man über das Wesen der die Embryogenese nach der genannten Richtung hin modificirenden Kräfte eigentlich weiss. So viel steht fest, dass, falls wirklich mechanische Einflüsse, wie die angedeuteten, in Frage kommen, diese in so viele sich je nach den gerade obwaltenden Verhältnissen in ihren Einwirkungen verschieden äussernde und darum unberechenbare Einzelfactoren zerfallen, dass es geradezu unmöglich ist, über ihr Eingreifen in die Embryogenese zu einer wenn auch nur einigermassen klaren Vorstellung zu kommen.

Ich gehe nun über zu den Versuchen, welche in der Intention ausge-

1) Valentin, Ein Beitrag zur Entwicklungsgeschichte der Doppelmissgeburten. Vier ordt's Archiv für physiol. Heilkunde 1851, pag. 1.

$\left.{ }^{2}\right) \mathrm{Knoch}$, Ueber die Missbildungen des Salmonen- und Coregonus-Geschlechtes. Bulletin de la societé imp. des naturalistes de Moscou. T. X̌̃VI, 1872.

3) Ahlfeld, Die Missbildungen des Menschen, I. Abschnitt, Leipzig 1880, pag. 9 und 10. 
führt wurden, durch Veränderungen, die man am Ei selbst vornahm, Mehrfachbildungen künstlich zu erzengen. Man ging hier mit einer ganz bestimmten Voraussetzung an das Experiment heran, um durch den Ausfall des letzteren die erstere zu bewahrheiten, oder als eine irrige darlegen zu können. Valentin stellte sich zuerst die Frage, ob bei dem Vogelei durch eine künstliche partielle Längsspaltung des Embryonalkörpers eine Verdoppelung: zu erzielen sei. Zu diesem Behufe feilte er bei 24-48 Stunden in der Brutmaschine gelegenen Hühnereiern die Kalkschale an, um durch eine Oeffnung sich die Keimhaut zugänglich zu machen. Nach der Operation wurde die Oeffnung wieder verklebt und sodann das $\mathrm{Ei}$ in die Brütmaschine zurïckgebracht. Valentin erhielt jedoch nur in einem einzigen Falle mittelst dieses Verfahrens eine nach seiner Meinung thatsächliche Duplicität des gespaltenen Körpertheiles. In seinem Repertorium ${ }^{1}$ ) äussert er sich über diese Beobachtung in folgender Weise: „Ich hatte einen zweitägigen Embryo in seiner hinteren Körperhälfte der Länge nach gespalten und fand nach fünf Tagen Duplicität des Beckens und der hinteren Extremitäten. Doch waren die doppelten Theile in der Entwicklung weiter zurück, als die einfachen."

Valentin sagt selbst, dass ihm diese eine Erfahrung noch lange kein genügender Beweis für die willkürliche Erzeugung von Doppelmonstra sei, hat aber späterhin keine ähnliche Beobachtung mehr bekannt gegeben.

Le uckart und unter seiner Leitung Schrohe ${ }^{2}$ ) haben die Versuche Valentin's unter verschiedenen Modificationen wiederholt. Nachdem aus der Schale ein kleines Viereck herausgenommen war, wurde die Keimscheibe entweder mit einem feinen Staarmesser gespalten oder dieselbe durch einen Einstich mit einer feinen Nadel verletzt. Nach Aufgiessen einiger Tropfen frischen Eiweisses, um die Bildung eines lufthaltigen Raumes zu vermeiden, wurde die Oeffnung mit einem Stückchen Eischale wieder geschlossen und verklebt.

Bei den Eiern, welche schon vor Beginn der Bebrütung nach dem erörterten Verfahren behandelt wurden, zeigte sich, dass eine Spaltung der Keimscheibe selbst auf $2 \mathrm{Mm}$. Länge die Entwicklungsvorgänge nicht absolut aufhebt. Schrohe fand, dass bei etwa $2 / 3$ dieser Eier die Entwicklung des Embryo stattgefunden hatte; wo sie ausgeblieben war, kam es auch nicht zur Bildung des Gefässhofes. „In den sich entwickelnden Eiern war immer nur ein Embryo vorhanden, wenn auch missbildet, und die Wunde war stets vernarbt, sodass man in der Mehrzahl der Fälle nicht einmal die Stelle der Verletzung auffinden konnte."

Bezüglich der Läsion solcher Eier, welche vor der Vornahme derselben bereits einige Zeit bebrütet worden waren, theilt Schrohe mit, dass in etwa $3 / 4$ der Fälle noch eine Weiterentwicklung stattfand. Diese konnte sowohl den Embryo betreffen, als auch, wenn dieser zu Grunde ging, sich auf den Dotter- und den Gefässhof beschränken. Der letztere war, wenn er keinen oder einen abgestorbenen Embryo enthielt, in seiner Form meistens unregelmässig. „S Schritt auch der Embryo in der Entwicklung weiter, dann zeigte

1) pag. 169.

$\left.{ }^{2}\right)$ Schrohe, Untersuchungen iiber den Einfluss mechanischer Verletzungen auf die Entwicklung des Embryo. Dissert. Giessen 1862. 
er mehr minder Abweichungen von der Norm. Einzelne Theile des Embryo verkümmerten entweder oder sie gingen vollständig zu Grunde. Bei einer Spaltung des Embryo entwickelten sich entweder beide Hälften oder nur eine und die andere abortirte. In einigen Fällen trat eine Doppelbildung einzelner Organe auf, besonders des Herzens."

In dem Falle, in welchem sich eine Doppelbildung des Herzens einstellte, glaubt Schrohe, dass diese nicht eine Folge der Spaltung der Keimscheibe sei, da die Wunde am hinteren Ende derselben sich befand.

Leider hat $\mathrm{Schrohe}$ bei vielen seiner Fälle nicht angegeben, an welchem Theile des Embryo oder der Keimscheibe er die Verletzung angebracht und in welcher Richtung und Ausdehnung er gespalten habe. Dadurch verlieren diese Fälle sehr an Werth, weil man durch dieselben nicht erfährt, ob die Verletzung einer bestimmten Stelle der Keimhaut, sei es vor, sei es kurz nach Beginn der Bebrütung immer die gleichen Missbildungen zur Folge hat, was bei einem mehr systematischen Vorgehen leicht zu eruiren gewesen sein würde.

Einen Fall Schrohe's möchte ich noch erwähnen, bei dem es sich nach seiner Ansicht um eine zufällig intercurrirende Doppelmissbildung handelte. Ich gebe hier Schrohe's eigene Darstellung der bezüglichen Beobachtung wieder: „Das Ei war 16 Stunden bebrütet, ehe die Verletzung vorgenommen wurde. Ich machte eine Spaltung, wie ich vermuthe, in der Längsaxe. An der Keimscheibe war nichts Abnormes wahrzunehmen, sie war nur etwas oval. Die Untersuchung nahm ich am 4. Tage der Bebrütung vor. Beide Embryonen waren abgestorben und lagen am Rande der Wunde, welche kreisförmig war. Sie zeigten eine fast vollständig gleiche Entwicklung. Bei beiden ist das hintere Ende nur theilweise entwickelt, bei dem einen sowohl, wie bei dem andern sieht man nur eine Reihe von Wirbelplättchen. Die Herzen sind strangartig mit einander verbunden. Die Köpfe sind frei, fast vollständig normal, der eine ist etwas länglich, der andere mehr rund. Wäre nun Valentin's Behauptung richtig, dass durch Spaltung eines Keimes sich zwei Individuen entwickeln könnten, dann hätte in unserem Präparate kein Verwachsen der Herzen stattfinden dürfen, da nach den oben ausgesprochenen Erfahrungen eine Vernarbung der Wunde niemals eintritt, wenn sie nach schon längere Zeit stattgehabter Bebrütung gemacht wurde. Nicht erklärlich wäre es auch, warum gerade nur die Herzen sich wieder vereinigen sollten und nicht auch die übrigen Theile der Wunde. Nimmt man aber an, dass in dem betreffenden Falle ursprünglich zwei Keime vorhanden gewesen sind, die in gleicher Weise verletzt wurden, so lässt sich die fehlende Reihe von Wirbelplättchen durch Abort erklären. Man beobachtet ja nicht selten, dass nach Verletzungen der Keimscheibe einzelne Theile des Embryo vollständig zu Grunde gehen, während die übrigen in der Entwicklung fortschreiten."

Dieser Deutung, welche Schrohe von dem vorliegenden Falle gibt, vermag ich mich nicht anzuschliessen. Die Verletzung wurde an einer 16 Stunden bebrüteten Keimscheibe vorgenommen, also zu einer Zeit, in der vor dem vollkommen ausgebildeten Primitivstreifen-bereits der Kopffortsatz aufgetreten ist, und die ersten Spuren der Medullarwülste bemerklich sind. Die Spaltung wurde vermuthlich in der Längsaxe vorgenommen; ob sie eine 
totale war, d. h. die Keimscheibe ganz durchtrennte, darüber hat Schrohe keine Mittheilung gemacht. Meiner Ansicht nach war die longitudinale Spaltung keine totale, indem zwar die ganze bis dahin aufgetretene Embryonalanlage, also auch der Kopffortsatz median durchschnitten wurde, aber die vorderste Zone der Area pellucida wahrscheinlich verschont blieb. Die Hälften der Embryonalanlage entwickelten sich fort, mussten jedoch dabei den veränderten Verhältnissen Rechnung tragen. So konnte es kommen, dass bei jeder Hälfte der Rand des einen Medullarwulstes, als er bei seinem dorsalen Vordringen auf den der anderen Seite nicht traf, unter gleicher Krümmung weiter wachsend sich schliesslich mit dem bei der Spaltung hergestellten Schnittrande vereinigte, wodurch von ihm ebenfalls ein Rohr umschlossen wurde. Das Kopfende dieser so entstandenen Röhren konnte sich dann bei beiden Hälften noch etwas weiter entwickeln; dagegen konnte sich nur je eine Reihe von Urwirbeln ausbilden. Es liegt daher meiner Auffassung nach gar keine Zwillingsbildung vor, sondern nur die zwei Hälften der gespaltenen Embryonalanlage, die sich noch eine Zeit lang weiter entwickelten, in Folge der Wundbildung sich mit ihren hinteren Enden immer mehr von einander entfernten, während die vorderen Enden, unter denen sich inzwischen je eine Herzschlinge gebildet hatte, neben einander gestellt wurden. Auf dem Wege des intacten vordersten Theiles der Area pellucida konnte es dann zur Anlage eines Verbindungsstranges zwischen beiden Herzen kommen.

Die Versuche von Schrohe beweisen, wie aus dem eben Mitgetheilten hervorgeht, dass eine Läsion der Keimscheibe eine Missbildung des Embryo nach sich ziehen kann; dagegen wurde niemals durch dieselben eine Doppelbildung, nach der man strebte, erzielt. Sie geben aber ferner für den Befund Valentin's, über den oben berichtet wurde, insoweit eine Erklärung, als durch Schrohe festgestellt ist, dass die gespaltenen Embryonaltheile sich noch eine Zeit lang weiter entwickeln können. Vielleicht war dies in dem Valentin'schen Falle eingetreten, wodurch eine Doppelmissbildung leicht vorgetäuscht werden konnte.

Die negativen Erfolge von Leuckart und Schrohe mögen die Ursache gewesen sein, dass man in späteren Jahren die Versuche, Doppelbildungen experimentell herzustellen, als aussichtslos erachtete; man beschränkte sich meistens darauf, die äusseren Einwirkungen auf die Entwicklung des Eies weniger eingreifend und zwar in einer Weise zu gestalten, dass man hoffen durfte, auch ohne directe Läsion des Embryo Deformitäten zu erzielen. Diese Erwartung wurde nicht getäuscht; es gelang, die verschiedenartigsten Monstrositäten künstlich zu erzeugen. Doch betrafen dieselben immer nur Einzelembryonen, indem es bisher nicht glücken wollte, Axenverdoppelungen zu Stande zu bringen; wenigstens habe ich nach der Schrohe'schen Untersuchung in der Literatur keinerlei Verzeichnungen gefunden, nach denen das Bestreben, kürıstlich Doppelbildungen herzustellen, von Erfolg gekrönt gewesen wäre.

Vielleicht gehört hieher ein Versuch Rauber's an einem Forellenei, den dieser Forscher als einen gelungeneren unter mehreren anderen derselben Art bezeichnet. Rauber beabsichtigte, den Keimring von Forelleneiern an seinem Vorschreiten über die Dotterkugel zu hindern. Er vermochte dies 
durch die Wirkung einer kleinen stifttörmigen 'Hervorragung eines Holzplättchens zu erreichen, mit welchem das im Uebrigen intact gelassene Ei an passender Stelle mit Vorsicht seitlich comprimirt und in dieser Lage mehrere Tage hindurch festgehalten wurde. Bei der Untersuchung des Eies hatte die Keimhaut etwa ein Drittel der Dotterkugel umwachsen. Der Keimring trug an einer Stelle eine normale vordere Embryonalanlage. Nicht ganz diametral gegenüber befand sich am Keimring ein anderes Gebilde, eine „künstliche" vordere Embryonalanlage. Ueber dieselbe berichtet $\mathrm{R}$ auber wie folgt: „Der an dieser Stelle in das helle Mittelfeld hineinragende vollkommen deutliche Vorsprung hat fast genau das Ansehen eines Stückchens bilateral-symmetrisch zusammengetretenen Keimrings; man erkennt eine Art Primitivrinne, welche die beiden Hälften abtheilt und in einen Einschnitt des Randes ausläuft, statt von einer bei den Knochenfischen die Norm bildenden Randknospe begrenzt zu werden. Es ist auch gar nicht zu bezweifeln, dass sich in diesem Vorsprung im günstigsten Fall ein kleiner Theil von Rückenmark, Urwirbel, hätte bilden können u. s. w., wie es eben der betreffenden Keimringstrecke zukommt. Schwerlich aber wird man daran denken können, dass man es hier mit einer rudimentären vorderen Émbryonalanlage zu thun habe, obwohl in Wirklichkeit eine entfernte Aehnlichkeit der äusseren Form vorliegt, die ja auch auf andere Weise leicht zu erreichen ist. Vollständige Theilung des Keims nach geschehener Furchung gelang mir bisher nicht; ich zweifle indessen nicht daran, dass das Ergebniss gleichfalls ein negatives bezüglich der künstlichen Erzeugung von Doppelbildungen gewesen wäre $\left.{ }^{1}\right)^{.}{ }^{4}$

In dem gleichen Sinne wie Rauber, dass es zu den Unmöglichkeiten gehöre, künstlich Doppelmissbildungen hervorzubringen, spricht sich auch $\mathrm{Panum}$ aus. Derselbe verweist gegenüber den oben angeführten Mittheilungen Valentin's auf die Untersuchungen Lereboullet's, welche bewiesen haben, dass die mechanischen Erschütterungen auf das Vorkommen der Doppelmissbildungen bei Fischeiern gar keinen Einfluss haben ${ }^{2}$ ). Auch derjenige Forscher, dessen Stimme wegen seiner Erfabrungen auf dem Gebiete der experimentellen Erzeugung von Missbildungen am meisten in das Gewicht fallen muss, Dareste, äussert sich in Bezug auf die in Rede stehende Frage in folgender Weise: „La teratogénie ne peut dans son état actuel créer les monstres doubles comme elle crée les monstres simples $\left.{ }^{3}\right)$.

Man sieht, wie die genannten Forscher - und mit ihnen auch fast ausnahmslos diejenigen Autoren, welche sich mit der bezüglichen Frage beschäftigt haben - die künstliche Herstellung von Doppelmissbildungen entweder von vorneherein für eine baare Unmöglichkeit erklären, oder wenigstens dahin ihr Votum abgeben, dass dieselbe mit den bisher angewandten Methoden sich nicht erreichen lasse.

Wer sich auf den ersteren Standpunct stellt, wonach die Möglichkeit einer experimentellen Erzeugung von Mehrfachbildungen absolut zu negiren

1) Rauber, Die Theorien der excessiven Monstra. Zweiter Beitrag. Virchow's Archiv Bd. 74, 1878, pag. 117.

$\left.{ }^{2}\right)$ P a num, Beiträge zur Kenntniss der physiologischeñ Bedentung der angebornen Missbildungen. V irchow's Archiv Bd. 72, 1878, pag. 168 и. 169.

${ }^{3}$ ) Dareste, Production artificielle des monstruosités, pag. 282. 
sei, leistet natürlich gänzlich darauf Versicht, dass jemals diese Frage zur Entscheidung gebracht werden könne. Sicherlich mit Unrecht, denn durch das Misslingen der bisherigen auf Herstellung von Doppelmonstra gerichteten Bemühungen ist noch keineswegs bewiesen, dass das denselben vorschwebende Endziel ein absolut unerreichbares sei. Auf der anderen Seite stehen aber die Argumente, welche für ein dem Ei schon vor oder erst nach der Befruchtung zukommendes, die Anlage eines Doppelembryo nach sich ziehendes Bildungsvermögen angeführt werden, ebenfalls auf so schwachen Füssen, dass sich gewichtige Einwände gegen dieselben erheben lassen. So hat die Schultze'sche Theorie der zwei in einem Ei vorhandenen Keimbläschen bisher noch durch keine Wahrnehmung trotz der vielen in neuerer Zeit angesteliten Beobachtungen über die Befruchtungsvorgänge, welche bei Eiern mit zwei Keimbläschen jedenfalls in ungewöhnlicher Weise ablaufen müssen, irgend eine Stütze erhalten. Ebenso ist der anormale Befruchtungsvorgang, der sich durch das Eindringen mehrerer Spermatozoen in das Eiinnere kennzeichnet, in übereinstimmender Weise von Hertwig und Fol nur bei pathologischen Eiern wahrgenommen worden, welche nur eine kurz dauernde Entwicklung aufweisen und bald absterben. Erst, wenn bei einem von mehreren Spermatozoen befruchteten Ei die Entwicklung einer Doppelbildung beobachtet und während einer längeren Zeitdauer verfolgt wäre, dann würde der Beweis erbracht sein, dass eine Befruchtung durch mehrere Spermatozoen Ursache der Doppelbildung sei. Ob aber die alleinige? - wäre eine weitere Frage. Bedenkt man die Stufenreihe, welche von der Ausbildung zweier durchaus getrennter normaler Zwillinge bis zu den minimalen Formen der Verdoppelung, die äusserlich sogar unsichtbar sind - ich erinnere an die Verdoppelung der Hypophysis, welche nach Ahlfeld ${ }^{1}$ ) den geringsten Grad der Duplicitas anterior darstellt - continuirlich sich verfolgen lässt, so wird man sicher Grund haben, daran zu zweifeln, dass eine jede Doppelbildung ursächlich auf einen übermässig gesteigerten Bildungstrieb des Eies zurückzuführen sei.

Ich halte daher die Fassung der erörterten Frage, wonach die beiden oben genannten Hypothesen über die Ursache der Doppelbildungen sich gegenseitig ausschliessen sollen, für eine nach dem gegenwärtigen Stande unserer Kenntnisse unzulässige. In Anbetracht der nur geringen positiven Anhaltspuncte, welche uns zu Gebote stehen, kann die Annahme nicht von der Hand gewiesen werden, dass in dem einen Falle ein übermässiger Bildungstrieb des Eies, in dem anderen äussere, die normale Entwicklung beeinträchtigende Umstïnde die Anlage eines Doppelembryo hervorgerufen haben.

Da nun den beiden sich bisher gegenüberstehenden Hypothesen meiner Ansicht nach die gleiche Berechtigung zuerkannt werden muss, so scheint mir die Lösung des Räthsels, welches den Doppelbildungen zu Grunde liegt, ebenfalls auf zweifache Art in Angriff zu nehmen sein. Man wird einerseits die Folgen einer willkührlich durch mehrere Spermatozoen veranlassten Befruchtung genauer zu studiren haben. Nach Fol findet letztere statt, wenn die Eier von Seesternen noch nicht völlig reif sind oder zu lange im Seewasser gelegen haben. Bringt man derartige Eier unter möglichst günstige

1) Ahlfeld, Die Missbildungen des Menschen pag. 73. 
Verhältnisse, so lassen sich vielleicht einzelne eine genügende Zeit am Leben erhalten, um an ihnen fortgeschrittenere Stadien von Doppelbildungen beobachten zu können.

Der andere, soweit ich es zu übersehen vermag, weniger schwierige Weg, welcher eingeschlagen werden kann, beruht in dem Versuch, auf die Entwicklung eines Eies sehr frühzeitig und in einer Weise einzuwirken, welche hoffen lässt, dass die Ontogenese hierdurch zu der doppelten Anlage von Embryonen oder Embryonaltheilen hingeleitet werde. Dieses letztere Ziel hatte ich mir bei den im Folgenden zu beschreibenden Experimenten gesteckt. Ich stellte dieselbe an dem Vogelei an, dessen normale Entwicklung mir am geläufigsten war. Ausserdem hatten mich die im vorigen Capitel geschilderten Erfahrungen belehrt, wie am Vogelei die Anlage einer Mehrfachbildung in den ersten Entwicklungsstadien beschaffen ist. Es war mir dadurch die Bahn gezeigt, welche die Entwicklung von Doppelembryonen einschlägt, und es stand zu erwarten, dass diese Kenntnisse meinen Versuchen zu Gute kommen würden.

Bei der Wahl der Methode, welche bei meinen Experimenten zur Anwendung kam, war in erster Linie unter sämmtlichen Mitteln eine prüfende Umschau zu halten, welche zu den Zeiten des älteren Ge offroy St. Hilaire, der nach den neueren Mittheilungen Dareste's ${ }^{1}$ ) als der Begründer der experimentellen Teratologie anzusehen ist, gebraucht wurden, um im Innern eines auszubrütenden Vogeleies eine Missbildung zu erzengen. Diese Mittel, welche in einer Veränderung der normalen Entwicklungsbedingungen bestehen, lassen sich am zweckmässigsten in mechanische, thermische und respiratorische Einwirkungen gliedern.

Mechanische Einwirkungen. Zu den geringfügigsten Eingriffen dieser Art gehört die verticale Stellung des Eies während der Bebrütung. Dieselbe ist hier anzuführen, weil dadurch der Dotter und damit die Keimscheibe in eine von der normalen Lage bei Horizontalstellung des Eies abweichende Position gebracht wird. Wegen des specifisch leichteren Gewichtes des Dotters gegenüber dem Eiweiss wird der erstere immer bei jeder Anordnung des Eies eine möglichst hohe Stelle einzunehmen suchen. Diese bereits 1674 von Langly ${ }^{2}$ ) entdeckte Thatsache bringt es mit sich, dass bei Horizontalstellung des Eies der Dotter ziemlich dicht unter der Schale gelegen ist; der specifisch leichteste Bezirk des Dotters wiederum fällt zusammen mit der Keimscheibe, welche somit immer nach oben sich kehren und desshalb der Schale am nächsten zu liegen kommen muss, ein Umstand, der für den Zutritt des Sauerstoffs der umgebenden Atmosphäre durch die poröse Schale zür Keimscheibe von der grössten Bedeutung sein muss. Es ist begreiflich, dass die Verticalstellung der Eier die Keimscheibe an einen anderen Platz innerhalb der Eischale bringen muss, je nachdem das Ei seinen stumpfen oder spitzen Pol nach oben wendet; in beiden Fiallen wird aber die Keimscheibe unter ganz andere Entwicklungsbedingungen gestelltiswerden, als wie sie bei der normalen Bebrütung gegeben sind. Die durch die verticale Stellung be-

1) 1. c. pag. 32-37.

$\left.{ }^{2}\right)$ Langly, Observationes quaedam de generatione animalium pag. 136. Gerlach, Entstehungaweise der Doppelmisslildungen. 
dingten mechanischen Verhältnisse werden besonders in den Entwicklungsstadien sich geltend machen müssen, in denen der Embryo einer Drehung unterliegt, und es werden sich um diese Zeit leicht Anomalien in der Lagerung des Embyro einstellen können.

Die verticale Stellung der Eier hat schon Réaumur ${ }^{1}$ ) angewandt. Nach seinen Angaben scheint jedoch dieselbe keinen Einfluss auf die Entwicklung der Embryonen ausgeübt zu haben. Nach ihm hat sich der ältere Geoffroy St. Hilaire ${ }^{2}$ ) des gleichen Verfahrens zur Erforschung der Entstehungsweise von Missbildungen bedient und will hierdurch verschiedenartige Monstrositäten zu Wege gebracht haben. Ferner hat Liharzik ${ }^{3}$ ) in der zweiten Hälfte der Brütezeit die Eier vertical gestellt und hat hierdurch sehr beachtenswerthe Resultate erzielt. Bekanntlich geht der Embryo, wenn er ein gewisses Alter erreicht hat, im Innern des Eies eine Drehung ein, indem er seine ursprüngliche Lage, welche wir in einem früheren Capitel „Normalstellung“ nannten, verlässt. Er gibt die bisherige zur Längsaxe des Eies senkrechte Lagerung auf und dreht sich so, dass er sich mit seiner Längsaxe zu dem langen Durchmesser des Eies parallel stellt, wobei er in den meisten Fällen den Kopf gegen den stumpfen, das Schwanzende gegen den spitzen Eipol kehrt. Im Anfange der zweiten Hälfte der Bebrütung hat diese Drehung bereits stattgefunden und man hat es dann in der Hand, je nach der Anordnung des senkrecht gestellten Eies, bald den Kopf (stumpfen Eipol), bald das Schwanzende des Embryo (spitzen Eipol) nach oben oder nach unten zu wenden. Liharzik, welcher in dieser Weise seine Versuche ausführte, konnte nach dem Ausschlüpfen der Hühnchen feststellen, dass immer der in der zweiten Hälfte der Brütezeit nach unten gekehrte Körpertheil eine besondere Ausbildung erfahren hatte, während die andere Körperhälfte in ihrer Entwicklung zurückgeblieben war. Er erhielt so einerseits Hühnchen mit grösserem und dickerem Kopf, mit kürzerem, breiterem Hals und einem kleinen schmalen Bauche; andererseits Hühnchen mit sehr kleinem Kopfe, dagegen mit dickerem, umfangreicherem Bauch. Diese Resultate wurden vermuthlich durch die grössere Blutzufuhr veranlasst, welche die tieferliegenden Körpertheile nach dem Gravitationsgesetze erhalten mussten.

Auch Dareste hat von der verticalen Stellung der Eier zur Production von Missbildungen mit Erfolg Gebrauch gemacht $\left.{ }^{4}\right)$.

Eine zweite Methode, auf die auszubrütenden Eier mechanisch einzuwirken, beruht in einer Erschütterung der Eier, welche beliebig oft vorgenommen werden kann. Nach den Erfahrungen der beiden Geoffroy St. Hilaire wird durch heftiges Schütteln der Eier die Entwicklung der Embryonen gestört

1) Réaumur, Art de faire éelore et d'élever en toute saison des oiseaux domestiques de tontes especes, soit par le moyen de la chaleur du fumier, soit par le moyen du feu ordinaire. Paris 1751.

2) Fitenne Geoflry St. II laire, Sur les déviations organiques provoquées et observées dans les établissements d'incubation artificielle. Mémoires du Muséum 'T. XIII, pag. 289, 1826;.

3) Liharzik, Das Geset\% des menschlichen Wachsthums und der unter der Norm zuriirkgeblicbene Brustkorb als die erste und wichtigste Ursache der Rhachitis, Serophulose und Tubereulose. Wien 1858.

1) 1. c. pag. 15:. 
oder aufgehoben; der jüngere Geoffroy theilt hierüber unter anderem mit, dass eine starke Erschütterung der Eier in der Längsaxe die Entwicklung des Embryo um mehrere Tage verzögern könne ${ }^{1}$ ). Die geringen Erschütterungen dagegen, welche durch oftmaliges Umlegen der Eier während der Brütezeit verursacht werden, scheinen nicht den mindesten Einfluss auf die Entwicklung zu haben, wie Réaumur schon nachgewiesen hat; es ist ja bekannt, dass die Brüthennen täglich die Lage ihrer Eier verändern, indem sie die mittleren Eier mehr nach der Peripherie schieben und die peripheren in die Mitte bringen.

Es ist ferner der Versuch gemacht worden, Eier während der Bebrütung continuirlich zu bewegen. Lombardini hat im Brütofen mehrere Tage lang Hühnereier um ihre Längsaxe langsam in der Art rotiren lassen, dass in jeder Minute eine Rotation gemacht wurde. Er konnte als Folge dieses Verfahrens häufig eine abnorme Lagerung des Embryo beobachten ${ }^{2}$ ).

Eingreifender als die bisher genannten sind diejenigen mechanischen Einwirkungen, welche mit einer Verletzung der Eischale verbunden sind. Soweit sich diese Manipulationen einfach auf letzteres beschränken, $d . h$. in einem Durchlöchern oder in einem Bruche der Eischale bestehen, so wird dadurch der Gaswechsel zwischen der äusseren Atmosphäre und dem Eiinnern geändert, und es sind diese Eingriffe demnach eher den respiratorischen zuzuzählen. Hier sollen nur solche mechanische Einwirkungen zur Sprache kommen, welche nach Läsion der Schale den Embryo direct treffen. Schon oben habe ich der Versuche Valentin's, Leuckart's und Schrohe's gedacht; ähnlicher Art sind die Experimente von Scymkiewizc ${ }^{3}$ ). Derselbe hat bei Hühnereiern, welche 24-36 Stunden in dem Brütofen gelegen waren, die Eischale mit einem Grabstichel angebohrt und ein rundes Stück derselben sammt der zugehörigen Schalenhaut entfernt, worauf mit einem Staar- oder Lanzenmesser an der einen oder anderen Seite des Embryo parallel mit dem Primitivstreifen ein Schnitt geführt wurde. Hierauf wurde die runde Oeffnung mit einem Deckgläschen verschlossen ${ }^{4}$ ) und mit Wachs verklebt, wonach das Ei noch auf zwei Tage in den Brütofen zurückgebracht wurde. In Folge dieses Eingriffes fand er gewöhnlich den Embryonalkörper durch cystenförmige Wucherungen mehr oder weniger zerstört, nur ausnahmsweise konnte er eine normale Weiterentwicklung constatiren.

Ausser der directen Läsion der Keimscheibe hat man ferner versucht, nach Perforation der Keimscheibe durch Einführung von Nadeln auf die Keim-

1) Js. Geoffroy St. Hilaire, Histoire générale et particulière des anomalies de l'organisation chez l'homme et les animaux, ou Traité de teratologie. Paris 1836, Tome III.

$\left.{ }^{2}\right)$ L. Lom bardini, Intorno alla genesi delle forme organiche irregolari negli uccelli e ne' batrachidi. Pisa 1868. Referat in dem Jahresbericht von Virchow und Hirsch 1868, pag. 167 .

$\left.{ }^{3}\right)$ Scymkiewizc, Beitrag zu der Lehre von den künstlichen Missbildungen am Hühnerei. Wiener Sitzungsber. 1875, LXXII. Bd., Abtheilung III, pag. 139.

4) Die Methode, nach dem Abtragen eines Stückchens der Eischale die Oefrnung mit einem Glas zu verschliessen, wurde schon von Beguelin (Mémoire sur l'art de couver les ceufs ouverts. Hist. de l'Acad. de Berlin 1749, pag. 71) angegeben, um mit Hiilfe derselben das Fortschreiten der Entwicklung der Eier während der Bebrütung verfolgen zu können. 
scheibe entwicklungsstörend einzuwirken. Der jüngere Geoffroy St. Hilaire hat in dieser Richtung experimentirt und Eier, in welche Nadeln eingeführt waren, die nachher befestigt wurden, der Brütwärme ausgesetzt; er erzielte hierdurch ein Ausbleiben jeglicher Entwicklungsvorgänge. Auch Valentin berichtet in seinem Repertorium, Bd. II, pag. 168, über ähnliche Versuche. Nach 24-28stündiger Bebrütung der Eier suchte er durch Auslassen eines Theiles des Eiweisses aus einer in die Schale gefeilten Oeffnung und nachfolgenden senkrechten oder schiefen Stellung der Eier bei fortgesetzter Bebrütung, sowie durch das Durchziehen von Fäden, welche in der Nähe der Keimhaut verliefen, die Entwicklung des Embryo zu modificiren. Auf diese Weise gelang es ihm, abgesehen von unglücklichen Zerstörungen des Ganzen, bisweilen monströse Embryonen zu erzielen.

Schliesslich hat auch Schrohe ${ }^{1}$ ) eine gleiche Methode angewandt, indem er mittelst eines eingeführten Fadens den Dotter herabdrüickte. Hierdurch wurde eine locale Pression auf den Embryo ausgeübt und das Zutreten der atmosphärischen Luft zu dem letzteren verringert. Die bei diesen Versuchen beobachtete Procedur bestand darin, dass eine Nadel mit einem Faden eingeführt wurde und unter Vermeidung einer Läsion des Dotters auf der entgegengesetzten Seite des Eies ausgestochen wurde. Der Faden wurde sodani langsam durchgezogen und über dem Eie zusammengeknotet. Das letztere wurde hierauf in den Brütofen gebracht, und zwar in einer Lage, dass der Knoten des Fadens nach oben sah. Die Untersuchung der Eier, welche gewöhnlich am 4. Tage vorgenommen wurde, ergab Missbildungen ganz ähnlich denen, die aus einer directen Verletzung der Keimhaut resultirten, worüber bereits oben berichtet wurde. „Zuweilen war nur der Dotterhof allein oder zugleich mit dem Gefässhof entwickelt, letzterer war immer unregelmässig, öfters achtförmig. Die Einschnürung derselben entsprach der Richtung des Fadens."

Thermische Einwirkungen. Von Réa u mur ist festgestellt worden, dass die günstigste Temperatur für das Gedeihen des Embyro während der ganzen Brütezeit sich auf $32^{\circ} \mathrm{R}$. (=40 ${ }^{\circ} \mathrm{C}$.) beläuft. Doch kann auch bei einer sich während der Bebrütung auf $30^{\circ} \mathrm{R}$. constant erhaltenden Temperatur ein Ausschlüpfen der Hühnchen erreicht werden. Diese geringen Schwankungen über und unter der Mitteltemperatur von $32^{0} \mathrm{R}$. erscheinen um so begreiflicher, wenn man bedenkt, dass die Hennen in den verschiedenen Jahreszeiten ihre Eier ausbrüten und die äussere Temperatur nicht ohne jeden Einfluss auf den Wärmegrad bleiben kann, dem die von der Brüthenne bedeckten Eier ausgesetzt sind.

Auch der Umstand, dass die Brüthenne während des Tages ein oder zweimal die Eier verlïsst, wird eine geringe Herabsetzung von deren Temperatur zur Folge haben müssen. Dies ist in der ersten Zeit geführlicher für die Entwicklung der Embryonen - es bedecken auch um diese Zeit die Hennen beim Verlassen der Eier dieselben mit Stroh - als in der letzten Brütwoche, in welcher die Embryonen schon eine grössere Eigenwärme besitzen und darum unabhängiger von der umgebenden 'Temperatur sind. Er- 
fahrungsgemäss bedecken auch die Hennen ihr Nest in der letzten Zeit der Bebrütung weniger sorgfältig.

Ferner spielt hinsichtlich der Höhe der Brütetemperatur die Individualität bis zu einem gewissen Grade eine Rolle. So wissen wir durch Féry d'Esclands, dass die Verschiedenheit der Racen einen Unterschied der Brütetemperatur bis zu 2 Graden bedingt ${ }^{1}$ ). Derselbe macht auch Angaben über ein geringes Abnehmen der Temperatur während der ganzen Brütezeit; er konnte mehrfach beobachten, dass die Brütwärme unter Hennen vom Anfang bis zum Ende der Brütezeit sich allmählig um $2^{\circ}$ vermindert hatte.

Réaumur war auch der erste, welcher festzustellen suchte, inwieweit Temperaturschwankungen, welche das Ei während der Bebrütung treffen, von dem im Eiinnern sich entwickelnden Embryo ertragen werden können. Er vermochte zu constatiren, dass aus Eiern, deren Temperatur während der Brütezeit innerhalb weniger Stunden oder sogar mehrerer Tage bis auf $28^{\circ}$, ja selbst bis auf $25^{\circ}$ gesunken war, doch schliesslich die Hühnchen zum Auskriechen gelangten. Ist während der ganzen Brütedauer die Temperatur eine herabgesetzte $\left(30^{\circ}-31^{\circ}\right.$ R.), so kommen die Hühnchen erst später zum Ausschlüpfen, es findet also unter diesen Umständen eine langsamere Entwicklung statt. Bezüglich des Steigens der Temperatur während der Bebrütung gibt Réaumur an, dass dieselbe für einige Zeit selbst $38^{\circ}-40^{\circ} \mathrm{R}$. betragen kann, ohne dass hierdurch die Embryonen sämmtlich zum Absterben gebracht werden, was bei längerem Andauern dieses Temperaturgrades jedoch stets erfolgen muss. Wurden die Eier nur auf kurze Zeit, etwa stundenlang, aber öfter, einer Temperatur von $37^{\circ} \mathrm{R}$. ausgesetzt, so konnte dies ohne Schaden für den Embryo geschehen; eine Temperatur von $35^{\circ}-36^{\circ} \mathrm{R}$. wurde sogar während mehrerer Tage ertragen. Bei einer ständigen Temperatur von $33^{\circ}-33,5^{\circ} \mathrm{R}$. kamen die Hühnchen etwas früher zum Ausschlüpfen.

Während Réaumur bei seinen Versuchen das Ziel-im Auge hatte, zu eruiren, unter welchen Temperaturverhältnissen die Entwicklung des Embryo gänzlich sistire, wurden von Panum die gleichen oder ähnlichen Versuche mehr in der Absicht angestellt, zu erfahren, welche pathologische Veränderungen der Embryo bei anormaler Brütetemperatur erleiden müsse. Er kam dabei zu dem Resultate, dass „die Temperaturschwankungen unter den äusseren Ursachen der Entstehung von Missbildungen in Vogeleiern den ersten Platz einnehmen ${ }^{2}$ ).

Die hauptsächlichsten Ergebnisse, zu welchen die Experimente Panum's führten, sind folgende:

a) Bei Eiern, welche am zweiten oder dritten Tage aus dem Britofen genommen, $1-2^{1 / 2}$ Stunden einer Temperatur von $11^{\circ}-13^{\circ} \mathrm{C}$. ausgesetzt und hierauf wieder in den ersteren zurückgebracht wurden, erlitt die Embryonalentwicklung keine Störung. Diese trat jedoch fast immer ein, wenn sie in obiger Temperatur $4 \frac{1}{2}$ S Stunden sich befanden, ehe sie wieder weiter bebriitet wurden.

b) Langsame Abkühlung von Eiern der gleichen Entwicklungsstadien

1) Féry d'Esclands, F́tudes sur l'incubation artificielle. Bulletins de la Société d'acclimatation. III. Série, T. II pag. 582, 1875.

2) 1. c. pag. 141 . 
innerhalb 10 Stunden bis auf $22{ }^{\circ} \mathrm{C}$, worauf sie wieder in die normale Brütwärme kamen, bewirkte meistens ein Absterben der Embryonen. Innerhalb der 10 Stunden war demnach vermuthlich im Innern des Eies die Temperatur tiefer gesunken, als es bei der rascheren Abkühlung während eines 21/2 stündigen Aufenthaltes in einer Temperatur von $11^{\circ}-13^{\circ} \mathrm{C}$. der Fall gewesen war.

.c) Eine Erhöhung der Wärme über die Norm ist bei fortgesetzter Bebrütung für die normale Entwicklung gefährlicher als ein Sinken unter die Norm, welches länger vertragen werden kann.

d) Wurde ein in den obengenannten Entwicklungsstadien befindliches Ei an einem warmen Sommertage 12 Stunden und länger der freien Luft ausgesetzt und hierauf wieder weiter bebrütet, so blieb zwar der Embryo am Leben, es entstand aber in der überwiegenden Mehrzahl der Fälle eine Missbildung.

e) Die so zu Stande gekommene Missbildung ist jedoch bei einzelnen Eiern, selbst bei ganz gleicher äusserer Einwirkung und Entwicklungsstufen, eine variable. Von Einfluss auf die Form derselben ist die Entwicklungsstufe, bei welcher die Abkühlung eintrat.

f) Die Widerstandsfähigkeit gegen die Temperaturschwankungen war in den einzelnen Fällen eine individuell verschiedene.

Dareste hat von der Methode der Herabsetzung oder Steigerung der Brütwärme wohl den umfassendsten Gebrauch gemacht, um mit Hülfe derselben Missbildungen der Embryonen zu erzeugen. Nach seiner eigenen Aussage hat ihm dieses Verfahren die meisten seiner Missbildungen geliefert ${ }^{1}$ ).

Von grossem Interesse sind seine Erfahrungen, zu welchen er bei seinen Studien über die Entwicklung des Embryo in unter- oder übernormaler Brütetemperatur gelangte. Die oben erwähnten Angaben Réaumur's, wonach eine etwas herabgesetzte Brütwärme eine Verlangsamung, eine etwas gesteigerte dagegen eine Beschleunigung der Embryonalentwicklung bedinge, konnte Dareste mehrfach bestätigen. Bei $41^{\circ}-42^{\circ} \mathrm{C}$. geht die Ausbildung des Embryo sehr rapid vor sich; derselbe erreicht in 24-30 Stunden bereits eine Entwicklungsstufe, welche unter normaler Temperatur erst nach drei Tagen sich einstellt. Bei $30^{\circ} \mathrm{C}$. dagegen gelangte der Embryo in das gleiche Entwicklungsstadium erst nach 7-8tägiger Bebrütung.

Auch die Thatsache, dass bereits bei einer Temperatur von $25^{\circ}-30^{\circ} \mathrm{C}$. die Entwicklung des Embryo beginnen kann, hat Dareste genauer verfolgt. Bekanntlich hat $\mathrm{K}$ ölliker die bei den genannten niederen Temperaturgraden sehr langsam fortschreitende Ausbildung der Embryonalanlage für die Untersuchung der ersten Entwicklungsstadien des Hühnchens verwerthet ${ }^{2}$ ). Seinem Beispiele ist später Koller gefolgt ${ }^{3}$ ). Dareste hat nun festgestellt, dass die bei $25^{\circ}-30^{\circ} \mathrm{C}$. - also in einer 'Temperatur, welche an heissen Sommertagen in unseren Klimaten häufig eintritt - beginnende Entwicklung äusserst langsam sich vollzieht und sehr bald, nämlich in einer Entwicklungszeit,

\footnotetext{
1) 1. c. pag. 73.

$\left.{ }^{2}\right)$ Kölliker, Entwicklungsgeschichte des Menschen und der höheren Thiere 1879, pag. 99.

3) Koller, Beiträge zur Kenntniss des Hühnerkeims im Beginne der Bebriitung. Sitzungsber. der Wiener Akad. der Wissenschaften Bd. IXXX, pag. 316, 1879.
} 
welche der Bildung des Herzens und der Area vasculosa entspricht, cessirt, worauf der Embryo einer allmähligen Zersetzung anheimfällt. Der Fruchthof erscheint alsdann ohne Inhalt; späterhin verschwindet auch das übrige Blastoderma gänzlich oder wenigstens theilweise.

Brütet man Eier bei einer Temperatur von $30^{\circ}-35^{\circ} \mathrm{C}$. eine längere Zeit hindurch, so dauert die langsam fortschreitende Entwicklung der Embryonen eine Weile an; dieselbe kann schliesslich noch ein Stadium erreichen, welches die Embryonen der unter normaler Temperatur bebrüteten Eier nach dem dritten Tage aufweisen. Dann aber cessirt ebenfalls die Entwicklung; der Embryo kann jedoch in diesem Zustande, ohne abzusterben, noch eine gewisse Zeit verharren. Dareste wirft die Frage auf, ob der Grund dieser Erscheinung nicht darin zu suchen sei, dass wegen der geringeren Wärme die Intensität der Respiration des Embryo zu seiner weiteren Ausbildung nicht mehr genüge. Aus den mitgetheilten Thatsachen geht hervor, dass die Entwicklung des Embryo auch bei relativ niederen Wärmegraden beginnen und eine Zeit lang andanern kann; dann aber müssen die betreffenden Eier, damit der Embryo nicht abstirbt, stetig zunehmenden Temperaturen ausgesetzt werden. Daraus folgt, dass man bei einer Bestimmung der gesammten bis zur vollendeten Entwicklung erforderlichen Wärmemenge den für die einzelnen Perioden des embryonalen Lebẻns nöthigen Minimaltemperaturen Rechnung tragen muss.

Im Anschluss an die verschieden rasche Entwicklung und darum kürzere oder längere Brütedauer bei etwas höherer oder niedrigerer Temperatur, als es der Norm entspricht, kommt Dareste auf eine Frage zu sprechen, welche für die Bildungsgeschichte der Thiere von der grössten Bedeutung ist. $\mathrm{Er}$ hat dieselbe schon in einer früheren Mittheilung behandelt ${ }^{1}$ ). Diese Frage betrifft die Ursachen der Zwergbildung, sowie die Beziehungen der Grössenverhältnisse eines Thieres zu der Dauer von dessen embryonaler Entwicklung.

Dareste geht von dem Satze aus, dass die Gesammtentwicklung eines Organismus von zwei grundverschiedenen Vorgängen abhängig sei; erstens von den Bildungsvorgängen, welche die Form des ganzen Thierkörpers sowohl als die der Organe zu Wege bringen, und zweitens von den Vorgängen des einfachen Wachsthums, welche sich in einer durch Vermehrung der histologischen Elemente bedingte Volumsvergrösserung der bereits geformten Körpertheile und Organe äussern. Die beiderseitigen Vorgänge sind durch sehr innige Beziehungen mit einander verknüpft; es ist jedoch nicht absolut nothwendig, dass dieselben parallel neben einander verlaufen, sondern sie können in gewissen ,Fällen sich sogar antagonistisch gegenüberstehen. Schon Js. Geoffroy St. Hilaire hat einen solchen Antagonismus betont, und durch denselben die Anomalien der Körpergrösse zu erklären versucht. Dareste hat damit übereinstimmende Beobachtungen gemacht. In Füllen, bei welchen in Folge der über die normale etwas erhöhten Brütetemperatur die Entwicklung sehr rapid vor sich gegangen war, hatten die Vorgänge der Formation über die des Wachsthums das Uebergewicht erlangt, was manch-

1) Dareste, Sur certaines conditions de la production du nanisme. Comptes rendus T. LX, pag. 1214, 1865. 
mal zu ausgesprochener Zwergbildung führte. So hatte ein Embryo unter den angedeuteten Umständen bereits nach 24-26stündiger Bebrütung eine Entwicklungsphase erreicht, welche nahezu der 60. Stunde bei normaler Bebrütung entspricht; er hatte sich also beinahe dreimal so rasch entwickelt als in der Norm. Allein der betreffende Embryo zeigte eine ungemein geringe Körperlänge. Diese betrug auch nur circa den dritten Theil der Länge eines der gleichen Entwicklungsstufe angehörigen normalen Embryo. Es beruht demnach die Zwergbildung auf einem Zurückbleiben des Wachsthums hinter den formativen Vorgängen, was auf den Einfluss einer relativ hohen Brütetemperatur zurückzuführen ist. Die von Féry d'Esclands beobachteten differenten Brütetemperaturen bei verschiedenen Racen und die dadurch verursachten kürzeren Brütezeiten hängen demnach vermuthlich mit der Körpergrösse der einzelnen Racen zusammen. Auch bei den Säugethieren steht die Länge der Embryonalzeit in einem gewissen Verhältniss zu der Körpergrösse der betreffenden Thierspecies, indem auch hier der Grundsatz im Allgemeinen durchgeführt ist, dass die Körpergrösse einer Thierspecies mit der Dauer ihrer Tragzeit zunimmt.

Ob umgekehrt bei langsamer Entwicklung in Folge von etwas herabgesetzter Brütetemperatur die Vorgänge des Wachsthums über die der Formation prädominiren, und schliesslich daraus Riesenbildungen resultiren, dariiber stehen Dareste keine Erfahrungen zu Gebote. Derselbe hält es für möglich, dass die Incongruenz der beiden genannten Vorgänge auch durch andere Einflüsse bedingt sein könne, als durch die Temperatur.

Ich habe schliesslich noch eine Methode zu erörtern, welche ebenfalls auf einer anormalen thermischen Einwirkung auf das Ei während der Brütezeit beruht, und die zur Herstellung von Bildungsanomalien angewandt worden ist. Sie besteht in einer ungleichen Erwärmung des Eies und wurde zuerst von Dareste angegeben. Mit Hülfe dieser äusserst sinnreichen Methode lassen sich bereits in der ersten Entwicklungszeit bestimmte Anomalien der Keimhaut hervorbringen, ein Erfolg, der bisher noch durch kein anderes Verfahren erzielt werden konnte. Während die bisher besprochenen Abänderungen der Brütetemperatur das ganze Ei gleichmässig betreffen, so wird durch das Dareste'sche Verfahren ein einziger beliebig ausgewählter Punct der Eioberfläche einer erhöhten Temperatur ausgesetzt, und von diesem aus theilt sich die zugeführte Würme dem iibrigen Ei mit, indem die betreffende Stelle das Wärmecentrum bildet, von dem aus die Wärme nach der Peripherie hin gleichmässig ausstrahlt.

Um einer Stelle der Eioberfläche eine Würmequelle zuzuführen, benützte Dareste die Bebrütung der Eier in freier Luft mittelst eines Apparates, dessen Princip von einem Amerikaner, Namens Cantelo, angegeben worden ist, den aber Dareste verbessert hat. Dieser Apparat besteht aus mehreren Röhren, in denen durch zweckmässige, hicr nicht näher zu beschreibende Vorrichtungen fortwiihrend warmes Wasser von gleicher Temperatur circulirt; der Durchmesser der Röhren beträgt $8 \mathrm{Ctm}$. Unter die Röhren werden nun die zu bebrïtenden Eier, welche ihrerseits wieder auf einer Flanellunterlage aufruhen, in der Weise gebracht, dass jedes derselben mit einer Stelle seiner Oberflïclıe die Wïrmequelle, d. h. eine Röhre des Apparats beriihrt. Will 
man nun normale Hühnchen ausbrüten, so muss der bei Horizontalstellung des Eies culminirende Punct der Eioberfläche an die Wärmeröhre anstossen. In diesem Falle ist der Culminationspunet des Eies dicht über dem Mittelpuncte der Keimscheibe gelegen; beide fallen demnach, wenn man die äusserst geringe Höhendistanz zwischen beiden vernachlässigt, zusammen. Da nun die Keimhaut, von ihrem Mittelpuncte ans gerechnet, nach der Peripherie hin gleichmässig weiter vordringt, indem sie allmählig den Dotter umwächst, so geht dieses Auswachsen in gewissem Sinne parallel einher mit der Ausbreitung der Wärme, die ja auch von dem mit dem Mittelpuncte der Keimhaut zusammenfallenden Würmecentrum aus gleichmässig nach allen Seiten hin ausstrahlt. Fällt dagegen der Culminationspunkt des Eies (worunter im Folgenden diejenige Stelle der Eioberfläche verstanden sein soll, unter welcher bei horizontal gestelltem Ei der Mittelpunct des Blastoderma sich befindet) nicht mit dem Wärmecentrum zusammen, d. h. berührt das Ei mit einer anderen Stelle als seinem Culminationspuncte die Wärmeröhre, so wächst die Keimhaut ungleichmässig und anormal. Dies ist dadurch begründet, dass die einzelnen von dem Mittelpunct der Keimhaut gleich weit entfernten Bezirke derselben differente Wärmemengen erhalten, was ein stärkeres Wachsthum an den besser erwärmten Abschnitten involvirt. Man kann demnach Anomalien des Blastoderma und der Area vașculosa herstellen, wenn man die Wärmequelle von dem Culminationspuncte wegverlegt, und zwar lassen sich je nach der Wahl der Contactstelle der Eischale mit der Wärmeröhre beliebige, im Voraus bestimmbare Anomalien erzeugen. 'Diese Entdeckung Dareste's ist von der grössten Tragweite, denn sie liefert den Beweis, dass äussere Eingriffe die Entwicklung der Keimhaut nach bestimmten von dem Experimentator beabsichtigten Bahnen hin lenken können.

Begreiflicher Weise coincidiren Culminationspunct und Contactstelle des Eies mit der Wärmeröhre nur dann, wenn das Ei direct unter der Röhre gelegen ist, d. h. wenn alle Puncte der Eioberfläche tiefer als die Contactstelle liegen. In allen anderen Positionen fallen die beiden Puncte nicht zusammen. Die Entfernung zwischen den beiden darf jedoch keine grosse werden, sonst würde die Entwicklung der Keimhaut gänzlich unterbleiben. Es müssen daher alle Versuche, welche eine Anomalie des Blastoderma anstreben, wenn sie gelingen sollen, sehr exact vorgenommen werden. Zur Bestimmung der Entfernung zwischen Culminationspunct und Contactstelle hat Dareste zwei ziemlich einfache geometrische Constructionen angegeben. Ich unterlasse es hier, näher auf dieselben einzugehen, indem ich auf die_in dem Dareste'schen Buche befindlichen Zeichnungen dieser Constructionen verweise ${ }^{1}$ ), ohne welche eine Erklärung kaum verständlich sein würde.

Für unsere Betrachtungen ist es von grossem Interesse, die Resultate, welche Dareste mit Hülfe dieser Methode erhalten hat, des Genaueren kennen zu lernen. Es gelang ihm, statt der normalen mehr oder weniger rundlichen Gestalt der Keimhaut und der Area vasculosa längliche Formen derselben von sehr differentem Aussehen und Verhalten herzustellen. Die Lage des Embryo in diesen abnorm gestalteten Kémhäuten, sowie deren

1) 1. c. pag. 149-152. 
Lagebeziehungen zu der Längsaxe des Eies liessen sich ebenfalls nach Belieben variiren. Was die längliche Form der Keimhaut und des Gefässhofes anlangt, so bilden dieselben Ellipsen; bei dem Gefässhof zeigten die Ränder der Ellipse vor dem Kopfende deśs Embryo eine mehr oder minder deutlich ausgesprochene Einbuchtung. Die beiden Ellipsen können nun zu der Längsaxe des Eies verschieden orientirt sein. Ihr langer Durchmesser kann mit der letzteren parallel oder zu ihr senkrecht gerichtet sein, ferner kann sie zu derselben auch schief gestellt sein. In allen diesen Fällen besitzt der Embryo, so verschieden er auch im Innern der Ellipse des Gefässhofes sowohl wie der grösseren Ellipse der ganzen Keimhaut gelagert sein kann, doch seine gesetzmässige Stellung und Anordnung im Innern des Gesammteies, d. h. er nimmt stets die Normalstellung ein. Es ist daher nur die Keimhaut, welche durch das Dareste'sche Verfahren gegenüber dem Embryo sowohl als im Gesammtei eine Lageverschiebung in Folge ungleichen Wachsthums erlitten hat.

Aus dem Umstande, dass in allen Fällen der Embryo seine Normalstellung im Ei unverändert beibehalten hat, ergibt sich auch seine Stellung im Innern der Ellipse. Er wird parallel mit deren kürzerem Durchmesser verlaufen, wenn deren Längsaxe mit dem längeren Durchmesser des Eies gleich gerichtet ist; dagegen wird der Embryo in dem Längsdurchmesser der beiden Ellipsen liegen, wenn deren grössere Diameter mit der kurzen Eiaxe zusammenfallen.

Liegt nun die Embryonalaxe parallel zur kürzeren Axe der Ellipse des Gefïsshofes, so kann der grössere Theil der letzteren entweder zur Rechten oder zur Linken des Embryo gelegen sein ${ }^{1}$ ). Im anderen Falle, wenn die Embryonalaxe mit der Lïngsaxe der Ellipse zusammenfällt, kann das grössere Segment der Ellipse entweder vor das Kopfende oder hinter das Schwanzende des Embryo zu liegen kommen.

Um nun diese oder jene der vier letztgenannten Möglichkeiten zu erziclen, gibt Dareste folgende Vorschriften an:

Will man eine senkrechte Stellung der Embryonalaxe zum längeren Durchmesser der beiden Ellipsen erhalten, so muss das Ei so gelagert sein, dass die Längraxe des künftigen Embryo parallel zu dem Verlaufe der Wärmeröhre zu liegen kommt, dabei wird das Ei etwas schief zur Wärmeröhre gostellt, so dass der eine Eipol ein wenig über den anderen zu liegen kommt. Ist der stumpfe Pol etwas höher erhoben, so wird man späterhin das grössere Stück der Ellipse der Keimhaut links von dem Embryo finden; steht dagegen der spitze Eipol etwas höher, so wird das rechts von dem Embryo liegende Segment der Ellipse dis ausgedehntere werden müssen.

Will man eine Parallelstellung der Embryonalaxe zu dem längeren Durchmesser der beiden Ellipsen erreichen, so muss das Ei so angeordnet werden, dass die Längsaxe des künftigen Embryo senkrecht zu der Verlaufsrichtung der Wärmeröhre zu liegen kommt. Befindet sich bei einem so gestellten Ei die Wärmequelle, d. h. die Wärmeröhre, näher an der Kopfregion der späteren Embryonalanlage, so wird der vor dem Kopfende des Embryo

1) Die Begriffe rechts und links bezichen sich auf die Dorsalansicht des Embryo, wemn derselbe so gestellt ist, dass er sein Kopfende von dem Beschauer wegwendet, demselben dagegen sein Schwamzende zukehrt. 
gelegene Theil der Area vasculosa der mächtigere werden müssen; ist sie dagegen dem Schwanzende näher, so wird das grössere Segment der Ellipse hinter den Embryo zu liegen kommen.

Die zur Embryonal- und Eiaxe mit ihrem längeren Durchmesser schief gestellten Ellipsen kommen dadurch zu Stande, dass die Wärmequelle nicht direct vor oder hinter der Embryonalanlage, sondern etwas mehr rechts oder links von der Linie der Längsaxe derselben liegt, wodurch eine ungleiche Entwicklung der seitlich von dem Embryo befindlichen Theile des Blastoderma nach der Wärmequelle hin bedingt wird.

An die willkührlich verursachten Anomalien der Keimhaut schliessen sich, wie Dareste ferner nachgewiesen hat, sehr häufig Formfehler und Monstrositäten des Embryo selbst an. Unter diesen steht obenan der Situs inversus viscerum, der sich, wenn auch nicht constant, dann einstellt, wenn die Entwicklung der Area vasculosa mehr nach links hin durch die entsprechend angeordnete Wärmequelle zu incliniren gezwungen war. Es erscheint dann die Herzschlinge anstatt, wie normal, rechts vom Embryo auf dessen linker Seite und der Kopf legt sich später statt mit der linken, mit der rechten Seite auf dem Dotter auf.

Eine weiterhin sehr wichtige Thatsache, welche eine oftmals wiederkehrende Folgeerscheinung der ungleichen Erwärmung der zu bebrütenden Eier darstellt, ist von Dareste beobachtet worden. Sie besteht darin, dass die Blutinseln der weniger erwärmten Theile der Area vasculosa in ihrer Entwicklung gehemmt werden; die in ihnen gebildeten Blutkörperchen bleiben eingeschlossen, indem die Blutinseln eines mehr oder minder grossen Bezirkes des Gefässhofes nicht mit in die Bildung der Gefässnetze einbezogen werden. Dadurch wird ein Theil der neugebildeten Blutkörperchen verhindert; zu circuliren und zum Herzen zu gelangen; das embryonale Blut enthält nicht die normale Menge von Blutkörperchen, was zu den Erscheinungen der Hydropsie führt, wodurch der Embryo eine verschieden hochgradige Verunstaltung erfährt und schliesslich absterben muss. In Bezug auf diese von Dareste ausführlich erörterten Vorgänge muss ich auf das Original verweisen.

Respiratorische Einwirkungen. Unter dieselben zähle ich alle diejenigen durch äussere Umstände hervorgerufenen Veränderungen der normalen Bebrütung, welche den Gasaustausch, der durch die poröse Kalkschale hindurch zwischen den Zellen der Keimhaut und der äusseren Atmosphäre stattfindet, beeinträchtigen. Jede Zelle muss, um am Leben zu bleiben, Sanerstoff aufnehmen und Kohlensäure abgeben können; man kann diese Vorgänge die Respiration der Zellen nennen. Damit eine Zelle nun respiriren kann, muss ihr eine genügende Menge Sauerstoff zugeführt werden, und sie muss in der Lage sein, die in ihrem Protoplasma entstehende Kohlensäure auszuscheiden. Die Apparate der Athmung und Girculation, welche wir in so verschiedener Ausbildung in der Thierreihe antreffen, dienen den genannten Zweeken; sie ermöglichen die Respiration der Zellen des Organismus. Viel cinfacherer Natur sind die Respirationsvorgïnge in der ersten Entwicklungszeit bei den Zellencomplexen der Keime, aus denen der Thierkörper sich entwickelt. Hier geht durch die Dottermembran hindurch auf dem Wege der 
Diffusion die Aufnahme und Abgabe der beiden Gase vor sich. Bei den Vögeln nun schieben sich ausser der Dottermembran noch eine dünne Eiweissschichte, die Schalenhaut und die Kalkschale zwischen die Keimscheibe und die äussere Atmosphäre ein, durch welche hindurch die Diffusion der Gase stattfinden muss. Derselben wird durch den Umstand, dass die Keimscheibe wegen ihres geringeren specifischen Gewichtes immer bestrebt ist, die höchste Stelle im Ei einzunehmen, wodurch sie bei Horizontalstellung dicht unter die Kalkschale zu liegen kommt, ein wesentlicher Vorschub geleistet.

Die hier zu erörternden Einwirkungen beeinflussen desshalb die Respiration der Zellen der Keimhant, weil sie den Zutritt der äusseren Luft resp. des Sauerstoffes in das Innere des Eies anormal gestalten, indem sie denselben entweder steigern oder beschränken. Man wird ihn steigern, wenn man die Hindernisse, welche die Gasdiffusion zu überwinden hat, verringert, z. B. durch Bruch oder künstliche Verdünnung der Kalkschale: man wird ihn verringern, wenn man die Hindernisse vermehrt, was sich durch partielles oder auch totales Ueberziehen der Schalenoberfläche mit impermeablen Stoffen bewerkstelligen lässt. Dass durch ein solches Verfahren die normale Entwicklung der Keimhaut gestört, unter Umständen ganz aufgehoben wird, kann keinem Zweifel unterworfen sein. Gehört ja doch die Respiration der Zellen zu den unumgänglich nöthigen Lebenserfordernissen, und ist diese in irgend einer Weise geschmälert, so werden auch die Processe der Zellenvermehrung und des Zellenwachsthums, auf denen ja die Entwicklung beruht, zu leiden haben.

Was diejenigen Versuche und Beobachtungen anlangt, die eine Vermehrung des Luftzutrittes in das Innere des Eies während der Bebriitung bezweckten, so ist hier der Mittheilungen Réaumur's, welcher bei Eiern mit allzu dünner Schale nie ein Ausschlüpfen der Hühnchen erzielen konnte, und ferner aller jener Experimente zu gedenken, bei denen eine Verletzung der Eischale stattfand. Ge offroy St. Hilaire der Aeltere erhielt nach Perforation der Schale nur verkrüppelte Hühnchen; nach Panum ${ }^{1}$ ) hat ein Bruch der Schale gewöhnlich Absterben des Embryo oder Nichtentwicklung zur Folge. Auch ist hier an die früher bei Erörterung der mechanischen Einwirkungen angeführten Versuche von Valentin, Leuckart und Schrohe zu erinnern, welche gezeigt haben, dass die Entwicklung des Embryo, wenn man bei der Lïsion der Schale vorsichtig zu Werke geht und die Oeffnung wieder schliesst, nicht sofort sistirt wird.

Schen wir von den letztgenannten Versuchen ab, so sind die Resultate Réaumur's, Geoffroy's und Panum's doch nicht der Art, dass man dieselben der vermehrten Sauerstoffzufuhr allein zuschreiben könnte, da ja bei zu dünner Eischale, oder bei einem Bruch, oder Perforation derselben anch die Verdunstung des Eiweisses ungewöhnlich rasch vor sich gehen muss, wodurch eine Reihe abnormer Zustïnde geschaffen wird, durch welche sich das Ausbleiben oder die Störung der Entwicklung hinreichend erklären lïsst. Den experimentellen Eingriff in der Weise zu grestalten, dass dadurch unter Vermeidung der berührten Uebelstände nur allein die Keimscheibe resp. der 
Embryo einem vermehrten Luftzutritt ausgesetzt wäre, was eine Art von andauernder Apnoë verursachen würde, dies gehört wohl in den Bereich der Unmöglichkeit. Es muss daher unentschieden bleiben, ob durch gesteigerte Sauerstoffzufuhr zu der Keimhaut die normalen Entwicklungsvorgänge überhaupt eine Alteration erleiden.

In bei Weitem vortheilhafterer Lage befindet man sich dagegen, wenn man beabsichtigt, den Luftzutritt zu dem Ei herabzusetzen oder ganz aufzuheben. Die ersten derartigen Versuche wurden schon von Réaumur ${ }^{1}$ ) angestellt. Derselbe hat in verschiedener Weise die Porosität der Eischale zu eliminiren gesucht, indem er die Eier entweder an ihrer ganzen Oberfläche mit Firniss überzog, oder sie unter Wasser ausbrütete. Es ergab sich, dass unter diesen Verhältnissen die Entwicklung unterblieb. Auch machte er die Bemerkung, dass bei Eiern, welche in sehr feuchter Luft ausgebrütet wurden, die Hühnchen nicht zum Auskriechen kamen, was er darauf zurückführt, dass durch die Feuchtigkeit der Luft die Poren der Eischalen verstopft wurden.

Dareste ${ }^{2}$ ), welcher die Versuche Réaumur's, die Eier vor der Bebrütung totaliter mit impermeablen Stoffen zu überziehen, wiederaufnahm, kam zu dem Resultate, dass, wenn sofort nach dem Legen der Eier die Schale luftdicht verschlossen wird, in denselben bei nachheriger Bebrütung keine Entwicklung stattfindet. Dareste wies jedoch auf die Verschiedenheiten des Erfolges hin, je nachdem die Eier mit trocknenden Firnissarten, wie z. B. Collodium, oder mit zähflüssigen Oelsorten überzogen wurden. In den mit Collodium behandelten Eiern trat bei der Bebrütung die Entwicklung ein, dauerte jedoch nur kurze Zeit an, indem sie nach vollendeter Ausbildung der Area vasculosa sistirte. Jedenfalls hat Dareste vollkommen Recht, wenn er zur Erklärung dieser Thatsache annimmt, dass der Collodiumüberzug nach dem Trocknen Sprünge erhielt und somit die Porosität der Schale nicht gänzlich, sondern nur theilweise aufgehoben worden war. Der Embryo konnte sich so lange ausbilden, als ihm die verminderte Menge des zutretenden Sauerstoffs zu seiner Respiration genügte; sobald dies nicht mehr der Fall war, musste er absterben.

Wenn dagegen Eier sofort, nachdem sie gelegt waren, mit einer Decke zähflüssigen Oeles versehen und sodann der künstlichen Bebrütung unterworfen wurden, so blieb jegliche Entwicklung aus. Waren jedoch einige Tage nach dem Legen der Eier vergangen, ehe sie mit dem Oele überstrichen wurden, so begann zwar die Entwicklung, hielt aber sehr bald an. In der Zeit zwischen dem Legen der Eier und der Application des Oelüberzuges hatte sich schon die Luftkammer bilden können; der in ihr enthaltene Sauerstoff war für die erste Entwicklung hinreichend; als derselbe verbraucht war, musste die letztere aufhören.

Die Ergebnisse des Versuches Dares’te's klären die Angaben von

1) Réa um u r, Sur la manière de conserver les oufs. Mém. de l'Acad. des sc. 1735, pag. 465. - Art de faire éclore etc. T. I, pag. 247 und T. II, pag. 317.

2) Dareste, Sur l'influence, qu'exerce sur le développèment du poulet l'application total d'un vernis ou d'un enduit olénginenx sur la coquille de l'œuf. Ann. des sc. nat. T. XV, pag. 5, 1860. 
Baudrimont und Martin-Saint-Ang ${ }^{1}$ ) in befriedigender Weise auf, welche mit den Erfahrungen Réaumur's nicht im Einklang zu stehen schienen. Die beiden Forscher hatten vier Eier gänzlich überfirnisst und nach darauf folgender Bebrütung derselben gefunden, dass die Entwicklungsvorgänge zwar begonnen hatten, aber sehr bald ihr Ende erreicht haben mussten.

Während Réaumur das totale Ueberfirnissen der Eier hauptsächlich in der Absicht vornahm, dieselben zu conserviren, oder die Einwirkung dieses Verfahrens auf ihre Entwicklungsfähigkeit zu prüfen, und auch bei den Versuchen der anderen Autoren, die ich nannte, die letztere Intention die leitende war, wurde die gleiche Methode auch zum Zwecke der Erzeugung von Missbildungen benutzt; natürlich durfte man bei derartigen Experimenten nicht die ganze Eioberfläche überfirnissen, sondern man suchte den zutretenden Sauerstoff quantitativ zu verringern, indem man nur Theile der Eischale für Gase impermeabel machte.

Die Versuche, welche auf einem partiellen Ueberfirnissen der Eischale beruhen, wurden zuerst von dem älteren Geoffroy St. Hilaire unternommen ${ }^{2}$ ). Es gelang ihm bei Eiern, deren Schale er vor der Bebrütung über die Hälfte mit Wachs überzogen hatte, mehrmals Missbildungen zu Stande zu bringen. Nach ihm haben Baudrimont und Martin-Saint-Ange ${ }^{3}$ ) diese Experimente in der Art abgeändert, dass sie nur eine Längshälfte des Eies überfirnissten. Die Eier entwickelten sich ohne Störung, wenn die von dem Firnissüberzuge freie Hälfte während der Bebrütung nach oben zu gekehrt war; wenn dagegen die gefirnisste Hälfte oben lag, so stand die Entwicklung bald stille.

Auch Dareste hat die Methode der partiellen Firnissüberzüge zur Herstellung von Missbildungen in Anwendung gezogen ${ }^{4}$ ). Wenn er vor oder in den ersten Tagen der Bebrütung den spitzen Eipol überfirnisste, wurde die Entwicklung in der Mehrzahl der Fälle gestört; wenn dagegen die gleiche Application erst später nach der Ausbildung der Allantois vorgenommen wurde, so geschah dies ohne Schaden für den Embryo. Wenn Dareste jedoch die stumpfe Polhälfte der Eier mit Firniss überzog, so erhielt er je nach der Zeit, in welcher er diese Procedur vollzog, verschiedene Resultate. Firnisste er die Eier am Anfang, oder in den ersten Tagen der Bebrütung, so konnte er bei der späteren Untersuchung der Eier beobachten, dass die Allantois, falls die Entwicklung des Embryo überhaupt nicht unterblieben oder stille gestanden war, statt im stumpfen Eiende an die Wand der Luftkammer sich

1) Bandrimont et Martin-Saint-Ange, Recherches anatomiques et physiologiques sur le développement du foutus et en particulier sur l'évolntion embryonnaire des Uiseanx et des Batraciens. Recueil des Savants étrangers 1851.

2) Geoffroy St. Hilaire, Mémoire sur les diflérents états de pesanteur des oufs au commencement et à la fin de l'incubation. Journal complémentaire des sciences médicales T. VII, pag. 271, 1820.

Sur des déviations organiqunes provoguées et observées dans les établissements d'incubation artificielle. Mémoires du Musénm T. XIII, parg. 289, 1826.

$\left.{ }^{3}\right)$ 1. c.

${ }^{4}$ ) Dareste, Sur l'influence, qu'exerce sur le développement du poulet l'application partielle d'un vernis sur la corquille de l'ouf. Annales des seiences naturelles. IV. Série. Zoologie T. IV, pag. 119, 1855.

Ferner eine kurze Nitheilung in den Comptes rendus 1855, pag. 963. 
anzulegen, der Eischale an einer anderen nicht gefirnissten Stelle adhärirte. Dareste schreibt es diesem Umstande zu, dass in den betreffenden Eiern der Embryo am Leben geblieben war. Die Allantois, das zweite der Respiration des Embryo dienende Organ, wächst in der Norm gegen die Wand der Luftkammer, in deren Innerem sich nach den Analysen von Baudrimont und Martin-Saint-Ange ein grösserer Procentgehalt von Sauerstoff und ein geringerer von Kohlensäure befindet, als in der das Ei umgebenden Atmosphäre. In Folge des Firnissüberzuges des stumpfen Eiendes musste in der Luftkammer sich dieses Verhältniss zweifelsohne zu Ungunsten des Sauerstoffs ändern. Indem nun die Allantois nach einer anderen, ungefirnissten Stelle der Eioberfäche hinstrebte und hier adhärirte, war es ihr möglich geworden, die Respiration des Fötus im Gange zu halten, wodurch die weitere Entwicklung nicht gehindert wurde. Als Folgeerscheinungen des abnormen Allantoisansatzes fasst Dareste geringgradige Missbildungen an den Embryonen auf, die er in einigen Fällen beobachtete.

Wurde das stumpfe Eiende etwa am 5. Tage der Bebrütung, zu einer Zeit, wo die Allantois sich bereits an die Wand der Luftkammer inserirt hatte, gefirnisst, so gingen die Embryonen in Folge von Asphyxie zu Grunde. Wenn dagegen dieses Verfahren zu einer späteren Zeit, in welcher die Allantois sich bereits über die ganze Innenfläche der Eischale ausgebreitet hatte, vorgenommen wurde, so konnte dadurch keine beträchtliche Behinderung der Wechselbeziehungen zwischen der Allantois und der äusseren Luft mehr verursacht werden; die Entwicklung des Embryo ging ungestört weiter.

Im Allgemeinen hat Dareste, der auch noch in anderer Weise Theile der.Oberfläche mit Firniss überzog — so z. B. wie Baudrimont und MartinSaint-Ange nur die Längshälfte von Eiern -, auf seine diesbezüglichen Untersuchungen folgende Ergebnisse erhalten. Unter den durch das erörterte Verfahren gesetzten Bedingungen findet erstens eine beträchtliche Verringerung der Production von Blutkörperchen statt, und zwar vorzugsweise in den Bezirken der Area vasculosa, welche unter der gefirnissten Fläche der Eischale gelegen sind; es kommt dadurch eine ausgesprochene Anämie der Keimhaut zu Stande. Zweitens wird es unter besagten Verhältnissen sehr leicht zu einer Asphyxie kommen können, deren Grad von den mit der Ausdehnung der Firnissüberzüge sich mehrenden Respirationsbehinderungen abhängt ${ }^{1}$ ).

$\mathrm{Zu}$ den respiratorischen Einwirkungen sind ferner jene Versuche zu zählen, bei denen die Eier in irrespirabeln Gasarten ausgebrütet wurden. Nach Viborg ${ }^{2}$ ) bleibt unter solchen Umständen die Entwicklung gänzlich aus. Ferner möchte ich hier die schon von Réaumur betonten schädlichen Einflüsse fauler Dünste, wie sie ein abgestandenes Ei verbreitet, auf die in der Ausbrütung befindlichen benachbarten Eier erwähnen. Es ist ja bekannt, dass faule Eier für die im gleichen Neste liegenden gesunden von dem grössten Nachtheile sind; dieselben können, falls sie nicht zeitig entfernt werden, ansteckend auf die anderen wirken, und sie in Folge von putrider Infection ebenfalls zum Abstehen bringen.

$\left.{ }^{1}\right)$ D a reste, Recherches sur la production artificielle-etc. pag. 79.

$\left.{ }^{2}\right)$ Det Kongel. Danske Videnskavernes Selskabs Skrivter for Aar. 1803 og 1804,

III. Bd. Kjöbenhavn 1805, 4, pag. 231. (Siche P a n u m 1. c. pag. 18.) 
Ausser den in Vorstehendem angeführten mechanischen, thermischen und respiratorischen Einwirkungen hat man zum Behufe der Herstellung von Missbildungen auch noch Eier während der Bebrütung electrischen Strömen ausgesetzt und ferner den Einfluss des Magnetismus auf die Entwicklung geprüft.

Mit electrischen Strömen scheinen zuerst Prévost und Dumas ${ }^{1}$ ) operirt zu haben. Im Jahre 1868 hat Lombardini ${ }^{2}$ ) gleichfalls dieselben auf auszubrütende Eier wirken lassen, indem er mittelst in die Schale eingestossener Platinelectroden durch Eier sowohl schwache constante Ströme als auch Entladungsschläge, sowie insbesondere Inductionsströme leitete. Durch diese Eingriffe vermochte er unter 43 Eiern in 19 Fällen Anomalien und Missbildungen der verschiedensten Art zu erzielen.

Die Einwirkung des Magnetismus auf die Entwicklung des Embryo hat Maggiorani studirt ${ }^{3}$ ), indem er sowohl unter Brüthennen, als auch im Brütofen die Eier während der Incubation zwischen die Pole von Magneten brachte. Unter den von M a g g io ra n i angegebenen Ergebnissen seiner Untersuchungen möchte ich die folgenden hervorheben. In den dem magnetischen Einflusse unterworfenen Eiern ist die Entwicklung im Vergleiche zu den von jenem Einfluss frei gebliebenen Eiern fast immer verzögert. Trotzdem scheinen die Hühnchen vorzeitig ihre Eier $7^{\Perp}$ verlassen. Die ausgeschlüpften Kücken besitzen noch ein spärliches Gefieder und sind in den ersten 3-4 Tagen in bevorzugter Weise häufigen, ohne sichtliche Ursache eintretenden Todesfällen ausgesetzt; sie zeigten jedoch eine grössere Lebhaftigkeit, als. Hühnchen, die aus nicht magnetisirten Eiern stammten.

Die Untersuchungen, über deren Resultate ich soeben referirt habe, beweisen zweifellos und unbestritten die Thatsache, dass äussere Einwirkungen dic Entwicklung der Embryonen im Ei modificiren können. Allerdings sind die durch dieselben hervorgerufenen inneren Vorgänge, welche zu Anomalien und Monstrositäten führen, sowie die Ursachen, warum überhaupt auf gewisse äussere Einflüsse hin die Embryogenese von der Norm abweicht, erst zum kleinsten Theile erkannt und aufgeklürt. Wenn wir vorerst die zuletzt angeführten Einwirkungen des electrischen Stromes, sowie des Magnetismus, ferner diejenigen Versuche, welche auf einer Läsion der Schale oder des Embryo selbst beruhen, ausser Betracht lassen und somit nur die Folgeerscheinungen der anderen experimentellen Eingriffe in das Auge fassen, so stellt sich heraus, dass eine jede der drei hauptsächlichen Abänderungen der normalen Entwicklungsbedingungen - sowohl die auf mechanischem Wege, als in thermischer oder respiratorischer Hinsicht verursachten Einwirkungen - wichtige und bedeutsame Erfolge aufzuweisen hat. $\mathrm{Zu}$ denselben rechne

1) Prévost und Dumas, Mémoire sur le développement du poulet dans l'ouf. Annales des sciences naturelles. I. Série. T. XII, Jag. 417, 1826.

$\left.{ }^{2}\right)$ L. Lombardini, Intorno alla genesi delle forme organiche irregolari negli necelli e ne' batrachidi. Pisa 1868.

a) K. Maggiorani, Ueber den Einfluss des Magnetismus auf das befruchtete Ei. Allg. Wiener med. Zeitung 1879, Nr. 36. 
ich nicht jene mehrfach bestätigten Beobachtungen, wonach héftiges Schütteln oder Temperaturschwankungen eine Missbildung des Embryo hervorgerufen haben, wenn ich damit auch keineswegs deren allgemeines Interesse verkenne. Meiner Ansicht nach sind durch derartige Manipulationen, insbesondere durch zeitweise Abkühlung oder höhere Erwärmung der auszubrütenden Eier, pathologische Processe eingeleitet worden, vermuthlich Störungen des Blutkreislaufes an dieser oder jener Stelle, sowohl des Embryo als der Keimhaut, die wiederum zu geringerer Entwicklung der betroffenen Theile und somit zur Bildung von Deformitäten Veranlassung gegeben haben. Wir erfahren eben durch alle diese Experimente nur das Eine, dass in Folge dieses oder jenes Eingriffes überhaupt Missbildungen zu Stande gekommen sind, und zwar ganz ungleichartige, indem nach dem nämlichen Eingriff und unter sonst gleichen Umständen in dem einen $\mathrm{Ei}$ diese, in dem anderen jene Missbildung sich entwickelte. Es sind demnach die bei den in Rede stehenden Versuchen zur Anwendung gekommenen Methoden nicht der Art, dass sie uns darüber Aufklärung verschaffen können, wie, wo und warum die ersten $A b$ weichungen von der normalen Entwicklung, welche schliesslich zu Missbildungen führen, begonnen haben.

Diesen mehr einem unbestimmten Ziel zusteuernden experimentellen Eingriffen stehen jene um vieles werthvolleren Untersuchungen gegenüber, durch deren Resultate festgestellt worden ist, dass auf gewisse, präcis ausgeführte äussere Eingriffe auch die Entwicklungsvorgänge eine bestimmte Antwort geben, d. h. dass in der Mehrzahl der Fälle eine dem jeweiligen Eingriff entsprechende Bildungsanomalie sich einstellt. Mit anderen Worten, es folgen auf bestimmte Abänderungen der normalen Entwicklungsbedingungen bestimmte Formabweichungen des Embryo oder des Blastoderma.

Zwar sind es nur wenige Beobachtungen, die hier zu nennen sind, aber sie besitzen eine grosse Tragweite, denn sie eröffnen eine Perspective, welche dem experimentellen Embryologen und Teratologen das anzustrebende Ziel, wenn auch noch aus weiter Ferne vor Augen führt. Dieses besteht in der willkührlichen Erzeugung im Voraus zu bestimmender Formen von Missbildungen. Unter den Untersuchungen, welche ich hier im Sinne habe, steht obenan die von Dareste, dessen Verfahren auf einer thermischen Einwirkung, nämlich auf ungleicher Erwärmung des Eies basirt. Ich habe bereits eingehend auseinandergesetzt, wie Dareste, indem er verschiedene Stellen der Eischale mit der Wärmequelle in Berührung brachte, ganz beliebige Formen des Blastoderm und der Area vasculosa erhielt. Diese Entdeckung, dass man die Gestalt der Keimhaut von aussen her nach Belieben modificiren kann, ist von fundamentaler Bedeutung, denn sie berechtigt zu der Hoffnung, dass das Gleiche sich auch für den Embryo wird erreichen lassen, dessen erste Anlage einen nur wenig von den übrigen Keimhautbezirken differenten 'T'heilabschnitt des Blastoderms darstellt.

Ein zweites, auf mechanischer Wirkung beruhendes Verfahren, welches ebenfalls ermöglicht, bestimmte Theile des Embryo in ihrer Ausbildung zu bevorzugen, ist das von Liharzik angegebene. Dasselbe geht, wie wir wissen, von bestimmten Voraussetzungen aus und beweist den Einfluss der Gravitation auf die Entwicklung, da ja bei Verticalstellung des Eies in der zweiten Hälfte 
der Bebrïtung immer die nach unten gekehrten Körpertheile sich stärker ausbilden als die anderen. Man kann allerdings durch diese Methode, wemn man den stumpfen Eipol nach untęn wendet, den Kopftheil, im umgekehrten Fall den Beckentheil des Embryo zu besonderer Entfaltung bringen; allein es wird sich voraussichtlich diese verschiedene Ausbildung in späterer Zeit nach dem Ausschlüpfen wieder ziemlich ausgleichen und somit keine auffallende Verunstaltung des Körpers persistiren. Ferner kann in der späten Entwicklungszeit, in welcher der experimentelle Eingriff erst stattfindet, kaum mehr ein hoher Grad von Missbildung erzielt werden. Immerhin zeichnet sich das Liharzik'sche Verfahren doch insofern von den meisten anderen aus, als durch dasselbe im Voraus bestimmbare Körpertheile den besagten Störungen ausgesetzt werden.

Schliesslich glaube ich den beiden genannten Methoden noch eine dritte anfügen zu sollen, welche ebenfalls, wenn auch nicht so regelmässig wie jene, eine bestimmte Entwicklungsanomalie zur Folge hat. Dieselbe ist den respiratorischen Einwirkungen zuzurechnen und besteht in einem Ueberfirnissen des stumpfen Eipols. Wie Dareste nachwies, wird durch dieses Verfahren die Allantois häufig von ihrer normalen gegen den stumpfen Pol hin zielenden Wachsthumsrichtung abgelenkt, indem sie nach einer anderen, nicht gefirnissten Stelle der Eioberfläche hin vordringt.

Wie man sieht, reduciren sich die zahlreichen experimentellen Methoden, welche zur Herstellung von Monstrositäten bei dem Hühnerei seitens der verschiedenen Forscher ausgeübt worden sind, auf die geringe Anzahl von drei, sobald man an sie die Anforderung stellt, dass sie bestimmte Veränderungen des Embryo oder der Keimhaut bewirken sollen. Aber auch von diesen drei betrifft nur eine einzige den Embryo selbst, und diese kann erst in einer späten für die Erzielung von stärkeren Deformitäten nicht mehr günstigen Entwicklungszeit angreifen. Die beiden anderen Methoden aber betreffen nicht den Embryo selbst, sondern nur seine Adnexa, die Area vasculosa und das Blastoderm einerseits, sowie die Allantois andererseits. Aus diesen Grïnden wird es begreiflich erscheinen, dass die künstliche Erzeugung von Missbildungen bei vielen Forschern in Misscredit gekommen ist und man sich abfüllig iiber dieselbe iusserte, da man es bisher noch bei keinem Verfahren sicher in der Hand habe, immer und jedesmal nach Belieben diese oder jene Form einer Missbildung höheren Grades zu produciren.

Wenn ich diesen absprechenden Urtheilen eine gewisse Berechtigung auch zugestchen muss, so würde ich es auf der anderen Seite doch für sehr verfehlt halten, wollte man das oben bezeichnete Ziel, welches der experimentellen Embryologie und 'Teratologie gesteckt ist, als ein unerreichbares und die dasselbe verfolgenden Bemühungen als aussichtslose hinstellen. Wenn man in Erwägung zicht, wie verhältnissmässig wenige Gelehrte sich mit dem genannten $/$ weige wissenschaftlicher Forschung eingehender befasst haben, so kann es nicht Wunder nehmen, dass die experimentelle Richtung in der Entwicklungsgeschichte noch in den ersten Anfüngen sich befindet und man darf daher von derselben heutzutage noch keine zu grossen Leistungen erwarten. Ich für meinen 'Theil bin der Meinung, dass derjenige Gelehrte, der es zur Aufgabe seines Tebens gemacht hat, die Bedingungen zu erforschen, unter welchen 
die Abweichungen von der normalen Embryonalentwicklung auftreten, und der selbst unter den zeitweise ungünstigsten Verhältnissen den eingeschlagenen Weg, welcher ihn zu so bedeutenden Entdeckungen führen sollte, unbeirrt weiter verfolgte, wohl am ehesten in der Lage ist, der von ihm vertretenen Wissenschaft eine Prognose zu stellen. Gegen Ende der Einleitung zu seinen Recherches sur la production artificielle des monstruosités spricht Dareste, indem er zur Theilnahme an seinen experimentellen Studien auffordert, die sichere Erwartung aus, dass derartige Bemühungen von Erfolg gekrönt werden würden. Diese Hoffnung wird durch das Zeugniss Darwin's in nicht geringem Grade bekräftigt, welcher in seinem Werke über die Abstammung des Menschen die Untersuchungen Dareste's als für die Zukunft viel versprechende bezeichnet ${ }^{1}$ ), eine Anerkennung, auf die der verdiente französische Forscher gewiss mit Recht stolz sein kann.

Als ich mir überlegte, welche unter den vielen Methoden, mit Hülfe derer man versucht hatte, im Innern des Vogeleies Monstrositäten hervorzurufen, wohl die geeignetste und aussichtsvollste für die künstliche Production von Doppelmissbildungen sein könnte, so schien mir die von Dareste angegebene ungleiche Erwärmung des auszubrütenden Eies vor allen anderen den Vorzug zu verdienen. Denn wenn es möglich ist, die Entwicklung und das Wachsthum der Keimhaut nach einer bestimmten Richtung hin am meisten fortschreiten zu lassen, warum sollte es nicht auch gelingen, auf diejenigen Entwicklungsvorgänge in der Keimhaut, welche das Zustandekommen der Embryonalanlage anbahnen, ebenfalls von aussen her einzuwirken. Jedoch wird man zu dieser Erwartung erst dann berechtigt sein, wenn es sich erreichen lässt, dass der äussere Eingriff in einer entsprechend frühen Zeit von der Keimhaut empfunden wird. Ich dachte zuerst daran, statt einer zwei Wärmequellen anzuwenden und diese an geeigneten Stellen der Eioberfläche anzubringen, habe jedoch, da mir kein hiezu geeigneter Brüteapparat zu Gebote stand, dieses Vorhaben vorerst aufgegeben, indem ich in Erwägung zog, dass ich ja auch durch ein anderes Mittel als durch die Wärme die Vorgänge der Zellenvermehrung und Wachsthums, auf denen ja jegliche Entwicklung beruht, wohl würden beeinflussen lassen. Für diese ist nicht nur die Wärme, sondern in noch höherem Grade der Sanerstoffzutritt ein unbedingtes Erforderniss. Die Physiologie der Zelle, welche den experimentellen Nachweis erbracht hat, dass ohne Sauerstoff keine Zelle sich am Leben erhalten könne, lehrt fernerhin, dass das Wachsthum und die durch Theilung erfolgende-Verlinehrung nur bei solchen Zellen stattfindet, welche sich auf der Höhe ihrer Lebensfunction befinden, und welche in Bezug auf Ernährung und Respiration unter den günstigsten Verhältnissen stehen. Daraus geht hervor, dass bei Zellencomplexen von grösserer oder geringèrer Ausdehnung an denjenigen . Stellen, wo die Zellen unter den vortheilhaftesten Existenzbedingungen sich befinden, deren Vermehrung und Wachsthum am intensivsten vor sich gehen wird, während beide Vorgänge an minder gut situirten Stellen langsamer ab-

1) Darwin, Die Abstammung des Menschen und die geschlechtliche Zuchtwahl Deutsche Uebersetzung von Carus Bd. II, pag. 341. 
laufen müssen. Das Gleiche wird auch für den Zellencomplex der Keimscheibe des gelegten Hühnereies Geltung beanspruchen dürfen, und es ist mit der grössten Wahrscheinlichkeit anzunehmen, dass eben die Stelle der Keimscheibe, in der durch eine stärkere Zellenvermehrung sich die Bildung der Embryonalanlage einleitet, im Bezug auf die berührten Verhältnisse am günstigsten situirt sei. Es ist bekannt, dass die Zellen der Keimscheibe ihre Nahrungsstoffe von dem darunter gelegenen Dotter, den Sauerstoff dagegen von der äusseren Luft beziehen, und es ist das mehrfach betonte Lageverhältniss der Keimscheibe, welche als der specifisch leichteste Theil des Dotters immer nach oben und ferner wegen der geringeren Schwere des Dotters gegenüber dem Eiweiss bei Horizontalstellung des Eies immer dicht unter den Culminationspunct der Schalenoberfläche zu liegen kommt, für den Sauerstoffzutritt von der grössten Bedeutung. Die Versuche von Baudrimont und Martin-Saint-Ange haben gezeigt, dass man von der einen Längshälfte der Eischale unbeschadet der Entwicklung den Luftzutritt abhalten kann, wenn man die ungefirnisste Schalenhälfte während der Bebrütung nach oben kehrt. Ich selbst habe mehrfach noch weitergehende Versuche angestellt, indem ich noch grössere Strecken der Eioberfläche überfirnisst habe, und nur eine kleine runde Stelle von etwa 2 Ctm. Durchmesser freiliess. War diese, während das Ei in horizontaler Stellung bebrütet wurde, nach oben gewendet, kam sie also unmittelbar über die Keimscheibe zu liegen, so blieb die Entwicklung niemals aus, und dauerte mindestens 2-3 Tage an. Dadurch ist die $W$ ichtigkeit des vorhin hervorgehobenen Lageverhältnisses der Keimscheibe im Ei experimentell bewiesen und es geht aus diesen Versuchen ferner hervor, dass die Keimscheibe aus der umgebenden Luft den zur Entwicklung nöthigen Sauerstoff fäst ausschliesslich durch den unmittelbar über ihr liegenden Bezirk der Eischale hindurch bezieht.

Hat man nun die Absicht, an einer bestimmten Stelle der Keimhaut die Zellen unter bevorzugte Existenzbedingungen zu bringen, so wird es sich darum handeln müssen, zu der betreffenden Stelle entweder eine grössere Zufuhr von Nährmaterial oder von Sauerstoff hinzuleiten, als zu den übrigen Partien. Das erstere wird sich mit unseren jetzigen Hülfsmitteln nicht erreichen lassen, dagegen gehört das letztere, da man es ja in der Hand hat, von bestimmten Stellen der Eioberfläche den Sauerstoff abzuschliessen, nicht zu den Unmöglichkeiten. Da ja die Keimscheibe unmittelbar unter der Culminationsstelle der Eioberfläche bei Horizontalstellung des Eies liegt, indem sich zwischen sie und die Schalenhaut nur eine minimale Eiweissschichte einschiebt, so ist sie dem auf die genannten Voraussetzungen basirenden Experimente nicht unzugänglich. Man wird den Firnissüberzug und die Lagerung des Eies so einrichten müssen, dass bei den zu den Versuchen beniitzten Eiern, welche in horizontaler Stellung zu fixiren sind, gewisse Stellen der Schalenoberfläche, die den zu bevorzugenden Bezirken der Keimscheibe entsprechen, nicht ïberfirnisst werden. Die freibleibenden Stellen bilden dann. gewissermassen die Sauerstoffquellen für die darunter liegende Keimscheibe; die einer jeden Sauerstoffquelle am nächsten liegenden Zellenbezirke werden sich unter besseren Existenzbedingungen befinden, als die entfernter gelegenen; die ersteren werden daher unserer Voraussetzung nach eine gesteigerte Zellen- 
vermehrung und somit lebhaftere Entwicklungsprocesse aufweisen müssen, als die letzteren.

Ist unsere Annahme, wonach durch das erörterte Verfahren auf bestimmte Stellen der Keimscheibe entwicklungsfördernd eingewirkt werden könne, richtig, so hat man es in der Hand, da man ja die Normalstellung der Embryonalanlage kennt, also weiss, in welchen Keimhautbezirk der Embryo mit seinem Kopfende oder hinterem Ende zu liegen kommt, die Ausbildung beliebig gewählter Theile desselben gegenüber anderen Abschnitten des Embryonalkörpers sich rascher und voluminöser vollziehen zu lassen. Man braucht ja nur den Firnissuiberzug, sei es vor oder in der ersten Zeit der Bebrütung, so einzurichten, dass gewisse Stellen der Schale unweit der in ihrer Entwicklung zu fördernden Embryonaltheile frei bleiben, und wird so auf experimentellem Wege eine ungleiche Ausbildung des Embryonalkörpers und damit Monstrositäten erhalten können.

Aber nicht nur auf die schon gebildete Fruchtanlage, sondern auch auf deren Zustandekommen wird vielleicht durch das genannte Verfahren ein Einfluss ausgeübt werden können. Das Auftreten derselben besteht ja in einer intensiveren Vermehrung der Ektodermzellen, welche an einer bestimmten Stelle der Keimhaut beginnt. Wenn nun die oben ausgesprochene Vermuthung zutreffend ist, dass die normale Stelle der Embryonalanlage für die Zellenvermehrung die günstigsten Verhältnisse darbiete, so ist die Annahme nicht allzu kühn, dass man die Bildung der Embryonalanlage an eine beliebige Stelle der Keimhaut verlegen könne, wenn man durch das geschilderte Verfahren eben diese gegenüber allen andern Bezirken der Keimhaut günstiger situirt. Würde sich diese Erwartung bestätigen, so würde sich daran die zweite Frage anschliessen, ob es möglich sei, durch Eröffnung von zwei Sauerstoffquellen zwei Stellen der Keimhaut in dem erörterten Sinne zu begünstigen, um vielleicht dadurch das Auftreten zweier Embryonalanlagen, resp. einer Doppelbildung zu erzielen.

Wie man sieht, ist es die Methode der partiellen Firnissüberzüge, welche mir die besten Resultate für die Production von Doppelmissbildungen zu versprechen schien. Ich habe bereits angedeutet, wie dieselbe angewandt werden muss, wenn hiedurch die gewünschte Einwirkung auf die Bildungsvorgänge in der Keimhaut mit Aussicht auf Erfolg ausgeübt werden soll. Man wird sich vor dem Firnissen der Eier darüber klar sein müssen, welche Bezirke der Keimhaut bevorzugt werden sollen, um dem entsprechende Stellen der Schalenoberfläche ungefirnisst zu lassen. Hierin beruht der wesentliche Unterschied des von mir vorgeschlagenen Verfahrens gegenüber der Art und Weise, wie bei den früheren Versuchen Theile der Schalenoberfläche impermeabel gemacht wurden. Während die letzteren mehr in der Intention angestellt wurden, um zu erfahren, ob und in welcher Weise die Entwicklung des Embryo beeinträchtigt würde, wenn man grössere oder geringere Strecken der Schale, die stumpfe oder spitze Polhälfte, oder eine Längshälfte für Gase undurchgängig machte, so lag den in Folgendem zu beschreibenden Experimenten eine ganz bestimmte Voraussetzung zu Grunde, indem je nach der beabsichtigten Einwirkung gewisse Stellen der Schale von den Firnissiiberzügen befreit bleiben mussten. 
Da man nun verschiẹdene Bezirke der Keimhaut auswählen kann, um in ihnen eine energischere Zellenvermehrung resp. Entwicklung zu veranlassen, so wird man demgemäss auch verschiedene Stellen der Schale ungefirnisst lassen müssen. Damit ist ausgesprochen, dass die Versuche sehr variirt werden können, je nach dem Plane, welcher bei deren Ausführung befolgt wird.

In einem früheren Abschnitte ist die erste Anlage der verschiedenen Formen von Doppelbildungen eingehend besprochen und gezeigt worden, an welchen Stellen der Keimhaut sich deren Genese besonders häufig einleitet. Es scheint darum gerathen, diesen Fingerzeig nicht unbenutzt zu lassen, will man die Experimente mit mehr Aussicht auf Erfolg unternehmen. Es werden desshalb diejenigen Stellen der Keimhaut mit einer grösseren Sauerstoffzufuhr zu versehen sein, in welchen erfahrungsgemäss die ersten Entwicklungsvorgänge beginnen, die zu der beabsichtigten Form der Doppelbildung führen.

Um eine zu weit gehende Zersplitterung meiner Versuche zu vermeiden, schien es mir angezeigt, vorerst darauf zu verzichten, die Production verschiedener Formen von Doppelbildungen anzustreben; ich hielt es um so mehr für geboten, mich zunächst auf eine einzige Form zu beschränken, da ja die in Anwendung kommende Methode erst nach mehreren Seiten hin auf ihre Leistungsfähigkeit geprüft werden musste. Angesichts der in vielen Fällen zu erwartenden Misserfolge war voraussichtlich über den Werth meines Verfahrens erst dann ein Urtheil möglich, nachdem mittelst desselben recht zahlreiche Experimente und zwar sämmtlich zu demselben Zwecke und immer in der gleichen Weise oder jedenfalls nur unter ganz geringen Abänderungen ausgeführt worden waren.

Bei der Wahl unter den einzelnen Formen von Doppelbildungen habe ich mich für die Duplicitas anterior entschieden. Ich habe dieser aus verschiedenen Gründen den Vorzug gegeben. Erstens schien sie mir unter allen andern Doppelbildungen der künstlichen Production die günstigsten Chancen zu gewähren, da sich bei ihrer Genese, wie wir wissen, in der ersten Zeit die Embryonalanlage ganz normal verhält, und erst später, während ihres Vordringens in die Area pellucida, anormaler Weise nach zwei Seiten hin divergirt. Es schien mir am leichtesten, die zum Zustandekommen dieser Divergenz nöthigen Bedingungen herzustellen. Zweitens sind die Fülle vorderer Verdopplung von Hühnerembryonen in der Literatur bekanntlich nur sehr gering vertreten, wesshalb eine Bereicherung derselben an solchen Fiillen sehr zu wünschen ist. Schliesslich hoffte ich, durch den Ausfall der zu besagtem Zwecke angestellten Experimente am besten über die Richtigkeit der meiner Methode zu Grunde liegenden Voraussetzung Aufschluss $\%$ erhalten, nämlich über die Frage, ob überhampt eine ungleiche Entwicklung der Keimhant oder des Embryo resultirt, wenn zu gewissen Stellen derselben eine grössere Sauerstoffzufuhr hingeleitet wird.

Um eine Duplicitas anterior zu erzielen, verfuhr ich bei dem Firnissen der Eier in folgender Weise: es wurde auf die Schale eines Eios mit Bleistift eine Linie gezogen, welche von dem Mittelpunkt des stumpfen Poles aus zu dem des spitzen Poles und von da nach dem Ausgangspunkte zuruickgeführt 
wurde. Diese Linie, welche, wenn man das Ei als eine Kugel auffassen dürfte, einem grössten (Längen-) Kreise entsprechen würde, theilt die Oberfläche der Eischale in zwei Hälften ab; ich will sie kurz als „Richtungslinie" bezeichnen. Hatte ich die Richtungslinie aufgezeichnet, so wurde die eine Hälfte der Schale mit rasch trocknendem Firniss überstrichen. Nach dem Trocknen der Firnissschichte wurde das Ei so auf einen Eiträger gelegt, dass die frei gebliebene Hälfte nach oben gekehrt war, und die Richtungslinie in eine Horizontalebene fiel. Den Eiträger selbst, auf dem das Ei von nun an nicht mehr aus seiner Lage verschoben werden darf, habe ich hierauf so vor mich hingestellt, dass der stumpfe Pol des Eies nach links, der spitze nach rechts gekehrt war. Sodann zeichnete ich auf die ungefirnisste Schalenhälfte die Figur eines $\mathrm{Y}$ in der $\mathrm{W}$ eise auf, dass der hintere Schenkel des $\mathrm{Y}$ in einer von beiden Eipolen gleich weit entfernten Aequatoriallinie verlief. Die Breite der drei Schenkel des $\mathrm{Y}$ war nicht in allen Fällen die gleiche; sie differirte zwischen 5 und $10 \mathrm{Mm}$. Auch der nach vorne zu offene Winkel, den die beiden paarigen Schenkel des $\mathrm{Y}$ mit einander bildeten, variirte zwischen 70 und $50^{\circ}$. Der hintere Schenkel des Y, dessen Lünge in den einzelnen Fällen zwischen 12 und $20 \mathrm{Mm}$. schwankte, grenzte mit seinem freien Ende an die mir zugewendete Hälfte der Richtungslinie, während die beiden paarigen Schenkel mit ihren freien vorderen Enden an die von mir abgewendete Hälfte der Richtungslinie entweder ganz oder wenigstens nahezu heranreichten. Ich will hier einschalten, dass ich nach einigen Versuchen es für rationeller erachtete, den hinteren unpaaren Schenkel des Y gänzlich wegzulassen, sodass die Figur eines V entstand, welches jedoch die gleichen Grössenverhältnisse und die gleichen Lagebeziehungen zur Richtungslinie und Aequatoriallinie zeigen muss, welche ich soeben für die beiden vorderen paarigen Schenkel des $\mathrm{Y}$ angegeben habe.

War nun die eine oder die andere Figur auf die Eischale in der beschriebenen Weise aufgezeichnet worden, so wurde auch die restirende Hälfte der Eischale mit Ausnahme des $\mathrm{Y}$ oder des $\mathrm{V}$ mit Firniss überzogen und sodann das Ei mit seinem Träger in den Brütofen gebracht. Für gewöhnlich habe ich immer gleich mehrere Eier, 4-6 an der Zahl, gefirnisst, und liess sie gleichzeitig sich im Brütofen entwickeln. Die Untersuchung der Eier wurde am dritten bis zum sechsten Tage vorgenommen.

Durch das Ueberziehen der Eischale mit Firniss unter Schonung der Y- oder V-förmigen Stellen, war nun der in das Eiinnere eindringenden Luft ein bestimmter Weg angewiesen worden. Der hintere Schenkel des Y im einen, oder die Spitze des V im andern Falle lag nahezu über, oder jedenfalls in einer nur geringen Entfernung von derjenigen Stelle der Keimhaut, in welcher der Primitivstreif auftritt, während die paarigen Schenkel der beiden Figuren mehr seitwärts von der Keimscheibe verliefen. Demnach mussten dié seitlichen Theile des Fruchthofes, da sie näher an die Sanerstoffquelle zu liegen kamen, einen intensiveren Stoffwechsel erlangen und unterhalten als die mehr der Medianlinie genäherten Bezirke. Auf diese Wciso hofte ich die Embryonalanlage in ihrem vorderen-Theile, oder was dasselbe sagen will, entweder das vordere Ende des Primitivstreifens oder wenigstens den Kopffortsatz desselben nach beiden Seiten hin abzuziehen, um so ein 
Divergiren der Embryonalanlage in zwei Schenkel und, daran anschliessend, eine Dicephalie zu erzielen.

Dass mir dies in einzelnen günstigen Fällen auch wirklich gelungen, wird man aus den Ergebnissen meiner Versuche, deren Schilderung ich sogleich folgen lasse, ersehen. Ich habe zu denselben nach und nach 60 Eier verbraucht. Von diesen enthielten 20 normal gebildete Embryonen ${ }^{1}$ ); nur waren dieselben ohne Ausnahme zeitlich in ihrer Entwicklung zurück, einige nur verhältnissmässig wenig, die andern aber in ziemlich hohem Grade. Diese verlangsamte Embryogenese ist wohl zweifelsohne in der Reduction des in das Innere des Eies eindringenden Luftquantums in Folge der Firnissüberzüge begründet. Bei weiteren 14 Eiern vermochte ich überhaupt keine Embryonalbildung zu erkennen; die Keimhäute derselben waren theils sehr klein — nur wenig grösser als die Keimscheibe des unbebrüteten Hühnereies — theils hatten sie sich unregelmässig ausgedehnt, jedoch ohne dass eine Area pellucida und opaca bei ihnen zu unterscheiden gewesen wären. Diese negativen Befunde möchte ich weniger dem experimentellen Eingriff zur Last legen, als anderen Ursachen. Vielleicht handelte es sich um unbefruchtete Eier; oder, da meine Versuche im Sommer ausgeführt wurden und viele der'hiezu benützten Eier, die ich allerdings ganz frisch zugetragen bekam, oft über eine Woche lang in meinen um die genannte Zeit ziemlich hoch temperirten Arbeitszimmern lagen, ehe sie zur Verwendung kamen, so konnte leicht eine langsame Entwicklung bei denselben eingetreten sein, nach deren Stillstand eine allmählige Zersetzung der Keimhaut und des Embryo stattfand.

Von den restirenden 26 Eiern zeigten 19 ausgesprochene Abnormitäten der Embryonalentwicklung; bei den letzten 7 Eiern endlich erschien es mir zweifelhaft, ob diè bei ihnen vorgefundenen Formabweichungen nicht als zufällige zu betrachten seien, ob sie nicht vielleicht auch dann eingetreten wären, wenn man vor der Bebrütung das Firnissen der Schale gänzlich unterlassen hätte.

Die in den 19 Eiern enthaltenen Keimhäute habe ich nach den Entwicklungsstadien, welche die abnorm beschaffenen Embryonen derselben darboten, geordnet, und werde nachstehend dieselben in der Reihenfolge schildern, dass die frühesten Entwicklungsphasen den Anfang machen. Der leichteren Uebersicht halber bei der Besprechung der Resultate meiner Versuche habe ich die einzelnen Keimhäute numerirt.

Nr. 1. Die Keimhaut (Fig. 1, Taf. VIII) war am vierten Tage der Bebrütung aus dem Ei herausgenommen worden. Die Area pellucida und opaca sind deutlich zu unterscheiden. Die erstere hat hinsichtlich ihrer Form noch am meisten mit einem Viereck Aehnlichkeit, von dem zwei Ecken abgerundet sind, während die beiden anderen Ecken durch einen Schrïgschnitt abgetrennt erscheinen. Der längere Durchnesser des durchsichtigen Fruchthofes beliiuft sich auf $3 \frac{1}{2}$, der kürzere auf $3 \mathrm{Mm}$. Von einem Primitivstreifen oder einer sonstigen Embryonolanlage ist nichts \%u be-

1) Durch die bereits mitgetheilten Erfahrungen Dareste's über die zuweilen vorkommende Incongruenz der formativen Entwieklungsvorgänge und der des embryonalen Wachsthums anfmerksam gemacht, habe ich die Körperlänge der meisten dieser 20 Embryonen mit der von normal bebrïteten Embryonen der gleichen Stadien verglichen, und konnte in vielen Fällen constatiren, dass dieselbe bei den ersteren etwas geringer war, als bei den letzteren. 
merken; dagegen ist in der Nähe des Randes der Area pellucida an einer Stelle, welche wahrscheinlich in den Bezirk des Primitivstreifens gefallen wäre, eine kleine, rundliche Verdickung des Blastoderm wahrzunehmen.

Das Ektoderm ist über den Rand der Area opaca um eine beträchtliche Strecke weiter peripherwärts gewachsen.

Nr. 2. Das Ei wurde am vierten Tage untersucht. Die Keimhaut desselben (Fig. 2, Taf. VIII) zeigt eine Area pellucida und opaca, welche jedoch auf einer Seite sich nicht scharf von einander abheben. Die Area pellucida besitzt die Gestalt eines Vierecks, dessen Ecken abgerundet, dessen Seiten bogenförmig eingebuchtet sind. An der muthmasslichen Eintrittsstelle des Primitivstreifens beobachtet man eine breitere Verdickung der Keimhaut, welche, in den durchsichtigen Fruchthof vordringend, mit zwei Zacken endet; es macht den Eindruck, als ob es sich um die ersten Stadien der Entwicklung von zwei nebeneinander in den durchsichtigen Fruchthof eindringenden Primitivstreifen handeln würde.

Die Grenzen des Ektoderm, welches sich über den Rand der Area opaca hinaus bereits ausgedehnt hatte, sind in der Fig. 2, Taf. VIII nicht wiedergegeben worden.

Nr. 3. Das Ei wurde am dritten Tage der Bebrütung geöffnet. Die Keimhaut (Fig. 3, Taf. VIII) besass eine deutlich abgegrenzte Area opaca und pellucida. Die letztere zeigt bereits schon eine leicht birnförmige Gestalt, indem das Zuwachsstück im Begriff ist, sich mit ihr zu vereinigen. Der Längsdurchmesser des durchsichtigen Fruchthofes beträgt 2,3 Mm. Der Primitivstreifen zeigt an einem vordern Ende eine unbestreitbare Bifurcation. Die Länge eines jeden der beiden Schenkel wird sich ungefähr auf den dritten Theil der Gesammtlänge des Primitivstreifens bemessen, so dass demnach nur dessen vorderes Drittheil verdoppelt erscheint. Von dem hinteren Rande der Area pellucida bis zur Spitze des Divergenzwinkels der beiden Schenkel messe ich 1,2 Mm. Eine Primitivrinne ist noch nirgends bemerklich; das Mesoderm ist bereits in den Anfängen vorhanden; doch ist seine Grenzlinie beiderseits von den Primitivstreifen noch sehr undeutlich.

Das Ektoderm hat nur wenig die Ränder der Area opaca überwachsen. Im Entoderm der Area pellucida sind bei durchfallendem Lichte zahlreiche Furchungskugeln zu erkennen.

Nr. 4. Das Ei wurde am vierten Tage aus dem Brütofen genommen. Die Keimhaut (Fig. 4, Taf. VIII) theilt sich deutlich in eine Area opaca und pellucida ab. Letztere ist länglich und besitzt einen längeren Durchmesser von $2 \mathrm{Mm}$. Sie enthält eine oblonge Verdickung, welche an ihrem einen Ende etwas seitlich umbiegt, und welche wohl die in der Zersetzung befindliche Embryonalanlage darstellt.

Das Ektoderm hat den Rand der Area opaca nur wenig überwuchert.

Nr. 5. Das Ei wurde am vierten Tage untersucht. In der Keimhaut (Fig. 5, Taf. VIII) sind Area pellucida und opaca gut gegen einander abgegrenzt; die erstere ist oval und besitzt einen längeren Durchmesser von $2 \mathrm{Mm}$. Der Primitivstreifen ist schon aufgetreten; er stellt jedoch nur eine kurze Verdickung der Keimhaut im hinteren Theile des durchsichtigen Fruchthofes dar und zeigt eine merkwürdige Verbildung., $V_{\text {on }}$ seiner hintern Hälfte geht gegen die Furchungshöhle zu cine zapfenförmige Wucherung ab, welche nur von der ventralen Seite aus ersichtlich ist. Die dorsale Seite der Keimhaut lässt an der Abgangsstelle der Wucherung eine feine Oeffnung erkennen, so dass eine hohle Beschaffenheit- der letzteren nicht unwahrscheinlich ist. Dieselbe würde dann eine ventralwärts gerichtete, blindsackförmige Ausstiilpung der Keimhaut bilden.

Das Ektoderm ist noch nicht sehr weit peripherwürts vorgedrungen. 
Nr. 6. Die Keimhaut (Fig. 6, Taf. VIII) wurde am dritten Tage der Bebrütung dem Ei entnommen. Die Area pellucida und opaca heben sich gut von einander ab; der durchsichtige Fruchthof hat sein Zuwachsstück bereits erhalten, ist länglich und besitzt einen Längsdurchmesser von $3 \frac{1}{2} \mathrm{Mm}$. Der Primitivstreifen grenzt mit seinem hintern Ende an den Rand der Area opaca an; dasselbe besitzt eine ventralwärts gerichtete, rundliche Anschwellung. Der mittlere Theil des Primitivstreifens ist sehr undeutlich, das vordere Ende dagegen wieder etwas besser ausgebildet. Eine Primitivrinne ist nicht vorhanden; die Grenzen des Embryonalschildes sind sehr deutlich markirt.

Das Ektoderm hat nur um ein Geringes den Rand der Area opaca überschritten.

Nr. 7. Das Ei wurde am Anfange des dritten Tages aus dem Brïtofen herausgenommen. In der Keimhaut (Fig. 7, Taf. VIII) sind die beiden Areae sehr gut von einander zu unterscheiden. Die Area pellucida besitzt eine ovale Form; ihre Länge beträgt $3^{1} / 2 \mathrm{Mm}$. Das Entwicklungsstadium der Embryonanlage entspricht der 15.-16. Stunde bei normaler Bebrütung. Vor dem Primitivstreifen ist bereits der Kopffortsatz, resp. Chorda dorsalis aufgetreten und schon verhältnissmässig lang geworden, so dass die Anlage der Rückenfurche und der Kopffalte wohl in nächster Zeit sich hätte einstellen müssen. Das mittlere Keimblatt hat schon eine ziemliche Ausdehnung erlangt. Es hat, abgesehen von dem vorderen Bezirke der Area pellucida, deren Rand schon überall überschritten. Eine vordere Amnionfalte ist angedeutet.

Das Ektoderm hat sich nur mässig über die Grenzen der Area opaca hinaus ausgedehnt.

Das Pathologische an der in Rede stehenden Keimhaut besteht in einem abnormen Verhalten des Primitivstreifens. Derselbe zeigt eine mehr von seiner hinteren Hälfte ausgegangene starke Wucherung, welche dorsalwärts gerichtet ist. Dieselbe ist, wie es scheint, solide, von kugelig spindelförmiger Form und lässt auf der rechten Seite einen seichten Einschnitt erkennen; hinter der Wucherung befindet sich noch ein ganz kurzes Stückchen des Primitivstreifens, innerhalb dessen er normale Verhältnisse aufweist, indem hier eine Primitivrinne erkennbar ist; auch in dem vor der Wucherung gelegenen Abschnitte ist die Primitivrinne ausgebildet. Die Wucherung selbst besitzt auf ihrer dorsalen Oberfläche nicht die geringste Spur einer rinnenförmigen Einsenkung.

Nr. 8. Das Ei wurde am vierten Tage aus dem Brütofen genommen und untersucht. Die Keimhaut (Fig. 1, Taf. IX) ist gut ausgebildet; der durchsichtige Fruchthof hebt sich von der Area opaca deutlich ab. Der erstere hat eine längliche Form, sein Lïngsdurchmesser beträigt $3 \mathrm{Mm}$. Die Dorsalfläche der Keimhaut lässt sehr deutlich eine Rückenfurche erkennen, welche vorne und hinten an geschwulstartige Massen angrenzt. Bei nüherem Zusehen bemerkt man, dass die hintere Geschwulst von dem Primitivstreifon gebildet wird, der zu einer dorsalwïrts prominenten lïnglichen Verdickung angeschwollen ist; eine Primitivrinne existirt nicht. Von dem vorderen Ende des Primitivstreifens sieht man conisch sich verjüngend die Chorda abgehen, welche sich jedoch nicht mehr weit am Boden der Rückenfurche verfolgen lässt. Vor dem vorderen Ende der Rückenfurche, welches durch die hier convergirenden und sich aneinanderlegenden Rückenwülste gebildet wird, befindet sich eine unregelmässig umgrenzte Oeffinung, welche in eine gegen den Dotter und nach vorne zu gerichtete ventrale Ausstülpung führt, deren vorderes Ende durch die dünne Keimhaut durchscheint. Es ist also hier anstatt der normalen dorsalen Ausstïlpung des Blastoderms, als welche man die Anlage des Vorderdarms in der ersten Zeit auflassen kann, cine solche anfgetreten, welche die entgregengesetzte Richtung einschlug. 
Entlang der Medullarfurche haben sich beiderseits eine Reihe von Urwirbeln gebildet, die bei der Betrachtung der Dorsalfläche nur schwer zu sehen sind, dagegen auf der ventralen Fläche der Keimhaut deutlicher hervortreten.

Das mittlere Keimblatt ist schon mehr entwickelt, es ist fast überall - nur vorne ausgenommen - über den Rand der Area pellucida hinausgewuchert; es hat eine kartenherzförmige Gestalt; in dem Ausschnitt des Herzens liegt das durchscheinende vordere Ende der Ausstülpung. Die letztere erscheint auf der ventralen Seite als eine entsprechend grosse zapfenartige Wucherung.

Der Durchmesser der gesammten Keimhaut beträgt etwa $8 \mathrm{Mm}$.

Nr. 9. Das Ei wurde' am vierten Tage der Bebrütung untersucht. Die Keimhaut (Fig. 2, Taf. IX) zeigt eine birnförmige Area pellucida, welche gegen die Area opaca sich gut abgrenzt. Das Blastoderma macht den Eindruck, als ob es bereits in der Zersetzung begriffen sei; doch lïsst sich die Form des Embryo noch durchaus erkennen. Seine Ausbildung entspricht etwa der 20. Stunde des ersten Tages bei normaler Entwicklung. Auffallend ist seine geringe Länge, welche sich nur auf 1,75 Mm. bemisst, während die Länge eines dem gleichen Entwicklungsstadium angehörigen normalen Embryo etwa $3 \mathrm{Mm}$. beträgt. Die Hälfte der gesammten Länge des Embryo wird von dem Primitivstreifen eingenommen, welcher eine längliche wulstförmige Verdickung darstellt; eine Primitivrinne ist nicht wahrzunehmen. Vor dem Streifen liegt eine nur schwach vertiefte Rückenfurche, welche vorne mit einer sehr gut ausgebildeten Kopffalte abschliesst; die letztere ist jedoch so stark verbreitert, dass die Medullarfurche an ihrem vordern Ende in die Quere ausgezogen erscheint, wodurch ihre Gestalt eine Tförmige wird. Es gewinnt dadurch den Anschein, als ob das vordere Ende der Medullarfurche, allerdings unter sehr stumpfem Winkel in zwei kurze Schenkel divergire. Man könnte demnach die breite Kopffalte also aus zwei neben einander gelegenen bestehend, auffassen, wofür auch die nur unbedeutende Länge der Medullarfurche sprechen würde. Leider war es mir unmöglich, die Chorda dorsalis, welche im hinteren Theile der Rückenfurche sehr deutlich zu beobachten ist, bis an ihr vorderes Ende zu verfolgen. Es muss daher unbestimmt bleiben, ob sie einfach verlief, oder ob sie vorne vielleicht eine Bifurcation aufwies.

Betrachtet man die Keimhaut von der ventralen Seite aus, so kann man die bereits beginnende Anlage des Vorderdarms wahrnehmen; dieselbe ist eine ungemein breite.

Das mittlere Keimblatt hat, wie die Abbildung zeigt, schon eine ziemliche Ausdehnung erlangt. Der Durchmesser der ganzen Keimhaut beträgt $7 \mathrm{Mm}$.

Nr. 10. Das Ei wurde am dritten Brütetage untersucht. Die Keimhaut (Fig. 3, Taf. IX) besitzt eine Area pellucida von länglicher Form, deren Lüngsdurchmesser 3,7 Mm. beträgt. Die Ausbildung des Embryo entspricht den letzten Stunden des ersten Brütetages bei normaler Entwicklung. Die Rückenfurche ist vollkommen ausgebildet, es sind 5 Urwirbelpaare aufgetreten, die Kopfdarmhöhle ist in der Anlage begriffen. Der Primitivstreifen, welcher noch überall deutlich zu erkennen ist, hat eine Lünge von 1,7 Mm. Auffallend und anormal bei dem Embryo ist seine kurze, gedrungene Gestalt, indem er, inclusive des Primitivstreifens, nur 3,4 Mm. lang ist, während die Lünge eines im gleichen Stadium befindlichen normalen Embryo mindestens 4,2 Mm., gewöhnlich sogar schon 4,5 Mm. beträgt. Ferner überrascht bei dem Embryo die ungemeine Breite des vorderen Endes der Rückenfurche, sowie der Kopfdarmhöhle. Die erstere ist nahez̃ $1 \mathrm{Mm}$. breit, wiilurend bei einem gleich entwickelten normalen Embryo dieselbe nur eine Breite von 0,5 $\mathrm{Mm}$. bis höchstens $0,75 \mathrm{Mm}$. besitzt. 
Das Mesoderm zeigt eine ähnliche Ausdehnung wie im vorigen Falle; die vordere Amnionfalte ist bereits angedeutet. Der Durchmesser der gesammten Keimhaut beläuft sich auf $9-10 \mathrm{Mm}$.

Nr. 11. Das Ei wurde am dritten Tage der Bebrütung geöffnet. Die Keimhaut (Fig. 4, Taf. IX) hat mit der vorigen sehr viele Aehnlichkeit. Die Area pellucida ist gleichfalls von länglicher Form und enthält einen Embryo, der einem nur wenig weiter fortgeschrittenen Entwicklungsstadium angehört, wie der des vorigen Falles, indem der vordere Theil der Rückenfurche und die Kopfdarmhöhle etwas weiter ausgebildet erscheinen. Die Länge des Embryo ist die gleiche wie bei $\mathrm{Nr}$. 10, nämlich 3,4 Mm.; er ist demnach ebenfalls in seinem Längenwachsthum hinter einem normal bebrüteten Hühnerembryo der gleichen Ausbildung zurückgeblieben. Die Unregelmässigkeit besteht auch hier in einer ungewöhnlichen Breite der vorderen Rückenfurche; jedoch ist dieselbe verhältnissmässig nicht ganz so stark, wie beim vorigen Embryo.

Die Zahl der Urwirbelpaare beträgt 4-5; der Primitivstreifen, deșen hinteres Ende noch die Reste der Sichel zeigt, lässt in seiner Rinne einen sehr gut ausgebildeten Axenfaden erkennen.

Das Mesoderm hat sich entsprechend der Entwicklungsstufe des Embryo ausgedehnt; die vordere Amnionfalte ist schon aufgetreten. Der Durchmesser der gesammten Keimhaut beträgt $10 \mathrm{Mm}$.

Nr. 12. Das Ei wurde am vierten Tage der Bebrütung untersucht. Die Keimhaut (Fig. 5, Taf. IX) enthält eine Area pellucida, deren Gestalt länglich bisquitförmig ist. Der Embryo entspricht hinsichtlich der Zahl der Urwirbelpaare; sowie der Grösse des noch nicht geschlossenen Theiles des Medullarrohrs einem normal - bebrüteten Hühnerembryo der 26.-28. Stunde. Diesem Entwicklungsstadium ist jedoch seine Länge nicht proportional, welche nur 3,3 Mm. beträgt, also mindestens um $1 \mathrm{Mm}$. hinter der normalen Embryonallänge dieses Stadiums zurücksteht. Während die hinteren Abschnitte des Embryo normal gebildet sind, zeigt das in der Entwicklung etwas zurückgebliebene Kopfende mehrfache Unregelmässigkeiten; dieselben betreffen den Schluss des Medullarrohres, der sich an drei Stellen noch nicht vollzogen hat; dadurch sind drei quere Oeffnungen entstanden, von denen die beiden vorderen spaltförmig sind und dicht hintereinander liegen. Die dritte Oeffnung ist queroval und liegt etwas weiter von den ersteren entfernt. Durch diese Unregelmässigkeit im Schlusse des Medullarrohres ist eine Verbildung desselben im Kopftheile eingeleitet worden; die Gehirnbläschen erscheinen mangelhaft angelegt, sodass sie kaum zu erkennen sind. Der Kopftheil ist ferner etwas verbreitert; die Kopfdarmhöhle besitzt eine Lünge von $0,5 \mathrm{Mm}$; d die Herzhälften sind in der Anlage begriffen.

Die Area vasculosa hat, indem sie sich besonders stark seitlich von dem Embryo ausdehnte, eine querovale Form angenommen. Der Durchmesser der gesammten Keimhaut beträgt $12 \mathrm{Mm}$.

Nr. 13. Das Ei wurde am vierten Tage der Bebrütung geöffnet. Die Keimhaut (Fig. 6, 'Taf. IX) besitzt eine Area pellucida, welche länglich ausgezogen und in ihrem vorderen 'Theile stark verbreitert ist. Der Embryo gehört einem Entwicklungsstadium an, welches unter normalen Verhältnissen un die 30. Stunde der Bebrütung erreicht wird. Auch hier ist es der Kopftheil, welcher ein unregelmässiges Aussehen besityt. Es macht den Eindruck, als ob das sehr breit angelegte Hirnrohr, nachdem es sich geschlossen hatte, zusammenklappte, wodurch sich seine Wände theilweise berühren inussten, und sodann in weiteren Wachsthum nach einer Seite hin umbog.

In der Gegend des Sinus rhomboidalis hat sich das Medullarrohr noch nicht 
ganz geschlossen. Die Ränder der Medullarwülste haben sich hier auffallender Weise nur in der Mitte des Sinus vereinigt, so dass ober und unter dieser Stelle das Medullarrohr noch klafft.

Es haben sich ferner zwei Herzen entwickelt; ausserdem sind die vorderen Urwirbelpaare, sowie auch das Kopfende augenscheinlich etwas breiter als normal.

Der Embryo ist nur 4,2 Mm. lang, demnach mindestens um 1,5 Mm. kürzer wie ein gleich entwickelter normaler Embryo.

Die Area vasculosa, deren Vena terminalis bereits sichtbar ist, zeigt in ihren hinteren Bezirken eine entschieden bessere Ausbildung der Blutinseln, als wie vorne. Bezüglich ihrer Form ist zu bemerken, dass sie ebenfalls leicht queroval ist. Der Durchmesser der gesammten Keimhaut beträgt 12-13 $\mathrm{Mm}$.

Nr. 14. Das Ei wurde am vierten Brütetage geöffnet. Die Keimhaut enthält einen Embryo, dessen Entwicklungsstufe den ersten Stunden des dritten Brütetages entspricht. Bezüglich seiner Länge ist er jedoch hinter diesem Stadium merklich zurückgeblieben; dieselbe beträgt nur 5,5 Mm., während ein dem genannten Stadium angehöriger normal bebrüteter Hühnerembryo, den ich zur Controle gemessen habe, $7 \mathrm{Mm}$. lang ist. Der Embryo ist sonst normal gestaltet; das Kopfende liegt mit seiner linken Seite der Keimhaut auf, Scheitel- und Nackenhöcker sind schon aufgetreten; die Herzschlinge normal, ebenso die Gehirn- und Augenanlagen. Die Kiemenbögen sind bereits zu erkennen, dessgleichen die Ohrgrübchen. Die Bildungder Beckendarmhöhle steht bevor. Die Area pellucida ist länglich, bisquitförmig, die Area vascula rundlich, hat einen Durchmesser von nicht ganz $11 \mathrm{Mm}$.

Das Absonderliche der Keimhaut beruht in dem Fehlen eines Amnion, indem die Kopfscheide desselben nicht zur Ausbildung gekommen ist.

Nr. 15. Das Ei wurde am fünften Brütetage untersucht. Es enthielt einen Embryo (Fig. 7, Taf. IX), der in seiner Entwickling etwas weiter fortgeschritten ist, wie der eben besprochene; dies gilt besonders für den hintern Abschnitt des Embryo, wo bereits die Beckendarmhöhle sich angelegt hat; dagegen ist das Kopfende gegenüber der mittleren und hinteren Körperregion in der Bildung weit zurück. Was die Länge des Embryo anlangt, so beläuft sich dieselbe auf 5,3 $\mathrm{Mm}$.

Die Formanomalie betrifft nur das Kopfende, welches eine ungemeine Verbreiterung zeigt; sein querer Durchmesser beträgt 1,5 Mm. Ueber die Deutung der den Kopf zusammensetzenden Gebilde bin ich mir nicht ganz klar geworden. Man bemerkt drei nebeneinander gelegene Hirnbläschen, welche die vorderste und breiteste Abtheilung des Kopfes bilden; das Bild erinnert etwas an das Aussprossen der primitiven Augenblasen aus dem primären Vorderhirn; doch glaube ich kaum, dass die seitlichen Bläschen die stark vergrösserten primären Augenanlagen vorstellen, da sie nach hinten zu unmittelbar in die folgenden Hirntheile übergehen, welche durch eine dorsale, longitudinale Einbuchtung in zwei Abtheilungen gebracht werden. Zutreffender, aber auch nicht in allen Punkten befriedigend erscheint mir die Annahme, dass das Hirnrohr doppelt angelegt worden war, und jedes derselben sich etwas um seine Längsaxe gedreht habe, das eine nach rechts, das andere nach links, wodurch es zu einer Verschmelzung der schon vor der Drehung etwas ventralwürts gerichteten Vorderhirnbläschen kommen musstè. Nach dieser Auffassung hätte man das mittlere der drei nebeneinander gelegenen Blïschen als gemeinsames Vorderhirn, jedes der beiden seitlichen als Mittelhirn anzusprechen, an welche sich auf jeder* Seite je ein Hinterhirn anschliessen würde.

Der Vorderdarm ist einheitlich, ebenso existirt-nur ein Herzschlauch, dessen Schlinge nach rechts gewendet ist; dieselbe ist jedoch, da das Herz sich noch nicht sehr entwickelt hat, ziemlich kur\%. Die Area pellucida hat sich sehr in die Lünge 
ausgedehnt, ihr breiterer Theil liegt hinten. Die Area vasculosa ist rundlich und besitzt einen Durchmesser von 18-20 Mm.

Nr. 16. Das Ei wurde am sechsten Tage der Bebrütung eröffnet, und die Keimhaut ausgeschnitten. Der Embryo (Fig. 8 A und B, Taf. IX), dessen Herz kräftig pulsirte, fiel durch seine abnorm geringe Längenentwicklung und ferner durch sein stark verbreitertes, soweit es sich jetzt schon erkennen liess, verdoppeltes Kopfende auf. Seine Länge bemass sich auf nur 5,2 Mm., trotzdem er bereits die vorderen und hinteren Extremitätenstummel aufwies, und somit einem Entwicklungsstadium angehörte, welches Anfangs des fünften Tages bei normaler Bebrütung erreicht wird. Bei der Untersuchung des frischen Embryo in einer lauwarmen $1 / 2 \%$ igen Kochsalzlösung überraschte mich das lange Anhalten des Herzschlages, den ich noch nirgends so gut, wie in diesem Falle, lange Zeit hindureh beobachten konnte. Anfünglich war ich bemüht, die erkaltete Kochsalzlösung durch warme immer wieder zu ersetzen, um die Herzpulsation im Gange zu halten; später habe ich es aufgegeben und überliess den Embryo sich selbst. Trotzdem die Kochsalzlösung vollkommen abgekühlt war, fuhr das Herz, wie ich mich durch zeitweiliges Nachsehen überzeugte, fort, zu schlagen, und als ich $2^{1 / 2}$ Stunden nach Eröffnung des Eies den Embryo schliesslich in die Erhärtungsflüssigkeit brachte, hatte das Herz immer noch, wenn auch in verlangsamtem Rhythmus, seine Pulsationen ausgeführt. Bei normal bebrüteten Eiern, deren Keimhaut vom Dotter losgelöst und in der erwärmten Kochsalzlösung untersucht wurde, ist es mir niemals, trotz aller Bemühungen und Cautelen geglückt, die Action des embryonalen Herzens länger als $1 / 2-3 / 4$ Stunde im Gange zu erhalten. Desto mehr musste mich die ungemeine Lebenszähigkeit des Herzens bei dem in Rede stehenden monströsen Embryo überraschen.

Der sorgfültig erhärtete Embryo zeigte nun auf das Deutlichste eine Verdoppelung des Kopfendes, jedoch nur eine theilweise, indem sie sich auf das Hirnrohr beschränkte. Die Dorsalansicht liess deutlich die durch einen tiefen Einschnitt getrennten Hirntheile erkennen; bei beiden Hirnrohren waren die drei primitiven Hirnblïschen gut entwickelt. Die Ventralansicht des Kopfes (Fig. 8 B, Taf. IX) zeigt jedoch nur eine einheitliche Gesichtsanlage; die primitive Mundbucht ist bereits gebildet, der erste Kiemenbogen und sein Oberkieferfortsatz tritt deutlich hervor; ober dem letzteren liegt jederseits die wulstige Vorwölbung eines jeden Gehirnrohres, in welcher ein kleines Grübchen sich befindet; ob letzteres das Linsengrübchen darstellt oder vielleicht das Riechgrübchen, muss ich unentschieden lassen. Im ersteren Falle wären die beiden Vorwölbungen als Augenblasen, im letzteren als Hemisphürenblasen aufzufassen. In beiden Fällen würde jedes der genannten Gebilde von je einem Gehirnrohre entstanden sein.

Die Kopfdarmhöhle ist einheitlich; ebenso das Her", dessen Schlinge nach rechts sieht; die Beckendarmhöhle ist schon ziemlich entwickelt. Die Area pellucida liat sich ziemlich gleichmässig erweitert; die Area vasculosa ist annähernd rundlich und besityt einen Durchmesser von 22-25 Mm.

Nr. 17. Das Ei wurde am fünften Tage der Bebrütung untersucht. Es enthielt einen Embryo, dessen Entwicklungsstadium etwa dem Ende des dritten oder dem Anfang des vierten Tages bei normaler Bcbrütung entsprach. Das Her\% pulsirte lebhaft; die Extremitätenanlagen sind bereits vorhanden, ebenso die Kiemenbögen und Kiemenspalten, die Ohrgrübchen, die Riechgrübchen, die Hemisphïrenbläschen; auch die Allantoisblase hat sich schon vorgewölbt. Die genannten Organe sind sïmmtlich normal entwickelt. Der Embryo liegt mit seiner linken Kopfseite der Keimhaut auf; seine Körperliinge vom Scheitelhöcker bis zum Beckenende gemessen, betrïgt $7,5 \mathrm{Mm}$. Demnach stimmt dieselbe mit der Entwicklungsphase des Embryo so riemlich überein. 
Die Anomalie der vorliegenden Keimhaut beruht in dem vollstïndigen Mangel des Amnion.

Die Keimhaut hatte schon den grösseren Theil des Eies umwachsen. Der Durchmesser der Area vasculosa beläuft sich auf 28-30 Mm.

Nr. 18. Das Ei wurde am fünften Tage der Bebrütung geöffnet. Seine Keimhaut besass einen Embryo, welcher fast gleich weit entwickelt war, wie der soeben beschriebene. Auch hinsichtlich seiner Körperlänge stimmt er mit dem letzteren überein; ebenso in der Ausbildung des Kopfes, der Extremitäten etc. Eine Allantoisblase ist dagegen noch nicht erkenntlich. Ferner ist die sehr starke Nackenkrümmung hervorzuheben, welche der Embryo zeigt.

Auch bei der in Rede stehenden Keimhaut betrifft die Unregelmässigkeit der Entwicklung nicht den Embryo, sondern das Amnion. Dasselbe hat zwar angefangen, sich zu entwickeln, indem eine kleine vordere und hintere Amnionfalte unschwer zu beobachten ist, scheint jedoch sehr frühzeitig aufgehört zu haben, sich weiter auszubilden. Die Entfernung der beiden sehr kleinen Amnionfältchen von einander beträgt etwa $5 \mathrm{Mm}$. Das vordere befindet sich in der Höhe des Herzens und ist von dem Abschnitt des Embryonalkörpers bedeckt, welcher zwischen der Nackenkrümmung und den vorderen Extremitätenanlagen gelegen ist; das hintere Amnionfältchen wird von dem hintersten Theile des Beckenendes eben noch überdeckt. Die beiden Amnionfalten, welche ihrer Ausbildung nach einem viel jüngern Embryo entsprechen, sind gewissermassen markirte Stellen der Keimhaut, deren Lagebeziehungen zu dem Embryo das nach vorwärts gerichtete Wachsthum desselben sehr gut illustriren.

Die Keimhaut verhält sich hinsichtlich ihrer peripheren Ausdehnung wie die des vorigen Falles; sie hat ebenfalls den Aequator der Dotterkugel bereits überschritten. Der Durchmesser der Area vasculosa beträgt circa $30 \mathrm{Mm}$.

Nr. 19. Das Ei wurde am sechsten Tage der Bebrütung geöffnet. Es enthielt einen Embryo (Fig. 9 A und B, Taf. IX), welcher seiner Entwicklung nach sämmtliche bisher besprochenen übertrifft, indem sowohl die Allantoisblase sich schon stark ausgedehnt hat, als auch die Extremitäten in ihrer Ausbildung ziemlich weit fortgeschritten sind. Seine Lage auf der Keimhaut ist eine sehr ungewöhnliche. Derjenige Körperabschnitt, welcher von der stark ausgeprägten Nackenkrümmung bis zum hinteren Embryonalende reicht, liegt mit seiner linken Seite der Keimhaut auf und wendet die rechte dem Beschauer zu, während der vor der Nackenkrümmung befindliche Körperabschnitt, welcher mit dem ersteren einen rechten Winkel bildet, sich so um seine Längsaxe nach rechts gedreht hat, dass das Gesicht nach unten, und die Dorsalseite nach oben gekehrt ist. Der Kopf des Embryo ist verbreitert und missgestaltet. Eine von der Scheitelgegend aus einschneidende Spalte zerlegt ihn in zwei Hälften, die aller Wahrscheinlichkeit nach zwei Hirnrohren entsprechen. Die Verdoppelung reicht jedoch nicht sehr weit nach hinten; die Gegend des Nachhirns ist zwar noch etwas verbreitert, doch ist sie unstreitig einfach vorhanden. Ebenso ist die untere Gesichtshälfte einfach, indem eine einheitliche Mundbucht vorliegt, die seitlich von je einem Oberkieferfortsatz, unten von dem ersten Kiemenbogen umgrenzt wird. Die obere Gesichtshälfte wird dägegen durch die erwähnte, bis nahe an die Mundbucht vordringende Spalte in zwei Abtheilungen gebracht; dicht neben dieser Spalte liegt jederseits ein Bläschen, welches ich für ein Hemisphärenbläschen zu halten geneigt bin, während mir die beiden lateralen Blïschen, von denen ein jedes nach aussen und hinten von der Mundbucht liegt, rücksichtlich ihrer Deutung nicht ganz klar geworden sind.

Die Kiemenbögen und Kiemenspalten verhalten sich normal, ebenso das Her\%, 
welches, als das Ei eröffnet wurde, lebhaft pulsirte und verhältnissmässig lange seine Contractionen fortsetzte, jedoch bei Weitem nicht so lange, wie bei dem unter $\mathrm{Nr}$. 16 angeführten Embryo.

Was die Grössenverhältnisse des Embryo anlangt, so ist der Abschnitt des Embryonalkörpers zwischen der Nackenkrümmung und dem Beckenende $8 \mathrm{Mm}$., der übrige Theil, von der Nackenkrümmung bis zur Spalte der Scheitelgegend $5 \mathrm{Mm}$. lang.

Die Bildung des Amnions ist gänzlich unterblieben. Die Allantois dagegen ist im Auswachsen begriffen. Die Dimensionen der gesammten Keimhaut, sowie der Area vasculosa zeigen ein ähnliches Verhalten, wie bei den zwei letzten Keimhäuten.

In Rücksicht auf die Keimhäute der sieben Eier, von denen oben bemerkt wurde, dass ihre nur geringgradigen Formabweichungen nicht absolut auf Rechnung des experimentellen Eingriffs gesetzt zu werden brauchen, indem sie vielleicht auch ohne diesen eingetreten wären, möchte ich noch erwähnen, dass die meisten derselben Entwicklungsstadien darboten, welche der Anlage der Rückenfurche vorausgehen. Bei mehreren von ihnen war der Primitivstreifen nur sehr schwach entwickelt und von geringer Länge; auch die Area pellucida war verhältnissmässig klein. Zwei Keimhäute gehörten etwas älteren Entwicklungsphasen an; bei der einen lag eine geringe Unregelmässigkeit im Schluss des Medullarrohres, bei der andern ein, wie mir schien, etwas verbreitertes Kopfende vor.

Die in Vorstehendem genauer beschriebenen 19 Keimhäute lassen sich hinsichtlich ihrer Entwicklungszeit am besten in 3 Abtheilungen bringen; die ersten 7 Keimhäute fallen in die Zeit der Anlage und Ausbildung des Primitivstreifens und seines Kopffortsatzes; die folgenden 6 Keimhäute (Nr. 8-13) gehören einer Entwicklungszeit an, welche mit dem Auftreten der Kopffalte anfängt, und mit dem vollständigen Schluss des Medullarrohres beendet ist; die letzten 6 Keimhäute dagegen $(\mathrm{Nr} .14-19)$ befinden sich in einer noch späteren Periode der Entwicklung, welche mit dem vollendeten Schlusse des Medullarrohres beginnt.

Unter den sämmtlichen 19 Keimhäuten sind es nur 2, bei denen eine unbestrittene, vordere Verdoppelung erzielt worden ist; die eine unter Nr. 3 aufgeführte (Fig. 3, Taf. VIII) gehört der ersten Abtheilung an, und zeigt einen in seinem vorderen Drittheil verdoppelten Primitivstreifen; die zweite Keimhaut $\mathrm{Nr}$. 16 (Fig. 8, Taf. IX) repräsentirt dagegen eine viel spätere Entwicklungsperiode, und lässt ein zweifaches Hirnrohr auf das Deutlichste erkennen. Diesen zwei Fällen schliessen sich die Keimhäute Nr.9, 15 u. 19 (Fig. 2, Fig. 7 und Fig. 9, Taf. IX) an, bei denen eine theilweise Verdoppelung des Kopfendes für wahrscheinlich erachtet werden muss. Es folgen dann die Keimhäute Nr. 10 und 11 (Fig. 3 und 4, Taf. IX) mit ausgesprochener Verbreiterung des vordersten Abschnittes des Medullarrohres, sowie des ganzen embryonalen Kopfendes, während in Nr. 12 u. 13 (Fig. 5 u. 6, 'Taf. IX) vermuthlich die gleiche Ursache zu den Unregelmässigkeiten in der Schliessung und der Form des Hirnrohres geführt hat. Wenn man die angeführten Abnormitäten des embryonalen Kopfendes überblickt, welche in Folge der angewandten Methode sich einstellten, so will es mir scheinen, als ob der experimentelle Eingriff bei den einzelnen Keimhäuten die Embryonal- 
entwicklung in verschieden hohem Grade beeinflusst haben. So viel geht meiner Ansicht nach aus den erhaltenen Resultaten hervor, dass es in den bezeichneten Fällen gelungen ist, die Embryonalanlage von der Medianlinie mehr oder weniger abzuziehen; am vollkommensten in den zwei Keimhäuten, welche eine Bifurcation des vorderen Embryonalendes aufweisen, weniger gut in den Keimhäuten, bei denen nur eine Verbreiterung des Kopfendes eingetreten ist, welche ja ebenfalls auf einem nach beiden Seiten hin gerichteten grösseren Wachsthum und Volumzunahme beruht. Somit haben meine Experimente ein entschieden positives Resultat ergeben, das allerdings hinsichtlich der Regelmässigkeit seines Eintreffens und der minimalen Anzahl wirklich erzielter vorderer Verdoppelungen noch sehr zu wünschen übrig lässt.

Zieht man jedoch den Umstand in Betracht, dass bei meinen Experimenten ein Verfahren befolgt wurde, welches noch sehr der Verbesserung bedarf, indem sowohl das Ueberfirnissen exacter vorgenommen werden $\mathrm{kann}$, als auch die Stellen der Schale, welche ungefirnisst bleiben müssen, noch präciser festzustellen sind, so wird man zu dem Schlusse gelangen, dass an eine noch relativ unvollkommene Methode, wie die von mir ausgeübte, auch noch keine zu grossen Anforderungen gestellt werden dürfen.

Diejenigen Keimhäute, bei denen eine Duplicitas anterior wirklich aufgetreten ist, berechtigen jedenfalls zu der begründeten Hoffnung, dass man auf dem zur Erzeugung dieser Missbildung eingeschlagenen Wege schliesslich das gewünschte Ziel erreichen werde. Es wird darum bei einer etwaigen Wiederaufnahme meiner Versuche vor allen Dingen nöthig sein, die Methode möglichst zu vervollkommnen. Leider ist gegenwärtig meine Zeit durch anderweitige Verpflichtungen so in Anspruch genommen, dass es sich nicht voraussagen lässt, wann es mir möglich sein wird, die in Rede stehenden Untersuchungen weiter zu führen. Sollte dies von anderer Seite unternommen werden, so würde es mich sehr freuen, hiezu die Anregung gegeben zu haben, und ich möchte daher an diesem Orte nicht unterlassen, auf einige Momente, welche bei einer Wiederholung und Verbesserung meines Verfahrens in erster Linie berücksichtigt werden müssen, aufmerksam zu machen.

Was zunächst die ungefirnisst zu lassenden Stellen der Eischale anlangt, so wird zu prüfen sein, ob statt der $\mathrm{Y}$ - und V-förmigen Figuren nicht besser an den Enden der 3 Schenkel des $Y$ liegende rundliche oder längliche Bezirke der Schale vom Firnissüberzuge befreit bleiben. Ferner muss ausfindig gemacht werden, welche Distanz die ungefirnissten Stellen von einander haben müssen, damit der Versuch das bestmögliche Resultat liefere. Ausserdem wäre nachzusehen, ob nicht durch Abfeilen der freibleibenden Stellen, wodurch die Schale verdünnt und damit der Luftzutritt in das Eiinnere an den betreffenden Orten vermehrt wird, sich günstigere Ergebnisse erzielen lassen. Auch auf die Zeit, welche von dem Legen der Eier bis zum Beginn der Bebrütung verstreicht, muss Acht gegeben werden, was ich bei den bisherigen Versuchen zu meinem Bedauern versäumt habe. Es ist denkbar, dass in einer bestimmten Zeit nach dem Legen die Eier sich in den für das Gelingen der Experimente günstigsten Zuständen befinden, wenngleich vicles dafür spricht, dass frische Eier geeigneter sind, als ältere. Endlich muss bei der Lagerung der Eier darauf gesehen werden, dass ihre Längsaxe genau hori- 
zontal verläuft. Dass man bei dem Bezeichnen der frei zu lassenden Stellen, sowie bei døm Ueberfirnissen der Eischale exact zu Werke gehen muss, habe ich oben bereits angedeutet.

Ausser den schon genannten Abnormitäten des Kopfendes wird man bei der Durchmusterung der 19 Keimhäute ein anormales Verhalten des hinteren Embryonalendes als ein relativ häufiges Vorkommniss constatiren können. Ich habe hier die Anschwellungen des Primitivstreifens im Sinne, welche sowohl bei den Keimhäuten der ersten als der zweiten Abtheilung mehrfach zu finden sind. Bei den ersteren sind es, wie die Keimhäute 5, 6 und 7 (Fig. 5, 6, 7, Taf. VIII) zeigen, nur partielle Intumescenzen des Primitivstreifens, welche mehr dessen hintere Abschnitte betreffen und in Form von zapfenartigen Wucherungen aufgetreten sind. Bei den etwas älteren Keimhäuten der zweiten Abtheilung und zwar bei Nr. 8 und 9 (Fig. 1 und 2, Taf. IX) stellt sich der ganze Primitivstreifen als eine längliche, wulstförmige Verdickung dar. Diese Befunde, welche auf einer im hinteren Embryonalbezirke abnorm gesteigerten Vermehrung und Wucherung der Keimhautzellen beruhen, scheinen mir sehr dazu angethan, die Richtigkeit der Voraussetzungen, welche bei dem Firnissen der Eioberfläche massgebend waren, zu beweisen.

Dadurch, dass die Sauerstoffquelle dem hinteren Theile der Keimscheibe am nächsten lag, musste hier vor Allem eine erhöhte Vermehrung der Zellen verursacht werden. Dass auch in den Keimhäuten der dritten Gruppe nicht ähnliche Befunde zur Beobachtung kamen, dürfte darin seinen Grund haben, dass späterhin mit der Ausbildung des ersten Blutkreislaufes die durch den experimentellen Eingriff bedingte, bessere Versorgung des hinteren Keimhautbezirkes mit Sauerstoff mehr und mehr aufgehoben wird; ferner wird der angeschwollene Primitivstreifen, wenn sich über seinem vorderen Theile das Medullarrohr schliesst, und wenn die Beckenkrümmung auftritt, unsichtbar werden müssen. Dass ausserdem auch eine Rückbildung des abnorm verdickten Primitivstreifens in den späteren Entwicklungsstadien eben so gut eintritt, wie wenn derselbe normal gebildet wäre, ist wohl ohne Weiteres anzunehmen.

Ich möchte fernerhin als ein Ergebniss meiner Experimente den Umstand hervorheben, dass bei den meisten Keimhäuten die Grösse und Länge der Embryonalanlage oder des Embryo hinter der Norm zurückgeblieben ist, und zwar ist diese Differenz in einigen Fällen eine sehr beträchtliche. Auch an dieser Erscheinung kann nur der experimentelle Eingriff Schuld sein, in Folge dessen die vorderen Keimhautbezirke und später die vorderen Theile des Embryo während der ersten Entwicklungszeit nur mangelhaft mit Sauerstoff versorgt wurden. Auch in späteren Entwicklungsperioden konnte der erste Blutkreislauf wegen des durch die Firnissüberzüge behinderten Gasaustausches die zur Vermehrung der Zellen nöthigen Bedingungen nur unvollkommen herstellen. Dadurch musste das Wachsthum des Embryo verringert werden, während die Formbildung andererseits, für welche die geringe Zellvermehrung ausreichte, ihren Fortgang nahm. Es liegen demnach hier Verhiiltnisse vor, welche eine ähnliche Incongruenz der formativen und Wachsthums-Vorgiinge bei der Embryonalentwicklung nach sich ziehen, wie sie Dareste durch eine etwas über die Norm erhöhte Brïtetemperatur zu Stande 
gebracht hat, was bereits früher eingehender besprochen wurde. Aller Wahrscheinlichkeit nach ist durch die Behinderung der Respiration, welche man durch zweckmässig ausgeführtes Firnissen von Theilen der Eischale bewirken kann, ebenso gut eine $Z$ wergbildung des Hühnchens zu erzielen, als durch Steigerung der Brütetemperatur. Ein wichtiger Unterschied zwischen diesen beiden Methoden, durch welche sich in der erörterten Weise die normale Entwicklung modificiren lässt, muss jedoch betont werden. Während eine etwas über die Norm erhöhte Brütetemperatur die formativen Vorgänge ungemein beschleunigt und andererseits das Wachsthum verringert, übt die Behinderung: der Respiration auf beide Processe in der Weise ihren Einfluss aus, dass sowohl das Wachsthum reducirt, als die Formation sehr retardirt wird. Letzteres kann man an den Embryonen der 19 Keimhäute sehr gut constatiren, welche fast ausnahmslos die der jeweiligen Brütedauer entsprechenden Entwicklungsstadien noch lange nicht erreicht haben.

Von Interesse scheint mir ferner das gänzliche Fehlen oder die nur sehr rudimentäre Ausbildung des Amnions zu sein, was bei den der dritten Abtheilung angehörenden Keimhäuten durchweg zu beobachten war. Den Grund dieser Entwicklungshemmung stelle ich mir in der Weise vor, dass in Folge der durch das Ueberfirnissen erschwerten Respiration an den betreffenden Keimhautstellen keine so lebhafte Zellvermehrung stattfand, wie sie für die Ausbildung und rasche Vergrösserung des Amnions erforderlich ist. In besonders günstigen Fällen, wie bei der Keimhaut Nr. 18, konnten sich vielleicht Amnionfalten anlegen; dieselben mussten jedoch aus den genannten Gründen sehr bald ihr Wachsthum einstellen, was dazu führte, dass sie von dem sich vergrössernden Embryo späterhin überdeckt wurden. Aus dem Fehlen oder der baldigen Sistirung der Amnionbildung ist zu folgern, dass der unter den obwaltenden Verhältnissen in nur mässiger Quantität zu der Keimhaut gelangende Sauerstoff fast ausschliesslich der Embryonalbildung selbst zu Gute kam. Diese konnte durch den experimentellen Eingriff zwar bedeutend retardirt werden - auch das embryonale Wachsthum liess sich beschränken - dagegen konnte nur in vereinzelten Fällen die Entwicklung gänzlich hintangehalten oder bereits in einem sehr frühen Stadium zum Stillstand gebracht werden. Allein auch in diesen wenigen Fällen kann es sich um solche Eier gehandelt haben, die mir ausnahmsweise nicht ganz frisch mehr zukamen, und die vielleicht schon $2-3$ Wochen alt geworden waren, ehe sie in den Brütofen gebracht wurden, wesshalb sie bereits ihre Entwicklungsfähigkeit mehr oder minder eingebüsst hatten. In dieser Weise erkläre - ich mir die Beschaffenheit der Keimhaut Nr. 1, deren Area pellucida keine Embryonalanlage enthält. Die Keimhaut war, als ich das Ei untersuchte, ihrem Aussehen nach noch nicht abgestorben, gehörte aber vermuthlich einem älteren $\mathrm{Ei}$ an, dessen ohnehin durch die Lünge der Zeit geschwächtes Entwicklungsvermögen unter der Einwirkung des experimentellen Eingriffes nicht mehr im Stande war, die Bildung des Embryo einzuleiten. Es konnte zwar. in diesem Falle in Folge der Brutwärme eine langsame Vermehrung der Zellen, wozu der in das Ei tretende Sauerstoff-eben noch hinreichte, und somit eine Ausdehnung der Blastoderma erfolgen, aber zu einer energischeren Zellwucherung, wie sie die Anlage des Primitivstreifens erheischt, waren die 
nöthigen Bedingungen nicht gegeben. Vielleicht ist die kleine rundliche Verdickung, welche in der Nähe des Randes der Area pellucida in letzterer aufgetreten ist, gewissermassen als ein schwacher, bald aufgegebener Versuch zur Bildung eines Primitivstreifens aufzufassen, dessen regelrechtes Entstelien unter den obwaltenden unguinstigen Verhältnissen unmöglich war.

Dass in den wenigen Fällen der ersten Abtheilung (Keimhaut Nr. 1, 2 und 4, Fig. 1, 2 und 4, Taf. VIII) das Ausbleiben resp. das frühzeitige Aufhören der Entwicklung des Embryo nur zum geringsten Theile durch den Firnissiiberzug bedingt worden ist, geht auch aus dem Umstande hervor, dass bei einem Drittheil der zu den Versuchen benutzten Eier, wenn wir von dem mehrfach beobachteten geringeren Embryonalwachsthum absehen, die Entwicklung keinerlei Störung erlitt. Diese Thatsache, dass in 20 Eiern keine Bildungsanomalien zu bemerken waren, während doch in den anderen Eiern sich dieselben in verschieden hohem Grade einstellten, beweist aufs Neue, dass bei der Entwicklung der Embryonen eine Reihe von individuell variablen Factoren mitspielt, welche in Betracht zu ziehen sind, wenn man auf experimentellem Wege die Embryogenese modificiren will. Erst dann, wenn diese Factoren durchaus oder wenigstens zu ihrem grössten Theile erkannt sind, wird man hoffen dürfen, dass die künstliche Erzeugung von Bildungsanomalien einigermassen constante Resultate erzielen werde. Ich habe schon zu wiederholten Malen auf das Alter der Eier hingewiesen, welchem meiner Ansicht nach die bei den einzelnen Eiern bestehenden Verschiedenheiten der Entwicklungsbedingungen hauptsächlich zuzuschreiben sind. Je länger das Ei bereits gelegt ist, desto mehr dehnt sich die Luftkammer aus. Es bedarf keiner weiteren Auseinandersetzung, dass die von mir geübte Methode der partiellen Firnissüberzüge bei einem frisch gelegten Eie ganz andere Folgen haben muss, als bei einem älteren Eie, dessen Luftkammer schon geräumiger geworden ist. Bei dem ersteren treffen alle jene früher erörterten Voraussetzungen zu, indem der Sauerstoff nur durch die ungefirnissten Stellen der Eischale hindurch zu der Keimscheibe gelangen kann; bei dem letzteren jedoch haben wir in der Luftkammer, deren Luft nach den Erfahrungen von Baudrimont und Martin-Saint-Ange einen grösseren Sauerstoffgehalt besitzt, wie die äussere Atmosphäre, eine im Eiinneren selbst befindliche Sauerstoffquelle, deren Vorhandensein die durch den experimentellen Eingriff beabsichtigten Einwirkungen auf die Entwicklung der Keimscheibe bedeutend abschwächen oder vielleicht gänzlich eliminiren muss. Leider sind mir diese Ueberlegungen erst nach Abschluss meiner Versuche gekommen, und ich muss daher sehr bedauern, über das Alter der zu meinen Experimenten benutzten Eier keine Angaben machen zu können, da ich dasselbe damals nicht berücksichtigt habe. Es scheint mir jedoch recht gut möglich, dass jene 20 Eier, welche normale Embryonen enthielten, bereits einige 'Tage gelegen hatten, ehe sie in den Brütofen kamen und es ist vielleicht auf diesen Umstand das negative Ergebniss der diesbezüglichen Versuche in erster Linie zurückzuführen.

Schliesslich möchte ich noch einer mehr physiologischen Beobachtung gedenken, welche ich bei meinen Untersuchungen zu machen Gelegenheit hatte. Dieselbe betrifft die ungemeine Lebensziihigkeit der unter erschwerten 
Respirationsverhältnissen befindlichen Embryonen. Zeugniss davon gibt das stundenlange Andauern des Herzschlags, welches bei dem monströsen Doppelembryo Nr. 16 beobachtet werden konnte. Dass die Herzen von Hühnerembryonen nach Entfernung der Eier aus dem Brütofen im Innern derselben lange Zeit noch in Action bleiben, ist eine bekannte 'Thatsache; auf derselben beruhen unter anderem die früher erwähnten Versuche Panu m's, welcher zur Herstellung von Missbildungen die Eier aus dem Brütofen auf einige Zeit herausnahm, sie abkühlen liess und dann wieder in die Brütwärme zurückbrachte. Es ist ferner in neuerer Zeit durch mehrfache Erfahrungen bestätigt worden, dass auch dem menschlichen Fötus ein relativ hoher Grad von Lebenszähigkeit zukommt. So konnte Pflüge ${ }^{1}$ ), welcher einen menschlichen Embryo von etwa 18-20 Tagen, den er erst spät am Abend erhalten, während der Nacht in einem kalten Zimmer aufbewahrt hatte, am anderen Morgen bei Untersuchung derselben noch in Pausen von je 20-30 Secunden wiederkehrende Herzpulsationen wahrnehmen. In ähnlicher Weise konnte Rawitz ${ }^{2}$ ) bei einem älteren $8 \mathrm{Ctm}$. langen menschlichen Fötus (das denselben enthaltende in toto abortirte Ei hatte einen Durchmesser von $11 \mathrm{Ctm}$.) volle vier Stunden hindurch den Herzschlag studiren. Ich selbst habe im vergangenen Sommer in Folge der Liebenswürdigkeit eines mir befreundeten Collegen, der mir kurz nach dem stattgefundenen Aborte einen menschlichen Fötus von $101 / 4 \mathrm{Ctm}$. Kopfsteisslänge brachte, die Contractionen des Herzens etwa drei Stunden nach der Ausstossung des Embryo noch in vollem Gange wahrgenommen.

Man kann somit in der aus dem langen Anhalten des Herzschlages zu folgernden Lebenszähigkeit der Embryonen von Warmblütern, so interessant dieselbe auch an und für sich ist, keine allzu überraschende Erscheinung mehr erblicken, da ja zu wiederholten Malen auf dieselbe hingewiesen worden ist. Dagegen ist die Thatsache, dass Hühnerembryonen, welche während der Bebrïtung unter Respirationsbehinderungen zu leiden hatten, eine viel bedeutendere Lebenstenacität aufweisen, wie normale unter gewöhnlichen Verhältnissen bebrütete Embryonen bisher noch nicht beobachtet worden. Dieselbe scheint mir aber in mancher Hinsicht beachtenswerth. Dass die in Rede stehende grössere Widerstandsfähigkeit sich erst im Laufe der Entwicklung ausbildet und demnach als eine erworbene Eigenschaft aufzufassen ist, ergibt sich aus der einfachen Ueberlegung, dass Hühnerembryonen, welche sich unter normalen Bedingungen entwickeln, diese gesteigerte Lebenszähigkeit nicht besitzen. Ihr Auftreten scheint somit mit der Anpassung des Embryo an die durch den äusseren Eingriff gesetzten ungünstigen Entwicklungsbedingungen Hand in Hand zu gehen. Meiner Ansicht nach erhält der Embryo das Vermögen, den seine Existenz und Fortbildung bedrohenden schädlichen Einflüssen, die von aussen her auf ihn einwirken, möglichst Stand zu halten, nur durch eine vermehrte Leistungsfühigkeit des Herzens, indem das letztere durch eine kräftigere und beschleunigtere Action die erwähnten Schädlichkeiten bekämpft. Es handelt sich demnach um eine functionelle

1) Pf'lüger, Die Lebenszähigkeit des menschlichen Fötus. Pf'lüger's Archiv Bd. XIV, pag. 628, 1877.

2) Rawitz, Die Lebenszähigkeit des Embryo. Archiv für Anatomie und Physiologie 1879, pag. 69. 
Anpassung“ Seitens des embryonalen Herzens in dem Sinne, wie sie von Roux ${ }^{1}$ ) in seinem unlïngst erschienenen Buche eingehend erörtert worden ist. Dieses erhöhte Leistungsvermögen des Herzens wird bei dem aus dem Ei entfernten Embryo eben durch die grössere Widerstandsfähigkeit manifestirt, welche sich in der langen Andauer der Herzschläge kundgibt, auf welche sogar eine allmählige Abkühlung bis auf etwa $18-20^{\circ}$ C. nur wenig verlangsamend einwirkte.

Durch die functionelle Anpassung des embryonalen Herzens an den in Folge des Ueberfirnissens eintretenden Sauerstoffmangel und die daraus resultirende gesteigerte Functionsfähigkeit desselben erklärt es sich auch, wesshalb die unter so ungünstigen Verhältnissen befindlichen Embryonen verhältnissmässig lange Zeit am Leben bleiben können, was durch meine Versuche festgestellt worden ist. Es wäre jedenfalls eine lohnende Aufgabe, den Einfluss der Firnissüberzüge auf die Herzthätigkeit der sich entwickelnden Embryo genauer zu studiren, was mir bei meinen Experimenten ferner lag, und desshalb nur beiläufig berücksichtigt wurde.

Nach den Erfahrungen der Teratologie scheint es äusserst wahrscheinlich, dass bei missbildeten Embryonen eine Steigerung der Leistungsfähigkeit des Herzens häufig auftritt, und zwar überall da, wo die dem Herzen zuigemessene Aufgabe anwächst. Es ist ja bekannt, dass Embryonen von der höchsten Verunstaltung, die wegen des Fehlens der wichtigsten Organe absolut unlebensfähig sind, nicht selten bis an das Ende der intrauterinen Entwicklung gelangen. Dies wäre geradezu unmöglich, wenn nicht bei diesen Monstrositäten die Herzthätigkeit eine ungemein lebhafte wäre, indem gerade dieses Organ, da es fortwährend thätig ist, eine Ausbildung erfährt, welche zu der der anderen Organe bedeutend contrastirt, welche aber auch ein vermehrtes Leitungsvermögen zur Folge haben muss.

Unter Bezugnahme auf die Ergebnisse meiner Experimente, welche ich vorstehend geschildert habe, möchte ich zum Schlusse dieses Capitels noch die Methode, welche dabei befolgt wurde, einer kurzen Besprechung und Kritik unterzichen. Einen glänzenden Erfolg hat dieselbe, wie ich gerne zugebe, bis jetzt noch nicht aufzuweisen, denn dazu ist die Zahl der wirklich erzielten Doppelmissbildungen eine viel zu geringe. Doch steht zu erwarten, dass eine systematisch vorgenommene Verbesserung meines Verfahrens dazu führen wird, dass auch die Resultate regelmässiger eintreffen werden. Ich habe bereits oben angegeben, welche Vorversuche anzustellen sind, und nach welcher Richtung hin experimentirt.werden muss, um zu einer vollkommeneren und exacteren Handhabung der Methode zu gelangen. Dass diesclbe wirklich leistungsfïhig ist, beweisen die, wenn auch nur wenigen, vorderen Verdoppelungen, welche in den gefirnissten Eiern sich entwickelt haben. Unmöglich können dieselben rein zufällige sein, denn wie sollten bei der ungemein grossen Seltenheit der Duplicitas anterior bei Hühnerembryonen diese gerade in den zu den Versuchen gebrauchten Eiern, deren Zahl je eine relativ ge- 
ringe ist, wiederholt zur Beobachtung kommen, während ich die gleiche Form der Missbildung ausserdem niemals wahrnehmen konnte, trotzdem ich bei meinen entwicklungsgeschichtlichen Untersuchungen die Keimhäute von mehr als 1000 Eiern, welche die verschiedensten Stadien der Ontogenese darboten, zu prüfen Gelegenheit hatte. Es steht somit fest, dass die experimentelle Abänderung der normalen Bebrütung die Veranlassung zu dem Auftreten der angestrebten Doppelmissbildung gegeben haben muss. Es wurde durch die Beschränkung des Luftzutrittes in das Eiinnere auf bestimmte Stellen der Schale die nach vorne sich verlängernde Embryonalanlage aus der Medianlinie des Fruchthofes nach den beiden Seiten hin, wo mehr Sanerstoff zu den Keimhautzellen gelangen konnte, abgezogen und dadurch eine Bifurcation derselben zu Stande gebracht.

Auch einer anderen Anforderung, welche ich an meine Methode stellte, ist dieselbe gerecht geworden. Durch die mehrfach beobachtete stärkere Ausbildung des hinteren Theiles der Embryonalanlage ist der Beweis erbracht worden, dass wirklich durch die auf bestimmte Stellen der Keimhaut vorzugsweise gerichtete Sauerstoffzufuhr eine lebhaftere Zellbildung an den betreffenden Stellen eingeleitet werden kann.

Es liegt in der Natur der Sache, dass die Entwicklung sich in der erörterten Weise nur in den frühesten Stadien beeinflussen lässt. Ganz abgesehen von der Bifurcation, welche zur Zeit des Auftretens der Rückenfurche bereits sich vollzogen haben muss, wird auch eine localisirte stärkere Zellenwucherung sich nur so lange erzielen lassen, als die Area vasculosa noch nicht ausgebildet ist. Mit dem Zustandekommen des Blutkreislaufes geht aurch eine gleichmässige Vertheilung des Sauerstoffes einher. Es empfiehlt sich desshalb, die Eier bereits vor der Bebrütung in der bewussten Weise mit Firniss zu überziehen. Schon nach dem ersten Brütetage hat diese Manipulation keinen Zweck mehr.

Durch die mit Hülfe meiner Methode gewonnenen Resultate ist auch die Art und Weise, wie eine Beeinträchtigung der Respiration zu Missbildungen führen kann, genauer erkannt worden. Seit den von Geoffroy St. Hilaire, Dareste und Anderen gemachten Erfahrungen, dass durch partielle Firnissüberzüge der Eischale Missbildungen zu Wege gebracht werden können, hat man über die dabei obwaltenden Ursachen nur unbestimmte Muthmassungen hegen können; die eigentlichen causae efficientes, welche die Abweichungen von dem normalen Entwicklungsgang veranlassen, waren nichts weniger als aufgeklärt. Dareste, welcher nach dem Firnissen des stumpfen Eipols auch mehrfach geringe Missbildungen an den Embryonen selbst vorfand, ist geneigt, die letzteren als secundäre, bedingt durch die Anomalie der Allantois, aufzufassen. Bei meinen Versuchen dagegen wurden zweifellos die Störungen der Entwicklung primär hervorgebracht, indem die Zellen der Keimhaut in Folge des experimentellen Eingriffs an gewissen Stellen unter bessere, an anderen jedoch unter ungünstigere Existenzbedingungen versetzt wurden. Es liegt desshalb sehr nahe, anzunehmen, dass :̈hnliche Verhältnisse, wie wir sie künstlich hervorriefen, indem an bestimmten Bezirken der Eioberflïche für die in das $\mathrm{Ei}$ eindringende Luft der Weg offen gelassen, an anderen dagegen versperrt wurde, bei einzelnen Eiern auch schon von vorneherein vorliegen. 
Vielleicht sind es abnorme Verdickungen der Dottermembran, welche Theile der Keimscheibe überdecken, oder locale Verdickungen der Kalkschale in Gestalt von kleinen warzenförmigen Excrescenzen (Mamillen), welche den Sauerstoffzutritt zur Keimhaut abnorm gestalten. Jedenfalls wird durch die besagten Bịldungen an den betreffenden Stellen der eindringenden Luft die Passage erschwert und es kann desshalb zu den allenfalls unter ihnen gelegenen Keimhautbezirken nur eine geringere Sauerstoffmenge gelangen, als zu anderen Abschnitten des Blastoderma. Es sind daher ganz ähnliche Bedingungen gegeben, wie bei meinen Versuchen und ich stehe darum nicht an, zu behaupten, dass in solchen Fällen prädisponirende Momente für die Genese von Entwicklungsanomalien oder Missbildungen vorhanden sind. 


\section{Verwachsung oder Spaltung?}

Verfolgt man die historische Entwicklung der Anschauungen, welche im Laufe der Zeit über den Bildungsmodus der Doppelmonstra aufgestellt wurden, so wird man finden, dass dieselben nach den jeweiligen Errungenschaften der normalen Embryogenie zwar verschiedentliche Umgestaltungen erfahren haben, dass in ihnen aber auch heute noch die gleichen principiellen Gegensätze ausgesprochen sind, wie dies in früheren Zeiten der Fall war. Es ist die alte Streitfrage, ob die Doppelmissbildungen durch Verwachsung oder durch Spaltung resp. Theilung entstanden seien, welche noch in den letzten Jahren Gegenstand einer lebhaften Discussion gewesen ist. Es wird daher zunächst meine Aufgabe sein müssen, eine kurze übersichtliche Darstellung der beiden sich gegenüberstehenden Theorien zu geben, um sodann im Anschluss an dieselbe, sowie unter Bezugnahme auf die in den vorausgegangenen Abschnitten mitgetheilten Ergebnisse zu den beiden Theorien Stellung nehmen zu können.

Die Verwachsungstheorie, mit der ich beginnen will, reicht bis in den Anfang des vorigen Jahrhunderts zurück. Lémery scheint der Erste gewesen zu sein, der die Entstehungsweise der Doppelmissbildung aus einer Verschmelzung zweier aus verschiedenen Eiern stammender ursprünglich wohlgeformter Embryonen ableitete; er glaubte, dass dieselbe in Folge einer im Uterus auf die beiden Embryonen einwirkenden Pression zu Stande komme. Indem er diese seine Meinung in der Pariser Academie im Jahre 1724 anssprach, veranlasste er in derselben eine sich über eine Reihe von Jahren hin erstreckende Discussion ${ }^{1}$ ). Unter Lémery's Gegnern war es hauptsächlich Winslow, welcher die selbstständige Entstéhungsweise einer jeglichen Missbildung vertrat. Es ist hier daran zu erinnern, dass in der ersten Hälfte des vergangenen Jahrhunderts die Präexistenz- oder Evolutionstheorie, wonach der ganze Organismus bereits im Keime vorgebildet sein sollte, noch die alleinherrschende war. Es ist begreiflich, dass mit dieser Theorie im engsten Zusammenhang die Meinung stand, dass anch die Missbildungen als Wesen eigener Art bereits im Keime präexistiren sollten. Erst als in Folge der

1) In den Mémoires de l'Academie des sciences lässt sich diese Discussion von 1724 bis 1743 verfolgen. 
bahnbrechenden Untersuchungen C. F. Wolff's ${ }^{1}$ ) die Theorie der Epigenese begann, die Evolutionstheorie aus dem Felde zu schlagen, musste auch jene Lehre von der Präexistenz der Monstra fallen.

Die Hypothese Lémery's von dem Zusammenwachsen zweier verschiedenen Eiern angehörenden Embryonen hat auch in unserem Jahrhundert Vertheidiger gefunden; es sind hier vor allem die beiden Geoffroy St. Hilaire zu nennen, welche den bezeichneten Bildungsmodus vertreten. Insbesondere hat der jüngere Geoffroy St. Hilaire in seinen diesbezüglichen Schriften die Verwachsung zweier Embryonen befürwortet. Dieselbe werde jedoch nicht, wie Lémery meint, durch Druckwirkungen von aussen verursacht, sondern sie sei begründet in der Tendenz ähnlicher embryonaler Theile zur Vereinigung, indem die Verwachsung der beiden Componenten zu einer Doppelmissbildung immer gleichartige Regionen und Organe betreffe. Es ist das von Geoffroy St. Hilaire dem Vater aufgestellte Gesetz der Verwandtschaft des Gleichen zu dem Gleichen (Loi de l'affinité de soi pour soi), welches für die Verwachsung nach Geoffroy St. Hilaire dem Jüngeren massgebend ist ${ }^{2}$ ).

Auch unter den deutschen Gelehrten besass die Theorie Lémery's Vertreter; unter diesen führe ich $\mathrm{Barkow}^{3}$ ) und $\mathrm{H}$. Meckel von Hems$\mathrm{bach}^{4}$ ) an, welche sich Beide für eine Verwachsung zweier in verschiedenen Eiern sich entwickelnder Embryonen aussprachen, der Letztere jedoch unter der Modification, dass die beiden Eier von einer Zona umschlossen seien.

Im Jahre 1855 fand wiederum im Schosse der Pariser Academie eine lebhafte Debatte über die uns beschäftigende Frage statt ${ }^{5}$ ). Auf der einen Seite stehen v. Quatrefages, Serres und J. Geoffroy St. Hilaire, auf der anderen Coste; der Letztere spricht sich für die Bildung eines Doppelmonstrum in einem einzigen $\mathrm{Ei}$ aus und bekämpft, hauptsächlich gestuitzt auf die Vorgänge der normalen Entwicklung, die Annahme, dass Doppelmissbildungen sich von zwei Eiern ableiten; ihm gegenüber haben die erstgenannten Gelehrten einen schwierigen Stand, ihre Anschauungen zu vertheidigen. So sieht sich v. Quatrefages genöthigt, für gewisse Fälle die Zeit der Verschmelzung zweier Eier vor die Befruchtung zu verlegen, während sie dagegen in anderen nach derselben erfolge, wie dies eine von Geoffroy bei einem Hühnchen gemachte Beobachtung beweise. Ueber diesen Fall berichtet der später sich an der Discussion betheiligende J. Geoffroy St. Hilaire, dass es sich um ein grosses Hiihnerei gehandelt habe, welches zwei Dotter enthielt, wie man vor der Bebriitung durch Spiegelung hatte nachweisen können. In demselben entwickelte sich eine omphalopage Doppelmissbildung.

1) Wolff, Theoria generationis 1759. Ferner: De formatione intestinorum in Novi commentarii $\Lambda$ cademiae se. Petrop. 1768 mud 1769. T. XII ı. XIII, deutsch von Meckel, Halle 1812.

2) Isidore Geoffroy Saint-Hilaire, Historre générale et particulière des anomalies de lorganisation che\% l'homme et les animaux. Paris 1836, 'T. III, pag. 530.

3) Barkow, Monstra animalium duplicia, per anatomen indagati.

4) II. Mteckel von He insbach, Ueber die Verhältnisse des Geschlechtes ete. in II iiller's Archiv 1850.

") Comptes rendus 'T. $\mathrm{XL}, 1855$. 
In einer etwas späteren Mittheilung legt Coste ${ }^{1}$ ) seine Anschauungen ausführlicher dar. Seine Beobachtungen über die Entwicklung der Knochenfische lassen ihm eine Verschmelzung zweier Dotter als baare Unmöglichkeit erscheinen; vielmehr hat er bei Knochenfischen eine Doppelbildung innerhalb einer einzigen Keimscheibe mehrmals angetroffen. Zu den gleichen Resultaten, wie Coste, gelangte Lereboullet ${ }^{2}$ ). Auf Grund seiner Erfahrungen über die Genese von Doppelbildungen des Hechtes spricht sich derselbe dahin aus, dass die zu einem Doppelmonstrum verschmelzenden Embryonen in einem Dotter und einem Keime sich bilden.

Auch für die Vögel und Säugethiere liess sich die ursprüngliche Verschmelzungstheorie Lémery's nicht mehr lange aufrecht erhalten. Was die Ersteren anlangt, so stellte es sich immer mehr heraus, dass die Ansicht der beiden Geoffroy St. Hilaire, wonach ein Doppelmonstrum nur in einem zwei Dotter umschliessenden Ei entstehen könne, sich nicht mit den beobachteten Thatsachen vereinigen liess. Das Ausschlüpfen einer omphalopagen Doppelbildung aus einem Ei mit zwei Dottern kann, wie ein von Panum beschriebener Fall zeigt ${ }^{3}$ ), in der Weise seine Erklärung finden, dass auf einem der beiden Dotter sich zw.ei Embryonen entwickelt haben, während auf dem anderen die Embryogenese gänzlich unterblieb. Somit kann die oben mitgetheilte Beobachtung Geoffroy St. Hilaire's, sowie anderweitige meist nur ungenaue Angaben über ähnliche Vorkommnisse nicht mehr als ein unumstösslicher Beweis für die Verschmelzung zweier auf getrennten Dottern entstandener Embryonen angeführt werden. Wohl die meisten Erfahrungen über die Entwicklung von Eiern mit zwei Dottern hat Panum gesammelt ${ }^{4}$ ), dem 77 Hühnereier und 3 Gänseeier, welche ein derartiges Verhalten zeigten, zu Gebote standen. Derselbe hat niemals bei Ausbrütung dieser Eier auch nur die geringsten Spuren einer Verwachsung von zwei je einem der beiden Dotter zugehörenden Embryonen constatiren können. Schon aus diesem Grunde musste die Möglichkeit eines derartigen Vorkommens sehr problematisch erscheinen. Ausserdem verlor die Theorie Lémery's durch die immer zahlreicher werdenden Angaben über die Entwicklung von żwei Embryonen oder einer Doppelmissbildung auf einem einzigen Dotter immer mehr an Wahrscheinlichkeit.

Bezüglich der Säugethiere hat schon J. Geoffroy St. Hilaire zugegeben, dass eine Verschmelzung zweier Embryonen nicht eintreten könne, wenn jeder derselben seine eigenen Hüllen, Amnion und Chorion, oder auch nur ein eigenes Amnion besitze ${ }^{5}$ ). Wäre daher zu jener Zeit die Bildung der Eihüllen'so vollstïndig bekannt gewesen, wie heutzutage, so würde nach der eben citirten Aeusserung Geoffroy selbst nicht mehr daran haben zweifeln können, dass bei Süugern nur für eineiige Zwillingsembryonen eine Verwachsung anzunehmen sei. Erst mit der Erkenntniss, dass nur solche Embryonen

1) Comptes rendus T. XL, pag. 913, 1855.

$\left.{ }^{2}\right)$ Comptes rendus T. XL, pag. 854, 916, 1028, 1064.

3) P a num, Untersuchungen über die Entstehung der Missbildungen pag. 234 und 238, Taf. XII, Fig. 1-3.

4) 1. c. parg. 215.

5) 1. c. 'T. III, pag. 529, Anmerkung 2. 
von einer gemeinsamen Amnionhïlle umgeben sein können, welche in einem Eie sich gebildet haben, war die Verwachsungstheorie, insofern sie die beiden Componenten einer Doppelmissbildung von verschiedenen Eiern bei den Säugethieren und dem Menschen ableitete, als endgültig widerlegt zu betrachten. Man könnte zwar noch zu Gunsten derselben geltend machen, dass bei zwei neben einander im Uterus gelegenen Eiern - ich habe hier hauptsächlich die beim Menschen vorkommenden Verhältnisse im Auge - ein allmähliges Schwinden der die Amnionhöhlen beider Embryonen trennenden membranösen Scheidewand eintreten kann, allein es fällt dies jedenfalls in eine so späte Entwicklungszeit, dass eine Verwachsung der beiden nun in einer gemeinsamen Höhle eingeschlossenen Zwillinge unmöglich erscheinen muss.

Aus dem Gesagten ist zu ersehen, wie die Verwachsungstheorie allmählich eine andere Fassung erhielt. Es sind nicht zwei in verschiedenen Eiern entstandene Embryonen, sondern eineiige Zwillingsembryonen, deren Anlage gleichzeitig erfolgt und welche mit einander verschmelzen. In dieser Weise stellen sich in unserer Zeit die Anhänger der Verwachsungstheorie die Bildung der Doppelmonstra vor. Jeder, der dieser Anschauung huldigt, hat sich wiederum auf folgende Fragen Antwort zu geben: Erstens, wie findet die Anlage von zwei Embryonen innerhalb eines Eies statt, und zweitens, in welcher Ausdehnung, zu welcher Zeit, und wodurch erfolgt die Verschmelzung der beiden Zwillinge? Es liegt in der Natur der Sache, dass in Bezug auf die letzteren Fragen je nach der Art der resultirenden Doppelmonstra auch Verschiedenheiten hinsichtlich ihres Bildungsmodus obwalten müssen. So müssen z. B. zweifelsohne andere Bedingungen gegeben sein, wenn es zur Genese einer Duplicitas posterior kommen soll, als wenn eine dicephale Missbildung sich entwickelt. Da nun über die ersten Stadien der Doppelbildung nur bei einzelnen Vertebratenclassen und selbst da verhältnissmässig wenige positive Beobachtungen bis in die letzten Jahre vorlagen, so ist es begreiflich, dass sich die einzelnen Autoren vielfach auf theoretische Erwägungen angewiesen sahen. Ein solches Vorgehen musste aber nothwendiger Weise zu mannigfachen Differenzen der Ansichten hinführen. Ferner waren die thatsächlichen Erfahrungen, welche in Betreff der ersten Anlage der Doppelbildungen den einzelnen Forschern zu Gebote standen, theilweise dazu angethan, die schwebenden Controversen womöglich noch verworrener zu machen. Es sind nämlich mehreren Beobachtern Vogeleier zu Gesicht gekommen, deren Dotter zwei getrennte Areae pellucidae aufwies. Diese sind entweder in einer gemeinsamen Area opaca enthalten oder jeder derselben kann von einem eigenen Ringgebiet umschlossen sein. In letzterem Falle besitzt der Dotter zwei getrennte Keimhäute, deren Entfernung von einander wiederum eine wechselnde sein kann. Das Vorkommen von zwei Keimhäuten auf einem einzigen Dotter ist durch die Untersuchungen von Panum und neuerdings durch die von Dareste über allen Zweifel erhoben worden. Es können demnach bei den Vägeln - für die Säugethiere liegen überhanpt noch keine Angaben über das Vorkommen zweier Fruchthöfe auf einer einzigen Keimblase vor - die Doppelembryonen sich in verschiedener Weise anlegen, entweder in einer oder in zwei Areae pellucidae; liegen diese in gesonderten Keimhäuten, so werden sie weiter von einander entfernt sein, und darum 
auch die in ihnen sich bildenden Embryonen einen grösseren Abstand zwischen sich lassen müssen. Man hat demnach in Betreff der Bildung von Doppelmonstra auf die genannten Verschiedenheiten in dem Verhalten der Fruchthöfe Rücksicht zu nehmen, was jedoch von Seiten der Autoren leider vielfach vernachlässigt worden ist. Dass auch in einem gemeinsamen Fruchthofe die Anlage einer Doppelbildung sich verschieden verhalten kann, brauche ich im Hinblick auf die früheren Capitel nicht näher auseinander zu setzen.

Unter den Vertretern der Verwachsungstheorie möchte ich ausser den schon genannten Forschern noch B. Schultze, Panum und Dareste anführen, deren Ansichten hier noch in Kürze erörtert werden sollen.

B. Schultze ${ }^{1}$ ) will die Doppelbildungen der Achsenorgane von denen der Extremitäten und sonstigen äusseren oder inneren Organgruppen getrennt wissen, und wendet nur auf erstere den Namen „Doppelmonstra" an. Die Genese derselben führt er in letzter Linie auf eine Duplicität des Keimbläschens eines Eies zurück. Diese habe das Zustandekommen von zwei Fruchthöfen zur Folge, in denen die Embryonalanlagen gleichzeitig auftreten. Die gegenseitigen Lagebeziehungen der beiden Fruchthöfe mit ihren Embryonalanlagen ist für die Form und den Grad der resultirenden Doppelmissbildungen entscheidend. Die berührten Bildungsvorgänge präcisirt Schultze in den nachstehenden Sätzen:

„Alle Doppelmonstra entstehen in einem Ei."

${ }_{\pi}$ Doppelmonstra entstehen durch gleichzeitige ursprüngliche Differenzirung in Eiern, deren Dotter zwei. Keimbläschen enthält, von deren grösserer oder geringerer Entfernung von einander der Grad der Duplicität abhängt." Ferner gebe ich noch von den Resultaten Schultze's, die er am Schlusse seiner Arbeit zusammengefasst hat, die folgenden wieder:

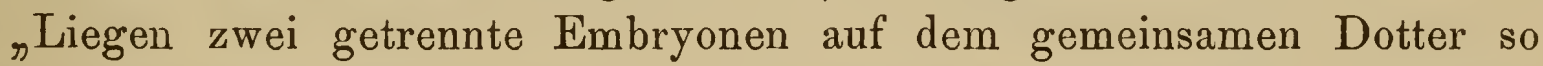
nahe bei einander, dass sie von einem Amnion umhüllt-werden, so hängt es allein von der erfolgenden oder nicht erfolgenden Trennung des Dotters ab, ob die Embryonen sich zu einem getrennten Zwillingspaar oder zu einem am Bauche verwachsenen einnabligen Monstrum entwickeln. Diese Trennung des Dotters wird stets erfolgen, wenn die Embryonen mit den Köpfen oder Schwänzen gegen einander gerichtet sind, vielleicht nie bei paralleler Axenlage. ${ }^{*}$

${ }_{n}$ Sind dagegen die beiden aus einem Dotter entstandenen Embryonen so weit von einander entfernt, dass über jeden ein eigenes Amnion sich bildet, so findet bei jeder Stellung der Axen diese Trennung des Dotters statt, und es entsteht das vollendetste aller Doppelmonstra, das im gemeinsamen Chorion getrennte Amnion mit vollkommenen Zwillingen enthaltende Ei. So kehrt der höchste Grad monströser Duplicität in seinem Resultat zur Norm zurück."

Während die erste der beiden citirten Abhandlungen Schultze's sich hauptsächlich auf die Säugethiere bezieht, beschäftigt sich die zweite auch eingehender mit der Genese der Doppelmissbildungen bei den Vögeln. Bei diesen entstehen die Doppelmonstra meist in einem $\mathrm{Ei}$, jedoch muss die Möglichkeit zugegeben werden, dass auch zwei Dotter verschmelzen, wodurch

1) B. Schultze, Ueber anomale Duplicität der Axenorgane. Virchow's Archiv Bd. 7, 1854. Ferner: Sur les Monstres doubles. Comples rendus 1856, I, Nr. 23. 
die Bildung einer Doppelmonstrositït veranlasst werden könne. Schultze hat demnaeh den Standpunct von J. Geoffroy St. Hilaire, was die Säuger anlangt, vollständig, dagegen hinsíchtlich der Vögel noch nicht so ganz verlassen, was nicht sehr auffallend erscheinen kann, da seine zweite Mittheilung: vom Jahre 1856 datirt, also nur ein Jahr nach der oben erwähnten Discussion in der Pariser Academie erschienen ist.

Panum, der sich schon in seinem mehrfach erwähnten Buche für die Verwachsungstheorie günstig geäussert hat, indem er auf Grund seiner Beobachtungen einer doppelten Keimscheibe auf dem Dotter von Vögeln die Doppelheit der Keimanlage in einer sehr frühen Periode der Eibildung beginnen lässt ${ }^{1}$ ), hat vor einigen Jahren nochmals der Verwachsungstheorie lebhaft das Wort geredet ${ }^{2}$ ). Seiner Ansicht zufolge sind durch frühere Beobachtungen die folgenden fün Puncte unzweifelhaft festgestellt:

1. ${ }_{n}$ Alle Doppelmissbildungen kommen auf einem einfachen Dotter zu Stande, und sie entstehen niemals durch Verwachsung zweier auf verschiedenen Dottern entwickelter Keime, oder durch Verschmelzung zweier in einem Ei vorhandener Dotter."

2. In Vogeleiern kommen bisweilen auf einem gemeinschaftlichen Dotter zwei ursprünglich vollkommen getrennte Keimanlagen vor und zwei Embryen, ron welchen bisweilen jeder mit seinem eigenen Bluthofe und seinem eigenen Amnion versehen ist, während bisweilen zwei übrigens ganz selbstständige Embryen einen gemeinschaftlichen Bluthof und ein gemeinschaftliches Amnion haben."

3. Durch experimentell hervorgebrachte mechanische Spaltungen einer einfachen Keimanlage auf den frühesten Stadien ist niemals eine wirkliche Verdoppelung der Axengebilde oder irgend eines Organes zu Stande gebracht worden."

4. „Es kommen in Fischeiern (und zwar verhältnissmässig häufig) Doppelmissbildungen vor, deren allererste Anlage schon bei Entstehung des Primitivstreifens von Anfang an vorn verdoppelt, hinten aber einfach ist und es ist bei Berücksichtigung etwas weiter entwickelter, aber immerhin noch sehr junger Doppelmissbildungen nicht zu bezweifeln, dass in anderen Fällen schon auf dem Stadium des Primitivstreifens auch hinten verdoppelte, vorn einfache Anlagen zu Doppelmissbildungen vorkommen."

5. „In allen Fällen, wo es (in Fischeiern) gelungen ist, den Fortgang der Entwicklung an Doppelmissbildungen vom frühesten Beginn, d. h. von der Anlage des Primitivstreifens an während längerer Zeit zu verfolgen, hat es sich immer gezeigt, dass die ursprünglich verdoppelten Partien immer weiter mit einander verwachsen und zu einem einheitlichen Körpertheile verschmelzen. Dahingegen hat man niemals eine zunehmende Verdoppelung durch fortschreitende Spaltung eines ursprünglich einfachen Theiles der Körperanlage beobachtet."

Die in dem Absatz 5) befürwortete Verschmelzung zweier ursprünglich verdoppelter Partien zu einem einheitlichen Körpertheil leitet Panum haupt-

1) 1. c. pag. 242.

$\left.{ }^{2}\right)$ P п п и m, Beiträge zur Kenntniss der physiologischen Bedeutung der angebornen Misslildungen. Virchow's Archiv Ba. 72, 1878, pag. 165. 
sächlich aus den Beobachtungen Lereboullet's ab, welcher an missbildeten Hechteiern, auf denen die Embryonalanlagen vorn und hinten einfach, in der Mitte aber verdoppelt waren, ein allmähliges Zusammenwachsen, sowie schliesslich eine äusserliche Vereinfachung der mittleren Körpertheile verfolgen konnte. Es handelt sich hier um Missbildungen, welche später Oellacher Terata mesodidyma nannte und deren Genese der letztgenannte Forscher auf eine Spaltung der ersten Embryonalanlage zurückführen möchte. Ich werde später auf die Ansichten Lereboullet's und Oellacher's noch zurückkommen und bemerke hier nur vorläufig, dass den richtigen Bildungsmodus der Terata mesodidyma späterhin Rauber nachgewiesen hat, indem er zeigte, dass dieselben Hemmungsbildungen darstellen. Dass diese Mesodidymi mit ihren mittleren Abschnitten später bei fortschreitender Entwicklung nach und nach verwachsen, und endlich für die äussere Inspection einfach werden, erklärt sich sowohl durch die Volumvergrösserung der ursprünglich doppelten Theile, als hauptsächlich durch das in frühen Entwicklungsstadien vorwiegend stattfindende Längenwachsthum der Embryonen.

Hinsichtlich der weiteren in der angegebenen Arbeit Pan um's enthaltenen Ausführungen hebe ich nur noch hervor, dass Panum die verschiedenen Formen der Doppelmissbildungen auf 5 ursprüngliche Hauptstellungen der Primitivstreifen zurückführt; dieselben können parallel oder winkelig zu einander gestellt sein, oder in einer Linie verlaufen; die beiden letzten Anordnungen zerfallen in je zwei Unterabtheilungen, indem die Kopfenden der Primitivstreifen entweder einander genähert erscheinen, resp. sich entgegenstehen oder von einander abgewendet sind. Auch eine Kreuzung der Primitivstreifen ist Pa.n um geneigt anzunehmen. Diese verschiedenen Stellungen leitet Panum ab von älteren Missbildungen; er schliesst demnach von den bereits mehr oder weniger ausgebildeten Formationen auf die Anfangsstadien, indem er für diese die gangbaren Begriffe „Primitivstreifen" verwendet. Wie die Primitivstreifen sich anlegen, darauf geht $\mathrm{Panum}$ nicht ein und motivirt dies dadurch, dass über das Stadium der Bildung der Primitivstreifen hinaus die Entstehung der Doppelmissbildungen nicht durch Beobachtungen zu verfolgen sei. „Wir müssen es daher unentschieden lassen, worauf das abnorme Resultat der Dotterfurchung und der ersten Bildung des Primitivstreifens beruht, ob es, wie B. Schultze vermuthet hat, vom Vorhandensein zweier Keimbläschen oder von einer zu üppigen Bildung und abnormen Verdoppelung eines grösseren oder kleineren Theils, der beim Furchungsprocess entstandenen ersten Urzellen der Keimanlage abhängen mag. Es lässt sich in diesen Fällen oft darüber disputiren, ob es sich hier um ein theilweise verdoppeltes Individuum handelt, oder um zwei theilweise verkrüppelte Individuen. Man mag das aber auffassen, wie man will, so muss man doch zugeben, dass in solchen Fällen eine partielle Verdoppelung einer übrigens einfachen oder eine partielle Einfachheit einer übrigens doppelten Keimanlage als der erste der Beobachtung zugängliche Ausgangspunct schon von Anfang . an, d. h. auf dem Stadium des Primitivstreifens gegeben ist" ${ }^{1}$ ).

Ferner möchte ich darauf aufmerksam machen, dass Pan u m die Be-

1) l. c. pag. 169 u. 170. 
zeichnung "Primitivstreifen " bei Fischembryonen noch in demselben Sinne gebraucht, wie bei den Vogel- und Säugethierembryonen. Dies ist heutzutage nicht mehr zulässig, da durch die neueren embryologischen Untersuchungen festgestellt ist, dass der Primitivstreifen der Vögel und Süuger bei den niederen Wirbelthierclassen kein Analogon hat. Bei den Ersteren ist streng zwischen einer Primitivrinne und einer später auftretenden Medullarrinne zu unterscheiden. Bei den Amphibien und Fischen jedoch bleibt die Bildung der Primitivrinne, da kein Primitivstreifen sich entwickeit, gänzlich aus, und es legt sich sofort die Medullarrinne an.

Während für Schultze und Panum bei der Beurtheilung der Teratogenie der Doppelmissbildungen die normale Entwicklungsgeschichte nicht in erster Linie massgebend war, hat Dareste ${ }^{1}$ ), dessen Anschauungen nun dargelegt werden sollen, die normale Embryogenese zum Ausgangspuncte seiner Betrachtungen über die Bildung der Doppelmonstra gemacht. Seine Beobachtungen betreffen ausschliesslich die Classe der Vögel.

Nach Dareste entsteht in der Norm der Embryo aus einem homogenen Blastem, welches zwischen den beiden ursprünglichen Blättern der Keimscheibe dem Ektoderm und dem Entoderm in Erscheinung tritt; dasselbe wird als ᄁDisque embryonnaire ${ }^{*}$ bezeichnet. Aus demselben geht der Primitivstreifen und das Gefässblatt hervor; der erstere bildet sich aus den medialen Theilen des Disque, das letztere aus den lateralen. Im Falle einer Doppelmissbildung entstehen in einer einzigen Keimhaut zwei Disques embryomnaires, die nothwendigerweise bei ihrem Wachsthum sich berühren und vereinigen müssen. Aus dieser Vereinigung ergeben sich je nach dem Grade der Entfernung sehr verschiedene Folgeerscheinungen. Sind nämlich die beiden Disques durch eine gewisse Entfernung von einander getrennt, so können sie sich nur mit den Gefässblättern vereinigen; sind sie jedoch einander sehr nahe, so werden diejenigen Theile, welche zu den Primitivstreifen sich umbilden, an einander stossen, und ihre Verschmelzung wird ein Doppelmonstrum hervorbringen. Derartige Vereinigungen können demnach nur in der ersten Entwicklungszeit stattfinden, wenn die Embryonen aus einem noch nicht differenzirten gleichartigen Zellenmaterial sich aufbauen.

Ueber die verschiedenen Arten der Vereinigung gibt D areste im Allgemeinen an, dass bei einer sehr frühzeitigen Verschmelzung der betreffende Körpertheil vollständig einfach sich gestalten kann; kommt eine solche etwas später zu Stande, so wird der von der Verwachsung betroffene Theil alle möglichen Abstufungen des Doppelseins aufweisen können, wie man sie später an den ausgebildeten Organen desselben wahrnimmt.

Das Mitgetheilte lässt bereits den Standpunct erkennen, den Dareste in der uns beschäftigenden Frage einnimmt. Dareste bezeichnet ihn als die Doctrin der primitiven Dualität, versteht aber hierunter etwas ganz anderes wie in früherer Zeit Lémery. „Ich glaube zwar, wie Lémery, dass die Doppelmissbildungen aus der mehr oder weniger vollständigen Verschmelzung zweier Embryonen resultiren; aber diese Verschmelzung erfolgt und kann nur erfolgen während der Bildung der Embryonen selbst, und sie

1) Production artificielle des Monstruosités. 
entsteht in jedem Falle bei den Wirbelthieren aus einem besonderen Zustand der Cicatricula, welcher in der Keimhaut für das Auftreten von zwei Bildungsherden bestimmend ist. Die zwei Componenten einer Doppelmissbildung sind demnach von dem Momente ihres Erscheinens unter einander auf mittelbare Weise vereinigt, und es ist diese mittelbare Vereinigung die unerlässliche Bedingung für ihre unmittelbare Vereinigung oder ihre Verschmelzung ${ }^{\text {“ }}{ }^{1}$ ).

Dass im Sinne der alten Verwachsungstheorie zwei Embryonen, die auf verschiedenen Dottern sich gebildet haben, sei es mit ihren Körpern, sei es mit ihren Dottern, sich vereinigen können, hält Dareste seinen Erfahrungen nach für unmöglich. Vielmehr muss nothwendiger Weise angenommen werden, dass alle Doppelmissbildungen wie die Einzelembryonen sich auf einem einzigen Dotter entwickeln. Damit im engsten Zusammenhang steht die Frage nach der Bildung von Zwillingsembryonen, denn auch diese entstehen häufig auf einem gemeinsamen Dotter, und zwar in verschiedener Weise. Dieselben können entweder auf zwei getrennten Cicatriculae oder in einer gemeinsamen Keimscheibe sich bilden. Im ersteren Falle kommt Anfangs jedem der beiden Embryonen seine besondere Area pellucida, Gefässblatt und Amnios zu. Erst später kommen beim Auswachsen die beiden Keimhäute mit einander in Berührung und vereinigen sich. Dadurch entstehen Communicationen zwischen den Areae vasculosae beider Embryonen. So wird die anfänglich nur durch den gemeinschaftlichen Dotter vermittelte Verbindung zwischen beiden im Laufe der Entwicklungszeit immer inniger, da beide von dem gleichen Blute durchströmt werden und darum in eine gewisse Abhängigkeit von einander kommen. Gleichwohl macht das Vorhandensein eines getrennten Amnios jeden der beiden Embryonen bis zu einem gewissen Grade selbstständig. Die Entwicklung zweier Zwillinge in getrennten Keimhäuten ist denjenigen Fällen der Zwillingsschwangerschaft des Menschen an die Seite zu stellen, bei denen jeder der beiden Zwillinge, die in ein gemeinsames Chorion eingeschlossen sind, sein besonderes Amnios hat.

Was die Genese von Zwillingen auf einer Cicatricula betrifft, so glaubt Dareste, dass auch bei ihnen ganz am Anfange getrennte Areae pellucidae und Gefässblätter vorkommen, die aber unausbleiblich schon in frühester Zeit mit einander verschmelzen müssen. Das Gleiche kann bezüglich des Amnios statt haben; später vereinigen sich auch die beiden Allantoiden und bilden ein einheitliches Organ. Die beiden Zwillingsembryonen sind demnach durch ihre Annexa viel inniger verbunden als die in getrennten Cicatriculae entstehenden Zwillinge und es liegen darum für die Verwachsung der Embryonen selbst viel günstigere Bedingungen vor. Jedoch können die Zwillinge in beiden Fällen, mögen sie von zwei, oder nur von einer einzigen Cicatricula sich ableiten, abgesehen von dem durch ihre Annexa vermittelten Zusammenhang im Uebrigen getrennt bleihen; gleichwohl müssen sie mit der allmähligen Resorption des gemeinsamen Dotters immer näher an einander heranrücken, und schliesslich wird beim Ausschlüpfen ein Moment kommen, wo die beiden Zwillinge, in der Nabelgegend mit einander verbunden, sich nicht zu trennen vermögen. Es müssen daher bei den Vögeln in allen

1) l. c. pag. 283.

Gerlach, Entstehungsweise der Doppelmissbildungen. 
Fällen univitelliner Zwillingsbildung, bei denen die beiden Componenten nicht mit ihren Körpern selbst eine Verwachsung eingehen, Omphalopagen resultiren. Dieselben rechnet Dareste nicht eigentlich zu den Doppelmissbildungen. „Il n'y a que des jumeaux, qui ne peuvent pas se séparer, ou comme le disait J. Geoffroy St. Hilaire un cas d'omphalopagie."

Wenn zwei Embryonen sich auf einem gemeinsamen Dotter entwickeln, so können sie entweder in ihrer Ausbildung gleichen Schritt halten oder nicht. Es kann der eine normal sich verhalten, der andere dagegen verkümmern; im letzteren Falle erhält, wenn keine Verwachsung der Embryonen selbst stattgefunden hat, mit der Resorption des Dotters der verkümmerte Embryo den Character eines Omphalositen, dessen Ernährung von seinem Zwillingsbruder besorgt wird. Bei den Placentalien trennt sich bei der Geburt der normale Zwilling von dem Omphalositen, während bei den Vögeln der letztere mit dem Dotterreste in den Leib des normalen Embryo eingezogen wird, wodurch eine Inclusio abdominalis (Wolff) entsteht.

Ueber die Bildung der Doppelmonstrositäten bei Fischen spricht sich Dareste, da ihm keine eigenen Erfahrungen über diesen Gegenstand zu Gebote stehen, mit einer gewissen Reserve aus. Die Mehrzahl der Embryologen, die hierüber gearbeitet haben, stimmen darin überein, dass die Doppelmissbildungen der Fische (Knochenfische) auf einem einzigen Blastoderma zu Stande gekommen seien. Dareste wirft nun die Frage auf, ob nicht auch bei Fischen, wie bei den Vögeln, zwei Anfangs getrennte Keimscheiben vorkommen könnten. Eine solche Möglichkeit glaubt Dareste für gewisse Fälle nicht ganz von der Hand weisen zu dürfen. Nach ihm kommen hier diejenigen Doppelbildungen in Betracht, deren Embryonen sich auf derselben Dotterblase gänzlich isolirt entwickeln und die genetisch den vorhin besprochenen Omphalopagen der Vögel äquivalent sind. Nachdem noch Dareste der einzelnen Ansichten gedacht, die über die Genese der Doppelbildungen für die Fische aufgestellt wurden, kommt er zu dem Schlusse, dass auch hier, wie bei den Vögeln, der Bildung der Doppelmonstra ein schon vor jeglicher Embryonalentwicklung bestehender besonderer Zustand der Cicatricula zu Grunde liegen müsse.

$\mathrm{Zu}$ der Frage übergehend, wodurch jener eigenthümliche, objectiv nicht erkennbare Zustand der Cicatricula, welcher bereits vor dem Auftreten der Embryonalanlage für das Erscheinen einer Doppelbildung bestimmend ist, bedingt werde, gesteht Dareste zu, dass man hier vor einem Problem stehe, welches nach dem heutigen Stand der Wissenschaft als unlösbar erscheinen müsse. Sind in den bezüglichen Fällen bereits im Ovarium zwei Eier zu einem einzigen versehmolzen, oder waren in den betreffenden Eiern zwei Keimbläschen vorhanden oder zwei Balbiani'sche Bläschen? Diese Annahmen, welche sümmtlich das univitelline Entstehen der Doppelbildungen involviren, verlegen den Schwerpunct der Frage auf eine Anomalie des Eies, d. h. des weiblichen Zeugungsstoffes. Ebenso berechtigt erscheinen $\mathrm{D}$ areste die Vermuthungen, wonach ein abnormes Verhalten der mïnnlichen Geschlechtsproducte einen unregelmässigen Befruchtungsvorgang und hiermit implicite eine Doppelmissbildung veranlassen könnte. „Pour ma part je suis disposé à croire que la condition, qui détermine l'apparition de deux foyers de production em- 
bryonnaire dans une cicatricule unique appartient tantôt à l'élément mâle, et tantôt à l'élément femelle de la génération " ${ }^{1}$ ).

Von besonderer Wichtigkeit für unsere Betrachtungen sind diejenigen der mitgetheilten Resultate Dareste's, welche die verschiedenen Eventualitäten der Entwicklung von Doppelbildungen betreffen. Ich möchte sie desshalb nochmals kurz in den folgenden drei Sätzen zusammenfassen:

1) Entwickeln sich zwei Embryonen auf zwei Cicatriculae desselben Dotters, so tritt eine Vereinigung ihrer Annexa erst relativ spät ein; die Verschmelzung der Embryonen selbst ist nur bei sehr nahe an einander gelegenen Cicatriculae allenfalls möglich; schliesslich muss jedoch bei gleichmässig fortschreitender Ausbildung der beiden Componenten eine Omphalopagie resultiren.

2) Entwickeln sich zwei Embryonen auf einer einzigen Cicatricula, so tritt eine innigere Verbindung ihrer Annexa ein, wodurch die Verschmelzung der Embryonen selbst zu einem Doppelmonstrum in hohem Grade begünstigt wird. Unterbleibt jedoch die Verschmelzung der Embryonen, so entstehen unter der Voraussetzung einer gleichmässigen Weiterentwicklung der letzteren ebenfalls Omphalopagen.

3) Tritt bei der Entwicklung zweier Embryonen auf einer Cicatricula schon in den ersten Stadien der Embryonalanlage eine Verschmelzung der Gefässblätter und der werdenden Primitivstreifen ein, so entstehen unabweislich Doppelmissbildungen (deren Axenorgane theilweise sinfach sind).

Die Spaltungstheorie, zu der ich nun übergehen will, ist viel jüngeren Datums, als ihre Gegnerin, die Verwachsungstheorie. Es musste zuvor der Sieg der Epigenese über die Präformation vollständig entschieden sein, was wiederum zur Folge hatte, dass auch die noch von A. v. Haller ${ }^{2}$ ) vertretene Lehre der bereits im Keime präformirten Missbildungen als irrthümlich aufgegeben werden musste, ehe man anfing, die Genese der Missbildungen vom entwicklungsgeschichtlichen Standpuncte aus zu betrachten. Erst durch ein derartiges Vorgehen waren die Prämissen gegeben, auf die hin eine Theorie ins Leben treten konnte, welche in einer gewissen embryonalen Entwicklungsstufe eine verschieden hochgradige Spaltung des werdenden Organismus annimmt und darin die Ursache für die Bildungen der Doppelmonstra erblickt.

Der berühmte Begründer der Theorie der Epigenese, C. F. Wolff, hat auch die Missbildungen hinsichtlich ihrer genetischen Erklärung von den Fesseln befreit, welche ihnen durch die alte Lehre der Präexistenz auferlegt worden waren. Er weist Haller gegenüber schlagend nach, dass die Missbildungen keineswegs unmittelbare Werke des Schöpfers seien, sondern dass bei ihrer Bildung Naturkräfte thätig waren, die durch ein Hinderniss in ihrem gesetzmässigen Walten gestört worden seien ${ }^{3}$ ). Ess musste Wolff, der in Folge seiner entwicklungsgeschichtlichen Untersuchungen mit den verschiedensten Formen der Embryonalbildung vertraut war, der Gedanke sehr nahe liegen,

1) 1. c. pag. 308 .

2) A. v. Haller, Opera minora T. III, 1768.

3) Wolff, De ortu monstrorum. Novi commentarii Ac. sc. Petropol. T. XVII, pag. 560 und 567,1772 . 
dass so manche Missbildung eine frühe Entwicklungsstufe des normalen Organismus repräsentirt. Damit hatte Wolff die Entstehungsweise jener Monstrositäten, die wir als Hemmungsbildungen zu bezeichnen pflegen, aufgedeckt; es war in diesen Fällen der Organismus, indem die bildenden Kräfte nicht genügend wirksam waren, auf einem für eine frühere Entwicklungszeit normalen Zustand stehen geblieben.

Aber nicht nur die Hemmungsbildungen, sondern überhaupt alle Missbildungen, die Doppelmonstra mit eingeschlossen, führt Wolff auf eine abweichende Thätigkeit der Vegetationskraft zurück ${ }^{1}$ ). Wolff ist ein entschiedener Gegner der älteren Verwachsungstheorie. ${ }_{\text {N Non }}$ probabile est, fieri monstra ex gemellis compressis et concrescentibus", sagt er bei Gelegenheit einer Beschreibung eines Ovum simplex gemelliferum des Hühnchens ${ }^{2}$ ). Diese Bemerkung richtet sich offenbar gegen Lémery's Hypothese, wonach in Folge mechanischer Einwirkungen, wie durch Pression von aussen, eine Verschmelzung zweier Embryonen stattfinden könne. Dagegen scheint Wolff, wie aus einer Stelle seiner Abhandlung „de ortu monstrorum ${ }^{*}$ (pag. 570) hervorgeht, eine rein oberflächliche, nur durch die Haut vermittelte Vereinigung zweier Zwillinge für nicht unmöglich zu halten.

Aus dem Gesagten erhellt, wie W. der bildenden Kraft bei allen Entwicklungsvorgängen die Hauptrolle zuertheilt. Dieselbe wirkt bei der Bildung eines normalen Embryo in gesetzmässiger Weise, dagegen zeigt sie bei der Entwicklung der Monstra insofern ein regelwidriges Verhalten, als sie von gewissen Embryonalstadien an den Aufbau des bisher normal entwickelten Organismus bald mit zu grosser, bald mit zu geringer Energie vollziehe. Im ersteren Falle werden Monstra per excessum, und hierzu gehören die Doppelmissbildungen, im lezteren Hemmungsbildungen entstehen müssen.

Ganz auf den Schultern Wolff's steht bezüglich der Auffassung der Missbildungen J. F. Meckel. Dass auch dieser Forscher die Monstrositäten durch eine Ablenkung der Bildungskraft aus ihrer normalen Bahn zu erklären sucht, ersieht man aus den folgenden Citaten. „Wirkt diese bildende Kraft des männlichen und weiblichen Samens allein, so wird die normale Form des Embryo dadurch hervorgebracht; eine abweichende entsteht dagegen, wenn zu derselben Zeit irgend ein Hinderniss, irgend eine Unordnung, sie betreffe den Eierstock, die Trompeten, die Gebärmutter, den Unterleib, oder sie sei in der krankhaften Beschaffenheit der Zeugungsfeuchtigkeiten selbst begründet, jene bildende Kraft in ihrem Wirken stört; denn nothwendig muss eine aus der Vereinigung verschiedener Kräfte entstehende dritte Kraft einen anderen Erfolg bewirken, als wenn die bildende Kraft allein thätig ist.

Hierin ist eigentlich die ganze bessere Ansicht der Lehre von der Entstehung der Missbildungen begründet, wenngleich der Umstand nicht besonders hervorgehoben ist, dass die bildende Kraft auch an und für sich vom Normal abweichen kann."

${ }_{n}$ Die Richtung und Energie der bildenden Kraft aber kann durch so viele Momente abgeändert werden, als auf das Generations- und Nutritions-

1) Wolff, Theoria generationis 1759, pag. 134 und 135.

$\left.{ }^{2}\right)$ Novi commentarii Ac. sc. Petrop. T. XIV, pag. 478. 
geschäft einwirken und dieses abändern können, sie mögen nun vor der Begattung und Zeugung, oder während, oder nach derselben eintreten " 1).

In letzterer Hinsicht kommt Meckel gänzlich auf die Anschauungen Wolff's zurück, wonach Missbildungen aus früher normalen embryonalen $\mathrm{Zu}$ ständen hervorgehen, indem die formative Kraft von einer gewissen Entwicklungszeit an von der Norm abweicht. Wodurch jene Abänderung in dem Wirken der bildenden Kräfte bedingt sein könne, darüber hat Meckel keine bestimmten Angaben zu machen vermocht; er hebt nur hervor, dass die Zeugungsund Nutritionsvorgänge solche dynamische Momente mit sich bringen können. Einwirkungen mechanischer Natur, welche von aussen her jene Kräfte modificiren sollen, scheinen M. sehr unwahrscheinlich.

Was die Bildung der Doppelmonstra anlangt, so führt M. dieselben wie Wolff auf eine übergrosse Energie der bildenden Kräfte zurück und äussert sich über diese Puncte, sowie über die Beziehungen der Doppelmissbildungen zu den normalen Zwillingsembryonen in folgender Weise: „Offenbar muss man daher die Doppelmissgeburten als eigene durch ungewöhnliche Energie der bildenden Kraft entstandene Bildungen ansehen, die sich in dem Masse der Einfachheit und der Zwillingsschaft nähern, als die Energie der bildenden Kraft grösser oder geringer war" 2 ).

Eine Verschmelzung zweier Anfangs getrennter Individuen wird von Meckel auf das entschiedenste in Abrede gestellt. Viel eher kann das Gegentheil angenommen werden, indem sich vielleicht aus einem ursprünglich völlig einfachen Embryo eine Doppelmissgeburt entwickeln könne. Da in der Norm der Embryo im Anfange seiner Entwicklung aus zwei seitlichen Hälften bestehe, welche sich dorsalwärts und ventralwärts zur Bildung des Nerven- und Eingeweiderohres vereinigen, so könne es in gewissen Fällen möglich sein, dass die beiden Seitenhälften wegen einer zeitweise zu geringen Energie der Vegetationskraft nicht zur Vereinigung kommen, sich getrennt entwickeln, wodurch mehr oder weniger vollständige Doppelmissbildungen zu Stande kommen. Meckel sucht dieser seiner Vermuthung im Hinblick auf die künstliche Theilung von Polypen und Actinien eine grössere Wahrscheinlichkeit zu verleihen ${ }^{3}$ ).

Die letztgenannten Anschauungen Meckel's fanden besonders bei den Embryologen vielfachen Beifall, und es entwickelte sich aus ihnen späterhin die Spaltungstheorie, indem von Seiten mehrerer Gelehrten, welche jene mehr oder minder weitgehende frühzeitige Trennung der beiden embryonalen Seitenhälften befürworten, als Grund für diese Erscheinung zufällige, vielleicht von aussen her auf das Ei einwirkende Ursachen in Anspruch genommen wurden.

In diesem Sinne hat sich bereits im Jahre 1827 C. E. v. B a er geäussert im Anschluss einer von ihm beim Hühnchen beobachteten Doppelbildung ${ }^{4}$ ). Auch in einer späteren Abhandlung ist v. Baer für die Spaltungstheorie nachdrücklich eingetreten; jedoch muss nach ihm̌r schon in der allerersten Zeit der Embryonalbildung eine Spaltung der Axenorgane eingeleitet werden ${ }^{5}$ ).

') J. F. Meckel, Handbuch der pathologischen Anatomie Bd. I, 1812, pag. 37 u. 38.

$\left.{ }^{2}\right)$ l. c. pag. 70 .

$\left.{ }^{3}\right)$ 1. c. pag. 40.

4) Meckel's. Archiv fïr Anatomie und Physiologie 1827, pag. 576.

5) v. Baer, Mémoires de l'Acad. imp. d. St. Pétersbourg 1845. 
Ein Jahr nach dem Erscheinen der ersten der beiden citirten Mittheilungen $\nabla$. Baer's hat sich Joh. Müller gleichfalls für eine Spaltung des Embryo in sehr früher Entwicklungszeit erklärt ${ }^{1}$ ). „Etwas Bildsames wird auf der niedersten Stufe der Entwicklung, ehe es das Einzelne aus sich gesondert, was zu einer vollkommenen Ausbildung gehört, wenn es durch innere oder äussere Ursachen getheilt wird, in beiden Theilen die noch unentschiedenen, ungesonderten Momente des Ganzen gleich enthalten, die daher im Processe der Entwicklung zur Bildung gleicher Individuen in den gespaltenen Theilen procediren.

Die Theile sind auf dieser niedersten Stufe der Entwicklung noch so wenig verschieden, und enthalten so gleichviel vom Ganzen, dass sie selbst das in ihnen vom Ganzen Enthaltene zum Ganzen ausbilden können. Diese Art der Doppelbildung durch Theilung und Zeugung durch Doppelbildung muss daher den niedersten Thierformen zukommen, wie denn die Zeugung und Theilung durch Längenspaltung von den Polypen und besonders von den Vorticellen erwiesen ist. Aus gleichen Gründen muss diese Art der Doppelbildung dem Embryo des Menschen und der Thiere zu einer Zeit zukommen können, wo das Einzelne noch im Ganzen und vom Ganzen gleichviel in verschiedenen Theilen enthalten ist. Wenn nur äussere oder innere Ursachen dieser theilweisen Spaltung des noch unentwickelten Grundstoffes vorhanden sind, so müssen beide Theile das in ihnen vom Ganzen gleich Enthaltene zur Doppelbildung ausscheiden."

Kurz darauf bemerkt Joh. Müller weiterhin: „So bedarf es zu allen Erörterungen wahrer Doppelbildung nie der Annahme von Ineinsbildung zweier Keime; doch muss zum rechten Verständniss scheinbarer Annahmen wohl bemerkt werden, dass, wenn auch die in einem $\mathrm{Ei}$ von allem Anfang an wirklich doppelt vorhandenen Keime in der Regel getrennt bleiben, und nicht verwachsen, in sehr seltenen Fällen diese Verwachsung mit äusseren Theilen späterer Bildung, ja selbst mit den Schädelknochen eintreten kann, wobei aber die inneren Theile beider Embryonen getrennt bleiben. Diese Fälle sind von den Doppelbildungen ganz auszuschliessen und haben so wenig Wunderbares als die Verwachsung der verwundeten Finger bei den Erwachsenen, das. Aneinanderheilen natürlicher Theile desselben Individuums."

Joh. Müller führt demnach die wahren Doppelbildungen, worunter er ohne Zweifel solche mit theilweise einfacher Axe versteht, auf eine frühzeitige Spaltung der Embryonalanlage zurück, indem er eine partielle Verschmelzung und Ineinsbildung verwirft. Für solche Fälle jedoch, bei denen die beiden Componenten nur in geringem Grade mit oberflächlichen 'Theilen unter einander zusammenhängen, lässt er in derselben Weise wie Wolff eine Verwachsung zu.

Der Spaltungstheorie leistete, wie begreiflich, die früher eingehender mitgetheilte Angabe Valentin's ${ }^{2}$ ), aus einem Hühnchenembryo durch künstliche Spaltung eine Doppelmissbildung erzielt zu haben, wesentlichen Vorschub, und so sehen wir denn, wie unsere ersten deutschen Embryologen und Teratologen fast ausnahmslos den Standpunct Joh. Müller's theilen, indem sie eine

1) Joh. Mïller, Ueber die Metamorphose des Nervensystems in der Thierwelt. Meckel's Archiv 1828, pag. 18.

$\left.{ }^{2}\right)$ Valentin, Repertorium II, 1837, pag. 169. 
sehr frühe Spaltung des werdenden Organismus annehmen; ich nenne hier Valentin ${ }^{1}$ ), Bischoff ${ }^{2}$ ), Leuckart ${ }^{3}$ ), Förster ${ }^{4}$ ), Reichert ${ }^{5}$ ), von den jüngeren Forschern Dönitz ${ }^{6}$ ), Dittmer ${ }^{7}$ ), Oellacher ${ }^{8}$ ), Ahlfeld ${ }^{9}$ ).

Ueber die Art und Weise, wie die Spaltung sich vollziehe, sowie in Betreff der Entwicklungszeit, in welcher dieselbe stattfinde, gehen jedoch die Ansichten der genannten Gelehrten aus einander.

Bischoff kann nicht mit Meckel übereinstimmen, dass sich die Theilung erst nach dem Auftreten der Rückenplatte und Medullarrinne einstellen solle. Die Spaltung müsse in eine frühere Embryonalzeit verlegt werden, da das genannte Stadium nicht mehr einen Zustand primärer Indifferenz, sondern bereits eingetretener Differenzirung darstelle. Es sei gar nicht denkbar, dass jede der beiden Hälften der Rückenplatten, die schon die Elemente für ganz andere zukünftige Theile enthalten, jetzt nochmals die Elemente für neue Partien des Centralnervensystems in sich entwickeln solle ${ }^{10}$ ).

Reichert hat ausser der Längsspaltung einen nenen Modus der Spaltung aufgestellt. Nach ihm können auch Doppelbildungen durch eine quere Spaltung des Keimes entstehen. Was die Längsspaltung anlangt, so schliesst er sich eng an die Ansichten Meckel's an. Er betont die bilateral symmetrische Anlage des Wirbelthierkörpers, in welcher die linke und rechte Hälfte zweien Individuen angehören, die in der Norm mit Aufopferung der fehlenden Hälften sich vereinigen, und dadurch die Entwicklung eines bilateral construirten Körperbaues herbeiführen. Diese Vereinigung werde nun bei der Genese einer Doppelmissgeburt gestört und theilweise verhindert, in Folge dessen eine selbstständige Entwicklung und eine mehr oder minder vollständige Trennung der beiden Hälften resultire.

Die Querspaltung des Keimes lässt dagegen Reichert in einem der Bildung der Primitivorgane (Medullarrinne) vorausgehenden Entwicklungsstadium statthaben. Die dadurch verursachte Spaltung der Bildungsdotterzellenmasse soll das Auftreten von zwei totalen Embryonalanlagen veranlassen.

In vollkommener Harmonie mit Reichert befindet sich Dönitz. Auch er lässt neben der longitudinalen eine transervale Keimspaltung zu. Durch

1) 1. c.

$\left.{ }^{2}\right)$ Bischoff, Entwicklungsgeschichte mit besonderer Berücksichtigung der Missbildungen, in R. Wag $\mathrm{n}$ er's Handwörterbuch der Physiologie Bd. I, 1842, pag. 911.

$\left.{ }^{3}\right)$ Le uckart, De monstris, eorumque caussis et ortu 1845, pag. 74 .

$\left.{ }^{4}\right)$ Förster, Die Missbildungen des Menschen, Jena 1861, pag. 20.

$\left.{ }^{5}\right)$ Reichert, Anatomische Beschreibung dreier sehr frühzeitiger Doppelembryonen von Vögeln zur Erläuterung der Entstehung von Doppelmissgeburten. Arehiv für Anatomie und Physiologie 1864, pag. 744.

$\left.{ }^{6}\right)$ Dönitz, Beschreibung und Erläuterung von Doppelmissgeburten. Archiv für Anatomie und Physiologie 1866, pag. 518.

$\left.{ }^{7}\right)$ Dittmer, Zur Lehre von den Doppelmissgeburten. Arehiv füir Anatomie und Physiologie 1875, pag. 360 .

$\left.{ }^{8}\right)$ Oellacher, Terata mesodidyma von Salmo Salvelinus. Sitzb. der Wiener Acad. der Wissensch. Bd. LXVIII, 1873.

$\left.{ }^{9}\right)$ A hlfeld, Beiträge zur Lehre von den Zwillingen. Ārchiv für Gynäkologie Bd.IX, pag. 196.

$\left.{ }^{10}\right)$ l. c. pag. 912. 
die letztere jedoch werden im Gegensatz zur ersteren immer zwei vollständige Individuen angelegt, indem sämmtliche Primitivorgane doppelt vorhanden sind. Dönitz deducirt dieses Vorkommen einer Querspaltung aus denjenigen Fällen von Doppelbildungen (Hühnchen), in denen die Längsaxen der beiden Körper genau in einer Linie liegen; diese lassen sich nur durch die Annahme einer Querspaltung erklären, während die Doppelbildungen, deren Componenten mit ihren Längsaxen einen Winkel bilden, sich zur Noth auch aus einer Längsspaltung ableiten lassen. Der Beweis einer transversalen Spaltung könne aber nur an sehr jungen Embryonen geführt werden; eine derartige frühzeitige Doppelbildung sei die von ihm mitgetheilte ${ }^{1}$ ) (Fall 10 unserer zusammengestellten Fälle, Fig. 8, Taf. IV).

Die in Folge einer Querspaltung entstandenen Doppelembryonen verbinden sich mit ihren Kopfenden mehr oder minder innig mit einander, wodurch die verschiedenen Grade von Cephalopagen oder Janusformen zu Stande kommen.

Gegen die Annahme einer Querspaltung wendet sich nun Dittmer und führt des Näheren aus, dass ein bilateral symmetrischer Keimspaltungsprocess, bezüglich dessen Auffassung er ganz auf der Seite Reichert's steht, vollkommen hinreiche, um sämmtliche Doppelmissbildungen zu erklären. Die Lage der Embryonen des Dönitz'schen Falles sei die Folge einer Drehung der beiden ursprünglich neben einander gelegenen am Kopfende inniger verbundenen Embryonalanlagen. Die Kräfte, welche eine solche Drehung der Embryonen im Fruchthofe bewirken, beruhen nach Dittmer erstens im Breiterwerden der Anlagen selbst, wozu Raum gebraucht werde, der nur durch Auseinanderdrängen der beiden Anlagen geschafft werden könne. Es beginnen die Schwanzenden zu divergiren. Wenn nun zweitens die Rückenplatten sich erheben, und zwei sonst getrennte nur am Kopfende confluirende Medullarfurchen zu Stande kommen, so wird in dem Winkel, den die beiden Anlagen machen, und dessen Raum für die doppelten Rückenplatten zu klein ist, ein gewisser Druck, eine Art Keilwirkung stattfinden, durch welche die Embryonen in noch grössere Divergenz gebracht werden. Erst wenn dieselben in einer geraden Linie stehen, wird der Druck gänzlich aufhören ${ }^{2}$ ):

Schon in einem früheren Abschnitte wurden die Anschauungen Ahlfeld's, des jüngsten Verfechters der Spaltungstheorie, in Kürze erwähnt. Ahlfeld spricht sich gegen das primitive Vorkommen von zwei Keimscheiben auf einem Dotter aus. Ein von Panum beschriebener Fall, in dem die Areae vasculosae zweier eineiiger sieben Tage bebrüteter Entenembryonen sich eben berühren, beweist nach Ahlfeld wegen der vorgeriickten Entwicklungszeit nichts für die ursprüngliche Lage der beiden Cicatriculae. Diese können sehr wohl dicht neben einander gelegen haben, ja eine Einheit gewesen sein, die gespalten, und deren beide Theile bei der Entwicklung sich mehr oder weniger getrennt haben. Damit, dass Ahlfeld das Vorkommen zweier Cicatriculae auf einem Jotter bestreitet, ist zugleich ausgesprochen, dass er der Schultze'schen Hypothese, nach welcher ja in zwei

1) Dönitz l. c. pag. 522 .

2) Dittmer l. c. pag. 393 . 
ursprünglich getrennten Fruchthöfen die Componenten einer Doppelmissbildung entstehen sollen, feindlich gegenübersteht. Wäre die letztere Theorie richtig, so müsste bei den bekannten Fällen frühzeitiger Doppelbildungen vom Hühnchen der Fruchthof, welcher ja nach Schultze durch eine Verschmelzung zweier zusammengekommen sein soll, die Spuren der Fusion erkennen lassen, und demnach eine der jeweiligen Anordnung der Axen beider Embryonen entsprechende mehr regelmässige Form haben. In Wirklichkeit aber zeigt in den betreffenden Fällen sowohl bei divergenten embryonalen Längsaxen, als auch wenn dieselben in eine Linie zu liegen kommen, der Fruchthof häufig eine Kreuzesform oder eine unregelmässige Gestalt. Ahlfeld sieht nun in der besagten Form der Area pellucida bei den Doppelbildungen ein bedeutsames Argument für eine stattgehabte Drehung der beiden aus einer Längsspaltung hervorgegangenen Embryonalanlagen, und befindet sich demnach in diesem Puncte in vollkommener Uebereinstimmung mit Dittmer, dem er auch hinsichtlich der die Drehung veranlassenden Momente beipflichtet. Die Drehung kann jedoch nur bis zu dem Entwicklungsstadium andauern, in welchem die Gefässe des Fruchthofes sich bilden und ausbreiten; von dieser Zeit an verwachsen die Fruchtanlagen mit einander in der Lage welche sie zur Zeit gerade einnehmen.

Was die Spaltung der Fruchtanlage betrifft, so kommt dieselbe nach Ahlfeld bei Eiern vor, welche sich im Eierstock sowohl, als wie später während der Furchung ganz normal verhalten. Das Bildungsmaterial für den Embryo, welches sich nach der Furchung an einer Stelle sammelt, hat die normale Ausdehnung, oder es ist in übermässig reichlicher Menge vorhanden. In ihm vollzieht sich bereits vor der Bildung der Primitivrinne die Spaltung und zwar in longitudinaler Richtung.

Die Gründe für die Spaltung können in einer übermässigen Menge des Bildungsmaterials gesucht werden; eine erbliche Anlage ist ebenfalls nicht auszuschliessen.

Je früher die Spaltung beginnt, desto vollständiger greift sie durch die Fruchtanlage durch; kommt sie erst später zu Stande, so findet nur eine partielle Theilung der Keimanlage statt. Vermuthlich wirkt die trennende Kraft zuerst und am kräftigsten auf das Kopfende der Embryonalanlagen, was daraus zu schliessen ist, dass partielle Spaltungen der oberen Körpertheile am häufigsten beobachtet werden.

Hinsichtlich der spaltenden Kräfte hat Ahlfeld eine neue Hypothese aufgestellt; er glaubt, dass dieselben auf einer von Seiten der Eihülle (Zona pellucida) auf den Keim ausgeübten Druckwirkung beruhen. „Ist diese Hülle zu eng, während das Bildungsmaterial über die Norm vermehrt wird, so muss es zu einer Zerreissung der Umhüllungshaut, oder zu einer Spaltung

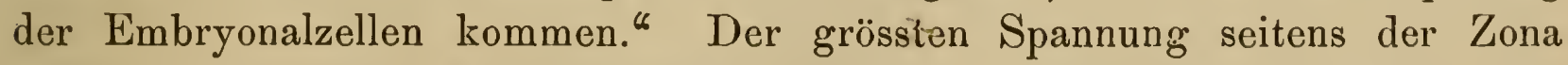
sind die am meisten hervorragenden Partien der Keimblase ausgesetzt. Im Fruchthof ist nun das meiste Zellenmaterial an der Stelle aufgespeichert, wo der Kopftheil des Embryo sich herausheben wird. Desshalb muss an dieser Stelle die Spaltung zuerst und am tiefsten auftreteñ.

Ueber den Mechanismus und das Resultat der Spaltung gibt Ahlfeld das Folgende an: 
${ }_{n}$ Wenn die spaltende Kraft als lineare Kraft wirkt, so kommt es nur zu einer Trennung der Fruchtanlage, die beiden Hälften liegen dann ruhig parallel neben einander. Wirkt die'Kraft aber als der Druck einer sphärischen Fläche, was wohl fast ausnahmslos der Fall sein wird, so muss nothwendiger Weise nach der Trennung noch ein Auseinanderweichen der getrennten Partien stattfinden, indem jede Hälfte auf der schiefen Ebene der Keimblase nach deren Aequator zu getrieben wird. War die Trennung eine vollständige, und der Druck von der Zona pellucida dauert in allen Theilen gleichmässig fort, so entfernen sich die Theile der Anlage und wir bekommen es mit einer Duplicitas parallela zu thun. War die Trennung eine partielle, so bleiben die noch nicht getrennten Theile auf ihrer Stelle liegen, die getrennten hingegen rücken auf den beiden schiefen Ebenen abwärts, i. e. sie divergiren. War die Trennung so weit vorgeschritten, dass nur noch an einem sehr kleinen Theile, entweder dem Kopf- oder dem Schwanzende, ein Zusammenhang stattfand, so werden die Embryonalkörper auf den schiefen Ebenen natürlicher Weise so weit sich entfernen, bis ihre Axen eine gerade Linie bilden, wenn nicht inzwischen die drückende Kraft nachgelassen oder die Fruchtanlagen durch Bildung von Gefässen auf dem Fruchthofe fixirt wurden. Dies ist der einfache Mechanismus der Drehung der Fruchtaxen. In den letzteren Fällen bekommen wir die Duplicitas posterior, wenn die beiden Köpfe noch zusammenhängen, die Duplicitas anterior, wenn die beiden Schwanzenden in Verbindung bleiben" ${ }^{1}$ ).

Vorstehend habe ich einen Ueberblick über die Anschauungen der einzelnen Forscher, sowohl der Anhänger der Verwachsungstheorie als ihrer Gegner, zu geben versucht. Unterzieht man die beiderseitigen Ansichten einem Vergleiche, so ist leicht zu ersehen, dass so schroff und unvermittelt, wie zu den Zeiten eines Lémery, ja noch zu denen eines Meckel und der beiden Geoffroy St. Hilaire heutzutage die beiden Theorien sich nicht mehr gegenüberstehen; sie sind einander entschieden näher gerückt, ja es gibt Puncte von nicht untergeordneter Bedeutung, in denen zwischen den Vertretern der beiden Richtungen eine merkliche Uebereinstimmung erzielt worden ist. So ist auf der einen Seite die Zweieiertheorie gegenwärtig als völlig überwunden zu betrachten, von Seiten der Anhänger der Spaltungstheorie ist dagegen die mehr oder minder tiefgehende Verschmelzung von mehr oberflächlichen Theilen zweier Embryonen für gewisse Fälle zugestanden worden. Ferner hat sich bezüglich der Zeit, in welcher die Doppelmissbildungen zuerst in Erscheinung treten, insofern eine Einigung ergeben, als fast alle Autoren zu dem Schlusse gelangten, dass dieser Zeitpunct mit den ersten Anfüngen der Entwicklung zusammenfallen müsse.

Trotz aller dieser Annäherungen herrschen jedoch in der Cardinalfrage, um die sich im Grunde genommen der ganze Streit dreht, auch heute noch zwischen den beiden Theorien die gleichen principiellen Gegensätze. Nach wie vor lautet die strittige Alternative:

1) A hifeld l. c. pag. 238. 
Sind es die Anfangsstadien der Entwicklung eines einzigen oder zweier Individuen, welche bei der Genese einer Doppelmissbildung, oder eineiiger in derselben Keimscheibe sich bildender Zwillinge zuerst zu Tage treten?

Wer die erste Frage bejaht, steht auf dem Boden der Spaltungstheorie, wer die letztere Möglichkeit befürwortet, ist ein Anhänger der Verwachsungstheorie. Wir können auch den ersteren Standpunct als den der primitiven Unität, den letzteren als den der primitiven Dualität oder Pluralität bezeichnen. Dass diese Begriffe den wahren Sachverhalt viel zutreffender wiedergeben, sowie, dass die Begriffe „Spaltung" ${ }^{*}$ und ${ }_{\text {Verwachsung }}{ }^{*}$ sehr leicht zu Verwirrungen führen und keineswegs die wirklichen bei der Entwicklung einer Doppelmissbildung obwaltenden Vorgänge richtig bezeichnen, gedenke ich in der Folge genauer auseinanderzusetzen.

Vorerst möchte ich jedoch die Auffassung Rauber's hinsichtlich der berührten Frage noch mittheilen. Dieser verdienstvolle Forscher ist weder den Anhängern der Spaltung noch denen der Verwachsung zuzuzählen; er beleuchtet aber die beiden Theorien in einer Weise, welche deutlich erkennen lässt, dass auch er von der Hinfälligkeit der beiden Gegensä̈tze „Spaltung“ und „Verwachsung", sowie von der Bedeutungslosigkeit des um sie geführten Streites überzeugt ist.

In seiner Abhandlung „Ueber die Theorien der excessiven Monstra“ zollt Rauber jener Controverse, indem er sie in einem kurzen Capitel behandelt, den schuldigen Tribut ${ }^{1}$ ). Sie sei von den beiderseitigen Anhängern zum Feldgeschrei erhoben worden und lasse sich darum nicht umgehen. Rauber sagt mit vollem Rechte, dass bei einer Discussion über die Zulässigkeit der Theilung (Spaltung) oder Verwachsung es sich zunächst darum handeln müsse, festzustellen, was eigentlich gemeint sei? Denn es könne ja die Theilung resp. die Verwachsung sowohl die Keime, als die Embryonalanlagen, als die Embryonen betreffen. Diese Unterscheidung müsse aber, um Verwirrungen vorzubeugen, gemacht werden.

Rauber bespricht znnächst jene Alternative in Bezug auf die Keime und hält die Theilung der Keime für das allein Mögliche. Er weist darauf hin, dass eine Mehrfachbildung vor dem Auftreten der Embryonalanlage im Zustande der Cicatricula eine einzige zusammenhängende Keimzellenmasse vorstelle. Wenn nun nach Rauber's Anschauungen eine Sonderung in Mittelscheibe und in Keimring eingetreten ist, so sind auch bereits statt einer zwei oder mehrere durch verschiedene Abstände von einander getrennte Embryonalanlagen im Keimringe vorhanden, die dann in die Mittelscheibe einstrahlen. Diese Theilungsform, welche man Divisio radialis nennen könnte, ist jedoch vorerst eine unvollständige, da durch sie keineswegs die Continuität der Keimblätter aufgehoben werde ${ }^{2}$ ). Sie könne aber unter Umständen nach beendeter Entwicklung, wenn Zwillinge geboren werden, eine vollständige

1) Virchow's Archiv Bd. 74, 1878, pag. 108.

$\left.{ }^{2}\right)$ Hier begegnet Rauber der Auffassung Dareste's, der, wie früher bereits erwähnt, ebenfalls betont, dass die beiden Componenten einer Doppelmissbildung von dem Momente ihres Erscheinens auf mittelbare Weise vereinigt sind. 
werden, indem dann erst der indirecte Zusammenhang zwischen beiden Zwillingen gänzlich aufgehoben werde.

Bei der Genese einer Doppelmissbildung bleibt die Trennung immer nur eine unvollständige, und es kann der Zusammenhang zwischen den beiden Embryonalanlagen resp. Embryonen in verschiedener Weise vermittelt werden, nämlich sowohl durch die Stammes- als auch nur durch die Seitenzonen, so dass hierdurch ein gewisses Stück dieser Zonen beiden Embryonen gemeinsam zukommt.

Es ist nach dem Vorhergehenden selbstverständlich, dass Rauber nicht für eine Theilung der Embryonalanlagen oder der Embryonen sein kann. „Dass Mehrfachbildungen nicht aus einer Theilung von Embryonalanlagen hervorgehen können, darüber dürfte ein Zweifel nicht mehr möglich sein." Diese Bemerkung hat meine volle und ungetheilte Zustimmung.

Was aber eine etwaige Verwachsung beider Embryonalanlagen oder Embryonen betreffe, so könne bei dem schon gegebenen Zusammenhange derselben eine solche primär überhaupt nicht statthaben. „Was man Verwachsung nennt, ist demnach eine secundäre Erscheinung, und die Behauptung, Mehrfachbildungen gingen hervor aus Verwachsung von Embryonen, ein Missverständniss, hervorgehend aus der Nichtunterscheidung der embryonalen Zonen und ihres primitiven Zusammenhanges bei den Mehrfachbildungen."

Schliesslich berührt $R$. die Möglichkeit, ob nicht vielleicht eine Verwachsung zweier Eier im Ovarium eintreten könne, und daraus eine Mehrfachbildung sich ableiten liesse; er wirft hierbei die Frage auf, warum man nicht lieber eine unvollständige Theilung ovarialer Eier annehme? Er vermeidet es aber wohlweislich, auf diese Puncte näher einzugehen.

Mit den Anschauungen Rauber's über Spaltung und Verwachsung harmoniren die meinigen in sehr vielen Puncten. Auch darin werde ich bei der Besprechung dieser beiden hypothetischen Vorgänge seinem Beispiele folgen, dass ich bezüglich derselben die einzelnen Hauptstadien des sich entwickelnden Organismus gesondert erörtern werde.

In Anbetracht der mannigfachen und zahlreichen! Möglichkeiten, welche besonders hinsichtlich der Verwachsung in Frage kommen, scheint es mir zum Zwecke einer übersichtlichen Darstellung geboten, in erster Linie zwischen der Entstehung von zwei Embryonen in getrennten Areae pellucidae und der Entwicklung derselben in einem gemeinschaftlichen durchsichtigen Fruchthofe zu unterscheiden. Den ersteren Bildungsmodus kann man biareale, den letzteren monoareale Entwicklung benennen.

\section{Die biareale Entwicklung.}

Das Vorkommen von zwei Areae pellucidae auf einem einzigen Dotter ist bei Vögeln eine sicher erwiesene Thatsache. Bei den Säugern jedoch und ebenso bei den Fischen sind analoge Verhältnisse bis jetzt noch nicht beobachtet worden, wesshalb die folgenden Betrachtungen nur für die Classe der Vögel Geltung beanspruchen können.

Die beiden univitellinen Areae pellucidae können, wie ein Vergleich der hierher gehörigen Fälle ergibt, eine verschieden grosse Entfernung zwischen 
sich lassen. Ist dieselbe beträchtlich, so wird jede Area pellucida von einem eigenen Ringgebiete umschlossen; es existiren dann auf dem Dotter zwei besondere Keimhäute. Ist dagegen die Entfernung zwischen beiden nur gering, so liegen dieselben in einer gemeinsamen Area opaca. In dieser können die beiden durchsichtigen Fruchthöfe wieder nur durch einen sehr dünnen oder durch einen breiteren Substanzstreifen getrennt sein.

Die Existenz von zwei gesonderten Keimhäuten auf einem Dotter ist bis in die jüngste Zeit bestritten worden. Meines Erachtens darf, seit Panum den bereits erwähnten Fall, bei dem in einem sieben Tage bebrüteten Entenei zwei vollkommen ausgebildete Areae vasculosae mit lebenden Embryonen vorgefunden wurden, beschrieben und abgebildet hat, nicht mehr an diesem Factum gezweifelt werden. Die rundliche Form der beiden Areae vasculosae, deren Grenzsaum nur an der Verwachsungsstelle unterbrochen ist, kann nur auf eine von zwei etwas entfernteren Centren ausgegangene, gleichmässig fortgeschrittene Ausbreitung der zwei Keimhäute bezogen werden. Ferner deutet die beträchtliche Distanz zwischen den beiden Embryonen, von denen jeder in seiner eigenen Area pellucida liegt, mit Nothwendigkeit darauf hin, dass im unbebrüteten Ei zwei Keimscheiben vorhanden gewesen sein müssen. $\mathrm{Ob}$ dieselben, wie $\mathrm{Ahlfeld}$ meint, ursprünglich näher aneinanderlagen, ja vielleicht durch Theilung einer einzigen entstanden sind, dies ist eine andere Frage, von der wir aber vorerst absehen wollen. Ferner hat Dareste drei Fälle beschrieben und durch Abbildungen illustrirt, bei denen eine doppelte Keimhaut vorlag. Ueber den einen Fall, bei dem die eine Area pellucida zwei Embryonen enthält, habe ich schon früher referirt (Fall 29, Fig. 9, Taf. VI). Die Abbildung lässt deutlich eine Grenzlinie erkennen, welche die Gebiete der beiden Keimhäute trennt. Die Form derselben ist sowohl durch ihre Aneinanderlagerung und Verschmelzung, als in Folge der dreifachen Embryonalbildung bei dem Flächenwachsthum der Keimhäute eine unregelmässige geworden. Die beiden anderen Fälle Dareste's sind auf Taf. I seines Buches (Fig. 4 und 5) bildlich dargestellt. Beide haben das Gemeinsame, dass in den zwei Keimhäuten die Entwicklung sehr früh aufgehört hat. Dagegen liegen auf dem einen Dotter die beiden Keimhäute dicht neben einander und sind an der Berührungsstelle verschmolzen; auf dem anderen sind sie durch eine nicht unerhebliche Distanz von einander getrennt.

Wahrscheinlich waren auch in der von Wolff beschriebenen Doppelbildung ${ }^{1}$ ) zwei ursprünglich getrennte Keimscheiben vorhanden. Hierfür spricht wenigstens die Entfernung der beiden Areae pellucidae; doch ist die Entwicklung in diesem Falle schon zu weit fortgeschritten, als dass sich Genaueres darüber feststellen liesse.

Bei den noch restirenden vier Fällen von biarealer Entwicklung ist nur eine einzige Keimhaut vorhanden, indem ein-gemeinsames Ringgebiet die beiden Areae pellucidae umfasst. Letztere können nun, wie ich schon hervorhob, bald dicht neben einander liegen, bald durch eine etwas breitere Zwischen- . distanz getrennt sein, was natürlich auch auf die Form der gesammten Keimhaut von Einfluss sein muss. Eine relativ weite Entfernung von einander

1) C. F. W o lff, Ovum simplex gemelliferum l. c. 
zeigen die beiden Areae pellucidae einer von Dareste beobachteten Doppelbildung. Der betreffende Fall ist auf Taf. XIV, Fig. 3 seines Buches abgebildet. Die Zeichnung lässt einen eben sich bildenden Gefässhof erkennen, der zwei Embryonen enthält; von diesen ist der eine wohlgebildet, die primitiven Augenblasen waren schon angelegt; die Herzschlinge führte bei Eröffnung des Eies Contractionen aus. Der zweite Embryo war nur unvollkommen entwickelt, der Kopf war rudimentär, das Herz fehlte; derselbe liegt zur rechten Seite des ersten Embryo. Die Areae pellucidae beider Zwillinge sind von ungleicher Ausdehnung; die des normalen Embryo ist von regelmässigem Umfange, während der andere seine äusserst enge Area pellucida fast vollständig erfüllt.

Auch bei der uns bereits bekannten Rauber'schen Dreifachbildung (Fall 30, Fig. 10, Taf. VI) handelt es sich um zwei Areae pellucidae, welche durch einen feinen an seinen beiden Enden dreiseitig verbreiteten Substanzstreifen getrennt werden. Ein gleiches Verhalten bietet ein von Reichert mitgetheilter Fall dar, bei dem ebenfalls eine solche feine Linie, welche zu beiden Seiten in eine dreieckige Verbreiterung auslief, die zwei Areae pellucidae von einander abgrenzte ${ }^{1}$ ). Jede derselben enthielt einen Embryo von der gleichen Entwicklungsstufe, wie sie in dem gleichfalls von Reichert beobachteten Falle 5 unserer Zusammenstellung (Fig. 4, Taf. IV) die beiden. Zwillinge aufweisen. Die Längsaxen der Embryonen der beiden Areae convergirten unter einem rechten Winkel nach vorne zu. Dadurch rücken die Kopfenden der beiden Embryonen ziemlich nahe an einander heran; zwischen ihnen geht die erwähnte Grenzlinie durch, welche aber von beiden Kopfenden noch um eine kleine Strecke entfernt ist.

Der letzte Fall endlich, den ich noch anzuführen habe, ist von Dareste auf Taf. XIV, Fig. 2 seines Buches abgebildet worden. Die beiden Areae pellucidae zusammen haben eine rhombische Form; in der kurzen Diagonale verläuft eine feine Linie, welche die beiden Areae von einander scheidet. Die Embryonen derselben liegen in einer Linie, welche mit der längeren Diagonale des Rhombus zusammenfällt. Sie wenden ihre Kopfenden einander zu, befinden sich also in Oppositionsstellung. Von der Grenzlinie sind ihre Kopfenden

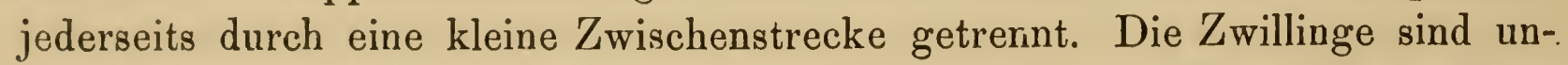
gleich entwickelt; der stärkere zeigt bereits die drei Hirnbläschen, eine grössere Anzahl von Urwirbeln, eine Herzschlinge etc.; der kleinere besitzt noch kein Herz, sein Kopfende hat einen nur sehr geringen Umfang.

Nachdem nun die einzelnen Fälle von biarealer Entwicklung erörtert sind, komme ich zu der Frage, wie man sich die Genese einer zweifachen Area pellucida auf einem Dotter vorzustellen habe. In Bezug auf die in getrennten Keimhäuten liegenden Areae kann die Beantwortung dieser Frage nicht schwer fallen. Hier liegt nur die eine Möglichkeit vor, dass schon vor der Furchung getrennte Cicatriculae bestanden haben, was wiederum darauf hindeutet, dass bereits in den ersten Zeiten der ovarialen Eientwicklung zwei in einem Follikel enthaltene Eizellen vorhanden waren, die bei der allmähligen Anlagerung der Dotterelemente verschieden weit von einander abgedrängt

1) Siehe die Abbildung dieses Falles in dem Archiv für Anatomie und Physiologie 1864, Taf XVIII, Fig. 5 u. 6. 
werden können. Später werden dieselben als Cicatriculae einem gemeinsamen Dotter aufliegen; das Ganze wird endlich, wenn die Dottermembran gebildet ist, von dieser umhüllt werden.

Die in einem gemeinsamen Blastoderm befindlichen Areae pellucidae lassen sich genetisch in verschiedener Weise erklären. Man kann unter Betonung der wechselnden Entfernung zwischen denselben annehmen, dass die bezüglichen Verhältnisse aus einer verschieden weit fortgeschrittenen Verschmelzung zweier ursprünglich getrennter Keimscheiben hervorgegangen seien. Mit demselben Rechte könnte man aber auch eine .Spaltung einer ursprünglich einfachen Keimscheibe, die in dem einen Falle weiter gediehen sei, als in dem anderen, befürworten.

Um diese beiden Ansichten hinsichtlich ihrer Wahrscheinlichkeit gegen einander abwägen zu können, muss man sich zuerst darüber klar sein, in welche Zeit jene hypothetischen Vorgänge der Spaltung und Verwachsung zu setzen sind. Man wird hierbei einen Zeitraum zu berücksichtigen haben, der sich von den Anfangsstadien der ovarialen Eientwicklung bis zum Beginn der Embryonalbildung in der Keimhaut erstreckt. Es wird sich darum handeln müssen, zu prüfen, ob entweder während, oder kurz nach der Furchung, oder bereits schon vor derselben während der ovarialen Eientwicklung die Processe der Theilung oder der Verwachsung stattgefunden haben mögen. Dass zwei in der Nähe gelegene Cicatriculae während oder kurz nach der Furchung zusammenrücken und verschmelzen können, halte ich für absolut unmöglich; dazu wären gewisse Compulsivkräfte nöthig, die aber dem Eie zu dieser Zeit vollständig abgehen. Ebenso wenig kann ich aber auch einer während der genannten Entwicklungsphase sich vollziehenden Theilung der Cicatriculae das Wort reden; denn der Furchungsprocess zerklüftet eben nur das vorhandene Material der Keimscheibe in kleinere Elemente, eine Umlagerung desselben, wie sie bei einer etwaigen auf langsamem Auseinanderrücken beruhenden Theilung erforderlich wäre, kann bei der Furchung nicht stattfinden. Es bleibt somit nur noch übrig, die beiden hypothetischen Vorgänge der Spaltung und Verwachsung in die Zeit der ovarialen Eibildung zu verlegen. Da wir nun wissen, dass die Cicatricula, wenn sie an der Oberfläche des bis auf ein gewisses Volumen angewachsenen Ovarialeies sichtbar geworden ist, von nun an bis zu dem Ausstossen des Eies aus dem Follikel und dem Beginn der Furchung die gleiche Stelle an der Eioberfläche beibehält, so scheint mir daraus gefolgert werden zu dürfen, dass in Eiern, deren Keimhaut nach der Furchung zwei Areae pellucidae aufweist, schon in einer sehr frühen Zeit der ovarialen Eientwicklung zwei mehr oder wen̈iger gètrennte resp. verschmolzene Cicatriculae vorhanden gewesen sein müssen. So kommen wir denn schliesslich zu dem Resultate, dass auch hier, wie bei den Eiern mit zwei durchaus getrennten Keimhäuten, vor dem Auftreten des Nahrungsdotters zwei Eizellen in demselben Follikel gelegen sein müssen, welche jedoch nicht gänzlich von einander geschieden sind, wie in jenen Eiern, sondern in einem mehr oder minder innigen Connex zu einander stehen. Man kann wegen ihres Zusammenhanges diese beiden Zellen mit B. Schultze auch als eine einzige grosse mit zwei Keimbläschen versehene Zelle auffassen. $\mathrm{Ob}$ sie von einer Mutterzelle, die sich nur unvollkommen getheilt hat, ab- 
stammen, oder ob zwei Anfangs getrennte Eizellen mit ihrem Zellprotoplasma eine stellenweise Verbindung eingegangen sind, hierüber lässt sich keine bestimmte Entscheidung treffen. Die zweite Annahme sagt mir jedoch aus dem Grunde mehr zu als eine Theilung, weil man bei Säugethieren zwar relativ häufig die Anlage und Ausbildung eines Follikels mit zwei Eiern zu beobachten Gelegenheit hat, dagegen meines Wissens niemals etwas über Theilungserscheinungen der Eizelle eines jungen eineiigen Follikels trotz der vielfachen Untersuchungen, die über das Ovarium vorliegen, berichtet worden ist. Wie bei den Säugethieren, so werden auch bei den Vögeln zuweilen bei der Anlage eines Follikels zwei Eizellen in denselben hineingelangen können. Treten sie nun mit ihrem Protoplasma mit einander in Verbindung, so können sie sich während der Anlagerung des Nahrungsdotters nicht von einander entfernen, sondern werden später zwei zusammenhängende Cicatriculae darstellen müssen.

Wir haben somit wahrscheinlich zu machen gesucht, dass das Vorkommen von zwei Areae pellucidae auf einem Dotter, mögen sie sowohl in einer gemeinsamen, oder in getrennten Keimhäuten gelegen sein, bereits in einer sehr frühen Zeit dadurch herbeigeführt wird, dass zwei Eizellen in das Innere eines sich eben anliegenden Follikels gelangen. Damit erklärt sich einigermassen auch jene immerhin auffallende Thatsache, dass unter der grossen Anzahl von Säugethiereiern, welche im Zustande der Keimblase besonders in neuerer Zeit den Embryologen unter die Augen gekommen sind, sich niemals eine solche befand, welche eine doppelte Keimanlage entsprechend den zwei Cicatriculae eines Vogeleies dargeboten hätte. Dass derartige Beobachtungen ausgeblieben sind, hat einen sehr natürlichen Grund. Es ist nämlich ein Ding der Unmöglichkeit, dass ein der doppelten Cicatricula eines Vogeleies analoger Zustand sich bei einem Säugethierei ausbilden könnte. Daran ist die Verschiedenheit der intrafollikulären Eientwicklung bei beiden Thierclassen Schuld. Werden bei den Säugethieren zwei Eizellen in denselben Follikel eingeschlossen, so erhält jede derselben sehr rasch ihr eigenes Eiepithel und in Folge dessen auch ihre eigene Zona pellucida; ferner kommt jede Eizelle in ihren eigenen Discus proligerus zu liegen. Auf diese Weise wird es verhindert, dass zwei Eizellen in nähere Beziehungen zu einander treten. Bei den Vögeln jedoch ist hierzu mehrfach Gelegenheit gegeben. Wie soeben auseinandergesetzt, können sich zwei Eizellen im Innern eines gerade angelegten Follikels befinden. Sie werden hier nicht durch Zellen, die sich zwischen sie einschieben, von einander geschieden, müssen darum längere Zeit in Berührung bleiben, und werden schliesslich, da ja bei den Vögeln das Eiepithel, von dem die Bildung der Dotterhant ausgeht, zugleich das Follikularepithel darstellt, von einer gemeinsamen Dottermembran umhüllt werden müssen. Je nachdem die beiden Zellen während der Zeit ihrer Auseinanderlagerung eine protoplasmatische Verbindung eingegangen sind oder nicht, werden nach der Furchung entweder zwei in einer gemeinsamen Keimhaut liegende Areae pellucidae oder zwei getrennte Keimhäute resultiren müssen.

Ferner können gleichzeitig in einem nur kurzen Zeitintervall zwei Eier sich vom Ovarium loslösen und in die Tube eintreten; in diesen Fällen kann 
es sich leicht ereignen, dass die beiden Eier im Eileiter während der Auflagerung der Eiweissschichten sich einander zu nahe kommen, und dann später eine gemeinsame Kalkschale erhalten. Es entstehen auf diese Weise die Eier mit zwei Dottern.

Die Differenz der intrafollikulären Entwicklung der Eier bei den Vögeln und bei den Säugethieren, die ich soeben hervorgehoben habe, ist, soweit mir bekannt, von Seiten der Autoren, welche über die Genese der Doppelmissbildungen sich verbreitet haben, kaum berücksichtigt worden. Prüft man aber von diesem Gesichtspuncte aus die Schultze'sche Theorie von dem Vorkommen zweier Keimbläschen im Bildungsdotter solcher Eier, in denen später Doppelmissbildungen auftreten, so scheinen sich mir die nachstehenden Folgerungen von selbst zu ergeben. Das Vorhandensein von zwei Keimbläschen kann mit einer gewissen Berechtigung für solche Eier von Vögeln supponirt werden, welche sich in einem zwei Eizellen enthaltenden Follikel entwickelt haben. Für die anderen Eier der Vögel, sowie für die Eier der Säuger entbehrt diese Annahme jeglicher Begründung.

Nachdem ich nun das muthmassliche Verhalten der Eier mit doppelter Area pellucida in den dem Beginn der Embryonalbildung vorausgehenden Entwicklungsperioden besprochen habe, komme ich zu den Veränderungen, die sich in derartigen Eiern während der Bebrütung vollziehen müssen. Wir wollen dabei voraussetzen, dass beide Cicatriculae entwicklungsfähig sind.

Liegen dem Dotter zwei getrennte Keimhäute auf, so wird sich von wegen ihres mit der allmähligen Genese des Embryo gleichzeitig einhergehenden Flächenwachsthums die Distanz zwischen beiden immer mehr verringern müssen. Eine Vereinigung der beiden Keimhäute wird naturgemäss um so früher zu Stande kommen, je geringer die ursprüngliche Entfernung zwischen beiden war. Eine Verwachsung der Embryonen wird dagegen erst am Ende der Bebrütung eintreten können; es wird dann, falls die Entwicklung der beiden $\mathrm{Zwillinge} \mathrm{gleichmässig} \mathrm{vor} \mathrm{sich} \mathrm{gegangen} \mathrm{war,} \mathrm{eine} \mathrm{omphalopage}$ Doppelbildung aus dem Ei ausschlüpfen.

Erfolgt dagegen die Bildung von zwei Zwillingen in einer zwei durchsichtige Fruchthöfe enthaltenden Keimhaut, so ist natürlich ein durch das Blastoderm vermittelter Zusammenhang zwischen beiden von vorneherein gegeben. Nur die beiden mittleren Keimblätter müssen sich noch vereinigen, und werden dies jedenfalls um so früher thun, je näher die beiden Areae pellucidae und somit auch die beiden Primitivstreifen an einander liegen. Bedeutend schwerer ist dagegen die Frage zu beantworten, ob eine Verwachsung der Embryonen selbst in diesen Fällen eintreten kann. Es scheinen mir bezüglich dieser Eventualität hauptsächlich zwei Momente in Betracht zu kommen: 1) die Entfernung der beiden durchsichtigen Fruchthöfe von einander und 2) die Richtung der Längenaxen beider Embryonen. Es ist aus der Entwicklungsgeschichte bekannt, dass die Area pellucida fast ausschliesslich in der Längsrichtung der Primitivstreifen sich ausdehnt, und zwar vergrössert sie sich, nachdem das Zuwachsstück zu ihr getreten, hauptsïchlich nach vorne zu; damit im Zusammenhang steht das vorwiegend vor den Primitivstreifen fallende embryonale Längenwachsthum. Setzen wir nun den Fall, dass in den beiden Areae pellucidae die zwei Primitivstreifen einen parallelen Verlauf ein- 
halten, so ist selbst, wenn die beiden Ersteren nur ein sehr dünner Substanzstreifen trennt, eine Verwachsung der sich ausbildenden Embryonalkörper nicht möglich, da deren Längenwachsthum sich nicht entgegengerichtet ist, sondern dieselben neben einander für ihre Volumvergrösserung Platz haben. Anders dagegen liegt die Sache, wenn die Primitivstreifen der beiden Areae pellucidae mit ihren Kopfenden convergiren oder gar in Oppositionsstellung sich befinden. Im letzteren Falle werden die beiden Embryonen sich direct entgegenwachsen, was unter der Voraussetzung eines nur sehr schmalen Substanzstreifens zwischen den beiden Areae die meisten Chancen für eine Vereinigung mit den Kopfenden darbietet. Trotzdem aber halte ich es für sehr unwahrscheinlich, dass selbst unter diesen Umständen eine Verwachsung der Kopfenden der zwei Embryonen zu Stande kommen kann. Jedenfalls ist die Distanz zwischen den Köpfen der wachsenden Zwillinge bei einer Keimhaut mit zwei Areae unter allen Verhältnissen immer grösser als die Zwischenstrecke der Keimhaut, welche die Kopfenden zweier rechtwinkelig oder. oppositionell gestellter Embryonen trennt, die sich in einer gemeinsamen Area pellucida entwickeln. Wenn wir nun finden, dass selbst hier, indem sich die Zwischenstrecke der Keimhaut entsprechend ausdehnt, die Verwachsung der Köpfe beider Embryonen häufig unterbleibt, so dürfen wir entschieden das Gleiche mit noch grösserer Wahrscheinlichkeit für die Fälle annehmen, in denen eine grössere und darum auch ausdehnungsfähigere Keimhautstrecke zwischen den Köpfen der in zwei gesonderten durchsichtigen Fruchthöfen sich ausbildenden Zwillinge gelegen ist. Ich gebe jedoch $\mathrm{zu}$, dass wegen der unzureichenden Anzahl hieher gehöriger Beobachtungen in dieser Frage eine sichere Entscheidung noch nicht zu treffen ist.

\section{Die monoareale Entwicklung.}

In einem früheren Abschnitte dieses Buches sind die Doppelbildungen, welche in einer gemeinsamen Area pellucida aufgetreten sind, zusammengestellt, und in dem darauf folgenden Kapitel ist ihre Entstehungsweise von den Gesichtspuncten der normalen Entwicklungsgeschichte aus eingehend erörtert worden. An dieser Stelle kann ich mich desshalb darauf beschränken, unter Bezugnahme auf die früher erhaltenen Resultate zu untersuchen, ob und unter welchen Umständen bei der monoarealen Entwicklung die Annahme einer Spaltung oder Verwachsung zulässig ist. Wir wollen hiebei nach dem Vorgange von Rauber zwischen Embryonalanlagen und Embryonen unterscheiden, wobei ich im Hinweis auf das die normale Entwicklungsgeschichte enthaltende Capitel daran erinnern will, dass das Stadium der Embryonalanlage mit den ersten Spuren der Anlage des P'rimitivstreifens beginnt, und bis zu der Entwicklungszeit reicht, in welcher die Anlage der Rückenfurche eben vollendet ist. Es muss daher unsere nächste Aufgabe darin bestehen, zu prüfen, ob während des Stadiums der Embryonalanlage eine Verwachsung oder eine Spaltung stattfinden kann. Die erstere Möglichkeit setzt natürlich das Vorhandensein von zwei Embryonalanlagen voraus.

Dass eine eigentliche Verwachsung zweier in einer einzigen Keimhaut sich bildenden Embryonalanlagen nicht mehr sich vollziehen könne, weil sie 
durch diese schon in mittelbarer Verbindung stehen, ist schon mehrfach urgirt worden; wir können daher, da der Begriff „Verwachsung“ immer eine vorher bestehende Trennung involvirt, höchstens nur von einer Verwachsung zweier von gesonderten Primitivstreifen auswachsenden mittleren Keimblätter sprechen. Eine Verschmelzung zweier Embryonalanlagen selbst, welche ja anfangs flach in der Ebene der Keimhaut ausgebreitet sind, und aus deren Keimblätter, soweit sie in ihren Bezirken sich befinden, sich zusammensetzen, ist dagegen von der Hand zu weisen. Erst in späteren Entwicklungsperioden, wenn sich die beiden Embryonen aus dem Niveau der Keimhaut erhoben haben, kann erst wieder von einer (allerdings nur secundären) Verwachsung die Rede sein, welche auf einer Verschmelzung vorher getrennter Körpertheile beider Embryonen beruht. Es scheint mir aus diesen Gründen zweckmässig, den Terminus „Verwachsung ${ }^{*}$ hinsichtlich des Vereinigungsmodus zweier Embryonalanlagen durch eine zutreffendere Bezeichnung zu ersetzen. Man kann sich vorstellen, dass die in die Area pellucida einstrahlenden Embryonalanlagen auf zweierlei Weise mit einander in Verbindung kommen, erstens dadurch, dass sie direct auf einander stossen, was ich als ein Confluiren bezeichnen möchte, und zweitens dadurch, dass sie beim Auftreten der Rückenwülste mit einem grösseren oder geringeren Theile ihrer Kopffortsätze auf den Boden einer theilweise gemeinsamen Medullarfurche zu liegen kommen, ein Vorgang, dem ich den Namen ${ }_{\text {Copulation }}$ * beilegte. Bei der ersteren Art der Vereinigung sind die Embryonalanlagen mehr activ, bei der letzteren mehr passiv betheiligt.

Das Confluiren zweier in die Area pellucida einwachsender Embryonalanlagen wird um so früher eintreten müssen, je mehr dieselben convergiren. Man kann sich ein Zusammentreffen der beiden schon vor oder erst nach vollendeter Ausbildung der Primitivstreifen, ferner während der Bildung der Kopffortsätze denken. Der muthmassliche Effect eines solchen Zusammentreffens kann wohl nur der sein, dass sich nach dem Momente der Vereinigung der bis dahin noch nicht gebildete Theil der Embryonalanlagen nur einfach anlegt. Die Richtung, welche dieser einfache Abschnitt einhält, wird, falls die beiden Embryonalanlagen mit der gleichen Wachsthumsenergie aufeinandergetroffen sina, durch eine Linie repräsentirt werden, welche mit der Richtungslinie der doppelt vorhandenen Embryonaltheile einen gleichen Winkel bildet. Letztere kann man als die beiden Katheten, erstere als die resultirende Diagonale eines Kräfteparallelogramms auffassen.

Diese rein theoretischen Deductionen entbehren jedoch vorerst noch jeglicher reellen auf Beobachtung beruhender Unterlage. Der eine v. Ba e r'sche Fall (3), welcher hier allenfalls angezogen werden könnte, ist in Beschreibung und Abbildung so unbestimmt gehalten, dass es nicht zulässig erscheint, denselben als Beleg für die Möglichkeit eines Confluirens zweier Embryonalanlagen auszuführen.

Dass zwei Primitivstreifen vor ihrer vollendeten Ausbildung bereits con- . fluiren können, halte ich übrigens für sehr problematisch; ihre Verlaufsrichtung müsste wegen der hierzu nöthigen starken Convergenz zu sehr von der radiüren Richtung abweichen; eher könnte man annehmen, dass zwei convergirende Primitivstreifen während ihres Einwachsens sich so genähert haben, dass sie 
schliesslich nach ihrer Vollendung mit den Kopfenden sich seitlich berühren; vor den beiden würde dann nur ein einziger Kopffortsatz sich anlegen. Auch scheint mir diese Möglichkeit annehmbarer als ein Confluiren von zwei Kopffortsätzen; dazu wäre bei dem Einstrahlen zweier Primitivstreifen unter einem Winkel von $90^{\circ}$ oder über $90^{\circ}$ oder $180^{\circ}$ wohl die beste Gelegenheit geboten. Es wurde aber bekanntlich bei den hieher gehörigen Doppelbildungen der zweiten und dritten Gruppe unserer Eintheilung niemals eine Vereinigung der beiden Embryonalanlagen vor dem Auftreten der Medullarrinne wahrgenommen.

Es scheint mir demnach, so lange nicht positive Beobachtungen für ein Confluiren zweier Embryonalanlagen vorliegen, geboten, diese Art der Vereinigung gänzlich fallen zu lassen. Somit bleibt die Copulation nur allein noch übrig, für deren Vorkommen die von Ahlfeld und Reichert beschriebenen Doppelbildungen (Fall 7, Fig. 6, Taf. IV und Fall 13, Fig. 2 A und B, Taf. V) als Belege angeführt werden können.

Die verschiedene Ausdehnung, welche die Copulation gewinnen kann, wofür die Anordnung der beiden Embryonalanlagen allein bestimmend ist, habe ich aber schon früher ausführlicher erörtert, so dass ich hier diese Verhältnisse als bekannt übergehen kann. Es genüge an dieser Stelle die Bemerkung, dass die Copulation oder, wie ich sie früher auch nannte, die primäre Vereinigung nur sehr selten stattzuhaben scheint.

Ich wende mich nun zu der Frage, ob der sich entwickelnde Organismus im Zustande der Embryonalanlage eine Spaltung der Art erleiden kann, dass aus den beiden Hälften je ein besonderer Embryo zur Ausbildung gelangt. Diese Frage ist absolut zu verneinen; die Hypothese der Theilung einer Embryonalanlage im Sinne der Anhänger der Spaltungstheorie, welche sämmtlich darunter eine totale oder partielle Theilung einer bereits einheitlich entwickelten Embryonalanlage verstehen, ist ein reines Phantasiegebilde, welches auf vollkommen unklaren Vorstellungen basirt, und mit den Resultaten der neueren embryologischen Forschung unvereinbar ist.

Die Spaltungstheorie wird, wie wir wissen, in verschiedenen Schattirungen vertreten, indem sowohl eine longitudinale als transversale Theilung befürwortet wurde, und ferner auch bezüglich der Zeit dieses supponirten Vorganges die Ansichten auscinandergehen. Sehr viel hat seiner Zeit von sich reden gemacht die von $\mathrm{Meckel}$ zuerst angedeutete, von $\mathrm{Reich}$ ert des Näheren ausgeführte Theorie der paarig symmetrischen Keimtheilung. Dieselbe beruht auf der Vorstellung, dass bei der normalen Entwicklung der Primitivrinne und Medullarrinne eine unvollkommene Längstheilung der Fruchtanlage vorliege, was ich für die Primitivrinne allenfalls noch zugeben könnte; dagegen kommt die Medullarrinne hauptsächlich durch Verdickung des seitlich von der Chorda befindlichen Mesoderms und die in Folge dessen sich erhebenden Rückenwülste zu Stande, wesshalb von einer unvollkommenen Längstheilung nicht die Rede sein kann. Diejenigen Autoren, welche eine letztere annehmen, glauben, dass bei der Genese von Doppelmissbildungen die weiteren normalen Entwicklungsvorgänge, wie der Schluss des Medullarrohres etc. durch ein Excessivwerden jener normalen Lüngsspaltung hintangehalten werde. Es werde dadurch die mediane Längsrinne $z u$ tief, und im Verlaufe derselben werde schliesslich die bliitterartige Embryonalanlage stellenweise durchtrennt. „Indem 
nun jede der selbstständig gewordenen Hälften die Fähigkeit besitzt, sich die ihr fehlende andere Hälfte zu ergänzen, entstehen so die Doppelmissbildungen, die in einem Theil, Kopf oder Rumpf oder beiden, zusammenhängen, und in diesen bilateral-symmetrisch, in den übrigen Theilen jedoch getrennt und paarigsymmetrisch sind."

Ganz abgesehen davon, dass eine vollständige Durchtrennung der gesammten Keimhaut bei Doppelbildungen, die in einer Area pellucida sich entwickeln, niemals zur Beobachtung gelangt ist, entsteht zunächst die Frage, was man unter selbstständig gewordenen Hälften zu verstehen hat. Jedenfalls ist hier der Phantasie ein sehr weiter Spielraum gelassen, und ich gestehe offen, dass ich mir ebensowenig von selbstständig gewordenen Embryonalhälften einen klaren Begriff machen kann, als ich es mir zurecht zu legen vermag, wie sich eine Embryonalhälfte so ergänzen kann, dass eine vollständige Embryonalanlage daraus entsteht.

Noch viel unverständlicher und den Vorgängen der Entwicklungsgeschichte sowohl, wie den Erfahrungen über das Verhalten frühzeitiger Doppelbildungen direct widersprechend, ist die Annahme einer Quertheilung der Embryonalanlage. Dieselbe hat jedoch bereits von Dittmer und Ahlfeld eine so schlagende Widerlegung erfahren, dass ich es für überflüssig erachte, hier nochmals die gegen diese Theorie von Seiten der beiden genannten Forscher angeführten Argumente zu wiederholen.

So bleibt mir denn nur noch übrig, die von Ahlfeld in der letzten Zeit warm befürwortete Hypothese einer Längsspaltung der Fruchtanlage vor dem Auftreten der Primitivrinne mit nachfolgender Drehung der beiden Hälften einer Kritik zu unterziehen. Was zunächst die Annahme einer Drehung anlangt, so glaubt Ahlfeld dieselbe aus der häufig kreuzförmigen oder unregelmässigen Form der Area pellucida folgern zu dürfen. Wenn wir die Reihe der zusammengestellten Doppelbildungen durchgehen, so seheint es einzig und allein der von Allen Thomson beschriebene Fall (Fall 25, Fig. 5, Taf. VI) zu sein, bei dem die Area pellucida eine Kreuzesform von solcher Ausdehnung besitzt, dass dieselbe eine Drehung der in früheren Stadien viel kürzeren Embryonalanlagen gestattet haben könnte. Dagegen scheinen mir die Fälle von Reichert (Fall 5, Fig. 4, Taf. IV), v. Baer (Fall 9, Fig. 7, Taf. IV), Dönitz (Fall 10, Fig. 8, Taf. IV), bei denen die durchsichtigen Fruchthöfe eine deutlich kreuzförmige Gestalt aufweisen, der Ahlfeld'schen Hypothese nicht gerade günstig zu sein. Die quere Ausdehnung der Area pellucida in der Höhe der Kopfenden oder mit andern Worten der quere Schenkel des Kreuzes ist in den genannten Fällen so unbeträchtlich im Verhältniss zur Längendimension, dass mir eine früher stattgefundene Drehung der beiden Embryonalanlagen, seien diese zu jener Zeit auch noch so unentwickelt und desshalb von nur geringer Grösse gewesen, nicht annehmbar erscheinen kann. Die Gestalt der Area pellucida dieser Doppelbildungen erklärt sich am einfachsten aus der normalen Entwicklungsgeschichte. Es wurde früher betont, dass in der Norm der durchsichtige Fruchthof nach Einverleibung des $\mathrm{Zu}$ wachsstückes sich kaum mehr nach rückwärts, sondern vorwiegend nach vorn zu ausdehnt. Im Falle nun bei einer Doppelbildung deren beide in Oppositionsstellung befindliche Embryonen mit den Kopfenden frühzeitig verwachsen, 
so kann die Ausdehnung des gemeinsamen durchsichtigen Fruchthofes nicht mehr vor die Köpfe der beiden Embryonen fallen, und als Aequivalent hiefür sehen wir eben nach beiden Seiten hin eine Vergrösserung desselben sich vollziehen.

Den hypothetischen Vorgang der Spaltung setzt Ahlfeld in eine Entwicklungszeit, in welcher die Primitivrinne noch nicht aufgetreten ist. Für das Hühnchen würde dieses Stadium dem Zustande der Keimhaut entsprechen, welcher in (Fig. 1 und 2, Taf. I) bildlich wiedergegeben ist. Die Embryonalanlage wird nun nach $\mathrm{A}$ hlfeld dadurch gespalten, dass von aussen resp. von oben auf dieselbe ein Druck Seitens der gespannten Zona pellucida ausgeübt werde, wie dies früher bereits auseinandergesetzt wurde. Gegen eine derartige Möglichkeit dürften sich nicht ungewichtige Gründe anführen lassen. Erstens ist die Zona sehr extensionsfähig, was schon daraus erhellt, dass sie dem Wachsthum des Eies kein Hinderniss entgegenzusetzen vermag. Ferner umschliesst die Dottermembran zur Zeit der auftretenden Embryonalanlage das Ei nicht so innig, dass sie auf dasselbe auch nur die geringste Compression ausüben könnte. Davon kann man sich leicht bei einem kurz angebrüteten Hühnerei durch Betasten des Dotters mit einem stumpfen Instrumente überzeugen. Bei den Säugern liegen die Verhältnisse für die Ahlfeld'sche Hypothese womöglich noch ungünstiger. Die äusserst dünne Zona ist zur Zeit des Auftretens der Area embryonalis so expansionsfähig, dass nach Einlegen der Keimblase in eine indifferente Flüssigkeit schon das Eindringen der letzteren in das $\mathrm{Ei}$ auf dem Wege der Diffusion hinreicht, um die Zona von der Keimblase selbst allseitig abzuheben. Sehr schön zeigen die Abbildungen Bischoff's ${ }^{1}$ ) von Kanincheneiern, die sich im Zustande der Keimblase befinden, den in besagter Weise zwischen Zona und Ektoderm entstandenen Zwischenraum. Die Zona würde sich von dem Ektoderm der Keimblase sicher nicht so leicht abdrängen lassen, wenn sie derselben dicht anliegen und sie eng umschliessen würde. In diesem Falle müsste bei der Aufnahme von Flüssigkeit die Höhlung der Keimblase selbst, deren Wand sich von der Zona nicht trennen könnte, sich ausdehnen. Man könnte zwar annehmen, dass die zwischen Zona und Keimblasenwand befindliche Flüssigkeit aus der letzteren selbst durch Transsudation in den genannten Zwischenraum gelangt sei; allein dies wird nothwendiger Weise mit einer Faltenbildung der Keimblase, deren Höhlung nicht mehr ad maximum gefüllt ist, einhergehen müssen. Da cine solche nicht beobachtet wurde, vielmehr die Keimblase nach ihrer Loslösung von der Zona eine vollständig runde oder leicht ovale Form beibehält, so ist jene Annahme nicht gut aufrecht zu erhalten.

Hauptsächlich scheint mir gegen die von Ahlfeld supponirte Druckwirkung der Zona die folgende Erwägung zu sprechen. Gibt man eine geringere Expansionsfähigkeit der Zona pellucida zu, wodurch allein eine Druckwirkung auf das wachsende Fi im Sinne A hlfeld's verursacht werden kann, so wird dieselbe nicht erst nach dem Auftreten der Embryonalanlage, sondern zweifelsohne schon vorher sich äussern müssen. Es wird daher an Stellen der Keimblase, welche einer besonderen Druckwirkung ausgesetzt sind, wie 
sie Ahlfeld bei der Spaltung in Anspruch nimmt, von vorneherein die Bildung der Embryonalanlage nicht gut stattfinden können. Haben jedoch die Wachsthumsvorgänge, welche das Auftreten der Fruchtanlage bedingen, den auf der betreffenden Stelle der Keimblase lastenden Druck der Zona überwunden, d. h. ist es zur Bildung der Embryonalanlage gekommen, so ist nicht einzusehen, wie plötzlich jener Druck wieder stärker werden, und die letztere langsam zertheilen soll. Ebensowenig aber, als die Druckwirkung erst in einer bestimmten Zeit nach "dem Erscheinen der Embryonalanlage sich geltend machen kann, wird dieselbe zu einer bestimmten' Zeit, d. h. nach vollzogener Spaltung aufhören, die Entwicklungsvorgänge zu beeinflussen. Beide Postulate sind aber in der Ahlfeld'schen Hypothese enthalten. Ahlfeld kann die Druckwirkung der Zona als spaltende Kraft nur von dem Auftreten der Embryonalanlage an, bis nach erfolgter Spaltung brauchen. Denn wenn sie nach dieser Zeit noch wirksam sein sollte, so müssten ja die beiden gespaltenen Hälften ganz nach den von ihm aufgestellten Gesetzen einer erneuten Spaltung unterliegen.

In dem Voranstehenden habe ich die Gründe angegeben, aus denen ich weder den von Ahlfeld vermutheten Spaltungsmechanismus, noch die von ihm vertretene Drehung der gespaltenen Embryonalhälften gutheissen kann. Ebensowenig bin ich seiner Meinung, was die Spaltung selbst anlangt, insofern man darunter eine Trennung früher vereinigter, resp. einheitlicher Gebilde versteht. Trotzdem ich daher augenscheinlich ein Gegner der Ahlfeld'schen Anschauungen bin, haben dieselben mit meinen eigenen dennoch so viele Berührungspuncte, dass es nicht überflüssig erscheinen wird, meine an einem anderen Orte bereits mitgetheilten Ergebnisse den Resultaten Ahlfeld's an die Seite zu stellen.

Den Entwicklungszustand, welchen Ahlfeld als Ausgangspunct für sämmtliche Doppelbildungen betrachtet, nehme auch ich an, jedoch nur für gewisse Formen der Doppelmonstra. Es sind dies die allerersten Bildungsstadien der Embryonalanlage eines einzigen Individuums. Während jedoch Ahlfeld der Meinung ist, dass in einer gewissen Zeit vor der Bildung der Primitivrinne eine Spaltung der gemeinsamen Fruchtanlage stattfindet, so halte ich dafür, dass unter besonderen Verhältnissen die nach vorne wachsende Embryonalanlage nach zwei Seiten hin divergiren kann. Findet dieses Divergiren schon vor Vollendung des Primitivstreifens statt, so erhält man, wie ich es künstlich herzustellen vermochte (Fig. 3, Taf. VIII) einen gabelig getheilten Primitivstreifen. Der Unterschied zwischen der Ahlfeld'schen Auffassung und der meinigen gipfelt demnach darin, dass Ahlfeld eine- mehr oder minder hochgradige Spaltung eines vorher einheitlichen Gebildes zulässt, während ich, jegliche Spaltung negirend, zu dem Resultate komme, dass diejenigen Theile der Embryonalanlage, welche später gespalten resp. verdoppelt erscheinen, von vorneherein zweifach angelegt, demnach niemals aus einer ursprünglich gemeinsamen Organanlage in Folge von Zertheilung hervorgegangen sind.

Ich komme zu einem zweiten Punkte, in dem Ahlfeld und ich bis zu einem gewissen Grade übereinstimmen. Es ist diesem Forscher nicht entgangen, dass bei vielen der bekannten Doppelbildungen in frïherer Zeit eine 
Lageveränderung der beiden Embryonen stattgefunden haben müsse. Ahlfeld glaubt jedoch, dass diese Ortsverschiebung auf einer Drehung beruhe und hat diese seine Ansicht insofern generalisirt, dass er für alle Fälle unvollkommener Spaltung, wenn die Embryonalanlagen mit ihren vorderen oder hinteren Enden noch zusammenhängen, eine der Spaltung auf dem Fusse folgende Drehung annimmt. Bezüglich der Drehung kann ich Ahlfeld, wie schon erörtert, nicht beipflichten; dagegen habe ich in einem früheren Abschnitt auf das durch die mesodermale Wachsthumsenergie verursachte Auseinanderrücken zweier neben einander in die Area pellucida einstrahlender Embryonalanlagen aufmerksam gemacht, und gezeigt, wie unter diesen Verhältnissen eine Lageverschiebung der beiden Primitivstreifen stattfinden kann, die allerdings mit einer Drehung manche Aehnlichkeit darbietet. Es wurde dann an demselben Orte noch des Weiteren darauf hingewiesen, von welchen besonderen Umständen der Grad dieser Lageverschiebung abhängt, und wie sich darauf wiederum die einzelnen Formen der Duplicitas posterior zurückführen lassen.

Nachdem wir nun die Möglichkeit einer Verwachsung oder Spaltung von Embryonalanlagen, die in einer Area entstehen, erörtert und dabei zu dem Resultate gelangt sind, beide Vorkommnisse in Abrede stellen zu müssen, gehe ich nun zu der Frage über, ob dieselben in einer späteren Entwicklungszeit statthaben können, d. h. ob eine Spaltung eines Embryo oder eine Verwachsung zweier monoarealen Zwillingsembryonen behauptet werden darf.

Dass eine Verwachsung zweier monoarealer Zwillinge nicht mehr primär sich vollziehen kann, ist einleuchtend, da die beiden je durch die gemeinsame Keimhaut schon mittelbar verbunden sind. Es handelt sich demnach nur um eine secundäre Verwachsung, welche in einer Vereinigung vorher getrennter embryonaler Körpertheile besteht. Ueberblickt man die Abbildungen, welche für die beobachteten Fälle frühzeitiger Doppelbildungen vorliegen (siehe die Figuren auf Taf. IV, V und VI), so muss jeglicher Zweifel daran schwinden, dass zwei Embryonen mit einander in dem eben erörterten Sinne verschmelzen. Zwar weisen die bekannt gewordenen Mehrfachbildungen. noch lange nicht eine continuirliche Stufenreihe hinsichtlich der Ausdehnung der Verschmelzung auf, doch lässt sich aus ihnen immerhin so viel mit Gewissheit schliessen, dass in der ersten Zeit, nachdem die beiden Embryonen aus dem Stadium der Embryonalanlage herausgetreten sind, eine Vereinigung zwischen ihnen in verschieden hohem Grade sich vollziehen kann. Auch ist ja von vielen Anhängern der Spaltungstheorie für gewisse Fälle von Doppelmissbildungen eine oberflächliche Verschmelzung zugegeben worden. Wenn wir demnach eine Verwachsung zweier Embryonen als sichergestellt betrachten müssen, so können jedoch in Rücksicht auf die Zeit und den Grad derselben die Meinungen auseinandergehen. Was die Zeit anlangt, so kann eine Verschmelzung nur bei sehr jungen Embryonen statthaben, da bei älteren das Integument derselben bereits zu sehr differenzirt ist und die beiden Zwillinge vor einer Verwachsung schützt. Eine genaue Zeitgrenze anzugeben, von der an eine Vereinigung nicht mehr möglich ist, dürfte schwer halten. 
Der Grad der Verwachsung hängt wesentlich von zwéi Momenten ab; erstens von der Grösse der sich berührenden Stellen der Körperoberfläche zweier Embryonen und zweitens von dem Zeitpunkt der Verschmelzung; je früher dieselbe stattfindet, desto inniger wird sie schliesslich werden müssen. Besonders der letztere Punct scheint mir von Interesse zu sein, da bei seiner Erörterung die Frage nicht unbeantwortet bleiben kann, ob, wie von Seiten der Anhänger der Verwachsungstheorie behauptet wird, aus der Verschmelzung zweier ein einheitlicher Körpertheil resultiren kann. Bei der Besprechung dieser Frage möchte ich die Axenorgane von den übrigen Organen trennen. Was die ersteren betrifft, so verweise ich auf meine früheren Ausführungen über die primäre Vereinigung der Embryonalanlagen und die secundäre Verwachsung von Embryonen, als deren Endresultate sich im ersteren Fall eine Doppelmissbildung mit partieller Einfachheit der Axenorgane (Kopf mit inbegriffen) herausstellte, während im letzteren Falle nachweislich Doppelbildungen mit durchaus getrennten Wirbelsäulen entstanden, deren Köpfe jedoch, falls sie in einer sehr frühen Zeit mit einander verwachsen waren, zwar äusserlich einfach, jedoch durchaus missgebildet erschienen. Je später die Verwachsung stattfand, desto deutlicher wird das Doppelsein des Kopfes dieser Missbildungen auch äusserlich zu Tage treten. müssen.

Die Vereinigung der lateral von der Axe gelegenen Organe kann sich ebenfalls in verschiedener Zeit vollziehen. Am Besten werde ich das vorher ausgesprochene Gesetz, dass desto inniger und hochgradiger die Verschmelzung sich gestaltet, je früher dieselbe beginnt, an einem Beispiele erläutern können. Ich wähle hiezu die Verschmelzung. der Extremitäten zweier neben einander gelegenen Embryonen, wie wir sie sehr gut in dem Dareste'schen Falle, der in Fig. 6, Taf. VI wiedergegeben ist, beobachten können. Wir sehen hier, dass sowohl die oberen, als die unteren Extremitätenstummel sich offenbar sehr kurze Zeit nach ihrem Aussprossen aus der Körperoberfläche berührt haben und mit einander verklebt sind. Was für einen schliesslichen Erfolg wird diese Verschmelzung nach sich ziehen? Unzweifelhaft werden die vereinigten mittleren Extremitäten von nun an einheitlich weiterwachsen und wenn später im Innern derselben das Skelett sich differenzirt, so wird es theilweise einfach sich anlegen, es wird voraussichtlich nur eine für die äussere Inspection einfache obere und untere Extremität entstehen müssen, deren Zergliederung jedoch ergeben wird, dass die proximalen Skeletttheile dieses dritten mittleren Extremitätenpaares doppelt, vielleicht theilweise schon verschmolzen, die distalen jedoch einfach sind. Würde die Vereinigung später erfolgt sein, so würden die Skelettheile der Extremitäten noch weiter distalwärts doppelt geworden sein.

Dieses eine Beispiel mag genügen, um die Wirkungen der Verschmelzung zu zeigen, welche je nach deren zeitlichem Auftreten sehr verschieden ausfallen können. Man wird aus ihm ersehen, dass eine partielle Duplicitït eines Organes nicht auf einer verschieden weitgehenden Ineinsbildung, wie Joh. Müller sich so treffend ausdrückt, sondern auf einer mehr oder minder frühzeitigen Verschmelzung noch nicht differenzirter Organeanlagen beruht. Der Annahme einer Ineinsbildung zweier schon differenzirter Organe, 
wie sie von Anhängern der Verwachsungstheorie mehrfach aufrecht erhalten wird, muss ich desshalb eben so entschieden entgegentreten, wie ich eine Spaltung bereits einheitlich angelegter Theile einer Embryonalanlage in zwei sich später zu vollständigen Theilen ergänzenden Hälften von der Hand weisen musste. Nach der Verschmelzung von Organen können sich diese nur dann theilweise einfach gestalten, wenn zur Zeit der Verschmelzung die Organtheile aus völlig gleichartigem noch nicht differenzirtem Gewebe bestehen.

So sehen wir denn, dass die einfachen Theile einer ausgebildeten Doppelbildung, mögen sie der Axe oder den sonstigen Organen angehören, niemals aus einer Verschmelzung früher doppelt vorhandener bereits differenzirter Organe, die schliesslich zur Ineinsbildung geführt hat, sich ableiten. Eine Ineinsbildung kommt überhaupt nicht vor und eine Verschmelzung kann nur daun zu einem theilweise einfachen Zustande eines Organs führen, wenn die betreffenden Organe in noch ganz rudimentärem Zustande sich vereinigen.

Die älteren Anhänger der Verwachsungstheorie glaubten, dass, wenn zwei embryonale. Theile, z. B. zwei Köpfe, mit einander bis zur Ineinsbildung verwachsen, die einander zugekehrten Kopfhälften durch Atrophie zu Gründe gehen. Dass ich eine derartige Auffassung für eine total irrige halte, geht aus den eben angestellten Betrachtungen mit Nothwendigkeit hervor. Damit soll jedoch keineswegs gesagt sein, dass bei der Genese von Missbildungen überhaupt keine Atrophie mitspiele; ich betone vielmehr ausdrücklich, dass derartige Processe zweifellos bei teratogenetischen Entwicklungsvorgängen gar nicht selten stattfinden, und immer dann eintreten, wenn ein embryonaler Körpertheil einer Druckwirkung, möge sie von Seiten eines Zwillingsembryo ausgehen oder in äusseren Ursachen begründet sein, ausgesetzt ist. Nur eine so hervorragende Rolle, wie man früher vielfach der Atrophie für die Bildung der Doppelmonstra zuschrieb, kann ich derselben nicht einräumen; ich erinnere daran, dass die Verwachsungstheorie, um ein anderes Beispiel anzuführen, bei einer Duplicitas anterior die beiden Seitenhälften des einfachen Körperabschnittes von zwei ursprünglich gesonderten Individuen ableitete, deren seitliche Verschmelzung zu einer vollständigen Atrophie der einander zugekehrten Seitenhälften geführt haben sollte.

Dic über das Wesen und die Folgen der Verwachsung zweier monoarealer Embryonen angestellten Erwägungen lassen sich in Bezug auf ihre Hauptergebnisse in folgender Weise recapituliren:

1) Je später die Verschmelzung beginnt, desto oberflächlicher wird die Vereinigung der beiden Embryonen sich gestalten.

2) Eine Verwachsung zweier Embryonen, wenn sie auch noch so frühzeitig erfolgt, zieht niemals eine partielle Einfachheit der Wirbelsäule nach sich.

3) Die Verwachsung von Organen oder Organtheilen kann, wenn dieselbe sehr frühzeitig, so lange noch keine Differenzirung der betreffenden Theile eingetreten ist, sich vollzieht, eine partielle Einfachheit der verschmolzenen Organe veranlassen.

4) Die Verschmelzung zweier bereits differenzirter Organe kann unter 
keinen Umständen bis zur Ineinsbildung führen, sondern és wird in diesen Fällen nur zu einer mehr oberflächlichen Vereinigung der beiden Organe kommen können.

Wir haben schliesslich noch zu untersuchen, ob eine Spaltung von Embryonen stattfinden könne. Hier kann ich mich kurz fassen, da in dieser Frage unter den Autoren so gut wie keine Meinungsverschiedenheit mehr herrscht. Selbst die Anhänger der Spaltungstheorie, soweit sie der neueren Zeit angehören, versetzen eine Theilung nur in das Stadium der Embryonalanlage: die Spaltung eines Embryo, wodurch eine theilweise Duplicität der Axenorgane entstehen solle, halten sie nicht für möglich.

Wir können daher als feststehend betrachten, dass nach der vollständigen Ausbildung der Medullarrinne nicht mehr durch Spaltung des Embryo eine Doppelmissbildung stattfinden kann. Bei dieser Gelegenheit möchte ich kurz auf die Frage eingehen, wie und zu welcher Zeit sich die Genese überzähliger Embryonaltheile bei einer Einfachbildung vollzieht; ich denke hier an überzählige Eingeweide, oder an verdoppelte Extremitätentheile, wie supernummeräre Finger etc. Man ist selbst von Seiten der Verwachsungstheorie vielfach geneigt, für diese Fälle eine Spaltung anzunehmen.- Ich kann dieser Auffassung, insofern man unter Spaltung eine passive Trennung vorher einheitlicher Theile versteht, nicht beipflichten.

Was die Verdopplung innerer Organe anlangt, so hat es sich bei vielen herausgestellt, dass dieselben, z. B. der Uterus bicornis, Hemmungsbildungen darstellen, und nicht durch unvollkommene Spaltung einer einheitlichen Anlage entstanden sind. In Bezug auf die Ueberzahl von Extremitätentheilen liegt eine interessante Beobachtung von Ahlfeld vor, welche eine Verdoppelung des Daumens betrifft. Ahlfeld fand nämlich zwischen den beiden Daumen einen amniotischen Faden, durch den seiner Ansicht nach die Daumenanlage gespalten worden war. Auch ich sehe in dem Amnionfaden die Veranlassung für die Genese von zwei Daumen, welche ich mir jedoch nicht in der Art denke, dass die Anlage eines gemeinsamen Daumens durch einen zwischen in dieselbe eindringenden Amnionfaden passiv eingefurcht wurde, sondern meines Dafürhaltens hat die sich entwickelnde Anlage, durch den Amnionfaden an ihrem normalen Verwachsen verhindert, nur da, wo kein Hinderniss bestand, also zu beiden Seiten des Fadens vordringen können, wodurch ein sich nach und nach vergrössernder Einschnitt in derselben entstehen musste. Als nun die Sonderung im Innern der Daumenanlage eintrat und die Anlage der Knochen stattfand, konnte jede der beiden Daumenhälften sich zu einem Finger organisiren. Man sieht, zwischen der Ahlfeld'schen und meiner Auffassung, die sich offenbar sehr nahe stehen, herrscht dieselbe Differenz, der ich auch schon früher, als die Spaltung der Embryonalanlage erörtert wurde, Ausdruck gegeben habe. Ahlfeld redet der passiven Spaltung, bereits einheitlich angelegter Theile das Wort, nach meiner Ansicht kann es sich um keine Spaltung handeln, da es überhaupt nicht zu einer einheitlichen Anlage der später doppelten 'Theile kommt, sondern bereits sehr frühe durch ein auf irgend eine Veranlassung hin anormales Wachsthum von vorneherein die später doppelten Theile sich doppelt anlegen. Der schliessliche Effect ist nach unserer beiderseitigen Meinung ein gleicher; nur theilt 
A hlfeld zur Herbeiführung dieses Zustandes dem betreffenden Embryonaltheile eine passive Rolle $\mathrm{zu}$, während derselbe nach meiner Meinung, indem er einem anormalen Wachsthum unterliegt, an dem Zustandekommen der Bildungsanomalie activen Antheil nimmt. Darin stimmen wir dagegen wieder überein, dass der fragliche Process - ich möchte ihn, um beiden Auffassungen gerecht zu werden, als scheinbare Spaltung bezeichnen - auf irgend eine äussere Veranlassung hin zu Stande kommt. Für das Doppelwerden des Daumens in dem genannten Falle ist ganz entschieden der im Wege stehende Amnionfaden das ursächliche Moment gewesen ${ }^{1}$ ). Für das Zustandekommen einer theilweise doppelten Embryonalanlage verlegt Ahlfeld die Hauptursache auf eine mechanische Einwirkung in Gestalt eines Seitens der Zona auf die Embryonalanlage ausgeübten Druckes, während ich, die Möglichkeit mechanischer Einwirkungen zugebend, auch noch die locale Behinderung des Sauerstoffzutrittes im Hinblick auf meine experimentellen Untersuchungen als eines der Momente hervorheben möchte; welche eine Bifurcation zur Folge haben können.

Zum Schlusse dieses Capitels, welches die Möglichkeit einer Verwachsung und Spaltung in verschiedenen Entwicklungsperioden behandelt, scheint es mir angemessen, die Ergebnisse unserer Betrachtungen nochmals kurz zu recapituliren.

Was die Verwachsung anlangt, so haben wir bei den Erörterungen über die biareale Entwicklung wahrscheinlich machen können, dass in der ersten Zeit der ovarialen Eibildung eine mehr oder minder weitgehende Vereinigung (Verwachsung) zweier Eizellen eines Follikels zu der Entstehung einer mit zwei Areae pellucidae versehenen Keimhaut Veranlassung gibt; unterbleibt diese Vereinigung, so werden bei den Vögeln späterhin zwei getrennte Keimscheiben dem Dotter aufliegen. Ich gebe mich der Hoffnung hin, dass dieses thatsächlich beobachtete Vorkommen von nun an nicht mehr in Zweifel gezogen wird, seit darauf hingewiesen wurde, dass zwei in einem Follikel eingeschlossene Eizellen bei den Vögeln in Folge der dieser Classe eigenthümlichen Entwicklungsprocesse im Eierstock, falls sie keine gegenseitige Verbindung eingehen, nothwendig das Zustandekommen zweier getrennter Keimscheiben bedingen müssen. Es werden daher, wenn beide - häufig scheint nur eine Cicatricula befruchtet zu werden - entwicklungsfühig sind, zwei '/willingsembryonen auf' einem Dotter entstehen müssen.

Im Stadium der Embryonalanlage kann von einer Verwachsung zweier sich entwickelnder Individuen nicht die Rede sein; sie können nur auf dem Wege der Copulation mit einander sich innig verbinden. Dagegen findet unzweifelhaft eine Verwachsung zweier Embryonen statt,

\footnotetext{
1) Un Missverständnissen vorzubengen, bemerke ich, dass Duplicitäten der Finger oder grösserer distaler Endabschnitte der Extremitäten, wie ganzer Hände und Füsse, nicht nur auf äussere Veranlassungen hin durch mechanische Ursachen zu Stande kommen, sondern dass fï̈ die Genese derartigrer Deformitäten sicherlich anch die Vererbung in Betracht zu zielien ist.
} 
die um so oberflächlicher bleiben wird, in je späterer Eńtwicklungszeit sie beginnt.

Während demnach eine Verwachsung vorher getrennter Embryonaltheile in gewissen Entwicklungsphasen sich vollziehen kann, mussten wir eine Spaltung für alle Perioden der Embryogenese ausschliessen. Für die Annahme der Spaltung einer Keimscheibe oder einer Embryonalanlage oder eines Embryo vermochten wir nicht die geringsten Unterlagen beizubringen. Auf keiner dieser Entwicklungsstufen vollzieht sich eine Trennung - weder eine totale, noch eine partielle - eines vorher einheitlichen Gebildes, was ja doch mit dem Worte Spaltung ausgedrückt werden soll. Dies haben in neuerer Zeit manche Autoren gefühlt und haben an die Stelle der Spaltung die Bezeichnung "Theilung" gesetzt, welche im Gegensatz zu der ersteren nicht nur als passiver, sondern auch als activer Begriff aufgefasst werden kann. Noch zutreffender würde man den fraglichen Vorgang als "Divergenz" bezeichnen können, womit die durch gewisse Ursachen bedingte anormale Entwicklung nach zwei auseinanderweichenden Richtungen hin am Besten wiedergegeben ist.

Die Bildung gewisser Doppelmonstra (Duplicitas anterior) auf dem Wege der Divergenz, scheint mir nun besonders durch die mitgetheilten experimentellen Untersuchungen nahezu sicher gestellt; ebenso sicher kommen jedoch andere Doppelmissbildungen auf dem Wege der Copulation zweier Embryonalanlagen zu Stande (Terata anakatadidyma und die Duplicitas posterior), während wiederum diejenigen Doppelmissbildungen, deren Wirbelsäule eine vollständige Verdoppelung aufweist, auf Verwachsung zweier Embryonen zurückzuführen ist.

Es sind somit bei der Genese der Doppelmissbildungen sehr verschiedene Vorgänge in Betracht zu ziehen, was allein schon zur Genüge erkennen lässt, dass gegenwärtig der alte Prinzipienstreit zwischen Verwachsung und Spaltung, da er mit unseren jetzigen embryogenetischen und teratogenetischen Kenntnissen unvereinbar ist, über Bord geworfen werden muss. Die Bildung der Doppelmonstra lässt sich keineswegs theoretisch nach einem bestimmten Schema construiren, indem man hiebei von den bereits ausgebildeten Formen der Doppelmonstra ausgeht, sondern man wird derselben nur dann auf die Spur kommen können, wenn man unter Bezugnahme auf die normale Entwicklungsgeschichte das vorhandene casuistische Material sehr früher Doppelbildungen sichtet; ein solches Vorgehen wird zu bestimmten Resultaten führen müssen, von denen aus erst Rückschlüsse auf die Genese bereits ausgebildeter Doppelmonstra erlaubt sein werden.

Bei einer früheren Gelegenheit habe ich angegeben, dass die Anhünger der Verwachsungstheorie hinsichtlich der Genese von Doppelbildungen den Standpunct der primitiven Dualität einnehmen, während die Vertreter der Spaltungstheorie naturgemäss die primitive Unität für das richtige halten. Auch zu diesen sich scheinbar direct gegenüberstehenden Auffassungen möchte ich schliesslich noch Stellung nehmen.

Wenn man bei der Prüfung der beiden Ansichten nur die ersten Stadien der Embryonalanlage ins Auge fasst, so wird man zu dem Ergebniss gelangen, dass bei der Genese gewisser Doppelmissbildungen die primitive 
Dualität, bei anderen dagegen (Duplicitas anterior) die primitive Unität vorliegt; somit schliesst die eine die andere keineswegs aus. Die Vorgänge der Copulation und Verwachsung setzẹn die primitive Dualität voraus und ebenso basirt die Divergenz einer in die Area pellucida einwachsenden Embryonalanlage selbstredend auf der primitiven Unität. Es herrschen demnach auch hier keine principiellen Gegensätze und es wäre verfehlt, wollte man sich die Genese der Doppelmonstra ausschliesslich von dem einen oder anderen Standpuncte aus zurecht legen. Dieser wie jener Versuch wäre einseitig und würde niemals zu einer durchaus befriedigenden Lösung des schwierigen Problems führen können. 


\section{Die Theorie der Radiation.}

Rauber hat vor einigen Jahren den Theorien der Verwachsung und Spaltung eine dritte gegenübergestellt, welche er als Radiation bezeichnete. Das von dem genannten Autor aufgestellte Princip der Radiation basirt auf der Voraussetzung, dass in der ersten Zeit der Ontogenese die mit ihrem peripheren Ende in den Keimring übergehende Embryonalanlage eine zum Centrum der Mittelscheibe (Area pellucida) radiäre Anordnung einhalte. Rauber nennt diese Art der Entwicklung monoradial. Bei der Genese einer Mehrfachbildung ist dagegen die Entwicklung pluriradial, weil mehrere radiär angeordnete Embryonalanlagen sich ausbilden. Den Vorgang der Radiation selbst präcisirt Rauber in folgender Weise: „Wie normal die vordere Embryonalanlage der Wirbelthiere als ein Vorstoss, eine Ausstrahlung des Randwulstes erscheint, so erscheinen die Mehrfachbildungen als mehrfache solche Vorstösse oder Ausstrahlungen des Randwulstes."

Ein bedeutsamer Unterschied zwischen der Rauber'schen Theorie und ihren beiden sich hartnäckig bekämpfenden Genossinnen ist allein schon aus der vorstehenden Definition ersichtlich. Während die Anhänger der Verwachsungstheorie sowohl, wie die ihrer Gegnerin an den ihnen von früheren Zeiten her überkommenen Vorstellungen principiell festhalten und diese ihrer Meinung nach unfehlbaren Glaubenssätze der Spaltung resp. Verwachsung, indem sie der fortschreitenden Erkenntniss der normalen Embryologie Rechnung zu tragen genöthigt waren, entsprechend modificiren mussten, hat Rauber in umgekehrter Richtung seinen zur Aufstellung des Princips der Radiation führenden Weg verfolgt. Ihm diente als Ausgangspunct die normale Entwicklungsgeschichte und auf Grund der embryogenetischen Vorgänge, die zur Bildung eines Einzelwesens führen, baute er seine Radiationstheorie auf. Unstreitig ist die Basis dieser Theorie eine viel solidere, als die der beiden anderen; sie kann im Besitze eines weit vollkommeneren Rüstzeuges getrost den Kampf mit jenen aufnehmen.

Aber auch die Radiationstheorie wird, wie die folgenden Betrachtungen nachweisen sollen, nur auf die Genese eines grossen Theiles von Doppelmissbildungen angewendet werden können; zur Erklärung der Bildungsgeschichte sämmtlicher Formen der Doppelmonstra wird sie nicht ausreichen. Ferner berücksichtigt sie nicht die biareale Entwicklung, da das Vorhandensein von zwei Cicatriculae auf einem Dotter von Rauber nicht als bewiesen anerkannt wird. Endlich scheinen mir, wie ich hier schon betonen will, die Rauber- 
schen Ausführungen insofern zu weit zu gehen, als Rauber die bei Vertretern der niedersten Classe der Wirbelthiere als richtig erkannten embryologischen Vorgänge zu sehr verallgemeinert, indem er die den einzelnen Wirbelthierclassen eigenen Verschiedenheiten der Ontogenie nicht genügend in Erwägung zieht. Wie soeben angedeutet, kann ich den Anschauungen Rauber's, so sehr ich mit den Grundgedanken seiner Theorie einverstanden bin, nicht in allen Puncten beipflichten. Um diese Differenzen zwischen unseren Ansichten besser beleuchten und begründen zu können, erscheint es nöthig, vorerst eingehender zu schildern, auf welche Prämissen hin Rauber seine Theorie aufgestellt hat, und zu welchen Consequenzen er schliesslich gelangt ist.

Da, wie erwähnt, die Theorie Rauber's von der normalen Embryogenie ausgeht, so müssen zunächst die Anschauungen desselben hinsichtlich der normalen Wirbelthierentwicklung, erörtert werden. Rauber gehört als ein eifriger Anbänger der $\mathrm{Haeckel}$ 'schen Gastraeatheorie zu denjenigen Forschern, welche diese Theorie auch für die Wirbelthiere durchführten. Eine kurze Notiz Rauber's vom Jahre 1874 lässt ersehen ${ }^{1}$ ), dass derselbe bereits um diese Zeit vergleichend embryologische Untersuchungen nach der angedeuteten Richtung hin anstellte, indem er die ersten Bildungsvorgänge des Hühnchens und der Knochenfische einem Vergleiche unterzog. Die nächsten Jahre brachten weitere Mittheilungen, in denen Rauber für beide Thierclassen die schon kurz nach der Furchung erkenntliche Gastrulaform des Keimes betont und ferner die Bedeutung des Randtheiles der Keimscheibe für die Genese des Embryo, worauf er schon in seiner früheren Mittheilung hingewiesen hatte, nochmals hervorhebt ${ }^{2}$ ). Auch die späteren Schriften Rauber's, von denen ich die wichtigsten unten citire $^{3}$ ), nehmen, soweit sie sich mit der Genese von Mehrfachbildungen befassen, vorzugsweise auf die bei den Knochenfischen und Vögeln stattfindenden Entwicklungsvorgänge Bezug, was zum Theil darin begründet ist, dass bei beiden Thierclassen frühzeitige Doppelbildungen am häufigsten beobachtet werden.

Die in den citirten Abhandlungen enthaltenen Ausführungen Rauber's concentriren sich in dem Bestreben, den Nachweis zu führen, dass in der Ontogenie aller Wirbelthiere insofern ein einheitlicher Grundzug sich ver-

1) Rauber, Ueber die embryonale Anlage des Hühnchens. Medic. Centralbl. 1874, Nr. 50, pag. 786.

$\left.{ }^{2}\right)$ Medic. Centralbl. 1875, Nr. 4 u. 17.

8) R a u ber, Ueber die erste Entwicklung der Vögel und die Bedeutung der Primitivrinne. Sitzungsber. der Leipziger naturf. Gesellschaft 1876, Nr. 1, 2, 3.

Ra uber, Primitivrinne und Urmund. Morphol. Jahrbuch Bd. II, 1876, pag. 550.

Rauber, Ueber die Stellung des Hühnchens im Entwicklungsplan. Leipzig 1876.

Rauber, Die Theorien der excessiven Monstra. Virchow's Archiv Bd. 71, pag. 193, 1877.

Rauber, Primitivstreifen und Neurula der Wirbelthiere in normaler und pathologischer Bezichung. Leipzig 1877.

Ra u ber, Die Theorien der excessiven Monstra. Zweiter Beitrag. Virchow's Arehiv Bd. 74, pag. 66 u. 551, 1878.

Rauber, Formbildung und Formstörung in der Entwicklung von Wirbelthieren. Morphol. Jahrbuch Bd. V, pag. 661, 1879 und Bd. VI, pag. 1 u. 129, 1880. 
folgen lasse, als die bei allen Vertebraten vorhandene Gastrula nach denselben Entwicklungsgesetzen in das nächstfolgende Stadium der Neurula übergeht. Hierunter wird die Entwicklungsphase verstanden, in welcher die erste Anlage und die Bildung des Nervenrohres sich vollzieht. Bei Mehrfachbildungen entsteht aus einer einfachen Gastrula eine mehrfache Neurula. Dies sind kurz gefasst die leitenden Ideen, welche die Rauber'schen Untersuchungen kennzeichnen. Um denselben näher treten zu können, müssen wir mit Rauber von den einfacheren Entwicklungsverhältnissen des Amphioxus ausgehen.

Durch die bekannten Untersuchungen Kowalewsky's ${ }^{1}$ ) ist für dieses niederste Wirbelthier festgestellt worden, dass es in einer sehr frühen Entwicklungszeit eine einblätterige Blase darstellt, welche durch Einstülpung zweiblätterig wird, womit das Gastrulastadium erreicht ist. Indem nun der Embryo sich verlängert, verengt sich die an dem einen Pol des länglich ovalen Gebildes liegende Einstülpungsöffnung, die wir Blastoporus, Gastrulamund oder Urmund nennen, immer mehr. Mit der allmähligen Streckung des Embryo flacht sich der später nach oben liegende 'Theil der Oberfläche nach und nach ab und indem die Ränder dieser Platte sich langsam erheben, entsteht die Rückenfurche, in deren Gebiet der dorsalwärts rückende Blastoporus mit eingezogen wird. Die Ränder der letzteren gehen unmittelbar in die Ränder der Rückenfurche über. Ist die Medullarrinne angelegt, so befindet sich der Embryo bereits im Neurulastadium; er besitzt ein Darmrohr (die Höhlung der früheren Gastrula), welches durch den Blastoporus mit dem Nervenrohr (Medullarrinne) communicirt.

Den Amphioxus verlassend, wenden wir uns zu den Fischen. Hier ist zu unterscheiden zwischen Cyclostomen und Ganoiden einerseits, und den Knochenfischen und Selachiern andererseits; erstere besitzen Eier, die einer holoplastischen Furchung unterliegen, während die Eier der letzteren meroplastisch sich furchen.

Unter den Cyclostomen sind es die Petromyzonten, deren Eifurchung und Entwicklung uns bekannt ist. Die Eier derselben machen eine totale und inäquale Furchung durch, so dass die obere Eihälfte sehr bald aus viel kleineren Furchungszellen besteht als die untere; schon früh tritt die Furchungshöhle auf, welche zwischen den kleineren Zellen der obern Eihälfte und den grossen Furchungszellen des übrigen Eies liegt. Die letzteren, welche den Nahrungsdotter vorstellen, werden nun durch die rasch sich mehrenden und zu einer mehrschichtigen Lage sich ordnenden kleineren Furchungszellen umwachsen. Dieser Vorgang erfolgt nicht gleichmässig, indem die Umwachsungsränder auf der einen Seitenhälfte des Eies rascher als auf der andern gegen den untern Eipol vorrücken. Da, wo der Umwachsungsrand am langsamsten fortschreitet, erscheint er bald etwas verdickt und gewulstet; er liegt ferner an dieser Stelle dem Nahrungsdotter nicht direct auf, wodurch zwischen beiden ein feiner spaltförmiger Raum entsteht. Aus diesen Gründen muss die be-

1) A. Kowalewsky, Entwicklungsgeschichte des Amphioxus lanceolatus. Petersburg 1867. K., Weitere Studien über dic Entwicklungšgeschiclite des Amphioxus lanceolatus, nebst einem Beitrage zur Homologie des Nervensystems der Würmer und der Wirbelthiere. M. Schultze's Arehiv Bd. XIII, pag. 181, 1876. 
sagte Stelle des Randes sich deutlicher von der Eioberfläche abheben, als die gegenüberliegende, nur dünne Randhälfte, welche sich gegen den grosszelligen Dotter nicht scharf abgrenzt. Den gewulsteten Theil des Randes nennt Rauber den Keimring der Cyclostomen ${ }^{1}$ ). Ist die Umwachsung nahezu vollendet, so umschliesst der Umwachsungsrand eine rundliche Oeffnung, welche das Dotterloch oder der Ruskoni'sche After heisst. Dieselbe lässt den grosszelligen Nahrungsdotter, der hier noch nicht überdeckt ist, durchblicken; sie führt ferner in die zwischen diesem und dem Wulste des Keimrings gelegene spaltförmige Höhle, welche die primitive Darmhöhle darstellt. Während die letztere sich nach aufwärts und vorne zu vergrössert, wird die Furchungshöhle immer kleiner und schwindet schliesslich gänzlich.

Die eben geschilderte Umwachsung hat zu einer Entwicklungsform geführt, welche als Gastrula der Cyclostomen aufzufassen ist. Nur ist deren Form wegen des Vorhandenseins des Nahrungsdotters keine so reine und vollkommene wie bei dem Amphioxus. Der Ruskoni'sche After repräsentirt den Blastoporus; der verdickte Theil seiner Umrandung oder der Keimring ist dorsalwärts gerichtet, wesshalb derselbe auch als dorsale Blastoporuslippe bezeichnet werden kann. Durch den Blastoporus gelangt man in die primitive Darmhöhle. Die Decke derselben hat sich schon während der Umwachsung in mehrere Schichten differenzirt, deren oberflächliche das Ektoderm bildet, während die unmittelbar über der Darmhöhle befindliche einschichtige Zellenlage das Entoderm darstellt. Die beiden Keimblätter gehen am Rande des Keimrings in einander über; zwischen ihnen liegt das Mesoderm, welches wahrscheinlich schon kurz nach Beginn der Umwachsung von der dorsalen Blastoporuslippe aus zwischen die beiden andern Blätter eingewachsen ist. Die Sonderung der oberflächlichen Zellenschichten des Eies in das Ektoderm, sowie die Ausbreitung des Mesoderm schreitet von der dorsalen Eihälfte auf die ventrale fort. Der Boden der Darmhöhle wird von den grossen Zellen des Nahrungsdotters gebildet, welche dem Entoderm zuzurechnen sind. Dieselben setzen sich seitlich und vorne unmittelbar in das einschichtige Entoderm der Decke fort.

Der Uebergang in das Neurulastadium erfolgt nun in der Weise, dass direct vor dem Blastoporus eine Rinne entsteht, indem sich seitlich von derselben durch Verdickungen des Mesoderms an den betreffenden Stellen Wülste erheben. Dieselben sind die Medullarwülste, welche nach hinten zu in die Ränder des Blastoporus übergehen; die Rinne selbst ist die Rückenrinne, die sich bis zu dem Blastoporus erstreckt, an welchem Orte das Medullarrohr mit der Darmrohranlage zeitweise verbunden ist ${ }^{2}$ ). Unter der Rückenfurche entsteht die Chorda dorsalis und zwar aus dem Entoderm (Calberla) ${ }^{3}$ ).

Die Entwicklung der Ganoiden, welche besonders bei den Stören unter-

') Ra in ber, Primitivstreifen und Neurula, pag. 6.

$\left.{ }^{2}\right)$ Cfr. Calberla, Ueber die Entwicklung des Medullarrohres und der Chorda dorsalis der Teleostier und der Petromyzonten. Morphol. Jahrb. Bd. III, 1877, pag. 249.

${ }^{3}$ ) Znm besseren Verständniss der ersten lintwicklungsvorgänge der Petromyzonten, welche sich ohne Zeichungen nur schwer veranschaulichen lassen, verweise ich auf die von M. Schultze (Die Entwicklung von Petromyzon Planeri. Gekrönte Preisschrift. Haarlem 185f5) sowie von Calberla gegrebenen Ablildungen. 
sucht ist, beruht im Wesentlichen auf den gleichen Vorgängen, wie bei den Cyclostomen, wesshalb ich glaube, dieselbe hier übergehen zu können.

Von den Selachiern, deren Eier meroplastisch sich furchen, kennt man am eingehendsten die Entwicklung der Haie. Wie bei den Vögeln gliedert sich das $\mathrm{Ei}$ in den Bildungsdotter oder die Keimscheibe, und den Nahrungsdotter. Nur die erstere unterliegt der Furchung, nach deren Ablauf sie aus einer grossen Zahl von Zellen besteht; die Keimscheibe besitzt zuerst eine linsenförmige Gestalt; ziemlich in der Mitte derselben kommt es durch Auseinandertreten der Zellen zur Bildung einer Höhle, der Furchungshöhle, über welcher die Keimscheibe sich verdünnt, so dass sie aus einer dünnern Mittelscheibe und einem dickeren Rande (Randwulst oder Keimring) besteht. An einer Stelle ist der Randwulst besonders verbreitert und verdickt; dieselbe kann man mit Balfour als Embryonalanschwellung bezeichnen, weil von hier die Bildung des Embryo ausgeht. Längsschnitte durch diesen verdickten Theil des Randwulstes zeigen, dass die obere Zellenlage der Keimscheibe, die wir als Ektoderm bezeichnen können, am Rande der Keimhaut unmittelbar in die untere Keimschichte, aus welcher das Entoderm und das Mesoderm sich entwickelt, umbiegt. Während nun die Keimhaut sich ausdehnt, wächst die Embryonalanschwellung und erscheint bald unter dem Bilde einer vom Randwulst centralwärts eingebogenen Schleife, welche, je mehr die Keimhaut die Dotterkugel umwächst, sich verlängert. Das Embryonalschild, wie wir diese Schleife nennen können, ist von einer Längsrinne, der Rückenrinne, durchzogen, die von den Rückenwülsten seitlich begrenzt ist. Da nun bei der beginnenden Umwachsung des Dotters der Theil des Randwulstes, aus dem die Embryonalanlage sich bildete, von dem·Dotter sich etwas abhob, entstand zwischen beiden eine Spalte, die sich nach vorne zu bei der fortschreitenden Umwachsung vergrössert und die primitive Darmhöhle darstellt. Mit deren Ausbildung schwindet die Furchungshöhle. Querschnitte durch die Embryonalanlage kurz nach Auftreten der Rückenfurche lassen erkennen, dass das Mesoderm die Medianlinie unter der Rückenfurche freilässt; hier bildet sich aus dem Entoderm die Chorda, welche bis zum hinteren Embryonalrande reicht. Hinsichtlich der Längenzunahme der Embryonalanlage gehen die Ansichten der Autoren auseinander; Balfou ${ }^{1}$ ) hat sich mehr für ein intussusceptionelles Wachsthum erklärt, während $\mathrm{His}^{2}$ ) annimmt, dass die Verlängerung der Embryonalanlage von rückwärts her erfolge; zu derselben sollen immer weitere Theile des Randwulstes treten, welche sich aneinanderlegen und miteinander in der Medianlinie verwachsen. Hat die Embryonalanlage eine gewisse Lünge erreicht, so erhebt sich ihr vorderes, wie ihr hinteres Ende mehr' und mehr über das Niveau der Eioberfläche; die Rückenwülste haben sich währenddem stärker entwickelt und beginnen nach rückwärts den hinteren Rand der Embryonalanlage zu überragen. Dies bringt es mit sich, dass die über das hintere Chordaende hinaus sich verlängernden Seitenhälften der Embryonalanlage etwas auseinandertreten, um nach kurzem Verlaufe aus ihrer bisherigen Richtung

1) Balfour, A Preliminary account of the development of the elasmobranch. fishes. Quat. Journ. of Micr. Science. Oct. 1874.

$\left.{ }^{2}\right)$ His, Ueber die Bildung der Haifischembryonen. Zeitschrift für Anatomie und Entwicklungsgeschichte 1876, pag. 108. 
nach abwärts und vorne umzubiegen, worauf sie bald wieder ihre Richtung ändernd seitlich in den ausserembryonalen dünneren Theil des Randwulstes übergehen. Die auseinandertretenden Schenkel des hinteren Embryonalendes hat Balfour Caudallappen, His Randbeugen genannt ${ }^{1}$ ). Später treten dieselben zu dem Schluss des Medullarrohres zusammen, dessen hinterer Abschnitt somit den ursprünglichen hinteren Embryonalrand überragen muss. Unmittelbar hinter dem letzteren erhält sich bei dem Zusammentreten der Caudallappen und der ausserembryonalen Randwulsttheile eine Oeffnung (Canalis neurentericus), durch welche das Medullarrohr zeitweise mit dem Darmrohre communicirt ${ }^{2}$ ). Bei der weiteren Umwachsung des Dotters Seitens der Keimhaut fahren die ausserembryonalen Randwulsttheile fort, sich hinter der Embryonalanlage zu vereinigen, was in einer geraden in der hinteren Verlängerung der embryonalen Längsaxe gelegenen Linie geschieht. Dadurch entfernt sich der Rand der Keimhaut nach hinten zu immer mehr von dem Embryo. Mit dem vollständigen Verschlusse der von dem successive sich verengernden Ringe des Randwulstes umgrenzten rundlichen Zone der Dotteroberfläche (Dotterloch) ist der Umwachsungsprocess beendet.

Bei den Knochenfischen, zu denen ich nun übergehe, verläuft die Furchung, die Genese der Furchungshöhle und damit einhergehend die Differenzirung der Keimscheibe in eine dünnere Mittelscheibe und einen dickeren Randwulst oder Keimring in ähnlicher Weise, wie dies soeben für das Ei der Selachier beschrieben wurde. Die Keimhaut beginnt sodann, den Dotter zu umwachsen, während sehr bald eine Stelle des Randwulstes sich verdickt und verbreitert, wodurch dieselbe als ein Vorsprung des Randwulstes in die Mittelscheibe hinein erscheint. Dieser Vorsprung stellt die Embryonalanlage dar oder, wie wir sie mit Rauber bezeichnen können, die vordere Embryonalanlage, da sie dem spätern Kopfende des Embryo entspricht. Längsschnitte durch dieselbe zeigen auch hier am hinteren Rande einen unmittelbaren Uebergang der Zellen der oberen Keimschichte in die der unteren. Während die Furchungshöhle allmïhlig schwindet, tritt bald in der grösser gewordenen vorderen Embryonalanlage die verhältnissmässig breit angelegte Rückenfurche auf, die sich jedoch bei der Streckung der Embryonalanlage rasch verschmälert; seitlich ist sie von den Rückenwülsten begrenzt, die vorne bogenförmig in einander übergehen. Auf Querschnitten, welche durch die Embryonalanlagen kurz nach dem Auftreten der Rückenfurche gelegt sind, kann man bereits die drei Keimblätter erkennen, das Ektoderm, ferner dem Dotter aufliegend das Entoderm, zwischen beiden die Mittellinie, wo sich aus dem Entoderm die Chorda bildend, freilassend, das Mesoderm. Hinsichtlich der mit der weiteren Umwachsung gleichzeitig einhergehenden Streckung der Embryonalanlage verweise ich auf die vortrefflichen Abbildungen von $\mathrm{His}^{3}$ ), welche diesen Vorgang sehr gut

1) Von den Randbeugen gibt $\mathrm{H}$ is (l. e.) in Fig. 5 und 6, Taf. VII sehr instructive Abbildungen.

$\left.{ }^{2}\right)$ Ueber die Genese dieser Communicationsöffnung gewähren die sehematischen Abbildungen in Balfour's Handb. der vergleichenden Embryologie (übersetzt von Vetter) Bd. II, 2. Hälfte, pag. 41, Fig. 19 eine sehr gute Vorstellung.

3) His, Untersuchungen über die Entwicklung von Knochenfischen, besonders äber diejenige des Salmeus. Zeitschrift für Anatomie und Entwicklungsgeschichte 1875, pag. 17, Fig. $1-5$. 
veranschaulichen. Wir sehen an denselben, dass die Rückenfurche Anfangs sehr kurz ist, sich hierauf etwas streckt, aber niemals bis zu dem hinteren Rande der Embryonalanlage reicht; der letztere erscheint nach riickwärts etwas vorgetrieben, was $\mathrm{His}$ als Randknospe bezeichnet; diese geht seitlich unmittelbar in die anliegenden Randwulsttheile über. Bei der Verlängerung und Vervollkommnung der vorderen zur totalen Embryonalanlage, schliesst sich die nur vorne gut ausgeprägte Rückenfurche sehr rasch zum Gehirnrohre, während sie nach hinten $\mathrm{zu}$ sich nicht sehr weit fortsetzt, indem hier das Medullarrohr sich nicht als Rohr, sondern als eine solide strangförmige Verdickung des Ektoderm anlegt, durch welche die Keimhaut dotterwärts kielartig vorgetrieben wird; erst späterhin tritt nach der Loslösung dieses soliden Medullarstranges vom Ektoderm durch Auseinanderweichen der Zellen desselben eine centrale Höhlung, d. h. ein Canal auf, wodurch die Umwandlung desselben in ein Rohr erfolgt. Die Umwachsung des Dotters unter allmähliger Verlängerung des Embryo hat His durch schematische Zeichnungen ungemein deutlich wiedergegeben ${ }^{1}$ ). Die Umwachsung geht ungleichmässig vor sich, indem die der Embryonallage gegenüberliegende Hälfte des Randwulstes einen viel grösseren Weg zurückzulegen hat, als die andere Hälfte. Am wenigsten verändert die Randknospe, welche ja sowohl der Embryonalanlage, als dem Randwulste angehört, ihre Lage auf der Dotteroberfläche. Gegen Ende der Umwachsung bildet der Randwulst einen kleinen ringförmigen Anhang des hinteren Embryonalkörpers, in welchen er schliesslich ganz aufgeht. Das von diesem Ringe umschlossene Dotterloch kommt sodann unter das Medullarrohr zu liegen. Nachdem auf diese Weise der Randwulst gänzlich dem Embryonalkörper einverleibt ist, wächst dessen hinteres Ende zum Schwanze aus.

Die allmählige Vervollkommnung resp. Längenzunahme der Embryonalanlage beruht nach der Ansicht von Oellacher vorwiegend auf interstitiellem Wachsthum, indem von der Stelle des Randwulstes aus, wo sich die Randknospe (Schwanzknospe) befindet, der Embryo sich nach vorne zu verlängere. Bei dem Forellenei rückt nach Oellacher ${ }^{2}$ ) die Randknospe selbst bei der Ausbreitung der Keimhaut nicht von der Stelle, so dass die Umwachsung des Dotters als eine einseitige aufzufassen wäre. $\mathrm{H}$ is und $\mathrm{Rauber}$ dagegen führen das Längenwachsthum der Embryonalanlage auf eine fortwährend stattfindende Apposition an das hintere Ende derselben zurück.' Bei der Umwachsung legen sich die angrenzenden Randwulsttheile hinter der bereits gebildeten Embryonalanlage successive an einander und verschmelzen in der Verlängerungslinie derselben, wodurch der Embryo auf Kosten des Randwulstes nach rückwärts wächst, indem fortwährend Randwulsttheile in den Embryonalkörper übergehen. Nach vollendeter Umwachsung ist der gesammte Randwulst zur Bildung des Embryo aufgebraucht worden. $\mathrm{H}$ is ${ }^{3}$ ) schildert den ganzen Vorgang in folgender Weise: ${ }_{-}$Die Uranlage des Körpers ist sonach ein platter Ring, dessen Breite und Dicke an einer Stelle, dem zukünftigen Kopfende ein Maximum, am gegenüberliegenden Schwanzende ein Minimum

1) 1. c. pag. 20 u. 21.

$\left.{ }^{2}\right)$ Oellacher, Beiträge zur Entwicklungsgeschichte nach Beobachtungen am Bachforelleneie. Zeitschrift für wissenschaftl. Zoologie Bd. XXIII, pag. 3 und 4.

3) 1. c. pag. 19 u. 20. 


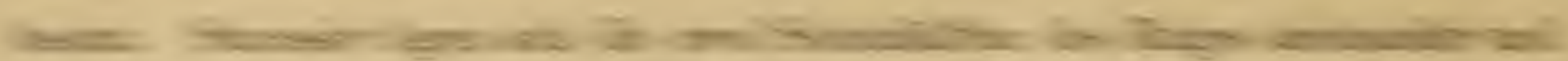

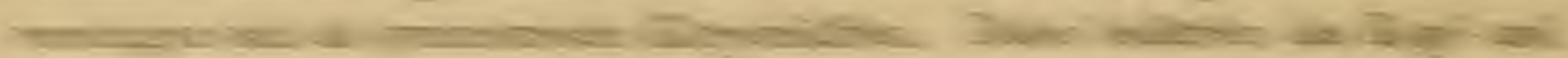

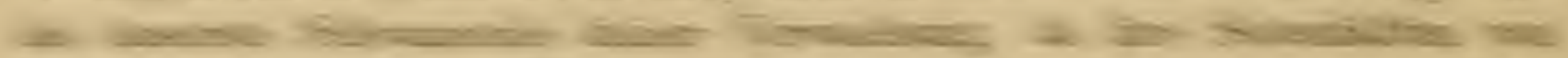

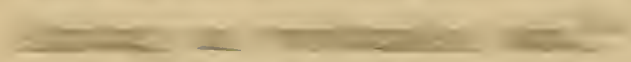

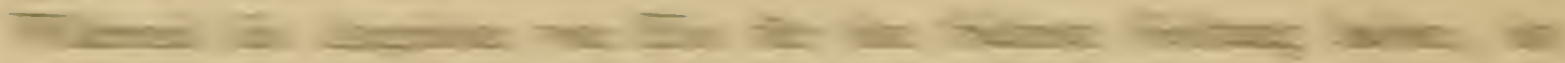
IT I.h

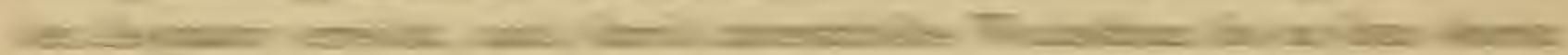

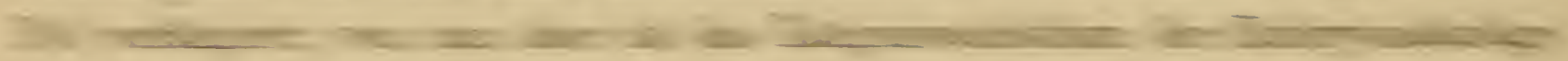

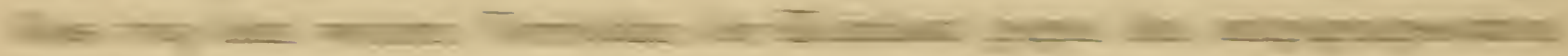

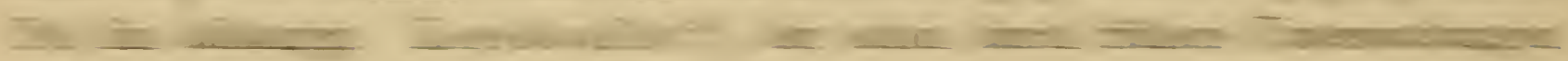

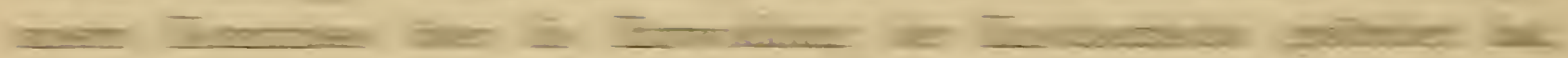

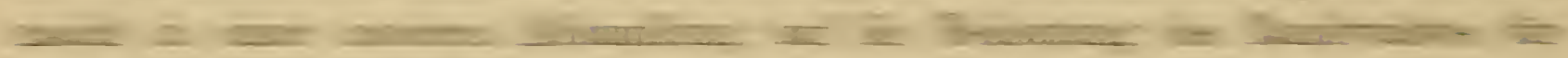

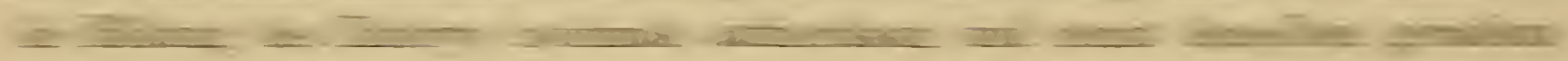

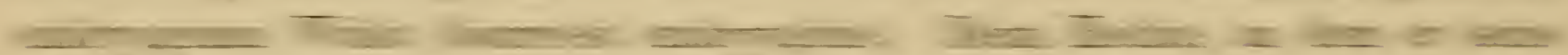

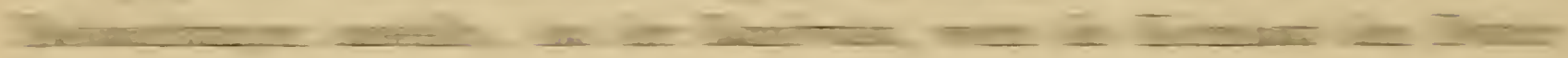

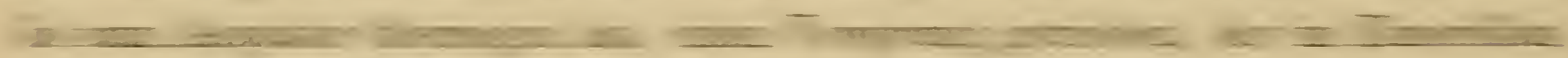

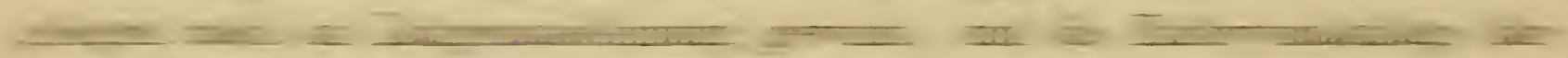

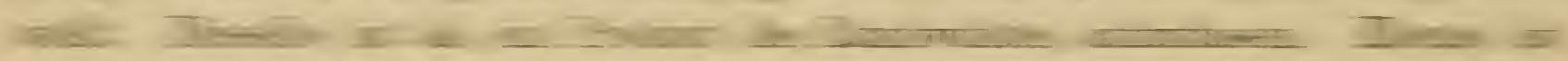

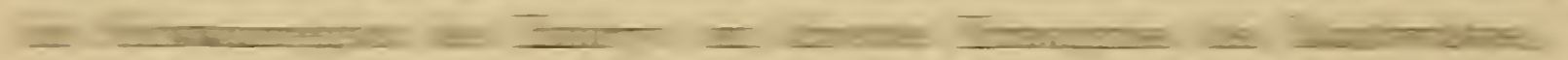

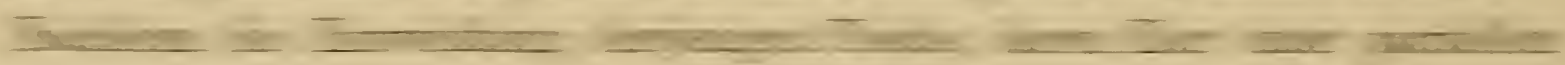

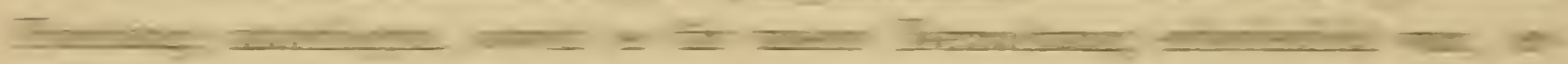

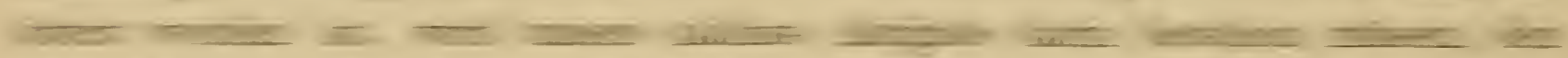
I $=0$

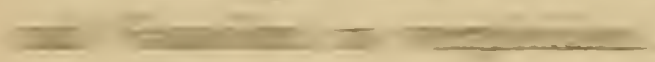

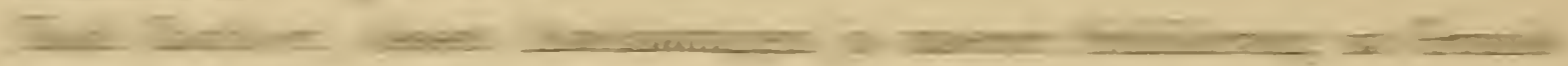

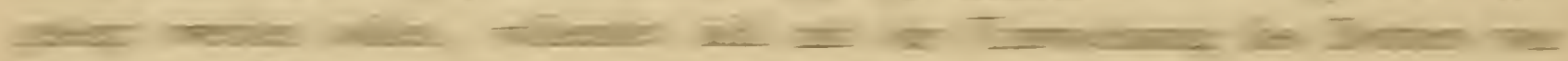

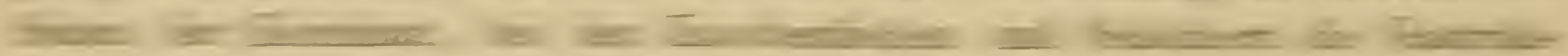

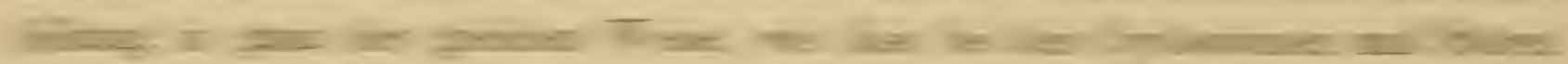

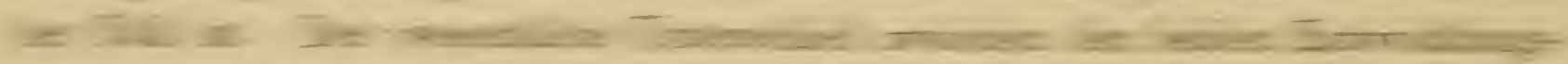

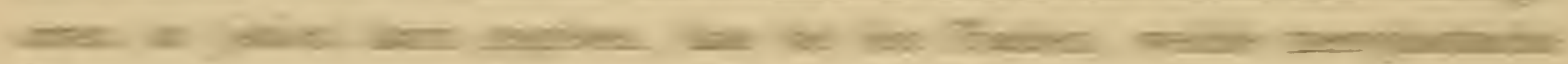

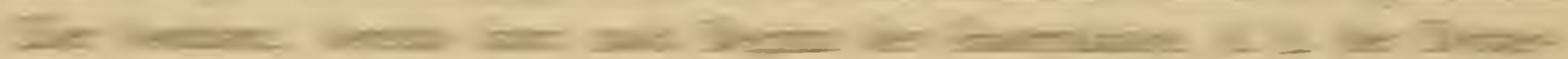

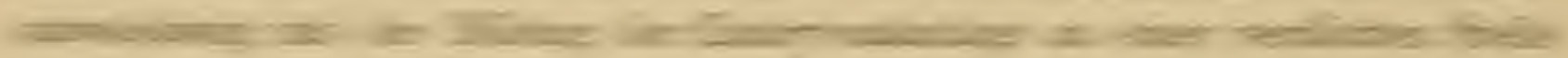
a

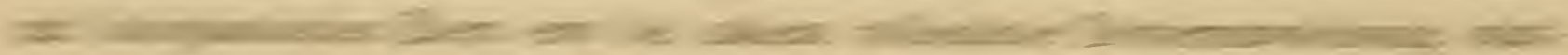

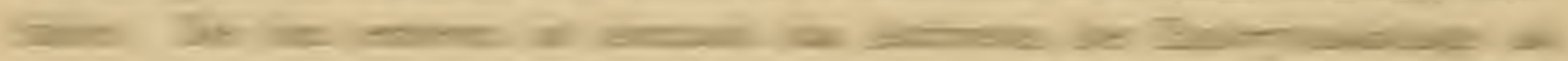

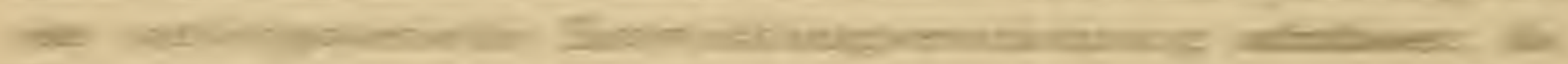

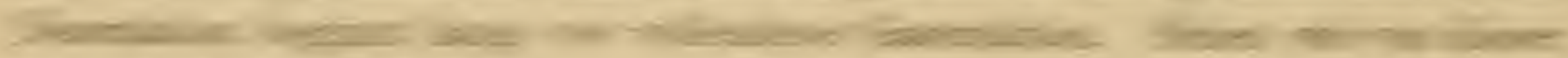

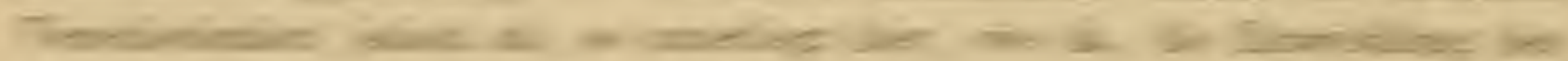

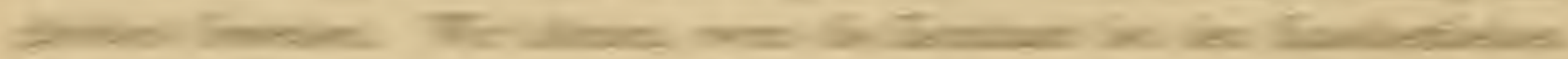

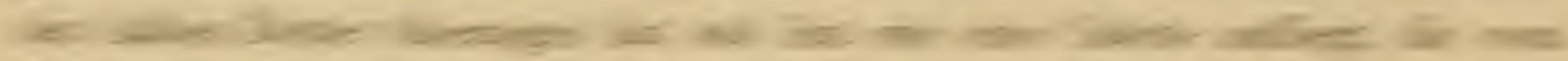

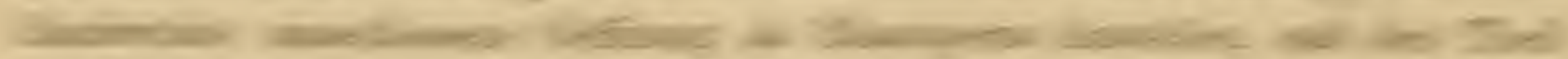

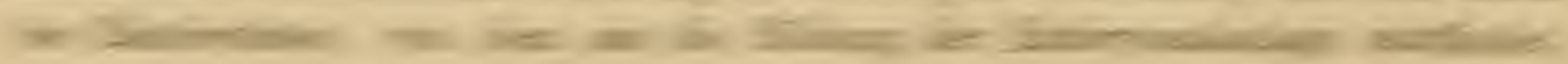

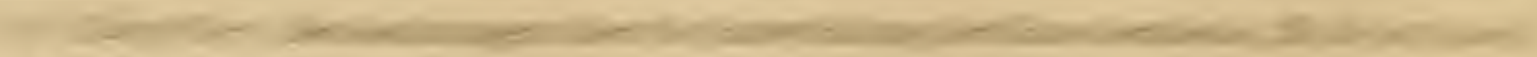

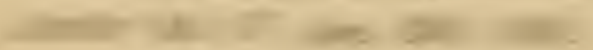

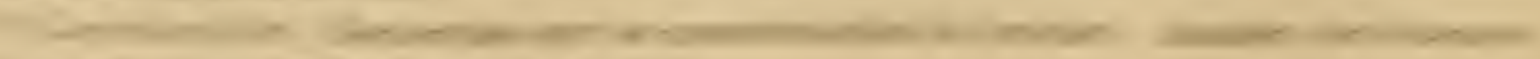

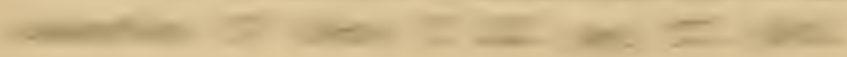




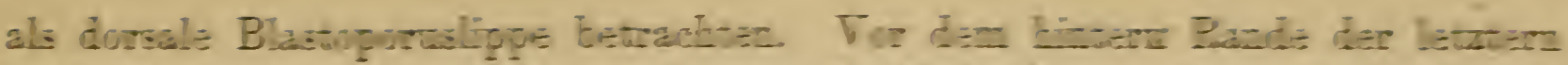

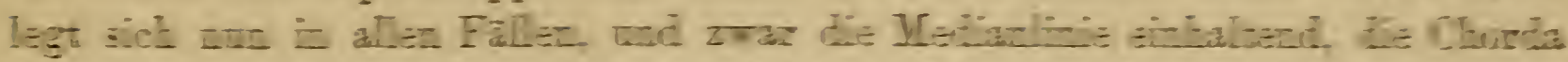

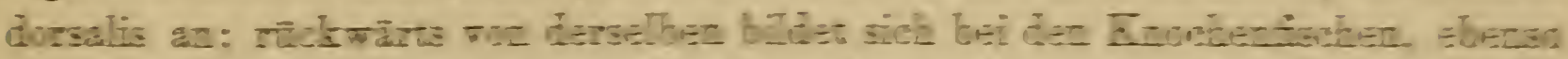

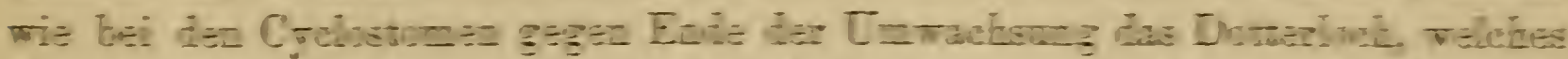

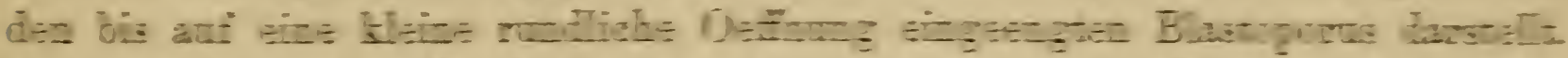

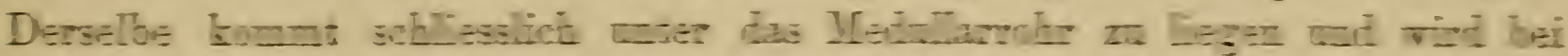
den Selschiem ztr Commuticatiust: rebr (Canalis netrenteriets).

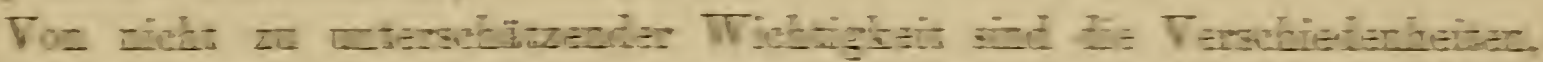

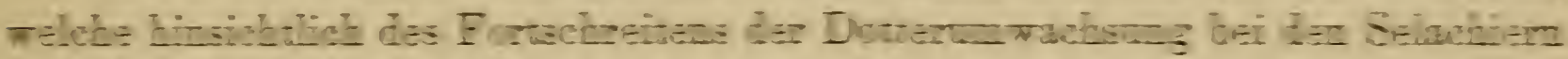

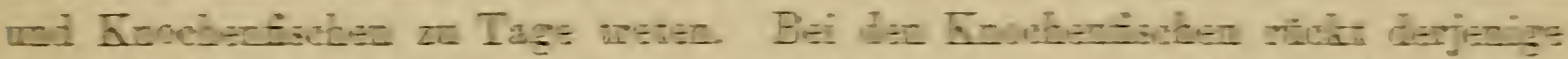

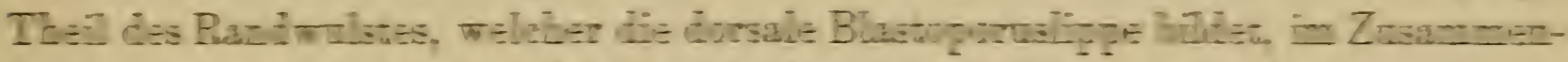

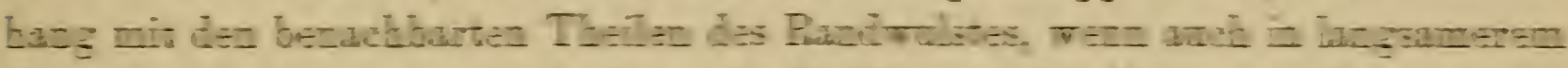

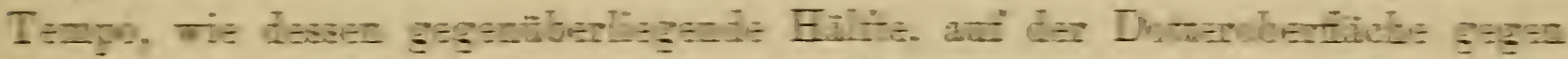

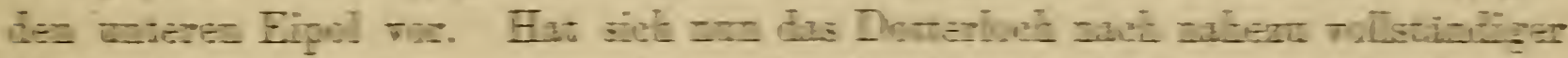

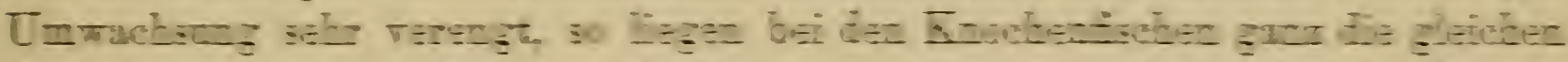

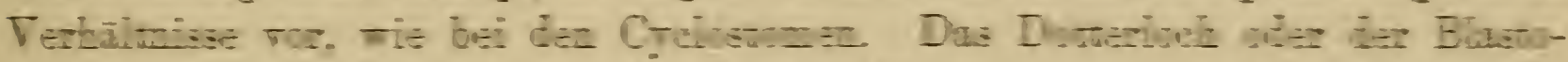

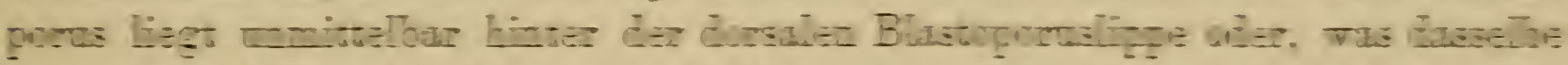

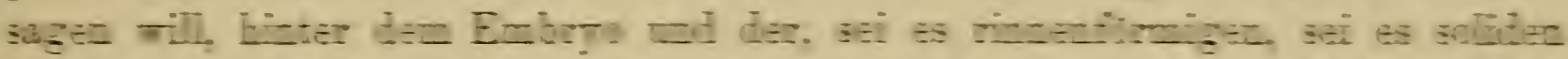

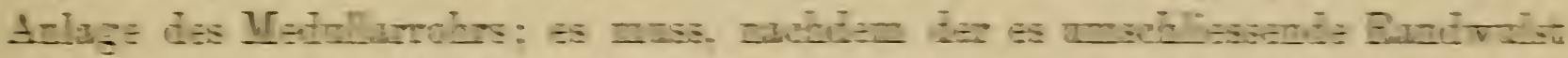

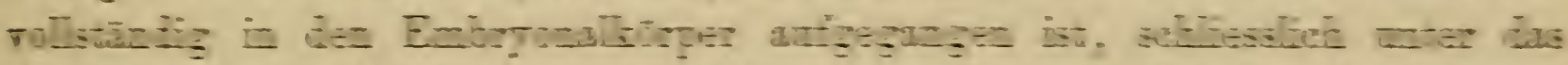

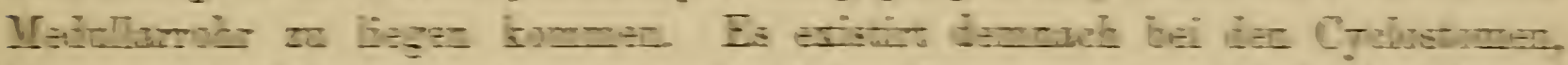

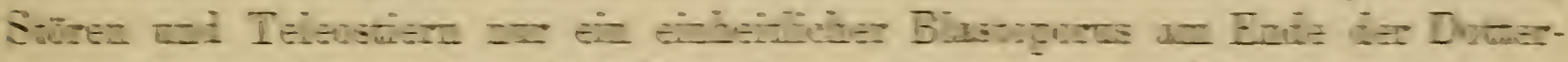

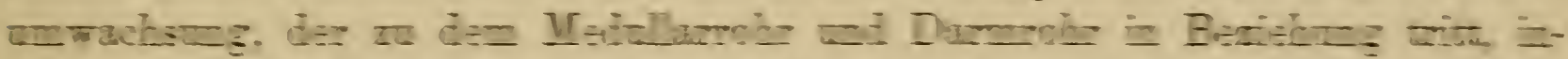

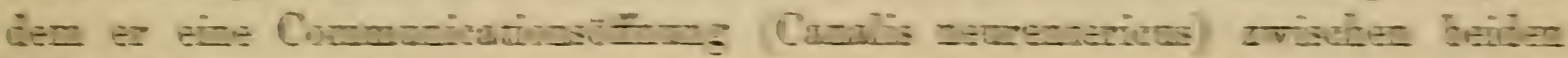
Bursteltit.

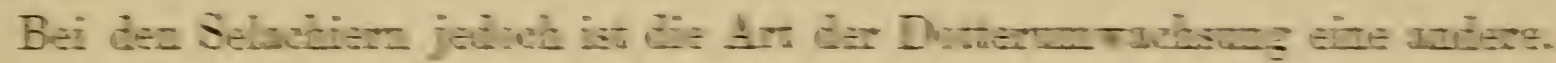

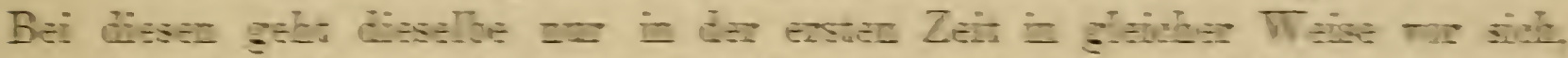

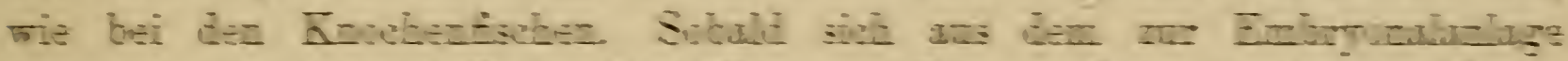

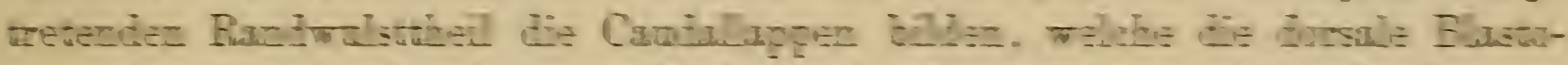

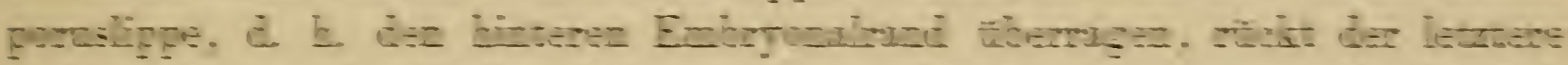

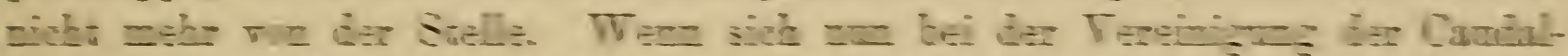

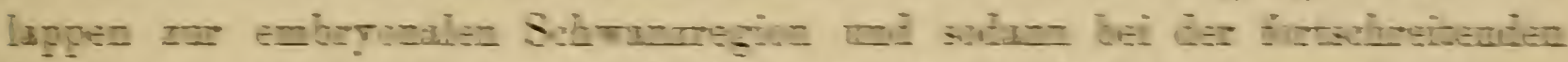

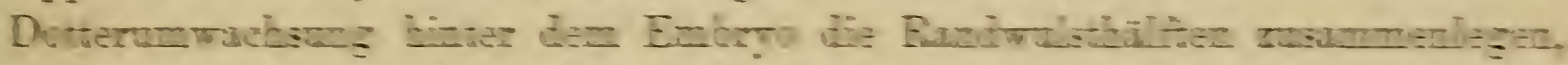

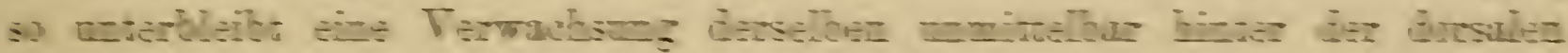

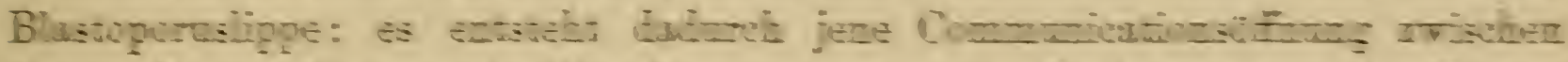

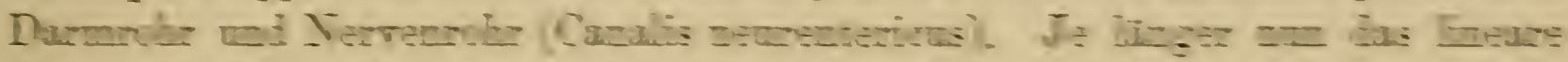

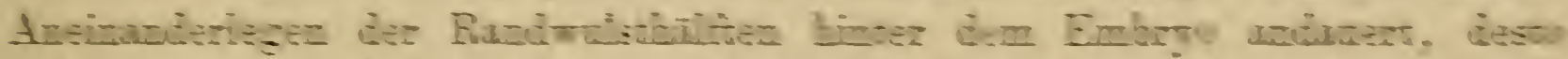

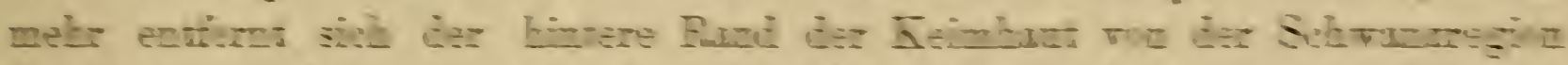

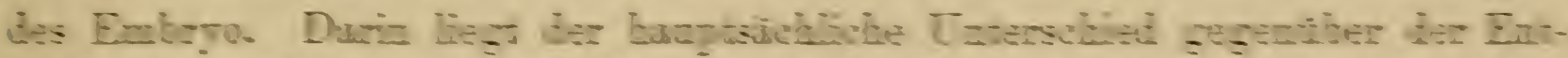

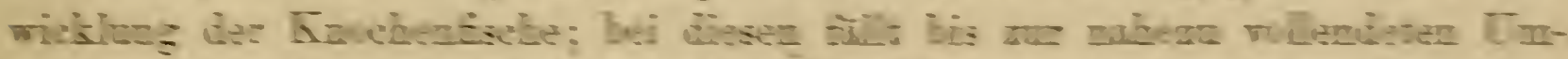

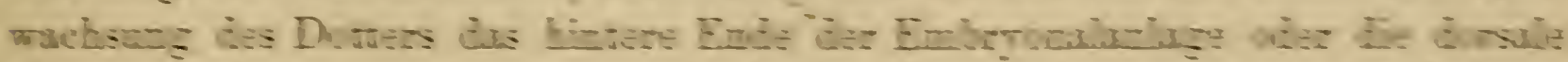

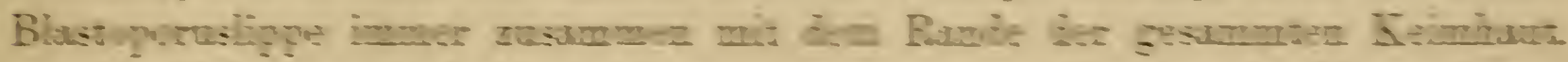

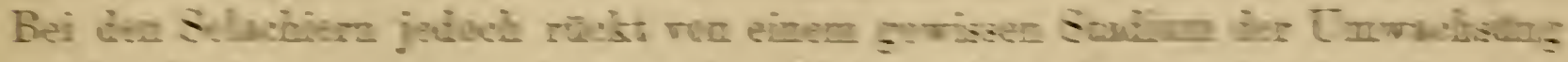

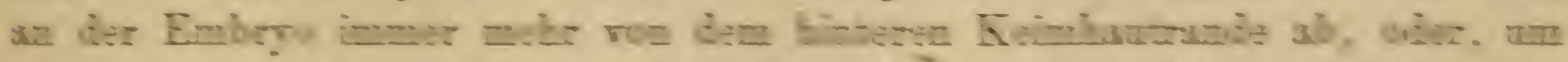

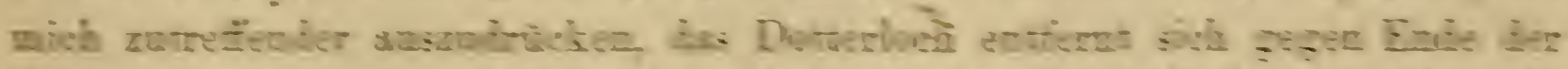

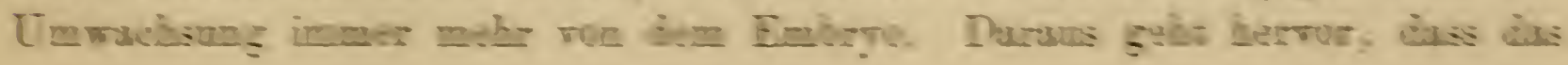


Dotterloch bei den Selachiern, wo es zu dem embryonalen Körper in keine Beziehungen tritt, nicht vollkommen homolog sein kann, dem Dotterloch der Teleostier, welches, wie wir wissen, mit in den Embryo eingezogen wird, unter dessen Medullarrohr es zu liegen kommt. Von einer Homologie kann nur so lange die Rede sein, als bei den Selachiern die dorsale Blastoporuslippe einen Theil der Umrandung des um diese Zeit noch sehr weiten Blastoporus bildete. Sobald nach Vereinigung der Caudallappen jene hinter der dorsalen Blastoporuslippe gelegene Communicationsöffnung zwischen Darm- und Nervenrohr (Canalis neurentericus) sich gebildet hat, ist die ursprüngliche Blastoporusöffnung in jene und in das Dotterloch zerfallen; mit andern Worten, es hat sich der Canalis neurentericus von der gemeinsamen grossen Oeffnung abgeschnürt, welche bisher von dem Ringwulste umrandet wurde. Demnach ist der Canalis neurentericus + dem Dotterloche bei den Selachiern homolog dem Blastoporus oder dem Dotterloche der Teleostier. Die berührten Verhältnisse sind desshalb von Bedeutung, weil sich das Verhalten des Blastoporus bei den Teleostiern eng anschliesst an die gleichen Entwicklungsvorgänge der Cyclostomen, während die Theilung des Blastoporus in den Canalis neurentericus und Dotterloch bei den Selachiern überleitet auf die hier in Betracht kommenden Entwicklungserscheinungen der Vögel.

Die Amphibien, deren erste Entwicklungsvorgänge ich noch zu schildern habe, besitzen holoplastische Eier, deren Furchung, wie bei den Cyclostomen inaequal vor sich geht. Hierauf folgt die Umwachsung der grossen Furchungselemente des Nahrungsdotters von Seiten der kleinen Furchungszellen, sowie die Bildung des Blastoporus ganz in der gleichen Weise, wie bei den Cyclostomen; auch die Differenzirung der Keimblätter, der Embryonalanlage, der Chorda findet nach den gleichen Entwicklungsgesetzen statt, so dass die Amphibien hinsichtlich der letztgenannten Entwicklungsvorgänge, wenn wir von untergeordneten Einzelheiten absehen, vollständig mit den Cyclostomen übereinstimmen.

Unter den neueren Arbeiten möchte ich das bekannte Werk Götte's ${ }^{1}$ ) über die Entwicklungsgeschichte der Unke hervorheben. Sehr schön lassen die trefflichen Abbildungen dieses verdienstvollen Autors die Beziehungen des Blastoporus zu dem Canalis neurentericus erkennen. Ferner möchte ich noch auf die Untersuchungen von Scott und Osborn ${ }^{2}$ ), sowie auf die von O. Hertwig ${ }^{3}$ ) hinweisen, welche beide die Entwicklung von Tritonen betreffen und die so ziemlich zu den gleichen Resultaten geführt haben. Die Entwicklung des Mesoderms, welche ich hier noch kurz anführen will, beginnt bei den Tritonen nach Hertwig schon in einer Zeit, in welcher die Ausbildung der Gastrula noch nicht ganz vollendet ist. „Sie nimmt ihren Ausgangspunkt allein von den Lippen des Blastoporus, von welchen aus sich linker- und rechterseits je eine kleinzellige Masse zwischen die beiden primüren Keimblïtter hineinschiebt, um sich von hier aus nach vorne und ventralwiirts ans-

1) A. Götte, Die Entwicklungsgeschichte der Unke. Leiprig 1875.

${ }^{2}$ ) W. B. Scott and H. F. Osborn, On the early developinent of the common Newt. Quart. Journ. of Micr. Science. Vol. XXIX, 1879.

3) O. II ertwig, Ueber die Entwicklung des mittleren Kcimblattes der Wirbelthiere. Sitzungsber. der Jenaischen Gesellschalt der Medic. u. Naturw. 1880, pag. 110. 
zudehnen. Am Mesoblast sind von Anfang an wenigstens 'zwei Lagen von Zellen, von welchen die eine an den Ektoblast, die andere an den Endoblast angrenzt, zu unterscheiden und als parietales und viscerales Blatt zu benennen." O. Hertwig gibt ferner an, dass das Mesoderm von Anfang an vollkommen paarig angelegt werde, indem in der Medianlinie sich zwischen die beiden Hälften Entodermzellen einschieben, aus denen die Chorda hervorgeht. Nachdem vorstehend die ersten Entwicklungserscheinungen bei den beiden niedersten Wirbelthierklassen, den Fischen und Amphibien, soweit es für unsere Zwecke nöthig war, erörtert worden sind, will ich nun zu der Genese der Doppelbildungen, wie sie von $\mathrm{R}$ a u ber für diese Thiere dargestellt wird, übergehen.

Unter den beiden Vertebratenclassen sind es fast ausschliesslich die Fische, von denen frühzeitige Mehrfachbildungen vorliegen, welche ja allein zur Erkenntniss der Genese derselben verwerthbar sind. Nur zwei Beobachtungen dieser Art sind meines Wissens bei Amphibien gemacht worden; die eine betrifft eine ältere, bereits der Metamorphose nahe Larve von Pelobates fuscus, welche von Bruch ${ }^{1}$ ) beschrieben worden ist; die andere eine Doppelbildung von Salamandra maculata, die von Spengel beobachtet und von Braun ${ }^{2}$ ) mitgetheilt worden ist.

Bei den Fischen dagegen sind Doppelbildungen viel häufiger; unter ihnen sind es wiederum die Knochenfische, bei denen die verschiedensten Arten der Doppelmonstra und zwar schon in den frühesten Entwicklungsstadien wahrgenommen wurden. Ausserdem sind einige vereinzelte Fälle von Doppelbildungen älterer Haifischembryonen oder neugeborener Haie bekannt geworden.

Das reichhaltigste Untersuchungsmaterial frühzeitiger Mehrfachbildungen von Knochenfischen (Hechten) stand Lereboullet zu Gebote, der in der oben citirten Abhandlung über dasselbe ausführlich berichtet. Die Resultate Lereboullet's haben zweifelsohne viel dazu beigetragen, dass Rauber zu der Theorie der Radiation hingeführt wurde; sie waren, wie R. selbst angibt ${ }^{3}$ ), grundlegend für die richtige Erkenntniss der bei der Genese von Doppelbildungen obwaltenden Entwicklungsvorgänge.

Die Untersuchungen Lereboullet's sind vor Allem desshalb so werthvoll, weil sie am lebenden Objecte angestellt wurden. Die Doppelmissbildungen wurden von frühen Entwicklungsstadien an beobachtet und die allmähligen Veränderungen, welche sie während ihrer Ausbildung bis zu ihrem Tode erlitten, auf das Sorgfältigste verfolgt. Man überblickt die Ergebnisse, zu denen Lereboullet gelangte, am besten aus seiner Zusammenstellung der verschiedenen Möglichkeiten, welche das Verhalten des Randwulstes und der Embryonalanlage darbieten kann ${ }^{4}$ ). Er schickt derselben eine kurze Schilderung der normalen Entwicklungsvorgänge voraus. Die erste Andeutung der Embryonalanlage nennt L. Embryonalstreifchen. Dasselbe erscheint im Anfang als eine kleine, gewöhnlich dreieckige Anschwellung des embryogenen Wulstes

1) Jenaische Zeitschrift Bd. VII, Heft 2.

2) Braun, Notiz über '/willingsbildungen bei Wirbelthieren. Würzburger Verhandlungen. N. F. Bd. IX, Heft 1 u. 2.

3) Theorien der excessiven Monstra: Virchow's Archiv Bd. 71, pag. 191.

4) 1. c. pag. 253 u. 254 . 
(Randwulst), die nach dem Eipole zu wächst, welcher der Oeffnung des Keimhautsackes gegenüber gelegen ist. Indem diese Anschwellung, welche ein Product des embryogenen Wulstęs ist, sich rasch verlängert, bildet sie sich in das Embryonalstreifchen um. Diese von dem embryogenen Wulste ausgehende Bildung kann nun verschiedene Anomalien aufweisen:

1) Es können statt einer zwei solcher Anschwellungen auftreten, welche bald nur sehr wenig, bald eine grössere Strecke weit von einander entfernt sein können. Jedes der von ihnen sich ableitenden beiden Embryonalstreifchen enthält eine besondere durchscheinende Furche (Rückenfurche) und in Folge eine besondere Chorda dorsalis.

Diese erste Anomalie zieht das Zustandekommen von Doppelmissbildungen nach sich, welche aus zwei Körpern bestehen, deren hintere Enden mit einander in wechselnder Ausdehnung vereinigt sind. In sehr früher Zeit kann nun bei ungleicher Entwicklung der eine der beiden Fischkörper verkümmern und schliesslich nur noch als eine Hervorragung dem Hauptkörper aufsitzen.

2) Der embryogene Wulst kann statt einer nur wenig verlängerten Anschwellung zwei hervorbringen, welche durchaus seitlich zusammenhängen; es entsteht so eine Lage von embryonaler Substanz, welche ein breites Embryonalstreifchen darstellt, das sehr bald zwei parallele Rinnen erkennen lässt; dieses gegenüber dem normalen Zustand ungemein breite Embryonalstreifchen hört nach vorne zu mit zwei Lappen auf.

Aus dieser Form der Anlage gehen Doppelmissbildungen mit zwei Köpfen hervor; letztere haben die Fähigkeit, sich zu einem gemeinsamen Kopfe zu vereinigen.

3) Der embryogene Wulst kann ausser einem breiten vorne zweilappigen Embryonalstreifchen, wie im Falle 2), noch eine weitere Anschwellung erzeugen, die zu einem Embryonalstreifchen auswächst. Das gleichzeitige Vorkommen dieser zwei Bildungen ist selten; es bedingt die Genese eines Embryo mit drei Köpfen.

4) Eine vierte Art von Anomalie in dem Verhalten des embryogenen Wulstes beruht darin, dass er selbst an der Bildung des Embryonalkörpers theilnehmen kann.

In diesem Falle entwickelt sich das Embryonalstreifehen nicht; man beobachtet an dem embryogenen Wulst nur eine sehr kurze Anschwellung von normaler Dicke, welche jedoch sich unverändert gleichbleibt, ohne auch nur die geringste Verlängerung zu erfahren. Alsdann ist es der embryogene Wulst selbst, in welchem die zum Aufbaue des embryonalen Körpers führenden Entwicklungsvorgänge ablaufen, und es entsteht ein Embryo, dessen Mittelkörper verdoppelt, dessen Kopf und Schwanz dagegen einfach ist.

5) Die von dem embryogenen Wulst erzeugte Embryonalanlage bleibt, statt sich in das Embryonalstreifchen umzubilden, kur\%, einem dümnen Faden ähnlich. Man sieht alsdann hieraus einen nur unvollstïndigen Embryo hervorgehen.

6) Der embryogene Wulst kann es endlich ganz und gar unterlassen, irgend eine Bildung hervorzubringen; er bleibt eine Zeit lang mverändert, dann verengert sich die von ihm umschlossene Oeffinung und schliesst sich grinzlich; es bildet sich eine vorspringende Anschwellung, bestehend aus 
einer Substanzanhäufung, aus der vormals der embryogéne Wulst sich zusammensetzte.

Diese letzte Anomalie hat die Genese zungenförmiger Embryonalkörper zur Folge, welche wohl den Schwanz der Fische repräsentiren.

Das unter 5) und 6) angegebene Verhalten des Randwulstes führt zur Bildung von Monstrositäten, bei denen gewisse Körpertheile nicht zur Entwicklung gelangen. Für die Genese der Doppelbildungen kommen nur die vier ersten Arten von Anomalien des Randwulstes in Frage. Unter diesen ist es die unter 4). angeführte, bei welcher ich noch kurz verweilen möchte, da aus derselben die höchst interessanten scheinbaren Doppelmissbildungen, bei denen die Verdoppelung den mittleren Körpertheil betrifft, sich ableiten. Der Körper dieser Monstrositäten besteht aus zwei sich vorn zum Kopfe, hinten zum Schwanze vereinigenden Armen, welche einen elliptischen mehr oder weniger überdeckten Theil der Dotteroberfläche zwischen sich fassen. Die beiden Arme jedoch bilden keineswegs vollständige Körpertheile, sondern sie repräsentiren nur je eine Seitenhälfte des normalen Körpers. Jeder der beiden Arme nämlich besteht nur aus einer einfachen Reihe von Urwirbeln, enthält jedoch ausserdem noch einen nervösen Strang, sowie eine Chorda. Es haben in Folge dessen die beiden Arme das Aussehen, als ob sie aus der Längstheilung eines einfachen Embryo in zwei symmetrische Seitenhälften hervorgegangen wären. Bei mehreren Fällen dieser Missbildung machte L. die Bemerkung, dass der eine der beiden Arme nach und nach verschwand, indem seine Substanz sich vertheilte und resorbirt wurde.

Die in Rede stehenden Doppelbildungen kommen nun nach L., wie bereits angedeutet, in der Weise zu Stande, dass die von dem embryogenen Wulst stammende Embryonalanlage anormal kurz bleibe und nur die Kopfregion aus sich hervorgehen lasse, während der Wulst selbst eine beträchtliche Dicke, eine grosse Reichhaltigkeit organisationsfähiger Materie darbietet. So kann jede Wulsthälfte, welche sich ja der einheitlichen Kopfregion anfügt, die einer embryonalen Seitenhälfte zukommenden Gebilde, wie die Urwirbel, die eine Hälfte des Nervenstranges; der Chorda, in sich erzeugen. Die aus dem embryogenen Randwulste entstandenen symmetrischen Seitenhälften würden, wenn sie nicht durch die zwischen ihnen befindliche Distanz getrennt wären, einen normalen einheitlichen Körper zusammensetzen. Daraus folgt, dass in diesen Fällen die verdoppelten Körper in der mittleren Embryonalregion in Wirklichkeit nur Körperhälften darstellen. Die Genese dieses Zustandes resümirt $\mathrm{L}$. in folgender Weise:

${ }_{n}$ Ainsi en resumé dans la monstruosité, qui nous occupe, le botrrelet embryogène ne donne naissance qui à la région céphalique, mais il se transforme lui-même pour constituer le corps embryonnaire et ce corps est composé de deux moitiés à cause de la forme annulaire du bourrelet générateur."

Wenden wir uns nun nach Erörterung der Untersuchungen Le reboull et's zu den die Entwicklung der Mehrfachbildungen behandelnden Auseinandersetzungen Rauber's. Soweit dieselben auf die Knochenfische Bezug haben, lässt sich meines Erachtens gegen die ungemein klare und allseitig befriedigende Darstellung dieses Autors kein irgend erheblicher Einwand erbringen. Es wird stets ein unbestreitbares Verdienst Rauber's bleiben, die bis zu den 
Arbeiten Lereboullet's noch vollkommen dunkle und durch die vielen Controversen dem Verständnisse noch mehr entrïckte Bildungsgeschichte der Doppelmonstra für die Knochenfische in einer Weise aufgeklärt zu haben, welche allen Anforderungen der modernen Embryologie entspricht.

Im Gegensatz zu Lereboullet, der in dem Randwulst das den Embryo erzeugende Organ erblickt, indem derselbe sowohl das Embryonalstreifchen, welches zu dem Haupttheile des Embryonalkörpers sich entwickle, als auch nach der Dotterumwachsung die Schwanzregion producire, fasst $R$ auber den Randwulst als die Embryonalanlage selbst auf. Nach ihm geht die ringförmige Embryonalanlage in der Weise in die Axentheile des Embryo über, dass die randständigen Ringhälften zu zwei parallelen Streifen mit vorderem und hinterem Schlussbogen in mehr verdeckter Weise sich zusammenschliessen. Es enthält demnach der Randwulst das Bildungsmaterial für den Embryo, dessen Umlagerung mit der Dotterumwachsung einhergeht. Hat sich als ein Vorstoss des Randwulstes die vordere Embryonalanlage eingestellt, so wird dieselbe durch die von hinten her successive zu ihr tretenden Randwulsthälften appositionell zur totalen nun linear angeordneten Embryonalanlage ergänzt. Es entsteht daher die letztere durch das Zusammenschliessen der Randwulsthälften auf cunjunctivem Wege. Das Auftreten einer dorsalen Längsrinne braucht jedoch nicht immer sofort mit der Conjunction der beiden Randwulsthälften stattzufinden, sondern es kann dieselbe erst nach vollzogener Conjunction sichtbar werden, da, wie Rauber bemerkt, der Anschluss der beiden Keimstreifen auf mehr verdeckte Weise unter Ausbildung einer Randknospe u. s. w. vor sich gehe ${ }^{1}$ ). Dieser Bemerkung Rauber's entnehme ich, dass er das Zusammenlegen der beiden Keimstreifen, i. e. Randwulsthälften nicht in rein figürlichem Sinne aufgefasst haben will, denn bei der Aneinanderlagerung zweier rundlicher Wülste muss es nothwendiger Weise zwischen ihnen zu einer rinnenförmigen Einsenkung kommen. Es scheint mir vielmehr daraus geschlossen werden zu dürfen, dass nur ein àllmähliges Eintreten der Zellsubstanz des Keimrings in die embryonalen Längshälften von $\mathrm{R}$ auber unter dem Begriff der Conjunction verstanden wird, eine Auffassung, die ich vollständig theile. Aus diesem Grunde scheint es mir aber zweckmässig, den Randwulst noch nicht Embryonalanlage zu nennen, sondern diese Bezeichnung erst dann auf den sich entwickelnden Organismus anzuwenden, wenn derselbe bereits eine lineare Axe erkennen lïsst.

Das von $R$ a u b er für die Genese der Mehrfachbildungen aufgestellte Gesetz ist bereits im Eingarige dieses Capitels kurz angeführt worden. Dasselbe hat Rauber in der folgenden Weise formulirt: „Wie normal die vordere Embryonalanlage als ein Vorstoss des Keimringes auftritt, so gelangen bei Mehrfachbildungen mehrfache solche Vorstösse zur Ausbildung." Diese Fassung bezieht sich jedoch, wie Rauber, um nicht missverstanden zu werden, hervorhebt, auf die Lage der bereits aufgetretenen vorderen Embryonalanlage an und in ihrem Zusammenhange mit dem Keimringe oder Randwulst, an welchem sie gewissermassen Vorsprünge, Vorstösse bilden und somit keineswegs auf die Genese dieses /ustandes; denn hiebei müsse ja in Anbetracht

1) Rauber, Primitivstreifen und Neurula pag. 57. 
des nur appositionellen Zuwachses, den die vorderen Embryonalanlagen von rückwärts her Seitens der Randwulsthälften erhalten, in Wirklichkeit eher an das Umgekehrte eines Vorstosses gedacht werden. Was die Zahl der vorderen Embryonalanlagen betrifft, die einem gemeinsamen Randwulst angehören können, so sind deren zwei relativ häufig, drei nur selten, mehr als drei überhaupt noch nicht zur Beobachtung gelangt. Ihre Entfernung von einander kann, wie schon Lereboullet betonte, eine sehr verschiedene sein. Liegen sie ganz nahe neben einander, so können sie seitlich zusammenhängen. Liegen sie dagegen so weit von einander, dass sie sich gegenseitig nicht stören, so müssen nothwendiger Weise ihre Längsaxen mit Eimeridianen zusammenfallen, wäh. rend sie im ersteren Falle meist mit ihren vorderen Enden divergiren. Die meridiane Einstellung der entfernter von einander gelegenen involvirt zugleich, dass dieselben auf Keimring und Urmund senkrecht stehen. Der Einstellungswinkel zweier vorderer Embryonalanlagen wird von Rauber durch die nach Längengraden auf der Peripherie des Keimrings bemessene Zwischendistanz der beiden peripheren Enden der Embryonalanlagen ausgedrückt. Der Einstellungswinkel kann nun ein sehr verschiedener sein; er kann bis auf $180^{\circ}$ sich steigern, in welchem Falle zwei opponirte Anlagen sich gegenüberstehen.

Die weitere Ausbildung einer doppelten vorderen Embryonalanlage sucht Rauber mit Hülfe von schematischen Zeichnungen klar zu machen, welche verschiedene Entwicklungsstadien einer Doppelbildung bei Knochenfischen wiedergeben ${ }^{1}$ ). Copien dieser Abbildungen habe ich in Fig. 7, Taf. VII, angefertigt. Die vorderen Embryonalanlagen haben bei der ersten dieser Figuren am Keimringe einen Einstellungswinkel von etwa $90^{\circ}$; sie theilen den Keimring in ein kleineres Stück, das also in unserem Falle $90^{\circ}$ besitzt, und in ein grösseres Stück ab, dessen Umfang dem entsprechend $270^{\circ}$ beträgt. Die kleinere Abtheilung des Keimrings nennt Rauber innere Zwischenstrecke, die grössere äussere Zwischenstrecke.

Wie bei der Bildung eines Einzelembryo, so wird auch hier die vordere Embryonalanlage durch die Conjunction der angrenzenden Keimringbezirke, welche successive von rückwärts her zum Embryonalkörper treten, zur totalen Embryonalanlage vervollständigt. Es werden demnach bei unserer Doppelbildung die beiden Zwischenstrecken zur Vervollständigung des Embryo allmählig aufgebraucht werden. Dies wird bei der innern Zwischenstrecke sehr bald wegen ihrer nur geringen Ausdehnung geschehen sein; dieselbe ist zur Hälfte in die eine, zur Hälfte in die andere Embryonalanlage übergegangen. Dabei mussten nothwendiger Weise die beiden anfänglich entfernteren Embryonalanlagen mit ihrer zunehmenden Vervollständigung sich immer `näher rücken, und schliesslich liegen ihre hinteren Enden, wenn die innere Zwischenstrecke gänzlich aufgebraucht ist, dicht neben einander (Fig. 7 B, Taf. VII). $\mathrm{Zu}$ gleicher Zeit hat sich auch die Axenstellung der beiden Anlagen geändert; während dieselben Anfangs convergirten, divergiren sie nun unter einem nach vorne offenen Winkel. Wie die beiden Hälften der inneren Zwischenstrecke, so haben auch gleich lange Theile der äusseren Z Zwischentrecke zur Verlïngerung der beiden Anlagen mitgeholfen. Sind nun-die letzteren mit ihren hin-

1) Primitivstreifen und Neurula pag. 73. 
teren Enden zusammengetreten, so können nur noch die restirenden Theile der äussern Zwischenstrecke den Aufbau des Körpers vollenden, der naturgemäss von nun an einfach sich, anlegen muss (Fig. 7 C, Taf. VII). Es hat sich demnach in der beschriebenen Weise eine Duplicitas anterior ausgebildet, und es ist einleuchtend, dass dieselbe um so hochgradiger sein wird, je länger die innere Zwischenstrecke, d. h. je grösser der Einstellungswinkel der vorderen Embryonalanlagen ursprünglich gewesen ist.

Die Bildung einer mit drei Köpfen versehenen Missbildung, welche durch das Auftreten von drei vorderen Embryonalanlagen eingeleitet wird, lässt sich nach dem Vorstehenden leicht construiren. Eine im Stadium der vorderen Embryonalanlage befindliche Mehrfachbildung dieser Art hat $\mathrm{R}$ au ber bei der Forelle beobachtet.

Den geschilderten Entstehungsmodus vermochte Rauber an frühen Stadien einer Duplicitas anterior von Lachsen und Salmlingen, welche ihm in relativ grosser Zahl zu Gebote standen, direct nachzuweisen ${ }^{1}$ ). Von Interesse sind ferner seine Angaben über die Entwicklung derjenigen Mehrfachbildungen, deren vordere Embryonalanlagen Anfangs einen Einstellungswinkel von $180^{\circ}$ besassen, sich also in Oppositionsstellung befanden. Einen derartigen Fall hatte Rauber bei dem Lachse und zwar in einem sehr frühen Stadium zu beobachten Gelegenheit. Bei dieser Anordnung der beiden Embryonalanlagen wird bei der Dotterumwachsung und der Vervollständigung der Embryonalkörper die gegenseitige Stellung der letzteren unverändert bleiben müssen. Da nämlich die innere und äussere Zwischenstrecke des Keimrings gleich lang sind, so wird hinter beiden Embryonalanlagen die Conjunction der zugehörigen Keimringbezirke bis zur Zeit des herannahenden Verschlusses des Dotterloches ungestört vor sich gehen können. Den normalen Entwicklungsvorgängen nach sollte man erwarten, dass bei dem Verschluss des Dotterloches, da beide Embryonen an demselben participiren, die letzteren sich zu einem gemeinsamen mittleren Leibesstiick, das an seinen äussersten Enden je einen Kopf trüge, vereinigen würden. Dies tritt jedoch nach Rauber's Erfahrungen nicht ein; sondern es lösen sich, bevor der letzte Rest des Dotterlochs sich geschlossen hat, die hintern Enden beider Embryonalanlagen vom Keimringe los, wobei natürlich an keine Continuitaitsunterbrechung zu denken ist, sondern nur an eine Differenzirung der hinteren Leibesenden vom Reste des Keimrings. Derselbe rückt dann hinter beiden Embryonen weiter, zwischen welchen sich endlich das Dotterloch schliesst. Auf diese Weise sind zwei vollständige Embryonalanlagen zu Stande gekommen, welche centralwïrts den gemeinsamen Nahrungsdotter zwischen sich fassen. Bald wachsen die hintern Leibesenden rasch in die Länge, und es entsteht ein Doppelfischchen, das einen Gastrodidymus darstellt.

Das Zustandekommen einer Duplicitas posterior bietet nach R a u ber eine grosse Analogie dar mit der Genese einer vorderen Verdoppelung. Bei einer Einfachbildung geht nach vollendeter Dotterumwachsung aus dem Schlussstiick des Keimringes der hintere Rumpftheil und mit ihm der Schwanz hervor. Wie die vordere Embryonalanlage als ein Vorstoss des Keimrings nach der

') Formbildung und Formstörung. Morphol. Jahrb. Bd. VI, pag. 130. 
Mitte der Keimhaut zu betrachten ist, so erscheint die Ausbildung des hinteren Körpertheils als ein Vorstoss nach rückwärts über das Ei hinaus; jedoch kommt im Gegensatz zu der Verlängerung des vorderen Embryonalkörpers, die durch Conjunction des Keimrings erfolgt, die rasche Verlängerung des hinteren Körperendes durch ein mächtiges intussusceptionelles Wachsthum zu Stande. In seltenen Fällen nun entwickelt sich das hintere Schlussstück des Keimringes statt nach einer, nach zwei oder selbst nach drei Richtungen hin, so dass hieraus eine doppelte oder dreifache Anlage des hinteren Leibesendes bei einheitlichem übrigem Körper resultirt.

Im Anschluss an die zur Genese einer vorderen oder hinteren Verdoppelung führenden Entwicklungsanomalien möchte ich eine, wie es scheint, nicht so sehr seltene Abweichung von der normalen Entwicklung besprechen, welche $\mathrm{zu}$ einer scheinbaren Duplicität führt, die aber auch mit einer wirklichen Verdoppelung sich combiniren kann. Es handelt sich um jene abnormen Entwicklungsprocesse, welche die Bildung einer Monstrosität einleiten, die bei einfachem Kopf- und Schwanzende in den mittleren Körpertheilen doppelt zu sein scheint. Diese Missbildungen sind, wie wir wissen, nach Ler eboullet's Ansicht die Folge einer mangelhaften Ausbildung der Embryonalanlage, aus der nur der Kopf hervorgehe, während in diesen Fällen stellvertretend die beiden Randwulsthälften die Bildung des Mittelkörpers besorgen sollen. In anderer Weise stellt Rauber die Bildungsgeschichte dieser Monstrositäten, welche er Hemididymi nennt, dar. Seine Beweisführung stützt sich auf die Beobachtung frühzeitiger Stadien dieser Missbildungen und es dürfte im Hinblick auf die von ihm abgebildeten Fälle ${ }^{1}$ ) wohl kaum mehr einem Zweifel unterworfen sein, dass die von ihm hinsichtlich der Entwicklung der Hemididymi vertretene Auffassung die allein richtige ist.

Die Hemididymi sind für $\mathrm{R}$ a u ber Hemmungsbildungen. Während in der Norm die Rumpfanlage des Embryo durch Conjunction zweier ursprünglich von einander abliegender Keimringbezirke entsteht, treten diese zuweilen bei der Dotterumwachsung in Folge irgend eines Hindernisses nicht zusammen; es unterbleibt ihre Conjunction; dessungeachtet schreitet in den beiden Keimringhälften die innere Differenzirung ununterbrochen fort. Jede Hälfte wird je eine halbe Chorda, eine Seitenhälfte des Markes, eine Urwirbelreihe zur Ausbildung bringen. Die beiden Hälften lassen nun, je nachdem sie mehr oder minder weit sich genähert haben, nach vollendeter Dotterumwachsung einen verschieden grossen Raum zwischen sich, in dem das Dotterloch gelegen sein muss; der hintere Körperabschnitt kann dagegen, weil er aus dęm hinteren Schlussstücke des Keimringes sich entwickelt, einfach sich gestalten. Mehrfach ist aùch bei Hemididymis eine hintere Verdoppelung beobachtet worden (Oellacher, Lereboullet), so dass es den Anschein gewinnt, als ob gerade die mangelhafte Conjunction ein prädisponirendes Moment für die Entwicklung von zwei besonderen hinteren Körperenden bildet.

Während demnach die unvollkommene Vereinigung der beiden Randwulsthälften eine Duplicitas posterior im Gefolge hảben kann, so scheint auf der anderen Seite die erstere wiederum durch eine vordere Verdoppelung ver-

1) Formbildung und Formstörung. Morphol. Jahrb. Bd. V, Fig. 19-24. 
anlasst werden zu können. Nach Rauber's Beobachtungen kann es nach dem Auftreten von zwei vorderen Embryonalanlagen, wenn dieselben nach dem Verbrauch der inneren Zwischenstrecke des Randwulstes mit einander sich vereinigt haben, leicht sich ereignen, dass der unmittelbare weitere Anschluss der äussern Zwischenstrecke zur Bildung eines gemeinschaftlichen Körpertheiles eine Hemmung erleidet. „In Folge solcher zeitlicher Hemmungen nun wird das Wachsthum der äusseren Zwischenstrecke des Randwulstes ebensowenig sistirt, als die Differenzirung innerhalb der Substanz derselben; beide Processe laufen ununterbrochen fort; es wird der Anschluss und die Vereinigung der beiden Hälften der Zwischenstrecke nur verzögert. Jede Hälfte wird darum vor ihrer Vereinigung mit der entsprechenden anderen Hälfte eine halbe Chorda, eine Seitenhälfte des Markes, ja schliesslich auch des Darmes u. s. w. zur Ausbildung bringen. Wenn die Hemmung genügend lange dauert, so wird ganz dieselbe Erscheinungsreihe zu Tage treten, welche wir bei der Bildung der sogenannten Meso- oder Hemididymi kennen gelernt haben, so dass die Gegenwart einer Doppelbildung als eine der Ursachen der Hemididymi betrachtet werden kann. Eine solche Bildung würde alsdann als Anahemididymus zu bezeichnen sein. Dauert die Hemmung kürzere Zeit, erfolgt der Anschluss der beiden Hälften der äusseren Zwischenstrecke an den Doppelkörper mit geringerer Verzögerung, so werden die Spuren der Hemididymi in dem gemeinschaftlichen Leibestheil im geringeren Grade sich ausprägen, der Anschein einer den ganzen Körper einnehmenden Verdoppelung wird alsdann geringer sein. Er wird sich stärker oder schwächer ausgeprägt auf längere oder kürzere Strecken in dem gemeinschaftlichen Leibestheil vorfinden müssen, je nachdem die Hemmung des Anschlusses eine längere oder kürzere Zeit danerte $\left.{ }^{1}\right) .^{\text {" }}$

Die Hemididymi habe ich jedoch nicht nur desshalb etwas eingehender behandelt, weil sie zu der Entwicklung von Doppelbildungen gewisse Beziehungen aufweisen können, sondern auch aus einem anderen Grunde. Man hat nämlich gerade die Hemididymi als ein Argument für die Richtigkeit sowohl der Verwachsungstheorie als der Spaltungstheorie des Oefteren hingestellt. So hat Panum ${ }^{2}$ ) die Beobachtung Lereboullet's, der bei einem Hemididymus eine schliessliche Vereinigung der getrennten mittleren Körpertheile eintreten sah, wodurch ein äusserlich einfaches Fischchen entstand, für die Verwachsungstheorie zu verwerthen gesucht, hat aber dabei unterlassen, zu bemerken, dass schon L e r eb o ul let die getrennten mittleren Körpertheile nur als die Seitenhälften einer einfachen Embryonalanlage aufgefasst hat. Damit ist schon zur Genüge dargethan, dass es sich in den betreffenden Fällen nicht um eine durch Verwachsung erreichte Vereinfachung früher doppelter Körpertheile handeln kann. Durch die Untersuchungen Rauber's ist eine Verwerthung der Hemididymi zu Gunsten der Verwachsung und Ineinsbildung vollends unmöglich gemacht worden.

Auf der anderen Seite wurden die an den in Rede stehenden Missbildungen angestellten Untersuchungen Oellacher's zur Bekräftigung der

1) Rauber, Theorien der excessiven Monstra. Virchow's Archiv Bd. 71, pag. 201.

$\left.{ }^{2}\right)$ P a num, Beitrïge zur Kenntniss der physiologischen Bedeutung der angebornen 
Spaltungstheorie angeführt ${ }^{1}$ ). Oella cher hatte nämlich bei Salmen mehrere dieser Missbildungen, die er Mesodidymi nennt, zu beobachten Gelegenheit und hat dieselben einer eingehenden Prüfung unterzogen ${ }^{2}$ ). Er fand in allen seinen Fällen nahe der Stelle, wo die völlige Spaltung des Embryo aufhört, oder wo die Wiedervereinigung der Hälften des Centralnervensystems beginnt, zwischen diesen letzteren eine eigenthümliche grosszellige, geschwulstartige Masse, welche dem Sinnesblatte angehört; an der gleichen Stelle tritt eine stumpfe Hervorragung des Dotters, hervor. Oellacher spricht nun die Vermuthung aus, dass an dem bezeichneten Orte die Dottermasse den Keim von unten her durchbrochen und ihn in grösserer oder geringerer Ausdehnung gespalten habe. Durch diese Annahme sucht Oellacher den Umstand zu erklären, dass die beiden gespaltenen Theile in den meisten Fällen ungleich seien und dass die Chorda in der einen Embryonalhälfte oft innerhalb gewisser Strecken oder auch ganz fehle.

Seit nun Rauber, der die Entstehungsweise der Terata mesodidyma schrittweise verfolgt hat, den Nachweis erbrachte, dass diese keineswegs secundäre Spaltbildungen darstellen, sondern dass der Spalt bereits primär in Folge von Nichtvereinigung vorhanden ist, erhalten auch-die Angaben Oellacher's über das Vorkommen jener stumpfen Hervorragung des Dotters eine gewisse Bedeutung; denn es ist äusserst wahrscheinlich, dass eben diese Eigenthümlichkeit des Dotters das Hinderniss für die normale Conjunction der Randwulsthälften gebildet haben mag.

Fassen wir daher das über die Terata hemididyma Gesagte kurz zusammen, so ergibt sich Folgendes. Dieselben beruhen auf einer nur scheinbaren Verdoppelung der mittleren Körperregion, die für sich allein bestehen, oder mit wirklicher Doppelbildung combinirt auftreten kann. Die Terata hemididyma sind weder durch Spaltung entstanden, noch kann, falls bei ihrer weiteren Entwicklung die getrennten Theile sich vereinigen, von einer Ineinsbildung die Rede sein, sondern die schliessliche Vereinigung ist als eine Verspätung normaler Entwicklungsvorgänge zu betrachten.

Vorstehend ist die Entstehungsweise der Mehrfachbildungen, wie sie von Rauber für die Knochenfische auf Grund eines zahlreichen Beobachtungsmaterials festgestellt worden ist, in den wesentlichsten Punkten auseinandergesetzt worden. Wie wir gesehen haben, lassen sich mit Hülfe der Radiationstheorie Rauber's sämmtliche Doppelbildungen der Knochenfische entwicklungsgeschichtlich in durchaus befriedigender und ansprechender Weise erklären. Rauber hat nun seine Theorie auf alle Wirbelthierclassen ausgedehnt. Da unter den Anamnia nur bei den Knochenfischen, unter den Amnioten nur bei den Vögeln frühzeitige Doppelmissbildungen angetroffen worden sind, so haben die Rauber'schen Ausführungen für die übrigen Classen und Ordnungen der Wirbelthiere einstweilen nur einen theoretischen Werth, da man ja bei dem vollständigen Mangel an beobachteten Fällen nicht im Stande ist, zuं

1) Siehe Ahlfeld, Beiträge zur Lehre von den \%willingen 1. c. pag. 250.

$\left.{ }^{2}\right)$ Oellacher, Terata mesodidyma von Salmo Salvelinus. Wiener Sitzungsber. Bd. 68, 1873, pag. 299. 
prüfen, ob das Rauber'sche Gesetz auch für die genannten Thiere Geltung hat. Was die Anamnia anbetrifft, so scheinen sich mir für sämmtliche Repräsentanten derselben die Anschauungen Rauber's sehr gut durchführen zu lassen, da sie die normale Entwicklungsgeschichte berücksichtigen und sich von dieser Seite gegen das Gesetz der Radiation kein besonderer Einwand erheben lässt. Dass bei den Selachiern, deren erste Entwicklungsvorgänge mit denen der Knochenfische die grösste Uebereinstimmung zeigen, auch die Genese der Mehrfachbildungen in gleicher Weise sich vollziehen wird, darf wohl mit grosser Wahrscheinlichkeit angenommen werden. Etwas anders liegen die Verhältnisse bei denjenigen Anamnia, deren Eier holoplastisch sind, den Cyclostomen, den Ganoiden und den Amphibien. Doch hat auch bei ihnen der Randwulst der 'Teleostier und Selachier sein Homologon und es ist bereits oben berichtet worden, dass Rauber den gewulsteten Theil der Blastoporusränder, von dem aus die Embryonalanlage sich bildet, bei den Cyclostomen geradezu als Keimring bezeichnet hat. Dass von diesem aus auch eine mehrfache Embryonalanlage ausgehen resp. ein mehrfacher Vorstoss stattfinden könne, ist ganz gut denkbar; auch darin gebe ich Rauber vollständig Recht, wenn er bemerkt, dass wegen der Beschaffenheit des Keimringes für zwei Embryonalanlagen der Platz sehr beschränkt ist, wesshalb dieselben, wenn sie auch angelegt werden, nicht gut eine fortgeschrittenere Entwicklungsstufe erreichen könnten ${ }^{1}$ ).

Auch auf die Amnioten darf die Rauber'sche Theorie meines Erachtens unbedenklich übertragen werden; jedoch reicht dieselbe, worauf später noch zurückzukommen ist, nicht zur Erklärung sämmtlicher Formen von Doppelmissbildungen aus.

Unter den Amnioten ist es, wie wir wissen, die Classe der Vögel, bei denen wegen der verhältnissmässig zahlreichen Beobachtungen frühzeitiger Doppelembryonen der Entwicklungsmodus der Mehrfachbildungen am genauesten sich verfolgen lässt. Wie bei den Knochenfischen, so ist auch bei den Vögeln nur an der Hand der normalen Entwicklungsgeschichte ein Verständniss für die Genese der Doppelmonstra zu gewinnen.

Die normale Ontogenie der Vögel wird daher den Ausgangspunkt für unsere Betrachtungen bilden müssen und wir werden zu prüfen haben, ob auf sie das Gesetz der Radiation angewendet werden darf. Wie Rauber, so komme auch ich zu dem Resultate, dass diese Frage zu bejahen sei; wir sind daher im Prinzipe einig; jedoch weichen unsere Ansichten bezüglich des Zustandekommens der Radiation weit von einander ab. R a uber huldigt der Auffassung, wonach auch bei den Vögeln die radienförmig angeordneten Embryonalanlagen, wie bei den Knochenfischen, hauptsächlich von rückwärts her Seitens des Keimrings ergänzt und vervollständigt würden, während meiner Meinung nach die Embryonalanlagen in die Area pellucida centralwärts vordringen und einwachsen, demnach als wirkliche centripetal gerichtete Vorstösse der Area opaca oder des Ringgebietes auftreten, welche, wenn sie eine gewisse Ausbildung erlangt haben, sich von den letzteren vollstiandig abtrennen und ganz in die Area pellucida zu liegen kommen.

') Rauber, Primitivstreifen und Neurula pag. 72. 
Wie man sieht, beruhen die Differenzen zwischen uns auf einer verschiedenen Auffassung der normalen Embryogenese. Ich glaube am besten den Unterschied der beiderseitigen Anschauungen klar machen zu können, wenn ich meiner in einem früheren Capitel dieses Buches gegebenen Darstellung der normalen Entwicklung des Hühnchens in den ersten Stadien eine kurze Beschreibung Rauber's über den gleichen Gegenstand gegenüberstelle. Dieselbe findet sich in der jüngsten die Genese von Missbildungen behandelnden Arbeit Rauber's ${ }^{1}$ ). „Im Besonderen verhalten sich die verschiedenen Theile der totalen Embryonalanlage des Hühnchens folgendermassen: Die vordere Embryonalanlage ist gegeben durch den der Area lucida angehörigen d. i. den primären Theil des Primitivstreifens; hierzu kommt die erst etwąs später deutlich hervortretende Apophysis cephalica (Kopffortsatz) desselben. Letztere deutet nicht die ganze Kopfanlage an; der hintere Abschnitt des Kopfes vom Gehörlabyrinth rückwärts gehört dem Vordergebiet des Primitivstreifens an. Der secundäre Theil des Primitivstreifens entwickelt sich aus der Substanz des Keimrings (der Area opaca) des Hühnchens und stellt den Haupttheil der mittleren und hinteren Embryonalanlage dar."

R a uber lässt demnach aus dem Primitivstreifen fast den ganzen Embryo sich entwickeln, mit Ausnahme des vor dem Gehörlabyrinth gelegenen Kopftheiles, der aus dem Kopffortsatz des Primitivstreifens hervorgehen soll. Nach meinen Erfahrungen entsteht jedoch der Haupttheil des Embryo vor dem Primitivstreifen, von dem nur ein Stück mit in den Embryonalbezirk einbezogen wird; der Kopffortsatz, welcher später in die Chorda dorsalis übergeht, tritt erst auf, wenn der Primitivstreifen vollständig ausgebildet ist und auch sein hinteres vorher im Bereich des Keimrings liegendes Ende der Area pellucida einverleibt ist. Dieses kann entweder an den Keimring noch eine Zeit lang angrenzen - in diesem Falle war das Zuwachsstück, das die Area pellucida erhielt, nicht sehr gross - oder es kann, wenn das Zuwachsstück das hintere Ende des Primitivstreifens nach rückwärts überragte, gänzlich von dem Keimringe abrücken. Häufig habe ich Primitivstreifen vorgefunden, welche dieses Verhalten zeigten, ohne dass vor ihnen auch nur eine Spur von einem Kopffortsatz bemerkbar gewesen wäre; der letztere tritt immer erst nach vollendeter Ausbildung des Primitivstreifens auf. Schon aus diesem Grunde kann ich die Ansicht Rauber's nicht theilen, wonach der Kopffortsatz bereits sich bilden soll, während der Primitivstreifen, der durch fortwährende vom Keimring abgegebene Substanzanlagerung nach rückwärts appositionell wachsen soll - Rauber nennt dies Wachsthum durch Association - noch in voller Ausbildung begriffen ist. Diese Darstellung der Bildung der Embryonalanlage beruht auf einer Verkennung der zeitlichen Aufeinanderfolge, welche zwischen der Vollendung des Primitivstreifens und der Anlage des Kopffortsatzes besteht.

Nach meiner in dem entwicklungsgeschichtlichen Abschnitte gegebenen Beschreibung eines Hühnerembryo vom Ende des ersten Tags der Bebrütung . (Fig. 7, Taf. I) ist in dieser Entwicklungszeit, in der bereits der Schluss des Medullarrohrs begonnen, ferner eine Anzahl von Jrwirbeln sich gebildet hat,

1) Formbildung und Formstörung. Morph. Jahrb. Bd. VI, pag. 41. 
noch deutlich der Primitivstreifen als hinterster Theil der gesammten Embryonalanlage zu "erkennen. Es war mir von Interesse, zu erfahren, wie Rauber sich mit dieser Thatsache, welche, doch deutlich zeigt, dass vor dem Primitivstreifen der Haupttheil der Embryonalanlage auftritt, abfindet. Hierüber fand ich in der Beschreibung $\mathrm{R}$ a u b er's, welche die von ihm beobachtete Drillingsbildung betrifft (Fig. 10, Taf. VI), die gewünschte Auskunft. Bei sämmtlichen drei Embryonalanlagen dieser Mehrfachbildung sieht man in der zugehörigen Zeichnung sehr deutlich Primitivstreifen und Primitivrinnen wiedergegeben, welche das hintere Ende der Embryonen ausmachen. Rauber bemerkt nun über dieselben das Folgende: „Man würde sich also irren, wenn man glauben wollte, die in Fig. 1 wahrnehmbaren Primitivstreifen und Primitivrinnen (pr) seien die ursprünglichen Primitivstreifen. Sie sind es weder in ihrem vorderen noch in ihrem hinteren Theile. Ihr vorderer Theil ist, wie gesagt, von den Medullarrändern bereits umfasst und als solcher darum nicht mehr wahrnehmbar. Ihr hinterer Theil aber ist neu gebildet, ein Product des Keimrings, dem ursprünglichen Primitivstreifen durch allmähliche Association beigefügt, wie ich dies Verhältniss bei anderer Gelegenheit ausführlich auseinandergesetzt und abgebildet habe $\left.{ }^{1}\right) .{ }^{4}$

Aus diesen Worten lässt sich die ganze Auffassung Rauber's über die Entwicklung der Embryonalanlage leicht herauslesen. Als Vorstoss des Keimrings erscheint in der Area pellucida der Primitivstreifen als „ vordere Embryonalanlage." Bald hat sich vor derselben der Kopffortsatz (der nach Rauber keine besondere Länge erreichen kann) ausgebildet; der Primitivstreifen selbst verlängert sich durch fortwährende Association nach rückwärts, während er in seinen vorderen Theilen successive sich in die Abschnitte des Embryonalkörpers umbildet, welche durch eine Medullarrinne und Medullarwülste sich kennzeichnen. Auch dieser Vorgang schreitet nach hinten zu fort und geht demnach parallel dem nach rückwärts gerichteten associativen Längenwachsthum des Primitivstreifens. Auf diese Weise entsteht allmählig die.mittlere und hintere Embryonalanlage. Gleichzeitig mit deren Bildung hat sich entsprechend der fortwährenden Verlängerung der Embryonalanlage nach hinten zu auch die Area pellucida nach rückwärts ausgedehnt. Schliesslich überholt jedoch deren Ausdehnung nach Beendigung des associativen Wachsthums des Primitivstreifens das hintere Ende desselben, und der Embryo gelangt gänzlich in die Area pellucida herein.

Vergleicht man diese Auffassung der ersten Bildungsvorgänge des Hühnchens mit meinen früheren, den gleichen Gegenstand betreffenden Ausführungen, so muss sofort ein bedeutsamer Unterschied zwischen beiden auffallen. Rauber nimmt bei der Bildung der Embryonalanlage nur ein durch den Kopffortsatz vermitteltes unbeträchtliches Wachsthum nach vorne an, indem er sich für ein weit überwiegendes Längenwachsthum nach rückwärts ansspricht. Nach meiner Ansicht ist bis zur Vollendung der Rückenfurche ein Längenwachsthum nach hinten absolut zu negiren; die Verlängerung der Embryonalanlage findet einzig und allein nach vorne hin statt. Hinsichtlich

1) Rauber, Gibt es Stockbildungen bei den Vertebraten? Morph. Jahrb. Bd. V, pag. 174. 
der Formveränderung der Area pellucida während der Ausbildung der Fruchtanlage lässt $\mathrm{R}$ auber die Vergrösserung derselben ausschliesslich nach rückwärts erfolgen, während ich der Meinung bin, dass die Area pellucida, nachdem ihrem hinteren Bezirke das Zuwachsstück sich eingefügt hat, ausschliesslich nach vorne hin sich ausbreitet.

Die von Rauber und mir vertretenen Auffassungen, zwischen denen, wie man sieht, keine sonderliche Uebereinstimmung herrscht, weichen wiederum von der Auffassung anderer Forscher, welche über die Entwicklung des Hühnchens gearbeitet haben, merklich ab. Wenn man bedenkt, dass das hierzu nöthige Untersuchungsmaterial verhältnissmässig leicht zu beschaffen ist, so muss es höchst wunderbar erscheinen, dass bei den einzelnen Autoren eine so verschiedene Beurtheilung der gleichen entwicklungsgeschichtlichen Bilder Platz greifen konnte. Die Schuld an dieser auffallenden Erscheinung tragen einerseits die grossen technischen Schwierigkeiten, mit welchen embryologische Untersuchungen verknüpft sind, andererseits aber möchte ich auch noch auf einige weitere hier in Betracht zu ziehende Momente hinweisen.

Eine richtige Auffassung ontogenetischer Vorgänge wird man nur dann gewinnen können, wenn man über eine Serie von Entwicklungsstadien verfügt, von denen ein jedes von dem vorhergehenden Stadium nur durch ein minimales Zeitintervall getrennt ist. Ist zwischen zwei aufeinanderfolgenden Stadien dieses Zeitintervall zu gross, d. h. fehlen die zwischen beiden liegenden Zwischenstadien, so wird an das Combinationsvermögen des Beobachters eine grössere Aufgabe gestellt, da derselbe genöthigt ist, sich die Zwischenstadien selbst zu construiren, um so die vorhandenen Lücken geistig auszufüllen. Dass hiebei leicht Fehlschlüsse gemacht werden können, die dann ihrerseits wieder weitere Irrungen nach sich ziehen, liegt auf der Hand. Ausserdem kommen, wie von vielen Embryologen übereinstimmend angegeben wird, ungemein häufig individuelle Verschiedenheiten der Entwicklung vor. Hat man desshalb unter seinen Präparaten das gleiche Stadium nur einmal vertreten, so kann man durch eine zufällige Anomalie desselben leicht irregeführt werden; hat man dagegen mehrere Präparate von dem gleichen Stadium vor sich liegen, so wird man unschwer aus denselben die der betreffenden Entwicklungszeit zukommende normale Gestaltung des Embryo herausfinden können.

Um mich von den angedeuteten Irrwegen möglichst fernzuhalten, habe ich meine Untersuchungen über die Entwicklung des Hühnchens damit begonnen, mir eine grosse Anzahl von Keimbäuten, welche den verschiedensten Entwicklungsstadien der ersten zwei Brütetage angehören, zu verschaffen. Dies nahm mehrere Monate und viele Mühe in Anspruch; allein ich gelangte dadurch in den Besitz von mehreren hunderten sorgfältigst gehärteter Keimhäute. Ein solcher Vorrath bringt den grossen Vortheil mit sich, dass man die einzelnen Entwicklungsstadien in mehreren Exemplaren zur Verfügung hat, und dieselben theils zur Herstellung von Dauerpräparaten für das Studium. von Flächenbildern, theils zur Anfertigung von Schnittserien in verschiedenen Richtungen verwenden kann.

Eine weitere Veranlassung zu einer irrthümlichen Beurtheilung von Entwicklungserscheinungen liegt nicht an dem unzureichenden Untersuchungs- 
material, sondern an dem Beobachter selbst. In unserer gerade auf entwicklungsgeschichtlichem Gebiete so theorienreichen Zeit wird jeder Autor, der einer bestimmten Theorie anhängt, selbst bei dem Bestreben, ohne alle Voreingenommenheit an eine neue embryologische Untersuchung heranzutreten, bei der Deutung der erhaltenen Bilder von seiner Theorie nicht unbeeinflusst bleiben können, was wiederum sehr leicht dazu führen kann, dass späterhin auch die Schilderung der betreffenden Entwicklungsvorgänge, ohne dass sich dessen der Autor bewusst ist, nicht ganz objectiv gehalten sein wird. Hiefür Belege aus der Literatur anzuführen, dürfte nicht schwer fallen. Es ist dies eine nicht zu verkennende Schattenseite der gegenwärtig herrschenden comparativen Behandlung der Entwicklungsgeschichte, welche allerdings gegenüber den grossartigen Erfolgen, derer sich diese Methode der Forschung zu erfreuen hat, kaum in das Gewicht fällt. Jedoch ist ohne allen Zweifel die vergleichende Embryologie vielfach in der Weise betrieben worden, dass man die bei einer Thierclasse als richtig erkannten Entwicklungserscheinungen auch auf andere Thierclassen übertragen hat, ohne dass bei letzteren eine allzu sorgfältige Prüfung der bezüglichen Entwicklungsstadien vorausgegangen wäre. Dass derartige Verallgemeinerungen leicht auf Abwege führen, ist einleuchtend. Denselben sind diejenigen Embryologen ganz besonders ausgesetzt, welche gleichzeitig oder kurz nach einander die Ontogenese verschiedener Thierclassen bearbeiten.

Vorstehend habe ich die wesentlichen Ursachen kurz berührt, welche hauptsächlich den mannichfachen Differenzen und Dissonanzen unserer heutigen Embryologen meines Erachtens zu Grunde liegen. Ich kehre nach dieser kleinen Excursion zu dem Ausgangspuncte dieser Erörterungen zu der Entwicklung der Embryonalanlage des Hühnchens zurück. Die hierüber aufgestellten Ansichten des Genaueren mitzutheilen, sie gegen einander abzuwägen und auf ihren Werth und ihre Wahrscheinlichkeit hin zu prüfen, würde für unsere Betrachtungen von nur geringem Belange sein.

Für unsere Zwecke kommt allein die Auffassung Rauber's in Betracht, welche bereits oben des Näheren auseinandergesetzt wurde. Um jedoch die Radiationstheorie in dem Umfange, wie sie von ihrem Begründer aufgestellt worden ist, vollständig übersehen und würdigen zu können, genügt es nicht, nur von der Ansicht R'auber's über den Entwicklungsmodus der Embryonalanlage des Hühnchens Kenntniss zu nehmen, sondern man wird auch zu untersuchen haben, wie Rauber zu jener Auffassung gelangte und wie er dieselbe begründet. 'Tritt uns die letztere für sich allein und unvermittelt entgegen, so wird sie uns seltsam und befremdlich erscheinen müssen, da sie den thatsächlichen Entwicklungsvorgängen, wonach, wie ein Blick auf die Fig. 4, 5, 6 und 7, Taf. I lehrt, der Haupttheil des Embryos sich vor dem Primitivstreifen anlegt, keineswegs entspricht. Wenn wir uns jedoch in den ganzen Gedankengang Rauber's hineinversetzen, so werden uns die Ausführungen dieses Autors in ganz anderem Lichte erscheinen; wir werden, wenn wir auch nicht in jeder Hinsicht, so namentlich nicht in Bezug auf den von ihm vertretenen Entwicklungsmodus des Hühnerembryo seinen Ansichten beistimmen können, doch ein volles Verständniss für dieselben gewinnen, ja ihnen uns in vielen Puncten direct anschliessen können. 
Der Schwerpunct der Ra uber'schen Untersuchungen liegt, soweit sie die höheren Wirbelthiere betreffen, in dem Bestreben, den Nachweis zu führen, dass der Urmund der Wirbelthiergastrula zu der Primitivrinne, die Substanzränder des Urmunds zum Primitivstreifen genetisch in Beziehung zu bringen seien. Da, wie wir wissen, nach $\mathrm{R}$ a ub er der Primitivstreifen der Vögel von vorne nach hinten zu successive in die mit einer Medullarrinne und Medullarwülsten versehenen Embryonaltheile sich umbildet, so wird demgemäss von ihm kein strenger Unterschied zwischen Primitivrinne und Medullarrinne gemacht. Für Rauber geht die Primitivrinne nach vorne, sobald die Medullarrinne anfängt, sich zu bilden, continuirlich in diese über. Daraus ist zugleich ersichtlich, dass $R$. den Primitivstreifen und die Primitivrinne nicht als eine nur den höheren Vertebratenclassen eigenthümliche Bildung auffasst, wie dies in neuerer Zeit mehr und mehr anerkannt und durchgeführt wird, sondern auch bei Fischen und Amphibien von einer Primitivrinne spricht, bei welchen natürlich dieser Begriff sich vollkommen mit dem zuerst auftretenden Theile der Medullarrinne deckt. In Bezug auf die Nomenclatur sei noch bemerkt, dass Rauber sehr häufig für Gastrulamund oder Blastoporus den Ausdruck „Urmund", „Blastostoma“ oder „Keimpforte" gebraucht.

Den Beweis für die Genese der Primitivrinhe der Vögel aus dem Urmund, sowie des Primitivstreifens aus den Urmundrändern sucht $\mathrm{R}$. mit Hülfe der vergleichenden Embryologie zu führen. Er geht dabei aus von den Angaben Kowalewsky's über die Entwicklung der Ascidien und des Amphioxus, welcher zu dem Ergebniss gelangte, dass bei den genannten Thieren die Medullarrinne eine Fortsetzung der (bei der Gastrulabildung stattgefundenen) Entodermeinstülpung auf dem embryonalen Rücken sei; Rauber führt hierüber aus der Arbeit Kowalewsky's das folgende Citat an: „Meine neuen Studien (über die Ascidien) ergaben mir, dass die Einstülpungsöffnung sich auf den Rücken des Eies begibt und die sich um dieselbe bildende Rinne zur Rückenrinne sich schliesst; aus der durch Einstülpung gebildeten Zellenschícht entsteht das Darmrohr und aus der auf den Rücken sich ziehenden Fortsetzung derselben das Nerven- oder Sinnesrohr. - Beim Amphioxus geht die Einstülpungsöffnung auch auf den Rücken über und die sie umgebenden Ränder schmelzen mit den Rändern der Rückenrinne zusammen, so dass ein unmittelbarer Zusammenhang zwischen dem Darmdrüsenblattrohre und dem Nervenrohre entsteht, was von mir auch bei den Plagiostomen und dem Frosche gefunden wurde, und sich auch für die Accipenseriden als richtig erwies $\left.{ }^{1}\right) .{ }^{\text {" }}$

Rauber sucht nun darzuthun, dass der von Kow alew sky für Ascidien und Amphioxus aufgedeckte Entwicklungsplan bei allen Wirbelthierclassen sich nachweisen lasse; nur die Säugethiere machen davon eine Ausnahme.

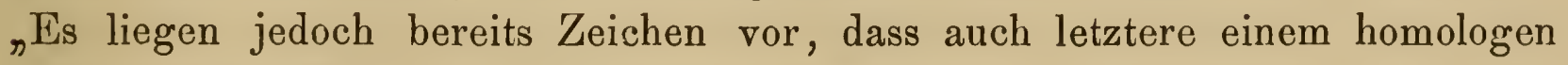
Plane folgen $\left.{ }^{2}\right) .{ }^{\text {" }}$

Was die Amphibien anlangt, so steht bei ihnen die Primitivrinne und mit ihr die Embryonalanlage in directer Verbindung mit dem Urmund, der Rusconi'schen Oeffnung; die Urmundränder gehen in die Medullarwülste

$\left.{ }^{1}\right)$ Kowalewsky, Embryologische Studien an Würmern und Arthropoden. 1871. pag. 29 u. 30.

2) Primitivrinne und Urmund 1. c. pag. 571 . 
über. Die gleichen Verhältnisse liegen bei den Cyclostomen und den Ganoiden vor. An die genannten Thierclassen, deren Eier holoplastisch sind, schliessen sich unter den Thieren mit meroplastischen Eiern zunächst die Knochenfische an; auch bei ihnen tritt die Rückenfurche und Embryonalanlage unmittelbar vor dem Blastoporus auf, der in die erstere mit einbezogen wird, indem seine Ränder in die Rückenwülste sich fortsetzen. Mit den Knochenfischen stimmen wieder, wie die Untersuchungen Balfour's gezeigt haben, die Selachier in Bezug auf die Randstellung der Embryonalanlage, die Primitivstreifen- und Rückenfurchenbildung in hohem Grade überein. Nur dauert bei den Knochenfischen die Randstellung der Embryonalanlage bis zur völligen Dotterumwachsung an, indem die sich schliessenden Urmundränder stets mit dem hinteren Körperende in Verbindung bleiben, während dagegen bei den Selachiern sich das hintere Ende des Körpers von den Urmundrändern ablöst, lange bevor der Schluss des Urmunds vollzogen ist. Eine auffallende Aehnlichkeit zeigt mit den Selachiern, was die Randstellung der Embryonalanlage und deren spätere Loslösung vom Rande betrifft, das Hühnchen.

Ehe ich jedoch auseinandersetze, dass auch die Vögel im Sinne Rau ber's einem homologen Entwicklungsgange folgen, muss ich erst kurz die Bildung des Primitivstreifens und des Mesoderma, wie sie von $R$. angegeben wird, schildern. Ich beziehe mich hiebei auf die in der $\mathrm{R}$ auber'schen Abhandlung ${ }_{\text {PPrimitivstreifen und Neurula }}{ }^{*}$ enthaltenen Angaben, welches in manchen Dingen von den in einer früheren Schrift (Primitivrinne und Urmund) gemachten Angaben abweichen.

Nach R. kann man bereits die Keimscheibe des frisch gelegten und befruchteten Hühnereies als Gastrula auffassen. Ihre Ränder umfassen den Urmund; die aus einer dünnen Mittelscheibe (Area pellucida) und dem verdickten Keimring (Area opaca) bestehende Keimhaut zeigt im hinteren Abschnitt der ersteren ein an den Keimring angrenzendes schildförmiges Feld, die Lunula entodermatica. Vor der Lunula liegt die Antilunula, welche beide zusammen die Area pellucida constituiren. Was die Zusammensetzung der Keimscheibe betrifft, so besteht dieselbe aus der Zellenlage des Ektoderms und aus dem primären Entoderm, welches im Bereiche der Antilunula nur dünn ist, aus netzförmig zusammenhängenden Zellenhaufen sich bildet, im Bereiche der Lunula eine mehrschichtige Zellenlage darstellt, die in den verdickten Randwulsttheil des Entoderms, der im Bereich des Keimrings liegt, nach hinten unmittelbar übergeht ${ }^{1}$ ). Die Lunula entodermatica, welche sich auf Kosten der Antilunula in den ersten Brütestunden vergrössert, ist ein Vorläufer des Primitivstreifens. Derselbe entsteht im Gebiete der Lunula dadurch, dass von beiden Seiten her die obern Zellenlagen des primären Entoderm sich gegen die Lüngsaxe zusammenschieben und hier einen medianen und nach dem alsbald erfolgenden Auftreten der Primitivrinne bilateralen Strang bilden. Damit ist zugleich die erste Mesodermanlage gegeben; die untere Zellenlage des

1) Rauber versteht unter Keimring des Hühnchens: Randwulst (dem primären Entoderm zugehörig) + bedeckentes Ektoderm. Die Lunula mit dem an sie angrenzenden Theile des Keimringes kann nach der Auffassung von Ra ub er mit der verdickten und verbreiterten Stelle des Keimringes der Knochenfische und der Selachier homologisirt werden, aus welcher die Embryonalanlage hervorgeht. 
primären wird zum secundären Entoderm. Ist die Primitivrinne aufgetreten, so erfolgt längs derselben eine innige Vereinigung des Ektoderm mit dem mesodermalen Zellenstrange des Primitivstreifens. Auch in dem hinter dem Primitivstreifen liegenden Theil der Keimhaut, d. h. in der Area opaca, stellt sich eine Differenzirung der dem primären Entoderm zugehörigen Randwulstzellen in Mesoderm und in secundäres Entoderm ein; diese Vorgänge finden in derselben Weise statt, wie in der Lunula und schliessen sich diesen unmittelbar an, so dass der Primitivstreifen nach hinten sich verlängert. Nur kann hier wegen der Dicke des Randwulstes die gegen die Medianaxe gerichtete Zellenverschiebung weniger leicht erfolgen, als im Bereich der Lunula. In Folge dessen sehen wir statt eines Streifens in der Area opaca eine breitere mit abgerundeten Rändern versehene mesodermale Substanzplatte auftreten, welche Rauber die Randplatte des Primitivstreifens nennt. Die letztere, mit der sich ebenfalls das Ektoderm inniger verbindet, bildet demnach den in der Area opaca gelegenen Theil des Primitivstreifens ${ }^{1}$ ).

Es beruht somit nach $R$. die Bildung des Primitivstreifens auf einer centripetalen Verschiebung der Zellen der unteren Keimschichte nach der zukünftigen Längsaxe und erst nachdem dieselbe erfolgt ist; findet das centrifugale Auswachsen des Mesoderms statt, als dessen in der longitudinalen Axe gelegene Verdickung der Primitivstreif sodann erscheint.

An dieser Stelle möchte ich noch eines Verhaltens des Keimhautrandes Erwähnung thun, welches von R. besonders betont wird. Wie schon Pander ${ }^{2}$ ) fand, ist der Rand der Keimscheibe zuweilen an der Stelle, wo ihn die hintere Verlängerungslinie der Primitivrinne schneidet, etwas eingekerbt. Rauber, der diesen Einschnitt als „Randkerbe“ bezeichnet, hält dieselbe für das ideale hintere Ende der Primitivrinne.

Nachdem wir uns mit der Genese des Primitivstreifens, so wie sie von Rauber für das Hühnchen dargestellt wird, bekannt gemacht, können wir uns den Ausführungen dieses Autors zuwenden, wonach auch bei den Vögeln der gleiche Entwicklungsplan, wie bei den Fischen und Amphibien, zur Geltung kommt. Nur von diesem Gesichtspunkte aus erklärt sich nach R. die Randstellung der Embryonalanlage des Hühnchens. Ferner ist, was die Primitivrinne anlangt, die Nähe ihres hinteren Endes am Rande der Keimscheibe, dem Urmund, ein bedeutungsvolles Moment. Die zuweilen vorkommende Randkerbe weist ferner darauf hin, dass nicht bloss ein idealer Zusammenhang zwischen Primitivrinne und Urmund unter allen Umständen anzunehmen sei, sondern dass er sich selbst, wenn auch in seltenen Fällen, thatsächlich ausprägen könne. Der Zusammenhang mit dem Urmund schliesst abèr auch den Zusammenhang mit der Urdarmhöhle, der v. Bae r'schen Keimhöhle selbstverständlich in sich ein. Würde die Keimscheibe des Hühnchens minder flach sein, so würde der directe Uebergang der-Rinne in die Höhle wahrscheinlich

1) Rauber versteht demnach unter Randplatte das etwas angeschwollene hintere. Ende des Primitivstreifens, welches nach meiner Aulfassung aus der Sichel desselben hervorgeht, und zuerst in der Area opaca liegt, später jedoch mit dem Zuwachsstiick in die Area pellucida gelangt. Je nach der ursprïnglichen fausdehnung der Sichel zeigt das hintere Ende des Primitivstreifens sehr verschiedene Dimensionen.

$\left.{ }^{2}\right)$ P a nder, Beiträge zur Entwicklung des Hühnchens im Ei. 1817. Taf. I, Fig. 3 u. 4. 
viel auffallender hervortreten. Die Primitivrinne, wahrscheinlich aber auch die Medullarrinne des Hühnchens, ist demnach nichts Anderes als die Fortsetzung der Urdarmhöhle auf den Rücken der Keimscheibe; da diese Fortsetzung nur von einer Stelle der Peripherie der Keimscheibe aus erfolgen kann, muss die Primitivrinne randwärts liegen. Fasst man aber die Primitivrinne als eine Fortsetzung der Urdarmhöhle auf, so müssen demgemäss die Primitivrinnenränder auch eine Fortsetzung der Urmundränder darstellen. Die ersteren sind nach $\mathrm{R}$. ein nach vorne gezogener Abschnitt des grossen ursprünglichen Urmundrandes. Es tritt demnach beim Hühnchen im Gegensatz zu den Knochenfischen, aber in Uebereinstimmung mit den Selachiern, nur ein Theil des Urmundrandes als Embryonalanlage auf. Rauber bezeichnet diese Entstehungsweise des Embryo als stomatogene. Selbst zu einer vorgerückten Zeit der Ausbildung des Primitivstreifens sei dieselbe noch bemerklich, indem über eine längere Zeitstrecke hin eine fortdauernde Uebernahme hinterer Keimscheibenbezirke in die Embryonalanlage stattfinde. Was aber den Anfang dieser Entstehungsweise anlangt, so ist, da die Primitivrinne verhältnissmässig spät erscheint, der eben sichtbar gewordene Primitivstreif schon gewissermassen zusammengetretener Urmundrand. Um sich daher die Entstehung des Primitivstreifens aus einer Vereinigung von Theilen des Urmundrandes besser zu veranschaulichen, braucht man nur das Auftreten der Primitivrinne in Gedanken auf eine etwas frühere Zeit zu verlegen.

Rauber zieht aus den vorstehenden Betrachtungen, welche ich grösstentheils mit des Autors eigenen Worten wiedergegeben habe, den Schluss, dass der Primitivstreif des Hühnchens als Embryonaltheil des Urmundrandes, die Primitivrinne als Embryonaltheil des Urmundeinganges zu betrachten sei.

Wenn man hinsichtlich der Bildungsart des Primitivstreifens, oder, was gleichbedeutend ist, der Primitivrinne, beziehungsweise Medullarrinne, die einzelnen Wirbelthierclassen vergleicht, so muss man nach $R$. eine disjunctive und eine conjunctive Form unterscheiden. Bei der disjunctiven Form wird eine zusammenhängende Substanzplatte, welche mit ihrer Basis an Urmund und Keimring grenzt, während sie sich mit ihrem abgerundeten vorderen Ende von letzteren mehr oder weniger entfernt, durch eine longitudinale, zum Keimring senkrecht gestellte, mehr oder minder tiefgreifende Rinne in zwei symmetrische Keimstreifen getrennt. Die Rinne ist die Primitivrinne, welche weder am vorderen, noch am hinteren Ende der Substanzplatte ganz durchgreift. Dadurch bleibt ein vorderer und hinterer Schlussbogen erhalten; der vordere umsäumt das Vorderende der Primitivrinne, der hintere ihr wirkliches oder ideelles hinteres Ende, den Urmund. Durch das Auftreten der Primitivrinne wird die Bilateralität der Embryonalanlage zum Ausdruck gebracht. Repräsentanten der disjunctiven Form der Primitivstreifenbildung sind die Vögel und vermuthlich anch die Säugethiere. Die conjunctive Form, welche wir bei den Knochenfischen und Selachiern vorfinden, besteht darin, dass zwei vorher getrennte, unter Umständen weit von einander abliegende Keimstreifen (Keimringtheile) durch Zusammenrücken sich mit einander verbinden und durch diese Verbindung den Primitivstreifen darstellen, dessen Rinne demnach als der Ausdruck der frühern Trennung erscheint. Auch hier greift die Primitivrinno weder auf den vorderen, noch den hinteren Rand des Primitivstreifens 
über, so dass auch bei dieser Bildungsform die Keimstreifen Primitivrinne und Urmund umfassen.

Die conjunctive und disjunctive Form bilden keine Gegensätze, sondern gehen unmittelbar in einander über. Hiefür lassen sich als Beispiele die Vögel anführen, bei denen nur der vordere Abschnitt der Embryonalanlage mittelst der disjunctiven Form, der hintere ausgedehntere Theil des Embryo mittelst der conjunctiven Form zu Stande kommt, indem die Embryonalanlage fortwährend von beiden Seiten her auf Kosten des Keimrings einen Zuwachs erhält, und so durch associatives Wachsthum nach rückwärts sich verlängert. Es ist daher auch bei dem Hühnchen der Keimring embryoplastisch, wenn er auch nur theilweise, wie bei den Selachiern, zum Aufbau des Embryo Verwendung findet, während er bei den Knochenfischen gänzlich aufgebraucht wird. Bei den beiden ersteren Thierclassen trennt sich die hintere Embryonalanlage, wie schon früher erwähnt, von dem Keimringe ab, lange bevor die Umwachsung des Dotters vollzogen ist. In ähnlicher Weise, wie bei den Vögeln, bildet sich nach Rauber auch bei den Cyclostomen, Stören und Amphibien der vordere Theil der Embryonalanlage nach der disjunctiven Form, während der hintere Abschnitt dem vorderen durch Conjunction allmählich sich anschliesst.

Nachdem wir uns mit dem Gedankengange und der Darstellung Rauber's vertraut gemacht haben, so werden wir dieselbe nochmals überblickend nicht umhin können, der geistvollen Durchführung einheitlicher Entwicklungsgesetze für das gesammte Reich der Wirbelthiere, welche uns in den Rauber'schen Abhandlungen entgegentritt, unsere volle Anerkennung zu zollen. Wenn auch das Gebäude, welches $\mathrm{R}$ a u b r errichtet hat, noch lange nicht vollendet ist und voraussichtlich in Zukunft manche Theile wieder eingerissen werden, um den Bau nach anderen Richtungen hin weiter zu führen, so werden doch stets die Grundpfeiler bestehen bleiben. Als einen solchen betrachte ich, um mich der Rauber'schen Ausdrucksweise zu bedienen, den Uebergang des Gastrulastadiums in das der Neurula, indem meines Erachtens bei allen Wirbelthieren der Satz Geltung beanspruchen kann, dass die Medullarrinne zu dem Blastoporus genetisch in bestimmten, gesetzmässigen Beziehungen steht.

Um nun über die Rauber'schen Anschauungen im Einzelnen ein Urtheil abgeben zu können, scheint es mir zweckmässig, eine Sonderung der Art eintreten zu lassen, dass ich dieselben in Rücksicht auf zwei Punkte prüfe; es soll erstens die Bedeutung des Keimrings für die Embryonalbildung und zweitens das Verhältniss der Medullarrinne zu dem Blastoporus unter Bezugnahme auf die Darlegungen Ra u er's untersucht werden.

Was die Bedeutung des Keimrings für die Embryonalanlage anlangt, so stimme ich mit Rauber darin vollkommen überein, dass von demselben die Bildung der Embryonalanlage bei allen Wirbelthieren (mit Ausnahme der Säuger) ausgeht oder zum mindesten angeregt wird. In Hinsicht auf die. Verwendung des Keimrings zur Embryonalanlage möchte ich mich jedoch nicht so allgemein fassen, sondern es scheint mir in dieser Beziehung ein Unterschied zu bestehen zwischen den Fischen und Amphibien einerseits und den Vögeln andererseits. Bei den ersteren Thierclassen betheiligt sich der 
Keimring an dem Aufbau des Embryo entschieden in viel höherem Grade, als bei den letzteren.

Zunächst soll auf die diesbezüglichen Entwicklungsvorgänge der Fische und Amphibien eingegangen werden. Dass bei den Cyclostomen, Ganoiden und Amphibien, und ebenso bei den Knochenfischen nach vollendeter Dotterumwachsung der ganze Keimring in die Embryonalanlage einbezogen wird, wird wohl von Niemanden bestritten werden. Um diese Zeit bildet, was bei den Knochenfischen am deutlichsten hervortritt, der hintere Umfang des Keimrings das hintere Ende der Embryonalanlage, wesshalb man diesen Theil des Keimrings mit vollem Recht als embryoplastisch bezeichnen darf. Anders verhält sich die Sache, wenn man sich die Frage vorlegt, ob der Keimring auch für die vordere und mittlere Embryonalanlage embryoplastisch sei, d. h. ob er als solcher mit allen seinen Bestandtheilen in grösserer oder geringerer Ausdehnung in die Embryonalanlage übertrete; die zweite Möglichkeit läge darin, dass nur Theile des Keimrings, d. h. ein Theil seiner Zellen, zu der Embryonalanlage abgegeben würden, was man als Auswachsen aus dem Keimringe bezeichnen könnte; die embryoplastische Verwendung des Keimrings (Conjunction) involvirt eine Verlängerung des Embryonalkörpers nach hinten, das Auswachsen mehr eine solche nach vorne zu. Eine scharfe Grenze zwischen beiden Möglichkeiten zu ziehen, dürfte allerdings schwer halten, was besonders für das erste Auftreten der Embryonalanlage gilt, welche ja anfänglich als eine verdickte und verbreiterte Stelle des Keimrings erscheint. R auber neigt sich für die genannten Thiere entschieden mehr der ersteren Annahme zu.

Für die Knochenfische dürfte der von R. befürwortete conjunctive Bildungsmodus wohl dem wahren Sachverhalt am nächsten kommen, worauf ja auch die pathologischen Fälle von mangelnder Vereinigung der Randwulsthälften dringend hinweisen. Vielleicht findet jedoch auch hier in der Norm ein etwas stärkeres intussusceptionelles Längenwachsthum der Embryonalanlage statt, als es von Rauber angenommen wird.

$\mathrm{Ob}$ dagegen bei der Bildung der vorderen und mittleren Embryonalanlage der Amphibien, Ganoiden und Cyclostomen der Keimring embryoplastisch betheiligt sei, scheint mir sehr fraglich zu sein. Was die vordere Embryonalanlage betrifft, so hat $\mathrm{R}$ a u ber für sie, wie wir wissen, die disjunctive Bildungsform für wahrscheinlich gehalten, während die übrigen Abschnitte des Embryo durch Conjunction associativ sich anschliessen sollen. Meines Erachtens ist die letztgenannte Art der embryonalen Längenzunahme wenigstens für die mittleren Embryonalstrecken von der Hand zu weisen, vielmehr scheint mir die Verlängerung der Embryonalanlage und das allmählige Abheben des Kopfendes von der Eioberfläche dadurch zu Stande zu kommen, dass in dem zu beiden Seiten der Mittellinie gelegenen Mesoderm, welches sich von den Rändern des Blastoporus aus entwickelt hat, eine lebhafte Zellentheilung und Zellenvermehrung sich einstellt, woraus ein rasches, vorwiegend nach vorne gerichtetes Flächenwachsthum resultirt. Durch das fortgesetzte interstitielle Wachsthum des Mesoderm und die damit verbundene Längenausdehnung desselben wird der Kopftheil der Embryonalanlage immer weiter vom Blastoporus nach vorne abgedrängt und dabei allmählig von der Eioberfläche abgehoben werden müssen. Eine Conjunction im Sinne R a uber's zur Herstellung 
der mittleren Embryonalanlage scheint mir bei den Thieren mit holoplastischen Eiern auch aus dem Grunde nicht sehr wahrscheinlich, weil zur Zeit des Auftretens derselben die Dotterumwachsung nahezu vollzogen und darum der Keimring keine solche Mächtigkeit und Ausdehnung mehr besitzt, welche für eine ergiebigere Conjunctionsleistung erforderlich wäre.

Bei den Selachiern hat der Keimring für die Herstellung der Embryonalanlage eine viel geringere Function zu erfüllen, wie bei den vorgenannten Thieren, indem, wie bekannt, nur ein Theil des Keimringes zur Bildung des Embryo Verwendung findet; der restirende Theil desselben hat, nachdem er sich von der Embryonalanlage getrennt hat, nur den Schluss des Dotterlochs zu besorgen. Was nun die Entstehungsweise des Embryo anlangt, so scheint mir, soweit die hier in Betracht kommenden Untersuchungen ein Urtheil gestatten, die Conjunction in den Vordergrund gestellt werden zu müssen. Die Embryonalanlage würde demgemäss durch eine longitudinale Verwachsung der betreffenden Stücke des Keimringes zu Stande kommen ( $\mathrm{R}$ auber, His) und sonach wären die letzteren als embryoplastisch zu bezeichnen.

Ich gehe nun zu der Frage über, welche Bedeutung dem Keimringe für den Aufbau der Embryonalanlage der Vögel zukommt. Die letztere beginnt, wie bei den Fischen und Amphibien, so auch bei den Vögeln, innerhalb des Keimrings oder der Area opaca sich zu bilden. Es ist in dem entwicklungsgeschichtlichen Capitel genau beschrieben worden, wie mit dem Auftreten der Sichel die Bildung des Primitivstreifens und damit die des Mesoderms ihren Anfang nimmt, wie sich ferner vor dem Primitivstreifen die Chorda, sowie der Haupttheil der Embryonalanlage entwickelt, in welche nur der vordere Theil des Primitivstreifens einbezogen wird, während der hintere schwindet. Wie man sieht, stehen diese Resultate meiner Untersuchungen mit der oben mitgetheilten Rauber'schen Darstellung der Genese des Primitivstreifens und der Ausbildung des letzteren zur Embryonalanlage in directem Widerspruch. Durchschnittsbilder, wie sie Rauber von seiner Lunula entodermatica gezeichnet hat ${ }^{1}$ ), habe ich niemals erhalten, ebensowenig als ich im Flächenbilde bei Keimhäuten unbebrüteter Hühnereier etwas von einer Lunula entdecken konnte. Ferner habe ich bei meinen sämmtlichen in Serienschnitte zerlegten Keimscheiben, welche Primitivstreifen auf den verschiedensten Stufen der Ausbildung enthielten, niemals solche Bilder zu Gesicht bekommen, aus denen auf ein Zusammenrücken der Zellen der unteren Keimschichte von beiden Seiten nach der Medianlinie, wodurch nach R. der Primitivstreif zu Stande kommen soll, hätte geschlossen werden dürfen. Bei allen Keimscheiben, die sowohl longitudinal, als transversal durchschnitten wurden, und deren Zahl ist keine unbeträchtliche, fand ich die Angaben Kölliker's bestätigt, wonach der Primitivstreif als eine Verdickung des Ektoderma sich anlegt.

Dass ich Rauber auch darin nicht beipflichten kann, dass der Primitivstreif zur Embryonalanlage sich umbildet, geht aus meiner entwicklungs: geschichtlichen Beschreibung allein schon zur Genüge hervor.

Nachdem dies vorausgeschickt ist, ergibt - es sich gewissermassen von

1) Primitivrinne und Urmund 1. c. Fig. 2. 
selbst, welche Ansicht ich hinsichtlich der Betheiligung des Keimrings an der Bildung der Embryonalanlage des Hühnchens vertrete. Nur die Sichel des Primitivstreifens, welche bei der, weitern Ausbildung des Embryo für denselben gänzlich in Wegfall kommt, ist meines Erachtens ein Product des Keimrings, und zwar des Ektoderms desselben. Die übrigen Theile des Primitivstreifens dagegen bilden sich innerhalb der Area pellucida und zwar aus deren Ektoderm. Demnach hat an deren Genese die Substanz des Keimrings keinen directen Antheil. Das Gleiche gilt natürlich auch von dem vor dem Primitivstreifen entstehenden Haupttheil der Embryonalanlage. Da ferner nach der Ausbildung des Primitivstreifens auch dessen hinteres Ende mit dem Zuwachsstück in die Area pellucida einbezogen wird, ja sogar häufig im Flächenbilde gänzlich vom Rande der Area opaca losgelöst erscheint, kann ein noch weiter andauerndes associatives Wachsthum nach rückwärts, wie es Rauber annimmt, unmöglich statthaben.

Ziehen wir daher aus diesen Betrachtungen das Facit, so wird folgendes ersichtlich werden. Beim Hühnchen bildet sich nur das hinterste Ende der Embryonalanlage, das später wieder für dieselbe in Wegfall kommt, aus der Substanz des Keimrings. Eine embryoplastische Verwendung des letzteren in dem oben definirten Sinne ist gänzlich auszuschliessen.

Wenn wir demnach bei den Thieren, deren Eier einer partiellen Furchung unterliegen, die Beziehungen des Keimrings zur Embryonalanlage einem Vergleiche unterziehen, so wird sich herausstellen, dass in allen Fällen die Embryonalanlage in der Peripherie der Keimscheibe im Gebiete des Keimrings zuerst in Erscheinung tritt. In Hinsicht auf den Verbrauch des Keimrings zur Embryonalanlage liegen die Verhältnisse bei den einzelnen Thieren sehr verschieden. Am ausgesprochensten zeigt sich die Verwendung des Keimrings zum Aufbau des Embryo bei den Knochenfischen, indem hier der gesammte Keimring eine embryoplastische und darum auch substanzielle Verwendung findet. Bei den Selachiern ist die letztere nur eine partielle, bei den Vögeln endlich hat sich eine embryoplastische Verwendung überhaupt nicht mehr erhalten und auch die substanzielle ist nur eine sehr minimale.

Es erübrigt noch, das Verhältniss der Medullarrinne zu dem Blastoporus bei den Wirbelthieren unter Berücksichtigung der R a ub èr'schen Untersuchungen zu besprechen. Diejenigen Thierformen, bei denen das Dotterloch den gesammten Blastoporus repräsentirt, wie die Cyclostomen, Ganoiden, Amphibien und die Knochenfische, lassen sich, was die genetische Beziehung der Medullarrinne zum Urmund anlangt, leicht auf die einfacheren für den Amphioxus von Kowalewsky gefundenen Entwicklungsvorgänge zurückführen. Es ist dies bereits bei Gelegenheit der für die genannten Thiere gegebenen entwicklungsgeschichtlichen S'childerungen von mir hervorgehoben worden, wesshalb an dieser Stelle eine nochmalige Auseinandersetzung des Uebergangs der Gastrula in das Neurulastadium unterbleiben kann.

Viel schwieriger dagegen hält es, bei den Selachiern, Reptilien und Vögeln, bei welchen die Embryonalanlage von dem sich schliessenden Dotterloche weit entfernt ist, ein Urtheil über die genetischen Bezichungen des Blastoporus zur Medullarrinne zu gewinnen. Hiezu kommt, dass man bei diesen Thieren, zumal bei den Reptilien und Vögeln, noch nicht zu einer Eini- 
gung gelangt ist, was man überhaupt als Blastoporus aufzufassen habe. Auf der einen Seite wird als solcher im Hinblick auf die Knochenfische das Dotterloch imponiren, während auf der andern Seite wiederum sehr vieles dafür spricht, dass der Blastoporus nicht so weit von der Embryonalanlage abliegen könne, sondern so angeordnet sein müsse, dass er in dieselbe aufgenommen werden kann. So hat bekanntlich Gasser bei Gänseembryonen mit über 14 Urwirbeln einen kurzen Verbindungscanal zwischen dem Hinterende des Medullarrohres und dem (späteren) Darmrohr aufgefunden (Canalis neurentericus), welcher den von den Medullarwülsten seitlich umschlossenen vorderen Theil des Primitivstreifens durchsetzt. Im Hinblick auf die Beziehungen, welche bei den Batrachiern und Haien zwischen Blastoporus und Nervenrohr existiren, indem an der Stelle des ersteren ein Verbindungscanal zwischen Darm- und Medullarrohr späterhin angetroffen wird, könnte man nach Gasser jenen Canalis neurentericus folgendermassen auffassen: „Der Blastoporus, Urmund, der Vogelkeimscheibe sei zu suchen im Bereiche des vorderen Theiles der Primitivrinne; diese stellte an sich gewissermassen einen unvollkommenen Blastoporus dar, der bei dem allmähligen Zurückweichen der Rinne deutlicher wird, nur an einer bestimmten Stelle bei den Gänseembryonen zum vollen Durchbruch zum Darmcanal führt. " 1 )

Im Anschluss an die wichtige Entdeckung Gasser's möchte ich die Angaben von Braun besprechen, denen zu Folge es bei Vogelembryonen an drei von einander zu trennenden Stellen zu einer Verbindung zwischen Rückenmark und Darm kommt, was am deutlichsten bei Entenembryonen zu beobachten sein soll. Die vorderste und frühzeitigste dieser Communicationen bẹfindet sich noch vor dem Primitivstreifen: Diese Oeffnung schliesst sich bald wieder, worauf eine zweite Verbindung sich einstellt, die ihrer Lage nach der von Gasser aufgefundenen Communication entspricht. Auch diese schliesst sich bald; die dritte und hinterste Communication tritt_erst auf, wenn der Schwanz selbst gebildet ist, und sich ventral zu krümmen beginnt. Sie liegt dicht vor der Schwanzspitze und stellt eine secundär zu Stande kommende Verbindung zwischen Schwanzdarm und Rückenmark her. Bei andern Vögeln, der Bachstelze, dem Wellenpapagei, der Taube, dem Hühnchen, konnte Braun die gleichen Bildungen ebenfalls nachweisen; nur ist der Grad ihrer Ausbildung bei den genannten Vögeln ein sehr verschiedener. ${ }^{2}$ )

Schliesslich habe ich noch der Untersuchungen von Kupffer und Benecke, sowie derer von Balfour und von Strahl zu gedenken, welche die ersten Entwicklungsvorgänge der Reptilien betreffen. Die Eier derselben unterliegen, wie ich vorausschicken will, der partiellen Furchung, wie die der Vögel, mit denen sie auch hinsichtlich der Bildung der Keimscheibe, der Dotterumwachsung etc. die grösste Aehnlichkeit haben. Ehe die Keimhaut den Dotter zur Hälfte umwachsen hat, ist in ihrer Mitte ein elliptisches Em-

1) Gasser, Der Primitivstreifen bei Vogelembryonen. 1878. Schriften der Gesellschaft zur Beförderung der gesammten Naturw. in Marburg, Bd. 11. Supplementheft I, pag. 83.

2) II. Bra un, Aus der Entwicklungsgeschichte dé: Papageien. III. Die Verbindungen zwischen Rückenmark und Darm bei Vögeln. Verhandlungen der physik. med. Gesellschaft in Würzburg. N. F. Bd. XV, 1 u. 2. Helt, pag. 120, 1881. 
bryonalschild aufgetreten, welches dadurch zu Stande kommt, dass sich im Bereiche desselben die Ektodermzellen erhöhen und cylindrisch werden. Nach den Beobachtungen von Kupfer, und Benecke ${ }^{1}$ ) kommt es nun in der Nähe des hinteren Randes des Embryonalschildes bei Eidechsen und Schildkröten zu einer ventralwärts und nach vorne gerichteten Einstülpung des Ektoderms. Die Eingangsöffnung in diese blindsackartige Einbuchtung fassen die beiden Autoren als Blastoporus, die letztere selbst als Gastrula auf, deren Höhlung jedoch nicht zum Urdarm, sondern weiterwachsend zur Allantois werden soll. Die Ränder des Blastoporus verdicken sich und von hier aus entwickelt sich das Mesoderm. Vor dem Blastoporus bildet sich die Medullarrinne, deren Grenzwülste in die verdickten Ränder des ersteren in derselben Weise übergehen, wie dies bei dem Amphioxus, den Batrachiern und Petromyzonten der Fall ist.

Balfour, der die Entwicklung der Eidechsen untersuchte, bestreitet gegen K. und B. die Verwendung jener blindsackförmigen Einstülpung, welche er an das vordere Ende des bei den Lacertilien nur kurzen Primitivstreifens verlegt, zur Allantois. Vielmehr komme es an der besagten Stelle zum Durchbruch durch das Entoderm, woraus ein Verbindungscanal zwischen Darm- und Nervenrohr entstehe, den er Canalis neurentericus nennt. Von der seitlichen Umgebung des Canals, sowie von dem Primitivstreifen aus wächst nach Balfour das Mesoderm zwischen die beiden anderen Keimblätter in derselben Weise ein, wie ich dies früher für das Hühnchen beschrieben habe. In der Medianlinie vor dem Canalis neurentericus bildet sich aus dem Entoderm die Chorda ${ }^{2}$ ).

Die Angaben Balfour's über den Canalis neurentericus der Eidechsen haben neuerdings durch Strahl eine Bestätigung erfahren. Nach diesem Autor besteht zwischen dem von Gasser bei Entenembryonen entdeckten Communicationscanal und dem Canalis myelo-entericus der Lacertilia die grösste Uebereinstimmung. Seine Beobachtungen über die Entstehung dieses Ganges und sein Verhältniss zur Allantois fasst Strahl folgendermassen zusammen ${ }^{3}$ ): ${ }_{\text {}}$ An frühen Keimscheiben von Lacerta vivipara findet sich auf der Ektodermseite eine Einstülpung nach dem Dotter zu, welcher an der Stelle liegt, wo Kölliker's Kopffortsatz und Primitivstreifen zusammenstossen. Diese Einstülpung bricht auf der Dotterseite durch das Entoderm und verbindet als Canalis myelo-entericus für längere Zeit das letzte Ende des Centralnervenrohres mit dem hintern Ende des Darmrohres. ${ }^{*}$ - Die Allantois legt sich zuerst als solider Zapfen im hinteren Theil des Primitivstreifens in der Pleuroperitonealhöhle an, höhlt sich unabhängig vom Darmrohr aus, wobei sich inmitten indifferenzirten Gewebes Entoderm bildet, und tritt später in Com-

1) Kupfer und Benecke, Die ersten Entwicklungsvorgänge am Ëi der Reptilien. Königstuerg 1878.

Kupfer, Die Entstehung der Allantois und die Gastrula der Wirbelthiere. Zool. Anzeiger Bd. II, Nr. 39, 1879.

${ }^{2}$ ) Balfour, On the early development of the Lacertilia, together with some observations on the nature and Relations of the primitiv Streak. Quarterly Journ. of microscop. scienc. Bd. XIX, 1879.

8) Strahl, Ueber die Entwicklung des Canalis myelo-enterieus und die Allantois der Eidechse. Archiv für Anatomie u. Physiologic. Anat. Abth. 1881, pag. 154. 
munication mit dem Enddarm." - Mit dem Canalis myelo-entericus steht die Allantois in erster Anlage gar nicht, später nur in soweit im Zusammenhange, als beide mit dem Enddarme communiciren."

Die Resultate und Schlussfolgerungen, zu denen Gasser, Braun, Kupffer und Benecke und Balfour gelangt sind, haben Rauber veranlasst, seinen Standpunct in der Blastoporusfrage nochmals zu präcisiren ${ }^{1}$ ). Indem Rauber seiner alten Auffassung getreu bleibt, führt er aus, dass die Vögel, Reptilien, Haie und wahrscheinlich auch die Säugethiere, welche in ihrer Entwicklung einen Embryonaltheil und einen Aussentheil des Blastoderm unterscheiden lassen, ein zweifaches Blastostomion (Blastoporus) entwickeln, nämlich ein dem gesammten Blastoderm zugehöriges und ein embryonales Blastostomion. Das erstere nennt R. Blastostomion primordiale s. verum, das letztere hingegen, welches den von Gasser und Kupffer und Benecke entdeckten Bildungen entspricht, Blastostomion consecutivum s. intermedium. Beide Pforten sind nur besonders bedeutsame Stellen des gesammten Blastostoma. Man erkennt leicht, dass hiermit wesentlich dasselbe gesagt sein soll, was $R$. in seiner frühern Abhandlung über Primitivrinne und Urmund bereits für das Hühnchen ausgesprochen hat. Am Ende der besagten Schrift nämlich wird hervorgehoben, dass der Primitivstreifen des Hühnchens als Embryonaltheil der Urmundränder, die Primitivrinne als Embryonaltheil des Urmundeinganges zu betrachten sei.

Sicherlich hat Rauber gegenüber Gasser und Kupffer Recht, wenn er behauptet, dass die am Kopfende des Primitivstreifens bei Vögeln und Eidechsen befindliche Oeffnung, welche in einen ventralwärts gerichteten Gang (Canalis neurentericus) führt, nicht der alleinige Blastoporus sein könne. Gegen eine solche Annahme spricht die Zugehörigkeit der genannten Bildung zu dem Primitivstreifen, die erst relativ späte Ausbildung des Canalis neurentericus, sowie das Vorhandensein einer zweiten vom Gesammtrande der Keimhaut umschlossenen Oeffnung. Meiner Ansicht nach hat Rauber ganz das Richtige getroffen, wenn er die Primitivrinne der Vögel als Embryonaltheil des Urmundeinganges bezeichnet. Es scheint mir allerdings unmöglich, dies bei den Vögeln selbst noch direct nachzuweisen, allein es deutet meines Erachtens vieles darauf hin, dass Primitivrinne und Dotterloch phylogenetisch von einem gemeinsamen Blastoporus abstammen. Um diesem Verhältniss Ausdruck zu geben, möchte ich im Anschluss an die von Rauber und Balfour gebrauchten Benennungen die Primitivrinne der Vögel als embryonalen Blastoporus, das Dotterloch dagegen als Dotterblastoporus bezeichnen. Die von Rauber betonte genetische Zusammengehörigkeit der beiden Bildungen wahrscheinlich zu machen, sei die Aufgabe der folgenden Betrachtungen.

Zunächst sei bemerkt, dass die eben erörterte Auffassung durch die klare und lichtvolle Darstellung, welche Balfour in seinem Handbuch der vergleichenden Embryologie der Gastrula- und Keimblätterbildung bei den Wirbelthieren hat zu Theil werden lassen, eine mächtige Stütze erhalten hat. Be-• züglich der Deutung des Primitivstreifens der Vögel und Reptilien (Sauropsiden)

1) Rauber, Die Lage der Keimpforte. Zoolog. Añzeiger 1879, Nr. 38.

Rauber, Die Gastrula der Wirbelthiere und die Allantois. Zoolog. Anzeiger 1880, Nr. 53.

Gerlach, Entstehungsweise der Doppelmissbildungen. 
knüptt Balfour an die von ihm bei Selachiern gefundenen Entwicklungserscheinungen an, durch welche die Bildung des Canalis neurentericus, sowie die Entfernung der Embryonalanlage vom Rande der Keimhaut zu Stande kommt. Ich habe diese Verhältnisse bereits früher, als die Art der Dotterumwachsung bei Selachiern und Knochenfischen miteinander verglichen wurde, erwähnt. Bei dieser Gelegenheit ist hervorgehoben worden, dass der Canalis neurentericus von der ursprünglichen durch den gesammten Ringwulst umrandeten Oeffnung des Blastoporus sich abschnürt, was dadurch geschieht, dass hinter dem Canalis neurentericus und der Embryonalanlage die ausserembryonalen Randwulsthälften während der Dotterumwachsung linear miteinander verschmelzen. In Folge dieses Vorgangs entsteht ein geradliniger Streif, welcher von dem hinteren Embryonalende zu dem Keimhautrande oder dem Dotterloche führt. Es sind demnach während der Dotterumwachsung aus der ursprünglichen gemeinsamen Blastoporusöffnung folgende drei Gebilde hervorgegangen: 1) der Canalis neurentericus, 2) jener Streif, welcher durch die lineare Verwachsung eines Theiles der Blastoporusränder entstanden ist, und 3) das Dotterloch. Der Canalis neurentericus bildet den embryonalen, das Dotterloch den Dotterblastoporus, deren Zusammengehörigkeit und A.bleitung von einem gemeinsamen Urmund bei den Selachiern durch eben jenen Verbindungsstreifen noch deutlich nachzuweisen ist.

Nach Balfour's Meinung ist nun zwischen den Selachiern einerseits und den Sauropsiden andererseits nur dann ein Vergleich möglich, wenn sich für letztere die mehr centrale Lage des Embryo im Blastoderm, sowie die Natur des Primitivstreifens genügend erklären lässt. Balfour nimmt zu diesem Behufe an, dass der Embryo der Sauropsiden seine centrale Lage im Blastoderm durch Abkürzung eines ähnlichen Processes erhalten hat, durch welchen der Selachierembryo bei der Dotterumwachsung sich vom Keimhautrande entfernte. Sonach würde der Primitivstreif der Vögel und Säugethiere dem linearen Streif, welcher den scheinbar gegen die Mitte der Keimhaut rückenden Selachierembryo mit dem Blastodermrande verbindet, mitsammt dem Canalis neurentericus der Selachier entsprechen. Mit Hülfe dieser Annahme lässt sich nach Balfour zwischen den Selachiern und Sauropsiden eine grosse entwicklungsgeschichtliche Uebereinstimmung nachweisen. Der Canalis neurentericus erscheint bei beiden als ein Theil des ursprünglichen gesammten Blastoporus. Sein vorderer Rand wird von der dorsalen Blastoporuslippe gebildet, welche diejenige Stelle der Keimhaut darstellt, wo Ektoderm und Entoderm in einander übergehen und vor der die Bildung der Chorda beginnt, sowie die Medullarfurche sich anlegt. Sie ist demnach der dorsalen Blastoporuslippe der Amphibien und Cyclostomen vollständig homolog. Die dorsale Oeffnung des Canalis neurentericus wird ferner auch bei den Sauropsiden seitlich von den Medullarwülsten umschlossen und fällt in das Bereich der Rückenfurche. Der hinter dern Canalis neurentericus liegende übrige Theil des Primitivstreifens ist ein rudimentäres Organ, welches dem mehrfach erwähnten Verbindungsstreifen der Selachier an die Seite zu stellen ist. Dass er nicht, wie dieser, bis zu dem hinteren Rande der Keimscheibe reicht, beruht auf seiner nur rudimentïren Ausbildung. „Die mehr oder weniger vollständige Verschmelzung der Keimblätter im Primitivstreifen ist einfach dadurch zu erklären, dass 
dieses Gebilde die verwachsenen Blastoporusränder repräsentirt, und wenn das Mesoblast von ihm nach aussen wächst, so ist darin wahrscheinlich ein Ueberrest einer ursprünglich dorsalen Einstülpung des Hypo- und Mesoblasts wie beim Frosch zu erblicken $\left.{ }^{1}\right) .{ }^{\text {" }}$

Die Vergleichung der Sauropsiden mit den Selachiern hat Balfour demnach zu dem Ergebniss geführt, dass der gesammte Blastoporus der ersteren ähnlich wie bei den letzteren aus drei Theilen besteht: 1) aus dem neurenterischen Canal, 2) aus dem dahinter folgenden Primitivstreifen und 3) aus dem Dotterblastoporus, der an dem vom Embryo abgewendeten Pol des Dottersacks liegt.

Wenn man diese Anschauungen Balfour's denen von Rauber gegenüberhält, so wird die grosse Uebereinstimmung $z$ wischen beiden auffallen müssen, denn beide Autoren sehen ja in dem Primitivstreifen der Vögel und Reptilien und dem in seinem Gebiete später auftretenden Canalis neurentericus einen Abkömmling des in einer früheren Zeit der Stammesgeschichte einheitlichen Blastoporus.

$\mathrm{Zu}$ den von R. und B. zur Begründung der eben erörterten Bedeutung des Primitivstreifens der Sauropsiden angeführten Argumenten möchte ich noch ein weiteres hinzufügen, welches von den genannten Autoren meiner Ansicht nach nicht genügend gewürdigt worden ist. Ich gehe dabei von der Thatsache aus, dass das Mesoderm sich von dem Primitivstreifen aus entwickelt. Da so ziemlich gleichzeitig mit dem Beginn des Auswachsens der Zellen des Primitivstreifens zwischen die beiden andern Keimblätter hinein die Primitivrinne auftritt, so erscheint es höchst wahrscheinlich, dass die Bildung der letzteren eine unmittelbare Folge des erstgenannten Vorganges ist. Mit andern Worten, das Auswachsen der Zellen des Primitivstreifens, womit die Mesodermentwicklung beginnt, steht mit dem Auftreten der Primitivrinne in innigem Causalnexus. Die letztere kann daher als eine, wenn auch nur geringgradige lineare Einbuchtung oder Einstülpung des an der betreffenden Stelle verdickten Ektoderms aufgefasst werden, von deren Rändern die Bildung des Mesoderms ausgeht.

Bei den Amphibien und Fischen entwickelt sich das Mesoderm von den Rändern des Blastoporus aus, und zwar, wie nach den neueren Untersuchungen zu schliessen, bereits in einer relativ frühen Zeit der Dotterumwachsung. Auf Grund der gleichen Bedeutung, welche die Ränder der Primitivrinne bei den Vögeln und Reptilien mit den Rändern des Blastoporus der Amphibien und Fische für die Genese des mittleren Keimblattes haben, muss nothwẹdigerweise gefolgert werden, dass mit der Theilung des einheitlichen Urmundes in einen embryonalen und Dotterplastoporus, welche bei den Vögeln und Reptilien phylogenetisch sich vollzogen hat, auch eine Theilung der Functionen mit einhergegangen sei. Bei den Cyclostomen, Batrachiern u. s. w. findet zugleich mit dem Beginn der Gastrulation die Differenzirung des Entoderms statt. Jedoch steht ausserdem damit noch die Entwicklung des Mesodermsim engsten Zusammenhang, welche, wie wir wissen, von den verdickten Blasto-

1) Balfour, Handbuch der vergleichenden Embryologic. Uebersetzt von Vetter. pag. 260. 
poruslippen ausgeht. Bei den Vögeln nun, bei denen unserer Auffassung nach ein zweifacher Blastoporus existirt, macht sich zwischen beiden eine Arbeitstheilung in der Weise bemerklich, dass die verdickten Ränder des Dotterplastoporus bei der Umwachsung des Dotters die Vervollkommnung und die Ausbreitung des Entoderms übernehmen, während die Ränder des etwas später auftretenden embryonalen Blastoporus oder der Primitivrinne die Bildung des Mesoderms zu besorgen haben.

Die vorstehende Schlussfolgerung lässt sich mit unseren Kenntnissen über die Entwicklung des mittlern Keimblattes der Wirbelthiere sehr gut in Einklang bringen. Ueberblickt man die Mesodermbildung der einzelnen Vertebratenclassen, so wird man gewahr werden, dass diese in verschiedene ontogenetische Zeiträume fällt. Bei dem Amphioxus beginnt dieselbe verhältnissmässig spät, wenn die Gastrula bereits vollendet ist; es bilden sich zwei seitliche divertikelartige Ausstülpungen des Entoderms, welche nahe am Vorderende des Embryonalkörpers von der Darmhöhle abgehen, und nach rückwärts wachsen. Bei Fischen und Amphibien entsteht das Mesoderm zweifelsohne viel früher, bevor die Dotterumwachsung und damit die Gastrulabildung vollendet ist. Nach O. Hertwig's neueren Untersuchungen ${ }^{1}$ ) kommt bei Tritonen das Mesoderm durch einen Einfaltungsprocess zu Stande, der zu beiden Seiten des Blastoporus beginnt und sich von da nach rechts und links von der Medianlinie, wo aus dem Entoderm (Chordaentoblast) die Chorda entsteht, nach vorne fortsetzt. Damit stimmen die Angaben Balfour's für die Selachier vollständig überein. Bei den zwei genannten Wirbelthierarten tritt daher die Mesodermanlage nicht wie bei dem Amphioxus am vorderen Embryonalende als Entodermausstülpung auf, sondern sie erscheint an der Stelle, wo Ektoderm und Entoderm in einander übergehen, am Rande des Blastoporus. Bei den Vögeln endlich entsteht in einer ontogenetisch noch früheren Zeit das Mesoderm, und zwar vom Ektoderm aus; anfänglich kommt es dabei, wie bei den Tritonen, zu einer Art von Einfaltung (Primitivrinne); sehr bald wächst jedoch das mittlere Keimblatt als solide Platte nach beiden Seiten hin weiter und zeigt vor dem Primitivstreifen eine entschieden paarig symmetrische Anordnung, indem es nach vorne sich zu beiden Seiten der Medianlinie ausbreitet. Die letztere bleibt vom Mesoderm frei, dagegen verdickt sich längs derselben das Entoderm zu dem Kopffortsatz, aus dem die Chorda hervorgeht. Die Abstammung des Mesoderm von dem oberen Keimblatt, zu welchem Resultate fast alle neueren Bearbeiter der ersten Embryonalentwicklung der Vögel gekommen sind, verliert alles Auffällige, wenn man erwägt, dass die Primitivrinne mit ihren Rändern einem dorsalen Abschnitte des ursprünglich einheitlichen Blastoporus entspricht. Ebensowenig kann die Thatsache, dass das Mesoderm nicht sofort in zwei Lagen sich anlegt, bei der flachen Beschaffenheit der anfünglich nur dünnen Keimhaut des Hühnchens überraschen. Dass der embryonale Blastoporus des Hühnchens, die Primitivrinne, nicht rundlich ist, wie der ihr homologe Canalis neurentericus der Selachier, hat wohl seinen Grund in der Grösse des Hühnereies und seiner Keimhaut; es handelt sich hier darum, dem rasch auswachsenden Mesoderm möglichst viele

1) 1. c. Siche auch O. und R. Hertwig, Dic Coelomtheorie. Jena 1881. pag. 58. 
Ausgangspuncte zu gewähren, und diese finden sich natürlich am Rande einer langgezogenen Oeffnung in bei weitem grösserer Anzahl vor, wie an einer kleinen rundlichen. Auf diese Weise kann die Keimhaut in viel kürzerer Zeit eine ausgedehnte Mesodermlage erhalten.

Aus dem Gesagten ergibt sich, dass ich auf das Zustandekommen des Canalis neurentericus am Vorderende der Primitivrinne kein sonderliches Gewicht lege. Dieser ist eine secundäre Bildung und desswegen nicht dem gleichnamigen Canal der Selachier homolog, welcher den embryonalen Blastoporus repräsentirt. Beim Hühnchen dagegen fasse ich die ganze Primitivrinne als embryonalen Blastoporus auf, wenn auch nur deren vorderer Theil in die Embryonalanlage einbezogen wird. Ferner möchte ich hier nochmals darauf hinweisen, dass der Primitivstreif in die Area pellucida einwächst, und dass die seitlich von ihm abgehenden flügelförmigen Mesodermplatten nach vorne zu weit über sein vorderes Ende hinaus sich ausbreiten, indem sie dabei die Medianlinie, in der sich vor dem Kopfende des Primitivstreifens die Chorda entwickelt, freilassen. Der vordere Rand der Primitivrinne stellt demnach die dorsale Blastoporuslippe dar, welche sich topographisch zu Chorda und Mesoderm ebenso verhält, wie das homologe und gleichnamige Gebilde der Reptilien, Selachier, Amphibien, Cyclostomen etc. Daraus geht aber mit Nothwendigkeit hervor, dass der Haupttheil der Embryonalanlage sich vor dem Primitivstreifen anlegen muss; dass letzterer selbst, wie Rauber meint, zur Embryonalanlage sich ausbilden soll, ist mit den erörterten Anschauungen unvereinbar. In der nach vorne gerichteten Wachsthumsverlängerung der Embryonalanlage der Vögel liegt aber ein bedeutsamer Unterschied gegenüber den ihnen sonst ontogenetisch nahestehenden Selachiern. Noch grösser erscheint der Unterschied zwischen den Vögeln und Knochenfischen; bei diesen verlängert sich die Embryonalanlage in der früher auseinander gesetzten Weise bis zur Beendigung der Dotterumwachsung hauptsächlich nach rückwärts. Wir müssen demnach in der nach vorne gerichteten Verlängerung der Fruchtanlage der Vögel eine phylogenetisch durch Anpassung an die gegebenen Verhältnisse erworbene besondere Eigenthümlichkeit erblicken. Dass die veränderten Gestaltverhältnisse des Urmunds die eigenthümlich rinnenförmige Form des embryonalen Blastoporus (Primitivrinne), welche besonders gegenüber der rundlichen Beschaffenheit des gleichwerthigen Gebildes der Selachier überraschen muss, ebenfalls im Laufe der Stammesgeschichte durch Anpassung erworben sind, bedarf keiner weiteren Auseinandersetzung. Jedenfalls lassen die soeben angestellten Erwägungen zur Genüge erkennen, dass nur bei den Vögeln, Reptilien und Säugern Primitivrinne resp. Primitivstreifen als 'einander homologe Gebilde existiren, indem von ihnen bei den genannten Thieren die Mesodermbildung ausgeht. Von einer Primitivrinne der Amphibien und Fische zu sprechen, davon sollte man füglich absehen; dieser Ausdruck kann sich hier nur auf einen Theil der Rückenfurche beziehen und es wird demnach darunter etwas ganz anderes verstanden, als bei Vögeln und Säugern. Leidẹr hat $R$ auber es unterlassen, diesen Unterschied zu machen. Würde er es gethan haben, dann hätte er allerdings seine Auffassung bezüglich der Ausbildung des Primitivstreifens des Hühnchens zur Embryonalanlage fallen lassen müssen. $\mathrm{Zu}$ der letzteren Anschauung ist er wohl zweifellos durch seine 
Untersuchungen über die Entwicklung der Knochenfische und Haie veranlasst worden, welche ihm die Annahme nahe legten, dass auch die Embryonalanlage des Hühnchens in der gleichen Weise, nämlich auf conjunctivem Wege, zur Ausbildung gelange. Diese Uebertragung der bei Knochenfischen gewonnenen Resultate auf das Hühnchen bildet den wesentlichsten Punct unserer beiderseitigen Meinungsverschiedenheiten.

Das Ergebniss unserer Betrachtungen lässt sich kurz folgendermassen zusammenfassen:

Während bei den Selachiern die Theilung des gesammten Urmundes in einen embryonalen Blastoporus (Canalis neurentericus) und einen Dotterblastoporus (Dotterloch) in die Zeit der Ontogenie fällt, hat sich bei den Vögeln im Laufe der Stammesgeschichte eine nicht nur locale, sondern auch functionelle Trennung des ursprünglich einheitlichen Urmundes in den embryonalen und Dotterblastoporus oder in Primitivinne und Dotterloch voll$\mathrm{z} \circ \mathrm{g}$ e $\mathrm{n}$.

Nachdem wir durch die vorstehenden Erörterungen über die ersten Entwicklungsvorgänge der einzelnen Wirbelthierclassen, sowie über deren gegenseitige phylogenetische Beziehungen einen Ueberblick über die entwicklungsgeschichtlichen Grundlagen der Ra uber'chen Radiationstheorie gewonnen haben, bleibt uns noch übrig, die bekannt gewordenen frühzeitigen Fälle von Doppelbildungen der Vertebraten, von den Gesichtspuncten der genannten Theorie aus zu betrachten. Es wird sich dabei herausstellen müssen, ob dieselben sich auf das Princip der Radiation zurückführen lassen, und wir werden an ihnen die Richtigkeit und den Werth dieser Theorie am besten erproben können.

Was die Knochenfische anlangt, auf welche sich die beobachteten Fälle früher Mehrfachbildungen bei den niedern Vertebratenclassen fast ausschliesslich beschränken, so ist bereits an einer andern Stelle hervorgehoben worden, dass sich bei ihnen sämmtliche Formen von Doppelmonstra mittelst der Radiation genetisch erklären lassen, und ich schliesse mich in dieser Hinsicht den Ausführungen Rauber's vollkommen an. Wir hätten demnach nur noch die Classe der Vögel in den Kreis unserer Betrachtung zu ziehen, da weder bei den Reptilien noch den Säugern hinreichend frühe Entwicklungsstadien von Doppelbildungen bisher zur Wahrnehmung gelangten; nur solche aber gestatten, wie schon wiederholt betont wurde, Rückschlüsse auf den Bildungsmodus der betreffenden Monstrositäten.

Wie aus der gegebenen Definition der Radiationstheorie ersichtlich, können nur diejenigen Mehrfachbildungen der Vögel herangezogen werden, deren Componenten in einem gemeinsamen Fruchthofe zur Ausbildung gelangten. Es kommt demnach die Radiationstheorie für die biareale Entwicklung nicht in Betracht, und es erscheint somit begreiflich, dass Rauber in dem Bestreben, sä mmtliche Formen der Doppelbildungen mit Hülfe der Radiation zu erklären, bei dẹn Vögeln nur die monoareale Entwicklung zugelassen hat.

Die Art des Auftretens zweier Primitivstreifen resp. zweier Embryonalanlagen in einem gemeinsamen Fruchthofe, die verschiedenen Möglichkeiten 
hinsichtlich der Länge des ihre peripheren Enden trennenden Keimringbezirkes, sowie die sonstigen Umstände, von denen die ungemein variablen Ausgänge der monoarealen Entwicklung zweier Primitivstreifen abhängt, haben bereits in früheren Capiteln eine eingehende Behandlung erfahren. Wir sind dabei zu dem Resultate gekommen, dass unter den Hauptformen der Doppelmissbildungen sowohl die Monstra a posteriori parte duplicia als auch die Terata anakatadidyma in Folge der Entwicklung zweier Primitivstreifen in einer Area pellucida sich ausbilden. Die genannten Arten der Doppelmonstra sind demnach, was ihre ersten Entwicklungsstadien anlangt, auf das Princip der Radiation zurückzuführen. Nur bezüglich der für sich allein bestehenden vorderen Verdoppelungen (Diprosopus, Dicephalus) ist es nicht gelungen, die gleiche Entstehungsweise darzuthun, und wir waren gezwungen, für dieselben einen besondern Bildungsmodus anzunehmen, den ich als Bifurcation einer ursprünglich einheitlichen Embryonalanlage bezeichnete.

Unterzieht man die Doppelbildungen der Knochenfische, sowie die Terata anakatadidyma und die hintern Verdoppelungen der Vögel in Bezug auf den Beginn, den Verlauf und das Endresultat ihrer Entwicklung einem Vergleiche, so ergibt sich die höchst interessante Thatsache, dass die Anfangsstadien bei beiden die ğrösste Uebereinstimmung aufweisen, während die Ausgänge, d. h. die schliesslich zu Stande kommenden Formen der Doppelmissbildungen bedeutende Verschiedenheiten erkennen lassen. Bei den Vögeln, wie bei den Knochenfischen, treten die beiden Embryonalanlagen als Vorstösse des Keimrings auf; bei den ersteren entwickelt sich im Falle einer Vereinigung der beiden aus dieser Anlage unter allen Umständen eine Duplicitas posterior, (die hie und da mit einer Duplicitas anterior complicirt sein kann), bei den letzteren dagegen entsteht einzig und allein eine vordere Verdoppelung. Es führt demnach der gleiche Anfang der Entwicklung zu geradezu entgegengesetzten Endresultaten. An diesem Ausgang ist die totale Verschiedenheit der Embryonalbildung bei beiden Thierclassen Schuld. Die Embryonalanlage der Vögel stellt von ihren ersten Anfängen an einen wirklichen Vorstoss des Ringgebietes dar, indem der Primitivstreif von dem letzteren aus in die Mittelscheibe hineinwächst; die erste Embryonalanlage der Knochenfische dagegen ist, wie wir wissen, nur ein scheinbarer Vorstoss, der dadurch in Erscheinung tritt, dass eine Stelle des Keimrings bei dessen Ausbreitung über die Dotteroberfläche zurückbleibt, während die angrenzenden Abschnitte weiterrücken; erst wenn dies geschehen, macht die Embryonalanlage den Eindruck eines Vorstosses; besser noch kann man sich dieselbe als eine schlingenförmige Einbuchtung des Keimrings vorstellen; sie wächst dadurch nach rückwärts, dass sich die beiden Schenkel der Schlinge durch Association und in Folge der Conjunction der beiden Keimringhälften verlängern. Wie in den Fällen, in welchen der Keimring zwei Embryonalanlagen trägt, diese beiden sich nähern, zusammentreten und sodann der restirende Körpertheil sich einheitlich anlegt, wodurch eine Duplicitas anterior entsteht, ist bereits erörtert worden. Bei den . Vögeln jedoch findet die Verlängerung der Embryonalanlage in Folge des activen Einwachsens derselben in die Mittelscheibe nicht nach rückwärts, sondern nach vorwärts statt. Sind nun zwei Fruchtanlagen resp. zwei Primitivstreifen vorhanden, so müssen sie wegen ihrer radiären Anordnung nach vorne 
zu mehr oder weniger convergiren. Es werden also gerade ihre vorderen Enden der Vereinigung am meisten ausgesetzt sein.

Dieser verschiedene Ausgang der Entwicklung nach dem Auftreten zweier Embryonalanlagen, wie er uns bei Vögeln und Knochenfischen entgegentritt, muss sich dadurch documentiren, dass bei den ersteren mit nur sehr wenigen Ausnahmen hintere Verdoppelungen, bei den letzteren dagegen vorwiegend vordere Verdoppelungen beobachtet werden. Es scheint mir dies von Neuem dafür zu sprechen, dass bei den Vögeln zum Aufbau der Embryonalanlage der Keimring keine embryoplastische Verwendung findet.

Der verschiedene Entwicklungsmodus der Fruchtanlage klärt auch die Thatsache auf, dass bei Vögeln Doppelembryonen mit verwachsenen Köpfen häufig, bei den Fischen dagegen derartige Monstrositäten niemals zur Beobachtung gelangen. Bei letzteren ist, selbst wenn die beiden Fischembryonen sich direct gegenüberstehen, d. h. in Oppositionsstellung sich befinden, ein Verwachsen der Kopfenden geradezu unmöglich, weil ja der zuerst vom Keim. ringe sich abhebende Theil der Embryonalanlage, welcher später zu dem Kopf sich umbildet, bei der weiteren Ausbildung der letzteren nach rückwärts nicht von der Stelle rückt.

Es ist oben bemerkt worden, dass Rauber auch die vorderen Verdoppelungen der Vögel sich nach der Radiationstheorie zurecht zu legen sucht. R. gibt zu, dass gerade diese Form der Doppelmissbildung besondere Schwierigkeiten für die Erklärung darbiete, und dass wegen der Seltenheit der hieher gehörigen Fälle über ihre Auffassung noch Zweifel bestehen können, wesshalb weitere Beobachtungen frühzeitiger Doppelmissbildungen dieser Art abzuwarten seien. Von seinen Anschauungen ausgehend, wonach der mittlere und hintere Abschnitt der Embryonalanlage durch Conjunction ins Leben trete, ist Rauber geneigt, im Falle einer Doppelbildung unter der Voraussetzung einer nur geringen Entfernung zwischen den beiden radiär gestellten Primitivstreifen eine forcirte Conjunction anzunehmen, wodurch die peripheren Enden der beiden letzteren einander näher gebracht würden und schliesslich der hintere Körperabschnitt nur einfach sich anlegen würde. Die Folge dieses hypothetischen Vorganges müsste eine allmählige Axenverschiebung der beiden Primitivstreifen sein, indem sie nach und nach aus ihrer anfïnglichen Convergenzstellung in eine nach vorne zu divergente Verlaufsanordnung übergeführt würden.

Ferner hält R. es für möglich, dass zwei anfünglich dicht neben einander gelegene und darum nahezu parallele Primitivstreifen durch den Vorgang der Conjunction in eine vordere Divergenzstellung gebracht werden könnten. Auch eine schon von vorneherein bestehende schwache Divergenz der Primitivstreifen, wie dies zuweilen bei zwei bis zur Berührung genäherten vorderen Embryonalanlagen der Knochenfische vorkomme, sei nicht undenkbar. Schliesslich hat nach Rauber die Annahme eine gewisse Wahrscheinlichkeit für sich, dass zwar zwei vordere Embryonalanlagen mit schwacher vorderer oder hinterer Divergenz zur weitern Ausbildung gelangen, nicht aber auch deren übrige Körperabschnitte, indem nur von einer derselben der restirende 'Theil des Embryonalkörpers vollendet werde, während er bei der andern atrophiren würde. Auch so könnten zwei Köpfe und nur ein Rumpf zur Entstehung kommen. 
Alle diese Vermuthungen Rauber's basiren mehr oder weniger auf der von ihm supponirten conjunctiven Bildung der Embryonalanlage. Ebensowenig als ich mich dieser Ansicht anzuschliessen vermag, kann ich mich mit der Annahme einer durch Conjunction zu Stande kommenden Vereinigung der peripheren Enden zweier Primitivstreifen befreunden. Ich erinnere hier nur daran, dass ich gerade $\mathrm{zu}$ den entgegengesetzten Resultaten gelangt bin, wonach die peripheren Enden zweier von sehr nahe gelegenen Stellen aus in die Area pellucida einstrahlender Primitivstreifen durch die Wachsthumsenergie der zwischen ihnen liegenden Mesodermtheile auseinandergedrängt werden.

Nachdem wir die Vorzüge, wie die Schwächen der Rauber'schen Radiationstheorie gewürdigt haben, will ich zum Schluss meine Ansicht über dieselbe in kurzen Worten darlegen:

Die Theorie der Radiation, welche die normalen Entwicklungsgesetze auch für diejenigen Fälle verwerthet, in denen statt einer zwei oder mehrere Embryonalanlagen von einem gemeinsamen Keimringe aus sich zu entwickeln beginnen, nimmt unter den andern über die Genese der Doppelbildungen aufgestellten Theorien bei Weitem den ersten Rang ein. Der durch das Princip der Radiation ausgesprochene Bildungsmodus der Doppelmissbildungen ist jedoch nicht der alleinige. Die Radiation trifft in der von Rauber ihr zugeschriebenen Ausdehnung nur für die niederen Wirbelthiere (Knochenfische) zu, bei den höheren Vertebraten (Vögeln) kommtausserihrnoch eine zweite Entstehungsart, die Bifurcation, in Betracht.

Endlich sei noch darauf aufmerksam gemacht, dass durch die Radiationstheorie eine von Seiten der Teratologen vielfach discutirte Erscheinung ihre höchst einfache und natürliche Erklärung findet. Ich meine die bei Doppelmissbildungen höheren Grades (vollkommenen Axenduplicitäten) sofort in die Augen fallende Thatsache, dass die beiden Componenten derselben an gleichartigen Körpertheilen mit einander verbunden sind. Ge offroy St. Hilaire hat dieses Vorkommen auf die Verwandtschaft des Gleichen zum Gleichen zurückgeführt; jedoch ist das Gesetz de l'affinité de soi pour soi nur ein anderer Ausdruck für die in Rede stehende Thatsache, ohne dass dadurch eine ursächliche Begründung derselben geboten wäre. Auch ist ihr weder von Seiten der Spaltungs- noch der Verwachsungstheorie eine befriedigende Erklärung zu Theil geworden. Hingegen ist durch das Wort „Radiation“ allein schon die Ursache der genannten Erscheinung namhaft gemacht. Es ist die radiäre Anordnung der beiden Embryonalanlagen, welche im Falle zu grosser Nähelage derselben nothwendiger Weise zu einer Vereinigung an gleichartigen Regionen und Organen führen muss. Sind die beiden Embryonalanlagen einander oppositionell gegenübergestellt, oder bilden sie einen rechten oder stumpfen Winkel, so werden nur die Kopfenden mit einander verschmelzen können; liegen ihre Längenaxen neben einander, so wird die Vereinigung die seitlichen Körpergegenden und zwar in gleichen Höhenabschnitten betreffen. Das Nähere hierüber ist bereits an einem andern Orte ausführlich besprochen worden. 


\section{Schlussbetrachtungen.}

Die vergleichende Prüfung sämmtlicher Fälle frühzeitiger Mehrfachbildungen, welche bei höheren Vertebraten beobachtet und beschrieben wurden, hat dazu geführt, gewisse Gesetze aufzudecken, nach denen die Entwicklung der verschiedenen Formen der Doppelmissbildungen vor sich geht. Jedoch ist dabei zu erinnern, dass diese Gesetze streng genommen nur für die Vögel Geltung beanspruchen können, da unter den höheren Wirbelthierclassen nur allein bei den Vögeln Fälle frühzeitiger Doppelbildungen bekannt geworden sind. Es wird sich nun fragen, ob man berechtigt ist, den für die Classe der Vögel erkannten Bildungsmodus der einzelnen Formen der Axenverdoppelungen auch auf die Reptilien und Säugethiere zu übertragen. Dies wird meines Erachtens nur dann zu gestatten sein, wenn gegen ein solches Vorgehen sich von Seiten der Entwicklungsgeschichte der letztgenannten Thiere kein Einwand erheben lässt. Es kommt daher wesentlich auf den Grad der Uebereinstimmung an, welchen die Reptilien, Vögel und Säugethiere bezüglich ihrer Ontogenie aufweisen. Würden hier solche Verschiedenheiten vorkommen, wie beispielsweise zwischen den Vögeln und Knochenfischen, so wäre auch ein gleicher Bildungsmodus der Doppelmonstra unannehmbar; denn, wie wir wissen, entsteht die gleiche Form der Doppelmissbildung, die Duplicitas anterior, bei den Knochenfischen auf ganz andere Weise wie bei den Vögeln; bei den ersteren anf dem Wege der Radiation, bei den letzteren durch Bifurcation.

Es ist jedoch die Entwicklung der drei höchststehenden Vertebratenclassen in den Anfangsstadien der Embryonalbildung eine ungemein gleichartige. Es tritt im Gegensatz zu den Fischen und Amphibien bei ihnen ein Primitivstreifen auf, welcher von der Peripherie nach der Mitte der Embryonalzone, mag dieselbe nun Embryonalfleck oder Embryonalschild heissen, einwächst und demnach eine radiäre Verlaufsrichtung einhält. Von dem Primitivstreifen aus, der bald eine mehr oder weniger vertiefte Rinne erhält, entwickelt sich nach beiden Seiten hin das Mesoderm, das in seiner vor den Primitivstreifen fallenden Ausbreitung ein entschieden paarig symmetrisches Verhalten zeigt. Vor dem Kopfende des Primitivstreifens entsteht als Entodermverdickung der Kopffortsatz, aus ihm die Chorda. Zu gleicher Zeit leitet sich die Bildung der Medullarrinne, der Medullarwülste ein, die sich nach rückwärts verlängern und den Primitivstreifen, sei es nur stückweise oder gänzlich, seitlich umschliessen. Alle diese Entwicklungsvorgänge kommen den 
drei höchststehenden Wirbelthierclassen gemeinsam zu. Es sind daher auch die gleichen Vorbedingungen für die Genese der Mehrfachbildungen und Doppelmonstra gegeben. Ein radiäres Einwachsen zweier Primitivstreifen in die Embryonalzone lässt sich bei den Reptilien wie bei den Säugern sehr wohl denken. Dies hätte zur Folge, dass der Bezirk der Embryonalzone zur Hälfte von dem einen, zur Hälfte von dem andern Primitivstreifen auf ganz die gleiche Weise in Anspruch genommen wird, wie es bei einer frühern Gelegenheit für das Hühnchen genauer ausgeführt wurde. Ebensogut wie die Annahme einer Radiation, ist die einer Bifurcation bei Reptilien und Säugern zulässig; denn auch bei ihnen wächst ja der Primitivstreifen und nach dessen vollständiger Ausbildung der Kopffortsatz, d. h. die werdende Chorda, nach vorne, und es liegt daher ebenfalls die Möglichkeit vor, dass die Embryonalanlage, nachdem sie eine Zeitlang bei ihrem Vorwachsen die Mittellinie eingehalten hat, nach beiden Seiten hin gabelig in zwei Schenkel divergirt, wodurch der Anlass zu einer künftigen vorderen Verdoppelung gegeben wird.

Es steht demnach der Annahme, dass auch bei den Reptilien und Säugern die Doppelmonstra sich in wesentlich derselben Weise anlegen und ausbilden, wie bei den Vögeln, von Seiten der Entwicklungsgeschichte „nicht nur kein Hinderniss entgegen, sondern die grosse Uebereinstimmung der Embryogenie bei den höhern Wirbelthieren macht es fast zur Gewissheit, dass bei ihnen auch die Teratogenie der Doppelmissbildungen nach den gleichen Regeln sich vollzieht.

Die Resultate meiner Untersuchungen; über welche in den einzelnen Capiteln dieser Monographie berichtet worden ist, haben nicht allein auf den Entstehungsmodus der Doppelmissbildungen Bezug, über deren Aussehen und Form sie in den verschiedenen Stadien ihrer Ausbildung. Aufklärung geben, sondern dieselben sind auch zum Theil der Art, dass sie nicht unwichtige Folgerungen in Betreff der den Doppelbildungen zu Grunde liegenden ursächlichen Momente gestatten. Den letzteren möchte ich an dieser Stelle noch eine kurze Erörterung zu Theil werden lassen.

Die Genese der Doppelbildungen kann allem Anscheine nach durch sehr mannigfache Umstände veranlasst werden; so wird man zunächst an eine besondere Eigenthümlichkeit des weiblichen Zeugungsproductes, des Eies denken können. Das Gleiche kann aber auch für den männlichen Zeugungsstoff supponirt werden, indem möglicherweise dem das Ei befruchtenden Spermatozoon eine aussergewöhnliche Beschaffenheit zukommt, wodurch auf die Furchung und Entwicklung eine Einwirkung nach der angedeuteten Richtung hin ausgeübt wird. Ferner kann ein irregulärer Befruchtungsvorgang bei ursprünglich normalen Geschlechtsproducten, die aber durch zufällige Einflüsse, denen sie ausgesetzt waren, eine Veränderung erlitten haben, in das Auge gefasst werden. Diesen verschiedenen Eventualitäten gesellen sich solche Momente hinzu, die • von aussen her die Entwicklung des Eies zu modificiren im Stande sind. Hier kommen Temperaturschwankungen der Umgebung des Eies, Veründerungen der normalen Respirationsverhältnisse, sowie mechanische Einwirkungen in Betracht. 
Damit sind in der Hauptsache alle Möglichkeiten angedeutet worden, von denen anzunehmen ist, dass sie die Genese von Doppelbildungen bedingen können. Es ist mehrfach die Meinung ausgesprochen worden, dass sämmtliche Doppelbildungen auf die gleiche Ursache zurückzuführen seien; ich erinnere an die Theorie B. Schultze's, welcher die Gegenwart zweier Keimbläschen in einem $\mathrm{Ei}$ als die alleinige Ursache hinstellt; ebenso pflegen die Anhänger der Spaltungstheorie nur äussere Einwirkungen gelten zu lassen, durch welche die Keimanlage in grösserer oder geringerer Ausdehnung longitudinal durchtrennt werden könne.

Im Hinblick auf die äusserst mannigfaltigen Formen und die wechselnde Ausdehnung der Axenverdoppelungen - ich möchte hier als Extreme die Duplicität der Hypophysis als den geringsten Grad vorderer Verdoppelung und die xyphopagen Doppelmissbildungen einander gegenüberstellen - erscheint mir die eben genannte Annahme von nur einer Entstehungsursache für sämmtliche Arten der Doppelmonstra und Mehrfachbildungen höchst einseitig; insbesondere dürften die Ergebnisse meiner Untersuchungen darthun, dass in dem einen Falle diese, in dem andern Falle jene Ursache die Genese der betreffenden Doppelbildung hervorrufen könne.

Zunächst möchte ich anknüpfen an die Erwägungen, welche über das Zustandekommen der biarealen Entwicklung angestellt wurden. Durch dieselben vermochten wir auf dem Wege der Exclusion den Nachweis zu führen, dass die Ursache der genannten Erscheinung darauf beruht, dass in einer sehr frühen Zeit der ovarialen Eientwicklung statt einer zwei Eizellen von einem gemeinsamen Follikel und in Folge dessen später auch von einer gemeinsamen Dottermembran umschlossen wurden. Das Nähere hierüber ist bereits früher auseinandergesetzt worden ${ }^{1}$ ). Es liegt daher die Ursache für die hier in Frage kommenden Doppelbildungen auf der weiblichen Seite. Jedoch ist zu bemerken, dass die biareale Entwicklung nur bei den Vögeln zur Beobachtung gelangte; bei den Säugethieren, welche sich hinsichtlich der zwischen Eizelle und Follikel bestehenden Wechselbeziehungen ganz anders verhalten, wie die Vögel und Reptilien, sind die Bedingungen für den Einschluss zweier Eizellen in eine gemeinsame Ziona pellucida nicht gegeben. Ferner sei erwähnt, dass bei den Vögeln die Bildung zweier Embryonen in gesonderten durchsichtigen Fruchthöfen nicht zu eigentlichen Doppelmonstrositïten, wenn wir uns der Dareste'schen Auffassung anschliessen wollen, führt, sondern nur zur Ausbildung von zwei Zwillingsembryonen, die sich am Ende ihrer Entwicklung nicht zu trennen vermögen, und desshalb Omphalopagen darstellen.

Was die monoareale Entwicklung von Mehrfachbildungen anlangt, so können meines Erachtens für deren Auftreten sämmtliche der oben genannten Ursachen, in dem einen Fall diese, in dem andern Fall jene, die Veranlassung gegeben haben. Wir wollen dieselben in zwei Kategorien abtheilen, indem wir diejenigen Momente, welche vor der Furchung die Entwicklung in dem bewussten Sinne beeinflussen, trennen von denjenigen, welche dies erst nach der Furchung zu thun im Stande sind. Die ersteren entziehen sich zur Zeit

1) Seite $158-160$. 
noch jeder eingehenderen Beurtheilung; es fehlen hierzu noch die nöthigen morphologischen Anhaltspuncte, da einerseits über eine absonderliche Beschaffenheit der männlichen und weiblichen Zeugungsstoffe - es lässt sich hier an ein doppeltes Keimbläschen und dergleichen beim Eie, an eine aussergewöhnliche Grössenentfaltung des Kopfes bei den Spermatozoen denken so gut wie keine Erfahrungen vorliegen, andererseits ungeachtet der schönen neueren Untersuchungen über die Befruchtung von O. Hertwig, Fol und Anderen dennoch die Pathologie und Anomalien dieses Vorganges noch zu wenig aufgedeckt sind. Wenn wir demnach auch nicht in der Lage sind, über die angedeuteten Verhältnisse uns klare Vorstellungen zu bilden, so wird man doch nicht daran zweifeln dürfen, dass in gewissen Fällen, sei es vor, sei es in Folge der Befruchtung, dem Eie eine abnorme Leistungsfähigkeit zu Theil wird, mag diese auf einem Ueberschuss an Bildungsmaterial oder auf einer Steigerung der Entwicklungsenergie beruhen, welche sich nach der Furchung in dem Auftreten einer Mehrfachbildung äussert.

Nach der Ansicht von Rauber ist es bereits zu der Zeit, in welcher die Furchung beginnt, entschieden, ob ein Einzelembryo oder eine Mehrfachbildung sich entwickeln wird. Rauber hält es demnach für unmöglich, dass äussere Ursachen, die nach der Furchung einwirken, Mehrfachbildungen zu Wege bringen können. Er nennt das Princip, nach welchem ein Ei und ein Keim entweder durch die Befruchtung oder schon vor derselben die Kraft der Entwicklung einer Mehrfachbildung besitzt, das Princip der monogerminalen primitiven Pluralität. Der Annahme von Rauber, dass bereits mit der Furchung eines Eies der Vollzug seiner jeweiligen Bestimmung begonnen hat, d. h., dass schon durch dieselbe auf das prädestinirte Endproduct der Entwicklung hingearbeitet wird, kann ich nicht beistimmen, da ich der Meinung bin, dass auch noch nach der Furchung auf die Gestaltung des sich bildenden Organismus ein bestimmender Einfluss ausgeübt werden kann. Nach R. müsste jeder Form der Doppelmissbildungen eine ganz bestimmte Art des Furchungsvorganges entsprechen, was mir nicht recht einleuchten will.

Die äusseren Ursachen, die erst nach der Furchung die Entwicklung auf abnorme Bahnen lenken, zerfallen, wie ich bei einer anderen Gelegenheit auseinandergesetzt habe, in mechanische, thermische und respiratorische; dieselben können sich auch mit einander combiniren. Während nach den bisherigen Untersuchungen der Einfluss der mechanischen und thermischen Einwirkungen auf die Entwicklung von Mehrfachbildungen noch nicht sicher nachgewiesen worden ist, haben meine am Vogelei angestellten Versuche, künstlich Doppelbildungen hervorzubringen, gezeigt, dass sich dieses Ziel durch eine Veränderung der normalen Respirationsverhältnisse erreichen lïsst. Sobald aber feststeht, dass auf experimentellem Wege Doppelbildungen hervorgerufen werden können, dann wird man erwarten dürfen, dass Einwirkungen ähnlicher Art, wie die künstlich hergestellten, der Genese eines Theiles der bei Sängern und Vögeln beobachteten Doppelmissbildungen zu Grunde gelegen haben.. Ich würde es für verfehlt halten, wollte man hier die respiratorischen allein in den Vordergrund stellen; ebensogut werden dabei wohl auch thermische und mechanische Momente eine Rolle spielen. Allerdings ist in dieser Hinsicht der Vermuthung ein weiter Spielraum gelassen, da man sich ja eine 
Reihe von Umständen vorstellen kann, unter denen Einwirkungen, wie die genannten, statt haben können.

Es ist hier noch eine weitere Frage zu berücksichtigen. Diese betrifft den Grad und die Form der Verdoppelung, welche durch äussere Einwirkungen verursacht werden können. Es wird schwer halten, selbst bei einem so zugänglichen Objecte, wie dem Vogelei, zu einer bestimmten Entscheidung darüber zu gelangen, ob in einem $\mathrm{Ei}$, in welchem ohne von aussen kommende Störungen sich ein normaler Einzelembryo entwickelt haben würde, durch das Eingreifen derselben die Genese von zwei Embryonalanlagen eingeleitet werden könne. Bei den bisherigen Untersuchungen, welche eine künstliche Herstellung der Doppelbildungen bezweckten und von Erfolg belohnt wurden, war es nur auf eine Duplicitas anterior abgesehen. Ob sich auch die andern Formen der Axenverdoppelungen durch äussere Einwirkungen hervorrufen lassen, oder ob hierzu bereits vor oder durch die Befruchtung die Veranlassung gegeben sein muss, darüber lässt sich zur Zeit noch kein endgültiges Urtheil abgeben. Man wird desshalb noch weitere experimentelle Untersuchungen, welche ein ähnliches Ziel, wie die von mir angestellten, verfolgen, abzuwarten haben.

Bei der monoarealen Entwicklung der Mehrfachbildungen haben wir zwei Vorgänge unterscheiden müssen, die als Radiation und Bifurcation bezeichnet wurden. Erstere beruht auf der Anlage und Ausbildung zweier Primitivstreifen, wodurch die Entwicklung von zwei Embryonen angebahnt wird, die entweder vollständig getrennt bleiben, oder sich gegenseitig in der weiteren Entwicklung stören können; in letzterem Falle entsteht dann eine Doppelmissbildung. Die Bifurcation hingegen setzt eine ursprünglich einheitliche Embryonalanlage voraus, die bei dem Einstrahlen in die Area pellucida in zwei Schenkel divergirt. Wie in Folge derselben vordere Verdoppelungen eintreten, ist des Oefteren erörtert worden. Hier möchte ich nur noch auf die Frage eingehen, ob durch die Bifurcation unter Umständen auch zwei gesonderte Embryonen ins Leben treten können, die bei den Vögeln am Ende der Bebrütung und Entwicklung in der Nabelgegend sich mit einander zu einer Omphalopagie verbinden. Diese Frage muss, wie ich glaube, bejaht werden; in solchen Fällen nämlich, in denen die Bifurcation sehr frühe erfolgt, werden die doppelt angelegten Theile des Primitivstreifen eine grössere Längenausdehnung erlangen. Entsteht dann vor jedem derselben je eine Rückenfurche, so werden die sich nach hinten verlängernden Rückenwülste die vordern Abschnitte der beiden Schenkel des Primitivstreifen seitlich umfassen, sich aber nicht nach rückwärts bis zur Bifurcationsstelle erstrecken. Auf diese Weise würden zwei vollkommene Embryonalanlagen entstehen, welche, wenn die nicht von den Medullarwülsten eingeschlossenen Theile des Primitivstreifen sich rückgebildet haben, keinen genetischen Zusammenhang mehr erkennen lassen. Zur Veranschaulichung dieser Verhältnisse dient die schematische Fig. 5, Taf. VII.

Man kann ferner die Bifurcation schon in eine Zeit verlegen, in welcher die Area pellucida überhaupt noch keinen Primitivstreifen enthält, es aber 
bereits im hintern Theile des Ringgebietes zur Bildung einer Sichel gekommen ist, von der aus zwei nach vorne divergirende Primitivstreifen in den durchsichtigen Fruchthof einstrahlen. Vielleicht mag es sich in dem unter Nr. 2 angeführten Falle meiner experimentellen Untersuchungen (Fig. 2, Taf. VIII) um das Anfangsstadium eines solchen Verhaltens, wie wir es eben supponirt haben, handeln. Den Fällen, in welchen die Entwicklung zweier Primitivstreifen von einer gemeinsamen Sichel ausgeht, würden diejenigen wiederum sehr nahe stehen, in welchen zwar anfänglich zwei gesonderte Sicheln mit je einem Primitirstreifen aufgetreten sind, bei denen es aber wegen der grossen Nähe beider Sicheln sehr bald zu einer Vereinigung der einander zugewendeten Enden dieser Gebilde kommt. So wäre denn durch die Verschmelzung der beiden eine gemeinsame Sichel zu Stande gebracht worden, von der zwei Primitivstreifen centralwärts abgehen. Der zuletzt angenommene Fall würde jedoch nicht mehr auf einer Bifurcation, sondern bereits auf einer Radiation beruhen. Man sieht, wie diese beiden der Entwicklung der Doppelmissbildungen zu Grunde liegenden Entwicklungsprincipien keineswegs sich unvermittelt gegenüberstehen, indem die $z$ wischen ihnen liegende Kluft durch leicht $\mathrm{zu}$ construirende Uebergangsformen sich ausfüllen lässt.

Zum Schlusse stelle ich die hauptsächlichsten Resultate meiner Untersuchungen nebeneinander.

1) Bei den Vögeln muss zwischen der biarealen und der monoarealen Entwicklung der Mehrfachbildungen unterschieden werden. Den Säugethieren kommt nur die letztere zu. Die biareale Entwicklung zieht die Genese von gesonderten Zwillingsembryonen nach sich, die jedoch am Ende der Entwicklung, da sie sich nicht gänzlich zu trennen vermögen, zú omphalopagen Zwillingen werden. Die monoareale Entwicklung führt einerseits bei den Säugern zu durchaus getrennten, bei den Vögeln zu omphalopagen Zwillingen, andererseits zu den verschiedenen Formen der Doppelmissbildungen.

2) Die monoareale Entwicklung kann sich auf zweierlei Art vollziehen, nach dem Principe der Radiation und nach dem der Bifurcation. Der eine wie der andere Bildungsmodus kann sowohl getrennte Zwillinge, resp. bei Vögeln Omphalopagen, als Doppelmissbildungen hervorbringen. Letztere anlangend, so kommt für die Genese der Terata anakatadidyma und der hinteren Verdoppelungen die Radiation, für die Genese der vorderen Verdoppe-lungen die Bifurcation in Betracht.

Die Bifurcation steht bezüglich der Häufigkeit ihres Vorkommens bei den Vögeln weit hinter der Radiation zurück.

3) Bei der Radiation strahlen zwei (oder drei) Embryonalanlagen in die Area pellucida unter einem wechselnden Convergenzwinkel ein; die Grösse . desselben hängt von dem Grade der Entfernung ab, welche zwischen den beiden peripheren Enden der Embryonalanlagen liegt.

4) Es scheinen jedoch gewisse Winkelstellungen besonders häufig wiederzukehren, so dass mit Rücksicht darauf die bekanntgewordenen Doppelbil- 
dungen leicht in verschiedene Abtheilungen gebracht werden können. Am zweckmässigsten dürften sich die vorliegenden Fälle in drei Gruppen eintheilen lassen, welche folgendermassen zu characterisiren sind.

I. Die Embryonalanlagen strablen neben einander ein (geringe Entfernung zwischen den peripheren Enden und desshalb nur schwache Convergenz).

II. Die Embryonalanlagen strahlen unter einem rechten oder stumpfen Winkel ein.

III. Die Embryonalanlagen strahlen in Oppositionsstellung, d. h. unter einem Winkel von $180^{\circ}$ ein.

Unter den veröffentlichten Fällen frühzeitiger Doppelbildungen findet sich die recht- oder stumpfwinklige Stellung der beiden embryonalen Längenaxen am häufigsten vor; demnach umfasst die zweite Gruppe die meisten Fälle. Hierauf folgt die erste Gruppe, während verhältnissmässig selten Oppositionsstellungen der Embryonalanlagen vorzukommen scheinen, so dass die dritte Gruppe am schwächsten vertreten ist.

5) Bei den der ersten Gruppe angehörigen Doppelbildungen kommt es in Folge der Nähelage beider Primitivstreifen zu einer Lageverschiebung derselben, welche durch die Wachstbumsenergie des zwischen ihnen liegenden Mesodermabschnittes verursacht wird. Die Lageverschiebung ist eine ungleichmässige, indem die peripheren Enden mehr, die vorderen oder die Kopfenden der beiden Streifen weniger von einander entfernt werden. Ferner ist die Lageverschiebung in dem einen Falle eine ergiebigere, als in dem andern. Von der Stärke derselben, d. h. von der schliesslich erreichten Entfernung der Kopfenden beider Primitivstreifen hängt das weitere Schicksal der beiden Embryonalanlagen wesentlich ab. So kommt es, je nachdem die Kopfenden der beiden Streifen mehr oder weniger auseinandergedrängt worden sind, zu einer parallelen oder zu einer schwach convergenten, oder sogar zu einer geringgradig divergenten Stellung der sich entwickelnden Kopffortsätze, d. h. der Chordae dorsales. Ausserdem hängt von der Stärke der Lageverschiebung die Entfernung zwischen den beiden Chordae dorsales ab. Entstehen nun durch das Auftreten der Rückenwülste die Medullarfurchen, so muss eine zu grosse Nähe der beiden Chordae unausbleiblich zu Entwicklungsstörungen führen. In Bezug auf dieselben macht sich der Grundsatz geltend, dass sich überall da, wo die Chordae bis auf eine gewisse Distanz (Copulationsnähe) aneinandergerückt erscheinen, die Rückenfurche nur einfach anlegt; unter den Boden derselben kommen dann die betreffenden Abschnitte der beiden Chordae zu liegen. Befinden sich beispielsweise die vorderen Abschnitte der Chordae im Bereiche der Copulationsnähe, so werden dieselben an dieser Stelle von den Wülsten einer einheitlichen Rückenfurche umfasst, und es unterliegen dadurch die beiden Embryonalanlagen innerhalb der genannten Region einer Vereinigung; dieser Vorgang kann als Copulation bezeichnet werden. Ebenso, wie die vorderen, so können auch andere Abschnitte der Chordae in grösserer oder geringerer Ausdehnung durch Copulation mit einander verbunden werden.

6) Durch den Vorgang der Copulation kommt die primäre Vereinigung zweier Embryonalanlagen zu Stande, welche der secundären Vereinigung oder der Verwachsung gegenüberzustellen ist. Die Copulation hat eine partielle 
Einfachheit des Rückenmarks und der Wirbelsäule zur Folge, während eine Verwachsung bei solchen Doppelmissbildungen stattgefunden haben muss, deren Componenten durchaus getrennte Wirbelsäulen besitzen. Die Verwachsung muss sich in gleicher Weise, wie die Copulation wegen der radiären Anordnung der beiden Embryonen immer in derselben Höhe, d. h. an gleichen Regionen vollziehen. Es können sowohl die Kopftheile, als die mittleren Rumpfabschnitte beider Embryonen verwachsen; auch kommt eine Vereinigung an beiden Stellen zugleich vor.

$\mathrm{Je}$ nachdem die primäre oder secundäre Vereinigung die vorderen oder die mittleren Regionen der beiden Embryonalkörper oder beide zugleich betrifft, entwickeln sich hintere Verdoppelungen oder Terata anakatadidyma.

7) Bei den zwei Componenten einer Mehrfachbildung, welche der zweiten oder der dritten Gruppe einzureihen ist, ist die Anordnung der embryonalen Längenaxen der Art, dass eine primäre Vereinigung nicht gut möglich ist, wenigstens war dieselbe für alle hierher gehörigen Fälle auszuschliessen. Dagegen sind vorzugsweise die Bedingungen für eine Collision der Kopfenden beider Embryonen gegeben. Demgemäss findet man bei den Doppelmissbildungen der zweiten Gruppe theils eine mehr oder minder tiefgehende Verschmelzung der beiden Köpfe, wodurch dieselben sogar als ein äusserlich zwar einfaches, dagegen in hohem Grade missgestaltetes Gebilde erscheinen können, theils aber auch nur einen mehr oberflächlichen Zusammenhang der beiden Köpfe, ferner der Hals- und Brustgegend. Bei den opponirt einstrahlenden Embryonalanlagen der dritten Gruppe endlich treffen im Falle einer Verwachsung die Köpfe direct auf einander, woraus verschiedene Formen der Kraniopagen resultiren.

8) Hinsichtlich der Lage der beiden Embryonen einer Doppelbildung im Gesammtei hat es sich herausgestellt, dass in vielen Fällen eine der beiden Embryonalanlagen diejenige Lage im Innern des Vogeleies einnimmt, welche in der Norm einem Einzelembryo zukommt; dieselbe kann darum als Normalstellung bezeichnet werden. Bei den Fällen der ersten Gruppe nimmt keiner der beiden Componenten der Doppelbildung die Normalstellung ein; diese würde in die Mitte zwischen beide Embryonen fallen. Dagegen hat man bei den Doppelbildungen der zweiten und dritten Gruppe zwischen einem die Normalstellung einnehmenden Stammembryo und dem zweiten oder accessorischen Embryo zu unterscheiden. In Fällen ungleicher Entwicklung beider Embryonen ist es vermuthlich der minder günstig situirte accessorische Embryo, welcher in der Ausbildung zurückbleibt.

9) Die Bifurcation geht im Gegensatz zur Radiation in der Weise vor sich, dass nur eine einzige Embryonalanlage in die Area pellucida einstrahlt, welche in ihrer weiteren nach vorwärts gerichteten Ausbildung bald früher, bald später die Medianlinie verlässt, um gäbelig divergirend in zwei Schenkel auszulaufen. Jeder dieser Schenkel entspricht dem bei Beginn der Bifurcation noch nicht gebildeten Theile der Embryonalanlage, so dass dieselbe vor der Bifurcationsstelle sich doppelt entwickelt, während sie hinter derselben einheitlich erscheint. Daraus ergibt sich, dass durch die Bifurcation die Doppelmissbildungen mit vorderer Duplicität ins Leben treten, deren höhere Grade (Ischio- 
pagus) ein frühzeitigeres Eintreten der Bifurcation voraussetzen, als diejenigen Formen der vorderen Verdoppelung, welche nur die Kopf- und Gesichtstheile betreffen (Diprosopus, Dicephalus),

10) Der Winkel, unter welchem bei der Bifurcation die doppelt sich anlegenden Embryonaltheile auseinanderweichen (Divergenzwinkel) ist ein wechselnder. Mit der Grösse desselben nimmt die Trennung und damit die Selbstständigkeit der doppelt gebildeten Körperabschnitte zu. 


\section{Tafelerklärungen.}

\section{Tafel I.}

Die in den Figuren 1-7 wiedergegebenen Keimhäute wurden, nachdem ihre Umrisse mittelst des Camera clara entworfen worden waren, bei auffallender Beleuchtung in der Dorsalansicht gezeichnet. Vergrösserung 15/1.

Fig. 1. Keimhaut eines 6 Stunden bebrüteten Hühnereies.

A $\mathrm{p}=$ Area pellucida.

$\mathrm{A}_{\mathrm{o}}=$ Area opaca.

$\mathrm{pr}=$ Primitivstreif (Sichelfortsatz).

$\mathrm{s}=$ Sichel des Primitivstreifen.

$\mathrm{B} f=$ Bogenfalte des Embryonalschildes.

$\mathrm{Gr}=$ Grenzlinie des Mesoderms.

Fig. 2. Keimhaut eines 8 Stunden bebrüteten Hühnereies.

Die gleiche Buchstabenbezeichnung wie in Fig. 1.

Fig. 3. Keimhaut eines 12 Stunden bebrüteten Hühnéreies; die Area opaca nicht angedeutet.
p r $=$ Primitivstreif mit der Primitivrinne.
$\mathrm{s}=$ Sichel des Primitivstreifen mit der Sichelrinne.
$\mathrm{B} \mathrm{f}=$ Bogenfalte des Embryonalschildes.
$\mathrm{Gr}=$ Grenzlinie des Mesoderms.
$\mathrm{A} \mathrm{v}=$ Area vasculosa.

Fig. 4. Keimhaut vom Hühnchen nach 14 stündiger Bebrütung. $\mathrm{pr}=$ Primitivstreif mit der Primitivrinne.

$\mathrm{s}=$ Sichel des Primitivstreifens mit der Sichelrinne.

$\mathrm{Bf}=$ Bogenfalte des Embryonalschildes (länglich ausgezogerr).

$\mathrm{Kf} \mathrm{s}=$ Kopffortsatz.

v. A $\mathrm{f}=$ Vordere Amnionfalte.

$\mathrm{Gr}_{\mathrm{r}}=$ Grenzlinie des Mesoderms.

A v $=$ Area vasculosa.

Fig. 5. Keimhaut eines 16 Stunden bebrüteten Hühnereies.

Die gleiche Buchstabenbezeichnung wie in Fig. 4.

Fig. 6. Keimhaut eines 20 Stunden bebrüteten Hühnereies.

$\mathrm{p} \mathrm{r}=$ Primitivstreif mit der Primitivinne.

K $\mathrm{f}=$ Kopf falte.

$\mathrm{S} z=$ Stammeszone. 
$\mathrm{P}_{\mathrm{z}}=$ Parietalzone.

$\mathrm{A}_{\mathrm{z}}=$ Aussenzone.

$\mathrm{h}=$ Stelle der künftigen Herzanlagen.

$\mathrm{R} \mathrm{M} \mathrm{w}=$ Rand der Medullarwülste, welcher sowohl die Stammeszone, als die Medullarfurche begrenzt.

ch = Chorda am Boden der Medullarfurche sichtbar.

$\mathrm{Ur}=$ Erstes Urwirbelpaar.

v. Af $=$ Vordere Amnionfalte.

$\mathrm{Gr}_{\mathrm{r}}=$ Grenzlinie des Mesoderms.

A $\mathrm{v}=$ Area vasculosa.

Fig. 7. Keimhaut eines 24 Stunden bebrüteten Hühnereies.

$\mathrm{N}=$ Naht des Medullarrohres am embryonalen Kopftheile.

$\mathrm{Ur}=$ Urwirbel.

$\mathrm{h}=$ Herzanlagen.

Die übrigen Buchstaben wie in Fig. 6 .

\section{Tafel II.}

Doppelbildung eines Hühnchens. Die Keimhaut wurde einem am 4. Tage der Bebrütung eröffneten Eie entnommen. Dorsalansicht. Auffallende Beleuchtung. .Vergrösserung $6 / 1$.

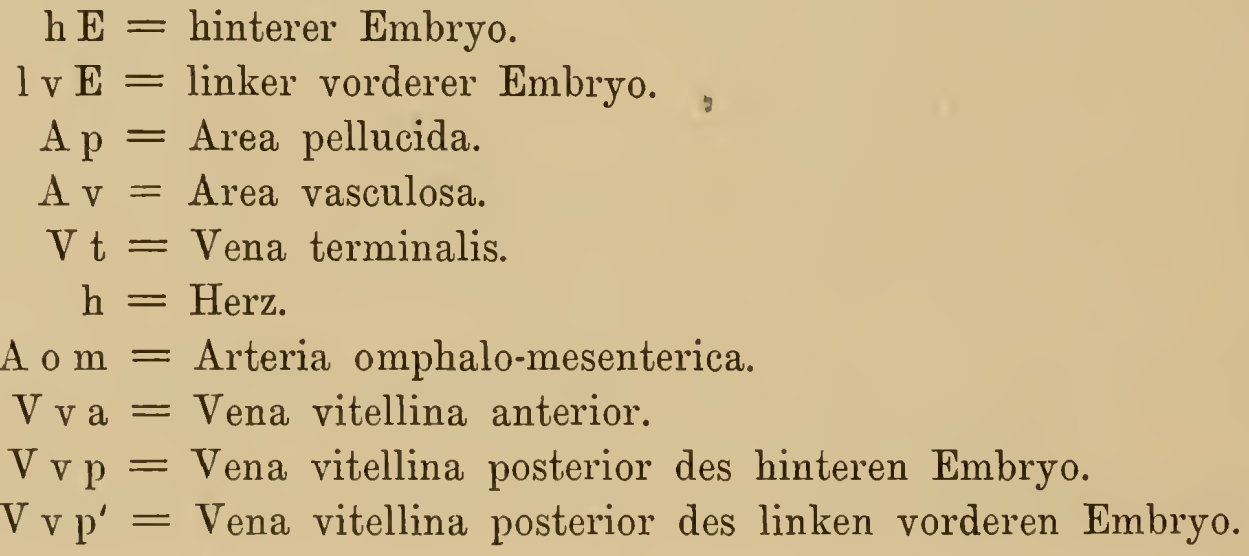

\section{Tafel III.}

Fig. 1. Doppelbildung des Hühnchens nach 20 stündiger Bebrütung. Dorsalansicht bei auffallender Beleuchtung. Vergrösserung 22/1.

p r $=$ Primitivstreif der hinteren Embryonalanlage.

p r' $r^{\prime}$ Primitivstreif der linken vorderen Embryonalanlage.

$\mathrm{Gr}, \mathrm{Gr}^{\prime}=$ Grenzlinien der mittleren Keimblätter der beiden Embryonalanlagen.

$\mathrm{E}_{\mathrm{s}}=$ Embryonalschild.

A $p=$ Area pellucida.

$\mathrm{A}_{0}=$ Area opaca.

Fig. 2. Doppelbildung des Hühnchens nach 48stündiger Bebrütung. Dorsalansicht bei auffallender Beleuchtung. Vergrösserung 18/1.

$\mathrm{V}, \mathrm{V}^{\prime}=$ Vorderes Hirnblïschen.

$\mathrm{M}, \mathrm{N}^{\prime}=$ Mittleres Hirnblïschen.

$\mathrm{H}, \mathrm{H}^{\prime}=$ Hinteres Hirnblïschen.

$\mathrm{U}_{\mathrm{r}}=$ Urwirbel.

II $=$ Der gemeinsame noch nicht zum Rohre geschlossene Theil der Medullarfurche. 


$$
\begin{aligned}
& \mathrm{A} \mathrm{p}=\text { Area pellucida. } \\
& \mathrm{Av}=\text { Area vasculosa. }
\end{aligned}
$$

Die punktirten Linien deuten die Lage der beiden Herzen an.

Die Figuren auf Taf. IV-VI sind Copien der von den einzelnen Autoren, welche Mehrfachbildungen bei Vögeln beobachtet haben, gegebenen Abbildungen. Die arabische Zahl, welche jeder Figur beigesetzt ist, bedeutet die Nummer der Reihenfolge, in welcher die Fälle im Texte zusammengestellt sind; die daneben stehende römische Zahl bedeutet die Gruppe, welcher nach der im Texte getroffenen Eintheilung der betreffende Fall zugehört.

Gemeinsame Buchstabenbezeichnung auf Taf. IV, V u. VI:

$\mathrm{A} \mathrm{p}=$ Area pellucida.

A $0=$ Area opaca.

$\mathrm{A} \mathrm{v}=$ Area vasculosa.

pr, $\mathrm{pr}^{\prime}, \mathrm{pr}^{\prime \prime}=$ Primitivstreif des ersten, zweiten, dritten Embryo.

$\mathrm{M} \mathrm{f}=$ Medullarfurche.

$\mathrm{Mr}=$ Medullarrohr.

ch = Chorda.

$\mathrm{h}=$ Herz.

$\mathrm{a}=$ Augenanlage.

$0=$ Ohrenanlage.

$\mathrm{v} \mathrm{h}=$ Vorderes Hirnbläschen.

$\mathrm{v} \mathrm{t}=$ Vena terminalis.

$\checkmark$ A f $=$ Vordere Amnionfalte.

h Af $=$ Hintere Amnionfalte.

\section{Tafel IV.}

Fig. 1. Doppelbildung aus einem 16-18 Stunden bebrüteten Hühnerei nach Allen Thomson.

Fig. 2. Nach hinten zu sich theilende Chorda dorsalis einer Doppelbildung aus einem noch nicht 24 Stunden bebrüteten Hühnerei nach v. Baer.

Fig. 3. Doppelmissbildung eines Hühnchens nach Dareste.

$\mathrm{K}=\mathrm{Kopfende}$ des grösseren Componenten.

$\mathrm{K}^{\prime}=$ Kopfende des kleineren Componenten.

Fig. 4. Doppelbildung aus einem Hühnerei vom zweiten Tage der Bebrütung, nach $R$ eichert.

Fig. 5. Doppelmissbildung aus einem 36 Stunden bebrüteten Hühnerei nach $\mathrm{R}$ a u b e r. Ahlfeld.

Fig. 6. Zwillingsmissbildung aus einem 36 Stunden bebrüteten Hühnerei nach

$\mathrm{Mf}=$ Medullarfurche, nach hinten $\mathrm{zu}$ sich theilend.

$\mathrm{zw}=$ Zwischenwulst (nach Ahlfeld ein 'Theil des sich erhebenden Amnion).

Fig. 7. Doppelmissbildung aus einem $\check{52}-54$ Stunden bebrüteten Hühnerei nach v. Baer.

$\mathrm{K}=$ verwachsene Kopftheile der beiden Embryonen.

Fig. 8. Doppelmissbildung aus einem 3 Tage bebrüteten Hühnerei nach Dön itz.

$\mathrm{hr}=$ die mit einander verwachseneir vorderen Enden der beiden Hirnrohre.

Fig. 9. Doppelmissbildung eines Hühnchens nach D areste. 


\section{Tafel V.}

Fig. 1. Doppelmissbildung eines Hühnchens nach Dareste.

M U r $=$ Mittlere (dritte) Urwirbelreihe.

Fig. 2. Doppelmissbildung aus einem 3 Tage bebrüteten Gänseei nach Reichert.

A. Dorsalansicht. B. Ventralansicht. v $d=$ Vordere Darmpforte.

Fig. 3. Doppelmissbildung aus einem 80 Stunden bebrüteten Hühnerei nach $\mathrm{R}$ a $\mathrm{u}$ b e r.

Fig. 4. Doppelbildung aus einem etwa 90 Stunden bebrüteten Hühnerei nach Ahlfeld.

Fig. 5. Doppelmissbildung eines Hühnchens nach Ahlfeld. $\mathrm{K}=$ Verwachsene Kopftheile der beiden Embryonen.

Fig. 6. Doppelmissbildung eines Hühnchens nach Dareste.

Fig. 7. Doppelmissbildung eines Hühnchens nach Dareste. $\mathrm{K}=$ Vereinigte Kopftheile der beiden Embryonen.

$\mathrm{RA}=$ Rand der gesammten Amnionfalte.

Fig. 8. Doppelmissbildung eines Hühnchens nach $D$ areste. $\mathrm{K}=$ Vereinigte Kopfenden beider Embryonen.

\section{Tafel VI.}

Fig. 1. Doppelmissbildung eines Hühnchens nach Dareste.

Fig. 2. Tripelembryo eines Hühnchens nach Dareste.

Fig. 3. Zwillingsbildung vom Hühnchen nach $\mathrm{D}$ areste. $\mathrm{R}$ a u ber.

Fig. 4. Doppelmissbildung aus einem $4^{1} \frac{1}{2}$ Tage bebrüteten Hühnerei nach $\mathrm{K}=$ Vereinigte Kopftheile beider Embryonen.

$\mathrm{RA}=$ Rand der gesammten Amnionfalte.

Fig. 5. Doppelbildung aus einem 5 Tage bebrüteten Gänseei nach. Allen Thomson.

Fig. 6. Doppelmissbildung aus einem Hühnerei nach Dareste.

$\mathrm{E}_{\mathrm{o}}=$ Anlage der oberen Extremität.

$\mathrm{E} \mathrm{u}=$ Anlage der unteren Extremität.

Fig. 7. Doppelmissbildung aus einem Hühnerei nach Dareste. al $=$ Allantois.

Fig. 8. Doppelmissbildung aus einem Hühnerei nach Dareste. A. Dorsalansicht. B. Ventralansicht des Kopfes.

a l = Allantois.

Fig. 9. Tripelembryo aus einem Hühnerei nach Dareste.

Fig. 10. Tripelembryo aus einem $2 \frac{1}{2}$ Tage bebrüteten Hühnerei nach R a u ber. $\mathrm{z} \mathrm{w}=$ Zwischenwulst.

Fig. 11. Etwas ältere Zwillingsmissbildung aus einem Entenei nach Dareste. Verbindung in der Stirngegend und mittelst des Dotterstranges.

$\mathrm{D}=$ Dotter.

\section{'T a fel VII.}

Die Figuren 1-4 sollen schematisch die verschiedenen Anordnungen der Chordae und der Rückenfurchen erliiutern, welche bei ursprünglich neben einander in die Area pellucida einstrahlenden Primitivstreifen einer Doppelbildung je nach dem Grade 
und der Art des Auseinanderrückens der vorderen Primitivstreifenenden möglich sind. Das Entwicklungsstadium, auf welches sich diese Schemata beziehen, entspricht dem der Figur 6, Tafel I, welche bei der Anfertigung der Zeichnungen zu Grunde gelegt wurde.

Gemeinsame Buchstabenbezeichnung:

$$
\begin{aligned}
& \text { A } p=\text { Area pellucida. } \\
& \mathrm{pr}=\text { Primitivstreif. } \\
& \mathrm{ch}=\text { Chorda. }
\end{aligned}
$$

RMw = Rand der Medullarwülste (= Grenzlinie der Rückenfurche).

Fig. 1. Schema einer Doppelbildung mit nach vorne convergirenden Chordae; der gemeinschaftliche Theil der Rückenfurche liegt vorne.

Fig. 2. Schema einer Doppelbildung mit nach vorne divergirenden Chordae; nur die vordersten und hintersten Abschnitte der Rückenfurche sind doppelt vorhanden.

Fig. 3. Schema einer Doppelbildung mit parallel gestellten Chordae; dieselben liegen längs ihres ganzen Verlaufes innerhalb der Copulationsnähe, wesshalb nur die hintersten Endabschnitte der Medullarfurchen doppelt vorhanden sind.

Fig. 4. Schema einer Doppelbildung, bei welcher die parallel verlaufenden Chordae ausserhalb der Copulationsnähe liegen, was zwei durchaus getrennte Rückenfurchen involvirt.

Fig. 5. Schematische Abbildung, welche die nach einer sehr früh erfolgenden Bifurcation des Primitivstreifens eintretende Ausbildung von zwei vollständigen Rückenfurchen und Chordae veranschaulichen soll.

Die gleichen Buchstaben, wie in den vorigen Figuren.

Die Fig. 6 u. 7 sind Copien von schematischen Abbildungen $R$ au ber's.

Fig. 6. Schema einer in einem sehr frühen Embryonalstadium stehenden Dreifachbildung eines Wirbelthieres. Keimring mit drei Embryonalanlagen.

Fig. 7. A, B, C. Schemata einer in verschiedenen Entwicklungsstadien befindlichen Doppelbildung der Knochenfische.

$$
\begin{aligned}
& a=\text { die eine vordere Embryonalanlage. } \\
& b=\text { die zweite vordere Embryonalanlage. } \\
& \mathrm{i}=\text { innere Zwischenstrecke. } \\
& \mathrm{e}=\text { äussere Zwischenstrecke. }
\end{aligned}
$$

Die Figuren auf Taf. VIII und IX stellen Abnormitäten von Keimhäuten und Embryonen des Hühnchens dar, welche nach experimenteller Abänderung der normalen Bebrütung erhalten wurden. Die den einzelnen Figuren beigesetzten Nummern beziehen sich auf die Reihenfolge, in welcher die Keimhäute im Texte aufgeführt wurden. Bezüglich der genaueren Erklärung der Figuren ist ebenfalls auf den Text zu verweisen.

Sämmtliche Figuren sind bei auffallendem Lichte gezeichnet.

Gemeinsame Buchstabenbezeichnung:

$$
\begin{aligned}
\mathrm{A} p & =\text { Area pellucida. } \\
\mathrm{A} \mathrm{o} & =\text { Area opaca. } \\
\mathrm{A} \mathrm{v} & =\text { Area vasculosa. } \\
\mathrm{pr} & =\text { Primitivstreif. } \\
\mathrm{M} \mathrm{f} & =\text { Medullarfurche. } \\
\mathrm{Mr} & =\text { Medullarrohr. } \\
\mathrm{Hr} & =\text { Hirnrohr. } \\
\mathrm{ch} & =\text { Chorda. }
\end{aligned}
$$




$$
\begin{aligned}
\mathrm{h} & =\text { Herz. } \\
\mathrm{Gr} & =\text { Grenzlinie des mittleren Keimblattes. } \\
\mathrm{vAf} & =\text { vordere Amnionfalte. } \\
\mathrm{Kf} & =\text { Kopffalte. } \\
\mathrm{Ur} & =\text { Urwirbel. }
\end{aligned}
$$

\section{Tafel VIII.}

Fig. 1 (Nr. 1). Keimhaut vom 4. Tage der Bebrütung. Die Area pellucida A p enthält eine kleine rundliche Verdickung; das Ektoderm ist über den Rand der Area opaca A o um eine beträchtliche Strecke hinausgewachsen. Vergrösserung 4/1.

Fig. 2 (Nr. 2). Keimhaut vom 4. Tage der Bebrütung. In der Area pellucida Ap, angrenzend an die Area opaca Ao, befindet sich eine zweizackige Verdickung z, vielleicht ein frühes Stadium von zwei neben einander einstrahlenden Primitivstreifen; die ausserhalb der Area opaca gelegene Zone der Keimhaut ist in der Zeichnung nicht angedeutet. Vergrösserung 4/1.

Fig. 3 (Nr. 3). Keimhaut vom 3. Tage der Bebrütung; die Grenzen der Area opaca Ao sind angedeutet. Der Primitivstreif pr geht in seinem vorderen Abschnitte gabelig in zwei Schenkel aus einander, welche beide von der Bogenfalte des Embryonalschildes $\mathrm{B}$ f umgeben werden. Vergrösserung $15 / 1$.

Fig. 4 (Nr. 4). Keimhaut vom 4. Tage der Bebrütung. Die Area pellucida A p enthält eine längliche Verdickung, wohl die in der Zersetzung befindliche Embryonalanlage. Vergrösserung $4 / 1$.

Fig. 5 (Nr. 5). Keimhaut vom 4. Tage der Bebrütung. Ventralansicht. Der Primitivstreif pr ist nur kurz und hat in seiner hinteren Hälfte gegen den Dotter $\mathrm{zu}$ eine hohle zapfenförmige Ausstülpung getrieben. Vergrösserung 4/1.

Fig. $6(\mathrm{Nr}$. 6). Keimhaut vom 3. Tage der Bebrütung. Das hintere Ende des Primitivstreifen pr besitzt eine gegen den Dotter gerichtete rundliche Anschwellung; Bogenfalte des Embryonalschildes sehr gut ausgeprägt. Vergrösserung 4/1.

Fig. 7 (Nr. 7). Keimhaut vom 3. Tage der Bebrütung. Dorsalansicht. Der Primitivstreif pr zeigt in seinem hinteren Abschnitt eine spindelförmige Anschwellung, die dorsalwärts gerichtet ist; der Kopffortsatz $\mathrm{Kfs}$ ist normal entwickelt, die vordere Amnionfalte v Af sichtbar. Vergrösserung 4/1.

\section{Tafel IX.}

Fig. 1 (Nr. 8). Keimhaut vom 4. Tage der Bebrütung. Dorsalansicht. Primitivstreif pr angeschwollen. Am vorderen Ende der Rückenfurche Mf eine ventralwärts und nach vorne gerichtete Ausstülpung der Keimhaut, deren vorderes Ende Z im vordersten Theile der Area pellucida in dem Einschnitte des Mesoderms durch die Keimhaut durchscheint. Vergrösserung 18/1.

Fig. 2 (Nr. 9). Keimhaut vom 4. Tage der Bebrütung. Dorsalansicht. Ungemein kurze Embryonalanlage; sehr breite Kopffalte K f. Primitivstreif angeschwollen. Vergrösserung 20/1.

Fig. 3 (Nr. 10). Keimhaut vom 3. Tage der Bebrütung. Dorsalansicht. Sehr breite Rückenfurche Mf, besonder's in ihrem vorderen Theile; der ganze Embryo besitzt eine auffallend kurze und gedrungene Gestalt, zumal in seinem vor dem Primitivstreifen liegenden Abschnitte. Vergrösserung 15/1.

Fig. 4 (Nr. 11). Embryo einer Keimhaut vom 4. 'Tage der Bebrütung. Dorsalansicht. Ungewöhnlich breite Rückenfurche. Im hinteren Theile der Primitivrinne ist ein Axenfaden ax sehr deutlich sichtbar. Vergrösserung 25/1. 
Fig. 5 (Nr. 12). Embryo einer Keimhaut vom 4. Tage der Bebrütung. Dorsalansicht. Unregelmässiger Schluss des Medullarrohres $\mathrm{Mr}$, welches im Hirntheile drei quere Oeffnungen aufweist. Im hinteren Embryonalabschnitt ist die Medullarfurche Mf noch offen. Vergrösserung 24/1.

Fig. 6 (Nr. 13). Embryo einer Keimhaut vom 4. Tage der Bebrütung. Dorsalansicht. Anomalie im Schlusse des Hirnrohres $\mathrm{Hr}$, ebenso im hinteren Abschnitte des Nervenrohres; zwei Herzen h, etwas verbreiterter vorderer Embryonaltheil. Vergrösserung 18/1.

Fig. 7 (Nr. 15). Embryo vom 5. Brütetage. Dorsalansicht. Anomalie des Hirnrohres, welches stark verbreitert erscheint, und nach vorne mit drei neben einander gelegenen Bläschen endet. (Siehe Text.) Vergrösserung 9/1.

Fig. 8 (Nr. 16). Embryo vom 6. Brütetage. A. Dorsalansicht des ganzen Embryo, B. Ventralansicht eines Kopftheiles. Deutliche Verdoppelung des Hirnrohres. Vergrösserung $6 / 1$.

$$
\begin{aligned}
\mathrm{E} & =\text { Extremitätenanlage. } \\
\mathrm{Mb} & =\text { Mundbucht. } \\
\mathrm{O} \mathrm{k} & =\text { Oberkieferfortsatz des ersten Kiemenbogens. } \\
1 . \mathrm{K} & =\text { Erster Kiemenbogen. }
\end{aligned}
$$

Fig. 9 (Nr. 19). Embryo vom 6. Brütetage. A. Dorsalansicht, B. Gesichtsseite des Kopfes. Starke Anomalie der Hirnanlage $\mathrm{Hr}$, wahrscheinlich partielle Verdoppelung. Vergrösserung $5 / 1$.

$$
\begin{aligned}
\mathrm{E} & =\text { Extremitätenanlage. } \\
\mathrm{Al} & =\text { Allantois. } \\
\mathrm{M} \mathrm{b} & =\text { Mundbucht. } \\
\mathrm{K} \mathrm{s} & =\text { Kiemenspalte. } \\
\mathrm{I} \mathrm{K} & =\text { Erster Kiemenbogen. } \\
\mathrm{O} \mathrm{k} & =\text { Oberkieferfortsatz des ersten Kiemenbogens. }
\end{aligned}
$$




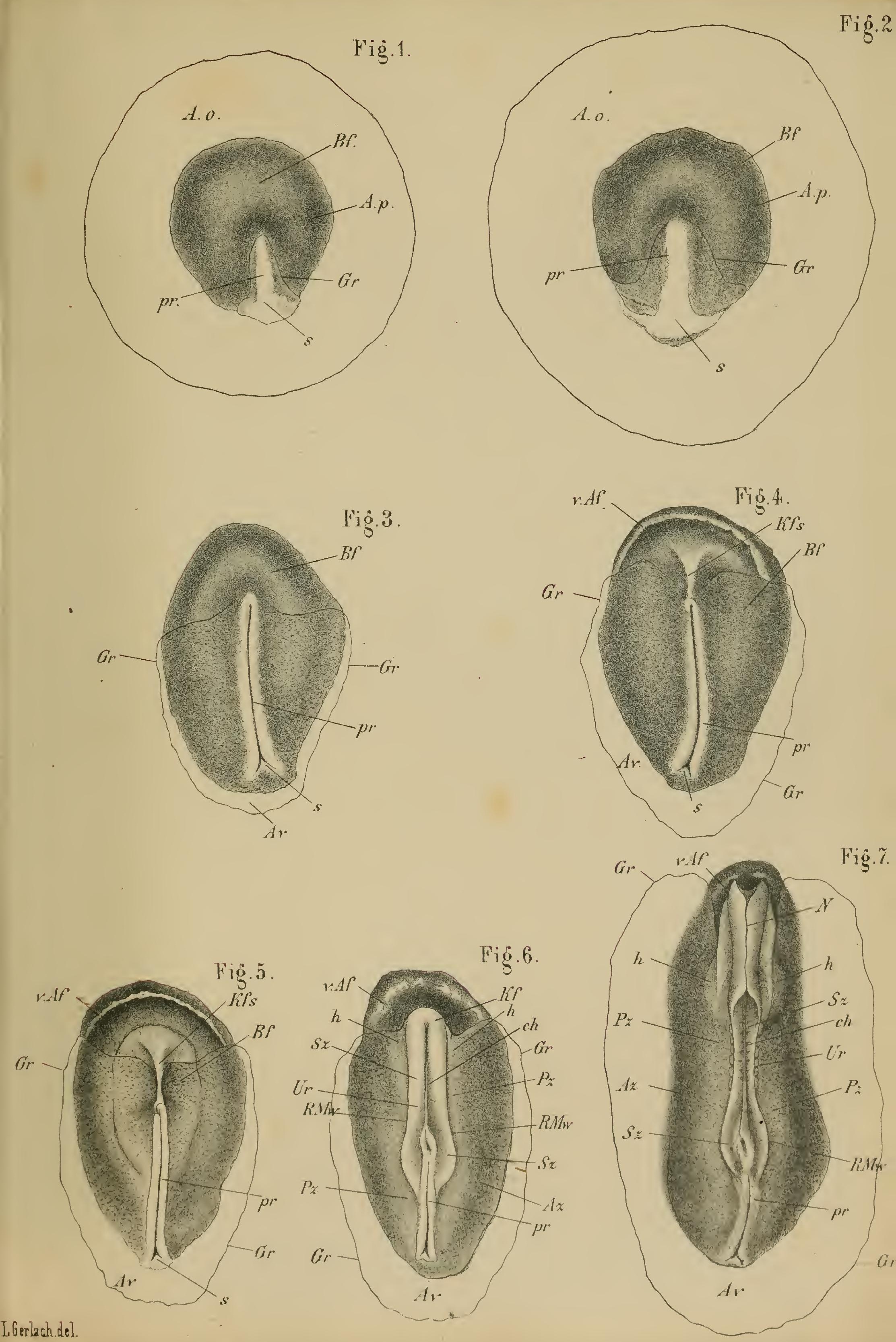



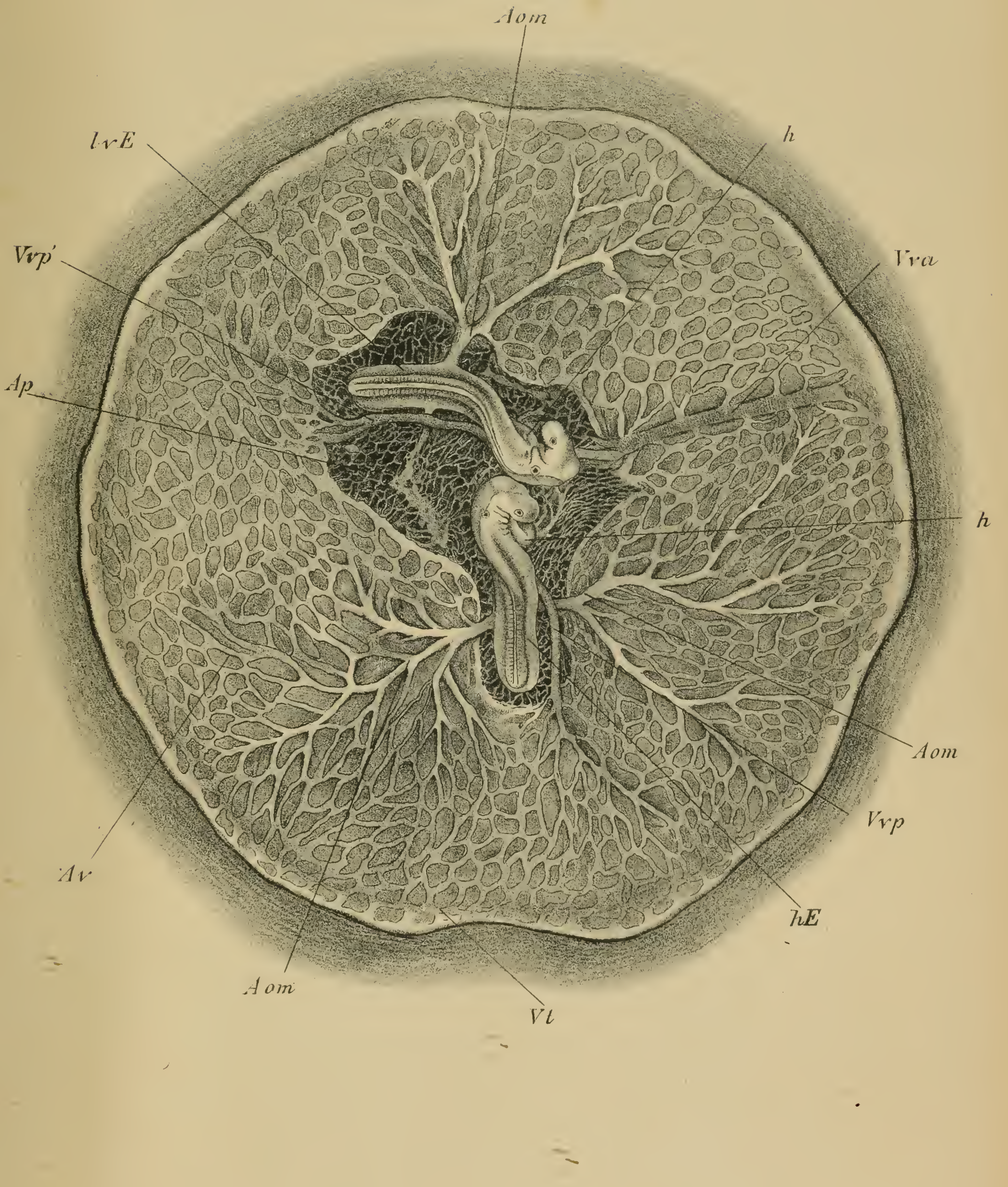





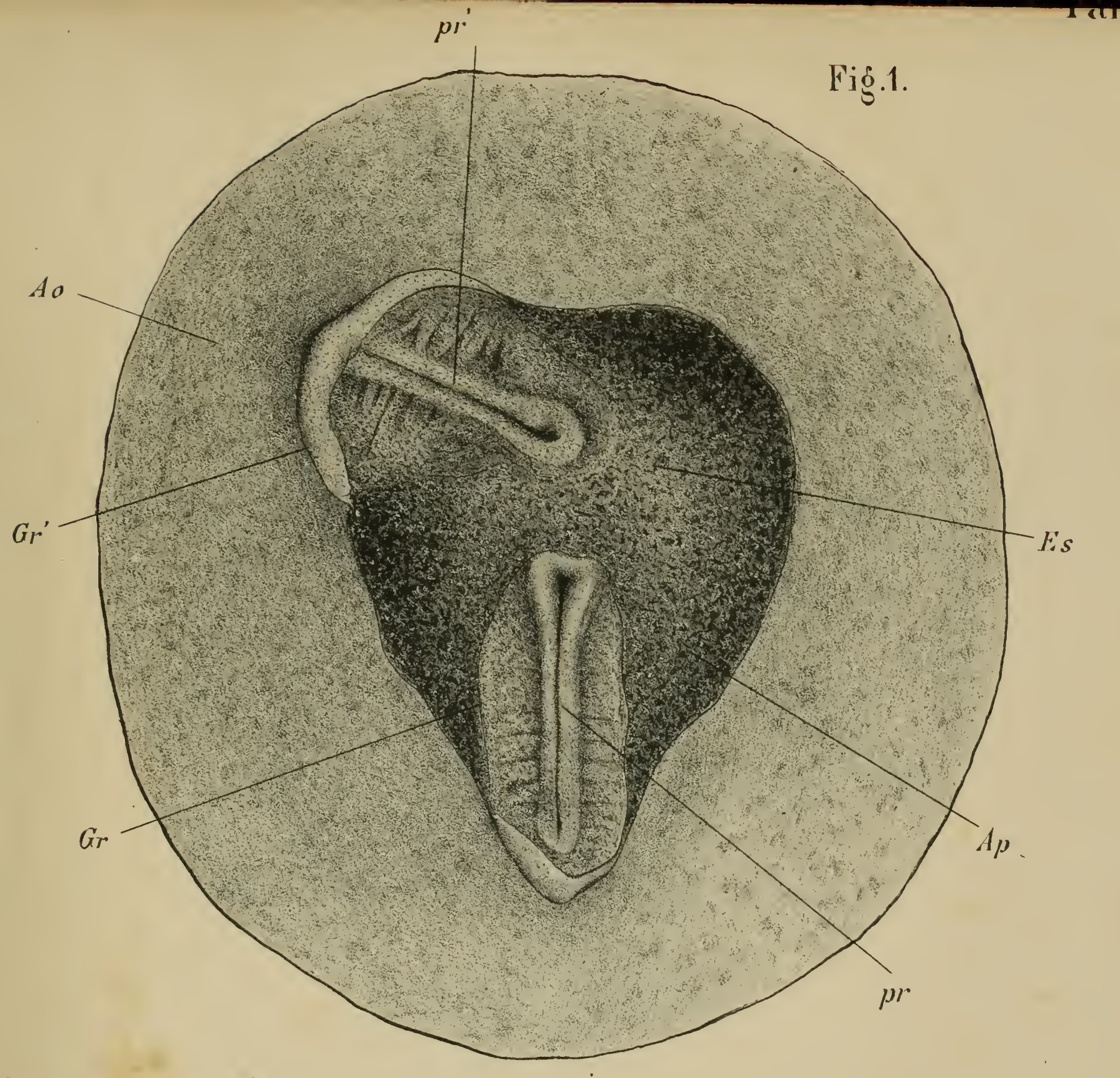

Fig. 2 .

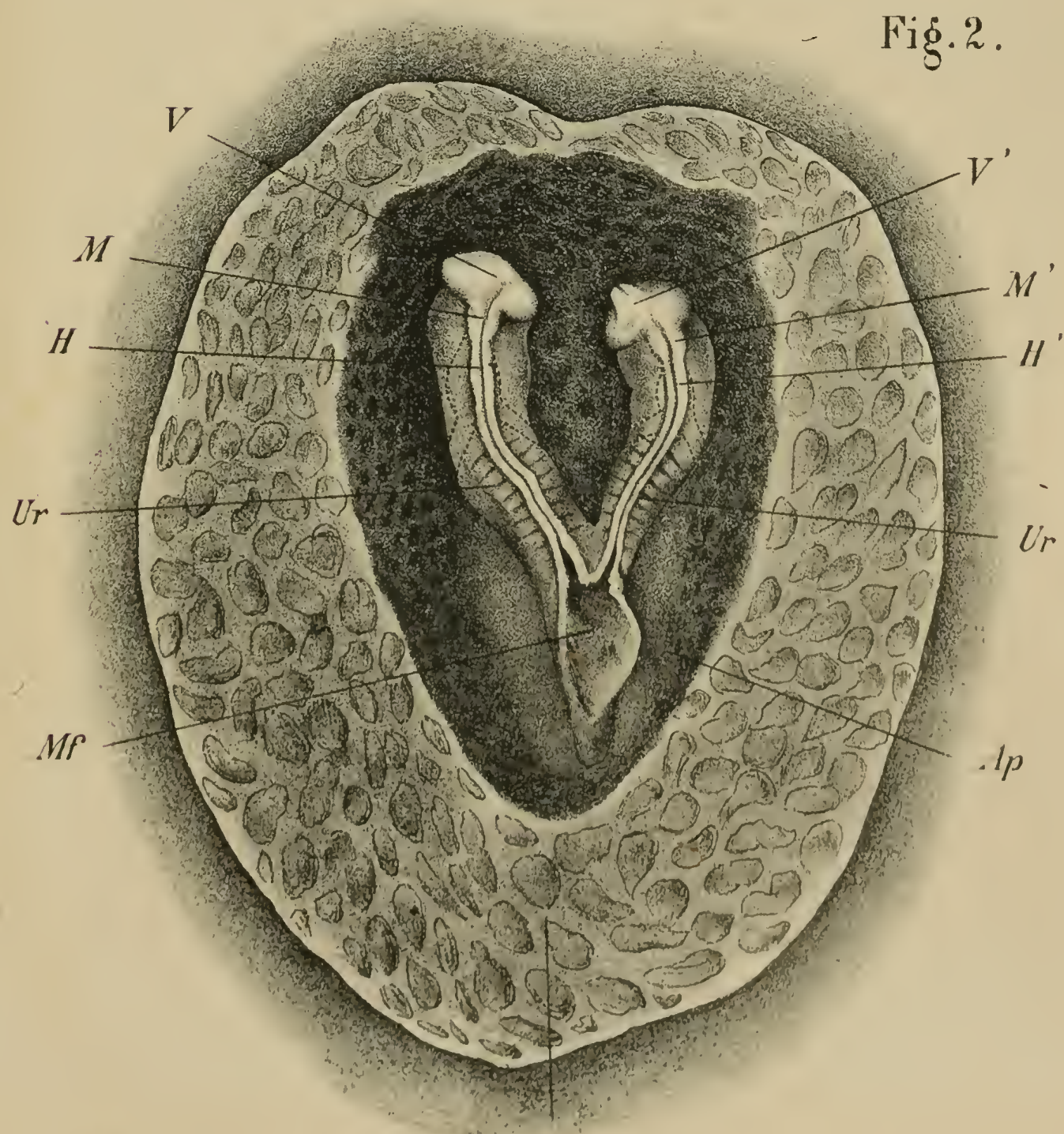






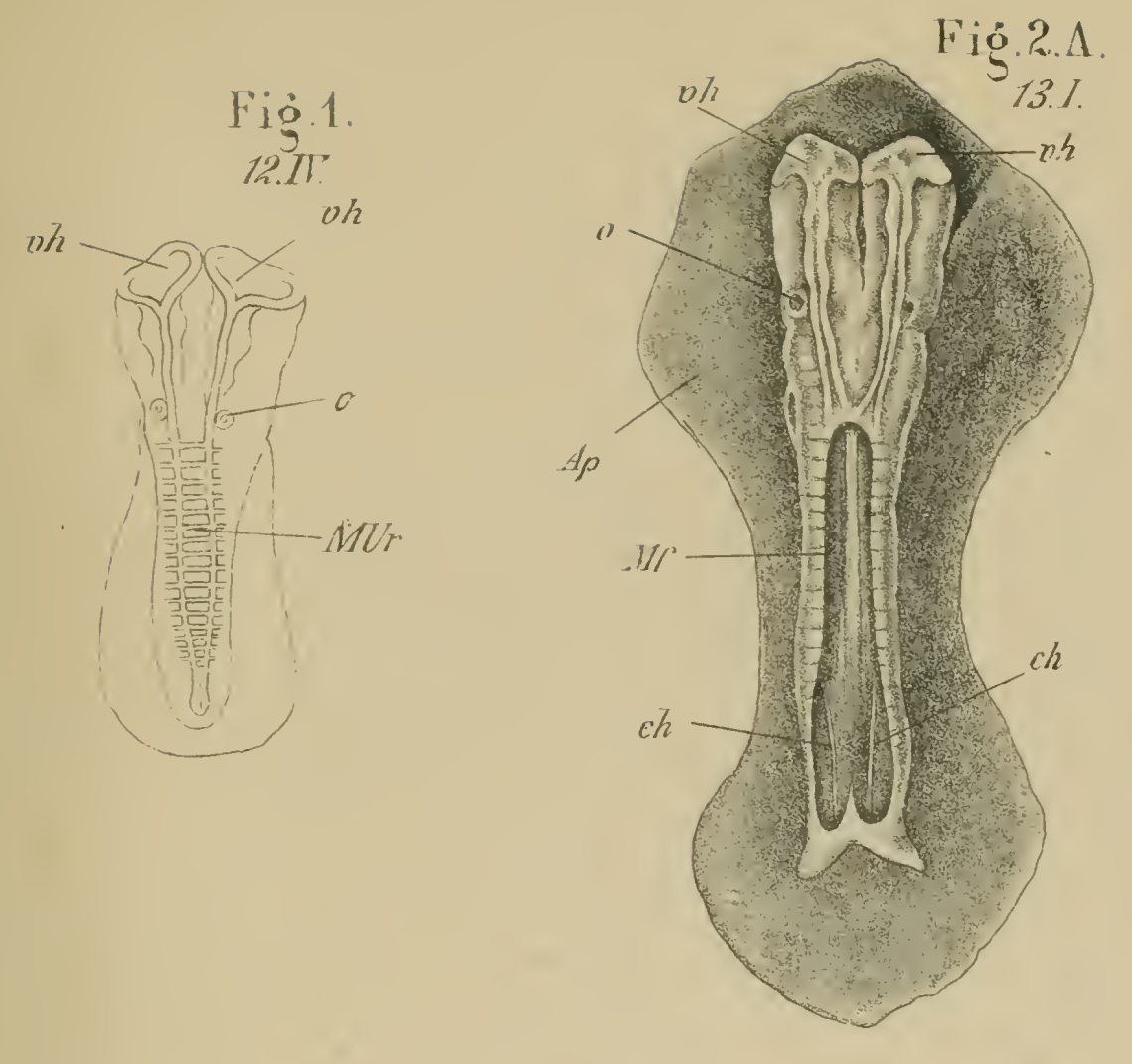

lighls

Fig. 3.
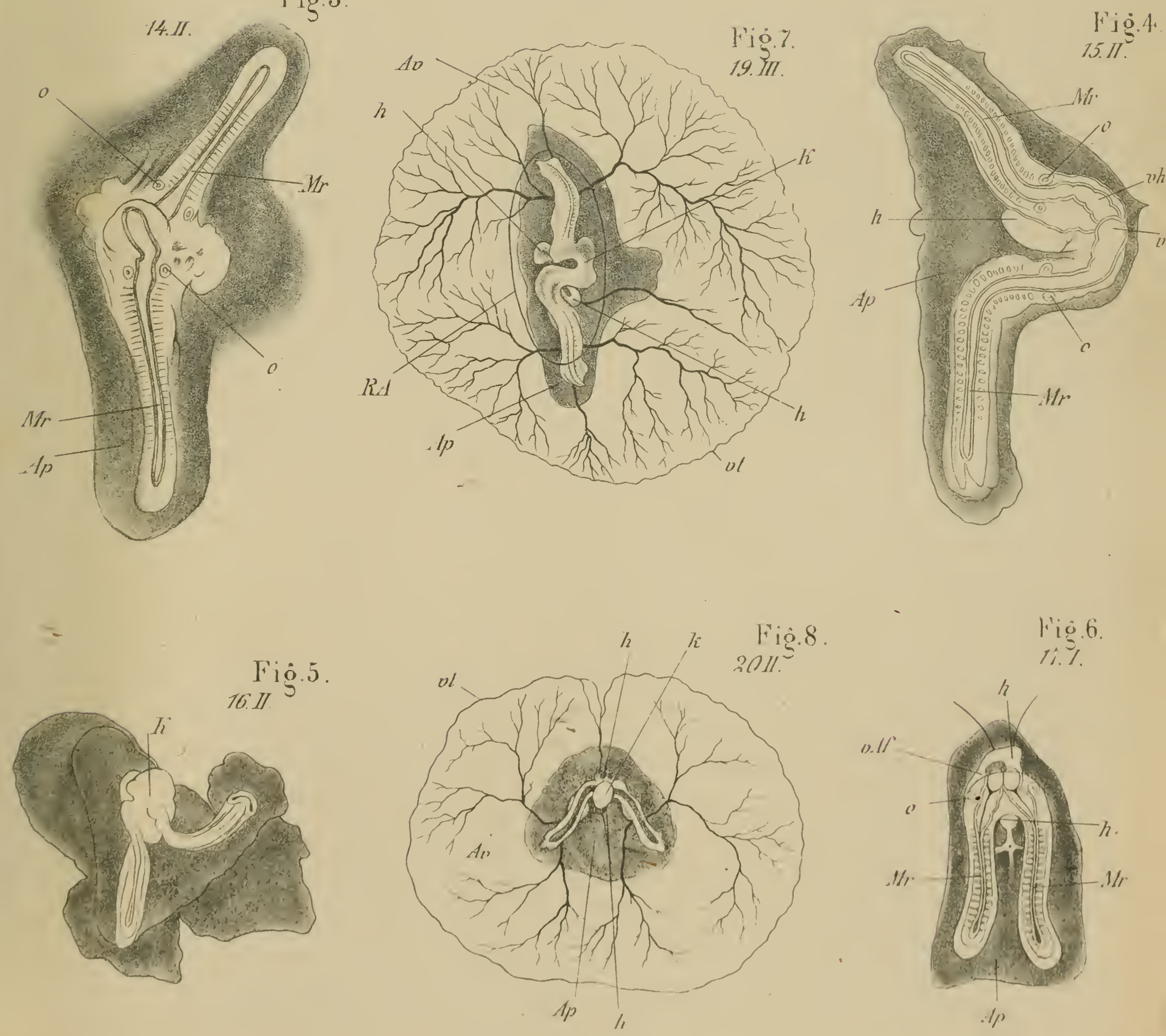

1. Gerlach del. 


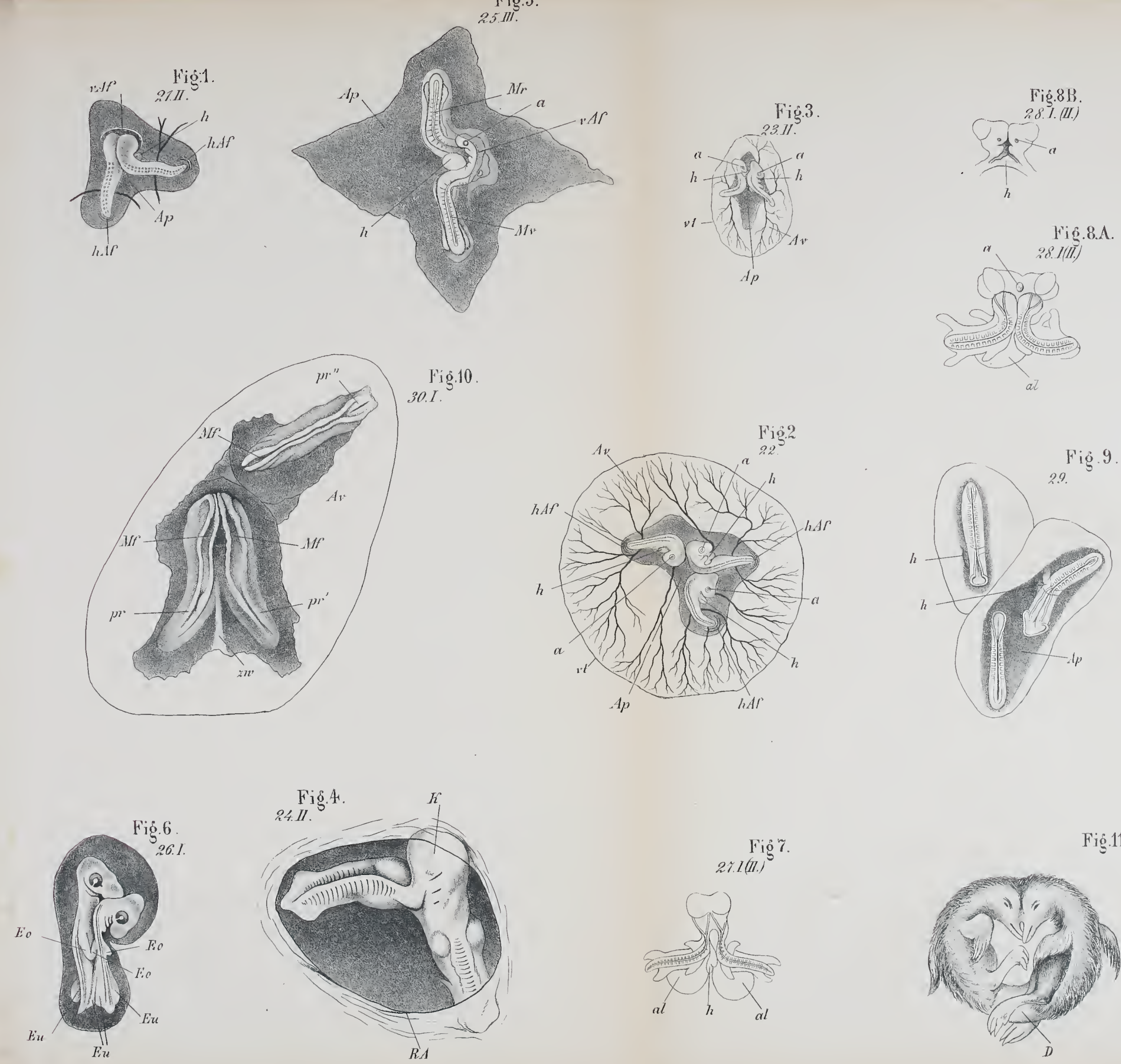

Fight.

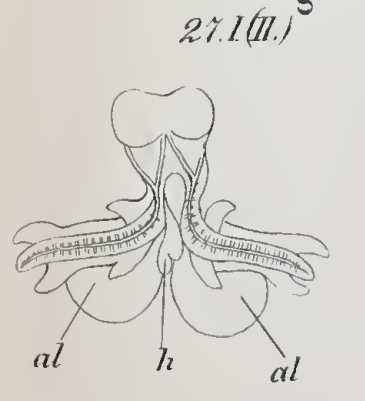

Fig. 11

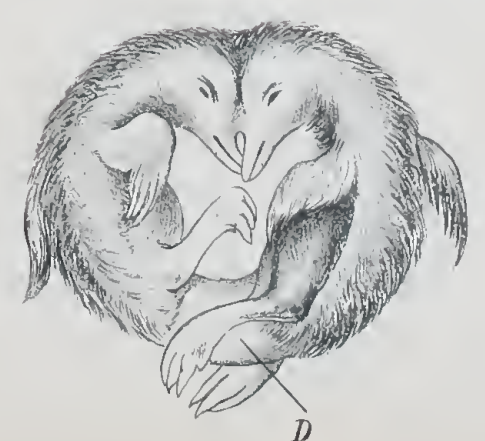



Figg.1.
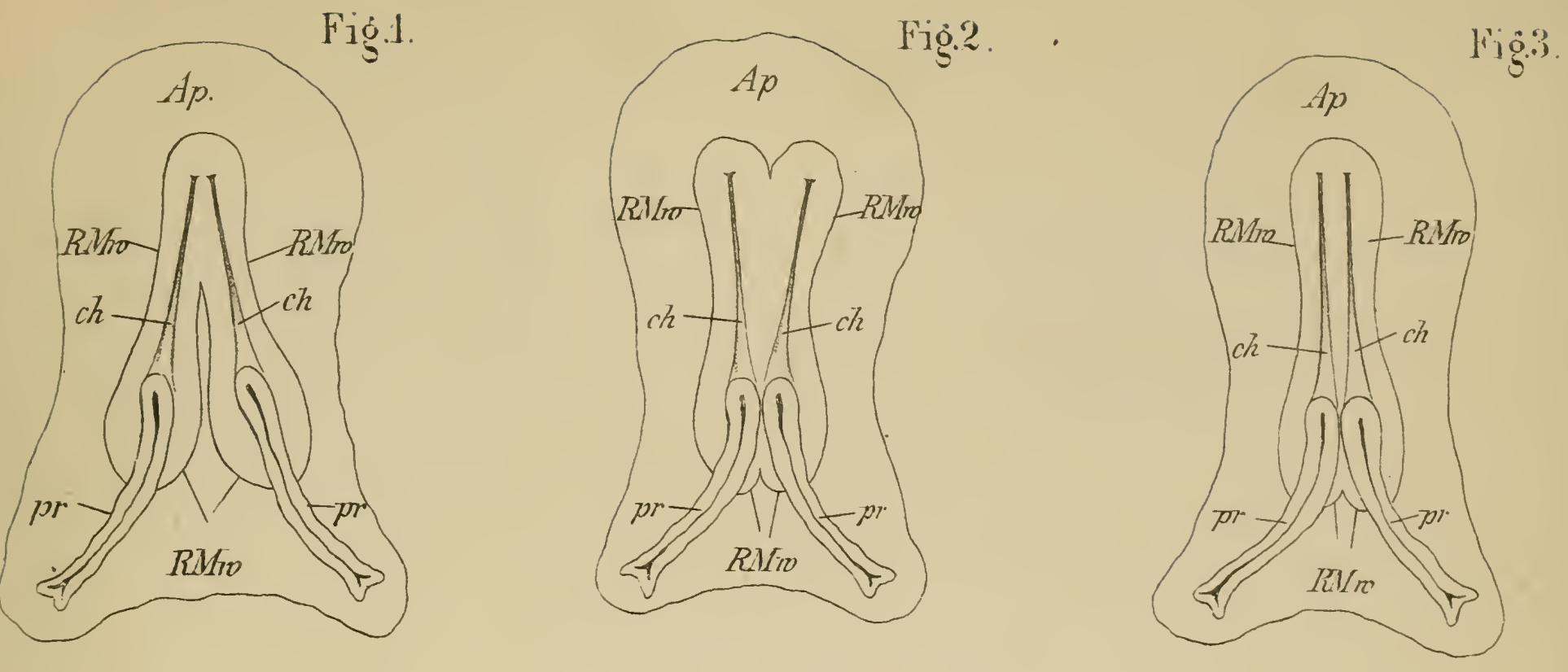

Fig 4 .

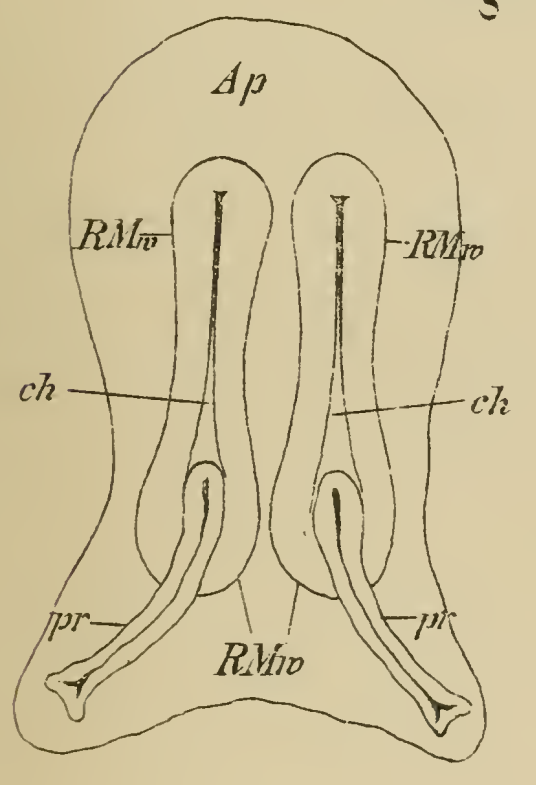

Fig 5 .

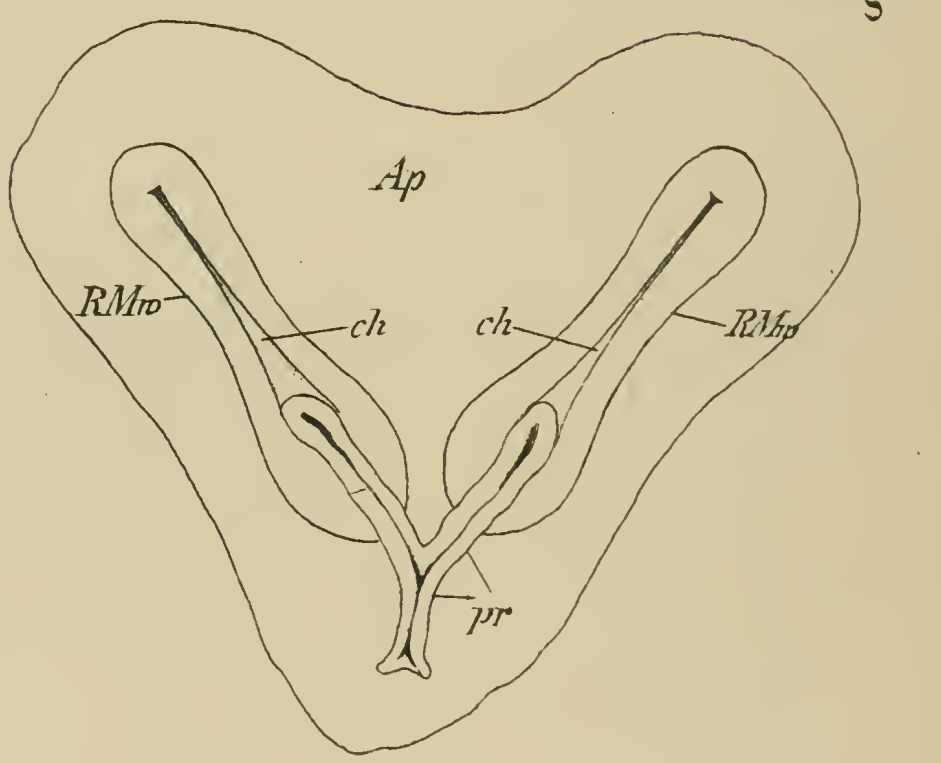

Fìg. 6 .
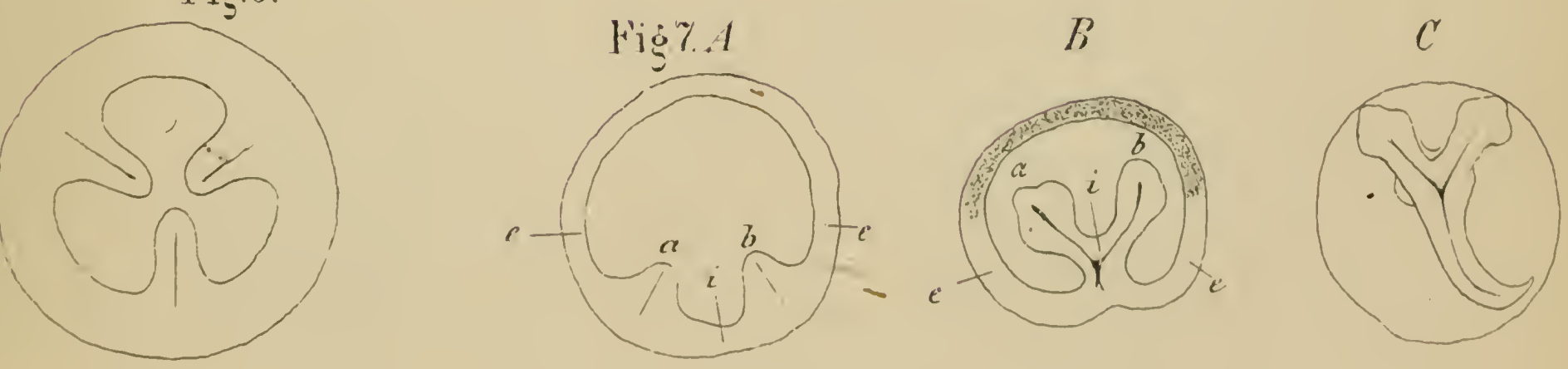


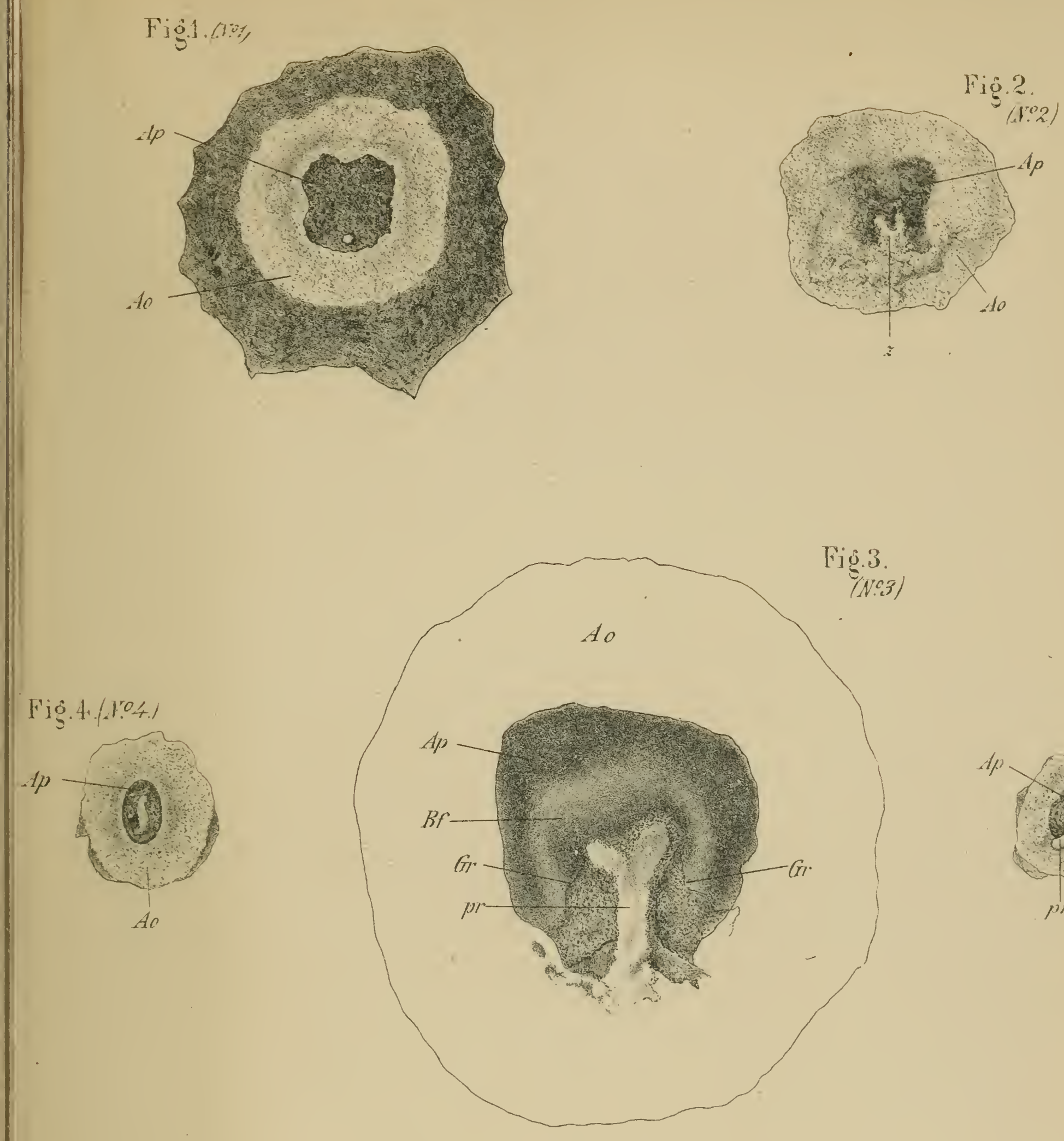

Fig 5.

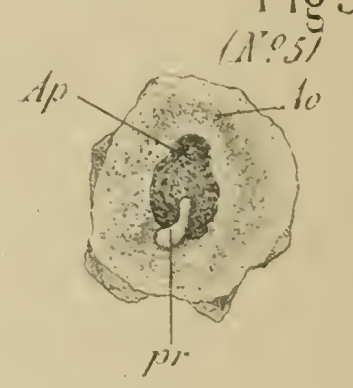

Fig.6. (1.6)
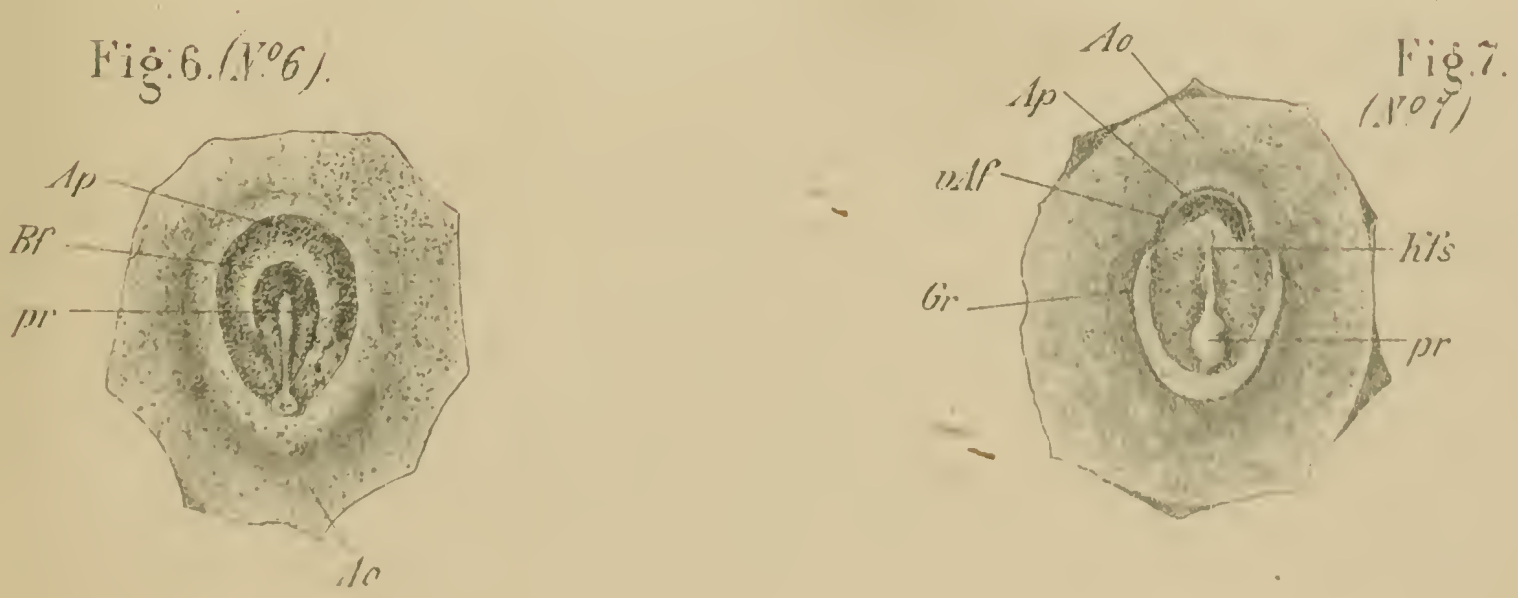





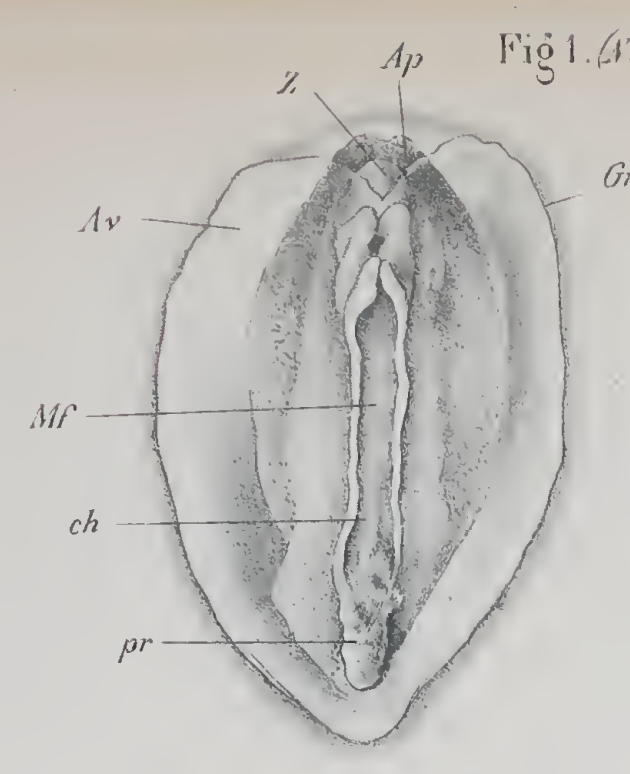

Highedarol

Hig.3. (10.10)

I IT:L 






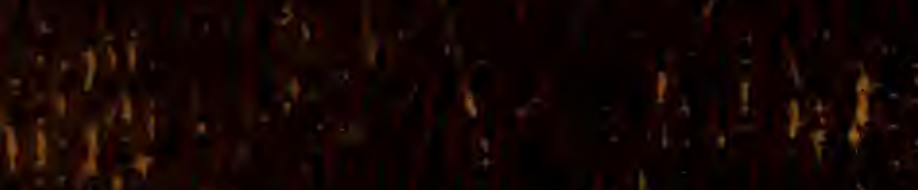

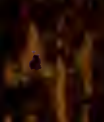

$$
1, \ldots
$$

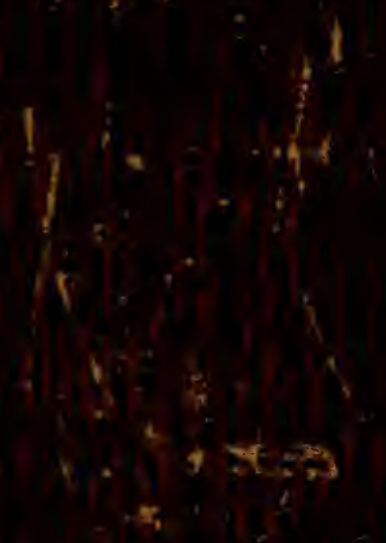

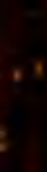

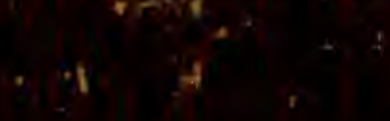

